University of Rhode Island

DigitalCommons@URI

Open Access Master's Theses

2000

\title{
Analysis of a Traffic Diversion Strategy Using Corism Traffic \\ Micro-Simulation Software
}

Daniel Ryan Abedon

University of Rhode Island

Follow this and additional works at: https://digitalcommons.uri.edu/theses

\section{Recommended Citation}

Abedon, Daniel Ryan, "Analysis of a Traffic Diversion Strategy Using Corism Traffic Micro-Simulation Software" (2000). Open Access Master's Theses. Paper 779.

https://digitalcommons.uri.edu/theses/779

This Thesis is brought to you for free and open access by DigitalCommons@URI. It has been accepted for inclusion in Open Access Master's Theses by an authorized administrator of DigitalCommons@URI. For more information, please contact digitalcommons-group@uri.edu. 
ANALYSIS OF A TRAFFIC DIVERSION STRATEGY USING CORSIM TRAFFIC MICRO-SIMULATION SOFTWARE BY

DANIEL RYAN ABEDON

A THESIS SUBMITTED IN PARTIAL FULFILLMENT OF THE REQUIREMENTS FOR THE DEGREE OF MASTER OF SCIENCE IN CIVIL ENGINEERING 
MASTER OF SCIENCE THESIS

OF

DANIEL RYAN ABEDON

APPROVED:

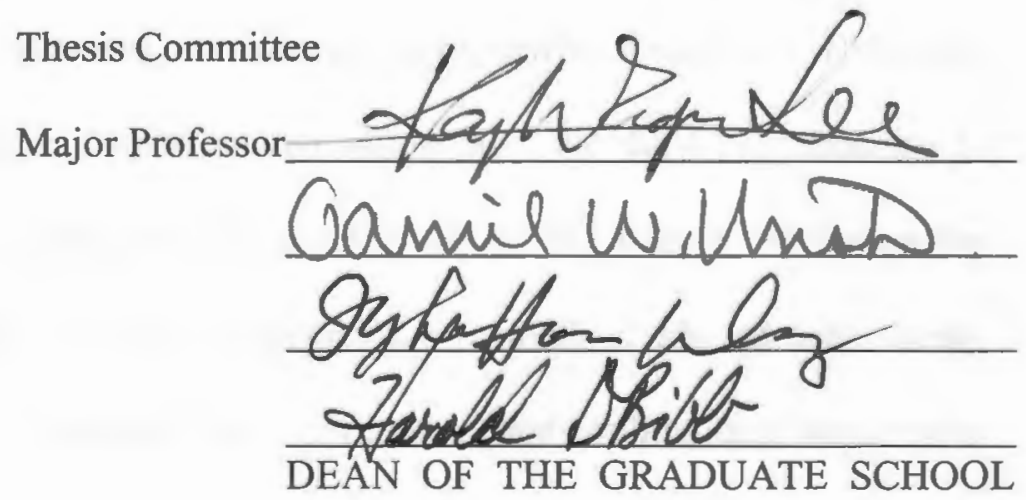

UNIVERSITY OF RHODE ISLAND 


\section{ABSTRACT}

Throughout the United States metropolitan area freeways are operating at or near capacity. Any disturbance in the traffic flow on these freeways, planned or unplanned, can result in varying degrees of congestion. Incident management programs have been established in urban areas nationwide to help reduce the magnitude of incident induced congestion. These programs focus mainly on the incident identification and response stage, and have only recently begun to develop the tools and techniques needed to manage the recovery stage. One technique that has been becoming more widely employed, with the increased focus incident management and overall traffic systems management, is alternate route traffic diversion. However, even when diversion strategies are employed, often only the main line freeway is evaluated and insufficient consideration is given to the effect of the diversion on the alternate route. Also, traffic diversion strategies are typically deployed only during extreme incidents and are seldom deployed or even analyzed for how they would help mitigate congestion related to minor traffic incidents. If delay on the freeway network as a whole is to be minimized, incident management programs need to incorporate comprehensive traffic management strategies and decision aids for the defining of traffic diversion strategies.

This study utilized Federal Highway Administration's (FHWA) traffic microsimulation software, CORSIM, to evaluate a freeway route diversion strategy that would increase traveler safety and alleviate congestion caused by minor incidents. The goal of the project was to reduce the impacts of minor incidents on a freeway 
system through the use of a methodically analyzed diversion strategy. The four specific objectives of the research were (1) to determine the impact of varying degrees of traffic diversion will have on the network evaluators for varying levels of traffic volumes encountering different incident situations; (2) to evaluate CORSIM and companion software as tools for performing this analysis; (3) to determine and document the procedure of the use of CORSIM in this facility; and (4) to recommend a diversion practice. The research analysis used typical measures of effectiveness to evaluate the effects of minor incidents and traffic diversion on a mainline and alternate route.

The results of the research show that CORSIM is a valuable tool for researchers, planners, or transportation engineers performing diversion strategy analysis. By utilizing CORSIM to simulate specific route diversion strategies valuable insights were gained into the effects that minor unplanned traffic incidents and deployed route diversion strategies will have on average network measures of effectiveness. It was found that the traffic condition the network is experiencing at the time of a minor incident and route diversion has distinct impacts on the network evaluators. CORSIM simulations demonstrated that the four levels of traffic condition tested produce distinct route diversion strategy recommendations. It was shown that the diversion modeled had a negative impact under AM peak traffic conditions, a slightly positive impact under 3/4 AM peak traffic conditions, significantly positive impact under 2/3 AM peak traffic conditions, and no impact under $1 / 2 \mathrm{AM}$ peak traffic conditions. The significance of these results is that they indicate that it is only beneficial to the entire network to divert traffic for certain incident situations when the 
network is operating at $3 / 4 \mathrm{AM}$ peak or $2 / 3$ AM peak traffic. At AM peak and 1/2 AM peak traffic condition, diversion was not found to be warranted for any of the minor incident situations modeled. 


\section{ACKNOWLEDGEMENTS}

Before I begin acknowledging all the people who made this research and thesis document possible, I want to thank God for the opportunities and gifts afforded me.

I gratefully acknowledge the help received from all the individuals and organizations in the completion of this thesis. First, I want to express my gratitude to my major professor, Professor K. Wayne Lee, for his encouragement, motivation, and guidance.

I am honored to have Professor Daniel W. Urish, Professor Jyh-hone Wang, and Professor Farhad Atash on my thesis defense committee. I am obliged to Professor Urish and Professor Lee for selecting me for a University of Rhode Island Transportation Center (URITC) fellowship that has enabled me to complete this

degree. I must also acknowledge Dr. Christopher Hunter for sharing his expertise and providing guidance throughout the research process.

I appreciate the support from RIDOT staff in various aspects of this project. Particularly, I acknowledge the help from Mr. Joe Bucci, Mr. Paul Annarummo, Ms. Cynthia Levesque, Mr. William Alves, Mr. Steven Devine, Mrs. Suzan Shanley-Szala, Mr. John Vorro, Mr. Ken Burke, Mr. Dave Ferguson, and Ms. Lue Anne Powers. I would also like to thank Brian Gray for his help in establishing my graduate office and equipment needed to carry out the research.

Mrs. Gail Paolino, Ms. Cathy Manchester and Mrs. Suzanne Wood have provided encouragement and assistance above and beyond anything I could have ever 
hoped to expect from such busy people. I would also like to thank fellow graduate students Mr. Todd Brayton and Mr. Edgar Kraus for their commiseration.

I must express my gratitude to all my friends outside URI who have supported me and provided necessary distractions throughout the course of my graduate studies and research project. I must thank Ms. Annalisa Gianfransisco, Ms. Nese Candas, Ms. Amy Dias, Mr. Todd Sollitto, Mr. Ryan Berrigan, Mr. Jarret Laven, and Mr. Daniel Sbrega for their aid in this capacity and for their continuing friendship and support.

In addition to the continuous support, I received at URI, I have also received unwavering encouragement from my entire family. I am grateful to my loving girlfriend, Tu Wong, for her patient support and thoughtful assistance throughout my graduate experience. I am eternally indebted to Mr. and Mrs. Jack and Geraldine Barry for their limitless generosity and continuous encouragement. I must also express my utmost gratitude to Mr. Jack Barry, Jr., Mr. James Barry, Mr. Michael Barry, Mr. Brendan Barry, Ms. Diamond Barry, and Ms. Elizabeth Barry for their love, understanding, and support that made the stress associated with this completing this research melt away daily.

Of course none of this would ever be possible without my loving sisters, Emily and Rebecca, and my wonderful parents, David and Pauline. Everything I am and have accomplished, and anything I may do or become, is because of my parents. Whatever I achieve is rooted in their love and guidance.

Finally, I am dedicating this research and final document to the loving memory of Mr. James P. Ryan, Mr. Byron H. Abedon, and Cathy. 


\section{TABLE OF CONTENTS}

Page

Stract ii

olknowledgements

Table of Contents vii

List of Tables $\mathrm{xi}$

List of Figures xiv

1. INTRODUCTION

1.1. Problem Statement

1.2. Goals and Objectives of the Research 2

1.3. Overview of the Thesis Document 6

2. STATE OF THE ART REVIEW OF TRAFFIC DIVERSION

SIMULATION PRACTICE 7

2.1. Background 7

2.1.1. Historical Perspective of Traffic Diversion 7

2.1.2. Traffic Diversion Practice in the United States 10

2.1.3. Traffic Diversion Practice in Rhode Island 11

2.2. Introduction to Traffic Simulation 13

2.3. Simulation Software Utilized in Research 15

2.3.1. CORSIM 15

2.3.2. The FRESIM Model 19

2.3.2.1. Car-Following Model 20

2.3.2.2. Lane-Changing Model 22 
2.3.3. Companion Software 26

2.3.3.1. Traffic Software Integrated System (TSIS) $4.2 \_26$

2.3.3.2. ITRAF 29

2.3.3.3. TRAFVU 31

2.4. Applications of CORSIM 33

2.5. CORSIM as a Tool for Developing Route Diversion Strategies 36

2.6. Summary 37

3. RESEARCH METHODOLOGY 39

3.1. Developing the Transportation Network for Simulation 39

3.1.1. Introduction 39

3.1.2. Defining the Study Area 40

3.1.3. Defining Necessary Assumptions 42

3.1.4. Defining Measures of Effectiveness 43

3.1.5. Obtaining and Inputting Modeling Data 45

3.1.5.1. Roadway and Ramp Geometry 45

3.1.5.2. Roadway and Ramp Traffic Volumes 54

3.1.5.3. Simulation Time Considerations 67

3.1.5.4. Simulation Random Seed Numbers and Replications 68

3.1.6. Validating the Model 69

3.1.6.1. Observational Validation Utilizing TRAFVU 70

3.1.6.2. Operational Validation: Floating Car Technique_71 
3.1.6.3. Comparison with the Results of Highway Capacity Software Analysis 77

3.1.6.4. Summary of Model Validation Process 81

3.2. Analysis Methodology 82

3.2.1. Introduction 82

3.2.2. Phase-I - Preliminary Analysis 82

3.2.2.1. Defining the Factors Associated with Traffic Incidents and Route Diversion 82

3.2.2.2. Modeling Traffic Incidents and Diversion in CORSIM Software 88

3.2.2.3. Overview of the $2^{\mathrm{k}}$ Factorial Statistical Analysis Technique 89

3.2.2.4. Application of the $2^{\mathrm{k}}$ Factorial Statistical Analysis Technique 90

3.2.2.5. Recommendations for Phase-II 99

3.2.3. Phase-II - Expanded Analysis Based on Preliminary Analysis 101

3.2.3.1. Application of Expanded Factorial

Experimental Design 101

3.2.3.2. Definition of Decision Criteria 102

3.2.3.3. Presentation of Results of Phase II 105

4. DISCUSSION OF RESULTS 117

4.1. Evaluation Based on Decision Criteria Defined 117 
4.1.1. AM Peak Traffic Conditions

4.1.2. 3/4 AM Peak Traffic Conditions

4.1.3. 2/3 AM Peak Traffic Conditions

4.1.4. 1/2 AM Peak Traffic Conditions

4.2. Summary

5. APPLICATION OF STUDY FINDINGS

5.1. Introduction

5.2. Development of Incident Management Protocol

6. CONCLUSIONS AND RECOMMENDATIONS 146

6.1. Conclusions 146

6.2. Recommendations 148 筑ENCES 150

APPENDIX A: Photographs of Typical Segments of the

Roadways in the Study Area 153

APPENDIX B: Car-Following Logic Employed by CORSIM 161

APPENDIX C: Coordinates of Nodes used to Model the Roadway Network 169

APPENDIX D: Figure Displaying Critical Traffic Volume Points and

Tables Listing the Corresponding Traffic Volume and Exiting Percentages 176

APPENDIX E: Results for Simulations Modeled with

AM Peak Traffic Conditions 186

APPENDIX F: Results for Simulations Modeled with

3/4 AM Peak Traffic Conditions 202 
APPENDIX G: Results for Simulations Modeled with

2/3 AM Peak Traffic Conditions 218

APPENDIX H: Results for Simulations Modeled with

$1 / 2$ AM Peak Traffic Conditions 234

APPENDIX I: Framework Summary of Research Methodology 250

APPENDIX J: Deployment Plan Utilizing National ITS Architecture 255 BIBLIOGRAPHY 270 


\section{LIST OF TABLES}

Page

3-1. Peak Hour Traffic Volumes determined from the

Highway Performance Monitoring System Report

3-2. AM Peak Traffic Volumes for the Simulated Network 62

3-3. AM Peak Traffic Volumes Linking the Mainline and Alternate Route 64

3-4. Speeds and Statistical Test Results for the Operational Validation of I-95 north Simulated Roadway 75

3-5. Speeds and Statistical Test Results for the Operational Validation of

Rt. 10 north Simulated Roadway 76

3-6 LOS Comparison Between HCS and CORSIM 80

3-7 Limits of Variability for the Four Factors Established 87

3-8 Levels of the Factors Analyzed in Phase-I Simulations 91

3-9 $\quad 2^{4}$ Experimental Design with Responses Determined by CORSIM 94

3-10 Results of the Test on Homogeneity of Variance of Speed Data 96

3-11 General Linear Model ANOVA Table for Phase-I Data 98

3-12 Recommendations for Phase-II Experiments 100

3-13 Results for AM Peak Traffic Conditions (Speed) 106

3-14 Results for AM Peak Traffic Conditions (Delay) 107

3-15 Results for 3/4 AM Peak Traffic Conditions (Speed) 108

3-16 Results for 3/4 AM Peak Traffic Conditions (Delay) 109

3-17 Results for 2/3 AM Peak Traffic Conditions (Speed) 110

3-18 Results for 2/3 AM Peak Traffic Conditions (Delay) 111

3-19 Results for 1/2 AM Peak Traffic Conditions (Speed) 112 
3-20 Results for 1/2 AM Peak Traffic Conditions (Delay)

3-21 General Linear Model ANOVA Table for the Network Speed 114

3-22 General Linear Model ANOVA Table for the Total Delay 115

4-1 Summary of Results 135

5-1 Incident Management Protocol 138 


\section{LIST OF FIGURES}

Page

1-1 Study Area 4

2-1 Typical CORSIM Output File

2-2 Lane-Changing Diagram 23

2-3 TSIS On-Screen Environment 28

2-4 ITRAF Graphical User Interface Environment 30

2-5 TRAFVU Movie Player Output File Display 32

3-1 Aerial Photo of the Thurber's Avenue Curve Segment in Study Area 49

3-2 Aerial Photo of Thurber's Avenue Curve Segment as Marked During the Dimensioning of the Network Geometry 50

3-3 CORSIM Input File Generated in ITRAF for the Thurber's Avenue Curve Gogment 51

3-4 TRAFVU Movie Player Output File of the Thurber's Avenue Curve Segment as Generated by CORSIM 52

3-5 Map of Critical Points in Study Area Roadway Network 60

3-6 ITRAF Traffic Volume Data Entry 66

4-1 Speed Comparison Graph for Peak Traffic Conditions 122 
4-2 Speed Comparison Graph for 3/4 Peak Traffic Conditions 126

4-3 Speed Comparison Graph for 2/3 Peak Traffic Conditions 126

4-4 Speed Comparison Graph for 1/2 Peak Traffic Conditions 133 


\section{CHAPTER 1. INTRODUCTION}

\subsection{Problem Statement}

Throughout the United States, metropolitan area freeways are operating at or near capacity. Any disturbance in the traffic flow on these freeways, planned or unplanned, can cause hours of congestion. Congestion associated with freeways has grown significantly in recent years. In 1975 , approximately $40 \%$ of urban interstate peak hour traffic flowed at an average speed of less than $35 \mathrm{mph}$. By 1990, this percentage had risen to almost $70 \%$. It has been estimated that by 2005 , urban congestion costs could be as high as $\$ 88$ billion and absorb 8 billion vehicle-hours (Institute of Transportation Engineers 1992). Furthermore, it is estimated that $60 \%$ of all congestion-induced delay is caused by traffic incidents (Garrison and Mannering 1990). A report for the California Department of Transportation (Caltrans) placed the cost of incident-related congestion at approximately $\$ 1$ million per day (Reiss and Dunn 1991). It is crucial to understand that although major traffic incidents cause severe traffic flow disruptions, minor traffic incidents can cause a substantial portion of the total delay attributable to incidents. A report by the Federal Highway Administration (FHWA) stated that minor incidents are responsible for $65 \%$ of all incident related delay, with major incidents accounting for the remaining 35\% (Reiss and Dunn 1991).

In addition to causing delays and increasing highway user costs, vehicles subjected to congestion produce excess emissions. Congestion is also being linked to the growing "road-rage" phenomena. Since transportation officials have realized that metropolitan areas will not be able to consistently curb freeway traffic congestion, 
incident related or otherwise, by adding highway infrastructure, there has been a nation-wide drive towards transportation system optimization. There are many components of transportation system optimization, one of which is incident management.

Incident management programs have been established in urban areas nationwide to aid in the reduction of the magnitude of incident induced congestion. These programs focus mainly on the incident identification and response stage, and have only recently begun to develop the tools and techniques needed to improve the recovery stage, particularly the utilization of traffic diversion strategies. Even when diversion strategies are employed, often only the main line freeway is evaluated while insufficient consideration is given to the effect of the diversion on the alternate route. Also, traffic diversion strategies are typically used only for extreme reductions in capacity and are seldom deployed for minor traffic incidents. If delay on a traffic network as a whole is to be minimized, then it is essential that incident management programs incorporate comprehensive traffic management strategies and innovative decision aids for the analysis of traffic diversion strategies so that they can be deployed for any situation that warrants them.

\subsection{Goals and Objectives of the Research}

In the City of Providence, RI, there is a segment of Interstate 95 (I-95) referred to as "Thurber's Avenue Curve". Travelers to the downtown area of the City of Providence and points further north often encounter extended delays because of congestion caused by traffic incidents on this curve segment because of substandard 
freeway geometry and high traffic volumes. The diversion strategy to be investigated utilizes Highway RI Route 10 northbound (Rt. $10 \mathrm{NB}$ ) as an alternate route around the "Thurber's Avenue Curve" segment described above and shown in Figure 1-1. Pictures of typical sections of I-95 NB and Rt. 10 NB in the study area can be seen in Appendix A. This diversion strategy is an excellent test case for this freeway-tohighway diversion study because Rt. 10 operates at or near capacity at peak travel periods and detailed analysis of the effects of the diverted traffic is required before a diversion plan could be deployed. Furthermore, when the RIDOT ITS initiative is complete, traffic diversion for minor freeway incidents will be feasible.

Traffic diversion for minor incidents will be possible because the ITS deployed will include the necessary data collection systems, surveillance systems, information dissemination systems, and central management systems to assess the status of incidents and guide travelers to alternate routes. The specific nature of these systems is explained in Chapter 2. This research could lead to the production of an incident management course of action for operators at the central transportation management center to follow at the time of an incident. With the ITS and this guideline in place route diversion strategies could be deployed efficiently based on sound analysis. 


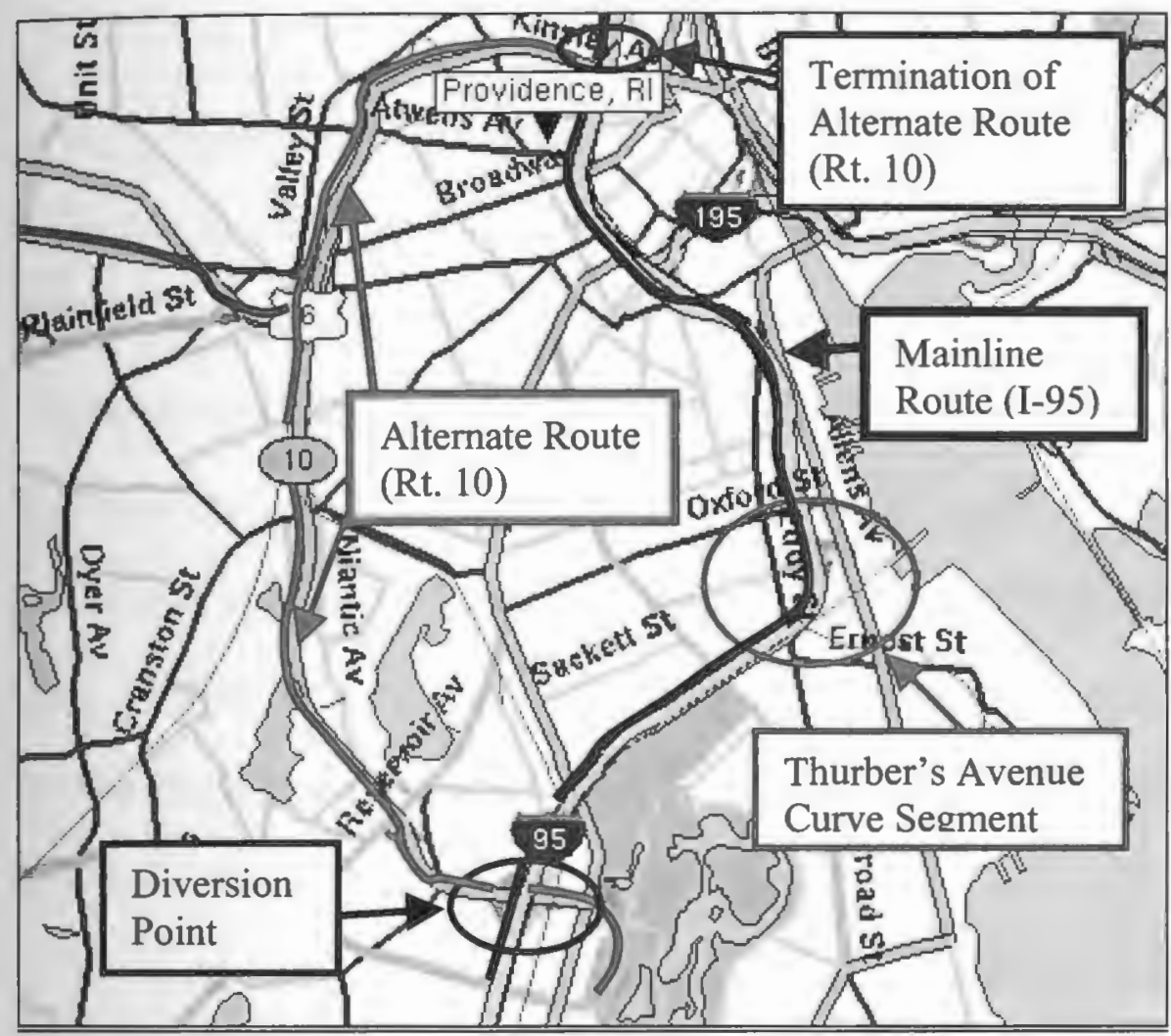

Figure 1-1 Locus Map 
This study utilized FHWA's traffic micro-simulation software, CORSIM, to determine the most efficient freeway-to-highway route diversion strategy for the I-95 NB/Rt. 10 NB roadway network that would alleviate congestion caused by incidents of varying lane blockages and durations on the "Thurber's Avenue Curve" segment of I-95 NB. The simulation roadway network delay time and roadway network vehicle speed were used as the measures of effectiveness for the situations simulated. The goal of this project was: to reduce the impacts of minor incidents on a freeway system through the use of a methodically analyzed diversion strategy. The four specific objectives of the research were:

- to determine the impact of varying degrees of traffic diversion would have on the network evaluators for varying levels of traffic volumes encountering different incident situations;

- to evaluate CORSIM and companion software as tools for performing this analysis;

- to determine and document the procedure of the use of CORSIM in this facility; and,

- to recommend a diversion practice.

Recent published documentation shows that CORSIM can suitably model freeway-to-arterial traffic diversion (Gragg and Demetsky 1995). To the date of publication, no documentation was found evaluating CORSIM as a freeway-tohighway (knth un-interrupted vehicle flows) diversion analysis tool. If it is determined that CORSIM can adequately model freeway-to-highway traffic diversion 
the software would aid transportation engineers in the analysis of traffic diversion strategies for a much broader array of situations.

\subsection{Overview of the Thesis Document}

This document begins with a detailed discussion on why the study is significant undertaken and what the study document strives to achieve. This introduction is followed by background information regarding traffic diversion and its place in transportation management today. Following the background information is the literature review that describes the model employed and pertinent applications of the simulation software that have been documented. The research methodology covers all aspects of the modeling and analysis processes and presents the results obtained from the simulation experiments. The results are then discussed in Chapter 4. Chapter 5 presents and describes a final product of the research that could be employed by RIDOT. Finally, Chapter 6 discusses the conclusions and the recommendations of the research. 


\section{CHAPTER 2. STATE OF THE ART REVIEW OF TRAFFIC DIVERSION \\ AND SIMULATION PRACTICE}

\subsection{Background on Traffic Diversion Practice}

\subsubsection{Historical Perspective of Traffic Diversion Practice in the United States}

Since the beginning of vehicular traffic, motorists have been deviating from mainline routes to alternate routes in the event of roadway congestion caused by traffic incidents. When roadways were few, alternate routes to desired destinations were few. However, as the automobile quickly replaced horse and buggy and, in many densely populated places, intra-city trolley ways as well, roadways began to blanket urban landscape. Over the years, roadways rapidly increased in length, traffic capacity, complexity, and function. The different types and usage of roadways naturally led to classifications, so that roadway function could be readily identified by classification. The most common classifications are: land access, arterial, collectors, highway, and freeway. The following is an example of how the roadway label relates to the function: a land access roadway is typically a neighborhood road that allows a private landowner to access their land by automobile. With these new vast networks of interwoven roadways, each having different functions, types of controls (signs and signals) and restrictions (speeds), travelers promptly identified various routes, composed of a hybrid of roadway types, to the same destination.

Until 1971, traffic diversion to alternate routes during the time of incidents were the product of either a segment of roadway experiencing a total loss of capacity and an emergency diversion to any possible alternate route or the familiarity of 
motorists with a given roadway network and their ability to readily navigate the system based on commercial radio traffic reports or learned knowledge and assessment of the prevailing traffic conditions. In 1971, District 7 of the Caltrans pioneered the development and deployment of alternate route plans for responding to the occurrence of major traffic incidents. Major traffic incidents are defined as incidents that severely reduce or eliminate a roadway's capacity for an extended period of time (Roper 1991). District 7 initiated the process of developing 2,500 alternate map routes for 475 miles of freeway. Each map identified several key components vital to the alternate route deployment process including identification of the problem location, primary and secondary alternate routes, deployment guidelines, manpower requirements and locations, required signing, necessary closures, responsible parties and associated phone numbers, and special notes unique to the incident area (Dunn et al. 1999). With Caltrans leading the way, other state agencies began to develop route diversion strategies for major incidents, recognizing that time, money, and resources could be saved and overall system safety would be increased.

Traffic diversion is based on the fact that drivers will divert from the usually quickest, or most popular route, to another alternate route if they perceive that they can reach their destination faster and safer using the alternate route. The alternate route is often times only utilized if the preferred route, or mainline route, is operating at a congested level. Congested levels are reached as vehicle demand exceeds a roadway's capacity, or if a segment of that roadway's capacity is reduced by an incident. A traffic incident is any event, planned or unplanned, that reduces the capacity of a segment of roadway effecting upstream traffic conditions (Dunn et al. 
1999). An unplanned traffic incident is commonly referred to as a "traffic accident". A planned traffic incident can take the form of routine roadway construction or some special event that has been pre-determined to cause traffic congestion. Furthermore, traffic congestion is broken into two main categories: recurring and non-recurring congestion (Dunn et al. 1999). Recurring traffic congestion occurs usually during commuter travel time periods causing the roadway to consistently experience a demand that exceeds its capacity. Examples of recurring congestion are Los Angeles freeways and Interstate 95 through New York City. Commuters on these roadways expect to experience delay under usual commuter period traffic flow conditions. Nonrecurring congestion occurs when a roadway segment's capacity is suddenly reduced or the roadway's demand exceeds its capacity either by a planned or unplanned incident (Dunn et al. 1999). This study investigates an alternate route strategy that would be deployed in the case of non-recurring congestion stemming from an unplanned traffic incident causing a sudden reduction in freeway capacity.

The practice of diverting traffic only for incidents that result in a complete loss of capacity has been the standard for incident management program traffic diversion plans. Until recently, transportation management centers (TMCs) have had limited means of collecting, processing, and responding to incident information quickly enough to make it beneficial to divert traffic for incidents that do not block all lanes (Dunn et al. 1999). Also, analysis of diversion strategies for various incident events calculation or with the assistance of computer simulation models has been extremely timely. However, RI and many other states now employ advanced transportation management centers (ATMCs) that integrate real-time traffic surveillance with 
variable message signs (VMSs) and/or dynamic message signs (DMSs) along the freeway. These and other ITS technologies will enable significantly more efficient incident data collection, data processing and information dissemination, making traffic diversion for minor incidents feasible. While ITS will facilitate the implementation and operation of actual traffic diversion, advances in computer processing and traffic simulation software, specifically with regards to the model input process and database construction, are making the use of simulation models increasingly economic and practical.

\subsubsection{Current Traffic Diversion Practice in the United States}

In 1999, Walter M. Dunn, Jr., Robert A. Reiss, and Stephen P. Latoski assembled Synthesis of Highway Practice 279, titled: Roadway Incident Diversion Practices. This document addresses a broad list of topics and profiles successful incident diversion practices. In particular, it focuses on alternate route plans for incidents that happen at random, resulting in the occurrence of nonrecurring congestion. The information reported in the synthesis is basically a summary of the results of a comprehensive survey questionnaire that was distributed to 59 different agencies throughout the United States (US) and Puerto Rico (PR). The research performed and reported in this document utilized the information compiled by Dunn, Reiss, and Latoski to gain a perspective on the national trends with regards to unplanned incident diversion practices and to determine what characteristics of unplanned traffic incidents are most influential in the decision to deploy an alternate 
route plan. This synthesis report also contributed to the defining of incident related characteristics defined in Chapter 3.

Based on the agencies surveyed in the aforementioned synthesis it can be stated that most deployed traffic diversion strategies responding to unplanned traffic incidents are the product of:

- interagency coordination, including identifying the lead agency;

- proven traffic incident detection techniques, including police patrols and roadway users;

- specific pre-determined sets of decision criteria based on roadway and traffic incident characteristics;

- resources to inform motorists of prevailing traffic conditions, including variable and dynamic message sign and highway advisory radio; and,

- resources to guide motorists along the alternate route.

The synthesis relates how various agencies use different criteria in deciding if traffic diversion is warranted. Also, it relates the different components for detection and guidance along the alternate route and states that all the components listed must be present in some form.

\subsubsection{Traffic Diversion Practice in Rhode Island}

The State of Rhode Island (RI) is on the cusp of deploying an ITS initiative that will revolutionize roadway system management throughout the state. This initiative already includes an advanced central transportation management center (TMC) in Providence, limited highway advisory radio (HAR) on the AM frequency 
1610 , four operational closed circuit video surveillance cameras, movable variable message signs (VMS) along I-95, and a volunteer program that uses participating commuters as probes during peak travel periods. With these components in place and many others nearing operation, RI will have the capability to perform efficient and effective route diversion during unplanned incidents.

Presently, the Rhode Island Department of Transportation (RIDOT) is in the process of developing a statewide traffic diversion plan for the major high volume roadways. The roadways included in the diversion plan are I-95, Interstate 195 (I195), Interstate 295 (I-295), Rt. 10, and US Highway Route 6 (Rt. 6). The plan being developed by RIDOT examines the entire state and the most important roadways from a volume and incident perspective, but it only considers incident situations that would block all lanes of traffic of a given freeway segment for extended periods of time. The plan is comprehensive and an important step for the incident management program, but it fails to analyze the effect of minor traffic incidents (situations that do not block all lanes of traffic) that cause much of the congestion in the Providence metropolitan area.

Beyond this route diversion plan, RIDOT is participating in the I-95 Corridor Coalition Information Exchange Program (IEP). This program enables RIDOT TMC operators to input incident data into a central database managed by TRANSCOM located in New Jersey. TRANSCOM then distributes the accumulated information to the agencies throughout the Northeast Corridor that require it. For example, any information on traffic incidents that may affect RI motorists is instantly sent to the 
RIDOT TMC to be disseminated appropriately through ITS components and other media.

\subsection{Introduction to Traffic Simulation}

The earliest computer simulation work in highway transportation occurred in the 1950's when the Road Research Library in the United Kingdom undertook an intersection simulation (May 1990). The first simulation work in the US was published in 1953 and reported on intersection and freeway models developed at the University of California at Los Angeles. This initial work was followed by intersection work at the University of Michigan, major arterial simulation at Philco, New York Port Authority, and freeway ramp merging simulation at the Midwest Research Institute. From the 1950's, computer simulation grew rapidly through the 1960's, 1970's, and 1980's (May 1990). However, it was not until the 1990's, and the advances in micro computing, that computer simulations run efficiently on personal computer systems.

Computer simulation models are typically employed to predict how real world systems will behave under a set conditions without having the real world system involved (Elefteriadou et al. 1999). They can play a major role in the analysis and assessment of a complex highway system and its components (May 1990). Computer simulation models incorporate various analytical techniques, such as car-following theory, lane changing theory, capacity analysis and emissions analysis. Simulation models are typically distinguished in the following ways: 
- Simulation models predict system performance on the basis of a representation of the temporal or spatial interactions between system components (Elefteriadou et al. 1999);

- Empirical models predict system performance on the basis of relationships developed through statistical analysis of field data (Elefteriadou et al. 1999); and

- Analytical models predict system performance using relationships among system components developed through theoretical considerations, tempered, validated, and calibrated by field data. (Elefteriadou et al. 1999)

Within traffic simulation there are three distinct categories of how the models replicate traffic: micro-, meso-, and macroscopic. The difference lies in the level of detail at which the traffic flow phenomena are being represented (Elefteriadou et al. 1999). Microscopic models capture the movement of every vehicle and contain processing logic to describe how the vehicles will behave. The behavioral description includes acceleration, deceleration, lance changes, passing maneuvers, turning movement execution, and headway gap acceptance. Macroscopic models employ flow-rate variables and other more general describers to model the traffic movements. Mesoscopic models fall in between micro- and macroscopic models. Mesoscopic models typically model the movement of clusters or platoons of vehicles and incorporate equations that indicate how these clusters interact.

Each of the three categories can be programmed as either deterministic or stochastic. A model is deterministic if no element of the model is subjected to 
randomness. The significance of a model being deterministic is that every simulation with the same inputs will produce exactly the same outputs. For a deterministic model, all model parameters are known in advance and all the outcome determinations by the model can be predicted with certainty before the simulation begins (Elefteriadou et al. 1999). The model is stochastic if random variables are used during the simulation to determine either specific values for model variables or actions of simulated vehicles (Elefteriadou et al. 1999). A stochastic model will generate varied results based on random number sequences. These are either set as default values in the program, or are user specified. The significance of a model being stochastic in nature is that identical inputs can produce varied outputs, effectively allowing for experimental sampling.

\subsection{Simulation Software Utilized in Research}

FHWA has been utilizing and developing various traffic simulation models to aid in the analysis of these effects. These models are micro- and macro- scopic in logic and combined with other companion software make up FHWA's TRAF family of software. The subsequent sections will describe the TRAF software applied in this research

\subsubsection{CORSIM}

The microscopic simulation model of the TRAF software is CORSIM, an abbreviation of Corridor Simulation. CORSIM combines two of FHWA's original microsimulation models, NETSIM, used for modeling urban surface roadway systems, 
and FRESIM, used for modeling freeway roadway systems. By combining these models, CORSIM is able to simulate more complete and realistic networks of freeways and urban surface roadways ("CORSIM" 1998). Presently, CORSIM is being employed by transportation engineers and planners to analyze a wide range of projects. From designing high occupancy vehicle (HOV) lanes to evaluating complex interchanges to analyzing intricate signalization schemes needed for urban intersections, CORSIM software has given traffic and road design engineers valuable information into how their designs will function under various traffic and roadway conditions. Figure 2-1 displays a typical section of a CORSIM output file as seen by the user on a computer monitor. It is important to note that input files are no longer generated in CORSIM. They are created in the graphical user interface (GUI) companion software, ITRAF, which will be described in a subsequent sub-section. 


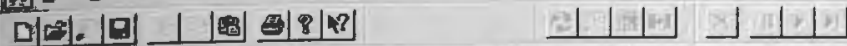

\begin{tabular}{|c|c|c|c|c|c|c|c|c|c|c|c|c|c|c|c|c|}
\hline \multicolumn{5}{|c|}{ Counier Now (Westem) } & \multicolumn{2}{|c|}{$\nabla 1$} & 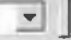 & \multirow[b]{2}{*}{18.0} & \multirow[b]{2}{*}{6.5} & \multirow[b]{2}{*}{6.2} & \multirow[b]{2}{*}{.3} & \multirow[b]{2}{*}{.96} & \multirow[b]{2}{*}{1.14} & \multirow[b]{2}{*}{.05} & \multirow[b]{2}{*}{499.} & \multirow[b]{2}{*}{9.} \\
\hline le 165 . & 95) & 167 & 166 & 0 & 1 & .9 & 15.7 & & & & & & & & & \\
\hline ( 65 , & 70) & 1785 & 1788 & 1058 & 12 & 23.8 & 248.2 & 475.3 & 16.0 & 8.1 & 7.9 & .51 & 1.91 & .95 & 1340 & 42. \\
\hline
\end{tabular}

NETWORK STATI STICS

VEHICLE-MILES $=9662.5$, VEHICLE-MINUTES $=11018.6$, MOVING/TOTAL TRIP TIME $=.819$ 。

AVERAGE CONTENT $=551.2$, CURRENT CONTENT $=586.0$, SPEED (MPH) $=52.62$,

TOTAL DELAY (VEH-MIN) $=1990.06$, TRAVEL TIME (MIN) /VEH-MILB $=1.14$, DEIAY TIME (MIN)/ VEH-MII

IINK

IINR TYPE

VEHTCLE TYPE-

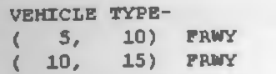

(15, 20) PRWY

(20, 25) PRUY

(25, 30)

( 30,35 )

( 35, 40 )

$(40,45)$

45,50
$(50,55)$

$(55,60)$

( 60,65 , 75 ,

( 80, 85)

$85,90)$
$(90,95)$

( 95, 100)

For Help. prass FI

3: tregiple

\begin{tabular}{rr}
1 & \multicolumn{1}{c}{2} \\
9.85 & 21.64 \\
10.97 & 23.45 \\
13.42 & 27.26 \\
16.21 & 33.86 \\
18.99 & 40.73 \\
8.34 & 16.95 \\
3.43 & 7.39 \\
6.74 & 15.20 \\
2.43 & 5.86 \\
3.19 & 7.29 \\
4.63 & 10.26 \\
5.33 & 11.35 \\
7.54 & 14.57 \\
6.34 & 10.95 \\
4.65 & 9.09 \\
2.46 & 5.38 \\
4.00 & 8.29
\end{tabular}

$$
\text { GALLONG }
$$

\section{3}

$\begin{array}{rr}13.95 & 9.04 \\ 13.54 & 10.22\end{array}$

$16.25 \quad 13.74$

$18.80 \quad 17.69$

$22.68 \quad 19.20$

$9.07 \quad 7.39$

$4.37 \quad 3.74$

$7.66 \quad 7.03$

$3.11 \quad 2.66$

4.01

5.29

5.67

5.68

3.04

3.07

1. 35

2.13

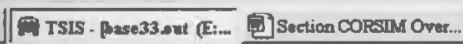

Figure 2-1 Typical Output File Generated by CORSIM.

PUEL CON\$LMPTION

$\begin{array}{rr}5 & 6 \\ 8.54 & 2.88 \\ 10.35 & 2.97 \\ 11.15 & 4.00 \\ 13.76 & 4.20 \\ 15.70 & 4.84 \\ 6.10 & 1.90 \\ 3.22 & 1.04 \\ 5.33 & 1.83 \\ 1.90 & .62 \\ 2.51 & .86 \\ 3.10 & 1.20 \\ 3.64 & 1.64 \\ 5.31 & 2.69 \\ 3.22 & 1.54 \\ 2.51 & .62 \\ 1.20 & .19 \\ 1.47 & .30\end{array}$

$\begin{array}{lc}7 & 1 \\ .00 & 15.99 \\ .00 & 14.73 \\ .00 & 12.58 \\ .00 & 13.49 \\ .00 & 14.27 \\ .00 & 11.72 \\ .00 & 14.65 \\ .00 & 14.45 \\ .00 & 16.56 \\ .00 & 16.30 \\ .00 & 14.07 \\ .00 & 12.83 \\ .00 & 8.59 \\ .00 & 10.51 \\ .00 & 13.57 \\ .00 & 14.11 \\ .00 & 14.94\end{array}$

$2^{\text {M.P.G. }}$

$23.23 \quad 2.88$ $22.30 \quad 3.03$ $20.25 \quad 2.65$

$21.34 \quad 2.76$ $22.09 \quad 2.83$

$19.27 \quad 2.54$ $22.56 \quad 2.74$

$21.64 \quad 2.90$ 23.312 .95 $29.06 \quad 2.99$ $21.56 \quad 2.85$ $20.62 \quad 2.77$ 15.392 .04 $18.53 \quad 2.55$ $21.69 \quad 2.68$ $20.64 \quad 2.92$ 22.65 Ln 2075. Col 7
4 5.49 4. 44 4. 15 4.77 4. 30 4.33

4. 31

4.72

4. 93

5.15

4.79

3.61

3.85

4.80

4.95 5.11 
CORSIM provides a wide range of output data, from link-by-link, time interval specific speed, link vehicle content, delay time, and travel time to total network statistics, relating cumulative emissions data by vehicle classification. Also, with regards to the output data, one of CORSIM's assets as a stochastic model is that it has the ability to generate varied outputs for identical inputs. The significance of the CORSIM model's stochastic nature is that the same traffic volumes can travel through the network in different patterns and produce varied network statistics. This means, for every situation modeled, statistical sampling can be performed, which increases researchers confidence in results.

One of the most desirable features of CORSIM with regards to this research is its capability to simulate timed incidents. Incidents can be modeled at any position in the network for any length of time within the overall simulation time. Also intricate to this research is the feature that allows the percentage of vehicles exiting the network to be varied during the simulation. This was how the traffic diversion is simulated. For the duration of an incident, the traffic diversion is modeled by adjusting the percentages of traffic exiting and volumes entering the system for a time interval equal to the length of the incident.

Another reason for choosing CORSIM software as the tool for this research is because it was developed and is supported by FHWA and promises to be a standard for traffic simulation in the US. FHWA displayed its dedication to the development and support of CORSIM in 1986 by establishing the Center for Microcomputers in Transportation (McTrans) at the University of Florida. McTrans provides technical 
advice, information exchange opportunities for researchers and engineers, as well as a wide range of transportation-related software. Since its creation, McTrans has been developing and sharing companion software for facilitating the use of CORSIM.

\subsubsection{The FRESIM Model}

As discussed earlier, only the FRESIM model within CORSIM was needed to simulate the diversion strategy for this study. Because the NETSIM model was not used, it will not be described in any more detail. FRESIM simulates the traffic behavior at a microscopic level with detailed representation of individual vehicles and their interaction with their physical environment. The environment includes geometry, merging sections, incidents and other vehicles. Vehicle interaction behavior is based on varying driver types, ranging from passive to aggressive. This behavior is coded and attached to the individual vehicles. The difference between the degree of passive and aggressive vehicles lies in their preset acceptance of minimum headway and their maximum acceleration, and emergency deceleration.

The acceptable headway, acceleration, and deceleration dominate the decisions of each simulated vehicle. Acceptable headway is the time space a vehicle will allow between itself and the vehicle directly in front of it. The time-space is computed based on the vehicles speed and its emergency deceleration rate. Also, the passive or aggressive nature of a vehicle is directly related to the car-following and lane changing characteristics of that vehicle. Since the car-following and lane-changing characteristics of each vehicle are paramount at the time of an incident and traffic diversion, it is important to completely understand the theory employed by FRESIM 
to simulate the actions. The next two subsections present discussion and description of the lane-changing and car-following models within FRESIM.

\subsubsection{Car-Following Model}

The car-following theory programmed in FRESIM is significant because it defines how vehicles in the model will interact with the environment and the other vehicles on the network. In the FRESIM model, each vehicle in each time increment is assigned one of the following characteristics: "a follower" (a vehicle following another vehicle) or "a leader" (a vehicle with no leader). The encoded car-following theory assumes that a follower vehicle will maintain a safe time-space between itself and its leader. This time-space is given by Equation 1 of the PITT Car-Following model and is presented in Appendix B. When the space is insufficient to maintain a "time-space safety cushion" in order to avoid a collision, the vehicle will decelerate in order to maintain a safe distance. At any given time interval, the acceleration of the follower vehicle is determined by the behavior of the "leader" vehicle and the downstream geometric conditions. This acceleration is compared against the vehicle's performance capabilities and adjusted if necessary. In order to avoid a collision, an emergency constraint overrides the car-following acceleration and maintains the safety cushion.

The behavior of the leader vehicle is dependent on the upcoming roadway geometry. The geometrics extending over a distance of 500 feet are able to be scanned by the vehicle. It is the geometry in this distance that dictates the vehicle's behavior. There are seven different states that are assigned to the lead vehicle. 
1. The vehicle is approaching a lane drop. When approaching a lane drop, the lead vehicle treats the end of the lane being dropped as a stopped vehicle. Similar to the car-following logic, the required deceleration is measured against the deceleration from the kinematic law for stopping the vehicle at the point the lane is dropped. The maximum of the two decelerations is assigned to the vehicle. If a determination is made that the vehicle does not have to decelerate in the current time step, then the computed acceleration is subjected to the vehicles attached performance parameters. The lead vehicle approaching a lane drop continues to move under this logic until the distance between the point of the lane drop and the vehicle's front bumper is reduced to less than or equal to 5 feet. At this moment, the vehicle is moved to the point of the lane drop and the speed and acceleration are both set at zero ("CORSIM" 1998).

2. Vehicle is Approaching a Blockage Incident. Similar to the lane drop situation, when the lead vehicle approaches a lane blockage, the required deceleration is measured against the deceleration from the kinematic law for stopping the vehicle at the point of blockage. The maximum of the two decelerations is assigned to the vehicle. In applying the car-following logic, a stopped vehicle is assumed to be present at the leading edge of the blockage. This situation continues until the distance between the blockage and the front bumper of the vehicle is less than or equal to 5 feet. The vehicle's speed and acceleration is then set to zero ("CORSIM" 1998). 
1. The vehicle is approaching a lane drop. When approaching a lane drop, the lead vehicle treats the end of the lane being dropped as a stopped vehicle. Similar to the car-following logic, the required deceleration is measured against the deceleration from the kinematic law for stopping the vehicle at the point the lane is dropped. The maximum of the two decelerations is assigned to the vehicle. If a determination is made that the vehicle does not have to decelerate in the current time step, then the computed acceleration is subjected to the vehicles attached performance parameters. The lead vehicle approaching a lane drop continues to move under this logic until the distance between the point of the lane drop and the vehicle's front bumper is reduced to less than or equal to 5 feet. At this moment, the vehicle is moved to the point of the lane drop and the speed and acceleration are both set at zero (“CORSIM"1998).

2. Vehicle is Approaching a Blockage Incident. Similar to the lane drop situation, when the lead vehicle approaches a lane blockage, the required deceleration is measured against the deceleration from the kinematic law for stopping the vehicle at the point of blockage. The maximum of the two decelerations is assigned to the vehicle. In applying the car-following logic, a stopped vehicle is assumed to be present at the leading edge of the blockage. This situation continues until the distance between the blockage and the front bumper of the vehicle is less than or equal to 5 feet. The vehicle's speed and acceleration is then set to zero ("CORSIM" 1998). 
3. Vehicle is Approaching the End of an Auxiliary Lane. The behavior of a vehicle approaching the end of an acceleration auxiliary lane is identical to that of the lane-drop behavior as described above ("CORSIM" 1998).

4. Vehicle is Not Affected by Geometrics. Any vehicle that is not influenced by any of the previously described cases will attempt to increase its acceleration to the maximum possible rate in an effort to attain the user specified free-flow speed of the facility, which depends on the freeway geometrics and the vehicle's operation characteristics (“CORSIM” 1998).

\subsubsection{Lane-Changing Model}

Lane-changing logic determines the amount of risk that a driver of a lanechanging vehicle will accept (lead gap) and the amount of risk that a driver in the target lane will accept (lag gap). Figure 2-2 is an illustration of this concept. The lanechanging logic is pertinent to this research because during the time of a traffic incident and route diversion there is typically a greater amount of lane-changing. The actual algorithm that CORSIM utilizes for lane changing can be found in Appendix B. 


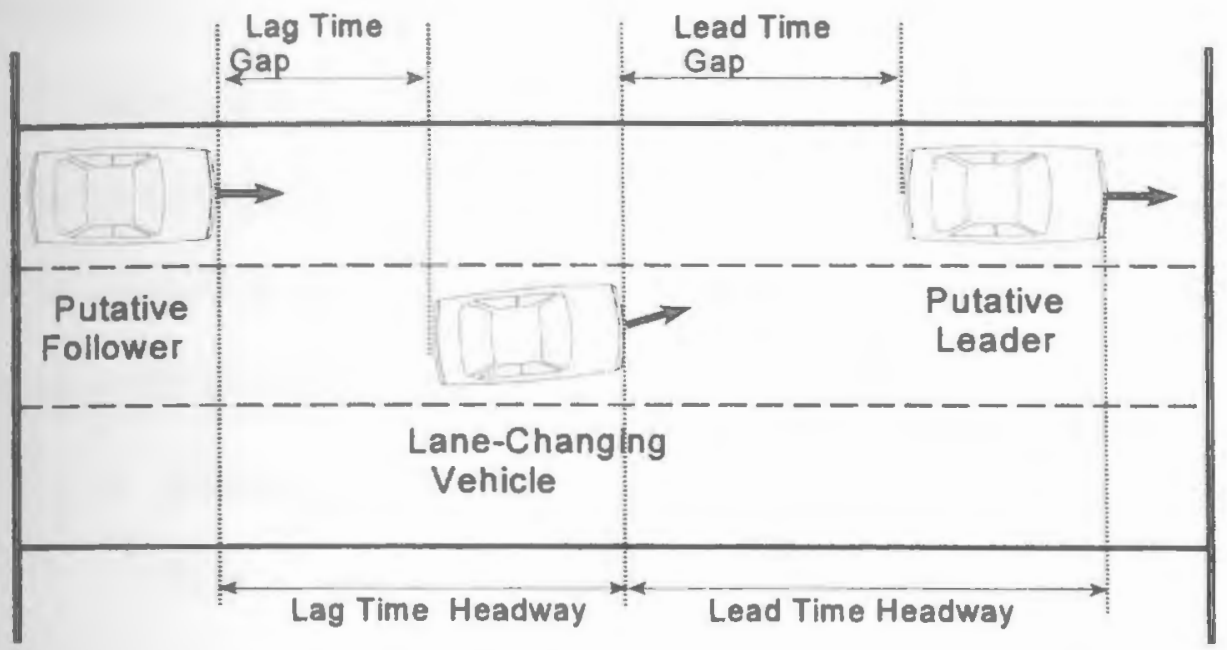

Figure 2-2 Lane-Changing Parameters Involved in FRESIM Model's LaneChanging Logic. 
The FRESIM model provides three types of lane changing schemes. The three schemes are:

1. Mandatory Lane Changing. The mandatory lane change is the most stringent of the three types. The vehicle accepts the greatest risk and tests the limits of the vehicle performance characteristics. A mandatory lane change occurs under the following conditions ("CORSIM" 1998):

- A vehicle is traveling in an acceleration auxiliary lane and must change lanes in order to merge with mainline traffic.

- A vehicle is not in the proper lane to exit the freeway and has passed an advance warning sign.

- A vehicle is in a lane, which will be dropped downstream and has passed an advanced warning sign.

- The vehicle is in a lane that is blocked downstream by an incident.

2. Discretionary Lane Changing. Discretionary lane changing occurs when vehicles change lanes to obtain a better position or to pass slower moving vehicles. The FRESIM model for discretionary lane changing depends on several driver behavioral parameters ("CORSIM" 1998):

- Motivation - pertains to a vehicle's desire for a lane change based on the vehicle's present speed.

- Advantage - pertains to when the lane change will be advantageous to the driver.

- Urgency - pertains to how strong the desire is to change lanes. 
A detailed discussion of these behavioral parameters and the governing equations can be in the Appendix B.

3. Anticipatory Lane Changing. Anticipatory lane changing refers to the lane changes that are performed by through moving vehicles to avoid potential slowdown caused by the traffic merging from a downstream on-ramp. (“CORSIM" 1998)

\subsubsection{FRESIM Limitations}

"Although FRESIM is probably the best freeway simulation program available, it does have some limitations that could be overcome with minor programming changes and enhancements" (Roess and Ulerio 1997). It has been documented that one of the main problems with FRESIM is its inability to predict the merging process with a high degree of accuracy. Another problem that has been encountered is that FRESIM allows some vehicles to miss their exit point. This is a very serious consideration for the research being performed. If vehicles miss the correct exit point, it inaccurately reflects the volume of traffic on both the main and alternate route. Because of this phenomenon the modeling technique was altered from its original format. The technique employed is described in detail in the research methodology.

Another commonly cited problem with CORSIM is that the output data is not the most relevant. Specifically, some of the summary statistics are reported on a cumulative basis, which in most instances requires the user to perform additional calculations to find the actual statistics for a given time period (Roess and Ulerio 
1997). Also, the CORSIM program provides no graphical output for some of the key network statistics.

Finally, and most importantly, much of the programming logic in FRESIM is based on field data that in some cases may not have been as extensive as necessary in the development of a program of its scope (Roess and Ulerio 1997). It has been stated that, "many of the deficiencies of the program could be overcome by conducting additional calibration/validation and sensitivity analyses to refine the models" (Roess and Ulerio 1997). This problem is dealt with in this research by performing a validation exercise on the network analyzed. The validation procedure and the results of this validation are reported on in Section 3.1.6 of Chapter 3.

\subsubsection{Companion Software}

\subsubsection{Traffic Software Integrated System (TSIS) 4.2}

The Traffic Software Integrated System (TSIS) is a collection of software tools for use by traffic engineers and researchers. Originally built as a simple shell around CORSIM, TSIS evolved into a sophisticated toolkit. TSIS was developed by FHWA, but is sold to the public through McTrans. The TSIS package is able to function on Microsoft Windows 95, Windows 98 and Windows NT 4.0. The version of TSIS used for this research supports the following programs: CORSIM, ITRAF, and TRAFVU.

One of the strengths of TSIS is that it can operate with software developed by other organizations. TSIS was designed and developed as an open architecture so that as other tools become available from FHWA and third parties they can be easily adapted to the shell environment. One of the major goals of the TSIS initiative is to 
provide a user interface that is intuitive and a system for integrating the component models. This will enable CORSIM and other FHWA software tools to be employed by traffic engineers who would like to use the models, but do not because of the lack of time to learn how to operate them. Of those researchers and engineers that already know and use the model, these tools ease the burden of creating the traffic networks, which in the past have been very labor-intensive and error-prone. Future versions of TSIS will include the ability to import graphical information systems (GIS), US Geological Survey (USGS), computer aided design (CAD), and other digital mapping information to make it increasingly more efficient to use the models. Figure 2-3 displays the TSIS environment as seen by a user on the computer monitor. As can be seen in the figure, multiple projects can be opened at once in the TSIS environment, each project can have numerous files relating to the network being modeled. 


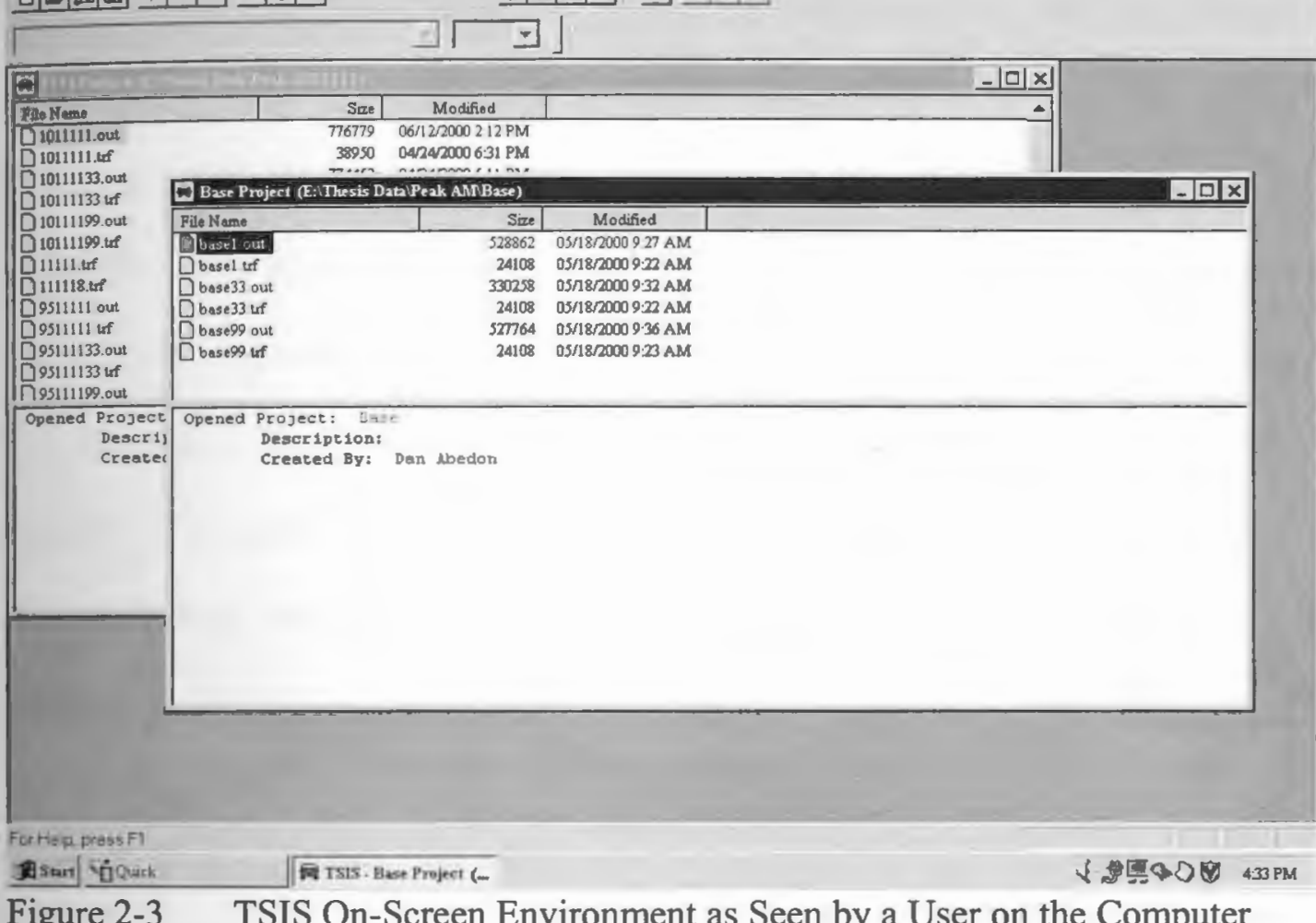

Monitor. 


\subsubsection{ITRAF}

ITRAF is the most significant software development with regards to data entry in CORSIM. ITRAF is a graphical CORSIM input processor that was developed by Oak Ridge National Laboratory as a TSIS add-in. Using ITRAF to graphically input the network and all it characteristics saves great amounts of time and provides the user with a visual representation of the configured network in a node and link form. Figure 2-4 displays a sample of the ITRAF software as seen by the user on a computer monitor. The segment of network shown is the Thurber's Avenue curve section of I95 NB through Providence, RI. Also shown is how an incident is entered into the software. 


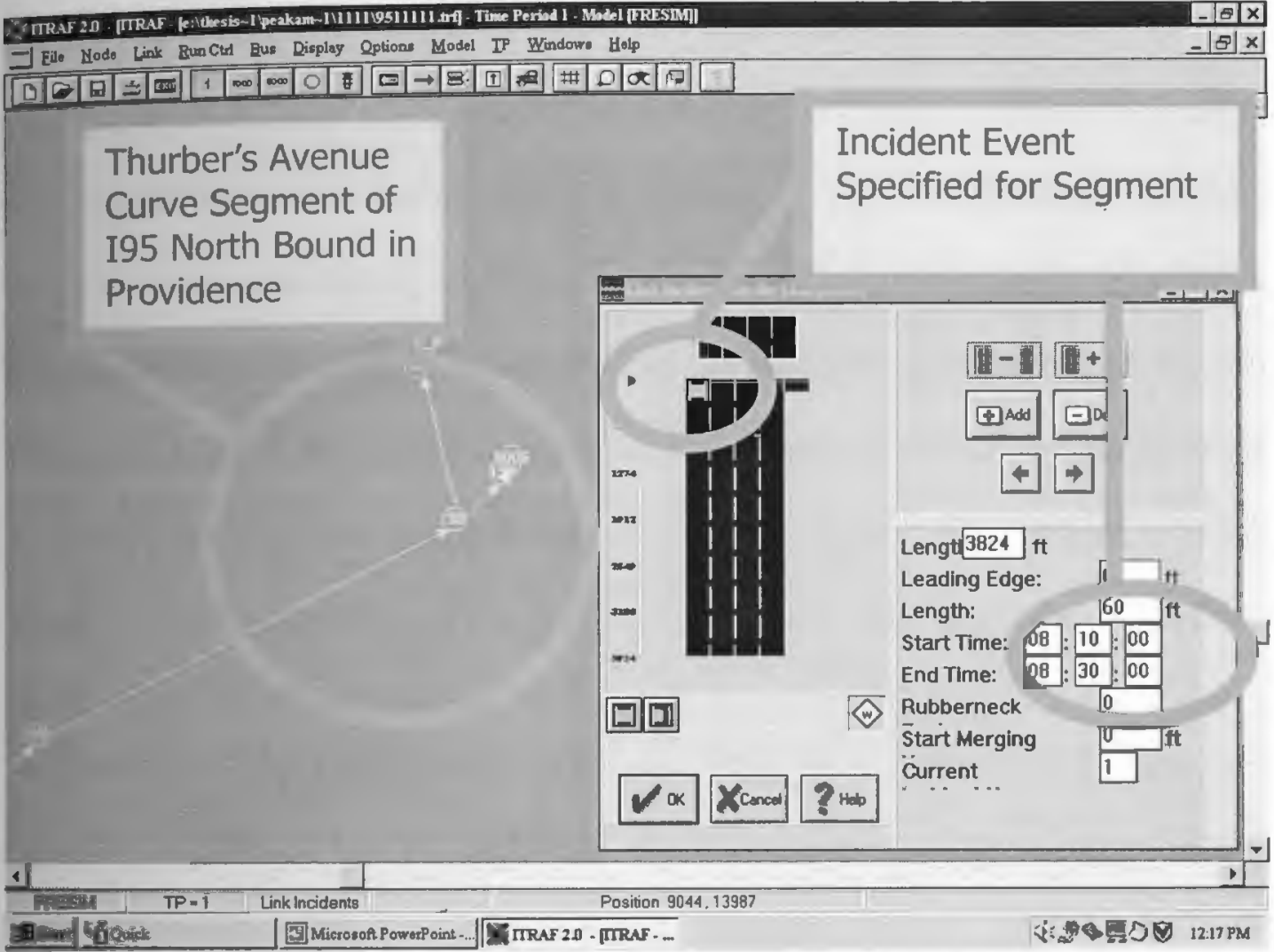

Figure 2-4 Graphical User Interface (GUI) Environment. (The segment of

network shown is the Thurber's Avenue curve section of I-95 NB in the study area.) 


\subsubsection{TRAFVU}

TRAFVU is an animation output processor that allows the user to view the results of a simulation. This movie player software is very helpful in model validation because the user can visually identify where the network is performing as intended and where problems exist. Also, TRAFVU has the ability to generate tables and twodimensional graphs for individual segments of the network. TRAFVU was developed by FHWA and is distributed through McTrans. Figure 2-5 displays a sample TRAFVU file as seen by a user on a computer monitor. The figure shown depicts an incident situation modeled during the research. 


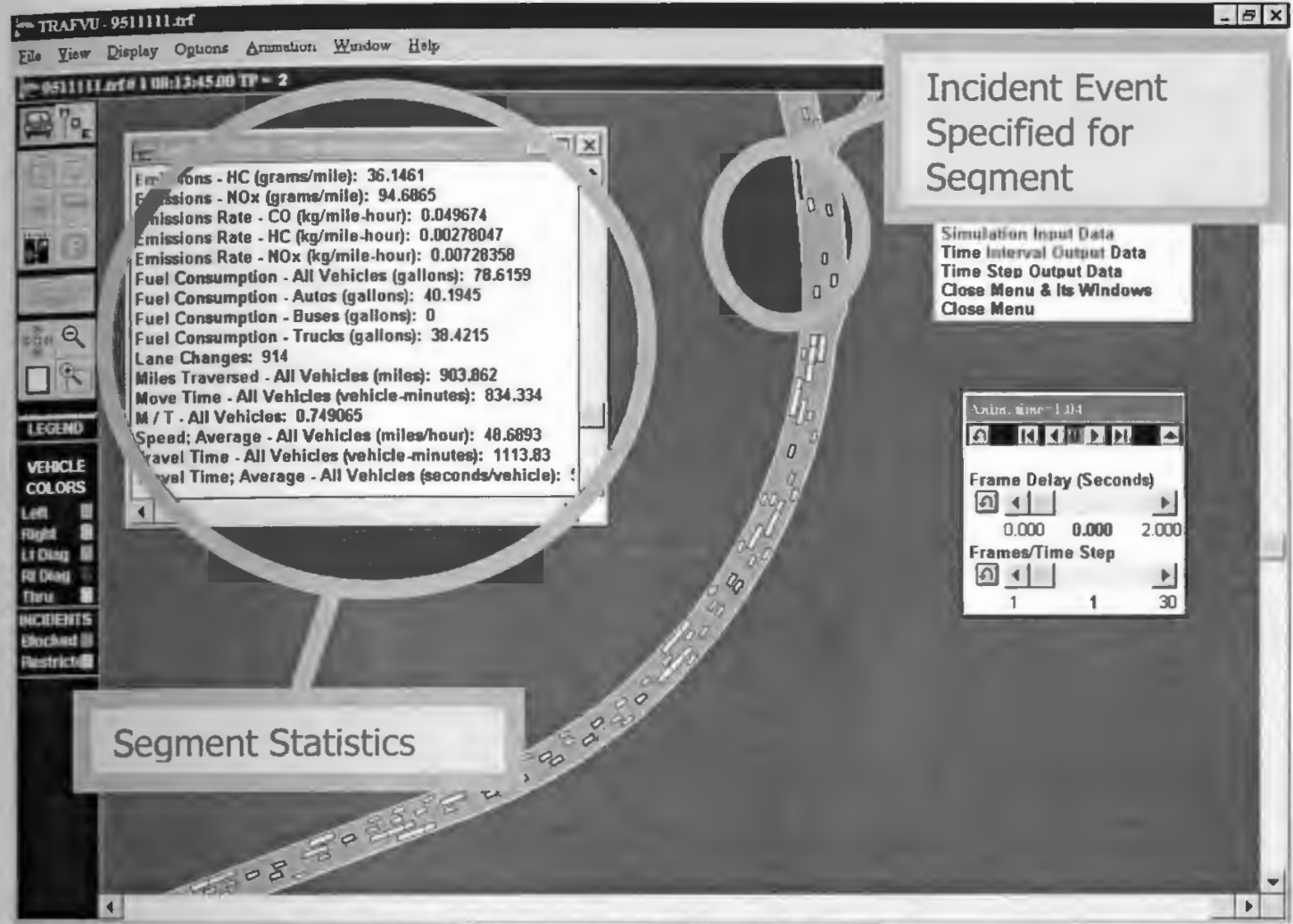

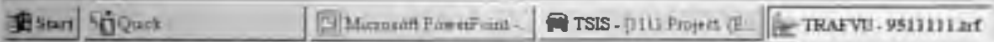

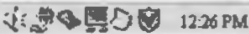

Figure 2-5 TRAFVU Movie Player Output File Display. 
This section cites and describes various successful applications of CORSIM and its companion software. These summaries are provided to illustrate where and how the model has been applied to help solve complex transportation engineering problems. The following examples were obtained from FHWA's TSIS support web site (www.tsis-fhwa.gov).

- Iowa Department of Transportation (IDOT) - Working with IDOT, FHWA Research and Development (R\&D) applied the advanced techniques within TSIS and CORSIM to evaluate proposed roadway interchange design alternatives in the Des Moines metropolitan area. The CORSIM simulation analysis provided a way for transportation engineers to evaluate several practical, but complex, design options. By utilizing the software it was estimated that millions of dollars were saved.

- North Dakota Department of Transportation (NDDOT) - FHWA R\&D assisted NDDOT in the use of TSIS and CORSIM to perform advanced operational analysis. The tool was employed to evaluate alternative corridor designs for a complex series of integrated freeway and non-freeway interchanges. CORSIM allowed NDDOT to demonstrate and communicate significant freeway performance degradation due to the introduction of one particular design where freeway speeds dropped approximately $20 \mathrm{mph}$. These speed differentials were determined to be significant and to pose a serious safety and operational problem. NDDOT realized a cost savings of at least $\$ 2.5$ million by eliminating the design and construction of a proposed on ramp. 
Another benefit was that approximately $\$ 600,000$ annual savings in peak-hour user costs.

- Virginia (VA) FHWA -The Virginia branch of FHWA utilized CORSIM and TSIS to analyze the impact of emergency vehicle traffic signal preemption across three coordinated intersections on Route 7 (Leesburg Pike near Landsdowne), VA. Using FHWA's Traffic Research Laboratory (TReL) as a test bed, ITT Systems utilized the Controller Interface Device (CID) to interface a modified version of the CORSIM simulation with Type 170 controllers programmed with the identical signal plans to those existing at the Route 7 intersections, with minor modifications to allow signal preemption. In this carefully controlled hardware-in-the-loop environment, CORSIM provided the microscopic simulation and tabulation of measures of effectiveness, but instead of CORSIM emulating controller features, the simulation package sent detector information to the physical controllers and read back phase indicators. Since CORSIM tabulates performance measures of effectiveness (MOE's), quantitative results with and without preemption measurements were obtained. Results showed that, for the geometric and operational conditions studied, the impact of emergency signal preemption on the signal coordination of the corridor was minor. Although several of the preemption cases had "statistically significant means" when compared to the base case (no preemption), the magnitude of the $1.6 \%$ increase in average travel time was considered minor. Relatively long spacing between intersections, platoon dispersion over long distances, and very long cycle lengths were judged to be some of the reasons 
for this increase. The information contained in this report will be of assistance to public agencies considering the installation on emergency signal preemption systems, and to ITS engineers.

- Oklahoma Department of Transportation (ODOT) - ODOT was planning extensive improvements to I-40 through Oklahoma City when FHWA helped the state use CORSIM to evaluate two design alternatives. Comparison of the operational results between the alternatives helped ODOT identify and recommend a preferred freeway design. In addition, the animation results for both alternatives were displayed at the public meetings. The movie animation helped ODOT discuss the traffic operations and answer questions from the public.

- Orlando, Florida (FL) - Preliminary functional capabilities, which are now part of TSIS, were used to perform a corridor operational analysis on several miles of a proposed expressway/I-4 systems interchange design to be located in downtown Orlando, FL. Based on the analysis, a recommended geometric design and traffic control enhancement produced a final design that dramatically improved overall system traffic performance. In addition, a final interchange design was recommended that allowed better traffic flow during construction with an overall design and construction savings of over $\$ 10$ million. 


\subsection{CORSIM Employed as a Tool for Route Diversion Strategies}

In 1995, two researchers, Catherine A. Cragg and Michael J. Demetsky, from the Virginia Transportation Research Council (A Cooperative Organization Sponsored Jointly by the Virginia Department of Transportation (VDOT) and the University of Virginia (UVA)) in cooperation with the FHWA undertook a study to determine whether simulation models could be used as decision aids for traffic diversion strategies. The study utilized CORSIM and TSIS to investigate improvements in the recovery phase of incident management and decision aids for defining strategies for effective traffic incident management along Interstate 66 in the Washington DC metropolitan area. These methods allowed for the identification and justification of cost saving measures while providing for safer and more effective traffic flow.

Cragg and Demensky ultimately concluded that CORSIM is a valuable tool in evaluating the effects of incidents on system wide traffic flow. Although they did find that the program cannot model every situation explicitly, an estimate of the amount of additional traffic the alternate route can accommodate can be determined. For incidents where only one lane is closed, there is often an optimum diversion percentage beyond which freeway delays increase due to friction caused by the weaving of vehicles attempting to exit. The physical capacity of the ramps and weaving sections to accommodate the diverted traffic is critical for successful diversion. If diverted vehicles cannot maneuver in the weaving section, excessive queuing on the mainline will result.

Similar to the diversion study performed by Cragg and Demensky, FHWA provided technical assistance to Montgomery County and the City of Rockville and 
demonstrated the applicability of CORSIM in the transportation planning process. Montgomery County and the City of Rockville, were already studying various alternatives to relieving congestion along Montrose Road, in Rockville, Maryland when FHWA was asked to provide technical assistance. CORSIM was used to show the operational benefits and degree of improvement in travel speeds of these proposed improvements.

\subsection{Summary}

Simulation has been used since the early 1950's to assist engineers with solving complex transportation problems that have not lent themselves to established analysis practices. Some examples of these, as described earlier, include freeway interchanges, intersections, and heavily traveled and extensively signalized arterials. Traffic diversion strategies for unplanned traffic incidents cannot be easily analyzed. Well-developed and validated simulation modeling could prove to be an effective tool in the development of a diversion strategy.

CORSIM has not been widely employed as a tool for the analysis of traffic diversion strategies. The reasons for this appear to be that the FRESIM model does not perform adequately when presented with large amounts of vehicles changing lanes. In addition, transportation engineers and researchers have not been able to allocate the time necessary to learn and apply this previously cumbersome simulation program. However, with development of ITRAF and TRAFVU, the modeling and validation processes are less demanding and more efficient. 
Also indicated in the various applications described, there are no documented cases of the software being used to model a freeway to highway route diversion. Cragg and Demensky's study involved an uninterrupted highway to urban arterial and the Montgomery County/Rockville example involved reallocation of traffic along a heavily congested arterial. These two studies are important because they increased the safety and functionality of the networks in question and attempted to set a modeling procedure for each of those types of traffic diversion. ,Through those studies, the programmers of the CORSIM software gain knowledge about improving the software for the future applications. 


\section{CHAPTER 3. RESEARCH METHODOLOGY}

\subsection{Developing the Simulation Model}

\subsubsection{Introduction}

One of the four objectives of the research is to define a representative modeling procedure for the use of CORSIM in the development of traffic diversion strategies. This objective is initially addressed in the first segment of this chapter and then continued through the second. The first segment discusses the procedure utilized to establish the network operating at normal AM peak traffic conditions (no incidents and no diversion). This segment begins with a detailed definition of the study area, proceeds through the accumulation and entry of the necessary modeling data, and concludes with the validation of the baseline model. The second segment discusses the procedure employed for modeling the location of the incidents, degrees of incident severity, and traffic diversion scenarios. These next two segments present comprehensive descriptions of the straightforward, yet thorough, modeling procedure developed. This procedure could be readily adapted by RIDOT, city or town planning or public works departments and applied to other transportation challenges in the State.

A comprehensive summary outline of the complete research methodology is presented in the next chapter, Chapter 4. This outline is presented as a concise reference for researchers who may intend to use this study as a platform for other knvestigations that could utilize microsimulation systems modeling. If the research methodology is already clearly defined, the initial development time for the simulation network is significantly reduced. By reducing the model development time, additional 
time can be allocated for other facets of the analysis; for instance, the experimental design could be expanded to include a higher degree of variability of specific factors.

\subsubsection{Defining the Study Area}

At the beginning of a modeling process the study area, or transportation system network, must be clearly defined. As stated and shown in the first chapter of this document, the study area included approximately 5 miles of I-95 NB and the entire length of Rt. 10 NB. This network was chosen because it consists of a distinct mainline route in I-95 NB, a distinct alternate route in Rt. $10 \mathrm{NB}$, a series of complex weaving and merging area, and is known to experience frequent incident related congestion. This study only investigates the NB direction of the network for two reasons. First, only one direction is needed to evaluate the simulation program (CORSIM) and the research methodology. Second, time constraints and the scope of the research did not permit any further investigations with the established methodology.

The mainline route in the study area is I-95 NB. This interstate freeway stretches along the eastern coast of the US as part of the freeway grid established in the 1950 's. I-95 is the most heavily traveled roadway in the Providence metropolitan area. The roadway operates at or near capacity during AM and PM peak travel periods for many reasons, but mostly because it is the most direct route from points south of Providence to two major metropolitan areas, Providence and Boston. Also, a driver on I-95 NB in the Providence metropolitan area has the option to exit or enter I$95 \mathrm{NB}$ at many points. These options include the choices to exit or enter via three 
other major state highways I-195, Rt. 10, and RI-146. I-95 NB through the study area has typically four-lanes. As can be seen in Figure 1-1, Rt. 10 NB is situated as a loop highway branching off from I-95 NB as it comes through Cranston, RI and reconnecting to I-95 NB in Providence. Also displayed in the figure is Thurber's Avenue Curve, which is a segment of I-95 NB that experiences frequent traffic incidents.

By visual inspection of the study area in Figure 1-1, it can be observed that Rt. 10 could be an appealing diversion route for travelers heading north to Providence in the case of a reduction in capacity on I-95 NB. By selecting Rt. 10 over I-95 a traveler can effectively avoid precarious roadway geometry, complex weaving, and merging sections that I-95 NB presents over its downtown segments. The sections of I-95 NB that present these characteristics and typical sections of Rt. 10 can be seen in Appendix A. Besides acting as a "loop" around these segments of I-95 NB, Rt. 10 NB has a termination point that provides three prime destination choices for travelers. Rt. 10 ends with three exit ramps presenting the following options: (a) enter the downtown Providence business district area, (b) re-enter I-95 NB, or (c) enter I-95 South (and access I-195 West to the coastline of Massachusetts). Rt. 10 NB has typically two-lanes, but expands to three and four lanes as it reaches it termination point in Providence. A typical two-lane section of Rt. $10 \mathrm{NB}$ can be seen in Appendix A.

The origin and termination points of the I-95 NB simulated corridor were chosen for two reasons. First, the beginning point had to be upstream form the I-95 NB exit to Rt. 10 NB and the termination had to be downstream from Rt. 10 re-entry 
point to I-95 NB. Second, the RIDOT had documented volume data for both of the exterior sections. The specific beginning and ending points of the simulated I-95 NB corridor studied correspond to the location of the documented traffic data that was available. These points for which traffic volume exists are located approximately one mile south of the exit to Rt. $10 \mathrm{NB}$ and $1 / 2$ mile north of the entry ramp from Rt. 10 NB. A more detailed discussion of the traffic volume data used for these points and throughout the network are presented in the preceding sections.

\subsubsection{Defining the Necessary Modeling Assumptions}

After a literature review was performed but before the network was modeled, a detailed list of modeling assumptions had to be formed. These assumptions must be made to limit the number of variables examined, decrease modeling time, and because certain parameters in the model cannot be modified without changing CORSIM programming language. Modifications to the encoded standard logic of the software is beyond the scope of this research. The major modeling assumptions made were:

1. That the alternate route (Rt. 10) and all on and off ramps on both the main line (I-95) and alternate route (Rt. 10) are operating under normal traffic flow conditions (no incidents) at all times;

2. That all pavement conditions are the same and that all surfaces have the same coefficient of friction;

3. That freeway grades will not need to be modeled because they are not maintained for distances long enough to significantly affect the network evaluator statistics; 
4. That all lane widths are consistent and that all shoulders have the same geometric characteristics;

5. That the traffic diversion modeling can begin exactly at the onset of the traffic incident time period and that it can end exactly at the end of the incident period;

6. That, due to a modeling protocol in CORSIM, modeling the Rt. 10 exit ramp and over pass in a way that is not exactly how this system exists will not create a difference in traffic flow characteristics through this section;

7. That all arterials directly connected to freeway ramps will not be affected by the diversion and are operating under normal flow conditions; and

8. That vehicles on the mainline will seek no other alternate route at the time of the incident other than Rt. 10 NB.

\subsubsection{Defining the Measures of Effectiveness}

Based on the literature reviewed and the preliminary evaluation of the CORSIM output files, it was decided that three summary network statistics would be used for validation of the model and evaluation of the diversion strategies tested. The measures of effectiveness (MOE) chosen were: cumulative network average vehicle speed and cumulative network travel time for two-hour simulations. It was noted that the cumulative average network speed could readily be converted into travel time if necessary. The two-hour simulation time interval chosen will be addressed in section 3.1.5.3. These network statistics are provided in tabular form in output text files for each simulation. These MOE's are defined as: 
Cumulative Average Network Speed $(\mathrm{mph})=$

Total Network Delay Time (Minutes) $=$
Total Number of Vehicle Miles

Traveled / Total Number of

Vehicle Hours Traveled

Average Delay per Vehicle Mile *

Total Number of Vehicle Miles

The reasons for choosing these MOE's as the network evaluators was because they are typically used in traffic analysis and can be readily associated to other network characteristics, like level of service (May 1990). CORSIM provides the cumulative network statistics needed to determine these MOE's as tabular network summary statistics which makes them easier to locate and record than some other statistics provided in the output files. Furthermore, speed and delay can be readily understood and can be converted to financial and environmental statistics readily. For example, delay time can be converted to a cost statistic by multiplying it by any hourly dollar factor or an environmental statistic by multiplying it by an emissions factor. The reason these conversion considerations are mentioned is because if this study, or study methodology, would be employed by a transportation agency it would be advantageous to employ evaluators that are used by policy and decision makers. 


\subsubsection{Obtaining and Inputting Modeling Data}

After the MOE's had been established, the next step was to determine what data would be ideal and, more importantly, what was actually available. Preferably, the input information for a model of this nature would include: roadway maps that shows the network geometry and lane configurations, detailed traffic volumes for all relevant points along the mainline and alternate route, all the percentages of the traffic exiting by ramp, and all the traffic volumes associated with each entry ramp. Early in the study it was determined that the high level of detail desired for the input data would not be attainable.

This section describes the information available and the methods of extrapolation used to generate the complete modeling data set. The section is divided into two sub-sections. The first deals with the roadway geometry and how it was obtained and modeled. The second covers the roadway and ramp traffic volumes and how they were obtained, extrapolated, and modeled.

\subsubsection{Roadway and Ramp Geometry}

The network geometry and lane configurations were obtained from satellite aerial photos. These aerial photos were downloaded from the Microsoft ${ }^{\mathrm{TM}}$ Terraserver ${ }^{\mathrm{TM}}$ website (www.terraserver.com). Aerial photos were chosen because they were readily available and because they provided the high level of detail needed to accurately model the network, especially with regards to lane configurations. The photos were downloaded at the scale of one-inch equals 300 feet, printed out, and then assembled on a $6 \times 8$-foot piece of foam board. The photos were then overlaid with 
transparency paper. The transparency overlay made it was possible to mark the map while having the option to remove the mark if modifications were necessary. This map enabled researchers to obtain the following network characteristics:

- mainline and alternate route orientation and geometry,

- number of lanes on all segments of both routes,

- exit and off ramp geometry,

- merge, diverge, and weaving area configurations, and

- acceleration and deceleration lane lengths.

With the map and transparency overlay assembled, a custom coordinate system was established so that the roadways and ramps of the network could be specified as nodes and links. The custom map was mounted on a wall and labeled with the coordinate system as it was developed. The coordinate system had to be measured in linear feet because that what is required by CORSIM. The positive horizontal, or $\mathrm{x}$, direction was specified from west to east beginning approximately 50 feet to the west of the western-most point on Rt. 10. The positive vertical, or y, direction was specified from south to north beginning approximately 100 feet south of the southernmost point on I-95. This mapping system allowed researchers to view all the network data that was being recorded and readily locate and modify any discrepancies efficiently.

After the number coordinate system specified, the network had to be defined as a series of nodes and links. "Nodes" and "Links" are terms used to describe the features of CORSIM that are used to model simulated networks. They are the most important design characteristics of the roadway network because all traffic volumes, 
roadway characteristics (number of lanes, free flow speeds, geometry), turning movements, and incidents are specified at the node or on the link. A node is placed at the following locations in the network: (1) wherever the network geometry changes from straight to having curvature; (2) at the boundaries of the network where traffic either enters or exits the system; (3) at all exit or entry ramps; and (4) wherever lanes are added or dropped. Links are basically the simulated roadway that connects the nodes. The entire study area roadway network was defined on the network map in the established coordinate system as nodes and links. Before the actual numbers were assigned to each node the researchers became familiar with the protocol for node labeling in the CORSIM User's Manual. The nodes for this modeling procedure are characterized as follows:

- External Nodes - an outer boundary, a node from which traffic enters or exits the system, represented in ITRAF by a hexagon and numbered 8000 8999.

- Internal Nodes - one completely embedded in the model. An internal node is represented by a circle and numbered from 1-750

It was determined that external nodes would be needed for every extreme entry and exit point of the network. Specifically, an external node would be needed at the beginning and ending of the two routes (I-95 and Rt. 10) and at the beginning of all entry ramps and at the termination of all exit ramps. Also it was decided that it would be advantageous to create a sequential numbering system for all the nodes. This numbering system was utilized because the output files arrange the output data by link, and the links are listed sequentially by order of beginning node. By instituting a 
sequential nodal representation from the southern-most points on each roadway a sequential output file is also created. A sequential output file was deemed valuable for output data collection and model validation phases. By increasing the node numbers by five, researchers are able to easily add nodes in places either unforeseen or desired later without eliminating the numerically ascending sequence established. Tables C-1 and C-2 located in Appendix C list the coordinates for all the nodes as scaled off the study map and estimates the length of the links created between the nodes. Table C-1 contains the geometric data used to model I-95 NB and Table C-2 contains all the geometric data used to model Rt. 10 NB.

The next series of figures utilizes the "Thurber's Avenue" curve segment of I95 NB to illustrate the roadway mapping, node and link determination, generation of the CORSIM input file using ITRAF, and final depiction of the modeled segment as displayed in a TRAFVU movie player file (Figures 3-1 through 3-4). The final depiction shows how the simulated network segment is represented in CORSIM. 


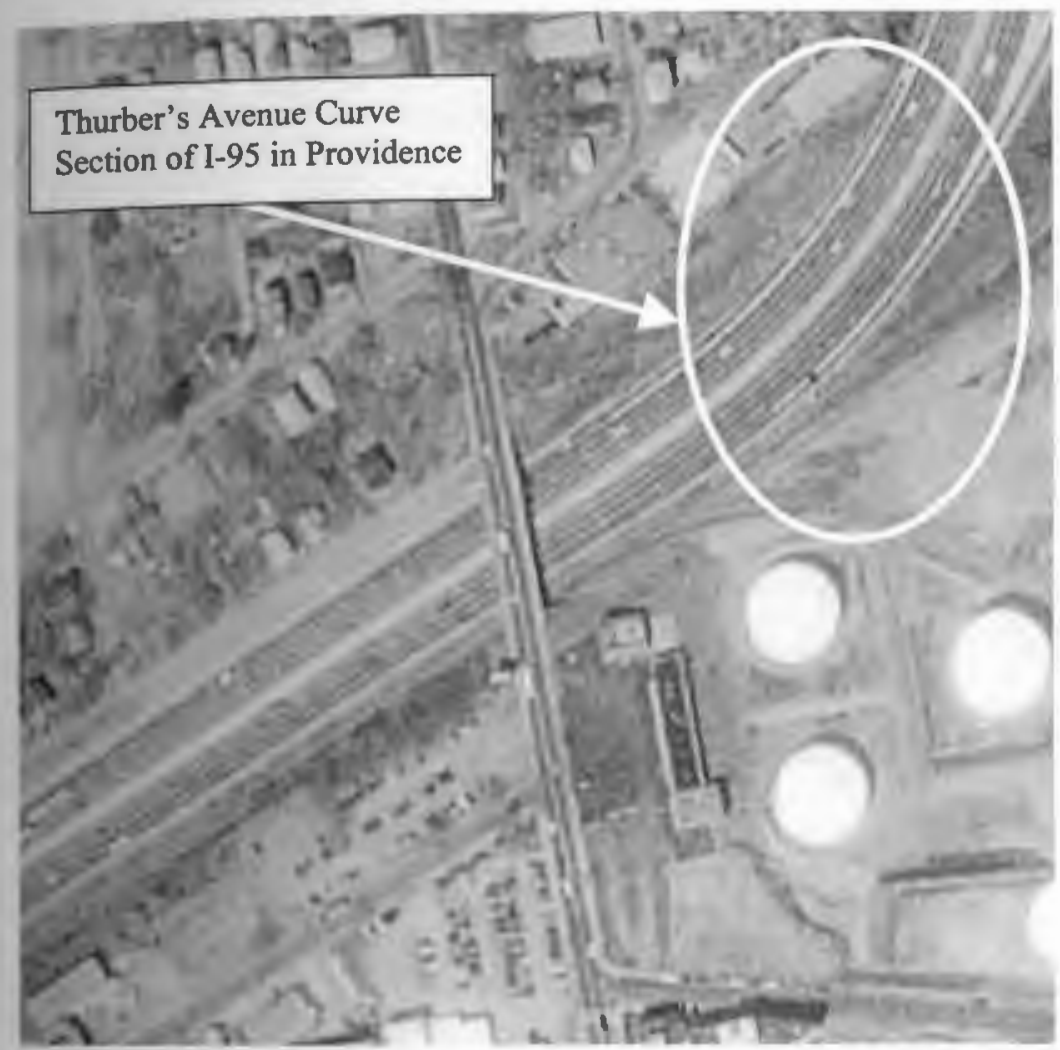

Figure 3-1 Aerial Photo of the Thurber's Avenue Curve Segment of I-95 in the

Study Area. (Photos like this were printed out and assembled on the foam board before being dimensioned using the scale provided by the website) 


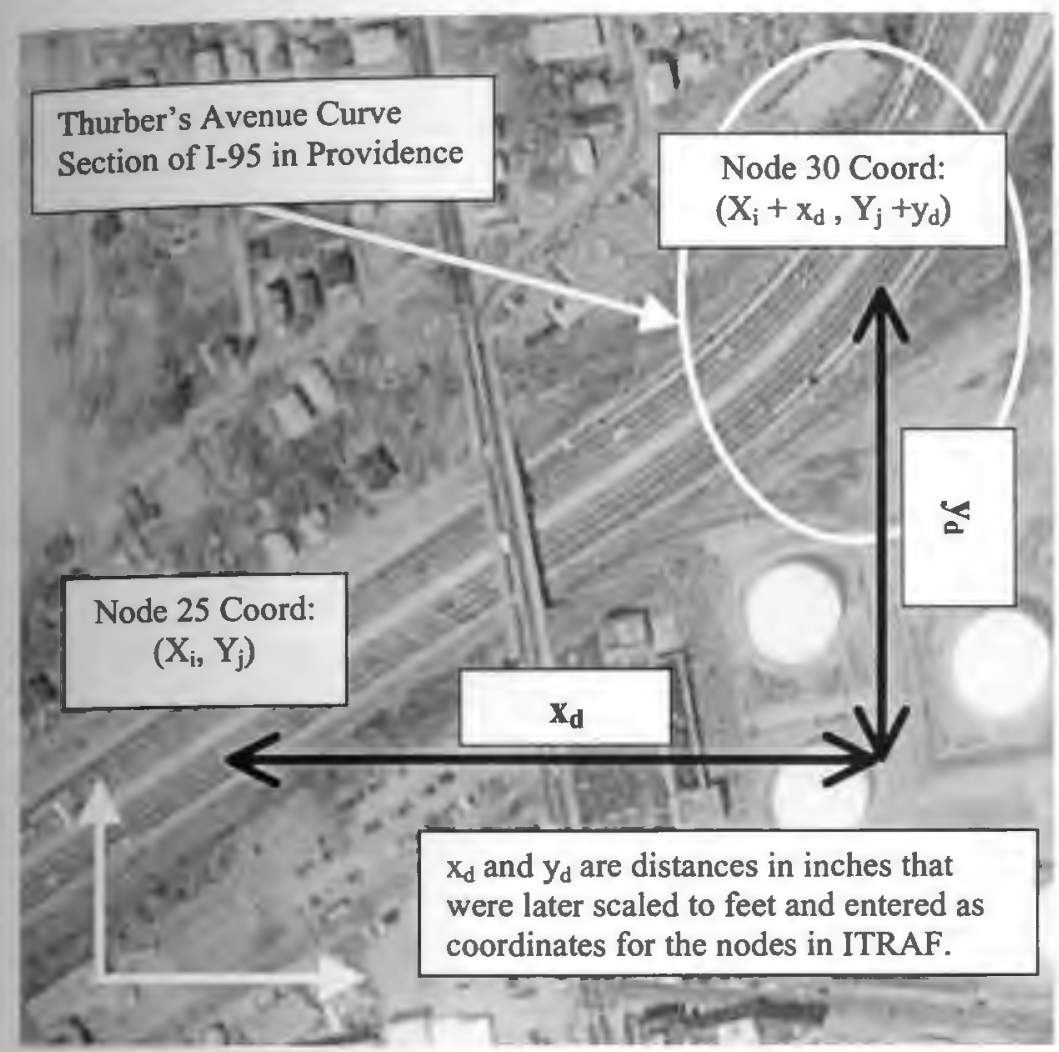

Figure 3-2 Aerial Photo of Thurber's Avenue Curve Segment as Marked During the Dimensioning of the Network Geometry. (At this point in the geometric modeling procedure the coordinates for the internal and external nodes were established.) 


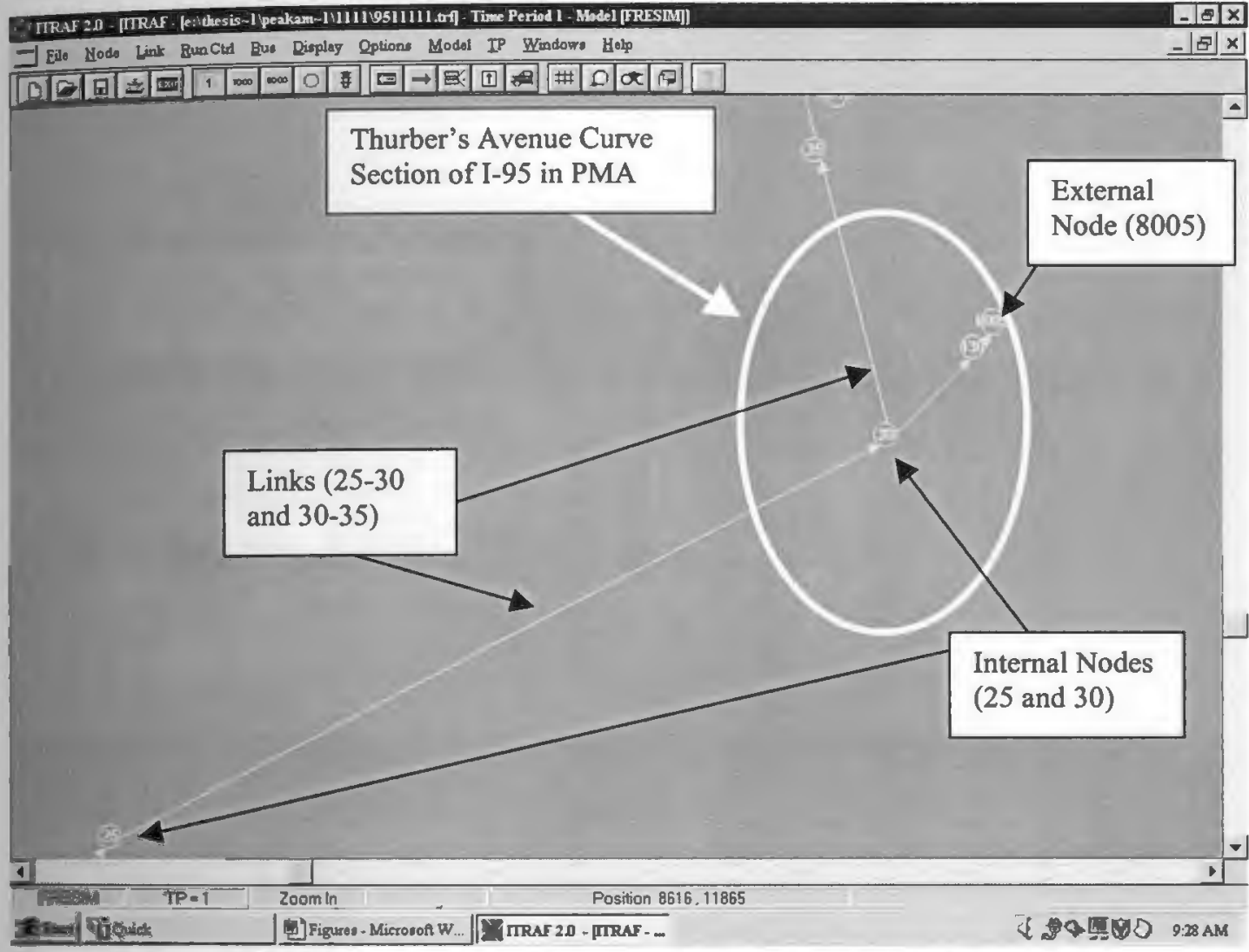

Figure 3-3 CORSIM Input File Generated for the Thurber's Avenue Curve

Segment of I-95 NB as Seen in the Previous Figures (Figures 3-2 and 3-3). 


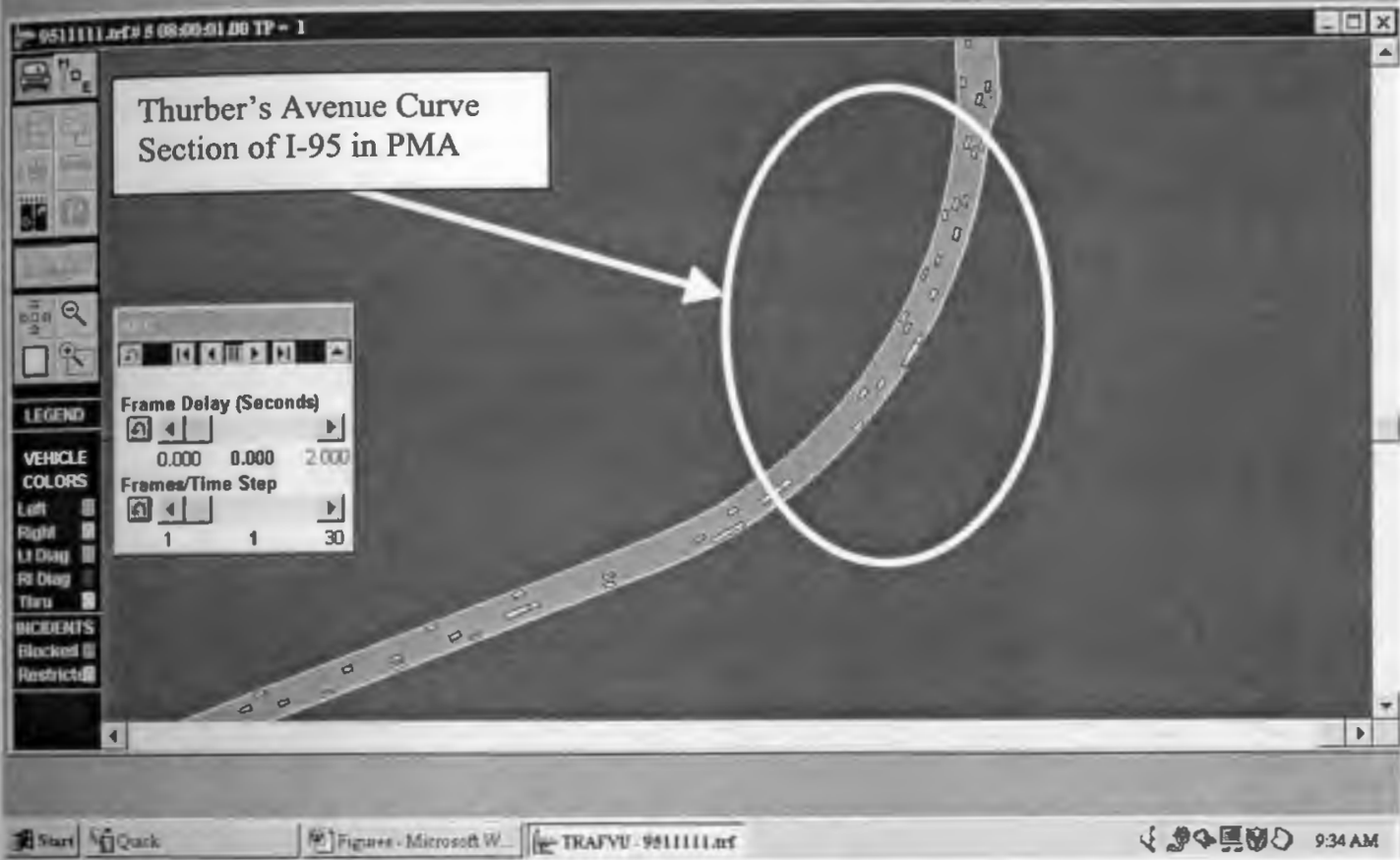

Figure 3-4 TRAFVU Movie Player Output File Representing the Thurber's

Avenue Curve Segment as Generated by CORSIM. 
At the beginning of the network modeling, it was thought that Rt. $10 \mathrm{NB}$ and I95 NB could be simulated as they exist in the real world. However, one uninterrupted flow facility cannot extend from the same type of facility. FRESIM does not allow an uninterrupted flow freeway (Rt. 10) to extend from another uninterrupted flow freeway (I-95). One of the major challenges of developing the simulation model arose while entering the network geometry.

The first attempt to overcome this obstacle was to utilize interface nodes. Interface nodes are used to seamlessly link the two models within CORSIM, FRESIM and NETSIM. Researchers experimented with deceiving the program by placing an interface node between the two "freeways". By modeling the network this way it was thought that the model would essentially resolve that the system being modeled went from freeway (I-95) to urban street network (Off Ramp to Rt. 10) and then back to freeway (Rt. 10). By using this short NETSIM link and interface nodes it was believed that the software would be manipulated into accurately modeling the network, as it existed. However, after initial tests were performed on the network established as such, it was determined that the simulated network was not performing as intended. This was concluded because the output statistics were determined to be un-reasonable and because unusual vehicle behavior was noted while monitoring the vehicles traveling across the network using the TRAFVU. It was determined that the network would have to modeled as two separate highways as opposed to one system as it exists in the real world. 
Modeling the network as two separate roadways was determined feasible because the network only had to be "broken" at three points. The three points are where Rt. 10 branches off of I-95 NB, where Rt. 10 enters I-95 NB at the southern most portion of the study area, and at the point where Rt. 10 returns to I-95 northern most portion of the study area. It was now necessary to calculate exactly how many vehicles would be exiting I-95 NB to Rt. $10 \mathrm{NB}$ and likewise back to I-95 NB at the termination Rt. $10 \mathrm{NB}$ for any given traffic volumes modeled. The procedure for determining the exiting and entering volumes for a given simulation situation is described in detail in the next section. In order to accomplish the separation of the network with in the model, the network was severed at its connecting ramp links. At the break between in the ramps external nodes were placed. These additional external nodes required traffic volumes based on the level of traffic volume modeled. Further explanation is provided in the validation sections found later in this chapter. Separating the two roadways was not found to detract from the integrity of the model.

\subsubsection{Roadway and Ramp Traffic Volumes}

With the network geometry established, the next step was to determine the traffic volumes to be entered at each entry node. The RIDOT was contacted in order to ascertain what traffic information could be provided for the two main roadways in the study area and the exit and entry ramps that connect to each. RIDOT provided their data submission sheets for the 1998 FHWA Highway Performance Monitoring System (HPMS) Report. 
The HPMS data was reviewed to determine which data was pertinent to this research. At first inspection, the HPMS data appears awkward because of the way that it is organized. Each section of all public roadways has its own page of data, but the report is not organized by roadway titles (For example: all of I-95 data is not grouped together, but rather, data for this roadway is dispersed among the other major highways in the state). The page for each section of roadway includes many statistics relating to the traffic on the section. However, for this research, only 3 section statistics were needed from the pages; average annual daily traffic (AADT), the Kfactor $(\mathrm{K})$, and the directional distribution factor (D). With these three factors the directional design hourly volume (DDHV) was computed and used as traffic volume input data for the model.

The DDHV typically represents the thirtieth highest peak hour volume of the year, and is calculated using the following equation:

$$
\mathrm{DDHV}=\mathrm{AADT} * \mathrm{~K} * \mathrm{D}
$$

(Equation 3-1)

Where: $\quad$ DDHV $=\quad$ directional design hourly volume $(\mathrm{vph})$

$$
\begin{aligned}
& \mathrm{AADT}=\quad \text { average annual daily traffic (vpd) } \\
& \mathrm{K}=\text { proportion of daily traffic occurring during the } \\
& \text { peak hour, expressed as a decimal } \\
& \mathrm{D}=\text { proportion of peak-hour traffic traveling in the } \\
& \text { peak direction, expressed as a decimal }
\end{aligned}
$$

Once the peak AM hourly volumes were determined multiplying these volumes by a factor relating to the new volume desired could attain any variation on this volume. For example, if the half peak volumes were needed then the peak volumes would be 
multiplied by a factor of one-half. Table 3-1 shows the calculations involved in determining the DDHV from the given information in the HPMS report. 
Table 3-1 Peak Hour Traffic Volumes Determined Using the HPMS Report.

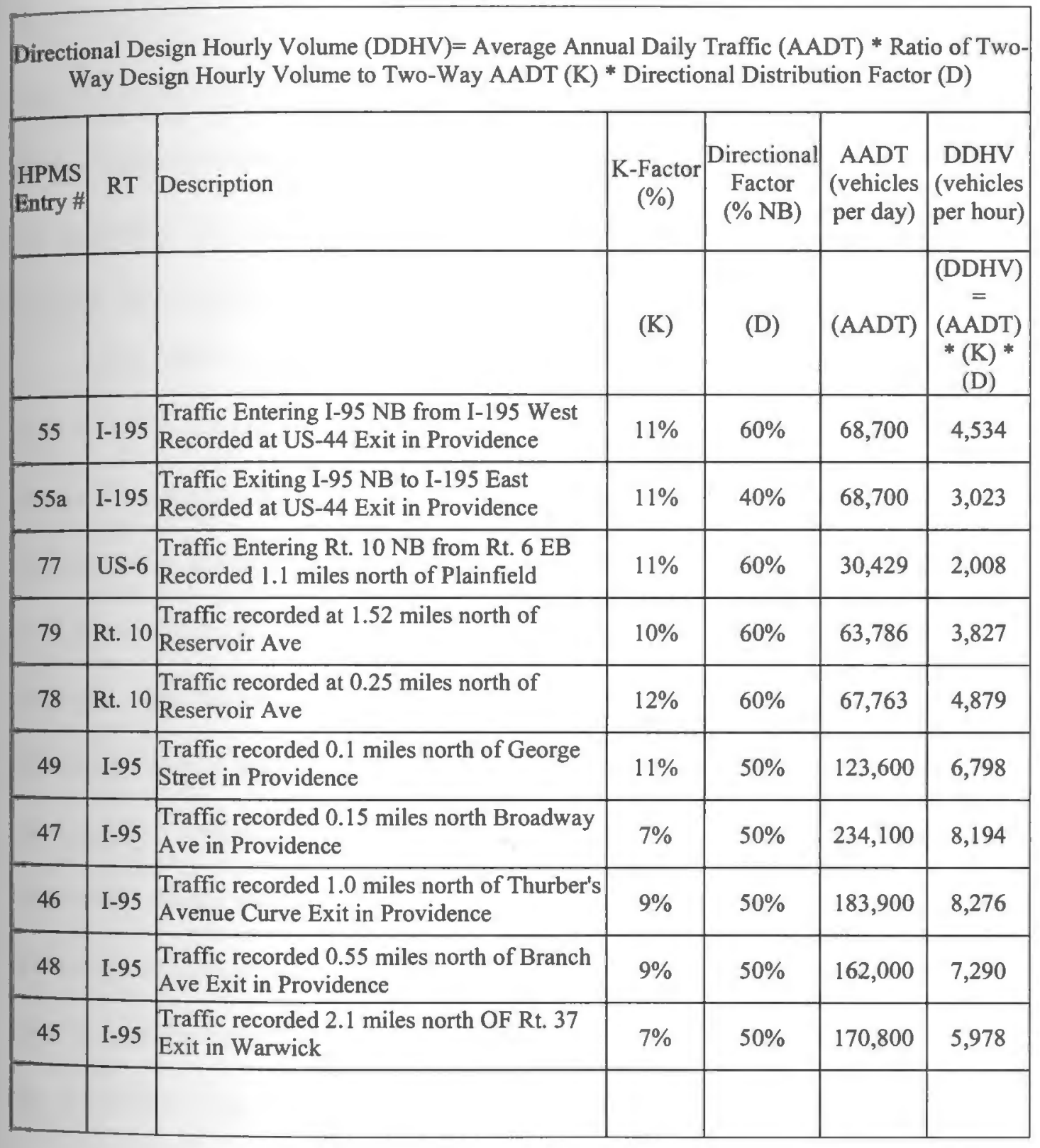


The volume data compiled for the network modeled consisted of five specific data points on I-95, two on Rt. 10, and three other locations at exit and entry points. These three other points are: where I-195 WB branches off from I-95 NB, where I-195 EB terminates at I-95 NB, and where Rt. 6 EB enters Rt. 10 NB. These three points are important with regards to the development of the complete traffic volume input because they represent places where large volumes of traffic enter or exit the network.

The HPMS data attained was sufficient enough to perform an extrapolation that was able to generate a complete traffic volume input data set. It was imperative that every external entry node had a representative DDHV. Extrapolating the HPMS data began by developing a traffic volume map of the network. This map is composed of the two mainline and alternate routes and all the exit and entry points in the network. The locations in between all entry and exit ramps in the network were labeled as critical points so that they could be linked to the calculations formed in the spreadsheet. These critical points correspond to every place along each route where the traffic volume will change due to exiting or entering traffic volume. For example, if there is an exit ramp, the traffic volume before is a critical point, and the volume after is a critical point because the volume will change based on some percentage of the vehicles exiting. The calculations used were based on deductive reasoning. For example, if a traffic volume upstream of an entry ramp was known and the volume directly downstream from the same ramp was known, then the difference in the volumes was determined equal to the amount of vehicles that should enter at that ramp. Figure 3-5 displays the volume map with the labels for the critical points for 
each roadway. Also shown in Figure 3-5 are the locations of the documented volume data obtained from the 1998 HPMS report. 


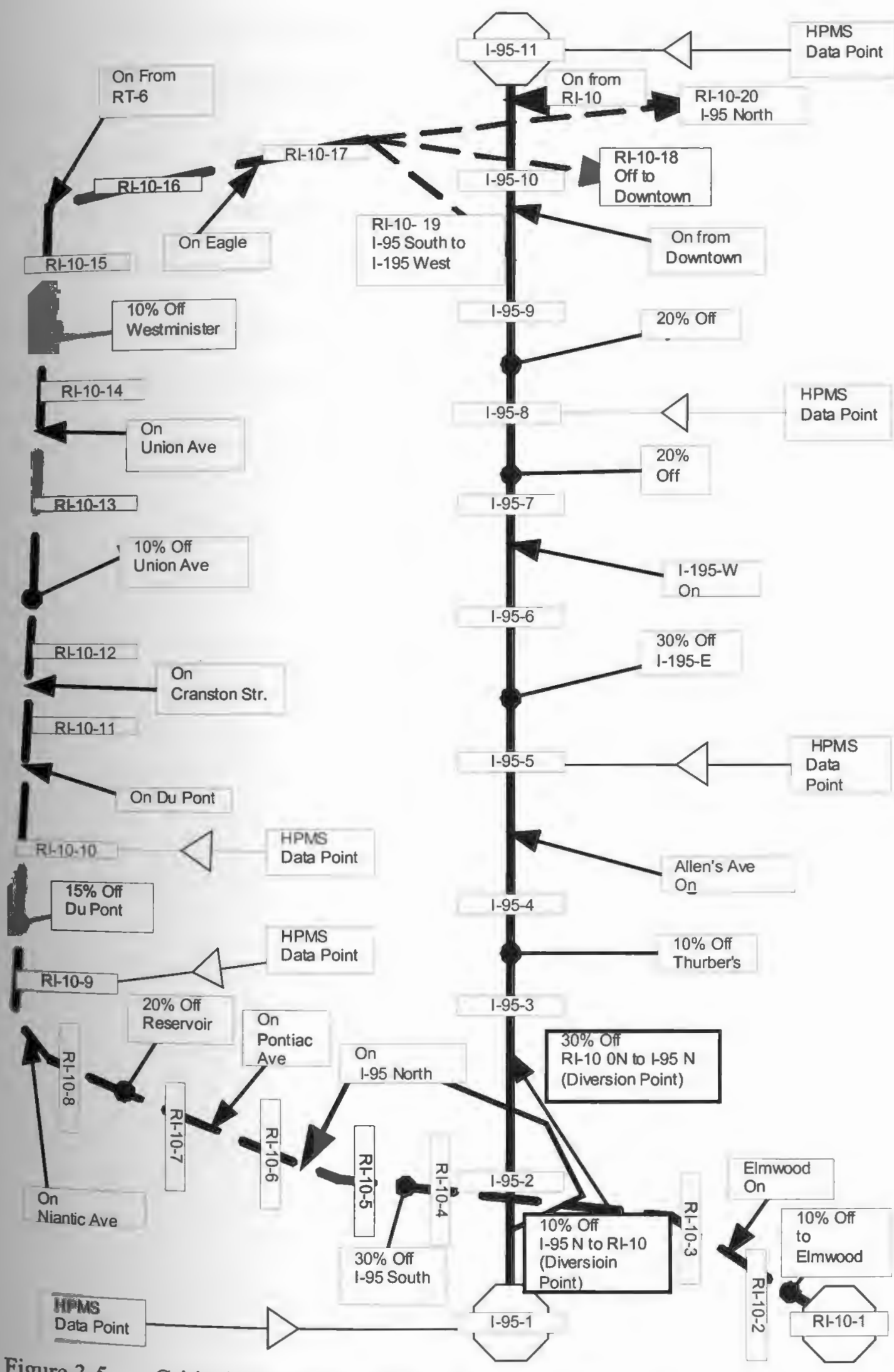

Figure 3-5 Critical Points in Study Area Roadway Network 
Using the traffic volume map displayed in Figure 3-5 a spreadsheet was created so that ranges of volumes and percentages of vehicles exiting could be manipulated until a representative data set was found. Since only limited documented data was known for each roadway and no documented data was available for the majority of their entry and exit ramps it was necessary to establish a method through which the volumes could be easily modified. Table 3-2 lists the peak hour volumes determined for the modeled roadways. The labels in this table; I-95-1, I-95-2, and so on, correspond to the critical points labeled in Figure 3-5. 
Table 3-2 AM Peak DDHV Used for the Model.

\begin{tabular}{|c|c|c|c|c|c|c|c|c|c|c|c|}
\hline \multirow{7}{*}{ 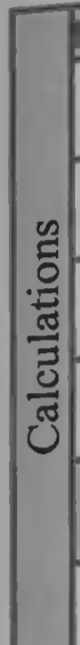 } & \multicolumn{11}{|c|}{ Tumber and Description of Points Corresponding to Traffic Volume Map for Study Area for I-95 } \\
\hline & I-95-1 & $1-95-2$ & $1-95-3$ & I-95-4 & I-95-5 & I-95-6 & I-95-7 & I-95-8 & I-95-9 & I-95-10 & I-95-11 \\
\hline & $\begin{array}{l}\text { Entry } \\
\text { Point }\end{array}$ & $\begin{array}{l}\text { Rt. } 10 \mathrm{~N} \\
\text { Off }\end{array}$ & $\begin{array}{l}\text { Rt. } 10 \mathrm{~N} \\
\text { On }\end{array}$ & $\begin{array}{c}\text { Thurber's } \\
\text { Off }\end{array}$ & Allen's On & $\begin{array}{l}\text { I-195 E } \\
\text { Off }\end{array}$ & $\begin{array}{l}\text { I-195 W } \\
\text { on }\end{array}$ & Broad Off & $\begin{array}{c}\text { Hartford } \\
\text { Off }\end{array}$ & $\begin{array}{l}\text { Downtown } \\
\text { On }\end{array}$ & $\begin{array}{c}\text { Rt. } 10 \\
\text { On }\end{array}$ \\
\hline & (vph On) & (\% Off) & (vph On) & $(\%$ Off) & (vph On) & $(\%$ Off) & $(\operatorname{vph} O \pi)$ & $(\%$ Off) & $(\%$ Off) & (vph On) & $\begin{array}{l}\text { (vph } \\
\text { On) }\end{array}$ \\
\hline & 6000 & $10 \%$ & 1000 & $5 \%$ & 1000 & $30 \%$ & 2500 & $10 \%$ & $30 \%$ & 200 & 1572 \\
\hline & \multicolumn{11}{|c|}{ Calculated Through Traffic at the Critical Point } \\
\hline & 6000 & 5400 & 6400 & 6080 & 7080 & 4956 & 7456 & 6710 & 4697 & 4897 & 6469 \\
\hline & \multicolumn{11}{|c|}{$\begin{array}{l}\text { Number and Description of Points Corresponding to Traffic Volume Map for Study Area for Rt. } \\
10\end{array}$} \\
\hline \multirow{13}{*}{$\frac{\sqrt{0}}{\frac{0}{0}}$} & RI-10-1 & RI-10-2 & RI-10-3 & $\mathrm{RI}-10-4$ & $\mathrm{RI}-10-5$ & RI-10-6 & RI-10-7 & RI-10-8 & RI-10-9 & RI-10-10 & $\begin{array}{c}\text { RI-10- } \\
11\end{array}$ \\
\hline & $\begin{array}{l}\text { Entry } \\
\text { Point }\end{array}$ & Elm. Off & Elm. On & To $[-95 \mathrm{~N}$ & To I-95 S & $\begin{array}{l}\text { I-95 On } \\
\text { (Div } \\
\text { Flow) } \\
\end{array}$ & $\begin{array}{l}\text { Pontiac } \\
\text { On }\end{array}$ & Res Off & Niantic On & $\begin{array}{l}\text { Du Pont } \\
\text { Off }\end{array}$ & $\begin{array}{l}\text { Du Pont } \\
\text { On }\end{array}$ \\
\hline & $($ vph On) & $(\%$ Off) & (vph On) & $(\%$ Off) & $(\%$ Off) & (vph On) & (vph On) & (\% Off) & (vph On) & $(\%$ Off) & $\begin{array}{l}(\mathrm{vph} \\
\text { On) }\end{array}$ \\
\hline & 3000 & $5 \%$ & 500 & $30 \%$ & $20 \%$ & 600 & 500 & $10 \%$ & 800 & $10 \%$ & 200 \\
\hline & \multicolumn{11}{|c|}{ Calculated Through Traffic at the Critical Point } \\
\hline & 3000 & 2850 & 3350 & 2345 & 1876 & 2476 & 2976 & 2678 & 3478 & 3131 & 3331 \\
\hline & \multicolumn{11}{|c|}{ Number and Description of Points Corresponding to Traffic Volume Map for Study Area } \\
\hline & RI-10-12 & RI-10-13 & RI-10-14 & RI-10-15 & RI-10-16 & RI-10-17 & RI-10-18 & RI-10-19 & RI-10-20 & & \\
\hline & $\begin{array}{c}\text { Cran. St } \\
\text { On }\end{array}$ & $\begin{array}{c}\text { Union Av } \\
\text { Off }\end{array}$ & $\begin{array}{c}\text { Union Av } \\
\text { On }\end{array}$ & $\begin{array}{c}\text { West Min } \\
\text { Off }\end{array}$ & $\begin{array}{c}\text { RI-6 On } \\
\text { (From } \\
\text { HPMS) }\end{array}$ & Eagle On & \begin{tabular}{|c} 
To \\
Downtow \\
$n$
\end{tabular} & To I-95 S & $\begin{array}{c}\text { To I-95 N } \\
\text { (Divert) }\end{array}$ & & \\
\hline & $($ vph On) & $(\%$ Off) & $($ vph On) & (\% Off) & (vph On) & (vph On) & (\% Off) & (\% Off) & (\% Off) & & \\
\hline & 200 & $10 \%$ & 200 & $10 \%$ & 2000 & 200 & $50 \%$ & $20 \%$ & $30 \%$ & & \\
\hline & \multicolumn{11}{|c|}{ Calculated Through Traffic at the Critical Point } \\
\hline & 3531 & 3178 & 3378 & 3040 & 5040 & 5240 & 2620 & 1048 & 1572 & & \\
\hline
\end{tabular}


Because of the modeling challenge described earlier, it was necessary to determine the traffic volumes at the three exit points that correspond to the points where the network was divided. Specifically, it was necessary to calculate how many vehicles exit to I-95 NB from Rt. $10 \mathrm{NB}$ at the southern portion of the study area, to Rt. 10 NB from I-95 NB, and to I-95 NB from RT-10 NB to I-95 NB at the termination of Rt. $10 \mathrm{NB}$ at the northern portion of the study area. These specific volumes were needed to link the two roadways. With these volumes, the network could be modeled as close to real-world conditions as possible. The traffic volumes at these three points could also be calculated for any given route diversion situation. Table 3-3 displays the peak volumes needed to link the two networks at this point in the research. 
Table 3-3 AM Peak Hour Volumes Needed to Link the Two Roadways.

\begin{tabular}{|c|c|}
\hline Dascription of Network & DDHV (vph) \\
\hline $\begin{array}{l}\text { Thaffic Exiting I-95 NB to Rt. } 10 \mathrm{NB} \\
\text { (Traffic Entering Rt. } 10 \mathrm{NB} \text { from I-95 } \\
\text { NB) }\end{array}$ & $\begin{array}{l}600 \text { (Based on } 10 \% \text { of the Traffic } \\
\text { Volume before the Rt. } 10 \mathrm{NB} \text { exit from I- } \\
95 \mathrm{NB} \text { ) }\end{array}$ \\
\hline $\begin{array}{l}\text { Thaffic Entering I-95 NB from Rt. } 10 \\
\text { NB at the southern most portion of the } \\
\text { tudidy area (Traffic Exiting Rt. } 10 \text { NB } \\
\text { to I-95 NB) }\end{array}$ & $\begin{array}{l}1005 \text { (Based on } 30 \% \text { of the Traffic } \\
\text { Volume before the I-95 NB exit from Rt. } \\
10 \mathrm{NB} \text { ) }\end{array}$ \\
\hline $\begin{array}{l}\text { Thaffic Entering I-95 NB from Rt. } 10 \\
\text { NB at the northern most portion of the } \\
\text { ffudy area (Traffic Exiting Rt. } 10 \text { NB } \\
\text { to I-95 NB) }\end{array}$ & $\begin{array}{l}1572 \text { (Based on } 30 \% \text { of the Traffic } \\
\text { Volume before the I-95 NB exit from Rt. } \\
10 \mathrm{NB} \text { ) }\end{array}$ \\
\hline
\end{tabular}


With the AM peak hour volumes determined, the geometric network of nodes and links assembled in ITRAF was revisited in order to add the entry volumes at the necessary entry nodes. Since the geometry of the network had been established earlier, the traffic volume data entry process was straightforward. To enter traffic volumes in the ITRAF GUI user environment the user must select the link between an exterior node and the first internal node of the roadway link so that a data entry window appears. In this window the volume of traffic to enter the system for a given time period is specified. At this time, the user can also specify the percentage of trucks for the roadway's segment and any predetermined lane distribution. If no lane distribution is specified, CORSIM randomly assigns the vehicles to their initial lanes. Lane distributions were not assigned because this research seeks to utilize the stochastic nature of the model. Time periods are user specified through the simulation time interval and will be explained in greater detail in the next section. Figure 3-6 displays the data entry process utilizing ITRAF. 


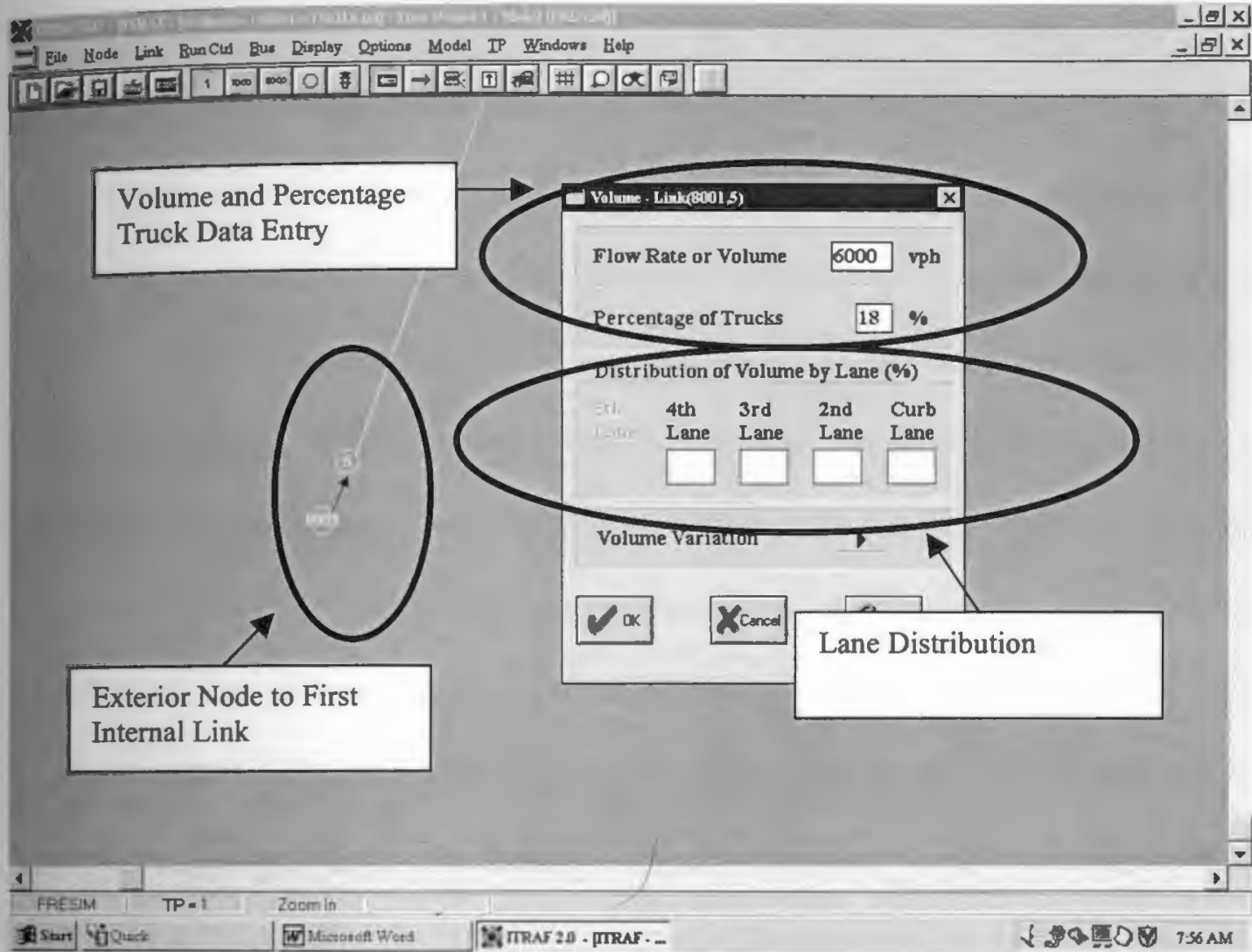

Figure 3-6 Traffic Volume Data Entry in ITRAF. 


\subsubsection{Simulation Time Considerations}

There are three main considerations when specifying time constraints within CORSIM. First is the pre-simulation time; the second is the overall simulation time period; and the third is the number of time periods within the overall simulation time. The pre-simulation time is the time prior to the actual simulation. During this time, the network is attempting to reach equilibrium, that is the number of vehicles entering the equals the number of vehicles exiting. During this period no network statistics are generated, but an indication is given at the conclusion of the allotted time. At the end of the specified time, CORSIM informs the user whether or not the network has reached equilibrium. This time can be left open allowing CORSIM to run until the network reaches equilibrium, at which point it will automatically start into the actual simulation period. For all simulations run) during this research, the pre-simulation time was not specified so that no simulation was begun before the network had reached equilibrium.

The actual simulation time interval was originally set at one-hour. This time was chosen because it was the standard found during the literature review. However, after a preliminary incident effect investigation was performed, it was decided that the one-hour time period was not allowing the traffic to fully recover after the event. Due to the degree of lane blockage and the duration of the incidents to be modeled, it was determined that a two-hour simulation time would be required.

The time intervals within the overall simulation time period are used for two purposes. First, by specifying time intervals within the total simulation time the user 
creates points at which CORSIM will generate cumulative network statistics. The two-hour simulation time used in this research was comprised of twelve ten-minute time periods. This means that for every ten-minutes of simulation time a cumulative table of network statistics were generated. These ten-minute reports aided researchers in assessing how the model was performing throughout the overall simulation time, especially as incidents were introduced. The specification of time intervals also enabled the researchers to insert various changes to the model during the course of the simulation. Specifically, researchers could vary volumes, percent of traffic exiting, and lane blockages for any number of time intervals created.

\subsubsection{Simulation Random Seed Numbers and Replications}

As discussed in the introduction, one of the assets of CORSIM is that it is a stochastic model that generates traffic volume patterns based on random seed numbers. The significance of the stochastic nature of the model is that the same traffic volumes are able to travel through the network in different patterns and produce varied network statistics. For every situation modeled, three simulations were performed, each with a different random seed number. This produced different outputs for the same traffic volumes and allowed for statistical analysis on the performance measures. The random seed numbers used were one (1), thirty-three (33), ninety-nine (99).

Three random seed numbers represent the three replications of each situation modeled. Whenever experiments are performed, it is very important to replicate the experiment, or sample, so that conclusions drawn about the results are not just based on one test. Basing conclusions on one sample leaves tremendous room for error 
because there is no other data to compare the results of the experiment with. Sampling also allows for statistical conclusions to be drawn about the results. The number of replications for each situation simulated in this research was three. Three samples in traffic simulation analysis is a professional standard (McShane 1994).

\subsubsection{Validating the Model}

One of the most important steps in any modeling process is the verification and validation phases. Verification and validation are methods used to assure that a model is performing as intended. These processes consist of various comparative tests that measure model consistency with theoretical and field data. Verification consists of comparing calculated values from a software model with corresponding values from the theoretical model. Model validation is divided into two distinct categories: conceptual validation and operational validation. Conceptual validation is a process of assessing the theoretical and software models against sound and accepted theoretical foundations. The operational validation process consists of comparisons between model operational predictions and measured real-world system operational behavior (Benekohal 1991).

This section explains the observational and operational validation of the specific simulation model developed for this research. An operational validation criterion includes threshold values on the quantitative measures of consistency between model results and real-world data. A model is never an absolutely accurate translation of the real-world system. Therefore, criteria for validation must be less than one hundred percent correspondence to the real-world system. However, criteria 
must be established so that a level of certainty in the model can be stated. The specific criteria and methods of operational validation for this model are discussed later in this chapter.

This section also reviews the execution of a computational comparison between the CORSIM model and Highway Capacity Software (HCS) model. Although the FRESIM model has been theoretically validated (Roess and Ulerio 1997), researchers determined that it would be advantageous to compare four representative links of the simulated network modeled to the results obtained from the standard traffic analysis software, HCS. The HCS tool is an extension of the Highway Capacity Manual (HCM) that was developed and continuously updated by the Transportation Research Board (TRB). This phase of the validation procedure was performed in order to provide researchers with an understanding of how the dynamic simulation model output was comparing to the static standard practice analysis technique.

\subsubsection{Observational Observation Utilizing TRAFVU}

The first step in the validation process was to run the simulations and then view them with the movie player companion software, TRAFVU. The validation simulations were run under the normal AM peak traffic volume conditions. Simulations run under normal conditions (experiencing no incidents) will be referred to as base line simulations throughout this section. The base line simulations will also employ the random seed numbers specified in the previous section $(1,33$, and 99$)$. By 
using this movie player companion software, researchers were able to assess how accurately the model was representing the actual conditions.

The first problems that came to the attention of the researchers during the observation of the base line simulations were the human errors in the modeling of the roadway geometry and lane alignments. If the lanes were not aligned correctly while modeling the network in ITRAF, then the traffic would become congested at the point of misalignment as if there was a sudden bottleneck. TRAFVU was excellent in exposing mistakes that may not have been evident by only examining output data.

Once these geometric set backs were resolved, the base line simulations were run again and the previously problematic areas were monitored. After the visual analysis rendered no problems and the model appeared to be functioning as intended, the next validation phase was begun.

\subsubsection{Operational Validation Utilizing the Floating-Car Technique}

The first step in the operational validation of the model was to establish the decision criteria for the level of significance at which the model would be considered statistically authenticate. It was determined that the operational validation of the model would consist of a statistical comparison of the simulation output speeds and the ones recorded in the field. The statistical comparisons performed were a F-test on the homogeneity of the variance and a two-sample t-test. The Bartlett's test determines if data sets are comparable. A two-sample t-test was performed in order to determine if the means of the two data sets could be considered not significantly different. Both the Bartlett's and the two-sample t-test were performed at a 0.05 level 
of significance, a standard found in the literature review (Meyers et al. 1998). The null $\left(\mathrm{H}_{0}\right)$ and alternative hypothesis $\left(\mathrm{H}_{1}\right)$ for each test are stated as follows:

F-test on the Homogeneity of the Variance:

$\mathrm{H}_{0}: \quad$ The Variances in the Two Data Sets Are Equal

$\mathrm{H}_{1}$ : The Variance in the Two Data Sets Are Not Equal

Reject $H_{0}$ in favor of $\mathrm{H}_{1}$ if the determined p-value is less than the stated level of significance $(0.05)$

Fail to Reject $\boldsymbol{H}_{\boldsymbol{0}}$ if the determined p-value is greater than the stated level of significance $(0.05)$

Two-Sample t-test on the Similarity of the Means

$\mathrm{H}_{0}$ : The Means of the Two Data Sets Are Equal

$\mathrm{H}_{1}$ : The Means of the Two Data Sets Are not Equal

Reject $\boldsymbol{H}_{0}$ in favor of $\mathrm{H}_{1}$ if the determined p-value is less than the stated level of significance $(0.05)$

Fail to Reject $\boldsymbol{H}_{0}$ if the determined p-value is greater than the stated level of significance $(0.05)$

If the field data sets were found to be equal to the simulation data sets, based on the statistical analysis, then the experiment would continue with the model 
unmodified. Conversely, if the field data sets were found to be significantly different from the simulation data then the model and all assumptions would be re-evaluated. At that point model modifications would be made, and the validation process would be repeated.

Once the decision criteria for the operational model validation were established the technique for field speed data collection was chosen. After reviewing methods described in various textbooks it was decided that the floating car technique would be adequate. The floating car technique is a practical, economic, and a widely used method in obtaining field data for roadways and validating traffic models (May 1990). The floating car technique consists of driving a test vehicle in the traffic stream and behaving as a standard vehicle. For this validation analysis the test vehicle would traverse both roadways (Rt. $10 \mathrm{NB}$ and I-95 NB) in the study area for a specified distance of one mile. The one-mile sections correspond to specific links within model. By using closely related roadway segments researchers gained insight into how the model output is comparing with the observed field data.

In order to obtain a representative speed for the segments of I-95 and Rt. 10 the floating car technique requires that the test vehicle behave like an "average" vehicle (May 1990). An "average" vehicle was defined for this research as a vehicle traveling in the second lane from the right, typically called the "travel lane" that attempts to pass one vehicle for every vehicle that passes it (May 1990). Both roadways were driven during the peak AM period under normal flow conditions (no incidents). The speeds noted for the three floating vehicle runs and the speeds obtained from the simulation runs can be found in Table 3-4 and Table 3-5. Table 3-4 contains the data 
complied for I-95 NB and Table 3-5 for Rt. 10. Also shown at the bottom of each of these tables are the results of the statistical tests discussed earlier in this section.

The simulated speeds shown for specified links in the network were obtained from the output files generated by CORSIM. The speeds obtained from the floating car analysis are for similar links on the actual roadways. Meaning the actual driven links begin about were the simulated links start and end one-mile after this start point. The simulated network lengths are more specific because they are generated in the software based on the node-to-node distances and the radius of curvature specified. For the floating car analysis only one-mile lengths were used because of the accuracy of the measuring equipment. The speeds for the floating car analysis were found by dividing the distance traveled by the time taken to reach the length. 
Table 3-4 Speeds and Statistical Test Results for Operational Validation of I-95 NB.

\begin{tabular}{|c|c|c|}
\hline $\begin{array}{l}\text { Conditions: Peak AM Commuter Traffic } \\
\text { (8 AM - 8:30 AM) }\end{array}$ & $\begin{array}{c}\text { Recorded Speed over } \\
1.0 \text { mile in Providence } \\
\text { I-95 (mph) }\end{array}$ & $\begin{array}{c}\text { Simulated Speed over } 1.3 \\
\text { miles of I-95 in Model } \\
\text { (mph) }\end{array}$ \\
\hline Test 1 & 58.4 & 56.6 \\
\hline Test 2 & 55.7 & 55.3 \\
\hline Test 3 & 53.5 & 56.5 \\
\hline Mam & 55.8 & 56.1 \\
\hline alundard Deviation & 2.45 & 0.70 \\
\hline \multicolumn{2}{|c|}{ Hamageneity of Variance F-test yields: Fail to Reject $\mathrm{H}_{0}$} & F-value $=12.25$ \\
\hline
\end{tabular}


Table 3-5 Speeds and Statistical Test Results for Operational Validation of Rt. 10 NB.

\begin{tabular}{|c|c|c|}
\hline $\begin{array}{l}\text { Conditions: Peak AM Commuter } \\
\text { Traffic (8 AM - 8:30 AM) }\end{array}$ & $\begin{array}{l}\text { Recorded Speed Over } \\
1.0 \text { mile of Rt. } 10 \text { in } \\
\text { Providence (mph) }\end{array}$ & $\begin{array}{l}\text { Simulated Speed over } 1.06 \\
\text { miles of Rt. } 10 \text { in Model } \\
\text { (mph) }\end{array}$ \\
\hline Test 1 & 60.2 & 56.5 \\
\hline Test 2 & 46.1 & 57.3 \\
\hline Test 3 & 57.7 & 57.2 \\
\hline Mon & 54.7 & 57.0 \\
\hline Stundurd Deviation & 7.55 & 0.46 \\
\hline \multicolumn{2}{|c|}{ Honnesueity of Variance F-tests yields: Reject $\mathrm{H}_{0}$} & F-value $=269.39$ \\
\hline 2-immile t-test p-value & & 0.650 \\
\hline
\end{tabular}


The F-value and p-value determined and stated in Table 3-4 for the operational validation of the I-95 NB roadway indicate the following:

- that the data is comparable because the variances are not significantly different, and

- that the means of the data sets are not significantly different.

The F-value and p-value determined and stated in Table 3-5 for the operational validation of the Rt. 10 NB roadway indicate the following:

- that the data set is not comparable because the variances were found to be significantly different, but that,

- based on the t-test performed, the means of the data sets are not significantly different.

This set of statements show that the model passed all aspects of the operational validation except the test on the comparability of the data sets for the Rt. 10. A possible remedy for this is to obtain more samples from the field to be incorporated into the F-test and t-test. However, due to time constraints this was not feasible. The model was considered to have passed the operational validation phase and was ready to be modified according to the incident/diversion experiments designed.

\subsubsection{Comparison with the Results of Highway Capacity Software Analysis}

The HCS software package has become the standard software for replicating the computational methodologies of the HCM, and it is regularly updated as changes to the manual occur (McShane et al. 1994). The HCM is the standard reference for capacity analysis procedures in the US (McShane et al. 1994). This document is 
published by the TRB and is supported by both the FHWA and the National Cooperative Research Program (NCHRP). After the model was validated through the observational and operational validation processes, output data from CORSIM for four specific links in the network were compared to results obtained from HCS software for the identical links. The HCS software was used to provide researchers with an understanding of how the CORSIM model results were relating to the standard procedures presented in the HCM. It is important to note that the HCS only performs analysis on individual segments of a network under static traffic conditions, were as this research sought to analyze the entire network under abnormal and dynamic traffic conditions. However, it was deemed important that the simulation model be compared to the standard practices.

The comparison consisted of determining the level of service (LOS) for the three distinct types of freeway sections as described by the HCM. The sections will consist of a two basic freeway sections ( $1 \mathrm{a}$ and $\mathrm{lb}$ ), one diverge area ramp junction section (2), and merge area ramp junction section (3). The actual sections examined were: (1a) a basic four-lane section of I-95 NB (1b) a basic two-lane section of Rt. 10 NB, (2) the diverging ramp junction section of I-95 NB to before the Rt. $10 \mathrm{NB}$ exit, and (3) the merging ramp junction section of Rt. 10 NB connecting I-95 NB to Rt. 10. These four sections were chosen because they are important in terms of how the network will function with regards to the route diversion analyzed.

The comparison proceeded by determining the LOS for the four sections using HCS and CORSIM. The LOS is a letter designation, ranging from A to F, that describes a range of operating conditions on a particular type of facility. The LOS 
was provided directly from HCS when the prevailing traffic and roadway conditions were entered. The CORSIM output data obtained from the output files for the link densities was converted to LOS designations by utilizing the tables for in the 1997 HCM (TRB 1997). It is important to note that the volumes and heavy vehicle percentages entered into HCS were identical to those entered into the CORSIM model and that the default values found in HCS were not adjusted.

After the LOS for each of the four sections was determined, the results were compiled in Table 3-6. Table 3-6 displays that the two techniques produced identical LOS designations for the I-95 NB sections (1a and 2). However, the Rt. $10 \mathrm{NB}$ sections show a discrepancy between the two designations. These results for the LOS are comparable. A platform for future research could be to determine why the discrepancies are occurring for the Rt. 10 sections analyzed. 
Table 3-6 LOS Comparison Between HCS and CORSIM

\begin{tabular}{|l|c|c|}
\hline Section of Roadway & LOS From HCS & LOS From CORSIM \\
\hline $\begin{array}{l}\text { (1a) Basic Section } \\
\text { of I-95 NB }\end{array}$ & D & D \\
\hline $\begin{array}{l}\text { (1b) Basic Section } \\
\text { of Rt. 10 NB }\end{array}$ & D & B \\
\hline $\begin{array}{l}\text { (2) Diverging Ramp } \\
\text { Junction Area of I-95 NB } \\
\text { upstream from the Rt. 10 } \\
\text { NB Exit Ramp }\end{array}$ & C & C \\
\hline $\begin{array}{l}\text { (3) Merging Ramp } \\
\text { Junction Area of Rt. 10 } \\
\text { NB downstream from the } \\
\text { I-95 NB entering traffic. }\end{array}$ & D & B \\
\hline
\end{tabular}




\subsubsection{Summary of Model Validation Process}

In summary, the validation process involved three phases. The first was the abservational phase, which entailed viewing the model in TRAFVU. The second was the operational phase, which consisted of a comprehensive statistical analysis. The third was a conceptual comparison between the standard freeway computational practice and the model used in this research. Although the validation was time consuming and difficult, it was essential to the modeling process. If the model was not validated, then it would be impossible to identify if it was accurately portraying the actual conditions it seeks to describe. Once the validation process was complete, the analysis methodology was addressed. 


\subsection{Analysis Methodology}

\subsubsection{Introduction}

This section will continue the description of the research methodology initiated in section 3.1. This section is divided into two major subsections that correspond to the two phases of analysis utilized during the research. The first phase presented explains the characteristics, or factors, associated with a traffic incident, how each of these factors was modeled in CORSIM, the preliminary experimental design and analysis that determined which of these factors would be fixed or varied in the second phase. The second phase involved expanding the preliminary experimental design to include greater ranges of variability for the factors found to be significant in the phase one analysis. This two-phase analysis technique was employed because it empowered researchers to reduce the range of variability for less significant factors while increasing the variability of those factors found to be most significant. By reducing the variability of certain factors the final experimental design was reduced, and modeling and simulation-processing time was saved.

\subsubsection{Phase-I - Preliminary Analysis}

\subsubsection{Defining the Factors Associated with Traffic Incidents and}

\section{Route Diversion}

Defining the factors for any experiment is a tactful step because a balance must be attained between the inclusion of all possible factors that could affect the outcome of experiment in some infinitesimal way and the failure to incorporate enough factors to accurately represent a given situation being tested. At the onset of this study it was 
noted that the factors chosen must be comprehensive enough to accurately represent the acident/diversion events tested, but, at the same time, be succinct enough to ensure that they could be quickly identified by a TMC at the time of an actual incident. As a guideline it was stated that: "the factors should be able to be quickly assessed through visual inspection over a video surveillance system comparable to the system employed by RIDOT". This guideline was established because incident management and traffic diversion focus heavily on decision and deployment time. Excess factors being evaluated at the time of an incident cost a TMC operator excess minutes. Additional minutes in assessment and response can decrease the safety of those involved in the incident and extend the related traffic congestion by hours. It was also determined that the factors will be analyzed as independent of each other.

Traffic incidents range in severity from one-vehicle breakdowns on roadway shoulders that last less than 10 minutes to events involving multiple vehicles that eliminate or severely reduce a roadway segment's capacity for hours. The scope of this research encompasses the investigation of the effects of "minor" traffic incidents only. At this point, it was important to establish the definition of a "minor" traffic incident as applied throughout this research. For this research, a minor traffic incident is any incident that blocks three or less lanes of traffic on a segment of freeway (I-95 NB) for a time less than or equal to forty minutes. This definition was formulated after reviewing literature concerning freeway incident events and diversion practices in the US (Laptopski 1999). I-95 NB is typically a four-lane roadway through the study area, so incidents involving all four lanes of traffic were deemed major and not prestigated. 
The first two factors determined are directly related to the definition of a minor traffic incident. Within the definition, two factors associated with traffic incidents can be distinguished. These factors are: (1) the number of lanes blocked by an incident or level of lane blockage and (2) the duration of incident. These two factors can be estimated by an observer at the scene of the incident or by a TMC operator monitoring an incident by surveillance video.

The next factor determined was the traffic condition, or level of traffic volume the network is operating at the time of an incident. This factor would significantly impact any decision that a TMC operator may make with regards to deploying a traffic diversion strategy. The notion that traffic volume would make a considerable impact on the network MOE's could be assumed intuitively, but the specific effect of distinct levels of traffic volume must be assessed. With the effects of various levels of traffic volume evaluated, TMC operators can confidently deploy or refrain from deploying a diversion strategy based on sound evidence. Also, traffic volume is a factor that can be readily assessed by a TMC operator. A TMC could make use of roadway detection devices like loop detectors or video detection software to immediately estimate a level of volume for the network.

The last and most difficult factor to characterize is the level of traffic diversion. For this research, this factor was defined as an exact percentage of traffic exiting from the mainline to the alternate route. The reason that this factor is challenging to define is because it would be impossible to divert a specific percentage of traffic to the alternate route during an actual incident situation. However, the 
percentage of traffic to be diverted could be linked to the strength of message disseminated at the time of the diversion.

With the four factors determined the focus was shifted towards the limits of variability for each factor. The range for the percentage of traffic to be diverted was set from zero to 20 percent above the normal percentage to exit at that point (10 percent). This range was instituted for two reasons. The first reason is that the single lane exit ramp to Rt. $10 \mathrm{NB}$ at peak AM volumes could not accommodate more traffic than 30 percent ( 20 percent for the diversion and 10 for traffic already exiting) of the I-95 NB through traffic at peak AM volumes. The traffic at this time would exceed the ramp's capacity and cause a congested situation. The second reason is that it has been noted in earlier research that CORSIM has difficulties simulating traffic exiting a freeway under severely congested conditions at percentages above $40 \%$ (Cragg and Demensky 1994).

The traffic volume range was set from AM peak to $1 / 2$ AM peak conditions. These limits were chosen for the volume because they could be easily calculated based on the earlier AM peak volume calculations and because they represent very distinct conditions that the roadways and ramps experience daily. The volumes utilized for this phase of experiments and the volumes used for the next phase are referenced in Appendix D. All volumes are based on the traffic flow map established earlier in Figure 3-6. This figure is also presented in Appendix D as Figure D-1.

The ranges for the level of incident and duration of incident are spelled out in the definition stated for minor traffic incidents. The ranges for the duration and level 
of incident were set at 20 to 40 minutes and zero to 20 percent respectively. Table 3-7 provides a summary of the factors to be modeled and the limits of their variability. 
Table 3-7 Limits of Variability for the Four Factors Established.

\begin{tabular}{|c|c|c|c|}
\hline $\begin{array}{c}\text { Traffic Volume } \\
\text { (vph) }\end{array}$ & $\begin{array}{c}\text { Level of Diversion } \\
\text { (\% of Traffic } \\
\text { Exiting the Main } \\
\text { Line) }\end{array}$ & $\begin{array}{c}\text { Level of Incident } \\
\text { (Lane Blockage) }\end{array}$ & $\begin{array}{c}\text { Duration of } \\
\text { Incident (Minutes) }\end{array}$ \\
\hline $1 / 2$ Peak AM & $0 \%$ & One Lane & 20 \\
\hline Peak AM & $20 \%$ & Three Lanes & 40 \\
\hline
\end{tabular}




\subsubsection{Traffic Incidents and Diversion in CORSIM Software}

Once the roadway network was established, entering a traffic incident situation in the ITRAF GUI was straightforward. The data required to specify the occurrence of a traffic incident include the following:

- the link on which the incident occurs

- the location of the incident on the link

- the length of roadway effected by the incident

- the time the incident begins and ends

- the rubberneck factor

The actual freeway in which segment the incident will occur is the "Thurber's Avenue" curve segment of I-95 NB. In the simulated network, this segment is the curved link between nodes 15 and 20. The incident was positioned at northern most end of this simulated link because on the actual segment this is most poorly designed section of the segment.

The length of the simulated roadway link that is affected by the incident is related to how many cars are involved in each lane of the traffic incident. The CORSIM manual advises that the incident be modeled as if each car is 20 feet. For this research a lane blockage consists of two cars. In addition to this length an additional 20 feet ahead of the incident should be included as a "rubbernecked zone". The rubbernecked zone was created by specifying an incident in the lane(s) to be blocked that consists of only a rubberneck factor (no physical blockage). The rubberneck factor is a characteristic associated with driver's tendency to slow down to observe traffic incidents. The factor was fixed at $10 \%$ because prior research 
determined that this setting most accurately describes what has been recorded for incident data (Cragg and Demensky 1994).

The total simulation time was two hours with the incident occurring ten minutes after the start of the simulation. This incident start time was chosen because it provided a period of normal traffic conditions to compare with subsequent periods of abnormal traffic conditions. As stated earlier, the limits incident duration range from 20 to 40 minutes. This meant that any incident modeled would be concluded before one hour of simulation has elapsed. By concluding the incident within one hour of simulation time the network would always have at least one hour to attempt to recover from the incident situation.

\subsubsection{Overview of the $2^{\mathrm{k}}$ Factorial Statistical Analysis Technique}

The $2^{\mathrm{k}}$ factorial experimental design was chosen for the preliminary analysis because it allows all factors for a given experiment to be analyzed at "high" and "low" levels and concludes which are the most significant. This conclusion is drawn based on statistical quantifiers given in a general linear model analysis of the variance (ANOVA) table. This technique is recommended for experiments where each factor's effects and the various interactions of factor's effects on the measures of effectiveness (MOE's) are unknown (Meyers et al. 1998). By utilizing this experimental design the significant factors can be investigated at greater degrees while those found to be insignificant can be fixed or removed from the expanded experimental design. For example, if the level of traffic volume was found to have had a significant impact while the duration of incident was found to have had an insignificant impact on the 
network evaluators, then the degrees of duration of incident would be fixed at the high and low levels established, while the degrees of traffic volume would be varied to obtain the most effective diversion scenario.

The significance of each factor is based on the computed p-values for the factors and combinations of factors and the stated level of significance. The level of significance used was 0.05 , the standard in statistical analysis of this nature (Meyers et al. 1998). The data was analyzed using MINITAB ${ }^{\mathrm{TM}}$ statistical analysis software. This software was obtained from the Department of Industrial Engineering and is a typical software package used in statistical analysis (Meyers et al. 1998).

\subsubsection{Application of the $2^{k}$ Factorial Statistical Analysis Technique}

The first step in the application of the $2^{k}$ Factorial Statistical Analysis Technique was to determine the two distinct levels at which each factor would be varied. It was decided that the factors be set at their high and low limits in accordance with the procedure for the analysis. MINITAB ${ }^{\mathrm{TM}}$ requires that numerical labels be attached to the levels of the factors. For the ranges specified in this phase, the number -1 was attached to the lower limits and the number +1 to the upper limits. Table 3-8 displays the levels at which the factors were fixed and how they were coded for their entry in MINITAB'M. 
Table 3-8 Levels of the Factors Analyzed in Phase-I Simulations.

\begin{tabular}{|c|c|c|}
\hline \multirow{2}{*}{ Factors } & \multicolumn{2}{|c|}{ Levels } \\
\cline { 2 - 3 } & -1 & +1 \\
\hline Traffic Volume (vph) & $-1=1 / 2$ Peak AM & $+1=$ Peak AM \\
\hline $\begin{array}{c}\text { Level of Diversion (\% of Traffic } \\
\text { Exiting the Main Line) }\end{array}$ & $-1=0 \%$ & $+1=20 \%$ \\
\hline Level of Incident (Lane Blockage) & $-1=$ One Lane & $+1=$ Three Lanes \\
\hline Duration of Incident (Minutes) & $-1=20$ & $+1=40$ \\
\hline
\end{tabular}


For these preliminary experiments it was necessary to determine the volumes at all the critical points in the network for both the peak and $1 / 2$ peak AM traffic and for both the $0 \%$ traffic diversion and $20 \%$ traffic diversion scenarios. This was necessary because the input volumes in each of the situations are unique and will significantly affect both the mainline and the alternate route. Appendix D contains tables that list, in accordance to all the critical points and entry and points established in Figure 3-5, all the input volumes used in the all Phase-I and Phase-II experiments.

With the factors established, the focus was shifted to the MOE's, or responses, to be examined. Since the speed, travel time, and delay time are all directly related, it was determined that only the cumulative average network speed would need to be analyzed for Phase-I. The cumulative average network travel time and total network delay time are both derived from the cumulative network average speed and the specified free flow speeds for the freeway links modeled. Phase-II analysis will provide analysis and discussion of all three evaluators.

Each combination of the factors at two different levels specified represents one simulated situation. For example, the network operating at AM peak traffic conditions, experiencing a three-lane incident lasting 20 minutes with no diversion deployed was one situation. The total number of situations that can be formed from four factors at two levels is 16 . Each of these 16 different situations was modeled and replicated by assigning three distinct random seed numbers. After replications were created the total number of simulation runs for Phase-I was 48 . The speed data needed was obtained from the network statistics found in the CORSIM output files and recorded in spreadsheets. These spreadsheets are located in Appendix E, F, G, and H. 
These four appendices contain all output data collected for both phases of experiments and for all three MOE's. The output data for the Phase-I experiments is found at the beginning of Appendix E, the appendix containing the output data for the AM Peak situations modeled, and Appendix $\mathrm{H}$, the appendix containing the output data for the $1 / 2$ AM Peak situations modeled. Actual CORSIM output files could not be printed out and included because each simulation output file consists of more than 100 pages.

The first step in the analysis was to collect and organize the network speed output data from each of the 48 CORSIM simulation output files. Since the network was modeled as two roadways, the network speed had to be calculated as a weighted average. A cumulative network average speed was found by dividing the sum of all the miles traveled on the two roadways and their ramps by the sum of the time taken to travel these respective distances. Table 3-9 lists the cumulative average network speed for each situation simulated. A complete display of the output data collected and the calculations performed to obtain the MOE's is located in tabular form in Appendix E and H. This table was entered into MINTAB ${ }^{\mathrm{TM}}$ and a general linear model ANOVA table was generated. 
Table 3-9 Phase-I Experimental Design with Speeds Determined by CORSIM.

\begin{tabular}{|c|c|c|c|c|}
\hline $\begin{array}{l}\text { Traffic Volume } \\
\text { (vph) }\end{array}$ & $\begin{array}{c}\text { Level of Diversion (\% of } \\
\text { Traffic Exiting the Main } \\
\text { Line) }\end{array}$ & $\begin{array}{l}\text { Level of Incident } \\
\text { (Lane Blockage) }\end{array}$ & $\begin{array}{l}\text { Duration of Incident } \\
\text { (Minutes) }\end{array}$ & \multirow{3}{*}{$\begin{array}{l}\text { Cumulative Average } \\
\text { Network Speed } \\
\text { (mph) }\end{array}$} \\
\hline$-1=1 / 2$ Peak & $-1=0 \%$ & $-1=$ One Lane & $-1=20$ Minutes & \\
\hline$+1=$ Peak & $+1=20 \%$ & $+1=$ Three Lanes & $+1=40$ Minutes & \\
\hline-1 & -1 & -1 & -1 & 60.5 \\
\hline-1 & -1 & -1 & -1 & 60.5 \\
\hline-1 & -1 & -1 & -1 & 60.6 \\
\hline-1 & -1 & -1 & +1 & 60.5 \\
\hline-1 & -1 & -1 & +1 & 60.5 \\
\hline-1 & -1 & -1 & +1 & 60.6 \\
\hline-1 & +1 & -1 & -1 & 61.6 \\
\hline-1 & +1 & -1 & -1 & 61.8 \\
\hline-1 & +1 & -1 & -1 & 60.2 \\
\hline-1 & +1 & -1 & +1 & 60.6 \\
\hline-1 & +1 & -1 & +1 & 60.5 \\
\hline-1 & +1 & -1 & +1 & 60.4 \\
\hline-1 & -1 & +1 & -1 & 35.8 \\
\hline-1 & -1 & +1 & -1 & 46.4 \\
\hline-1 & -1 & +1 & -1 & 46.5 \\
\hline-1 & -1 & +1 & +1 & 15.4 \\
\hline-1 & -1 & +1 & +1 & 28.4 \\
\hline-1 & -1 & +1 & +1 & 25.9 \\
\hline-1 & +1 & +1 & -1 & 50.5 \\
\hline-1 & +1 & +1 & -1 & 39.2 \\
\hline-1 & +1 & +1 & -1 & 49.7 \\
\hline-1 & +1 & +1 & +1 & 17.6 \\
\hline-1 & +1 & +1 & +1 & 17.4 \\
\hline-1 & +1 & +1 & +1 & 19.7 \\
\hline+1 & -1 & -1 & -1 & 43.0 \\
\hline+1 & -1 & -1 & -1 & 42.3 \\
\hline+1 & -1 & -1 & -1 & 43.0 \\
\hline+1 & -1 & -1 & +1 & 30.0 \\
\hline+1 & -1 & -1 & +1 & 33.7 \\
\hline+1 & -1 & -1 & +1 & 34.8 \\
\hline+1 & +1 & -1 & -1 & 27.5 \\
\hline+1 & +1 & -1 & -1 & 51.8 \\
\hline+1 & +1 & -1 & -1 & 16.8 \\
\hline+1 & +1 & -1 & +1 & 22.6 \\
\hline+1 & +1 & -1 & +1 & 25.0 \\
\hline+1 & +1 & -1 & +1 & 17.7 \\
\hline+1 & -1 & +1 & -1 & 22.0 \\
\hline+1 & -1 & +1 & -1 & 24.4 \\
\hline+1 & -1 & +1 & -1 & 24.3 \\
\hline+1 & -1 & +1 & +1 & 15.5 \\
\hline+1 & -1 & +1 & +1 & 19.6 \\
\hline+1 & -1 & +1 & +1 & 19.6 \\
\hline+1 & +1 & +1 & -1 & 16.6 \\
\hline+1 & +1 & +1 & -1 & 25.9 \\
\hline+1 & +1 & +1 & -1 & 12.5 \\
\hline+1 & +1 & +1 & +1 & 19.4 \\
\hline+1 & +1 & +1 & +1 & 19.1 \\
\hline+1 & +1 & +1 & +1 & 21.5 \\
\hline
\end{tabular}


Before an ANOVA table is generated, it is important to determine if the data sets were comparable. To determine this, the Bartlett's test on the homogeneity of the variance was performed, this test hypothesis was stated as follows:

$\mathrm{H}_{0}$ : the variance in data sets is homogeneous

$\mathrm{H}_{1}$ : the variance in data sets is not homogeneous

Bartlett's test is used when the data comes from normal distributions; Bartlett's test is not robust to departures from normality (Meyers et al. 1998). The criterion for rejection of the $\mathrm{H}_{0}$ is if the calculated p-value is less than the stated level of significance. The level of significance for the tests performed was 0.05 , a statistical standard for tests of this nature (Meyers et al. 1998). The Bartlett's test indicated that the variance in the data sets could be considered homogeneous and that the data sets were comparable. Table 3-10 displays the p-values determined for each of the four factors tested and the significance of this result. 
Table 3-10 Results of the Test on the Homogeneity of the Variance for Speed Data.

Cest on the Homogeneity of the Variance

All data test at 0.05 Level of Significance

Null Aypothesis $\left(\mathrm{H}_{0}\right)$ : No significance Difference in Variance

Altemative Hypothesis $\left(\mathrm{H}_{1}\right)$ : Significance Difference in Variance

Crileria for Rejection of $\mathrm{H}_{0}$ in Favor of $\mathrm{H}_{1}$ : p-value $<=0.05$

\begin{tabular}{|l|c|c|}
\hline Calume (Vol) & Determined p-value & Conclusion \\
\hline Renesntage Diversion (Div) & 0.113 & $\begin{array}{c}\text { Fail to Reject } \mathrm{H}_{0} \text { (No } \\
\text { Significant Difference) }\end{array}$ \\
\hline Dugree of Incident (Inc) & 0.447 & $\begin{array}{c}\text { Fail to Reject } \mathrm{H}_{0} \text { (No } \\
\text { Significant Difference) }\end{array}$ \\
\hline Dumation of Incident (Dur) & 0.116 & $\begin{array}{c}\text { Fail to Reject } \mathrm{H}_{0} \text { (No } \\
\text { Significant Difference) }\end{array}$ \\
\hline
\end{tabular}


The next step was to perform the General Linear Model Analysis of Variance (ANOVA) test in order to determine which factors and combinations of factors had significant effects on the response. For individual factors, or interaction between factors, the following hypothesis test was performed:

$\mathrm{H}_{0}$ : the factor or interaction between factors is not having a significant effect on the response

$\mathrm{H}_{1}$ : the factor or interaction between factors is having a significant effect on the response

The ANOVA table provides p-values for each of the factors and the combinations of the factors for the level of significance tested. A p-value less than the specified 0.05 level of significance signifies that $\mathrm{H}_{0}$ was rejected in favor of $\mathrm{H}_{1}$ and that the factor had a significant effect on the response. The ANOVA table displays a p-value for the interactions between the four factors. This relates which combinations of factors had significant effects on the response. Table 3-11 lists the results of the General Linear Model ANOVA obtained from MINITAB ${ }^{\mathrm{TM}}$. 
Table 3-11 General Linear Model ANOVA Table for Phase-I.

\begin{tabular}{|c|c|c|c|c|c|c|}
\hline Source & $\begin{array}{c}\text { Degrees of } \\
\text { Freedom }\end{array}$ & $\begin{array}{l}\text { Sequential } \\
\text { Sum of } \\
\text { Squares }\end{array}$ & $\begin{array}{c}\text { Adjusted Sum } \\
\text { of Squares }\end{array}$ & $\begin{array}{c}\text { Adjusted } \\
\text { Mean Sum of } \\
\text { Squares }\end{array}$ & F-Value & p-value \\
\hline Volnuse (Vol) & 1 & 5047.10 & 5047.10 & 5047.10 & 153.57 & 0.000 \\
\hline Pereantage Diversion (Div) & 1 & 127.40 & 127.40 & 127.40 & 3.88 & 0.058 \\
\hline Detroe of Incident (Inc) & 1 & 4872.27 & 4872.27 & 4872.27 & 148.25 & 0.000 \\
\hline Duretion of Incident (Dur) & 1 & 984.64 & 984.64 & 984.64 & 29.96 & 0.000 \\
\hline Vol * Div & 1 & 112.24 & 112.24 & 112.24 & 3.42 & 0.074 \\
\hline $\mathrm{Vol} *$ Inc & 1 & 736.33 & 736.33 & 736.33 & 22.40 & 0.000 \\
\hline Vol * Dur & 1 & 114.70 & 114.70 & 114.70 & 3.49 & 0.071 \\
\hline Div * Inc & 1 & 49.61 & 49.61 & 49.61 & 1.51 & 0.228 \\
\hline Div * Dur & 1 & 1.27 & 1.27 & 1.27 & 0.04 & 0.846 \\
\hline Ims * Dur & 1 & 176.33 & 176.33 & 176.33 & 5.37 & 0.027 \\
\hline Vol * Div * Inc & 1 & 78.03 & 78.03 & 78.03 & 2.37 & 0.133 \\
\hline Yol * Div * Dur & 1 & 47.60 & 47.60 & 47.60 & 1.45 & 0.238 \\
\hline Vol *Inc * Dur & 1 & 761.61 & 761.61 & 761.61 & 23.17 & 0.000 \\
\hline Div * Inc * Dur & 1 & 0.05 & 0.05 & 0.05 & 0.00 & 0.968 \\
\hline Vol * Div * Inc * Dur & 1 & 43.32 & 43.32 & 43.32 & 1.32 & 0.259 \\
\hline Finor: & 32 & 1051.70 & 1051.70 & 1051.70 & & \\
\hline Total & 47 & 14204.22 & & & & \\
\hline
\end{tabular}


The calculated p-values in Table 3-11 show that the volume, degree of incident, and duration of incident had significant effects on the response. However, the level of diversion did have a marginal effect on the response. Also found to be significant were the following combinations of factors: volume and incident, incident and duration, and volume, incident, and duration.

\subsubsection{Recommendations for Phase-II}

Based on the preliminary experiments performed and the subsequent analysis it was decided that only three of the four factors should be varied to greater degrees between the established limits. However, since the diversion was found to have had a marginal effect on the MOE it was decided that it should be fixed at its stated limits for further evaluation. These decisions are based on the ANOVA analysis performed and the previously stated level of significance. The expanded experimental design executed in Phase-II includes the factors and levels described in Table 3-12. 
Table 3-12 Recommendations for Phase-II Experiments.

\begin{tabular}{|c|c|c|c|}
\hline $\begin{array}{c}\text { Traffic Volume } \\
\text { (vph) }\end{array}$ & $\begin{array}{c}\text { Level of Diversion (\% of } \\
\text { Traffic Exiting the Main } \\
\text { Line) }\end{array}$ & $\begin{array}{c}\text { Level of Incident } \\
\text { (Lane Blockage) }\end{array}$ & $\begin{array}{c}\text { Duration of Incident } \\
\text { (Minutes) }\end{array}$ \\
\hline $1=1 / 2$ Peak & $1=0 \%$ & $1=$ One Lane & $1=20$ Minutes \\
\hline $2=2 / 3$ Peak & $2=20 \%$ & $2=$ Two Lanes & $2=30$ Minutes \\
\hline $3=3 / 4$ Peak & & $3=$ Three Lanes & $3=40$ Minutes \\
\hline $4=$ Peak & & & \\
\hline
\end{tabular}




\subsubsection{Phase-II Expanded Analysis Based on Phase-I Preliminary Analysis}

\subsubsection{Application of the Expanded Experimental Design}

The Phase-I analysis showed that three of the four individual factors had significant impacts on the cumulative average network speed. The ANOVA table presented in Table 3-11 led to the decision to vary the factors as described in Table 3-

12. These four factors formed 72 different situations. These 72 situations modeled with the three random seed numbers brought the total number of simulations to be run in Phase-II to 216. For each of these 216 simulations three cumulative network statistics had to be recovered for both Rt. 10 and I-95. From these three cumulative network statistics collected the three MOE's were calculated. The three cumulative network statistics that were obtained for each simulation were:

Vehicle Miles Traveled- the total vehicle miles traveled by all vehicles on all network links during the two-hour simulation

Vehicle Minutes the total number of minutes needed to travel the

\section{Vehicle Miles Traveled}

Total Delay the sum of the delay in minutes for every vehicle that entered the network during the two-hour simulation

With these three statistics, the cumulative average network speed and total network delay could be calculated. 
The cumulative average network speed is found using the following equation:

Cumulative Average Network Speed $(\mathrm{mph})=[(\mathrm{Rt} .10$ Vehicles Miles Traveled

+ I-95 Vehicle Miles Traveled) / (Rt. 10 Vehicle Minutes + I-95 Vehicle Minutes)](60 Minutes / 1 Hour $)$

(Equation 3-2)

The total network delay was found using the following equation:

Total Network Delay (hours) $=($ Rt. 10 Total Network Delay +

I-95 Total Network Delay)(1 hour / 60 minutes)

(Equation 3-3)

With these equations in place the next step was to run all the simulations and acquire the three network statistics for each roadway for every simulation.

\subsubsection{Definition of Decision Criteria}

In an experimental procedure it is essential to state decision criteria before the results have been analyzed. The decision criteria for this research were divided into 2 basic cases. Although there were three different MOE's their decision criteria are essentially the same. The decision criteria are essentially a set of comparisons between the means of any two comparable simulation data sets. Comparable simulation data sets are data sets obtained from simulations modeled with identical traffic conditions and incident situations, but different levels of traffic diversion. For example: the network speed data set acquired from the simulation consisting of AM 
Peak traffic conditions, one lane of incident blockage lasting for 20 minutes with no traffic diversion were compared the with the data set acquired from the simulation consisting of AM Peak traffic conditions, one lane of incident blockage lasting for 20 minutes with traffic diversion. The decision criteria were put in place to objectively select one of two options. The options are either: (1) the diversion was beneficial to the overall system and is warranted for the given situation, or (2) the diversion was not beneficial to the overall system and is not warranted for the given situation.

The first step in the decision process was to examine the p-values for a Paired t-test performed on all comparable data sets. The Paired t-test was chosen because it is a testing technique that examines the similarities of data sets by testing if their means are significantly different or not. The test states the following hypothesis:

$\mathrm{H}_{0}$ :

The means of the two data sets Are Equal

(mean of diversion data $=$ mean of no diversion data)

$\mathrm{H}_{1}$ : The means of the two data sets Are Not Equal

(mean of diversion data $\neq$ mean of no diversion data)

Rejection

Criteria: $\quad$ Reject $\mathrm{H}_{0}$ if the p-value found is less than or equal to the stated level of significance (0.05). (The means of the data are not equal.)

Fail to reject $\mathrm{H}_{0}$ in favor of $\mathrm{H}_{1}$ if the p-value found is greater than the stated level of significance. (The means of the data are equal.) 
This t-test provided initial information on the effect the diversion had on the MOE's. Based on the three replications for each situation, the t-test calculates a test statistic that incorporates the variance and mean of each data set. By taking into account the mean and the variance, the t-test provides a measure of comparison that is more representative than merely comparing the sample means.

For the diversion to be considered warranted, the $\mathrm{H}_{0}$ stated in the t-test must be rejected and the difference in the means must favor the situation with diversion. The difference in the sample means was evaluated using the percentage differences and the actual differences between means of comparable data sets. Specifically, diversion was considered warranted if: the cumulative average network speed had increased and total network delay had decreased with diversion. On the other hand, diversion was considered not warranted if the cumulative average network speed had decreased and total network delay increased with diversion.

Also formulated during this part of the analysis were three General Linear Model ANOVA tables. The three tables are based on the three different responses, or MOE's, recorded for each of the replications modeled. These ANOVA tables display the p-values for each factor and the various interactions between the factors. The hypothesis and rejection criteria for these three tables are identical to those indicated in for the ANOVA analysis utilized in the Phase-I analysis of this research. Essentially, a p-value less than 0.05 indicates the factor, or interaction of factors, is significant. 


\subsubsection{Presentation of Results of Phase-II Experiments}

The results of the Phase-II experiments are summarized in Tables 3-13 through 3-22. Table 3-13 through 3-20 include the MOE's as calculated from the three network statistics described earlier, the p-values found for each Paired t-test performed, the percentage difference and the actual difference between the means of comparable data sets. These tables are arranged by the traffic volume conditions the simulation operated under and by MOE being reported. Specifically, Tables 3-13 and 3-14 contain the speed and delay, respectively, for the simulations run under AM Peak traffic conditions; Tables 3-15 and 3-16 contain the speed and delay, respectively, for the simulations run under 3/4 AM Peak traffic conditions; Tables 3-17 and 3-18 contain the speed and delay, respectively, for the simulations run under 2/3 AM Peak traffic conditions; and Tables 3-19 and 3-20 contain the speed and delay, respectively, for the simulations run under $1 / 2$ AM Peak traffic conditions. Table 3-21 and 3-22 display the General Linear Model ANOVA tables formulated for each response, or MOE. 
Table 3-13 Results for AM Peak Traffic Conditions (Cumulative Average Network Speed)

\begin{tabular}{|c|c|c|c|c|c|c|c|}
\hline \multirow{2}{*}{ Situation } & \multicolumn{2}{|c|}{$\begin{array}{c}\text { No Diversion } \\
\text { Mean of } 3 \\
\text { Samples }\end{array}$} & \multicolumn{2}{|c|}{$\begin{array}{l}\text { Diversion } \\
\text { Mean of } 3 \\
\text { Samples }\end{array}$} & \multirow{2}{*}{$\begin{array}{l}\text { p-values } \\
\text { from } \\
\text { Paired t- } \\
\text { Test }\end{array}$} & \multirow{2}{*}{$\begin{array}{c}\text { Percent } \\
\text { Difference } \\
\text { Between No } \\
\text { Diversion and } \\
\text { Diversion }\end{array}$} & \multirow{2}{*}{$\begin{array}{c}\text { Actual } \\
\text { Difference } \\
\text { Between No } \\
\text { Diversion } \\
\text { and } \\
\text { Diversion } \\
\text { (mph) }\end{array}$} \\
\hline & $\begin{array}{l}\text { Speed } \\
(\mathrm{mph})\end{array}$ & $\begin{array}{c}\text { Standard } \\
\text { Deviation } \\
\text { (mph) }\end{array}$ & $\begin{array}{l}\text { Speed } \\
\text { (mph) }\end{array}$ & $\begin{array}{c}\text { Standard } \\
\text { Deviation } \\
\text { (mph) }\end{array}$ & & & \\
\hline $\begin{array}{c}1 \text { Lane Blocked for } 20 \\
\text { Minutes }\end{array}$ & 42.8 & 0.4 & 32.1 & 17.9 & 0.418 & $-25 \%$ & -10.7 \\
\hline $\begin{array}{c}1 \text { Lane Blocked for } 30 \\
\text { Minutes }\end{array}$ & 35.7 & 1.3 & 30.0 & 14.4 & 0.538 & $-16 \%$ & -5.7 \\
\hline $\begin{array}{c}1 \text { Lane Blocked for } 40 \\
\text { Minutes }\end{array}$ & 32.8 & 2.5 & 21.8 & 3.7 & 0.068 & $-34 \%$ & -11.1 \\
\hline \begin{tabular}{|c|}
2 Lanes Blocked for \\
20 Minutes
\end{tabular} & 28.0 & 0.5 & 23.6 & 9.2 & 0.499 & $-16 \%$ & -4.4 \\
\hline $\begin{array}{c}2 \text { Lanes Blocked for } \\
30 \text { Minutes }\end{array}$ & 25.2 & 0.3 & 18.9 & 6.1 & 0.202 & $-25 \%$ & -6.2 \\
\hline $\begin{array}{c}2 \text { Lanes Blocked for } \\
40 \text { Minutes }\end{array}$ & 24.7 & 0.4 & 15.2 & 2.0 & 0.018 & $-38 \%$ & -9.5 \\
\hline $\begin{array}{c}3 \text { Lanes Blocked for } \\
20 \text { Minutes }\end{array}$ & 23.6 & 1.3 & 18.3 & 6.9 & 0.304 & $-22 \%$ & -5.3 \\
\hline \begin{tabular}{|c|}
3 Lanes Blocked for \\
30 Minutes
\end{tabular} & 16.9 & 7.6 & 16.0 & 4.9 & 0.863 & $-6 \%$ & -0.9 \\
\hline $\begin{array}{c}3 \text { Lanes Blocked for } \\
40 \text { Minutes }\end{array}$ & 18.2 & 2.4 & 20.0 & 1.3 & 0.304 & $10 \%$ & 1.8 \\
\hline
\end{tabular}


Table 3-14 Results for AM Peak Traffic Conditions (Total Network Delay)

\begin{tabular}{|c|c|c|c|c|c|c|c|}
\hline \multirow{2}{*}{ Situation } & \multicolumn{2}{|c|}{$\begin{array}{c}\text { No Diversion } \\
\text { Mean of } 3 \\
\text { Samples }\end{array}$} & \multicolumn{2}{|c|}{$\begin{array}{l}\text { Diversion } \\
\text { Mean of } 3 \\
\text { Samples }\end{array}$} & \multirow{2}{*}{$\begin{array}{l}\text { p-values } \\
\text { from } \\
\text { Paired t- } \\
\text { Test }\end{array}$} & \multirow{2}{*}{$\begin{array}{c}\text { Percent } \\
\text { Difference } \\
\text { Between No } \\
\text { Diversion and } \\
\text { Diversion }\end{array}$} & \multirow{2}{*}{$\begin{array}{c}\text { Actual } \\
\text { Difference } \\
\text { Between No } \\
\text { Diversion } \\
\text { and } \\
\text { Diversion } \\
\text { (hrs) }\end{array}$} \\
\hline & $\begin{array}{c}\text { Delay } \\
\text { (hrs) }\end{array}$ & $\begin{array}{c}\text { Standard } \\
\text { Deviation } \\
\text { (hrs) }\end{array}$ & $\begin{array}{c}\text { Delay } \\
\text { (hrs) }\end{array}$ & $\begin{array}{c}\text { Standard } \\
\text { Deviation } \\
\text { (hrs) }\end{array}$ & & & \\
\hline $\begin{array}{c}1 \text { Lane Blocked for } 20 \\
\text { Minutes }\end{array}$ & 549.19 & 15.46 & 1033.06 & 691.58 & 0.358 & $88 \%$ & 483.9 \\
\hline $\begin{array}{c}1 \text { Lane Blocked for } 30 \\
\text { Minutes }\end{array}$ & 869.51 & 71.30 & 1040.08 & 627.03 & 0.658 & $20 \%$ & 170.6 \\
\hline $\begin{array}{c}1 \text { Lane Blocked for } 40 \\
\text { Minutes }\end{array}$ & 1074.95 & 173.20 & 1412.76 & 331.09 & 0.115 & $31 \%$ & 337.8 \\
\hline $\begin{array}{c}2 \text { Lanes Blocked for } \\
20 \text { Minutes }\end{array}$ & 1413.00 & 32.56 & 1641.12 & 563.41 & 0.563 & $16 \%$ & 228.1 \\
\hline $\begin{array}{c}2 \text { Lanes Blocked for } \\
30 \text { Minutes }\end{array}$ & 1609.49 & 20.76 & 2231.46 & 628.09 & 0.218 & $39 \%$ & 622.0 \\
\hline $\begin{array}{c}2 \text { Lanes Blocked for } \\
40 \text { Minutes }\end{array}$ & 1636.58 & 49.68 & 2231.46 & 339.90 & 0.033 & $36 \%$ & 594.9 \\
\hline $\begin{array}{c}3 \text { Lanes Blocked for } \\
20 \text { Minutes }\end{array}$ & 1601.34 & 83.68 & 2275.08 & 736.65 & 0.232 & $42 \%$ & 673.7 \\
\hline $\begin{array}{c}3 \text { Lanes Blocked for } \\
30 \text { Minutes }\end{array}$ & 2115.92 & 688.00 & 2446.18 & 644.45 & 0.458 & $16 \%$ & 330.3 \\
\hline \begin{tabular}{|c|}
3 Lanes Blocked for \\
40 Minutes
\end{tabular} & 1897.16 & 114.60 & 2542.90 & 812.02 & 0.260 & $34 \%$ & 645.7 \\
\hline
\end{tabular}


Table 3-15 Results for $3 / 4$ AM Peak Traffic Conditions (Cumulative Average

Network Speed)

\begin{tabular}{|c|c|c|c|c|c|c|c|}
\hline \multirow{2}{*}{ Situation } & \multicolumn{2}{|c|}{$\begin{array}{c}\text { No Diversion } \\
\text { Mean of } 3 \\
\text { Samples }\end{array}$} & \multicolumn{2}{|c|}{$\begin{array}{l}\text { Diversion } \\
\text { Mean of } 3 \\
\text { Samples }\end{array}$} & \multirow{2}{*}{$\begin{array}{l}\mathrm{p} \text {-values } \\
\text { from } \\
\text { Paired t- } \\
\text { Test }\end{array}$} & \multirow{2}{*}{$\begin{array}{c}\text { Percent } \\
\text { Difference } \\
\text { Between No } \\
\text { Diversion and } \\
\text { Diversion }\end{array}$} & \multirow{2}{*}{$\begin{array}{c}\text { Actual } \\
\text { Difference } \\
\text { Between No } \\
\text { Diversion } \\
\text { and } \\
\text { Diversion } \\
\text { (mph) }\end{array}$} \\
\hline & $\begin{array}{l}\text { Speed } \\
(\mathrm{mph})\end{array}$ & $\begin{array}{c}\text { Standard } \\
\text { Deviation } \\
\text { (mph) }\end{array}$ & $\begin{array}{l}\text { Speed } \\
(\mathrm{mph})\end{array}$ & $\begin{array}{c}\text { Standard } \\
\text { Deviation } \\
\text { (mph) }\end{array}$ & & & \\
\hline $\begin{array}{c}1 \text { Lane Blocked for } 20 \\
\text { Minutes }\end{array}$ & 57.8 & 0.1 & 58.2 & 0.0 & 0.010 & $1 \%$ & 0.3 \\
\hline $\begin{array}{c}1 \text { Lane Blocked for } 30 \\
\text { Minutes }\end{array}$ & 52.8 & 7.4 & 58.2 & 0.1 & 0.330 & $10 \%$ & 5.5 \\
\hline $\begin{array}{c}1 \text { Lane Blocked for } 40 \\
\text { Minutes }\end{array}$ & 43.7 & 24.0 & 42.4 & 27.4 & 0.964 & $-3 \%$ & -1.3 \\
\hline $\begin{array}{l}2 \text { Lanes Blocked for } \\
20 \text { Minutes }\end{array}$ & 48.9 & 0.2 & 48.2 & 11.0 & 0.920 & $-1 \%$ & -0.7 \\
\hline $\begin{array}{c}2 \text { Lanes Blocked for } \\
30 \text { Minutes }\end{array}$ & 38.8 & 4.2 & 42.4 & 17.0 & 0.779 & $9 \%$ & 3.6 \\
\hline $\begin{array}{c}2 \text { Lanes Blocked for } \\
40 \text { Minutes }\end{array}$ & 27.0 & 11.8 & 25.9 & 21.6 & 0.963 & $-4 \%$ & -1.0 \\
\hline $\begin{array}{c}3 \text { Lanes Blocked for } \\
20 \text { Minutes }\end{array}$ & 31.7 & 1.7 & 34.5 & 5.1 & 0.292 & $9 \%$ & 2.8 \\
\hline $\begin{array}{c}3 \text { Lanes Blocked for } \\
30 \text { Minutes }\end{array}$ & 22.6 & 3.7 & 25.5 & 5.6 & 0.290 & $13 \%$ & 2.9 \\
\hline $\begin{array}{l}3 \text { Lanes Blocked for } \\
40 \text { Minutes }\end{array}$ & 14.4 & 4.2 & 19.2 & 0.2 & 0.197 & $34 \%$ & 4.8 \\
\hline
\end{tabular}


Table 3-16 Results for $3 / 4$ AM Peak Traffic Conditions (Total Network Delay)

\begin{tabular}{|c|c|c|c|c|c|c|c|}
\hline \multirow{2}{*}{ Situation } & \multicolumn{2}{|c|}{$\begin{array}{c}\text { No Diversion } \\
\text { Mean of } 3 \\
\text { Samples }\end{array}$} & \multicolumn{2}{|c|}{$\begin{array}{l}\text { Diversion } \\
\text { Mean of } 3 \\
\text { Samples }\end{array}$} & \multirow{2}{*}{$\begin{array}{l}\text { p-values } \\
\text { from } \\
\text { Paired t- } \\
\text { Test }\end{array}$} & \multirow{2}{*}{$\begin{array}{c}\text { Percent } \\
\text { Difference } \\
\text { Between No } \\
\text { Diversion and } \\
\text { Diversion }\end{array}$} & \multirow{2}{*}{$\begin{array}{c}\text { Actual } \\
\text { Difference } \\
\text { Between No } \\
\text { Diversion } \\
\text { and } \\
\text { Diversion } \\
\text { (hrs) }\end{array}$} \\
\hline & $\begin{array}{l}\text { Delay } \\
\text { (hrs) }\end{array}$ & $\begin{array}{c}\text { Standard } \\
\text { Deviation } \\
\text { (hrs) }\end{array}$ & $\begin{array}{c}\text { Delay } \\
(\mathrm{hrs})\end{array}$ & $\begin{array}{c}\text { Standard } \\
\text { Deviation } \\
\text { (hrs) }\end{array}$ & & & \\
\hline $\begin{array}{c}1 \text { Lane Blocked for } 20 \\
\text { Minutes }\end{array}$ & 83.71 & 0.61 & 76.87 & 0.38 & 0.002 & $-8 \%$ & -6.8 \\
\hline $\begin{array}{c}1 \text { Lane Blocked for } 30 \\
\text { Minutes }\end{array}$ & 135.29 & 81.62 & 74.17 & 1.28 & 0.325 & $-45 \%$ & -61.1 \\
\hline $\begin{array}{c}1 \text { Lane Blocked for } 40 \\
\text { Minutes }\end{array}$ & 480.52 & 679.08 & 659.97 & 1015.86 & 0.853 & $37 \%$ & 179.4 \\
\hline $\begin{array}{c}2 \text { Lanes Blocked for } \\
20 \text { Minutes }\end{array}$ & 248.62 & 5.10 & 244.35 & 192.40 & 0.972 & $-2 \%$ & -4.3 \\
\hline \begin{tabular}{|c|} 
Lanes Blocked for \\
30 Minutes
\end{tabular} & 490.62 & 84.00 & 451.44 & 482.33 & 0.908 & $-8 \%$ & -39.2 \\
\hline \begin{tabular}{|c|}
2 Lanes Blocked for \\
40 Minutes \\
\end{tabular} & 1114.22 & 653.62 & 451.44 & 930.53 & 0.909 & $-59 \%$ & -662.8 \\
\hline $\begin{array}{c}3 \text { Lanes Blocked for } \\
20 \text { Minutes } \\
\end{array}$ & 689.14 & 58.53 & 558.59 & 135.02 & 0.098 & $-19 \%$ & -130.6 \\
\hline \begin{tabular}{|c|}
3 Lanes Blocked for \\
30 Minutes \\
\end{tabular} & 1205.81 & 209.90 & 948.33 & 222.11 & 0.054 & $-21 \%$ & -257.5 \\
\hline $\begin{array}{c}3 \text { Lanes Blocked for } \\
40 \text { Minutes }\end{array}$ & 2280.24 & 629.20 & 2142.48 & 1061.82 & 0.882 & $-6 \%$ & -137.8 \\
\hline
\end{tabular}


Table 3-17 Results for 2/3 AM Peak Traffic Conditions (Cumulative Average

Network Speed)

\begin{tabular}{|c|c|c|c|c|c|c|c|}
\hline \multirow{2}{*}{ Situation } & \multicolumn{2}{|c|}{$\begin{array}{c}\text { No Diversion } \\
\text { Mean of } 3 \\
\text { Samples }\end{array}$} & \multicolumn{2}{|c|}{$\begin{array}{l}\text { Diversion } \\
\text { Mean of } 3 \\
\text { Samples }\end{array}$} & \multirow{2}{*}{$\begin{array}{l}p \text {-values } \\
\text { from } \\
\text { Paired t- } \\
\text { Test }\end{array}$} & \multirow{2}{*}{$\begin{array}{c}\text { Percent } \\
\text { Difference } \\
\text { Between No } \\
\text { Diversion and } \\
\text { Diversion }\end{array}$} & \multirow{2}{*}{$\begin{array}{c}\text { Actual } \\
\text { Difference } \\
\text { Between No } \\
\text { Diversion } \\
\text { and } \\
\text { Diversion } \\
\text { (mph) }\end{array}$} \\
\hline & $\begin{array}{l}\text { Speed } \\
(\mathrm{mph})\end{array}$ & $\begin{array}{c}\text { Standard } \\
\text { Deviation } \\
\text { (mph) }\end{array}$ & $\begin{array}{l}\text { Speed } \\
(\mathrm{mph})\end{array}$ & $\begin{array}{c}\text { Standard } \\
\text { Deviation } \\
(\mathrm{mph})\end{array}$ & & & \\
\hline $\begin{array}{c}1 \text { Lane Blocked for } 20 \\
\text { Minutes }\end{array}$ & 59.1 & 0.1 & 59.2 & 0.1 & 0.227 & $0 \%$ & 0.1 \\
\hline $\begin{array}{c}1 \text { Lane Blocked for } 30 \\
\text { Minutes }\end{array}$ & 46.4 & 21.7 & 59.2 & 0.1 & 0.416 & $27 \%$ & 12.8 \\
\hline $\begin{array}{c}1 \text { Lane Blocked for } 40 \\
\text { Minutes }\end{array}$ & 41.4 & 17.8 & 59.2 & 0.2 & 0.229 & $43 \%$ & 17.8 \\
\hline $\begin{array}{c}2 \text { Lanes Blocked for } \\
20 \text { Minutes }\end{array}$ & 52.4 & 0.3 & 58.6 & 0.3 & 0.001 & $12 \%$ & 6.1 \\
\hline $\begin{array}{c}2 \text { Lanes Blocked for } \\
30 \text { Minutes }\end{array}$ & 37.1 & 15.4 & 58.5 & 0.3 & 0.138 & $57 \%$ & 21.3 \\
\hline $\begin{array}{c}2 \text { Lanes Blocked for } \\
40 \text { Minutes }\end{array}$ & 30.7 & 11.3 & 58.2 & 0.3 & 0.054 & $90 \%$ & 27.5 \\
\hline $\begin{array}{c}3 \text { Lanes Blocked for } \\
20 \text { Minutes } \\
\end{array}$ & 35.9 & 2.8 & 36.1 & 7.1 & 0.953 & $1 \%$ & 0.3 \\
\hline $\begin{array}{c}3 \text { Lanes Blocked for } \\
30 \text { Minutes }\end{array}$ & 21.2 & 6.1 & 26.3 & 8.2 & 0.185 & $24 \%$ & 5.1 \\
\hline $\begin{array}{l}3 \text { Lanes Blocked for } \\
40 \text { Minutes }\end{array}$ & 16.0 & 5.1 & 19.9 & 6.8 & 0.432 & $25 \%$ & 4.0 \\
\hline
\end{tabular}


Table 3-18 Results for 2/3 AM Peak Traffic Conditions (Total Network Delay)

\begin{tabular}{|c|c|c|c|c|c|c|c|}
\hline \multirow{2}{*}{ Situation } & \multicolumn{2}{|c|}{$\begin{array}{c}\text { No Diversion } \\
\text { Mean of } 3 \\
\text { Samples }\end{array}$} & \multicolumn{2}{|c|}{$\begin{array}{l}\text { Diversion } \\
\text { Mean of } 3 \\
\text { Samples }\end{array}$} & \multirow{2}{*}{$\begin{array}{l}\text { p-values } \\
\text { from } \\
\text { Paired t- } \\
\text { Test }\end{array}$} & \multirow{2}{*}{$\begin{array}{c}\text { Percent } \\
\text { Difference } \\
\text { Between No } \\
\text { Diversion and } \\
\text { Diversion }\end{array}$} & \multirow{2}{*}{$\begin{array}{c}\text { Actual } \\
\text { Difference } \\
\text { Between No } \\
\text { Diversion } \\
\text { and } \\
\text { Diversion } \\
\text { (hrs) }\end{array}$} \\
\hline & $\begin{array}{c}\text { Delay } \\
\text { (hrs) }\end{array}$ & $\begin{array}{c}\text { Standard } \\
\text { Deviation } \\
\text { (hrs) }\end{array}$ & $\begin{array}{c}\text { Delay } \\
\text { (hrs) }\end{array}$ & $\begin{array}{c}\text { Standard } \\
\text { Deviation } \\
\text { (hrs) }\end{array}$ & & & \\
\hline $\begin{array}{l}1 \text { Lane Blocked for } \\
20 \text { Minutes }\end{array}$ & 58.70 & 0.53 & 54.30 & 0.64 & 0.018 & $-7 \%$ & -4.4 \\
\hline $\begin{array}{l}1 \text { Lane Blocked for } \\
30 \text { Minutes }\end{array}$ & 288.36 & 395.51 & 53.66 & 0.76 & 0.413 & $-81 \%$ & -234.7 \\
\hline $\begin{array}{l}1 \text { Lane Blocked for } \\
40 \text { Minutes }\end{array}$ & 297.01 & 409.66 & 53.20 & 2.12 & 0.412 & $-82 \%$ & -243.8 \\
\hline $\begin{array}{l}2 \text { Lanes Blocked for } \\
20 \text { Minutes }\end{array}$ & 157.16 & 2.90 & 61.65 & 2.68 & 0.001 & $-61 \%$ & -95.5 \\
\hline $\begin{array}{l}2 \text { Lanes Blocked for } \\
30 \text { Minutes }\end{array}$ & 277.92 & 8.64 & 61.20 & 4.06 & 0.001 & $-78 \%$ & -216.7 \\
\hline $\begin{array}{c}2 \text { Lanes Blocked for } \\
40 \text { Minutes }\end{array}$ & 417.01 & 14.79 & 61.20 & 2.84 & 0.001 & $-85 \%$ & -355.8 \\
\hline $\begin{array}{l}3 \text { Lanes Blocked for } \\
20 \text { Minutes }\end{array}$ & 469.11 & 61.38 & 417.43 & 122.60 & 0.534 & $-11 \%$ & -51.7 \\
\hline $\begin{array}{l}3 \text { Lanes Blocked for } \\
30 \text { Minutes }\end{array}$ & 870.23 & 151.56 & 776.97 & 250.11 & 0.585 & $-11 \%$ & -93.3 \\
\hline $\begin{array}{l}3 \text { Lanes Blocked for } \\
40 \text { Minutes }\end{array}$ & 1399.74 & 158.77 & 1164.71 & 325.19 & 0.400 & $-17 \%$ & -235.0 \\
\hline
\end{tabular}


Table 3-19 Results for $1 / 2$ AM Peak Traffic Conditions (Cumulative Average

Network Speed)

\begin{tabular}{|c|c|c|c|c|c|c|c|}
\hline \multirow{2}{*}{ Situation } & \multicolumn{2}{|c|}{$\begin{array}{c}\text { No Diversion } \\
\text { Mean of } 3 \\
\text { Samples }\end{array}$} & \multicolumn{2}{|c|}{$\begin{array}{l}\text { Diversion } \\
\text { Mean of } 3 \\
\text { Samples }\end{array}$} & \multirow{2}{*}{$\begin{array}{l}\text { p-values } \\
\text { from } \\
\text { Paired t- } \\
\text { Test }\end{array}$} & \multirow{2}{*}{$\begin{array}{c}\text { Percent } \\
\text { Difference } \\
\text { Between No } \\
\text { Diversion and } \\
\text { Diversion }\end{array}$} & \multirow{2}{*}{$\begin{array}{l}\text { Actual } \\
\text { Difference } \\
\text { Between No } \\
\text { Diversion } \\
\text { and } \\
\text { Diversion } \\
\text { (mph) }\end{array}$} \\
\hline & $\begin{array}{l}\text { Speed } \\
(\mathrm{mph})\end{array}$ & $\begin{array}{c}\text { Standard } \\
\text { Deviation } \\
\text { (mph) }\end{array}$ & $\begin{array}{l}\text { Speed } \\
(\mathrm{mph})\end{array}$ & $\begin{array}{c}\text { Standard } \\
\text { Deviation } \\
(\mathrm{mph})\end{array}$ & & & \\
\hline $\begin{array}{c}1 \text { Lane Blocked for } 20 \\
\text { Minutes }\end{array}$ & 60.5 & 0.0 & 60.3 & 0.7 & 0.668 & $0 \%$ & -0.2 \\
\hline $\begin{array}{c}1 \text { Lane Blocked for } 30 \\
\text { Minutes }\end{array}$ & 60.6 & 0.2 & 60.4 & 0.3 & 0.341 & $0 \%$ & -0.2 \\
\hline $\begin{array}{c}1 \text { Lane Blocked for } 40 \\
\text { Minutes }\end{array}$ & 60.6 & 0.1 & 60.5 & 0.1 & 0.190 & $0 \%$ & -0.1 \\
\hline $\begin{array}{c}2 \text { Lanes Blocked for } \\
20 \text { Minutes }\end{array}$ & 60.2 & 0.6 & 60.3 & 0.2 & 0.783 & $0 \%$ & 0.1 \\
\hline $\begin{array}{c}2 \text { Lanes Blocked for } \\
30 \text { Minutes }\end{array}$ & 60.0 & 0.1 & 59.9 & 0.3 & 0.846 & $0 \%$ & 0.0 \\
\hline $\begin{array}{c}2 \text { Lanes Blocked for } \\
40 \text { Minutes }\end{array}$ & 59.6 & 0.4 & 60.1 & 0.0 & 0.156 & $1 \%$ & 0.5 \\
\hline $\begin{array}{c}3 \text { Lanes Blocked for } \\
20 \text { Minutes }\end{array}$ & 42.9 & 6.2 & 46.4 & 6.3 & 0.631 & $8 \%$ & 3.6 \\
\hline \begin{tabular}{|c|}
3 Lanes Blocked for \\
30 Minutes \\
\end{tabular} & 32.0 & 8.8 & 31.5 & 9.6 & 0.965 & $-2 \%$ & -0.5 \\
\hline $\begin{array}{c}3 \text { Lanes Blocked for } \\
40 \text { Minutes }\end{array}$ & 23.2 & 6.9 & 18.2 & 1.3 & 0.327 & $-22 \%$ & -5.0 \\
\hline
\end{tabular}


Table 3-20 Results for $1 \frac{1}{2}$ AM Peak Traffic Conditions (Total Network Delay)

\begin{tabular}{|c|c|c|c|c|c|c|c|}
\hline \multirow[t]{2}{*}{ Situation } & \multicolumn{2}{|c|}{$\begin{array}{c}\text { No Diversion } \\
\text { Mean of } 3 \\
\text { Samples }\end{array}$} & \multicolumn{2}{|c|}{$\begin{array}{l}\text { Diversion } \\
\text { Mean of } 3 \\
\text { Samples }\end{array}$} & \multirow{2}{*}{$\begin{array}{l}\mathrm{p} \text {-values } \\
\text { from } \\
\text { Paired t- } \\
\text { Test }\end{array}$} & \multirow{2}{*}{\begin{tabular}{|c|} 
Percent \\
Difference \\
Between No \\
Diversion and \\
Diversion
\end{tabular}} & \multirow{2}{*}{$\begin{array}{c}\text { Actual } \\
\text { Difference } \\
\text { Between No } \\
\text { Diversion } \\
\text { and } \\
\text { Diversion } \\
\text { (hrs) }\end{array}$} \\
\hline & $\begin{array}{c}\text { Delay } \\
\text { (hrs) }\end{array}$ & $\begin{array}{c}\text { Standard } \\
\text { Deviation } \\
\text { (hrs) }\end{array}$ & $\begin{array}{c}\text { Delay } \\
\text { (hrs) }\end{array}$ & $\begin{array}{c}\text { Standard } \\
\text { Deviation } \\
(\mathrm{hrs})\end{array}$ & & & \\
\hline $\begin{array}{c}1 \text { Lane Blocked for } 20 \\
\text { Minutes }\end{array}$ & 28.78 & 0.61 & 28.23 & 0.99 & 0.203 & $-2 \%$ & -0.6 \\
\hline $\begin{array}{c}1 \text { Lane Blocked for } 30 \\
\text { Minutes }\end{array}$ & 28.89 & 0.40 & 28.37 & 1.93 & 0.651 & $-2 \%$ & -0.5 \\
\hline $\begin{array}{c}1 \text { Lane Blocked for } 40 \\
\text { Minutes }\end{array}$ & 28.97 & 0.57 & 27.46 & 0.34 & 0.048 & $-5 \%$ & -1.5 \\
\hline $\begin{array}{l}2 \text { Lanes Blocked for } \\
20 \text { Minutes }\end{array}$ & 29.02 & 0.57 & 29.66 & 1.10 & 0.306 & $2 \%$ & 0.6 \\
\hline $\begin{array}{c}2 \text { Lanes Blocked for } \\
30 \text { Minutes }\end{array}$ & 33.84 & 0.36 & 31.36 & 1.69 & 0.089 & $-7 \%$ & -2.5 \\
\hline \begin{tabular}{|c|}
2 Lanes Blocked for \\
40 Minutes
\end{tabular} & 36.59 & 3.07 & 31.36 & 0.65 & 0.050 & $-14 \%$ & -5.2 \\
\hline \begin{tabular}{|c|} 
Lanes Blocked for \\
20 Minutes
\end{tabular} & 208.72 & 58.92 & 159.31 & 52.96 & 0.475 & $-24 \%$ & -49.4 \\
\hline \begin{tabular}{|c|}
3 Lanes Blocked for \\
30 Minutes
\end{tabular} & 420.70 & 155.27 & 403.84 & 149.45 & 0.932 & $-4 \%$ & -16.9 \\
\hline $\begin{array}{c}3 \text { Lanes Blocked for } \\
40 \text { Minutes }\end{array}$ & 741.55 & 252.78 & 536.06 & 273.20 & 0.539 & $-28 \%$ & -205.5 \\
\hline
\end{tabular}


Table 3-21 General Linear Model ANOVA Table for the Speed Response

\begin{tabular}{|l|c|c|c|c|c|c|}
\hline \multicolumn{1}{|c|}{ Source } & $\begin{array}{c}\text { Degrees of } \\
\text { Freedom }\end{array}$ & $\begin{array}{c}\text { Sequential } \\
\text { Sum of } \\
\text { Squares }\end{array}$ & $\begin{array}{c}\text { Adjusted } \\
\text { Sum of } \\
\text { Squares }\end{array}$ & $\begin{array}{c}\text { Adjusted } \\
\text { Mean Sum } \\
\text { of Squares }\end{array}$ & F-Value & p-Value \\
\hline Volime (Vol) & 3 & 19741.75 & 19251.71 & 6417.24 & 88.93 & 0.000 \\
\hline Persentage Diversion (Div) & 1 & 140.17 & 153.25 & 153.25 & 2.12 & 0.147 \\
\hline Degres of Incident (Inc) & 2 & 22464.01 & 21832.34 & 10916.17 & 151.27 & 0.000 \\
\hline Duratiout of Incident (Dur) & 2 & 4176.79 & 4280.50 & 2140.25 & 29.96 & 0.000 \\
\hline Vol * Div & 3 & 1858.53 & 1780.95 & 593.65 & 8.23 & 0.000 \\
\hline Vol * Inc & 6 & 3467.49 & 3282.28 & 547.05 & 7.58 & 0.000 \\
\hline Vol * Dur & 6 & 864.14 & 924.37 & 154.06 & 2.13 & 0.053 \\
\hline Div * Inc & 2 & 158.63 & 136.47 & 68.23 & 0.95 & 0.391 \\
\hline Div * Dur & 2 & 161.95 & 152.37 & 76.19 & 1.06 & 0.351 \\
\hline Ins * Dur & 4 & 404.98 & 395.68 & 98.92 & 1.37 & 0.247 \\
\hline Vol * Div * Inc & 6 & 586.07 & 579.41 & 96.57 & 1.34 & 0.244 \\
\hline Vol * Div * Dur & 6 & 389.90 & 402.13 & 67.02 & 0.93 & 0.476 \\
\hline Vol * Inc * Dur & 12 & 1086.31 & 1108.12 & 92.34 & 1.28 & 0.237 \\
\hline Div * Inc * Dur & 4 & 78.75 & 78.75 & 19.69 & 0.27 & 0.895 \\
\hline Vol * Div * Inc * Dur & 12 & 329.70 & 329.70 & 27.48 & 0.38 & 0.969 \\
\hline Viror & 144 & 10391.26 & 10391.26 & 72.16 & & \\
\hline Total & 215 & 66300.44 & & & & \\
\hline
\end{tabular}


Table 3-22 General Linear Model ANOVA Table for the Delay Response

\begin{tabular}{|c|c|c|c|c|c|c|}
\hline Source & $\begin{array}{c}\text { Degrees } \\
\text { of } \\
\text { Freedom }\end{array}$ & $\begin{array}{c}\text { Sequential } \\
\text { Sum of } \\
\text { Squares }\end{array}$ & $\begin{array}{c}\text { Adjusted Sum } \\
\text { of Squares }\end{array}$ & $\begin{array}{l}\text { Adjusted } \\
\text { Mean Sum } \\
\text { of Squares }\end{array}$ & F-Value & $\mathrm{p}$-Value \\
\hline Volume (Vol) & 3 & 71173863 & 68696436 & 22898812 & 161.91 & 0.000 \\
\hline Perentage Diversion (Div) & 1 & 212514 & 161651 & 161651 & 1.14 & 0.287 \\
\hline Destee of Incident (Inc) & 2 & 24564875 & 23779078 & 11889539 & 84.07 & 0.000 \\
\hline Dutation of Incident (Dur) & 2 & 8080029 & 8058359 & 4029180 & 28.49 & 0.000 \\
\hline Val * Div & 3 & 3451069 & 3064781 & 1021594 & 7.22 & 0.000 \\
\hline $\mathrm{Vol}$ * Inc & 6 & 5350829 & 5000492 & 833415 & 5.89 & 0.000 \\
\hline Vol * Dur & 6 & 4315961 & 4414950 & 735825 & 5.20 & 0.000 \\
\hline Div * Inc & 2 & 21729 & 13718 & 6859 & 0.05 & 0.953 \\
\hline Div * Dur & 2 & 44665 & 45511 & 22756 & 0.16 & 0.852 \\
\hline Ino * Dur & 4 & 1869372 & 1832161 & 458040 & 3.24 & 0.014 \\
\hline Vol * Div * Inc & 6 & 383543 & 349775 & 58296 & 0.41 & 0.870 \\
\hline Vol * Div * Dur & 6 & 191951 & 209460 & 34911 & 0.25 & 0.960 \\
\hline Vol * Inc * Dur & 12 & 1508823 & 1440707 & 120059 & 0.85 & 0.600 \\
\hline Div * Inc * Dur & 4 & 123675 & 123675 & 30919 & 0.22 & 0.928 \\
\hline Vol * Div * Inc * Dur & 12 & 403035 & 403035 & 33586 & 0.24 & 0.996 \\
\hline Emor & 144 & 20366250 & 20366250 & 141432 & & \\
\hline Total & 215 & 142062182 & & & & \\
\hline
\end{tabular}


The actual network statistics recorded directly from the CORSIM output files and the calculations of the MOE's are presented in tables located in Appendix E, F, G, and H. Appendix E, F, G, and $\mathrm{H}$ contain the statistics and calculations for the AM peak, 3/4 AM Peak, 2/3 AM Peak, and 1/2 AM Peak volume situations modeled, respectively. Each set of tables in these four appendices was arranged by incident event and MOE being reported. These appendices are arranged in the following order: first the calculations for the cumulative network average speed are presented for every situation modeled, then the calculations for the cumulative network average travel time are presented for every situation modeled, and, finally, calculations for the total network delay are presented for every situation modeled. The data presented in the following tables will be discussed in the next chapter.

With this data compiled and analyzed the next step was to discuss the significance results and determine when the diversion strategy is warranted. This task is addressed in the next chapter. 


\section{CHAPTER 4. DISCUSSION OF RESULTS}

\subsection{Evaluation Based on the Decision Criteria Defined}

The discussion of the results centers on the previously stated decision criteria. The decision criteria put in place in the previous chapter was used to determine if the traffic diversion modeled had beneficial effects on the network. In order for the diversion strategy to be implemented for a given traffic condition and specific incident situation the following decision criteria was established:

1. The $\mathrm{p}$-value determined for the Paired t-test performed must indicate that there is a significant difference between the means of two comparable MOE data sets. A p-value of less than or equal to the stated level of significance $(0.05)$ indicates a significant difference between the means of the two data sets.

2. The percentage difference between the means of the MOE data sets without the diversion strategy deployed and the data sets with the diversion deployed meet the following criteria: positive for speed (i.e., the cumulative average speed increased for the situations with the diversion) and negative for delay (i.e., the total delay decreased for the situations with diversion)

If these two criteria were met then the diversion was considered beneficial for the entire network. If either criterion was not met, it was concluded that the diversion had no impact or a negative impact on the network. 
The subsequent sections of this chapter discuss the results presented in Tables 3-13 through 3-22. Tables 3-13 through 3-20 list the results for the paired t-tests performed on each set of comparable data. Tables 3-21 and 3-22 present the ANOVA tables generated using Minitab software for the final experimental design. The basic finding of the ANOVA tables generated for each of the MOE's was that three of the four factors being evaluated had significant impacts on the responses. However, the traffic diversion was the one factor not having a significant impact as an individual factor or as it interacts with other factors. The only exception to this was the interaction between the volume and the diversion. The evidence for this statement is found in Tables 3-21 and 3-22 where the p-values determined for individual factor of diversion and the interaction of factors involving diversion are each greater than the level of significance. The ANOVA table is not a directly related to the decision criteria because it does not provide a case-by-case indication of the impacts the diversion had on the MOE's. However, the ANOVA tables are used in overall determination of the general effects and impacts the factors and interaction between the factors had on the network MOE's.

The following sections of this chapter present discussion of the results in descending order of traffic condition modeled (i.e. AM peak traffic condition to $1 \frac{1}{2}$ AM peak traffic condition). The specific situations that indicated that the diversion had a significant beneficial effect on the MOE's are cited in these sections. Also, four figures, Figures 4-1 through Figure 4-4, generated from Tables 3-13 through 3-20 are presented along with a summary table of the recommended diversion strategy for every situation tested is referenced in Table 4-1. 


\subsubsection{Discussion of Results of Simulations Run Under AM Peak Traffic Conditions}

The results for the AM peak traffic conditions, as displayed in Tables 3-13 and 3-14 indicate that there are no cases where the diversion had a significant positive effect on the network MOE's. This statement is verified though an examination of the p-values found and the percentage differences calculated for all comparable simulation data sets. In most cases the p-values determined were considerably greater than the level of significance. For example, the p-values found for the speed as listed in Table $3-13$, in order of least severe incident (1 lane blocked for 20 minutes) to most severe incident ( 3 lanes blocked for 40 minutes) data, are: $0.418,0.538,0.068,0.499,0.202$, $0.018,0.304,0.863$, and 0.304 . These p-values are typical for all the MOE data collected for this traffic condition. They indicate that the means of the comparable data sets are not significantly different and that the diversion had no significant impact on the network MOE's.

Further evaluation of the percent differences indicate that the diversion strategy under AM peak traffic conditions had a negative impact on the network MOE's. Examination of the results of simulation that tested the situation consisting of two lanes blocked for forty minutes, indicate that the diversion is actually having a significant negative effect on the MOE's. This negative effect can be seen in the speed data in Table 3-13 by a p-value of 0.018 coupled with the percent difference in the means of $-38 \%$. The p-value determined for this situation is below the level of vignificance and the percent differences for the network MOE's are demonstrating that the network operated better without diversion. 
Another characteristic of the results for the AM peak traffic conditions is that the standard deviations calculated for the MOE's for the situations with diversion are, on average, greater than those for the simulations without the diversion. For example, the average standard deviation for the speed data from the AM peak data listed in Table 3-13 with diversion is $7.38 \mathrm{mph}$ verses $1.88 \mathrm{mph}$ without diversion. This is noteworthy because it conveys that the simulations are relating the random nature associated with traffic flow. An actual traffic diversion could be expected to yield random impacts on a network because every element involved, human controlled vehicles, is random. Future research could utilize more repetitions of each experiment to ensure that the large variances found are not due to the extreme cases in the distribution.

Figure 4-1 is presented to further illustrate the relationship between the degree of incident (number of lanes blocked and duration of blockage), level of diversion ( $0 \%$ or $20 \%$ diverted to the alternate route at the time of incident) and the cumulative average network speed for each scenario. Figure 4-1 was constructed using the network speed data found in Table 3-13. This figure reinforces that, at peak traffic conditions, the diversion had negative impacts on the network evaluators. The figure demonstrates this by displaying the relationships between the comparable data sets. If the diversion had had consistent positive effects on the network evaluators, then the curves for the diversion would be higher for each incident event than the curve for the situations that did not utilize diversion. However, Figure 4-1 shows that for each degree of incident, the cumulative average network speed is lower for those situations with the diversion than those without. This figure provides strong evidence that if the 
diversion strategy was deployed, while the network was operating at peak traffic conditions, it would not be improve the overall network performance. 


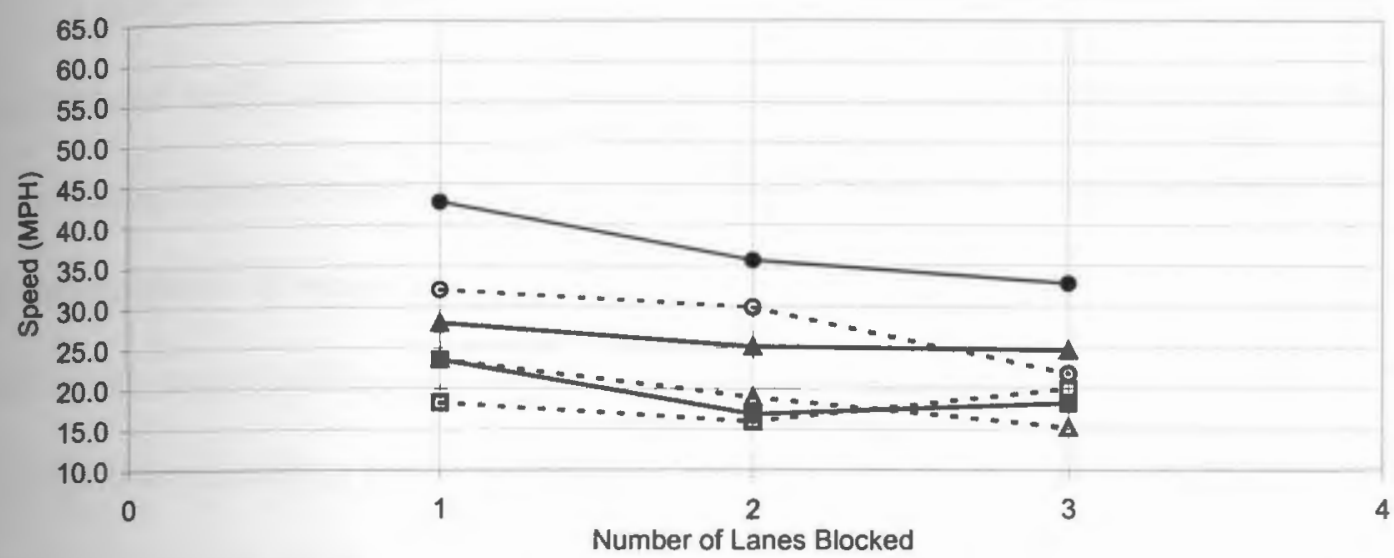

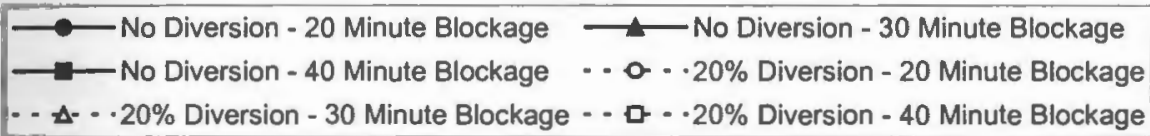

Figure 4-1 Relationship between the degree of incident (number of lanes blocked and duration of blockage), level of diversion ( $0 \%$ or $20 \%$ diverted to the alternate route at the time of incident) and the cumulative average network speed for $A M$ peak traffic conditions on the simulated network. 
Reasons for the diversion's negative effect on the network MOE's is attributed to diverted traffic causing excess merging on the alternate route and the increased lane-changing on the mainline at the point of diversion and at the termination of the alternate route. It was observed, using TRAFVU, that the excess traffic created by the diversion caused difficulties at the point of entry point and termination of Rt. 10. Congestion formed at the termination of Rt. 10 as the accumulation AM peak traffic and the diverted traffic from I-95 became too great to allow for smooth diverging to the three off ramps.

While observing the simulation in TRAFVU, I-95 NB was seen to have experienced varying affects from the excess lane-changing created by the diversion at the point of diversion. Although the results for these traffic conditions do not favor the diversion strategy, they do give crucial information concerning the effects a diversion strategy would have on the actual network. These lane-changing, merging, and diverging problems witnessed in the simulations are significant because traffic diverging under actual congested conditions follows complex irregular patterns (Hall and Zhou 1999). This implies that the CORSIM model is accurately representing severely congested flow conditions.

\subsubsection{Discussion of Results of Simulations Run Under $3 / 4$ AM Peak Traffic Conditions}

The results for the simulations modeled with $3 / 4$ AM Peak traffic conditions, as listed in Tables 3-15 and 3-16, reveal different effects on the MOE's than those 
observed for the simulations modeled with AM peak traffic conditions. For every MOE the situation that consisted of one lane being blocked for 20 minutes reveals that the tests indicate that the diversion was beneficial to the network. However, for most of the other cases the p-values are greater than the level of significance of 0.05 . This indicates that there was no significant difference in the means of the comparable data sets. The p-values found for the speed data, as listed in Table 3-15, in order of least severe incident ( 1 lane blocked for 20 minutes) to most severe incident ( 3 lanes blocked for 40 minutes), are: $0.010,0.330,0.964,0.920,0.779,0.963,0.292,0.290$, and 0.197 . Even though the statistical analysis is not indicating that the diversion had significant impacts on the MOE's, the means of the data sets indicate that the diversion is not detrimental to the network, as in the cases with AM peak traffic conditions. As listed in Table 3-15, the percent differences corresponding to each of the above p-values are: $1 \%, 10 \%,-3 \%,-1 \%, 9 \%,-4 \%, 9 \%, 13 \%$, and $34 \%$. In this case the p-values and the small percent differences clearly show that the diversion had no significant impact on the network evaluators. One reason for this phenomenon could be that there more replications are needed to provide more representative data sets for each situation.

Furthermore, the situations involving three lane blockages showed marginal statistical indications that the diversion was effective and affirmative percentage differences. Specifically, the p-values and percent differences determined for the speed and delay MOE's for the situations with three lanes blocked for durations of 20 , 30, and 40 minutes were: (for the speed data) 0.292 and $9 \%, 0.290$ and $13 \%, 0.197$ and $34 \%$ and (for the delay data) 0.098 and $-19 \%, 0.054$ and $-21 \%$, and 0.882 and - 
$6 \%$, respectively. The large percent differences between the means and the relatively small p-values indicate the diversion had a marginally beneficial effect on the network. Again, future research could utilize more repetitions of each experiment to obtain more pronounced results.

Figure 4-2 was constructed using the network speed data found in Table 3-15. It is presented to further illustrate the relationship between the degree of incident (number of lanes blocked and duration of blockage), level of diversion ( $0 \%$ or $20 \%$ diverted to the alternate route at the time of incident) and the cumulative average network speed for each scenario. This figure reinforces that, at $3 / 4$ peak traffic conditions, the diversion had slight positive or no significant impacts on the network evaluators. The figure demonstrates this by displaying the relationships between the comparable data sets. Since the diversion had slight positive effects on the network evaluators, the curves for the diversion are slightly higher for each incident event than the curve for the situations that did not utilize diversion. This figure, coupled with the discussion throughout this section, provides evidence that the diversion strategy could have positive effects on the network at $3 / 4$ peak traffic conditions. 


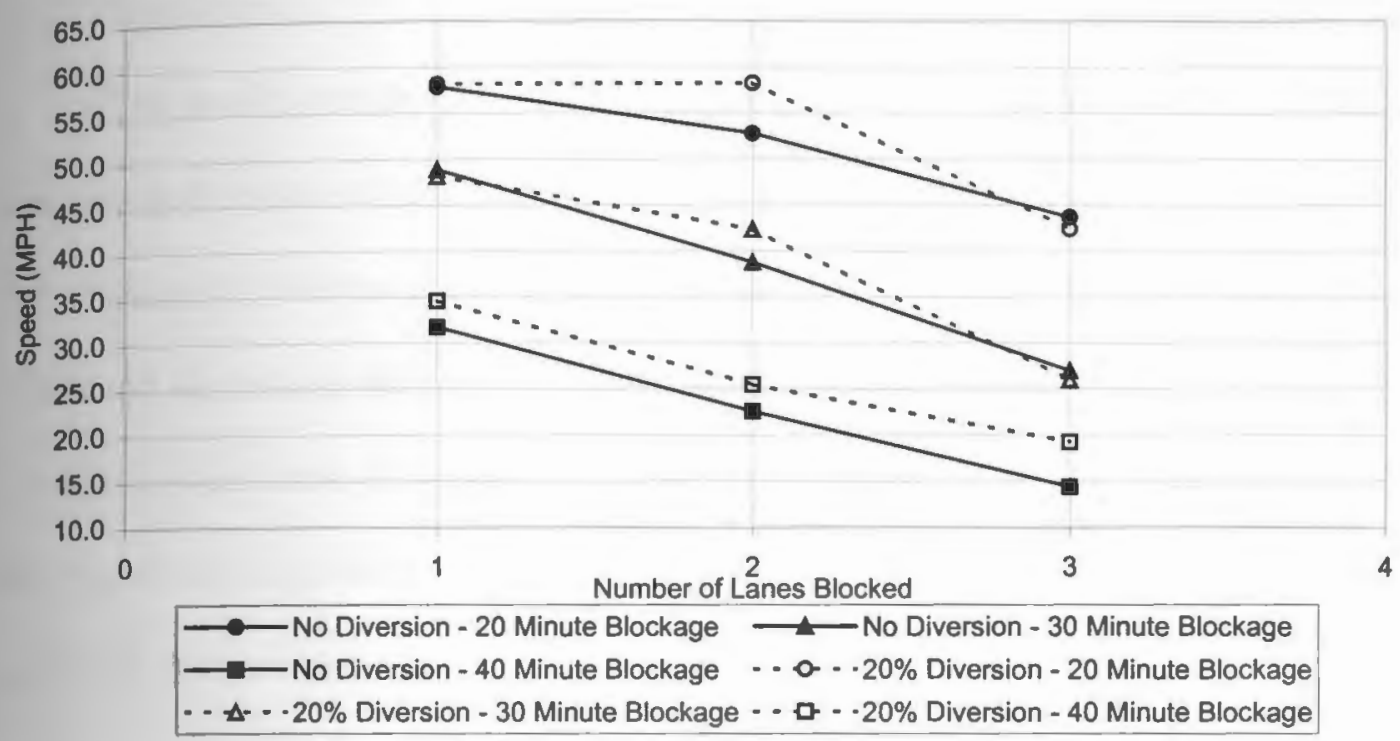

Figure 4-2 Relationship between the degree of incident (number of lanes blocked and duration of blockage), level of diversion ( $0 \%$ or $20 \%$ diverted to the alternate route at the time of incident) and the cumulative average network speed for $3 / 4 A M$ peak traffic conditions on the simulated network. 


\subsubsection{Discussion of Results of Simulations Run Under 2/3 AM Peak Traffic}

\section{Conditions}

The results for the simulation modeled with $2 / 3$ AM Peak traffic conditions demonstrated that the diversion had primarily positive effects on the network MOE's. The evidence for this statement is found in Tables 3-17 and 3-18 by examining the pvalues and the percent differences found for four of the nine cases indicate that there is a positive significant difference between the comparable data. The effect of the diversion is highlighted by large, positive, percent differences between the comparable means for the network speeds and the delay times. For example, as seen in Table 318 , the cases that indicated significant differences for the delay times indicated percent differences of $-7 \%,-61 \%,-78 \%$, and $-85 \%$ (negative percent differences are indicating that the delay with the traffic diversion is less than the delay without). There were four cases for which the diversion had significant positive effects on the network MOE's. These cases were: when the level of blockage was one lane and the duration of incident was 20 minutes, when the level of blockage was two lanes and the duration of incident was 20 minutes, when the level of blockage was two lanes and the duration of incident was 30 minutes, and when the level of blockage was two lanes and the duration of incident was 40 minutes. Furthermore, two instances were indicating that the diversion had marginal positive impacts on the network. These two situations were when the degree of lane blockage was three-lanes and the duration of the incident was 30 and 40 minutes. The evidence for this statement is found in the percent differences found for the comparable data sets. For the speed data the percent 
differences were $24 \%$ and $25 \%$ and for the delay data the percent differences were -11 and $-17 \%$

The standard deviations are less, on average, than those calculated for the simulations modeled with AM peak and $3 / 4$ AM peak traffic conditions. For example, the average standard deviations for the delay for the AM peak and $3 / 4 \mathrm{AM}$ peak for the cases with diversion are 597.14 and 449.08 hours, respectively, while the average standard deviation for the delay for the $2 / 3 \mathrm{AM}$ peak for the cases with diversion is 79.00 hours. This is indicating that the lane-changing, weaving, and merging problems present at the higher volumes are significantly less at this volume level. The reason for this could be that the traffic being diverted is below the threshold volume that causes the merging, diverging and lane-changing difficulties observed at the higher traffic volumes tested. This indication suggests that $2 / 3 \mathrm{AM}$ peak could be a threshold value for which greater volumes of traffic should not be diverted.

In addition, even if the paired t-test's indicated no significant difference, the percent differences in the means are indicating beneficial impacts for all cases. A typical example of this can be seen in the situation modeled with 2 lanes blacked for 30 minutes. For the speed data for this situation, as seen in Table 3-17, the t-test found was 0.074 indicating no significant difference in the data sets. However, the percent difference of $57 \%$ indicated that the diversion did have a beneficial effect on the network. The data from the simulation model indicates that at 2/3 AM peak traffic conditions the diversion strategy tested had the most beneficial impacts on the network for the set of traffic conditions modeled. 
Figure 4-3 is presented to further highlight the relationship between the degree of incident (number of lanes blocked and duration of blockage), level of diversion ( $0 \%$ or $20 \%$ diverted to the alternate route at the time of incident) and the cumulative average network speed for each scenario. Figure 4-3 was constructed using the network speed data found in Table 3-17. This figure displays that, at this level of traffic volume, the diversion had significant positive impacts on the network evaluators. The figure demonstrates this by displaying the relationships between the comparable data sets. Since the diversion had positive effects on the network evaluators, the curves for the diversion are consistently higher for each incident event than the curve for the situations that did not utilize diversion. 


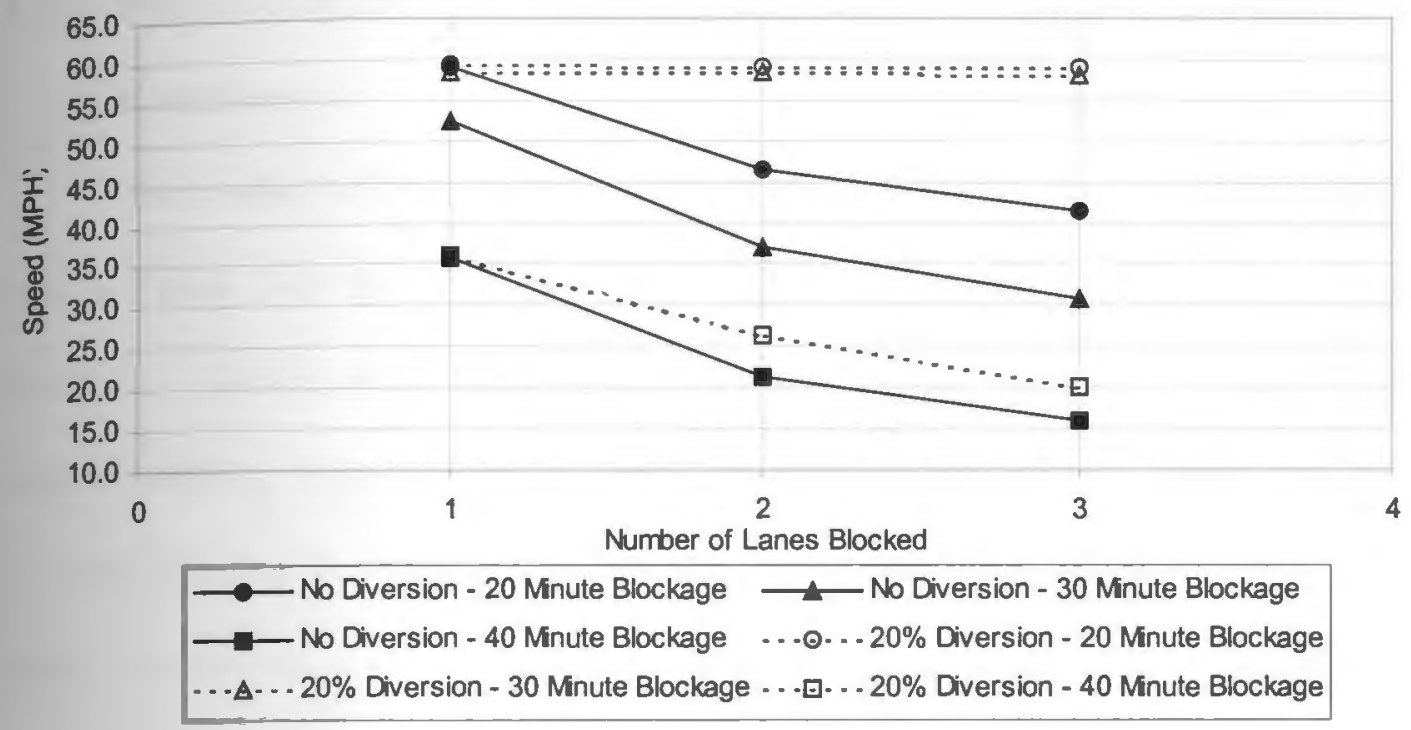

Figure 4-3 Relationship between the degree of incident (number of lanes blocked and duration of blockage), level of diversion $(0 \%$ or $20 \%$ diverted to the alternate route at the time of incident) and the cumulative average network speed for 2/3 AM peak traffic conditions on the simulated network. 


\subsubsection{Discussion of Results of Simulations Run Under $1 / 2$ AM Peak Traffic}

\section{Conditions}

The results for the simulations modeled with $1 / 2 \mathrm{AM}$ peak traffic conditions, as seen in Tables 3-19 and 3-20 do not continue the trend that the 2/3 AM peak data indicated. That is, in most cases the diversion had no significant impact on the network MOE's. However, in two cases, the p-values and percent differences found indicated that the diversion did have a significant beneficial impact on the MOE of delay. The two cases were: the situation that consisted of a degree of incident of onelane blockage lasting for 40 minutes and the situation that consisted of a degree of incident of two-lane blockage lasting for 40 minutes. The respective p-values for these two cases were 0.048 and 0.050 and can be seen in Table 3-19. The fact that the diversion did not have any considerable negative effects on the MOE's could be indicating that traffic conditions equal to, or less than, $1 / 2$ AM Peak could manage a greater percentage of diversion. The evidence for this is that the average percent difference in the means for the speed data for the 9 cases, as seen in Table 3-19, is $1.6 \%$.

Figure 4-4 is presented to further illustrate the relationship between the degree of incident (number of lanes blocked and duration of blockage), level of diversion ( $0 \%$ or $20 \%$ diverted to the alternate route at the time of incident) and the cumulative average network speed for each scenario. Figure 4-4 was constructed using the network speed data found in Table 3-19. This figure reinforces that, at $1 / 2$ peak traffic ponditions, the diversion had slight positive impacts on the network evaluators. The 
figure demonstrates this by displaying the relationships between the comparable data sets. Since the diversion had positive effects on the network evaluators, the curves for the diversion are higher for each incident event than the curve for the situations that did not utilize diversion. 


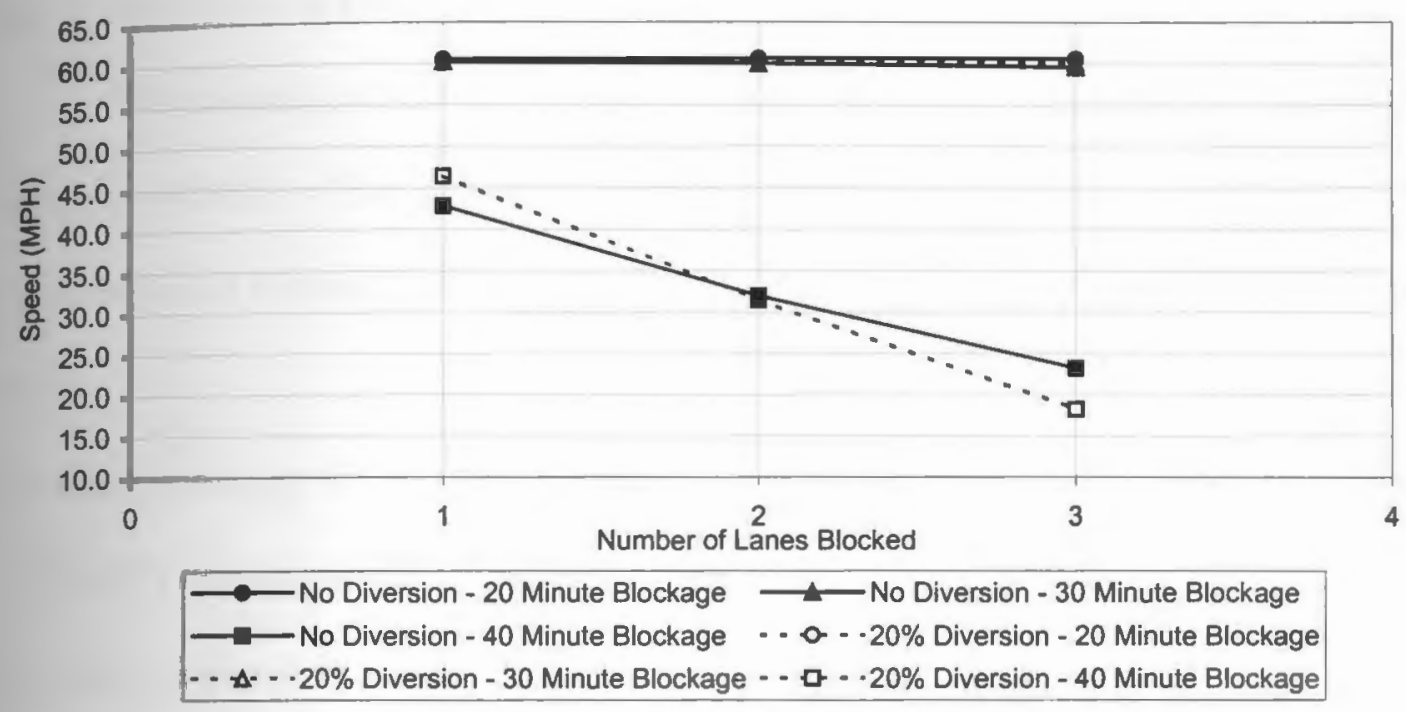

Figure 4-4 Relationship between the degree of incident (number of lanes blocked and duration of blockage), level of diversion ( $0 \%$ or $20 \%$ diverted to the alternate route at the time of incident) and the cumulative average network speed for $1 / 2 A M$ peak traffic conditions on the simulated network. 


\subsection{Summary of Discussion of Results}

The results are illustrating that traffic diversion had very distinct effects on the network MOE's. The following overall summary can be stated based on the examination of the results listed in Tables 3-13 through 3-20 and Figures 4-1 through 4-4:

- when operating at AM peak traffic conditions, the effects of the diversion on the MOE's were significantly negative;

- when operating at $3 / 4 \mathrm{AM}$ peak traffic conditions, the effects of the diversion on the MOE's were slightly positive or slightly negative;

- when operating at $2 / 3 \mathrm{AM}$ peak traffic conditions, the effects of the diversion on the MOE's were significantly positive;

- when operating at $1 / 2 \mathrm{AM}$ peak traffic conditions the effects of the diversion on the MOE's were marginally beneficial to insignificant.

Table 4-1 is presented as summary tables to display the significance of the results. The three tables show when diversion is recommend for the various situations tested. 
Table 4-1 Summary Results for Recommended Diversion Practice Based on Analysis and Stated Decision Criteria

\begin{tabular}{|c|c|c|c|c|}
\hline \multicolumn{5}{|c|}{ Diversion Practice For Incidents Blocking One Lane of Traffic } \\
\hline \multirow{2}{*}{$\begin{array}{l}\text { Duration of } \\
\text { Incident }\end{array}$} & \multicolumn{4}{|c|}{ Volume } \\
\hline & AM Peak & 3/4 AM Peak & 2/3 AM Peak & $1 / 2$ AM Peak \\
\hline 20 Minutes & ES & (D) & 23 & $\Sigma 3$ \\
\hline 30 Minutes & ¿3 & $\sum$ & 23 & 25 \\
\hline 40 Minutes & 23 & 23 & 23 & 23 \\
\hline & & & & \\
\hline \multicolumn{5}{|c|}{ Diversion Practice For Incidents Blocking Two Lanes of Traffic } \\
\hline \multirow{2}{*}{$\begin{array}{l}\text { Duration of } \\
\text { Incident }\end{array}$} & \multicolumn{4}{|c|}{ Volume } \\
\hline & AM Peak & 3/4 AM Peak & 2/3 AM Peak & 1/2 AM Peak \\
\hline 20 Minutes & 23 & 83 & D & 23 \\
\hline 30 Minutes & ¿s & ¿s & (D) & 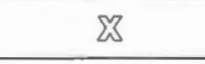 \\
\hline 40 Minutes & 23 & $\mathbb{Z}$ & D & $\Sigma$ \\
\hline & & & & \\
\hline \multicolumn{5}{|c|}{ Diversion Practice For Incidents Blocking Three Lanes of Traffic } \\
\hline \multirow{2}{*}{$\begin{array}{l}\text { Duration of } \\
\text { Incident }\end{array}$} & \multicolumn{4}{|c|}{ Volume } \\
\hline & AM Peak & 3/4 AM Peak & 2/3 AM Peak & 1/2 AM Peak \\
\hline 20 Minutes & 83 & 23 & ¿s & $\Sigma 3$ \\
\hline 30 Minutes & 23 & 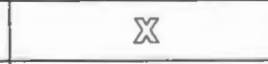 & 83 & 23 \\
\hline 40 Minutes & ¿ & 23 & 23 & $\Sigma$ \\
\hline \multirow{3}{*}{ Legend: } & D & \multicolumn{3}{|c|}{ Diversion is Recommend } \\
\hline & & & & \\
\hline & $x$ & \multicolumn{3}{|c|}{ Diversion is Not Recommend } \\
\hline
\end{tabular}




\section{CHAPTER 5. APPLICATION OF STUDY FINDINGS}

\subsection{Introduction}

During emergency situations, advanced transportation management center (ATMC) personnel have to operate under a high degree of pressure. One of the most intense situations presented to ATMC personnel is the occurrence of an accident on a major freeway. This type of emergency event demands that the actions taken by ATMC operators be precise and efficient. Any misuse of time during a traffic incident could result in excess traffic congestion, an increase in the probability of secondary incidents, and, most importantly, a decrease in the safety of those directly involved in the incident. These considerations make it imperative that ATMC operators and incident management personnel are well trained and have clear sets of procedures for managing all aspects of traffic incidents. Explicit, well-developed, procedures used in high-pressure circumstances reduce the deduction and reasoning time involved with making crucial decisions. Reducing decision time means that the response action for an incident situation is deployed more rapidly. Enacting the response measures sooner increases the safety of those involved in the incident and shortens the overall time needed to return the facility to normal traffic conditions.

\subsection{Development of Incident Management Protocol}

The results of the research provided a platform for the development of a set of protocols that could be executed by ATMC operators at the time of a traffic accident. These protocols are site specific for incidents occurring on Thurber's Avenue curve segment of I-95 NB. However, similar procedures could be developed for any 
freeway segments that experience frequent traffic incidents. A complete set of protocols would provide an ATMC a training tool and traffic management resource. Based on the results of this research, a possible configuration for these types of protocols was developed. This set of instructions is a significant product of this research. The protocol developed is referenced in Table 5-1.

The incident management protocol presented in Table 5-1 was developed directly from the evaluation of the results of the simulation experiments performed. The decision criteria stated enabled researchers to state, based on quantitative MOE's, if the traffic diversion strategy tested is warranted for 27 different minor traffic incident situations. The protocol displayed in Table 5-1 presents a set of procedures that could be followed by an ATMC operator at the time of an incident. The procedure developed includes: numbered sequential tasks, descriptions of the action to be taken to complete each task presented, and a recommended completion time for each task. The procedure also indicates the action that should be taken if the diversion is determined not warranted or if the incident situation does not resemble one of the 27 situations analyzed. 
Table 5-1 Incident Management Protocol Developed Using the Results of Research Analysis

\begin{tabular}{|c|c|c|c|}
\hline \multicolumn{4}{|c|}{$\begin{array}{l}\text { PROCEDURE FOR A TMC OPERATOR TO FOLLOW IN } \\
\text { ORDER TO DETERMINE A DIVERSION STRATEGY FOR A } \\
\text { MINOR INCIDENT ON (OR NEAR) THE THURBER'S } \\
\text { AVENUE CURVE SEGMENT OF I-95 NB IN PROVIDENCE, RI }\end{array}$} \\
\hline Step & Action & Description & $\begin{array}{l}\text { Estimated } \\
\text { Time to } \\
\text { Complete } \\
\text { the Action } \\
\text { (Seconds) }\end{array}$ \\
\hline \multirow{3}{*}{1} & \multirow{3}{*}{$\begin{array}{l}\text { Locate } \\
\text { Incident }\end{array}$} & $\begin{array}{l}\text { Utilize the following Advanced Traffic Management tools } \\
\text { to determine the location of the traffic incident: }\end{array}$ & \multirow{3}{*}{30} \\
\hline & & Video Surveillance & \\
\hline & & Driver Cell Phone Calls to Incident Hot Line & \\
\hline \multirow{4}{*}{2} & \multirow{4}{*}{$\begin{array}{l}\text { Assess } \\
\text { Incident }\end{array}$} & $\begin{array}{l}\text { Utilize the all surveillance tools and any on-site incident } \\
\text { information to determine the following incident } \\
\text { characteristics: }\end{array}$ & \multirow{4}{*}{30} \\
\hline & & Number of Vehicles Involved & \\
\hline & & Number of Lanes Being Blocked & \\
\hline & & Estimated Time to Return Segment to Full Capacity & \\
\hline \multirow{6}{*}{3} & \multirow{6}{*}{$\begin{array}{c}\text { Contact } \\
\text { Emergency } \\
\text { Service }\end{array}$} & $\begin{array}{l}\text { Initiate pre-established agency coordination by contacting } \\
\text { and providing the initial assessment of the incident to } \\
\text { proper rescue and police personnel including: }\end{array}$ & \multirow{6}{*}{120} \\
\hline & & State Police & \\
\hline & & Providence Police & \\
\hline & & Providence Fire and Rescue & \\
\hline & & Providence Special Hazards (If Necessary) & \\
\hline & & DEM and EPA (If Necessary) & \\
\hline
\end{tabular}


If the incident is blocking 4 LANES of I-95 NB immediately following obtain and follow the diversion strategy for major incidents

If the incident is blocking LESS THAN 4 LANES of I-95 NB continue following this procedure for minor incidents (Next Step - Step 4)

\begin{tabular}{|c|c|c|c|}
\hline \multirow[t]{2}{*}{4} & \multirow{2}{*}{$\begin{array}{l}\text { Activate } \\
\text { VMS }\end{array}$} & $\begin{array}{l}\text { Post on all VMS and DMS upstream from the Incident a } \\
\text { Message that warns drivers of the incident, but that does } \\
\text { not recommend that they seek an alternate route. An } \\
\text { example of a message that could be posted is: }\end{array}$ & \multirow[t]{2}{*}{30} \\
\hline & & $\begin{array}{l}\text { "Traffic Incident Ahead - Left } 2 \text { Lanes Blocked - SLOW - } \\
\text { Use Caution" }\end{array}$ & \\
\hline & \multirow[b]{2}{*}{$\begin{array}{l}\text { Activate } \\
\text { HAR }\end{array}$} & $\begin{array}{l}\text { The HAR radio should broadcast a message similar to that } \\
\text { being displayed on the VMS. An Example of a message } \\
\text { that could be broadcast is: }\end{array}$ & \multirow[t]{2}{*}{30} \\
\hline 5 & & $\begin{array}{l}\text { "Vehicles traveling NB bound on I-95 through the } \\
\text { Providence Metropolitan Area are advised that there is a } \\
\text { two lane traffic incident near exit 13, Thurber's Avenue } \\
\text { Exit. The incident is confined to the two left-most lanes. } \\
\text { Please reduce speed and use caution as you approach this } \\
\text { segment of roadway. Stay tune for updated messages as } \\
\text { the incident is further assessed" (Loop Message) }\end{array}$ & \\
\hline \multicolumn{4}{|c|}{ BEGIN TO DEVELOP DIVERSION STRATEGY } \\
\hline \multirow[t]{4}{*}{6} & \multirow{4}{*}{$\begin{array}{l}\text { Determine if } \\
\text { Flow on the } \\
\text { Alternate } \\
\text { Route is } \\
\text { Normal or } \\
\text { Not }\end{array}$} & $\begin{array}{l}\text { This is accomplished by determining if there are any } \\
\text { traffic incidents or other restrictions of flow on the Rt. } 10 \\
\text { NB. This should be done by quickly reviewing all video } \\
\text { surveillance cameras monitoring the alternate route. } \\
\text { Restrictions may include the following: }\end{array}$ & \multirow{4}{*}{30} \\
\hline & & Traffic Accidents & \\
\hline & & Road Construction & \\
\hline & & Planned events that add demand above normal & \\
\hline
\end{tabular}




\begin{tabular}{|c|c|c|c|}
\hline \multirow{2}{*}{7} & \multirow{2}{*}{$\begin{array}{l}\text { Proceed or } \\
\text { Abort } \\
\text { Deployment } \\
\text { of the } \\
\text { Diversion } \\
\text { Strategy }\end{array}$} & $\begin{array}{l}\text { Abort: If Normal Traffic Flow Conditions DO NOT } \\
\text { EXIST on Rt. 10 NB for the entire length of roadway } \\
\text { downstream from the on-ramp that delivers the diverted } \\
\text { traffic from I-95 NB then the Diversion Strategy should } \\
\text { be aborted. If the strategy is aborted then the operator } \\
\text { should continue to monitor the incident on I-95 NB and } \\
\text { Provide any assistance possible to emergency personnel. } \\
\text { Also, the VMS message originally posted and the HAR } \\
\text { message originally broadcast should remain for the } \\
\text { duration of the incident clearance. }\end{array}$ & \multirow[t]{2}{*}{10} \\
\hline & & $\begin{array}{l}\text { Proceed: If Normal Traffic Flow Conditions DO } \\
\text { EXIST on Rt. } 10 \text { NB for the entire length of roadway } \\
\text { downstream from the on-ramp that delivers the diverted } \\
\text { traffic from I-95 NB then the operator should proceed } \\
\text { with the development of the Diversion Strategy. While } \\
\text { the operator continues to decide whether or not to } \\
\text { recommend that traffic divert to Rt. } 10 \text { NB, the VMS } \\
\text { message originally posted and HAR originally broadcast } \\
\text { should remain. }\end{array}$ & \\
\hline \multicolumn{4}{|c|}{ If Step 7 Indicates PROCEED, then continue with Step 8} \\
\hline \multirow[t]{5}{*}{8} & \multirow{5}{*}{$\begin{array}{c}\text { Assess } \\
\text { Network } \\
\text { Flow } \\
\text { Conditions }\end{array}$} & $\begin{array}{l}\text { Noting the time of day and utilizing visual inspection } \\
\text { through video surveillance and any supplemental data } \\
\text { from loop detectors or video surveillance software, the } \\
\text { operator must estimate the prevailing traffic flow } \\
\text { conditions of both the mainline and alternate route. The } \\
\text { prevailing traffic conditions be summarized by one of the } \\
\text { following definitions: }\end{array}$ & 30 \\
\hline & & AM Peak Traffic & \\
\hline & & 3/4 AM Peak Traffic & \\
\hline & & 2/3 AM Peak Traffic & \\
\hline & & 1/2 AM Peak Traffic & \\
\hline \multirow{4}{*}{9} & \multirow{4}{*}{$\begin{array}{l}\text { Re-Assess } \\
\text { Incident }\end{array}$} & $\begin{array}{l}\text { Utilize the all surveillance tools and any on-site incident } \\
\text { information to determine the following specific incident } \\
\text { characteristics: }\end{array}$ & \multirow{4}{*}{30} \\
\hline & & Number of Vehicles Involved & \\
\hline & & Number of Lanes Being Blocked (1-3) & \\
\hline & & $\begin{array}{l}\text { Estimate Time to Clear }(20,30,40 \text { or greater than } 40 \\
\text { minutes) }\end{array}$ & \\
\hline
\end{tabular}




\section{Table 5-1 Continued From Previous Page}

\begin{tabular}{|c|c|c|c|}
\hline \multicolumn{4}{|c|}{ SPECIFIC DECISION CRITERIA NOTED } \\
\hline \multirow{4}{*}{10} & \multirow{4}{*}{$\begin{array}{l}\text { Note the } \\
\text { Three } \\
\text { Situation } \\
\text { Factors }\end{array}$} & $\begin{array}{l}\text { At this point the operator should have noted the four } \\
\text { characteristics of the situation at hand. The four } \\
\text { characteristics needed to proceed are: (1) prevailing traffic } \\
\text { conditions, (2) level of lane blockage, and (3) the duration } \\
\text { of the incident. These characteristics will dictate if the } \\
\text { diversion will be deployed or not. They must be } \\
\text { characterized within the following bounds: }\end{array}$ & 30 \\
\hline & & $\begin{array}{l}\text { 1. The Level of Flow is: Peak AM, 3/4 Peak AM, } 2 / 3 \text { Peak } \\
\text { AM, or } 1 / 2 \text { Peak AM }\end{array}$ & \\
\hline & & $\begin{array}{l}\text { 2. The Level of Lane Blockage is: } 1 \text { Lane Blocked, } 2 \\
\text { Lanes Blocked, or } 3 \text { Lanes Blocked }\end{array}$ & \\
\hline & & $\begin{array}{l}\text { 3. The Duration of Incident is: } 20 \text { Minutes, } 30 \text { Minutes, } \\
40 \text { Minutes, or greater than } 40 \text { Minutes. }\end{array}$ & \\
\hline 11 & $\begin{array}{l}\text { Determine if } \\
\text { Diversion is } \\
\text { Warranted }\end{array}$ & $\begin{array}{l}\text { Based on the } 3 \text { characteristics noted, the operator will turn } \\
\text { to the appropriate page and allocate the appropriate table } \\
\text { in the minor incident guideline and determine if the } \\
\text { diversion should be deployed for the specific situation. } \\
\text { These tables were formed using the results of a simulation } \\
\text { study that utilized CORSIM micro-simulation software. }\end{array}$ & 30 \\
\hline \multicolumn{4}{|c|}{ Locate the Incident Situation in the 12 Tables on the Next Four Pages } \\
\hline \multicolumn{4}{|c|}{$\begin{array}{c}\text { Note: The tables are organized by Prevailing Traffic Conditions, Then By Number of Lanes } \\
\text { Blocked, Then By Estimated Time to Clear }\end{array}$} \\
\hline 12 & $\begin{array}{c}\text { DO NOT } \\
\text { ACTIVATE } \\
\text { Diversion } \\
\text { Strategy }\end{array}$ & $\begin{array}{l}\text { Based on the situation described by the } 3 \text { characteristics } \\
\text { and the reference tables it is determined that the diversion } \\
\text { is not warranted, then the operator should continue to } \\
\text { monitor the incident and provide the emergency team with } \\
\text { whatever assistance is needed. Also, the VMS and HAR } \\
\text { should continue to relay the initial message of incident } \\
\text { description and caution. These messages should remain } \\
\text { until the complete clearance of the incident. If the incident } \\
\text { is under control and being managed the operator should } \\
\text { note any vehicle diversion to Rt. } 10 \text { without the prompting } \\
\text { of the TMC. }\end{array}$ & 10 \\
\hline 13 & $\begin{array}{c}\text { ACTIVATE } \\
\text { Diversion } \\
\text { Strategy }\end{array}$ & $\begin{array}{l}\text { Based on the situation described by the } 3 \text { characteristics } \\
\text { and the reference tables it is determined that the diversion } \\
\text { is warranted, and then the operator should activate the } \\
\text { pre-assigned messages for the HAR and VMS in the case } \\
\text { that a diversion is warranted. This language should be } \\
\text { strong enough to divert } 20 \% \text { of the I-95 NB traffic to Rt. } \\
10 \text {. These messages should remain until the complete } \\
\text { clearance of the incident. If the incident is under control } \\
\text { and being managed the operator should note any vehicle } \\
\text { diversion to Rt. } 10 \text { without the prompting of the TMC. The } \\
\text { operator should also continue to monitor the incident and } \\
\text { provide the emergency team with whatever assistance is } \\
\text { needed. }\end{array}$ & 30 \\
\hline
\end{tabular}


Table 5-1 Continued From Previous Page

\begin{tabular}{|c|c|}
\hline \multicolumn{2}{|r|}{ FOR AM PEAK TRAFFIC CONDITIONS } \\
\hline \multicolumn{2}{|r|}{ For Incidents Blocking 1 Lane } \\
\hline Duration of Incident (Minutes) & $\begin{array}{c}\text { Recommended Course of Action (Activate Diversion for or Do Not } \\
\text { Activate Diversion) }\end{array}$ \\
\hline 20 & Do Not Activate Diversion \\
\hline 30 & Do Not Activate Diversion \\
\hline 40 & Do Not Activate Diversion \\
\hline \multicolumn{2}{|r|}{ FOR AM PEAK TRAFFIC CONDITIONS } \\
\hline \multicolumn{2}{|r|}{ For Incidents Blocking 2 Lanes } \\
\hline Duration of Incident (Minutes) & $\begin{array}{c}\text { Recommended Course of Action (Activate Diversion for or Do Not } \\
\text { Activate Diversion) }\end{array}$ \\
\hline 20 & Do Not Activate Diversion \\
\hline 30 & Do Not Activate Diversion \\
\hline 40 & Do Not Activate Diversion \\
\hline & \\
\hline \multicolumn{2}{|r|}{ FOR AM PEAK TRAFFIC CONDITIONS } \\
\hline \multicolumn{2}{|r|}{ For Incidents Blocking 3 Lanes } \\
\hline Duration of Incident (Minutes) & $\begin{array}{c}\text { Recommended Course of Action (Activate Diversion for or Do Not } \\
\text { Activate Diversion) }\end{array}$ \\
\hline 20 & Do Not Activate Diversion \\
\hline 30 & Do Not Activate Diversion \\
\hline 40 & Do Not Activate Diversion \\
\hline
\end{tabular}


Table 5-1 Continued From Previous Page

\begin{tabular}{|c|c|}
\hline \multicolumn{2}{|c|}{ FOR 3/4 AM PEAK TRAFFIC CONDITIONS } \\
\hline \multicolumn{2}{|r|}{ For Incidents Blocking 1 Lane } \\
\hline Duration of Incident (Minutes) & $\begin{array}{c}\text { Recommended Course of Action (Activate Diversion for or Do Not } \\
\text { Activate Diversion) }\end{array}$ \\
\hline 20 & Activate Diversion \\
\hline 30 & Do Not Activate Diversion \\
\hline 40 & Do Not Activate Diversion \\
\hline & \\
\hline \multicolumn{2}{|c|}{ FOR 3/4 AM PEAK TRAFFIC CONDITIONS } \\
\hline \multicolumn{2}{|r|}{ For Incidents Blocking 2 Lanes } \\
\hline Duration of Incident (Minutes) & $\begin{array}{l}\text { Recommended Course of Action (Activate Diversion for or Do Not } \\
\text { Activate Diversion) }\end{array}$ \\
\hline 20 & Do Not Activate Diversion \\
\hline 30 & Do Not Activate Diversion \\
\hline 40 & Do Not Activate Diversion \\
\hline \multicolumn{2}{|c|}{ FOR 3/4 AM PEAK TRAFFIC CONDITIONS } \\
\hline \multicolumn{2}{|r|}{ For Incidents Blocking 3 Lanes } \\
\hline Duration of Incident (Minutes) & $\begin{array}{c}\text { Recommended Course of Action (Activate Diversion for or Do Not } \\
\text { Activate Diversion) }\end{array}$ \\
\hline 20 & Do Not Activate Diversion \\
\hline 30 & Do Not Activate Diversion \\
\hline 40 & Do Not Activate Diversion \\
\hline
\end{tabular}


Table 5-1 Continued From Previous Page

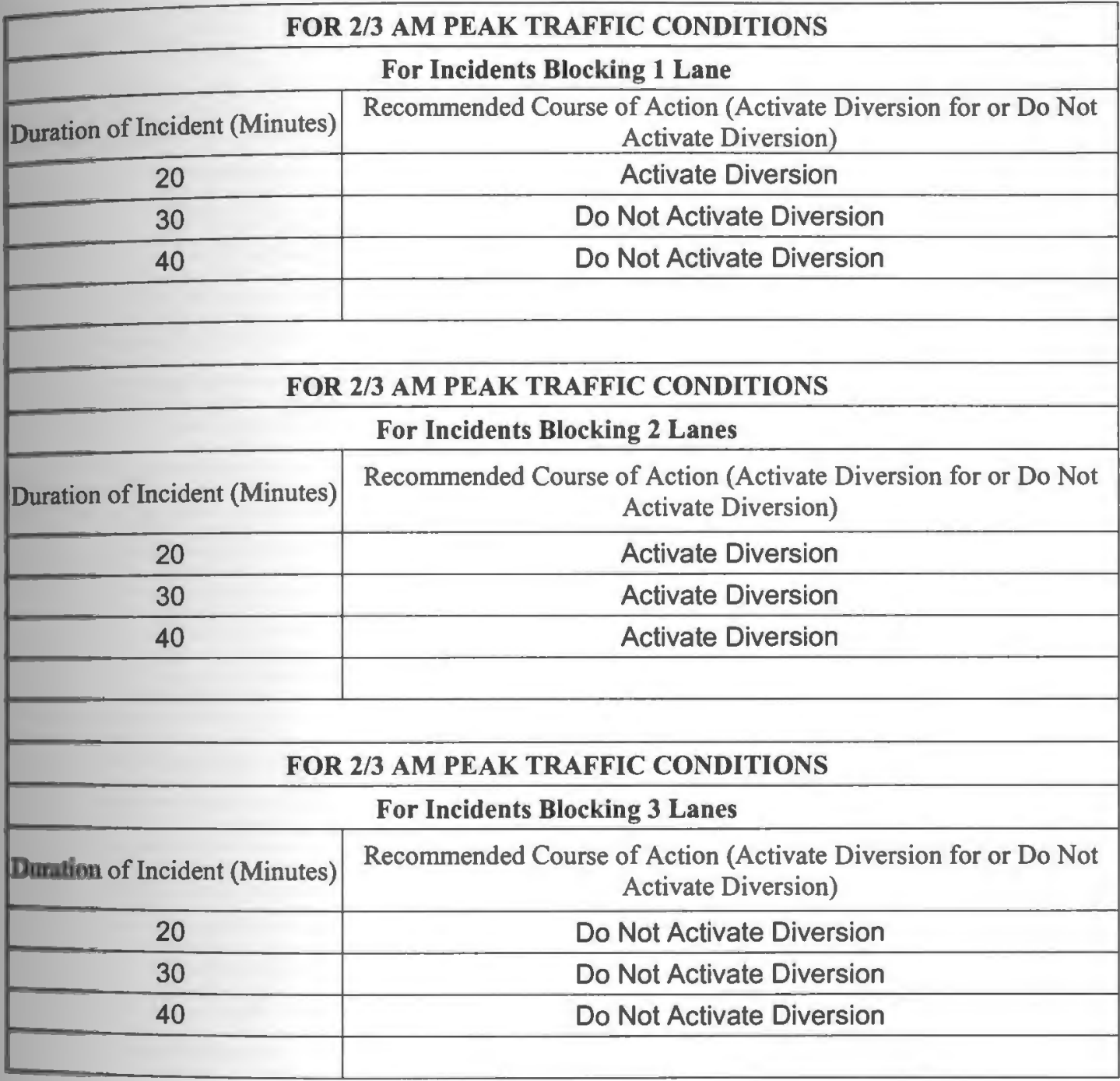


Table 5-1 Continued From Previous Page

\begin{tabular}{|c|c|}
\hline \multicolumn{2}{|r|}{ FOR 1/2 AM PEAK TRAFFIC CONDITIONS } \\
\hline \multicolumn{2}{|r|}{ For Incidents Blocking 1 Lane } \\
\hline Duration of Incident (Minutes) & $\begin{array}{c}\text { Recommended Course of Action (Activate Diversion for or Do Not } \\
\text { Activate Diversion) }\end{array}$ \\
\hline 20 & Do Not Activate Diversion \\
\hline 30 & Do Not Activate Diversion \\
\hline 40 & Do Not Activate Diversion \\
\hline & \\
\hline \multicolumn{2}{|c|}{ FOR $1 / 2$ AM PEAK TRAFFIC CONDITIONS } \\
\hline \multicolumn{2}{|r|}{ For Incidents Blocking 2 Lanes } \\
\hline Duration of Incident (Minutes) & $\begin{array}{c}\text { Recommended Course of Action (Activate Diversion for or Do Not } \\
\text { Activate Diversion) }\end{array}$ \\
\hline 20 & Do Not Activate Diversion \\
\hline 30 & Do Not Activate Diversion \\
\hline 40 & Do Not Activate Diversion \\
\hline \multicolumn{2}{|r|}{ FOR 1/2 AM PEAK TRAFFIC CONDITIONS } \\
\hline \multicolumn{2}{|r|}{ For Incidents Blocking 3 Lanes } \\
\hline Dumtion of Incident (Minutes) & $\begin{array}{c}\text { Recommended Course of Action (Activate Diversion for or Do Not } \\
\text { Activate Diversion) }\end{array}$ \\
\hline 20 & Do Not Activate Diversion \\
\hline 30 & Do Not Activate Diversion \\
\hline 40 & Do Not Activate Diversion \\
\hline
\end{tabular}




\section{CHAPTER 6. CONCLUSIONS AND RECOMMENDATIONS}

\subsection{Conclusions}

The results of the analysis performed on the output data from CORSIM enabled researchers to form a route diversion strategy for the network studied. The developed diversion strategy is based on the determined impacts of the factors modeled on the network evaluators. It was found that the diversion is not warranted for the majority of the situations tested. However, a significant finding of the research was that at $2 / 3$ AM peak traffic volume the diversion was found to having beneficial effects on the network for more of the incident situations than at any other traffic conditions simulated. This conclusion is shown in summary Table 4-1. It is an important finding because it indicates that there is a threshold level of traffic volume for which the route diversion is most beneficial.

The results from the ANOVA analysis as seen in Tables 3-21 and 3-22 and Figures 4-1 through 4-4 strongly indicate that the traffic condition the network is operating at is the most important factor in deciding if traffic diversion is warranted. The evidence for this statement is that the p-values found for each of the network responses, speed and delay, are indicating that the traffic volume factor is significant as an individual factor as well as when it interacts with each of the other three factors. This conclusion can be intuitively assumed based on a surface level evaluation of a given roadway network. However, a quantitative measure of the impacts of various incident events coupled with various traffic conditions and diversion strategies is mecessary to confidently deploy a diversion strategy. 
The findings indicate that more replications of each experiment may be warranted. The evidence for this statement is the magnitude of the variances in the data, particularly with regards to the situations employing the route diversion. More replications may give a better representation of the impacts of the diversion on the MOE's. By performing more experimental replications, the data set to be analyzed would be more representative. Also, researchers could increase the confidence in their findings by lowering the effects of extreme data on the statistical determinations.

CORSIM, coupled with the various companion software used in this research, performed adequately as tools for traffic route diversion analysis. CORSIM's stochastic nature produced varied outputs that allowed for statistical sampling and testing. CORSIM demonstrated that traffic diversion does not always produce the desired impacts on the entire network. This is significant because it indicates that by only analyzing the main line route, without considering the effects on the alternate route, a traffic diversion may merely relocated the congestion, in effect, failing to improve the overall network conditions. CORSIM is not perfect, but researchers must continue to utilize the software in experiments so that feedback can be provided to programmers. As the software improves, it will become more advantageous and efficient to apply it to the evolving complex challenges that face transportation officials. 


\section{Recommendations}

The recommendations that the research yielded are as follows:

(1) Recommended Diversion Practice - It is recommended that RIDOT's traffic division and TMC review the diversion protocol, presented in Chapter 5 in Table 5-1, before deploying it to help manage the traffic problems related to un-planned minor traffic incidents.

(2) CORSIM as a Tool for Diversion Strategy Analysis -A well-developed and validated CORSIM simulation model can be used to aid in the development of a Nway-to-highway route diversion strategy. It is recommended that CORSIM be utilized in traffic diversion simulation applications.

(3) Application of Research Methodology - It is recommended that the summary research methodology developed be applied for similar simulation projects that utilize CORSIM or similar traffic simulation models.

(4) Modification to Research Methodology - In some cases the t-tests are indicating that the diversion is not having a significant effect on network evaluators even through the percentage differences in the means are large. These large positive percent differences are indicating that the diversion is having a beneficial effect on the network. Because of this, the diversion could be recommended for more situations than is indicated based on the stated decision criteria. The diversion should be further studied utilizing more replications experiments. Performing more replications of each experiment may reduce the variance in the data and sharpen the differences between the comparable data sets. 

for a freeway route diversion strategy utilize the guidelines in the National ITS Architecture (NITSA) electronic document. An example of a plan developed from NITSA for the deployment of an advanced traffic management system (ATMS) capable of incident management and route diversion is presented in Appendix J. 


\section{REFERENCES}

Aycin, M.F. and Benekohal, R.F. (1999) "Comparison of Car-Following Models for Simulation", Transportation Research Board Paper No. 99-1200, in Tansportation Research Record 1678, National Research Council, Washington, D.C., pp. 116-127.

Banks, J.H. (1999) "Investigation of Some Characteristics of Congested Flow", transportation Research Board Paper No. 99-0125, in Transportation Research Record 1678, National Research Council, Washington, D.C., pp 128 -134.

Benekohal, R.F. (1991) "Procedure for Validation of Microscopic Traffic Flow Simulation Models" in Transportation Research Record 1320, Transportation Research Board, National Research Council, Washington, D.C., pp. 190-202.

Brock, et al. (1996) "A Compendium of Traffic Model Validation Documentation and Recommendations - Phase 1 - Tasks A-H", Federal Highway Administration, Washington, D.C.

Dunn, W.M. and Reiss, R.A. (1991) Freeway Incident Management Handbook, Report No. Federal Highway Administration-SA-91-056, Federal Highway Administration, Washington, D.C.

Dunn, W.M., Latoski, S., and Reiss, R. (1999) Roadway Incident Diversion Practices, National Cooperative Highway Research Program (NCHRP) Synthesis of Highway Practice 279, Transportation Research Board (Transportation Research Board), National Research Council, Washington, D.C.

Dutta, U., Tadi, R., Devadoss, D., and Poola, M. (1997) "Freeway Courtesy Patrol as a Roadside Assistance Program: Experience of Two Large Metropolitan Areas" paper presented at the $76^{\text {th }}$ Annual Meeting of Transportation Research Board, Washington, D.C.

lefteriadou, L et al. (1999) "Beyond the Highway Capacity Manual Framework for Selecting Simulation Models in Traffic Operational Analyses", in tansportation Research Record 1678, National Research Council, Washington, D.C., pp 96-106.

Fazio, J. and Rouphail, N.M. (1990) "Conflict in INTRAS: Application to Weaving Area Capacity Analysis", in Transportation Research Record 1287, National Research Council, Washington, D.C., pp 96-107.

Federal Highway Administration (1998) CORSIM User's Manual: Version 1.04, U.S. Department of Transportation, Washington, D.C. 
Federal Highway Administration (1998) ITRAF User Guide: Version 2.0, U.S. Department of Transportation, Washington, D.C.

Federal Highway Administration (1998) TRAFVU User's Manual: Version 1.01, U.S. Department of Transportation, Washington, D.C.

Federal Highway Administration (1998) TSIS User Guide: Version 4.2, U.S. Department of Transportation, Washington, D.C.

Gragg, C.A. and Demetsky, M. J. (1995) Final Report: Simulation of Route Diversion Strategies for Freeway Incident Management, Federal Highway Administration, Charlottesville, VA

Garrison, D. and Mannering, F. (1990) "Assessing the Traffic Impacts of Freeway Incidents and Driver Information", in ITE Journal 60(8), Institute of Tranportation Engineers, Washington, D.C., pp. 19-23.

Guiliano, G. (1988) Incident Characteristics, Frequency, and Duration of a High Volume Urban Freeway, Report No. Federal Highway Administration UCI-ITSWP-022, Federal Highway Administration, Washington, D.C.

Hall, F.L. and Zhou, M. (1999) "Investigation of Speed-Flow Relationship Under Congested Conditions on a Freeway", Transportation Research Board Paper No. 99-0402, Transportation Research Record 1678, National Research Board, Washington, D.C., pp. 64-72.

Institute of Transportation Engineers (1992) "Mobility Facts", Washington, D.C.

Levin, M. (1977) "Evaluating Location Effectiveness of Freeway Directional and Diversion Signs", Transportation Research Record (TRR) 644, Transportation Research Board, National Research Council, Washington, D.C., pp. 122-129.

Mass, Jr., C. (1998) "Estimating the Benefits of ITS technology in Incident Management: The Case of Northern Virginia" paper presented at the $77^{\text {th }}$ Annual Meeting of Transportation Research Board, Washington, D.C.

May, A.D. (1990) Traffic Flow Fundamentals, Prentice Hall Inc., Englewood Cliffs, NJ

McShane, W.R., Prassas, E.S., Roess, R.P. (1998) Traffic Engineering, PrenticeHall, Inc., Upper Saddle River, NJ

Myers, R.H., Myers, S.L., and Walpole, R.E. (1998) Probability and Statistics for Engineers and Scientists, Prentice Hall Inc., Upper Saddle River, NJ 
Roess, R.P. and Ulerio, J.M. (1997) Comparison of the 1994 Highway Capacity Manual's Ramp Analysis Procedures and the FRESIM Model, NCHRP Synthesis of Highway Practice 345, Transportation Research Board, National Research Council, Washington, D.C.

Roper, D.H. (1990) Freeway Incident Management, NCHRP Synthesis of Highway Practice 156, Transportation Research Board, National Research Council, Washington, D.C.

Transportation Research Board (1997) Highway Capacity Manuel, Special Report 209, Transportation Research Board, Washington, D.C., 
APPENDIX A

Photographs of Typical Segments of

The Roadways in the Study Area 


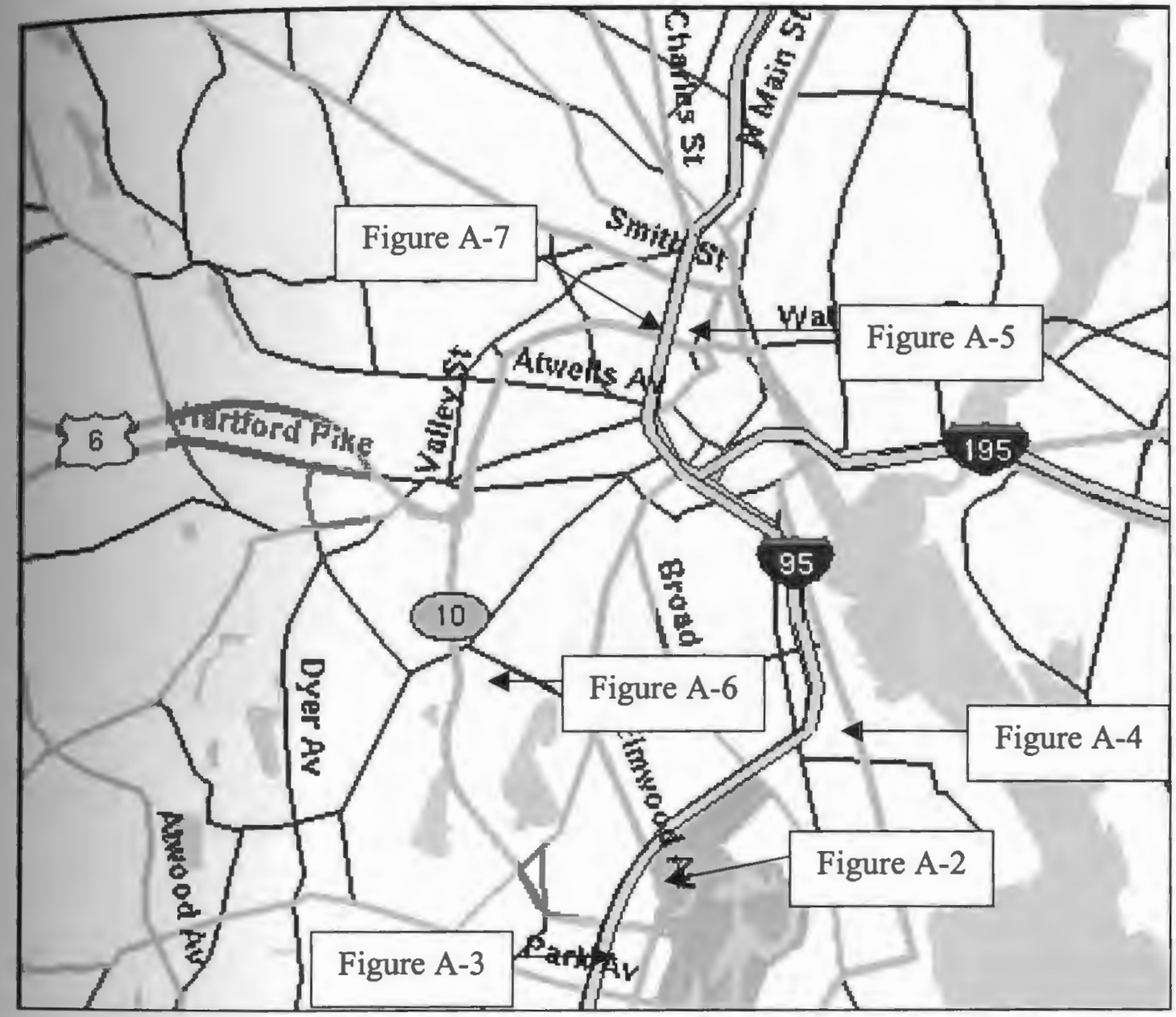

Figure A-1 Displays the Study Area as seen in the Introduction. The map is labeled with the locations of the subsequent photos. 


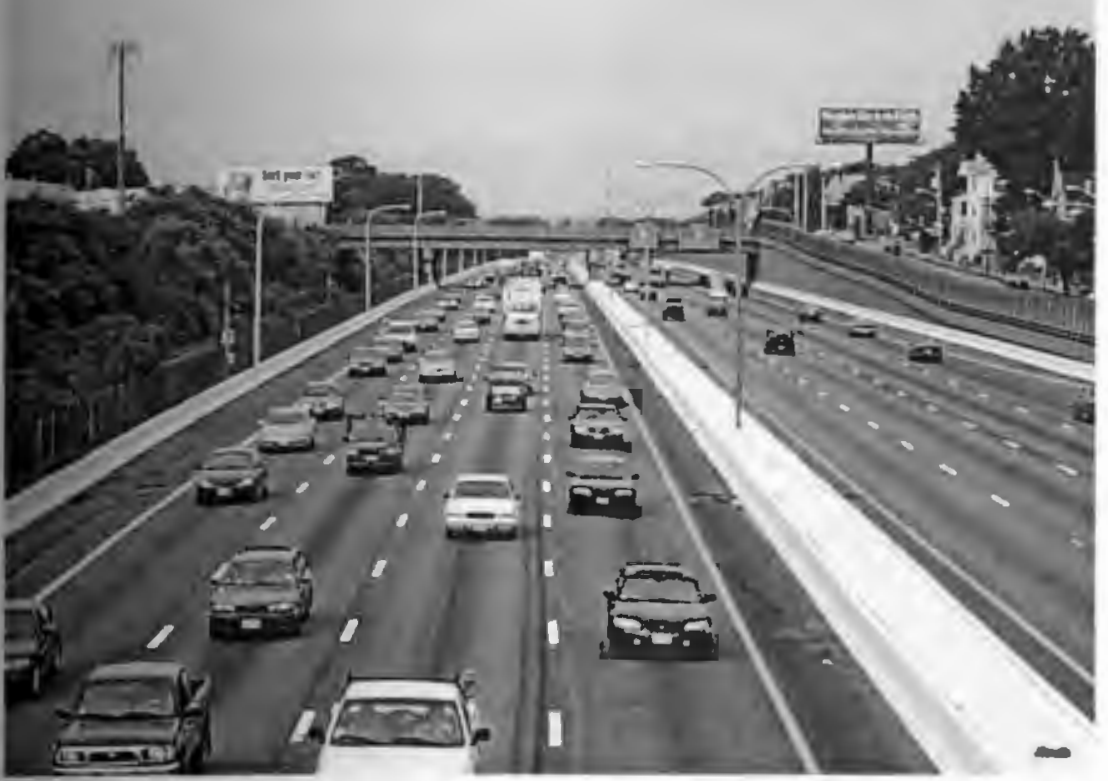

Figure A-2 Displays a typical section of Interstate-95 North in the Study Area (The north direction of freeway is coming out of the page.) 


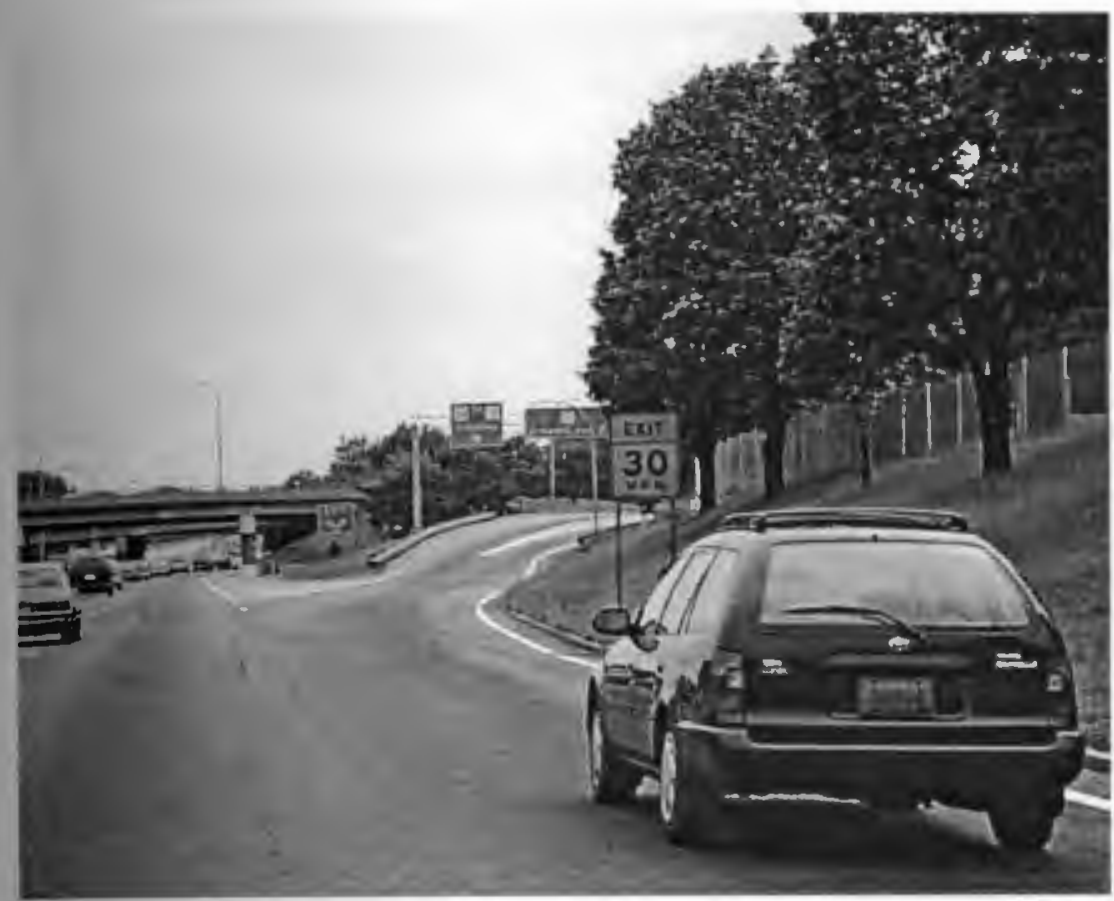

Figure A-3 Displays the diversion point from Interstate 95 North to Route 10 North. 


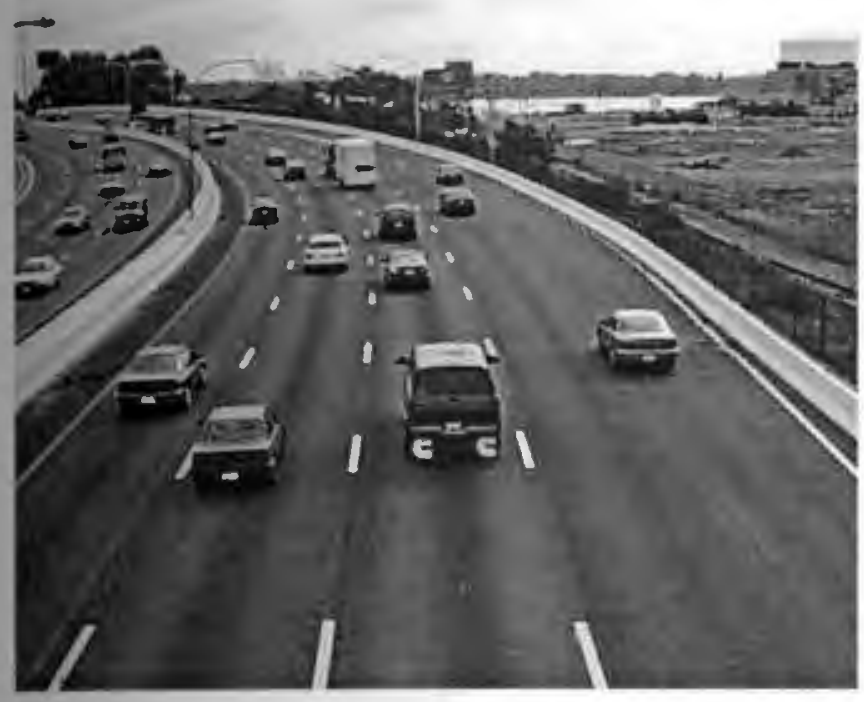

Figure A-4 Displays the "Thurber's Avenue Curve Section in the Study Area. This is the location of the incident in the model. 


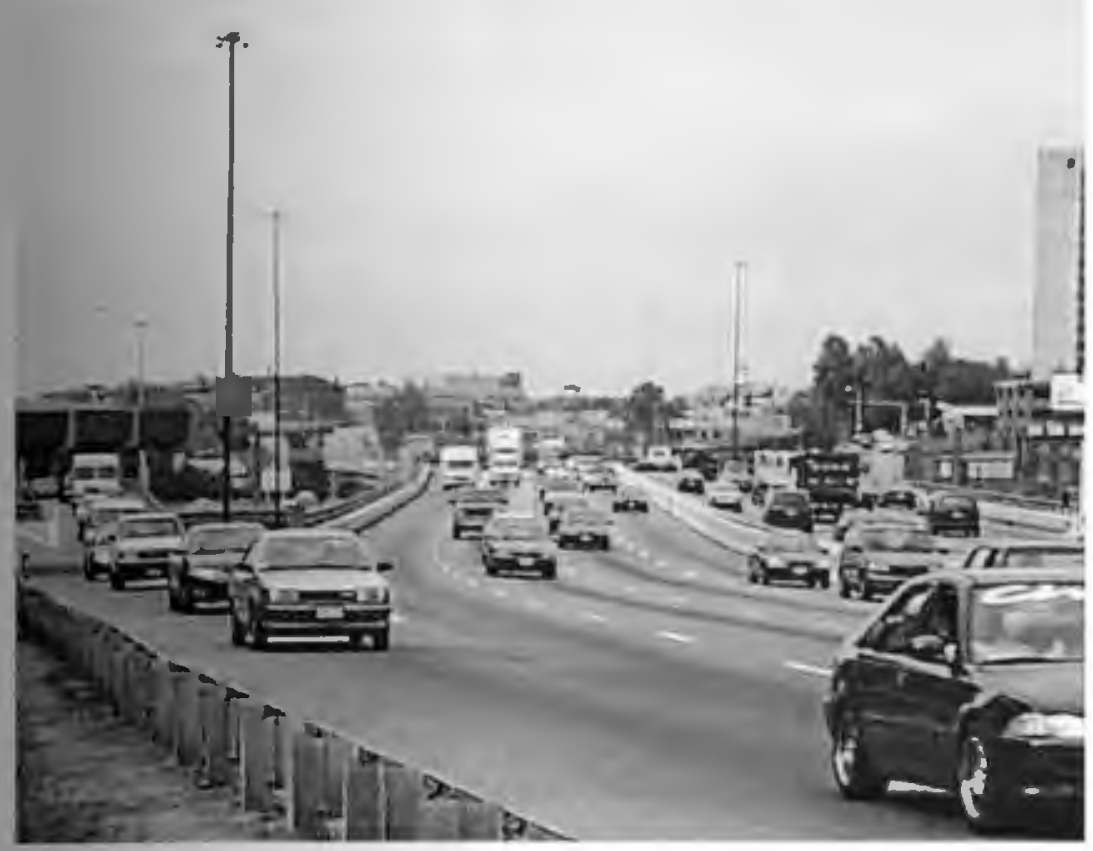

Figure A-5 Displays the Route 10 North traffic re-entering Interstate 95 North near the northern most point in the study area. 


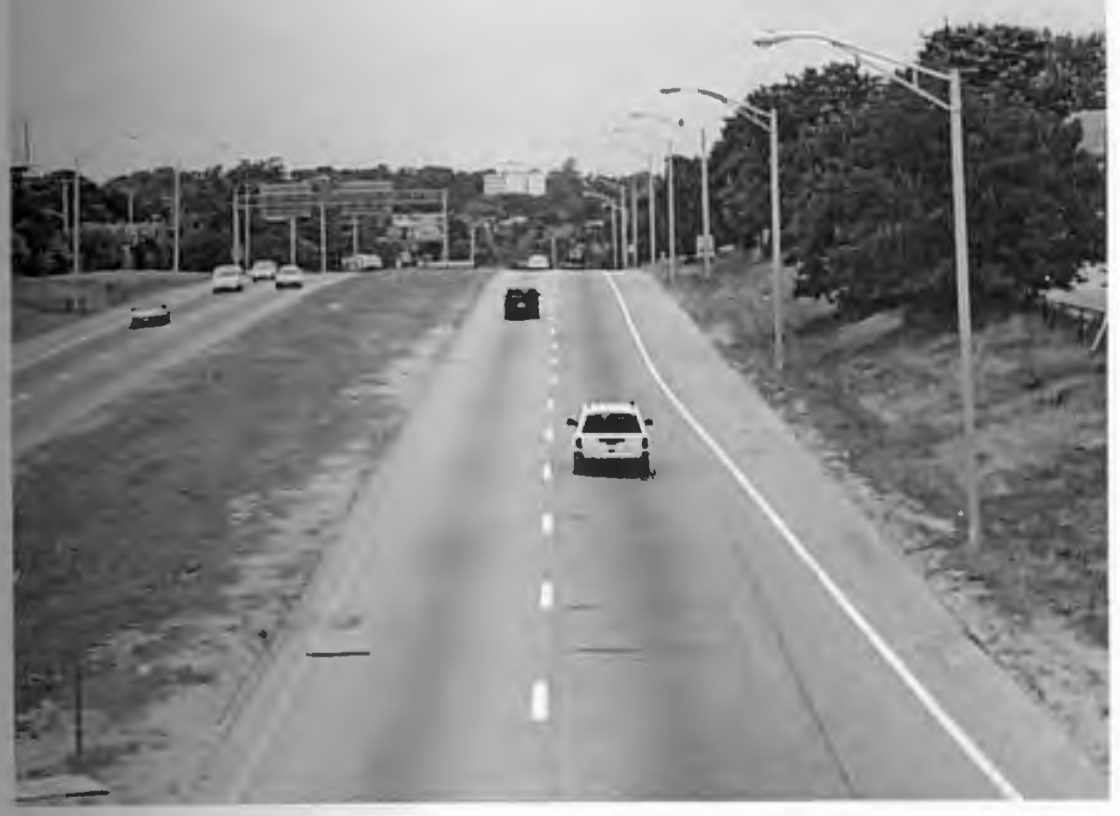

Figure A-6 Displays a typical section of Route 10 North in the Study Area (The north direction is going into the page.) 


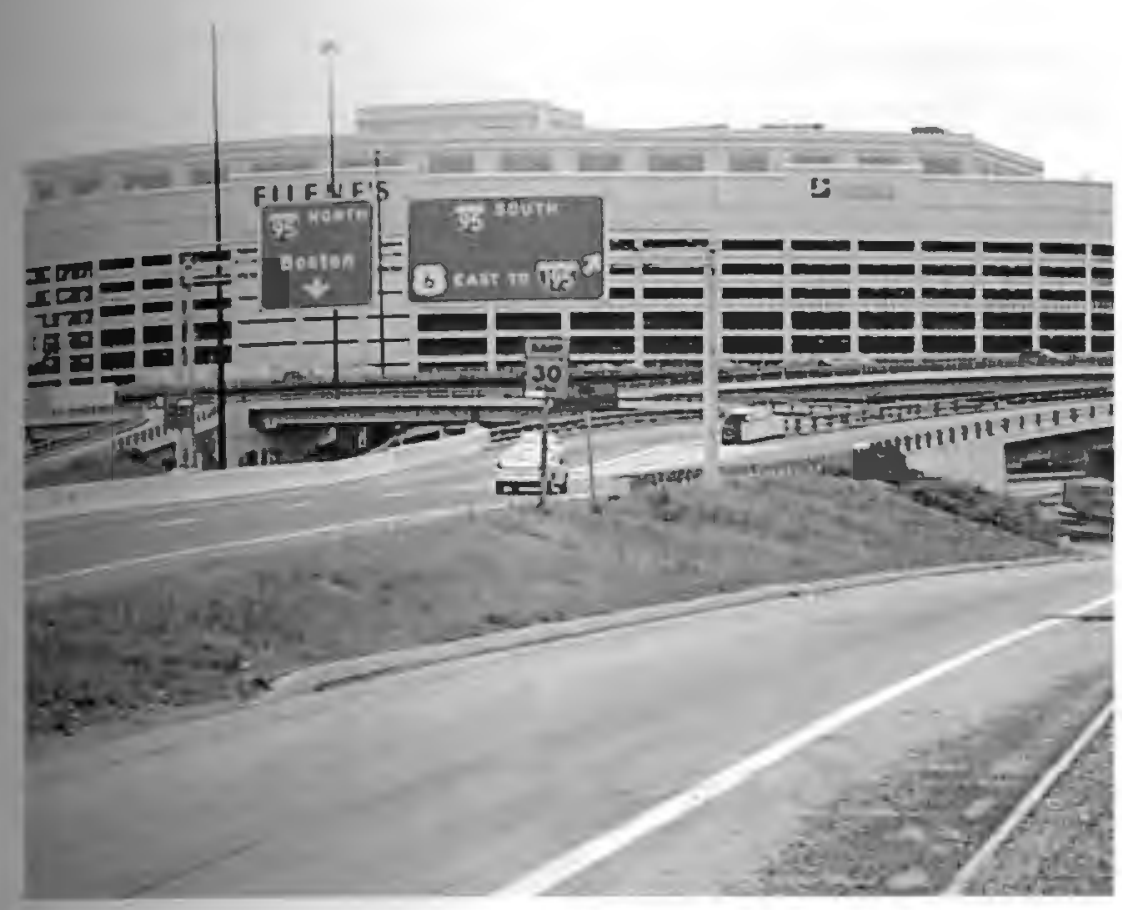

Figure A-7 Displays the options presented to a driver at the termination of Route 10 North in Providence. A driver can either (1) enter the downtown Providence area, (2) enter I-95 South, or (3) re-enter I-95 north. 
APPENDIX B

Car Following Logic Employed by CORSIM 


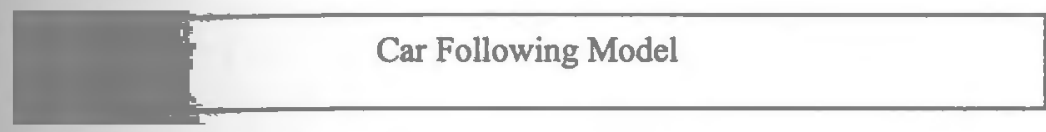

Please note the model derivation was ohtained from reference [5]. Refer to Figure A-1 and Table A-1 for a definition of all variak

Car-Following model.

In the PITT Car-Following Model, the basic assumption is that the follower vehicle will try to maintain a space headway equal to

$$
L+10+k v+b k(u-v)^{2}
$$

For the current calculation for the follower vehicle, we are given $x_{1}, u_{1}, y_{1} v$ and we must calculate $a$. The desired position at time $t+T$ is given by equation (1) as

$$
x_{1}-y_{1}=L+10-k v_{1}+b k\left(u_{1}-v_{1}\right)^{2}
$$

but $y_{1}-y-v T+\frac{a T^{2}}{2}$ and $v_{1} v+a T$ and thus equation (2) becomes

$$
x_{1}-\left(y+v T+\frac{a T^{2}}{2}\right)=L+10+k(v+a T)+b k\left(u_{1}-v\right)^{2}
$$

Note: Since the term $(u-v)^{2}$ is small, the approximation of $v_{8}=v$ is used. Any difference is accounted for by the calibration of $b$.

Solving for the acceleration of the follower vehicle using equation (3) results in

$$
a=2 \frac{\left[x_{1}-y-L-10-v(k+T)-b k\left(u_{1}-v\right)^{2}\right]}{\left[T^{2}+2 k T\right]}
$$

Equation (4) represents the basic car-following relationship. The term involving the constant $b$ was introduced to allow for high relative closing speed behavior observed empirically. The value of $b$ has been calibrated to

$$
b=\left\{\begin{array}{c}
0.10 \text { for }(u-v)>10 \\
0 \text { for }(u-v)>0
\end{array}\right.
$$

The driver reaction time $\mathrm{c}$ is introduced into the car-following equations, after a has been calculated, when the new speed and position are defined

$$
v_{1}-v+a(T-c)
$$

and

$$
y_{1}=y+v T+\frac{a(T-c)^{2}}{2} \text { where } c<T
$$



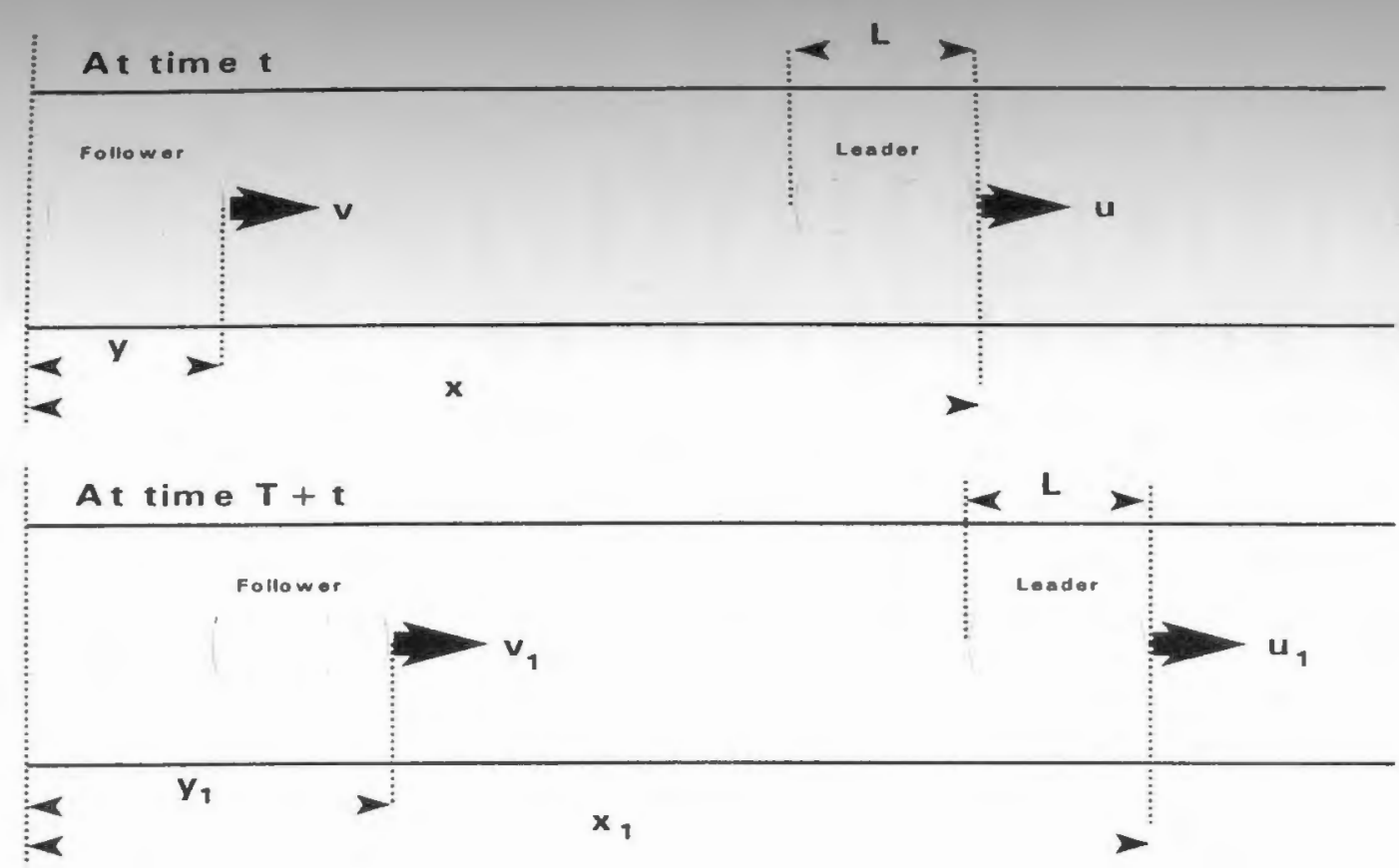

Figure A-1

Illustration of key variables for the PITT Car-Following Model 
Variable Definition Table for the PITT Car-Following Model

\begin{tabular}{|c|l|}
\hline Variable & Definition (all dimensions are in feet and/or seconds) \\
\hline$k$ & car following parameter (driver sensitivity factor) \\
\hline$L$ & length of the leading vehicle \\
\hline$T$ & time scanning interval \\
\hline$c$ & lag (driver reaction time, always less than $T$ ) \\
\hline$e$ & maximum emergency deceleration $\left(15 \mathrm{ft} / \mathrm{sec}^{2}\right)$ \\
\hline$x$ & position of leader at time $t$ \\
\hline$u$ & speed of leader at time $t$ \\
\hline$y$ & position of follower at time $t$ \\
\hline$V$ & speed of follower at time $t$ \\
\hline$a$ & acceleration of follower in the interval $(t, t+T$ ) \\
\hline$x_{1}$ & position of leader at time $t+T$ \\
\hline$u_{1}$ & speed of leader at time $t+T$ \\
\hline$y_{1}$ & position of follower at time $t+T$ \\
\hline$V_{1}$ & speed of follower at time $t+T$ \\
\hline$b$ & calibration constant \\
\hline
\end{tabular}


An emergency constraint overrides the car-following rules established above to prevent collisions. The basic concept provides that the follower vehicle can stop safely behind the leader vehicle under the following conditions:

- The leader vehicle decelerates to a stop at the maximum emergency deceleration.

- The follower vehicle, starting at the lag time $\mathrm{c}$, later decelerates to a stop behind the leader vehicle at a deceleration rate within the maximum emergency deceleration limit.

If the leader stops at the maximum deceleration then $u_{1}=0$ and

$$
x_{1}=x+\frac{u^{2}}{2 e}
$$

The follower vehicle stopping at the maximum deceleration will also give

$$
y_{1}=y+c v+\frac{v^{2}}{2 e}
$$

Since the headway between the vehicles must exceed the length of the leader vehicle, equations (6) and (7) y: sld

$$
x_{1}-y_{1}-x-y+\frac{\left(u^{2}-v^{2}\right)}{2 e}-c v \quad L
$$

and reformulating this equation becomes

$$
x-y \geq L+c v+\frac{\left(v^{2}-u^{2}\right)}{2 e}
$$

but for $x-y \geq L$ for all $u, v$ and thus equation (8) is valid only if

$$
\begin{gathered}
c v+\frac{\left(v^{2}-u^{2}\right)}{2 e}=0 \\
v-\sqrt{\left(u^{2}+e^{2} c^{2}\right)}-e c
\end{gathered}
$$

The basic headway constraint then becomes

$$
x-y \geq L+c v+\frac{\left(v^{2}-u^{2}\right)}{2 e} \text { if } v: \sqrt{\left(u^{2}+e^{2} c^{2}\right)}-e c
$$

and

$$
x-y \geq L \text { if } v<\sqrt{\left(u^{2}+e^{2} c^{2}\right)}-e c
$$


If $x_{1}, u_{1}, y_{1} v$, and $T$ are given, then the acceleration $a$ of the follower vehicle for the time period $(t, t+T)$ must be determined such that the headway constraint is not violated.

Two possible cases can arise:

1. The follower vehicle has a speed $v_{1}>0$ at time $t+T$.

$$
\begin{gathered}
v_{1}=v+a(T-c) \\
y_{1}=y+v T+a \frac{(T-c)^{2}}{2} \text { if } T-c>0
\end{gathered}
$$

2. The follower vehicle comes to a stop during the interval $(t, t+T)$, assuming this occurs at time $t(1+p)$, where $0<p \geq 1$.

$$
\begin{gathered}
v_{1}-v+a(\rho T-c)=0 \\
y_{1}=y-\frac{v^{2}}{2 a}
\end{gathered}
$$

Substituting for $v_{1}$ and $y$, into equation (9) yields

$$
\begin{gathered}
x_{1}-y_{1} \geq L+c v_{1}+\frac{\left(v_{1}^{2}-u_{1}^{2}\right)}{2 e} \text { if } v_{1} \geq \sqrt{\left(u_{1}^{2}+\theta^{2} c^{2}\right)}-e c \\
x_{1}-y_{1} \geq L \text { if } v_{1}<\sqrt{\left(u_{1}^{2}+\theta^{2} c^{2}\right)}-e c
\end{gathered}
$$

From equations (10), (11) and (12)

$$
\begin{aligned}
& x_{1}-y-v T-a \frac{(T-c)^{2}}{2} \geq L+c v+c a(T-c)+\frac{\{v+a(T-c)\}^{2}-u_{1}^{2}}{2 e} \\
& \text { when } v_{1}=\sqrt{\left(u_{1}^{2}+e^{2} c^{2}\right)}-e c>0 \\
& x_{1}-y-v T-a \frac{(T-c)^{2}}{2}=L
\end{aligned}
$$

and

$$
\text { when } 0<v_{1}<\sqrt{\left(u_{q}^{2}+\theta^{2} c^{2}\right)}-e c
$$


and

$$
x_{1}-y+\frac{v^{2}}{2 a}=L
$$

when $v_{1}=0$

or

$$
\begin{aligned}
& a^{2}=\left[\frac{(T-c)^{2}}{2 e}, a \frac{(T-c)^{2}}{2}-c(T-c)=2 v \frac{(T-c)}{2 e}\right] \cdot\left[x_{1}-v-v T-L \quad c v \frac{\left(v^{2}-u_{1}^{2}\right)}{2 e}\right]>0 \\
& \text { when } v_{1} \sqrt{\left(u_{1}^{2}+e^{2} c^{2}\right)}-e c>0
\end{aligned}
$$

and

$$
-a \frac{(T-c)^{2}}{2}+x_{1}-y-v T-L=0
$$

$$
\text { when } 0<v_{1}<\sqrt{\left(u_{q}^{2}+\theta^{2} c^{2}\right)}-e c
$$

and

$$
a \leq \frac{-v^{2}}{2\left(x_{1}-y-L\right)}
$$

when $v_{1}-0$

Equation (13) reduces to

$$
a^{2}+a\left[e+\frac{2 e c}{(T-c)}+\frac{2 v}{(T-c)}\right]-\left[\frac{2 e}{(T-c)^{2}}\right]\left[x_{1}-y-v T-L-c v-\frac{\left(v_{1}^{2}-u_{1}^{2}\right)}{2 e}\right] \geq 0
$$

which yields

$$
a<-\frac{B}{2}+\frac{\sqrt{B^{2}+4 C}}{2}
$$

$$
\text { where } B=e+2\left[\frac{e c+v}{T-c}\right]
$$

and

$$
C=\left[\frac{2 e}{(T-c)^{2}}\right]\left[x_{1}-y-v T-L-c v-\frac{\left(v^{2}-y_{1}^{2}\right)}{2 e}\right]
$$

The condition $v_{1} \geq \sqrt{\left(u_{1}^{2}+\theta^{2} c^{2}\right)}-\theta c>0$ reduces to 
Equation (14) reduces to

$$
\text { a } \quad 2\left[\frac{x_{1}-y-v T-L}{(T-c)^{2}}\right]
$$

provided $0<v+a(T-c)<\sqrt{\left(u_{1}^{2}+e^{2} c^{2}\right)}-e c$

or

$$
-\frac{v}{(T-c)}<a<\frac{\sqrt{\left(u_{1}^{2}+e^{2} c^{2}\right)}-e c-v}{(T-c)}
$$

Equation (15) can be simplified to

$$
a-\frac{-v^{2}}{2\left(x_{1}-y-L\right)}
$$

provided a $\frac{-V}{(T-c)}$

Equations (16), (17), (18), and (19) are the constraints which determine the follower vehicle's acceleration which must be maintained in order to satisfy the emergency noncollision conditions.

Provided the vehicles are in a safe position at time $t$, then the above constant set will be sufficient for the vehicles at time $t+T$. In particular $B^{2}+4 C$ is always positive and thus the acceleration given by equation (16) has a real value.

The emergency constraint, however, is also used in the lane changing mechanism where the vehicles (in adjacent lanes) may not be in a safe position relative to each other in a longitudinal sense. In this case the following can occur:

1) The above constraint set provides real acceleration but it is greater than $e$ and thus the lane change is not initiated.

2) The discriminant $\left(B^{2}+4 C\right)$ is negative. In this case the lane change is automatically not initiated, sine the two vehicles must be in an unsafe relative position for occupying the same lane. 


\section{APPENDIX C}

Coordinates of Nodes used to Model the Roadway Network 


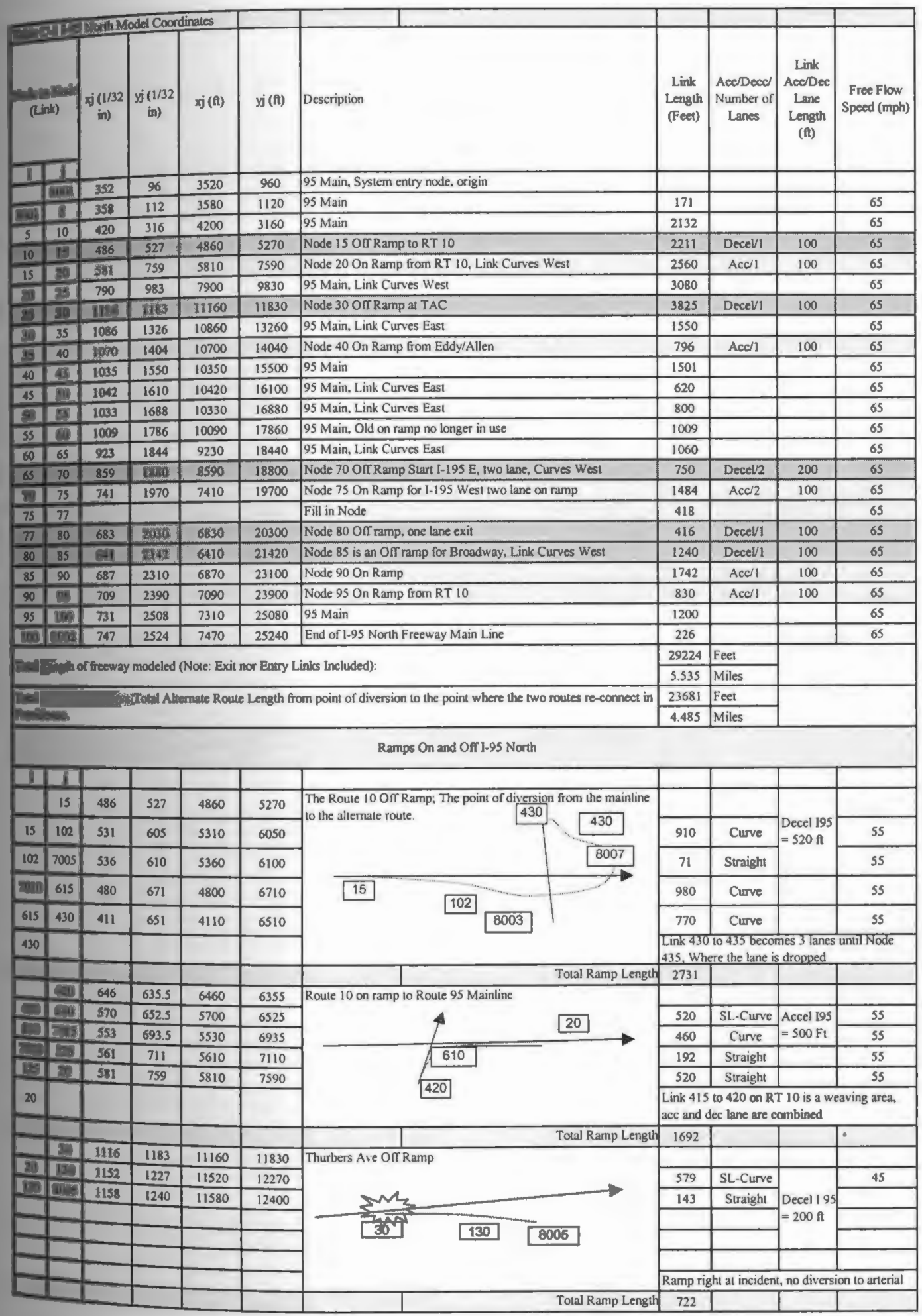




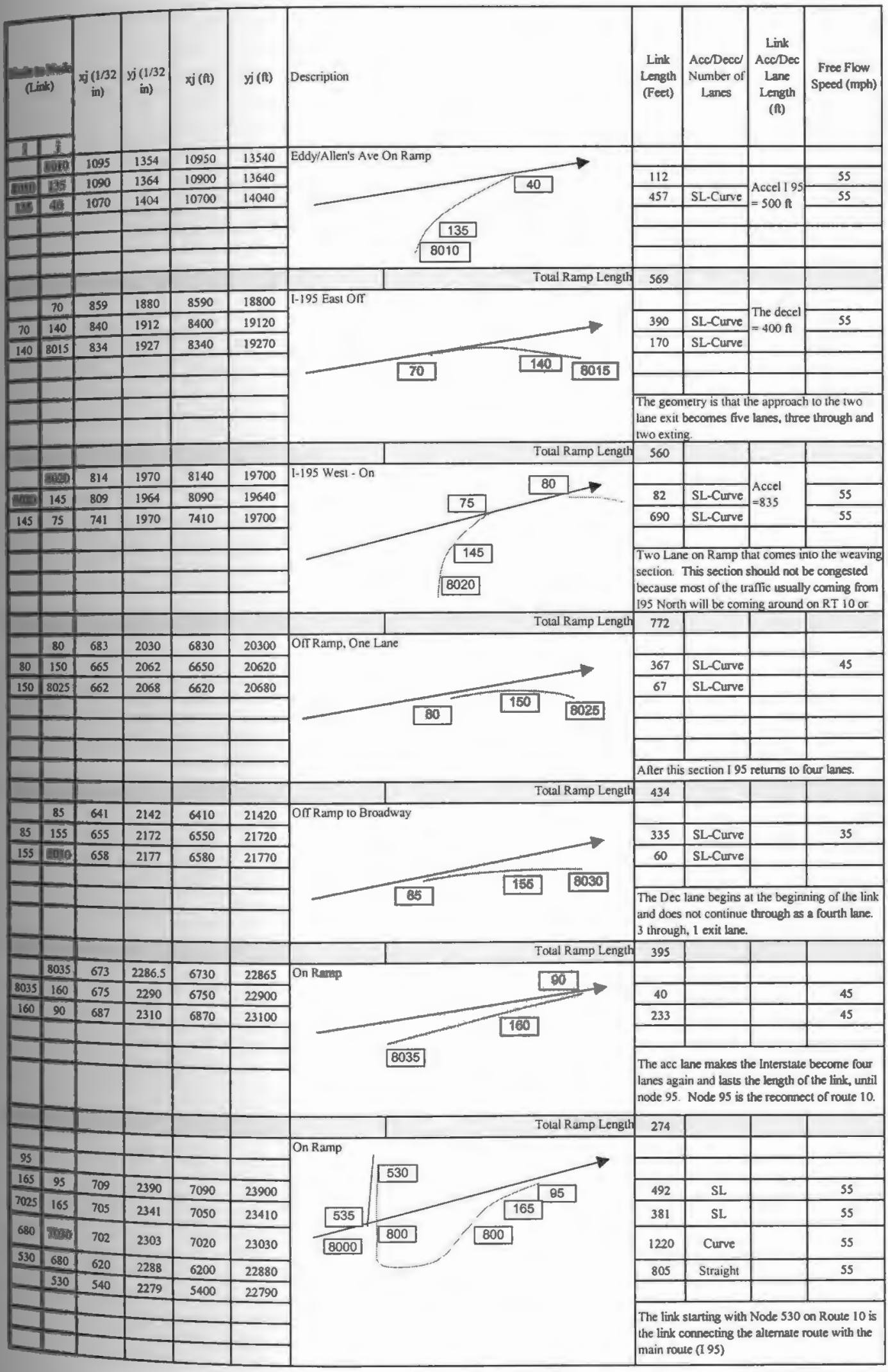




\begin{tabular}{|c|c|c|c|c|c|c|c|c|c|c|}
\hline (Lint) & $\begin{array}{c}x j(1 / 32 \\
\text { in })\end{array}$ & $\begin{array}{c}\text { yj (1/32 } \\
\text { in })\end{array}$ & $x j(\mathrm{i})$ & yj (t) & Descriplion & & $\begin{array}{l}\text { Link } \\
\text { Length } \\
\text { (Feet) }\end{array}$ & $\begin{array}{c}\text { AcoDecd } \\
\text { Number of } \\
\text { Lanes }\end{array}$ & $\begin{array}{c}\text { Link } \\
\text { Acc Dec } \\
\text { Lane } \\
\text { Length }\end{array}$ & $\begin{array}{l}\text { Free Flow } \\
\text { Speed (mph) }\end{array}$ \\
\hline i. 1. & & & & & & Total Ramp Length & 2898 & & & \\
\hline & & & & & & & & & & \\
\hline & & & & & & Toul Length of All I95 Ramp Links & 11047 & Feet & & \\
\hline & & & & & & Total Length of All l95 Ramp Links & 2.092 & Miles & & \\
\hline
\end{tabular}




\begin{tabular}{|c|c|c|c|c|c|c|c|c|c|c|}
\hline \multicolumn{11}{|c|}{ 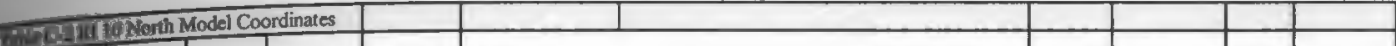 } \\
\hline \multicolumn{2}{|c|}{$\begin{array}{l}\text { Node to } \\
\text { Vode (Link) }\end{array}$} & $\begin{array}{l}\text { xi }(1 / 32 \\
\text { in) }\end{array}$ & $\begin{array}{c}\text { yj }(1 / 32 \\
\text { in })\end{array}$ & $x j(f t)$ & yj (ft) & \multirow[b]{2}{*}{ Traffic Entering from Park Ave. in Cranston } & \multirow[t]{2}{*}{$\begin{array}{l}\text { Link } \\
\text { Length } \\
\text { (Feet) }\end{array}$} & \multirow[t]{2}{*}{$\begin{array}{c}\text { Acc/Decc } N \\
\text { umber of } \\
\text { Lanes }\end{array}$} & $\begin{array}{c}\text { Link } \\
\text { Acc/D } \\
e c \\
\text { Lane } \\
\text { Length } \\
\text { (ft) }\end{array}$ & \multirow[t]{2}{*}{$\begin{array}{l}\text { Free Flow } \\
\text { Speed } \\
\text { (mph) }\end{array}$} \\
\hline & 8040 & 705.5 & 399.5 & 7055 & 3995 & & & & & \\
\hline 8040 & 400 & 712.5 & 415.5 & 7125 & 4155 & Node in Cran. at Beg of RT 10, off park ave, onelane & 175 & & & 60 \\
\hline 400 & 405 & 751.5 & 507.5 & 7515 & 5075 & Mainline, Straight Mainline Link & 999 & & & 60 \\
\hline 405 & 410 & 738.5 & 591.5 & 7385 & 5915 & Off Ramp SL-Curve East (down) exit ramp link & 870 & & & 60 \\
\hline$\$ 10$ & 415 & 682 & 627.5 & 6820 & 6275 & On Ramp SL-Curve East (down) on ramp link & 680 & & & 60 \\
\hline 415 & 416 & 670 & 632 & 6700 & 6320 & Fill in Node & 188 & & & 60 \\
\hline 416 & 420 & 646 & 635.5 & 6460 & 6355 & Off Ramp SL-Curve East (down) exit ramp link to $195 \mathrm{~N}$ & 186 & & & 60 \\
\hline 420 & 425 & 523. & 648.5 & $\$ 230$ & 6485 & Off Ramp, Straight section, exít to $195 \mathrm{~S}$ & 1237 & & & 60 \\
\hline 425 & 430 & 411 & 651 & 4110 & 6510 & On Ramp, Straight, on coming traflic from I9S North (POD) & 1120 & & & 60 \\
\hline 430 & 435 & 294 & 760 & 2940 & 7600 & Mainline link Curve West (Up) & 1720 & & & 60 \\
\hline 435 & 440 & 273 & 805 & 2730 & 8050 & On Ramp, Straight section, & 497 & & & 60 \\
\hline 440 & 443 & 270 & 890 & 2537 & 8262 & Off Ramp, Straight section, & 274 & & & 60 \\
\hline 443 & 445 & 239 & 848 & 2390 & 8480 & Fill in Node & 274 & & & 60 \\
\hline 445 & 450 & 202 & 895 & 2020 & 8950 & On Ramp, Straight & 598 & & & 60 \\
\hline 450 & 455 & 130 & 993 & 1300 & 9930 & Mainline, Straight & 1216 & & & 60 \\
\hline 455 & 460 & 62 & 1151 & 620 & 11510 & Mainline, SL-Curve West (up) & 1770 & & & 60 \\
\hline 460 & 465 & 80 & 1278 & 800 & 12780 & Off Ramp, SL-Curve West (up) & 1300 & & & 60 \\
\hline 465 & 470 & 103 & 1413 & 1030 & 14130 & On Ramp, SL-Curve East (Down) & 1384 & & & 60 \\
\hline 470 & 475 & 91 & 1526 & 910 & 15260 & On Ramp, Straight & 1136 & & & 60 \\
\hline 475 & 477 & 90 & 1530 & 900 & 15300 & Fill in Node & 41 & & & 60 \\
\hline 477 & 480 & 89 & 1583 & 890 & 15830 & Off Ramp, Straight (Curve it up) & $\$ 72$ & & & 60 \\
\hline 480 & 490 & 108 & 1741 & 1080 & 17410 & On Ramp Straight (Curve it Up) & 1600 & & & 60 \\
\hline 490 & 495 & 110 & 1750 & 1100 & 17500 & Fill in Node & 92 & & & 60 \\
\hline 495 & 500 & 131 & 1864 & 1310 & 18640 & Off Ramp Straight & 1251 & & & 60 \\
\hline 500 & 505 & 158 & 1963 & 1580 & 19630 & On Rarnp, Straight, Two Lanes from Rt 6 & 1026 & & & 60 \\
\hline 505 & 510 & 189 & 2018 & 1890 & 20180 & Mainline, Straight, but 1 acc lane ends and 4 lanes go to 3 & 631 & & & 60 \\
\hline 510 & 515 & 249 & 2130 & 2490 & 21300 & Mainline Straighu, and 3 lanes & 1271 & & & 60 \\
\hline 515 & 520 & 28. & 2207 & 3920 & 22070 & Off ramp, Curve, and Back to 2 lanes & 1730 & & & 60 \\
\hline 520 & 525 & 511 & 2229 & 5110 & 22290 & On Ramp Straight (Curve it Up) & 1235 & & & 60 \\
\hline 525 & 527 & $\$ 20$ & 2230 & 5200 & 22300 & Fill in Node & 314 & & & 60 \\
\hline 527 & 530 & 374 & 2233 & 5740 & 22330 & Off Ramp Straight, one lane exits, one stays straight & 316 & & & 60 \\
\hline 530 & 535 & 624 & 2230 & 6240 & 22300 & Mainline Staight, one lane & 501 & & & 60 \\
\hline 535 & 8045 & 624 & 2242 & 6240 & 22420 & Mainline Straight & 120 & & & 60 \\
\hline & & & & & & & & & & 60 \\
\hline \multirow{2}{*}{\multicolumn{7}{|c|}{ 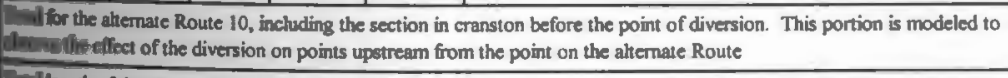 }} & 26325 & & & \\
\hline & & & & & & & 4.986 & & & \\
\hline \multirow{2}{*}{\multicolumn{7}{|c|}{ 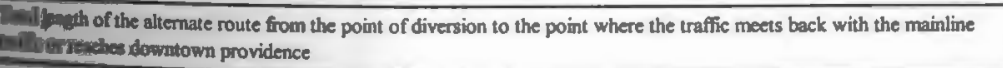 }} & 24778 & & & \\
\hline & & & & & & & 4.693 & & & \\
\hline
\end{tabular}

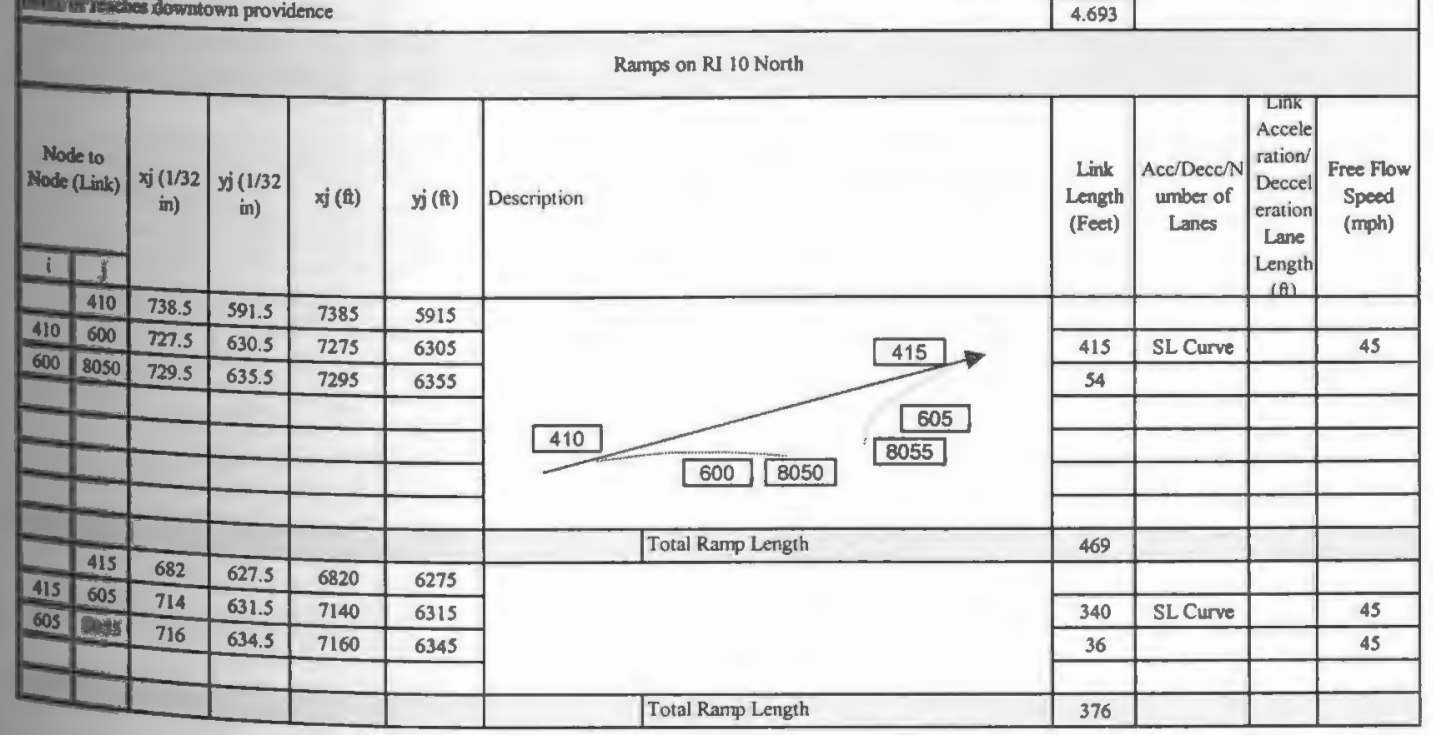




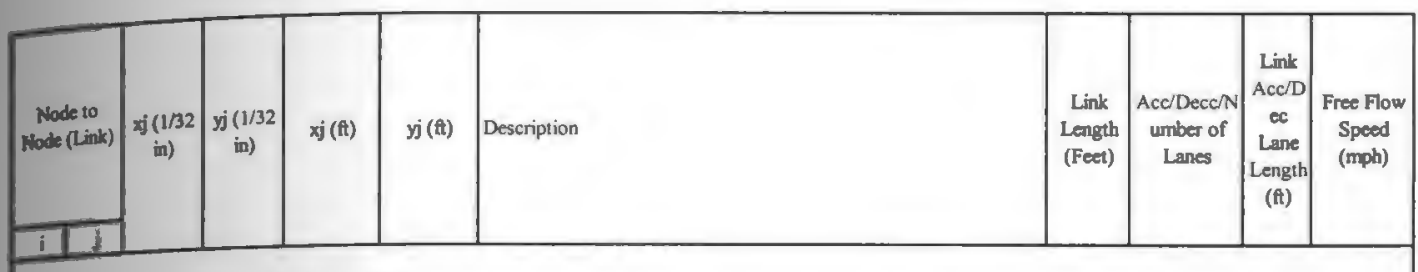

The Off Ramp at 420 is described on I 95 N Dara sheet

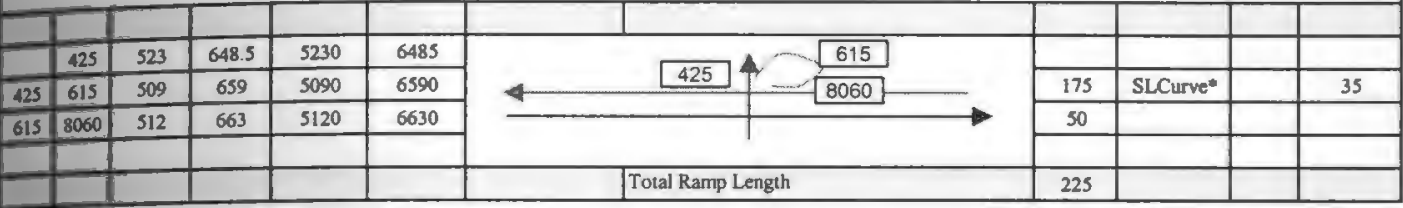

The On Ramp at 430 is described on the I 95 North Data Sheet

\begin{tabular}{|c|c|c|c|c|c|c|c|c|c|c|}
\hline & & & & & & & & & & \\
\hline & 440 & 273 & 805 & 2730 & 8050 & \multirow{4}{*}{\multicolumn{2}{|c|}{805}} & & & \multirow{4}{*}{$\begin{array}{l}50 \\
50 \\
\end{array}$} \\
\hline \multirow{4}{*}{ 단 } & \multirow{2}{*}{\begin{tabular}{|l|l|}
620 \\
8065 \\
\end{tabular}} & 289 & 788 & 2890 & 7880 & & & 233 & \multirow[t]{2}{*}{ SLCurve* } & \\
\hline & & 292 & 784 & 2920 & 7840 & & & 50 & & \\
\hline & & & & & & & & & & \\
\hline & & & & & & & Total Ramp Length & 283 & & \\
\hline & 445 & 239 & 848 & 2390 & 8480 & & & & & \\
\hline 445 & 625 & 229 & 868 & 2290 & 8680 & & 445 & 224 & SLCurve" & 50 \\
\hline 625 & 8070 & 231 & 864 & 2310 & 8640 & & का70 & 45 & & \\
\hline & & & & & & & & & & \\
\hline & & & & & & & Total Ramp Length & 268 & & \\
\hline & 450 & 202 & 895 & 2020 & 8950 & & & & & \\
\hline 450 & 630 & 219.5 & 887 & 2195 & 8870 & & 450 & 192 & SLCurve* & 50 \\
\hline en & Dias & 223.5 & 886 & 2235 & 8860 & & 630 & 41 & & 50 \\
\hline & & & & 0 & 0 & \begin{tabular}{|l|}
8075 \\
\end{tabular} & & & & \\
\hline & & & & & & & Total Ramp Length & 234 & & \\
\hline & 465 & 80 & 1278 & 800 & 12780 & & & & & \\
\hline ESS & DI & 96 & 1313 & 960 & 13130 & & 465 & 385 & SLCurve* & 50 \\
\hline CD & 8080 & 98 & 1321 & 980 & 13210 & & 635 & 82 & & \\
\hline & 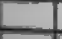 & & & 0 & 0 & & \begin{tabular}{|l|}
8080 \\
\end{tabular} & & & \\
\hline & & & & & & & Total Ramp Length & 467 & & \\
\hline & 470 & 103 & 1413 & 1030 & 14130 & & & & & \\
\hline 47 & 640 & 108 & 1388 & 1080 & 13880 & & 470 & 255 & SLCurve* & 50 \\
\hline 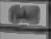 & Cos & 109 & 1383 & 1090 & 13830 & & 640 & 51 & & 50 \\
\hline 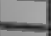 & - & & & 0 & 0 & 8085 & & & & \\
\hline & & & & & & & Total Ramp Length & 306 & & \\
\hline & ess & 91 & 1526 & 910 & 15260 & & & & & \\
\hline$\theta$ & 85 & 103 & 1489 & 1030 & 14890 & & 475 & 389 & SLCurve" & 50 \\
\hline 01 & (19) & 105 & 1482 & 1050 & 14820 & & 645 & 73 & & 50 \\
\hline & & & & 0 & 0 & 8090 & & & & \\
\hline & & & & & & & Total Ramp Length & 462 & & \\
\hline & 480 & 89 & 1583 & 890 & 15830 & & & & & \\
\hline 5 & 01 & 97 & 1609 & 970 & 16090 & & 480 & 272 & SLCurve* & 50 \\
\hline 5 & 13 & 99 & 1615 & 990 & 16150 & & 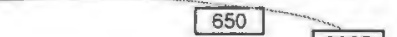 & 63 & & \\
\hline 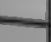 & & & & 0 & 0 & & 8095 & & & \\
\hline- & & & & & & & Total Ramp Length & 335 & & \\
\hline 87 & \pm 1 & 108 & 1741 & 1080 & 17410 & & & & & \\
\hline$\frac{19}{79}$ & (es) & 112 & 1697 & 1120 & 16970 & & 490 & 442 & SLCurve* & 50 \\
\hline 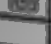 & (a) & 113 & 1686 & 1130 & 16860 & & 655 & 110 & & 50 \\
\hline$=$ & & & & 0 & 0 & 8100 & & & & \\
\hline 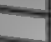 & & & & & & & Total Ramp Length & 552 & & \\
\hline [Dा & 3 & 131 & 1864 & 1310 & 18640 & & & & & \\
\hline (x) & 3 & 144 & 1884 & 1440 & 18840 & & 500 & 239 & SLCurve" & so \\
\hline 5 & 10 & 146 & 1888 & 1460 & 18880 & & & 45 & & \\
\hline & & & & 0 & 0 & & 8105 & & & \\
\hline & & & & & & & Total Ramp Length & 283 & & \\
\hline
\end{tabular}




\begin{tabular}{|c|c|c|c|c|c|c|c|c|c|c|c|}
\hline \multicolumn{2}{|c|}{$\begin{array}{l}\text { Node to } \\
\text { Node (Link) }\end{array}$} & $\begin{array}{c}x j(1 / 32 \\
\text { in) }\end{array}$ & $\begin{array}{c}y j(1 / 32 \\
\text { in) }\end{array}$ & $x \mathrm{j}(\mathrm{f})$ & $y j(\mathrm{f})$ & \multicolumn{2}{|l|}{ Description } & \multirow[t]{2}{*}{$\begin{array}{c}\text { Link } \\
\text { Length } \\
\text { (Feet) }\end{array}$} & \multirow[t]{2}{*}{$\begin{array}{c}\text { Acc/Decc/N } \\
\text { umber of } \\
\text { Lanes }\end{array}$} & \multirow[t]{2}{*}{$\begin{array}{c}\text { Link } \\
\text { Acc/D } \\
e c \\
\text { Lane } \\
\text { Length } \\
\text { (ft) }\end{array}$} & \multirow[t]{2}{*}{$\begin{array}{l}\text { Free Flow } \\
\text { Speed } \\
\text { (mph) }\end{array}$} \\
\hline - & DI & 158 & 1963 & 1580 & 19630 & \multirow{7}{*}{\multicolumn{2}{|c|}{\begin{tabular}{|l|}
505 \\
\end{tabular}}} & & & & \\
\hline E] & Es & 154 & 1926 & 1540 & 19260 & & & 372 & SLCurve* & & 50 \\
\hline \multirow[t]{7}{*}{ Ca } & पाt० & 153 & 1918 & 1530 & 19180 & & & 81 & & & so \\
\hline & & & & & & & & & & & \\
\hline & & & & & & & & & & & \\
\hline & & & & & & & & & & & \\
\hline & & & & & & & & & & & \\
\hline & & & & & & & Total Rarmp Length & 453 & & & \\
\hline & Ex] & 392 & 2207 & 3920 & 22070 & \multirow{3}{*}{\multicolumn{2}{|c|}{520}} & & & & \\
\hline 5 & 670 & 424 & 2203 & 4240 & 22030 & & & 322 & SLCurve" & & 50 \\
\hline \multirow[t]{4}{*}{$E$} & [था & 432 & 2204 & 4320 & 22040 & & & 81 & & & \\
\hline & & & & 0 & 0 & \multirow{2}{*}{\multicolumn{2}{|c|}{ Total Ramp Length }} & & & & \\
\hline & & & & & & & & 403 & & & \\
\hline & (13) & 511 & 2229 & 5110 & 22290 & \multirow{4}{*}{\multicolumn{2}{|c|}{525}} & & & & \\
\hline 519 & (6) & 490 & 2219 & 4900 & 22190 & & & 233 & SLCurve* & & 50 \\
\hline \multirow[t]{3}{*}{675} & [120] & 488 & 2218 & 4880 & 22180 & & & 22 & & & 50 \\
\hline & & & & 0 & 0 & & & & & & \\
\hline & & & & & & & Total Rarmp Length & 255 & & & \\
\hline \multicolumn{12}{|c|}{530 is the beginning of the off ramp leading to the mainline (I-95). The geometry is described on the 195 data sheet } \\
\hline & & & & & & & Total Length of All Rt 10 Rarmp Links & 5372 & Feet & & \\
\hline & & & & & & & Total Length of All Rt IO Ramp Links & 1.017 & Miles & & \\
\hline & & & & & & & Total for 195 and Rt10 Ramps & 3.110 & Miles & & \\
\hline & & & & & & & & & & & \\
\hline & & & & & & & Total Network Length & 10.521 & Miles & & \\
\hline & & & & & & & & & & & \\
\hline
\end{tabular}




\section{APPENDIX D}

Figure Displaying Critical Traffic Volume Points and

Tables Listing the Corresponding Traffic Volume and Exiting Percentages 


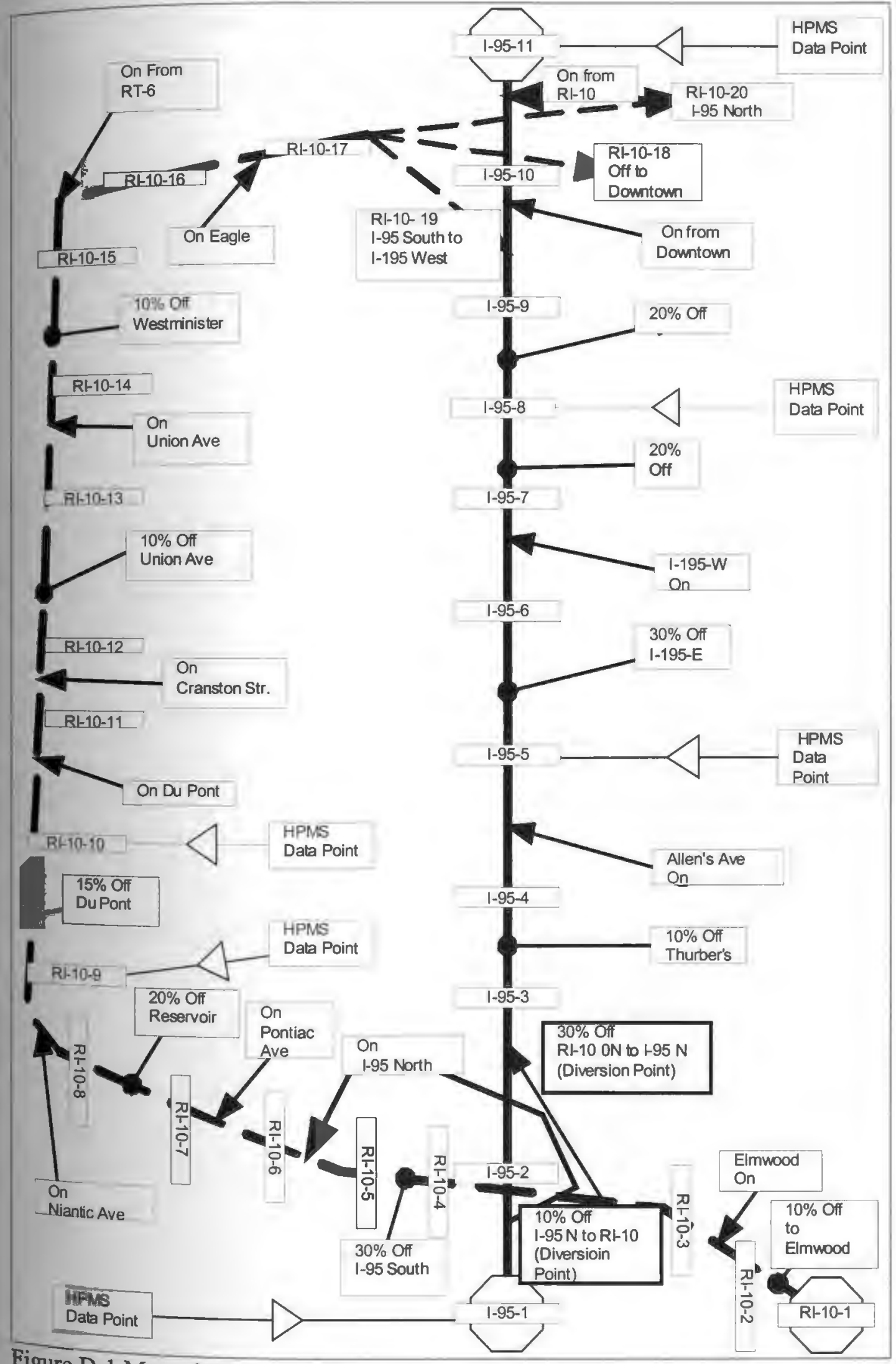

Figure D-1 Map of the Critical Traffic Volume Points in the Study Area. 
15 D-1 Displays Peak AM Traffic Volume determined for I-95 North and RI-10 North at all aribled

\begin{tabular}{|c|c|c|c|c|c|c|c|c|c|c|c|c|}
\hline \multirow{7}{*}{ 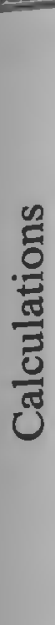 } & \multicolumn{12}{|c|}{ Number and Description of Points Corresponding to Traffic Volume Map for Study Area for I- } \\
\hline & $1-95-1$ & I-95-2 & I-95-3 & I-95-4 & I-95-5 & I-95-6 & $1-95-7$ & I-95-8 & I-95-9 & I-95-10 & & -11 \\
\hline & $\begin{array}{l}\text { Entry } \\
\text { Point }\end{array}$ & $\begin{array}{l}\text { RI-10 N } \\
\text { Off }\end{array}$ & $\begin{array}{l}\text { RI-10 N } \\
\text { On }\end{array}$ & Thurber's of & Allen's On & $\begin{array}{l}\text { I-195 E } \\
\text { Off }\end{array}$ & $1-195 \mathrm{~W}$ on & $\begin{array}{c}\text { Broad } \\
\text { Off }\end{array}$ & $\begin{array}{c}\text { Hartford } \\
\text { Off }\end{array}$ & $\begin{array}{l}\text { Dwntwn } \\
\text { On }\end{array}$ & & $\begin{array}{l}-10 \\
\text { ln }\end{array}$ \\
\hline & (ention) & $(\%$ Off $)$ & $($ vph On) & $(\%$ Off) & (vph On) & $(\%$ Off $)$ & (vph On) & $(\%$ Off) & $(\%$ Off & (vph On) & (vpl & On) \\
\hline & 6000 & $10 \%$ & 1000 & $5 \%$ & 1000 & $30 \%$ & 2500 & $10 \%$ & $30 \%$ & 200 & & 72 \\
\hline & \multicolumn{12}{|c|}{ Calculated Through Traffic at this Point } \\
\hline & 6000 & 5400 & 6400 & 6080 & 7080 & 4956 & 7456 & 6710 & 4697 & 48 & & $\begin{array}{l}64 \\
69\end{array}$ \\
\hline
\end{tabular}

Number and Description of Points Corresponding to Traffic Volume Map for Study Area for

\begin{tabular}{|c|c|c|c|c|c|c|c|c|c|c|}
\hline \multicolumn{11}{|c|}{ RI-10 } \\
\hline RI-10-1 & RI-10-2 & RI-10-3 & RI-10-4 & RI-10-5 & $\mathrm{RI}-10-6$ & RI-10-7 & RI-10-8 & RI-10-9 & RI-10-10 & $\begin{array}{c}\text { RI-10 } \\
11\end{array}$ \\
\hline $\begin{array}{l}\text { Entry } \\
\text { Point }\end{array}$ & Elm. Off & Elm. On & To I-95 N & To I-95 S & \begin{tabular}{|c|} 
I-95 On \\
(Div \\
Flow)
\end{tabular} & Pontiac On & Res Off & $\begin{array}{c}\text { Niantic } \\
\text { On }\end{array}$ & \begin{tabular}{|c} 
Du Pont \\
Off
\end{tabular} & $\begin{array}{c}\text { Du } \\
\text { Pont } \\
\text { On }\end{array}$ \\
\hline (opti On) & $(\%$ Off $)$ & $(\mathrm{vph}$ On) & (\% Off) & (\% Off) & $(\operatorname{vph} O n) \mid$ & (vph On) & (\% Off) & (vph On) & $(\%$ Off) & $\begin{array}{l}\text { (vph } \\
\text { On) }\end{array}$ \\
\hline 3000 & $5 \%$ & 500 & $30 \%$ & $20 \%$ & 600 & 500 & $10 \%$ & 800 & $10 \%$ & 200 \\
\hline
\end{tabular}

Calculated Through Traffic at this Point

\begin{tabular}{|l|l|l|l|l|l|l|l|l|l|l|}
\hline 3000 & 2850 & 3350 & 2345 & 1876 & 2476 & 2976 & 2678 & 3478 & 3131 & 3331 \\
\hline
\end{tabular}

Number and Description of Points Corresponding to Traffic Volume Map for Study Area

\begin{tabular}{|c|c|c|c|c|c|c|c|c|}
\hline 10 & RI-10-13 & RI-10-14 & RI-10-15 & RJ-10-16 & RI-10-17 & RI-I0-18 & RI-10-19 & RI-10-20 \\
\hline $\begin{array}{l}\text { Cran. St } \\
\text { On }\end{array}$ & $\begin{array}{c}\text { Union } \\
\text { Av Off }\end{array}$ & $\begin{array}{l}\text { Union } \\
\text { Av On }\end{array}$ & West Min Off & $\begin{array}{c}\text { RI-6 On } \\
\text { (From } \\
\text { HPMS) }\end{array}$ & Eagle On & To DwnTwn & To I-95 & $\begin{array}{l}\text { To l-95 N } \\
\text { (Divert) }\end{array}$ \\
\hline Yhen & (\% Off) & $(\mathrm{vph}$ On) & (\% Off) & (vph On) & (vph On) & $(\%$ Off) & (\% Off) & (\% Off) \\
\hline 200 & $10 \%$ & 200 & $10 \%$ & 2000 & 200 & $50 \%$ & $20 \%$ & $30 \%$ \\
\hline
\end{tabular}

Calculated Through Traffic at this Point

\begin{tabular}{|l|l|l|l|l|l|l|l|l|}
\hline 3531 & 3178 & 3378 & 3040 & 5040 & 5240 & 2620 & 1048 & 1572 \\
\hline
\end{tabular}




\begin{tabular}{|c|c|c|c|c|c|c|c|c|c|c|c|}
\hline \multirow{7}{*}{ 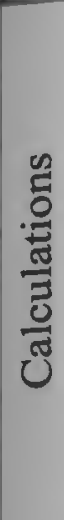 } & \multicolumn{11}{|c|}{ Number and Description of Points Corresponding to Traffic Volume Map for Study Area } \\
\hline & I-95-1 & $1-95-2$ & I-95-3 & [-95-4 & {$[-95-5$} & I-95-6 & {$[-95-7$} & I-95-8 & I-95-9 & $1-95-10$ & $1-95-11$ \\
\hline & $\begin{array}{l}\text { Entry } \\
\text { Point }\end{array}$ & $\begin{array}{c}\mathrm{RI}-10 \mathrm{~N} \\
\text { Off }\end{array}$ & $\begin{array}{c}\text { RI-10 N } \\
\text { On }\end{array}$ & Thurber's of & Allen's On & $\begin{array}{c}\text { I-195 E } \\
\text { Off }\end{array}$ & I-195 W on & $\begin{array}{c}\text { Broad } \\
\text { Off }\end{array}$ & \begin{tabular}{|c|}
$\begin{array}{c}\text { Hartford } \\
\text { Off }\end{array}$ \\
\end{tabular} & Dwntwn On & $\begin{array}{l}\text { RI-10 } \\
\text { On }\end{array}$ \\
\hline & (oplion) & $(\%$ Off $)$ & $($ vph On) & (\% Off) & $(\mathrm{vph} O \mathrm{On})$ & $(\%$ Off $)$ & (vph On) & $(\%$ Off $)$ & $(\% \mathrm{Off})$ & (vph On) & $($ (vph On) \\
\hline & 6000 & $30 \%$ & 170 & $5 \%$ & 1000 & $30 \%$ & 2500 & $10 \%$ & $30 \%$ & 200 & 1940 \\
\hline & \multicolumn{11}{|c|}{ Calculated Through Traffic at this Point } \\
\hline & 6000 & 4200 & 4370 & 4152 & 5152 & 3606 & 6106 & 5495 & 3847 & 4047 & 5987 \\
\hline \multirow{14}{*}{ 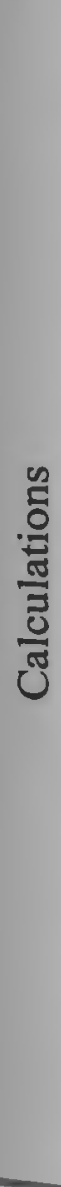 } & $\mathrm{Nu}$ & mber an & a Descri & ription of $\mathrm{P}$ & oints Corr & respondi & ing to Trafi & fic Volu & me Map fo & or Study Ar & rea \\
\hline & RI-10-1 & RI-10-2 & RI-10-3 & RI-10-4 & RI-10-5 & RI-10-6 & RI-10-7 & RI-10-8 & RI-10-9 & RI-10-10 & RI-10-11 \\
\hline & $\begin{array}{l}\text { Entry } \\
\text { Point }\end{array}$ & Elm. Off & Elm. On & To I-95 N & To I-95 S & \begin{tabular}{|c|} 
I-95 On \\
(Div \\
Flow) \\
\end{tabular} & Pontiac On & Res Off & Niantic On & Du Pont Off & $\begin{array}{c}\text { Du Pont } \\
\text { On }\end{array}$ \\
\hline & (ugh Ons) & $(\%$ Off) & $($ vph On) & (\% Off) & (\% Off) & $(\mathrm{vph} O \mathrm{O})$ & (vph On) & $(\%$ Off $)$ & (vph On) & $(\%$ Off $)$ & $(\mathrm{vph}$ On) \\
\hline & 3000 & $5 \%$ & 500 & $5 \%$ & $20 \%$ & 1800 & 500 & $10 \%$ & 800 & $10 \%$ & 200 \\
\hline & \multicolumn{11}{|c|}{ Calculated Through Traffic at this Point } \\
\hline & 3000 & 2850 & 3350 & 3183 & 2546 & 4346 & 4846 & 4361 & 5161 & 4645 & 4845 \\
\hline & \multicolumn{11}{|c|}{ Number and Description of Points Corresponding to Traffic Volume Map for Study Area } \\
\hline & $1019-12$ & RI-10-13 & RI-10-14 & RI-10-15 & RI-10-I6 & RI-10-17 & RI-10-18 & RI-10-19 & RI-10-20 & & \\
\hline & $\begin{array}{c}\text { Cran. St } \\
\text { On }\end{array}$ & $\begin{array}{l}\text { Union } \\
\text { Av Off }\end{array}$ & $\begin{array}{l}\text { Union } \\
\text { Av On }\end{array}$ & $\begin{array}{l}\text { West Min } \\
\text { Off }\end{array}$ & \begin{tabular}{|c|} 
RT-6 On \\
(From \\
HPMS) \\
\end{tabular} & $\begin{array}{l}\text { Eagle } \\
\text { On }\end{array}$ & To DwnTwn & $\begin{array}{c}\text { To I-95 } \\
\mathrm{S}\end{array}$ & $\begin{array}{l}\text { To l-95 N } \\
\text { (Divert) }\end{array}$ & & \\
\hline & (yplion) & (\% Off) & $(\mathrm{vph}$ On) & $(\%$ Off $)$ & (vph On) & $($ vph On) & (\% Off) & $(\%$ Off $)$ & $(\%$ Off) & & \\
\hline & 200 & $10 \%$ & 200 & $10 \%$ & 2000 & 200 & $50 \%$ & $20 \%$ & $30 \%$ & & \\
\hline & \multicolumn{11}{|c|}{ Calculated Through Traffic at this Point } \\
\hline & 5045 & 4541 & 4741 & 4267 & 6267 & 6467 & 3233 & 1293 & 1940 & & \\
\hline
\end{tabular}


Dahle D-3 Displays 3/4 Peak AM Traffic Volume determined for I-95 North and RI-10 North at all

\begin{tabular}{|c|c|c|c|c|c|c|c|c|c|c|c|}
\hline \multirow{5}{*}{ 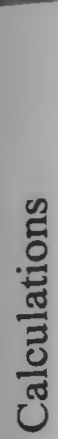 } & \multicolumn{11}{|c|}{ Number and Description of Points Corresponding to Traffic Volume Map for Study Area for I- } \\
\hline & I-95-1 & I-95-2 & I-95-3 & I-95-4 & I-95-5 & I-95-6 & I-95-7 & I-95-8 & I-95-9 & I-95-10 & I-95-11 \\
\hline & $\begin{array}{l}\text { Entry } \\
\text { Point }\end{array}$ & $\begin{array}{c}\mathrm{RI}-10 \mathrm{~N} \\
\text { Off }\end{array}$ & $\begin{array}{c}\text { RI-10 N } \\
\text { On }\end{array}$ & $\begin{array}{c}\text { Thurber's } \\
\text { Off }\end{array}$ & Allen's On & $\begin{array}{c}\text { I-195 E } \\
\text { Off }\end{array}$ & $\mathrm{I}-195 \mathrm{~W}$ on & $\begin{array}{c}\text { Broad } \\
\text { Off }\end{array}$ & $\begin{array}{l}\text { Hartford } \\
\text { Off }\end{array}$ & Dwntwn On & $\begin{array}{c}\text { RI-10 } \\
\text { On }\end{array}$ \\
\hline & $\begin{array}{l}\text { (vph } \\
\text { On) }\end{array}$ & $(\%$ Off) & $\begin{array}{l}(v p h \\
\text { On) }\end{array}$ & $(\%$ Off) & (vph On) & (\% Off) & (vph On) & (\% Off) & $(\%$ Off $)$ & (vph On) & $\begin{array}{l}\text { (vph } \\
\text { On) }\end{array}$ \\
\hline & 4500 & $10 \%$ & 750 & $5 \%$ & 750 & $30 \%$ & 1875 & $10 \%$ & $30 \%$ & 150 & 1179 \\
\hline
\end{tabular}

Calculated Through Traffic at this Point

\begin{tabular}{|l|l|l|l|l|l|l|l|l|l|l|}
\hline 4500 & 4050 & 4800 & 4560 & 5310 & 3717 & 5592 & 5033 & 3523 & 3673 & 4852 \\
\hline
\end{tabular}

Number and Description of Points Corresponding to Traffic Volume Map for Study Area for RI-10

\begin{tabular}{|c|c|c|c|c|c|c|c|c|c|c|}
\hline RI-10-1 & RI-10-2 & RI-10-3 & RI-10-4 & RI-10-5 & RI-10-6 & RI-10-7 & RI-10-8 & RI-10-9 & RI-10-10 & $\begin{array}{c}\text { RI-10- } \\
11\end{array}$ \\
\hline $\begin{array}{c}\text { Entry } \\
\text { Point }\end{array}$ & Elm. Off & Elm. On & To I-95 N & To I-95 S & $\begin{array}{c}\text { I-95 On } \\
\text { (Div } \\
\text { Flow) }\end{array}$ & Pontiac On & Res Off & Niantic On & $\begin{array}{c}\text { Du Pont } \\
\text { Off }\end{array}$ & $\begin{array}{c}\text { Du Pont } \\
\text { On }\end{array}$ \\
\hline $\begin{array}{c}\text { (vph } \\
\text { On) }\end{array}$ & $(\%$ Off) & $\begin{array}{c}\text { (vph } \\
\text { On) }\end{array}$ & $(\%$ Off) & $(\%$ Off) & $\begin{array}{c}\text { (vph } \\
\text { On) }\end{array}$ & (vph On) & $(\%$ Off & $(v p h$ On) & $(\%$ Off) & $\begin{array}{c}\text { (vph } \\
\text { On) }\end{array}$ \\
\hline 2250 & $5 \%$ & 375 & $30 \%$ & $20 \%$ & 400 & 375 & $10 \%$ & 600 & $10 \%$ & 150 \\
\hline
\end{tabular}

Calculated Through Traffic at this Point

\begin{tabular}{|l|l|l|l|l|l|l|l|l|l|l|}
\hline 2250 & 2138 & 2513 & 1759 & 1407 & 1807 & 2182 & 1964 & 2564 & 2307 & 2457 \\
\hline
\end{tabular}

Number and Description of Points Corresponding to Traffic Volume Map for Study Area

\begin{tabular}{|c|c|c|c|c|c|c|c|c|c|}
\hline $\begin{array}{c}\text { RI-10- } \\
12\end{array}$ & $\begin{array}{c}\text { RI-10- } \\
13\end{array}$ & $\begin{array}{c}\text { RI-10- } \\
14\end{array}$ & RI-10-15 & RI-10-16 & $\begin{array}{c}\text { RI-10- } \\
17\end{array}$ & RI-10-18 & $\begin{array}{c}\text { RI-10- } \\
19\end{array}$ & RI-10-20 & \\
\hline $\begin{array}{c}\text { Cran. St } \\
\text { On }\end{array}$ & $\begin{array}{l}\text { Union } \\
\text { Av Off }\end{array}$ & $\begin{array}{l}\text { Union } \\
\text { Av On }\end{array}$ & $\begin{array}{c}\text { West Min } \\
\text { Off }\end{array}$ & $\begin{array}{l}\text { RI-6 On } \\
\text { (From } \\
\text { HPMS) }\end{array}$ & $\begin{array}{c}\text { Eagle } \\
\text { On }\end{array}$ & To DwnTwn & $\begin{array}{c}\text { To I-95 } \\
\mathrm{S}\end{array}$ & $\begin{array}{l}\text { To I-95 N } \\
\text { (Divert) }\end{array}$ & \\
\hline $\begin{array}{l}\text { (vph } \\
\text { On) }\end{array}$ & $(\%$ Off $)$ & $\begin{array}{l}\text { (vph } \\
\text { On) }\end{array}$ & $(\%$ Off $)$ & (vph On) & $\begin{array}{l}\text { (vph } \\
\text { On) }\end{array}$ & $(\%$ Off) & $(\%$ Off $)$ & (\% Off) & \\
\hline 150 & $10 \%$ & 150 & $10 \%$ & 1500 & 150 & $50 \%$ & $20 \%$ & $30 \%$ & \\
\hline
\end{tabular}

Calculated Through Traffic at this Point

\begin{tabular}{|l|l|l|l|l|l|l|l|l|}
\hline 2607 & 2347 & 2497 & 2247 & 3747 & 3897 & 1949 & 779 & 1169 \\
\hline
\end{tabular}




\begin{tabular}{|c|c|c|c|c|c|c|c|c|c|c|c|}
\hline \multirow{7}{*}{$\frac{\mathscr{Z}}{3}$} & \multicolumn{11}{|c|}{ Number and Description of Points Corresponding to Traffic Volume Map for Study Area } \\
\hline & $1-95-1$ & $1-95-2$ & I-95-3 & I-95-4 & I-95-5 & $\mathrm{I}-95-6$ & I-95-7 & I-95-8 & $1-95-9$ & $\mathrm{I}-95-10$ & I-95-11 \\
\hline & $\begin{array}{l}\text { Entry } \\
\text { Point }\end{array}$ & $\begin{array}{c}\mathrm{RI}-10 \mathrm{~N} \\
\text { Off }\end{array}$ & $\begin{array}{c}\mathrm{RI}-10 \mathrm{~N} \\
\mathrm{On}\end{array}$ & $\begin{array}{c}\text { Thurber's } \\
\text { Off }\end{array}$ & Allen's On & $\begin{array}{c}\text { I-195 E } \\
\text { Off }\end{array}$ & $1-195 \mathrm{~W}$ on & $\begin{array}{c}\text { Broad } \\
\text { Off }\end{array}$ & $\begin{array}{l}\text { Hartford } \\
\text { Off }\end{array}$ & $\begin{array}{l}\text { Dwntwn } \\
\text { On }\end{array}$ & $\begin{array}{c}\text { RI-10 } \\
\text { On }\end{array}$ \\
\hline & (volh On) & $(\%$ Off) & $(\operatorname{vph}$ On) & (\% Off) & $($ vph On) & $(\%$ Off) & (vph On) & (\% Off) & $(\%$ Off) & (vph On) & $(\operatorname{vph}$ On) \\
\hline & 4500 & $30 \%$ & 128 & $5 \%$ & 750 & $30 \%$ & 1875 & $10 \%$ & $30 \%$ & 150 & 1455 \\
\hline & \multicolumn{11}{|c|}{ Calculated Through Traffic at this Point } \\
\hline & 4500 & 3150 & 3278 & 3114 & 3864 & 2705 & 4580 & 4122 & 2885 & 3035 & 4490 \\
\hline \multirow{14}{*}{ 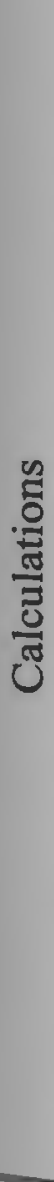 } & Nun & nber an & d Descri & ption of $\mathrm{P}$ & jints Corr & respondi & ing to Traff & fic Volu & me Map & or Study & Area \\
\hline & RI-10-1 & RI-10-2 & RI-10-3 & RI-10-4 & RI-10-5 & RI-10-6 & RI-10-7 & RI-10-8 & RI-10-9 & RI-10-10 & RI-10-11 \\
\hline & $\begin{array}{l}\text { Entry } \\
\text { Point }\end{array}$ & Elm. Off & Elm. On & To I-95 N & To I-95 S & \begin{tabular}{|c|}
$1-95$ On \\
(Div \\
Flow) \\
\end{tabular} & Pontiac On & Res Off & Niantic On & $\begin{array}{c}\text { Du Pont } \\
\text { Off }\end{array}$ & $\begin{array}{c}\text { Du Pont } \\
\text { On }\end{array}$ \\
\hline & घglo On) & $(\%$ Off $)$ & $($ (vph On) & $(\%$ Off) & $(\%$ Off $)$ & $(\mathrm{vph}$ On) & (vph On) & (\% Off) & (vph On) & $(\%$ Off $)$ & $($ vph On) \\
\hline & 2250 & $5 \%$ & 375 & $5 \%$ & $20 \%$ & 1350 & 375 & $10 \%$ & 600 & $10 \%$ & 150 \\
\hline & \multicolumn{11}{|c|}{ Calculated Through Traffic at this Point } \\
\hline & 2250 & 2138 & 2513 & 2387 & 1910 & 3260 & 3635 & 3271 & 3871 & 3484 & 3634 \\
\hline & \multicolumn{11}{|c|}{ Number and Description of Points Corresponding to Traffic Volume Map for Study Area } \\
\hline & $\begin{array}{c}\text { RI-10- } \\
12\end{array}$ & $\begin{array}{c}\text { RI-10- } \\
13\end{array}$ & $\begin{array}{c}\text { RI-10- } \\
14\end{array}$ & RI-10-15 & RI-10-16 & $\begin{array}{c}\text { RI-10- } \\
17\end{array}$ & RI-10-18 & $\begin{array}{c}\text { RI-10- } \\
19\end{array}$ & RI-10-20 & & \\
\hline & $\begin{array}{c}\text { Cran. St } \\
\text { On }\end{array}$ & $\begin{array}{l}\text { Union } \\
\text { Av Off }\end{array}$ & $\begin{array}{l}\text { Union } \\
\text { Av On }\end{array}$ & $\begin{array}{c}\text { West Min } \\
\text { Off }\end{array}$ & \begin{tabular}{|c|} 
RT-6 On \\
(From \\
HPMS)
\end{tabular} & $\begin{array}{l}\text { Eagle } \\
\text { On }\end{array}$ & To DwnTwn & $\begin{array}{c}\text { To I-95 } \\
\text { S }\end{array}$ & $\begin{array}{c}\text { To I-95 N } \\
\text { (Divert) }\end{array}$ & & \\
\hline & (vallons) & $(\%$ Off) & $(\mathrm{vph}$ On) & $(\%$ Off) & $(\mathrm{vph}$ On) & $(\mathrm{vph}$ On) & $(\%$ Off) & (\% Off) & $(\%$ Off) & & \\
\hline & 150 & $10 \%$ & 150 & $10 \%$ & 1500 & 150 & $50 \%$ & $20 \%$ & $30 \%$ & & \\
\hline & \multicolumn{11}{|c|}{ Calculated Through Traffic at this Point } \\
\hline & 3784 & 3406 & 3556 & 3200 & 4700 & 4850 & 2425 & 970 & 1455 & & \\
\hline
\end{tabular}


ble D-5 Displays 2/3 Peak AM Traffic Volume determined for I-95 North and RI-10 North at all critical

peints in the study area. The volumes displayed include a 0\% DIVERSION to RI-10

\begin{tabular}{|c|c|c|c|c|c|c|c|c|c|c|}
\hline $1-95-1$ & I-95-2 & I-95-3 & I-95-4 & I-95-5 & $1-95-6$ & I-95-7 & I-95-8 & I-95-9 & I-95-10 & I-95-11 \\
\hline \begin{tabular}{|l|} 
Entry \\
Point \\
\end{tabular} & $\begin{array}{c}\text { RI- } 10 \mathrm{~N} \\
\text { Off }\end{array}$ & $\begin{array}{c}\mathrm{RI}-10 \mathrm{~N} \\
\mathrm{On}\end{array}$ & $\begin{array}{c}\text { Thurber's } \\
\text { Off }\end{array}$ & Allen's On & \begin{tabular}{|c|} 
I-195 E \\
Off
\end{tabular} & $\mathrm{I}-195 \mathrm{~W}$ on & \begin{tabular}{|c|} 
Broad \\
Off
\end{tabular} & $\begin{array}{c}\text { Hartford } \\
\text { Off }\end{array}$ & Dwntwn On & $\begin{array}{c}\mathrm{RI}-10 \\
\mathrm{On}\end{array}$ \\
\hline (vphion) & $(\%$ Off $)$ & $(\mathrm{vph}$ On) & $(\% \mathrm{Off})$ & (vph On) & $(\%$ Off) & (vph On) & $(\%$ Off $)$ & $(\%$ Off) & (vph On) & $(\mathrm{vph} O \mathrm{On})$ \\
\hline 4000 & $10 \%$ & 667 & $5 \%$ & 667 & $30 \%$ & 1667 & $10 \%$ & $30 \%$ & 133 & 1048 \\
\hline \multicolumn{11}{|c|}{ Calculated Through Traffic at this Point } \\
\hline 4000 & 3600 & 4267 & 4053 & 4720 & 3304 & 4971 & 4474 & 3132 & 3265 & 4313 \\
\hline
\end{tabular}

Number and Description of Points Corresponding to Traffic Volume Map for Study Area for RI10

\begin{tabular}{|c|c|c|c|c|c|c|c|c|c|c|}
\hline RI-10-1 & RI-10-2 & RI-10-3 & RI-10-4 & RI-10-5 & RI-10-6 & RI-10-7 & RI-10-8 & RI-10-9 & RI-10-10 & RI-10-11 \\
\hline $\begin{array}{l}\text { Entry } \\
\text { Point }\end{array}$ & Elm. Off & Elm. On & To I-95 N & To I-95 S & $\begin{array}{c}\text { I-95 On } \\
\text { (Div } \\
\text { Flow) }\end{array}$ & Pontiac On & Res Off & Niantic On & Du Pont Off & $\begin{array}{c}\text { Du Pont } \\
\text { On }\end{array}$ \\
\hline (vpli On) $)$ & $(\%$ Off) & (vph On) & $(\%$ Off) & $(\%$ Off) & (vph On) & (vph On) & $(\%$ Off) & (vph On) & $(\%$ Off) & (vph On) \\
\hline 2000 & $5 \%$ & 333 & $30 \%$ & $20 \%$ & 400 & 333 & $10 \%$ & 533 & $10 \%$ & 133 \\
\hline
\end{tabular}

Calculated Through Traffic at this Point

\begin{tabular}{|l|l|l|l|l|l|l|l|l|l|l|}
\hline 2000 & 1900 & 2233 & 1563 & 1251 & 1651 & 1984 & 1786 & 2319 & 2087 & 2220 \\
\hline
\end{tabular}

Number and Description of Points Corresponding to Traffic Volume Map for Study Area

\begin{tabular}{|c|c|c|c|c|c|c|c|c|}
\hline & $1-10-1$ & RI-10-14 & RI-10-15 & RI-10-16 & RI-10-17 & RI-10-18 & RI-10-19 & RI-10-20 \\
\hline$\underset{\text { On }}{\text { Cran. St }}$ & $\begin{array}{l}\text { Union } \\
\text { Av Off }\end{array}$ & $\begin{array}{l}\text { Union } \\
\text { Av On }\end{array}$ & $\begin{array}{c}\text { West Min } \\
\text { Off }\end{array}$ & $\begin{array}{l}\text { RI-6 On } \\
\text { (From } \\
\text { HPMS) }\end{array}$ & $\begin{array}{c}\text { Eagle } \\
\text { On }\end{array}$ & To DwnTwn & $\begin{array}{c}\text { To I-95 } \\
\mathrm{S}\end{array}$ & $\begin{array}{l}\text { To I-95 N } \\
\text { (Divert) }\end{array}$ \\
\hline Whli On) & $(\%$ Off $)$ & (vph On) & (\% Off) & (vph On) & (vph On) & (\% Off) & $(\%$ Off $)$ & $(\%$ Off) \\
\hline 133 & $10 \%$ & 133 & $10 \%$ & 1333 & 133 & $50 \%$ & $20 \%$ & $30 \%$ \\
\hline
\end{tabular}

Calculated Through Traffic at this Point 
Thble D-6 Displays 2/3 Peak AM Traffic Volume determined for I-95 North and RI-10 North at all offied

\begin{tabular}{|c|c|c|c|c|c|c|c|c|c|c|c|}
\hline \multirow{7}{*}{ 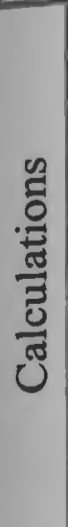 } & \multicolumn{11}{|c|}{ Number and Description of Points Corresponding to Traffic Volume Map for Study Area } \\
\hline & I-95-1 & I-95-2 & $1-95-3$ & $\mathrm{I}-95-4$ & I-95-5 & $1-95-6$ & $1-95-7$ & I-95-8 & I-95-9 & I-95-10 & I-95-11 \\
\hline & $\begin{array}{l}\text { Entry } \\
\text { Point }\end{array}$ & $\begin{array}{c}\text { RI- } 10 \mathrm{~N} \\
\text { Off }\end{array}$ & $\begin{array}{c}\mathrm{RI}-10 \mathrm{~N} \\
\text { On }\end{array}$ & $\begin{array}{c}\text { Thurber's } \\
\text { Off }\end{array}$ & Allen's On & $\begin{array}{c}\text { I-195 E } \\
\text { Off }\end{array}$ & I-195 W on & $\begin{array}{c}\text { Broad } \\
\text { Off }\end{array}$ & $\begin{array}{c}\text { Hartford } \\
\text { Off }\end{array}$ & Dwntwn On & $\begin{array}{c}\text { RI-10 } \\
\text { On }\end{array}$ \\
\hline & (vphi On) & $(\%$ Off $)$ & $($ (vph On) & $(\%$ Off) & (vph On) & $(\%$ Off $)$ & $($ vph On) & $(\%$ Off) & (\% Off) & (vph On) & (vph On \\
\hline & 4000 & $30 \%$ & 113 & $5 \%$ & 667 & $30 \%$ & 1667 & $10 \%$ & $30 \%$ & 133 & 1293 \\
\hline & \multicolumn{11}{|c|}{ Calculated Through Traffic at this Point } \\
\hline & 4000 & 2800 & 2913 & 2768 & 3434 & 2404 & 4071 & 3664 & 2565 & 2698 & 3991 \\
\hline
\end{tabular}

Number and Description of Points Corresponding to Traffic Volume Map for Study Area

\begin{tabular}{|c|c|c|c|c|c|c|c|c|c|c|}
\hline RI-10-1 & RI-10-2 & RI-10-3 & RI-10-4 & RI-10-5 & RI-10-6 & RI-10-7 & RI-10-8 & RI-10-9 & RI-10-10 & R1-10-11 \\
\hline $\begin{array}{l}\text { Entry } \\
\text { Point }\end{array}$ & Elm. Off & Elm. On & To $1-95 \mathrm{~N}$ & To I-95 S & \begin{tabular}{|c}
-95 On \\
(Div \\
Flow) \\
\end{tabular} & Pontiac On & Res Off & Niantic On & Du Pont of & $\begin{array}{c}\text { Du Pont } \\
\text { On }\end{array}$ \\
\hline (uph On) & $(\%$ Off) & $(\mathrm{vph}$ On) & $(\%$ Off) & (\% Off) & $($ vph On) & (vph On) & $(\%$ Off) & (vph On) & $(\%$ Off $)$ & $($ vph On) \\
\hline 2000 & $5 \%$ & 333 & $5 \%$ & $20 \%$ & 1200 & 333 & $10 \%$ & 533 & $10 \%$ & 133 \\
\hline \multicolumn{11}{|c|}{ Calculated Through Traffic at this Point } \\
\hline 2000 & 1900 & 2233 & 2122 & 1697 & 2897 & 3231 & 2908 & 3441 & 3097 & 3230 \\
\hline
\end{tabular}

Number and Description of Points Corresponding to Traffic Volume Map for Study Area

\begin{tabular}{|c|c|c|c|c|c|c|c|c|c|c|}
\hline RI-10-12 & RI-10-13 & RI-10-14 & RI-10-15 & RI-10-16 & RI-10-17 & RI-10-18 & RI-10-19 & RI-10-20 & & \\
\hline $\begin{array}{c}\text { Cran. St } \\
\text { On }\end{array}$ & $\begin{array}{c}\text { Union } \\
\text { Av Off }\end{array}$ & $\begin{array}{l}\text { Union } \\
\text { Av On }\end{array}$ & $\begin{array}{c}\text { West Min } \\
\text { Off }\end{array}$ & $\begin{array}{c}\text { RT-6 On } \\
\text { (From } \\
\text { HPMS) }\end{array}$ & $\begin{array}{c}\text { Eagle } \\
\text { On }\end{array}$ & To DwnTwn & $\begin{array}{c}\text { To I-95 } \\
\text { S }\end{array}$ & $\begin{array}{c}\text { To I-95 N } \\
\text { (Divert) }\end{array}$ & & \\
\hline (vili On) & $(\%$ Off & (vph On) & (\% Off) & (vph On) & (vph On) & (\% Off) & (\% Off) & (\% Off) & & \\
\hline 133 & $10 \%$ & 133 & $10 \%$ & 1333 & 133 & $50 \%$ & $20 \%$ & $30 \%$ & & \\
\hline 3364 & 3027 & 3160 & 2844 & 4178 & 4311 & 2156 & 862 & 1293 & & \\
\hline
\end{tabular}


the D-7 Displays 1/2 Peak AM Traffic Volume determined for I-95 North and RI-10 North at all

mints in the study area. The volumes displayed include a $0 \%$ DIVERSION to RI-10

\begin{tabular}{|c|c|c|c|c|c|c|c|c|c|c|}
\hline I-95-1 & I-95-2 & I-95-3 & I-95-4 & $1-95-5$ & $1-95-6$ & I-95-7 & I-95-8 & I-95-9 & I-95-10 & I-95-11 \\
\hline $\begin{array}{l}\text { Entry } \\
\text { Point }\end{array}$ & $\begin{array}{c}\mathrm{RI}-10 \mathrm{~N} \\
\text { Off } \\
\end{array}$ & \begin{tabular}{|c|}
$\mathrm{RI}-10 \mathrm{~N}$ \\
On
\end{tabular} & Thurber's Of & Allen's On & $\begin{array}{c}\text { I-195 E } \\
\text { Off } \\
\end{array}$ & I-195 W on & $\begin{array}{c}\text { Broad } \\
\text { Off }\end{array}$ & $\begin{array}{c}\text { Hartford } \\
\text { Off }\end{array}$ & Dwntwn On & $\begin{array}{c}\text { RI-10 } \\
\text { On }\end{array}$ \\
\hline whion) & $(\%$ Off $)$ & $(\mathrm{vph}$ On) & (\% Off) & (vph On) & $(\%$ Off) & $(\mathrm{vph} O \mathrm{On})$ & $(\%$ Off) & $(\%$ Off) & (vph On) & $(\mathrm{vph}$ On) \\
\hline 3000 & $10 \%$ & 500 & $5 \%$ & 500 & $30 \%$ & 1250 & $10 \%$ & $30 \%$ & 100 & 786 \\
\hline \multicolumn{11}{|c|}{ Calculated Through Traffic at this Point } \\
\hline 3000 & 2700 & 3200 & 3040 & 3540 & 2478 & 3728 & 3355 & 2349 & 2449 & 3235 \\
\hline
\end{tabular}

Number and Description of Points Corresponding to Traffic Volume Map for Study Area for RI-

\begin{tabular}{|c|c|c|c|c|c|c|c|c|c|c|}
\hline RI-10-1 & RI-10-2 & RI-10-3 & RI-10-4 & RI-10-5 & RI-10-6 & RI-10-7 & RI-10-8 & RI-10-9 & RI-10-10 & RI-10-11 \\
\hline $\begin{array}{l}\text { Entry } \\
\text { Point }\end{array}$ & Elm. Off & Elm. On & To I-95 N & To I-95 S & $\begin{array}{c}\text { I-95 On } \\
\text { (Div } \\
\text { Flow) }\end{array}$ & Pontiac On & Res Off & Niantic On & Du Pont Off & $\begin{array}{c}\text { Du Pont } \\
\text { On }\end{array}$ \\
\hline (ugh On) & (\% Off) & $(\mathrm{vph} O \mathrm{On})$ & (\% Off) & (\% Off) & $(\mathrm{vph} O \mathrm{n})$ & (vph On) & (\% Off) & (vph On) & (\% Off) & $(\mathrm{vph}$ On $)$ \\
\hline 1500 & $5 \%$ & 250 & $30 \%$ & $20 \%$ & 300 & 250 & $10 \%$ & 400 & $10 \%$ & 100 \\
\hline
\end{tabular}

Calculated Through Traffic at this Point

\begin{tabular}{|l|l|l|l|l|l|l|l|l|l|l|}
\hline 1500 & 1425 & 1675 & 1173 & 938 & 1238 & 1488 & 1339 & 1739 & 1565 & 1665 \\
\hline
\end{tabular}

Number and Description of Points Corresponding to Traffic Volume Map for Study Area

\begin{tabular}{|c|c|c|c|c|c|c|c|c|}
\hline $10-12$ & RI-I0-13 & RI-10-14 & RI-10-15 & RI-10-16 & RI-10-17 & RI-10-18 & RI-10-19 & RI-10-20 \\
\hline $\begin{array}{c}\text { Cran. St } \\
\text { On }\end{array}$ & $\begin{array}{l}\text { Union } \\
\text { Av Off }\end{array}$ & $\begin{array}{l}\text { Union } \\
\text { Av On }\end{array}$ & $\begin{array}{l}\text { West Min } \\
\text { Off }\end{array}$ & $\begin{array}{c}\text { RI-6 On } \\
\text { (From } \\
\text { HPMS) }\end{array}$ & Eagle On & To DwnTwn & $\begin{array}{c}\text { To } 1-95 \\
\mathrm{~S}\end{array}$ & $\begin{array}{l}\text { To I-95 N } \\
\text { (Divert) }\end{array}$ \\
\hline Medr Ons) & $(\%$ Off $)$ & $($ vph On) & (\% Off) & (vph On) & $(\mathrm{vph} O \mathrm{n})$ & (\% Off) & $(\%$ Off) & $(\%$ Off $)$ \\
\hline 100 & $10 \%$ & 100 & $10 \%$ & 1000 & 100 & $50 \%$ & $20 \%$ & $30 \%$ \\
\hline
\end{tabular}

Calculated Through Traffic at this Point

\begin{tabular}{|l|l|l|l|l|l|l|l|l|}
\hline 1765 & 1589 & 1689 & 1520 & 2520 & 2620 & 1310 & 524 & 786 \\
\hline
\end{tabular}




\begin{tabular}{|c|c|c|c|c|c|c|c|c|c|c|c|}
\hline \multirow{7}{*}{$\frac{\mathscr{0}}{\frac{0}{3}}$} & \multicolumn{11}{|c|}{ Number and Description of Points Corresponding to Traffic Volume Map for Study Area } \\
\hline & I-95-1 & I-95-2 & I-95-3 & $1-95-4$ & $1-95-5$ & $1-95-6$ & I-95-7 & $1-95-8$ & I-95-9 & I-95-10 & I-95-11 \\
\hline & $\begin{array}{l}\text { Entry } \\
\text { Point }\end{array}$ & $\begin{array}{c}\text { RI-10 N } \\
\text { Off }\end{array}$ & $\begin{array}{c}\text { RI-10 N } \\
\text { On }\end{array}$ & Thurber's Of & Allen's On & $\begin{array}{c}\text { I-195 E } \\
\text { Off }\end{array}$ & I-195 W on & $\begin{array}{l}\text { Broad } \\
\text { Off }\end{array}$ & $\begin{array}{l}\text { Hartford } \\
\text { Off }\end{array}$ & Dwntwn On & \begin{tabular}{|c|} 
RI-10 \\
On
\end{tabular} \\
\hline & (sphi On) & $(\%$ Off $)$ & (vph On) & $(\% \mathrm{Off})$ & (vph On) & $(\%$ Off & (vph On) & (\% Off) & $(\%$ Off $)$ & (vph On) & $($ vph On) \\
\hline & 3000 & $30 \%$ & 85 & $5 \%$ & 500 & $30 \%$ & 1250 & $10 \%$ & $30 \%$ & 100 & 970 \\
\hline & \multicolumn{11}{|c|}{ Calculated Through Traffic at this Point } \\
\hline & 3000 & 2100 & 2185 & 2076 & 2576 & 1803 & 3053 & 2748 & 1923 & 2023 & 2993 \\
\hline \multirow{14}{*}{$\frac{\mathscr{Z}}{0}$} & $\mathrm{Nu}$ & mber ar & Id Descr & ription of $\mathrm{P}$ & oints Corn & respondi & ing to Traf & fic Volut & me Map f & or Study Ar & rea \\
\hline & RI-10-1 & RI-10-2 & $\mathrm{Rl}-10-3$ & RI-10-4 & $\mathrm{RJ}-10-5$ & $\mathrm{RI}-10-6$ & RI-10-7 & RI-10-8 & RI-10-9 & RI-10-10 & RI-10-11 \\
\hline & $\begin{array}{l}\text { Entry } \\
\text { Point }\end{array}$ & Elm. Off & Elm. On & To I-95 N & To I-95 S & \begin{tabular}{|c|}
$1-95$ On \\
(Div \\
Flow) \\
\end{tabular} & Pontiac On & Res Off & Niantic On & Du Pont Off & $\begin{array}{c}\text { Du Pont } \\
\text { On }\end{array}$ \\
\hline & (uplion) & (\% Off) & (vph On) & (\% Off) & (\% Off) & $(\operatorname{vph} O n)$ & (vph On) & (\% Off) & (vph On) & $(\%$ Off) & $(\mathrm{vph}$ On) \\
\hline & 1500 & $5 \%$ & 250 & $5 \%$ & $20 \%$ & 900 & 250 & $10 \%$ & 400 & $10 \%$ & 100 \\
\hline & \multicolumn{11}{|c|}{ Calculated Through Traffic at this Point } \\
\hline & 1500 & 1425 & 1675 & 1591 & 1273 & 2173 & 2423 & 2181 & 2581 & 2323 & 2423 \\
\hline & \multicolumn{11}{|c|}{ Number and Description of Points Corresponding to Traffic Volume Map for Study Area } \\
\hline & $80-10-12$ & RI-10-13 & RI-10-14 & RI-10-15 & RI-10-16 & RI-10-17 & RJ-10-18 & RI-10-19 & RI-I0-20 & & \\
\hline & $\begin{array}{c}\text { Cran. St } \\
\text { On }\end{array}$ & $\begin{array}{l}\text { Union } \\
\text { Av Off }\end{array}$ & $\begin{array}{l}\text { Union } \\
\text { Av On }\end{array}$ & $\begin{array}{l}\text { West Min } \\
\text { Off }\end{array}$ & $\begin{array}{c}\text { RT-6 On } \\
\text { (From } \\
\text { HPMS) }\end{array}$ & Eagle On & To DwnTwn & $\begin{array}{c}\text { To I-95 } \\
\mathrm{S}\end{array}$ & $\begin{array}{l}\text { To I-95 N } \\
\text { (Divert) }\end{array}$ & & \\
\hline & (opla On) & $(\%$ Off $)$ & (vph On) & $(\%$ Off) & (vph On) & $(\mathrm{vph}$ On) & (\% Off) & (\% Off) & (\% Off) & & \\
\hline & 100 & $10 \%$ & 100 & $10 \%$ & 1000 & 100 & $50 \%$ & $20 \%$ & $30 \%$ & & \\
\hline & \multicolumn{11}{|c|}{ Calculated Through Traffic at this Point } \\
\hline & 2523 & 2270 & 2370 & 2133 & 3133 & 3233 & 1617 & 647 & 970 & & \\
\hline
\end{tabular}




\section{APPENDIX E}

Results for Simulations Modeled with

AM Peak Traffic Conditions 


\begin{tabular}{|c|c|c|c|c|c|c|c|}
\hline \multirow{2}{*}{ Network Description } & \multicolumn{6}{|c|}{ Simulation Set Number } & 1.0 \\
\hline & \multicolumn{3}{|c|}{ Interstate 95 North } & \multicolumn{3}{|c|}{ Highway Route 10} & \\
\hline AM Volume; $0 \%$ & $\begin{array}{c}\text { Vehicle } \\
\text { Miles } \\
\text { Traveled } \\
\text { (miles) }\end{array}$ & $\begin{array}{c}\text { Vehicle } \\
\text { Minutes } \\
\text { (min) }\end{array}$ & $\begin{array}{c}\text { Cumulative } \\
\text { Average Speed } \\
195 \text { and all } \\
\text { Ramps (mph) }\end{array}$ & $\begin{array}{l}\text { Vehicle } \\
\text { Miles } \\
\text { Traveled } \\
\text { (miles) }\end{array}$ & $\begin{array}{l}\text { Vehicle } \\
\text { Minutes } \\
\text { (min) }\end{array}$ & $\begin{array}{l}\text { Cumulative } \\
\text { Average Speed } \\
\text { RT10 and all } \\
\text { Ramps (mph) }\end{array}$ & $\begin{array}{l}\text { Cumulative } \\
\text { Network } \\
\text { Average Speed } \\
\text { (mph) }\end{array}$ \\
\hline Random Seed Number & A & B & $\begin{array}{c}\mathrm{C}=\mathrm{A} /(\mathrm{B} / 60 \\
\mathrm{min} / \mathrm{hr})\end{array}$ & D & $\mathrm{E}$ & $\begin{array}{c}\mathrm{F}=\mathrm{D} /(\mathrm{E} / 60 \\
\mathrm{min} / \mathrm{hr})\end{array}$ & $\begin{array}{c}G=(A+D) / \\
{[(B+E) / 60} \\
\text { min/hr] }\end{array}$ \\
\hline 1 & 58683.1 & 86722.3 & 40.6 & 15542.4 & 16832.2 & 55.40 & 43.0 \\
\hline 33 & 58523.4 & 87975.9 & 39.9 & 14248.4 & 15254.3 & 56.04 & 42.3 \\
\hline 99 & 58363.8 & 86059.7 & 40.7 & 14200.7 & 15195.1 & 56.07 & 43.0 \\
\hline Cumulative Average Speed & & & 40.4 & & & 55.82 & 42.8 \\
\hline \multirow{2}{*}{ Network Description } & \multicolumn{6}{|c|}{ Simulation Set Number } & 2.0 \\
\hline & \multicolumn{3}{|c|}{ Interstate 95 North } & \multicolumn{3}{|c|}{ Highway Route 10} & \\
\hline $\begin{array}{l}\text { Dulk AM Volume; } 0 \% \\
\text { Duserthon In } 1 \text { Lane Block; } 30\end{array}$ & $\begin{array}{l}\text { Vehicle } \\
\text { Miles } \\
\text { Traveled } \\
\text { (miles) }\end{array}$ & $\begin{array}{c}\text { Vehicle } \\
\text { Minutes } \\
\text { (min) }\end{array}$ & $\begin{array}{l}\text { Cumulative } \\
\text { Average Speed } \\
195 \text { and all } \\
\text { Ramps (mph) }\end{array}$ & $\begin{array}{l}\text { Vehicle } \\
\text { Miles } \\
\text { Traveled } \\
\text { (miles) }\end{array}$ & $\begin{array}{l}\text { Vehicle } \\
\text { Minutes } \\
\text { (min) }\end{array}$ & $\begin{array}{l}\text { Cumulative } \\
\text { Average Speed } \\
\text { RT10 and all } \\
\text { Ramps (mph) }\end{array}$ & $\begin{array}{l}\text { Cumulative } \\
\text { Network } \\
\text { Average Speed } \\
\text { (mph) }\end{array}$ \\
\hline Random Seed Number & $\mathbf{A}$ & B & $\begin{array}{c}\mathrm{C}=\mathrm{A} /(\mathrm{B} / 60 \\
\mathrm{min} / \mathrm{hr})\end{array}$ & D & E & $\begin{array}{c}\mathrm{F}=\mathrm{D} /(\mathrm{E} / 60 \\
\mathrm{min} / \mathrm{hr})\end{array}$ & $\begin{array}{c}G=(A+D) / \\
{[(B+E) / 60} \\
\text { min/hr }]\end{array}$ \\
\hline 1 & 58225.7 & 110400.3 & 31.6 & 13621.7 & 15016.0 & 54.43 & 34.4 \\
\hline 33 & 58497.2 & 102618.3 & 34.2 & 14391.6 & 15427.6 & 55.97 & 37.0 \\
\hline 99 & 58497.2 & 102618.3 & 34.2 & 14337.1 & 20125.3 & 42.74 & 35.6 \\
\hline Curnulative Average Speed & & & 33.3 & & & 50.25 & 35.6 \\
\hline \multirow{2}{*}{ Network Description } & \multicolumn{6}{|c|}{ Simulation Set Number } & 3.0 \\
\hline & \multicolumn{3}{|c|}{ Interstate 95 North } & \multicolumn{3}{|c|}{ Highway Route 10} & \\
\hline $\begin{array}{l}\text { AM Volume; } 0 \% \\
\text { The In } 1 \text { Lane Block; } 40\end{array}$ & $\begin{array}{c}\text { Vehicle } \\
\text { Miles } \\
\text { Traveled } \\
\text { (miles) }\end{array}$ & $\begin{array}{c}\text { Vehicle } \\
\text { Minutes } \\
\text { (min) }\end{array}$ & $\begin{array}{c}\text { Cumulative } \\
\text { Average Speed } \\
\text { I95 and all } \\
\text { Ramps (mph) }\end{array}$ & $\begin{array}{l}\text { Vehicle } \\
\text { Miles } \\
\text { Traveled } \\
\text { (miles) }\end{array}$ & $\begin{array}{c}\text { Vehicle } \\
\text { Minutes } \\
\text { (min) }\end{array}$ & \begin{tabular}{|c|} 
Cumulative \\
Average Speed \\
RT10 and all \\
Ramps (mph)
\end{tabular} & $\begin{array}{l}\text { Cumulative } \\
\text { Network } \\
\text { Average Speed } \\
\text { (mph) }\end{array}$ \\
\hline Random Seed Number & A & B & $\begin{array}{c}\mathrm{C}=\mathrm{A} /(\mathrm{B} / 60 \\
\mathrm{min} / \mathrm{hr})\end{array}$ & D & $\mathrm{E}$ & $\begin{array}{c}\mathrm{F}=\mathrm{D} /(\mathrm{E} / 60 \\
\mathrm{min} / \mathrm{hr})\end{array}$ & $\begin{array}{c}G=(A+D) / \\
{[(B+E) / 60} \\
\min / \mathrm{hr}]\end{array}$ \\
\hline 1 & 57152.3 & 128820.2 & 26.6 & 17031.2 & 19451.4 & 52.53 & 30.0 \\
\hline 33 & 57815.5 & 114224.2 & 30.4 & 15921.6 & 17269.2 & 55.32 & 33.6 \\
\hline 99 & 58197.7 & 110218.9 & 31.7 & 15715.1 & 17112.3 & 55.10 & 34.8 \\
\hline Cumulative Average Speed & & & 29.4 & & & 54.24 & 32.7 \\
\hline Network Description & & & & & Simu & ation Set Number & 4.0 \\
\hline & & interstate 9 & 5 North & & Highway $\mathbf{R}$ & te 10 & \\
\hline $\begin{array}{l}\text { AM Volume; } 0 \% \\
\text { in } 2 \text { Lane Block; } 20\end{array}$ & $\begin{array}{c}\text { Vehicle } \\
\text { Miles } \\
\text { Traveled } \\
\text { (miles) }\end{array}$ & $\begin{array}{c}\text { Vehicle } \\
\text { Minutes } \\
\text { (min) }\end{array}$ & $\begin{array}{c}\text { Cumulative } \\
\text { Average Speed } \\
\text { [95 and all } \\
\text { Ramps (mph) }\end{array}$ & $\begin{array}{c}\text { Vehicle } \\
\text { Miles } \\
\text { Traveled } \\
\text { (miles) }\end{array}$ & $\begin{array}{c}\text { Vehicle } \\
\text { Minutes } \\
\text { (min) }\end{array}$ & $\begin{array}{c}\text { Cumulative } \\
\text { Average Speed } \\
\text { RT10 and all } \\
\text { Ramps (mph) }\end{array}$ & $\begin{array}{c}\text { Cumulative } \\
\text { Network } \\
\text { Average Speed } \\
\text { (mph) }\end{array}$ \\
\hline Random Seed Number & A & B & $\begin{array}{c}\mathrm{C}=\mathrm{A} /(\mathrm{B} / 60 \\
\mathrm{min} / \mathrm{hr})\end{array}$ & D & E & $\begin{array}{c}\mathrm{F}=\mathrm{D} /(\mathrm{E} / 60 \\
\mathrm{min} / \mathrm{hr})\end{array}$ & $\begin{array}{c}\mathrm{G}=(\mathrm{A}+\mathrm{D}) / \\
{[(\mathrm{B}+\mathrm{E}) / 60} \\
\mathrm{min} / \mathrm{hrl} \\
\end{array}$ \\
\hline 1 & 57273.2 & 135822.3 & 25.3 & 15542.4 & 16832.2 & 55.40 & 28.6 \\
\hline 33 & 57137.6 & 139388.9 & 24.6 & 14248.4 & 15254.3 & 56.04 & 27.7 \\
\hline 99 & 56936.8 & 139154.4 & 24.5 & 14200.7 & 15195.1 & 56.07 & 27.7 \\
\hline Cromulative Average Speed & & & 24.8 & & & 55.82 & 28.0 \\
\hline
\end{tabular}




\begin{tabular}{|c|c|c|c|c|c|c|c|}
\hline \multirow{2}{*}{ Network Description } & \multicolumn{6}{|c|}{ Simulation Set Number } & 5.0 \\
\hline & \multicolumn{3}{|c|}{ Interstate 95 North } & \multicolumn{3}{|c|}{ Highway Route 10} & \\
\hline $\begin{array}{l}\text { AM Volume; } 0 \% \\
2 \text { Lane Block; } 30\end{array}$ & $\begin{array}{l}\text { Vehicle } \\
\text { Miles } \\
\text { Traveled } \\
\text { (miles) }\end{array}$ & $\begin{array}{c}\text { Vehicle } \\
\text { Minutes } \\
\text { (min) }\end{array}$ & $\begin{array}{l}\text { Cumulative } \\
\text { Average Speed } \\
\text { I95 and all } \\
\text { Ramps (mph) }\end{array}$ & $\begin{array}{l}\text { Vehicle } \\
\text { Miles } \\
\text { Traveled } \\
\text { (miles) }\end{array}$ & $\begin{array}{l}\text { Vehicle } \\
\text { Minutes } \\
\text { (min) }\end{array}$ & $\begin{array}{l}\text { Cumulative } \\
\text { Average Speed } \\
\text { RT10 and all } \\
\text { Ramps (mph) }\end{array}$ & $\begin{array}{c}\text { Cumulative } \\
\text { Network } \\
\text { Average Speed } \\
\text { (mph) }\end{array}$ \\
\hline Random Seed Number & A & $\mathbf{B}$ & $\begin{array}{c}\mathrm{C}=\mathrm{A} /(\mathrm{B} / 60 \\
\mathrm{min} / \mathrm{hr})\end{array}$ & D & $\mathbf{E}$ & $\begin{array}{c}\mathrm{F}=\mathrm{D} /(\mathrm{E} / 60 \\
\mathrm{min} / \mathrm{hr})\end{array}$ & $\begin{array}{c}G=(A+D) / \\
{[(B+E) / 60} \\
\text { min/hr] }\end{array}$ \\
\hline 1 & 54399.4 & 147988.0 & 22.1 & 13621.7 & 15016.0 & 54.43 & 25.0 \\
\hline 33 & 54449.0 & 146274.0 & 22.3 & 14391.6 & 15427.6 & 55.97 & 25.5 \\
\hline 99 & 54562.0 & 146057.8 & 22.4 & 14337.1 & 20125.3 & 42.74 & 24.9 \\
\hline Cumulative Average Speed & & & 22.3 & & & 50.25 & 25.1 \\
\hline \multirow{2}{*}{ Network Description } & \multicolumn{6}{|c|}{ Simulation Set Number } & 6.0 \\
\hline & \multicolumn{3}{|c|}{ Interstate 95 North } & \multicolumn{3}{|c|}{ Highway Route 10} & \\
\hline 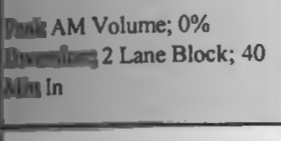 & $\begin{array}{l}\text { Vehicle } \\
\text { Miles } \\
\text { Traveled } \\
\text { (miles) }\end{array}$ & $\begin{array}{l}\text { Vehicle } \\
\text { Minutes } \\
\text { (min) }\end{array}$ & $\begin{array}{l}\text { Cumulative } \\
\text { Average Speed } \\
\text { I95 and all } \\
\text { Ramps (mph) }\end{array}$ & $\begin{array}{l}\text { Vehicle } \\
\text { Miles } \\
\text { Traveled } \\
\text { (miles) }\end{array}$ & $\begin{array}{l}\text { Vehicle } \\
\text { Minutes } \\
\text { (min) }\end{array}$ & $\begin{array}{l}\text { Cumulative } \\
\text { Average Speed } \\
\text { RT10 and all } \\
\text { Ramps (mph) }\end{array}$ & $\begin{array}{l}\text { Cumulative } \\
\text { Network } \\
\text { Average Speed } \\
\text { (mph) }\end{array}$ \\
\hline Random Seed Number & $\mathbf{A}$ & $\mathbf{B}$ & $\begin{array}{c}\mathrm{C}=\mathrm{A} /(\mathrm{B} / 60 \\
\mathrm{min} / \mathrm{hr})\end{array}$ & $\mathbf{D}$ & $\mathbf{E}$ & $\begin{array}{c}\mathrm{F}=\mathrm{D} /(\mathrm{E} / 60 \\
\mathrm{min} / \mathrm{hr})\end{array}$ & $\begin{array}{c}\mathrm{G}=(\mathrm{A}+\mathrm{D})] \\
{[(\mathrm{B}+\mathrm{E}) / 60} \\
\mathrm{min} / \mathrm{hr}]\end{array}$ \\
\hline 1 & 51142.0 & 149656.0 & 20.5 & 17031.2 & 19451.4 & 52.53 & 24.2 \\
\hline 33 & 51858.8 & 145770.9 & 21.3 & 15921.6 & 17269.2 & 55.32 & 24.9 \\
\hline 99 & 51645.1 & 144871.2 & 21.4 & 15715.1 & 17112.3 & 55.10 & 25.0 \\
\hline Cumulative A verage Speed & & & 21.1 & & & 54.24 & 24.7 \\
\hline \multirow{2}{*}{ Network Description } & \multicolumn{6}{|c|}{ Simulation Set Number } & 7.0 \\
\hline & \multicolumn{3}{|c|}{ Interstate 95 North } & \multicolumn{3}{|c|}{ Highway Route 10} & \\
\hline 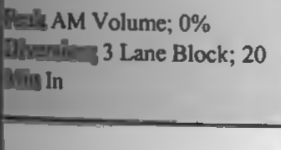 & $\begin{array}{l}\text { Vehicle } \\
\text { Miles } \\
\text { Traveled } \\
\text { (miles) }\end{array}$ & $\begin{array}{c}\text { Vehicle } \\
\text { Minutes } \\
\text { (min) }\end{array}$ & $\begin{array}{c}\text { Cumulative } \\
\text { Average Speed } \\
195 \text { and all } \\
\text { Ramps (mph) }\end{array}$ & $\begin{array}{c}\text { Vehicle } \\
\text { Miles } \\
\text { Traveled } \\
\text { (miles) }\end{array}$ & $\begin{array}{l}\text { Vehicle } \\
\text { Minutes } \\
\text { (min) }\end{array}$ & $\begin{array}{c}\text { Cumulative } \\
\text { Average Speed } \\
\text { RT10 and all } \\
\text { Ramps (mph) }\end{array}$ & $\begin{array}{c}\text { Cumulative } \\
\text { Network } \\
\text { Average Speed } \\
\text { (mph) }\end{array}$ \\
\hline Random Seed Number & $\mathbf{A}$ & B & $\begin{array}{c}\mathrm{C}=\mathrm{A} /(\mathrm{B} / 60 \\
\mathrm{min} / \mathrm{hr})\end{array}$ & D & $\mathbf{E}$ & $\begin{array}{c}\mathrm{F}=\mathrm{D} /(\mathrm{E} / 60 \\
\mathrm{min} / \mathrm{hr})\end{array}$ & $\begin{array}{c}\mathrm{G}=(\mathrm{A}+\mathrm{D}) / \\
{[(\mathrm{B}+\mathrm{E}) / 60} \\
\min / \mathrm{hr}]\end{array}$ \\
\hline 1 & 53887.3 & 172143.1 & 18.8 & 15542.4 & 16832.2 & 55.40 & 22.0 \\
\hline 33 & 54510.0 & 153885.4 & 21.3 & 14248.4 & 15254.3 & 56.04 & 24.4 \\
\hline 99 & 54722.5 & 155304.4 & 21.1 & 14200.7 & 15195.1 & 56.07 & 24.3 \\
\hline Cumulative Average Speed & & & 20.3 & & & 55.82 & 23.5 \\
\hline Netv & & & & & Simu & ion Set Number & 8.0 \\
\hline & & Interstate 95 & 5 North & & Highway R & te 10 & \\
\hline $\begin{array}{l}\text { AM Volume; 0\% } \\
\text { In Lane Block; } 30\end{array}$ & $\begin{array}{l}\text { Vehicle } \\
\text { Miles } \\
\text { Traveled } \\
\text { (miles) }\end{array}$ & $\begin{array}{c}\text { Vehicle } \\
\text { Minutes } \\
(\mathrm{min})\end{array}$ & $\begin{array}{l}\text { Cumulative } \\
\text { Average Speed } \\
195 \text { and all } \\
\text { Ramps (mph) }\end{array}$ & $\begin{array}{l}\text { Vehicle } \\
\text { Miles } \\
\text { Traveled } \\
\text { (miles) }\end{array}$ & $\begin{array}{l}\text { Vehicle } \\
\text { Minutes } \\
\text { (min) }\end{array}$ & $\begin{array}{l}\text { Cumulative } \\
\text { Average Speed } \\
\text { RT10 and all } \\
\text { Ramps (mph) }\end{array}$ & $\begin{array}{c}\text { Cumulative } \\
\text { Network } \\
\text { Average Speed } \\
\text { (mph) }\end{array}$ \\
\hline Rendom Seed Number & A & B & $\begin{array}{c}C=A /(B / 60 \\
\mathrm{min} / \mathrm{hr})\end{array}$ & D & $\mathbf{E}$ & $\begin{array}{c}\mathrm{F}=\mathrm{D} /(\mathrm{E} / 60 \\
\mathrm{min} / \mathrm{hr})\end{array}$ & $\begin{array}{c}\mathrm{G}=(\mathrm{A}+\mathrm{D})] \\
{[(\mathrm{B}+\mathrm{E}) / 60} \\
\min / \mathrm{hr}]\end{array}$ \\
\hline 1 & 32628.5 & 326112.3 & 6.0 & 13621.7 & 15016.0 & 54.43 & 8.1 \\
\hline 33 & 50695.4 & 167245.4 & 18.2 & $\$ 4391.6$ & 15427.6 & 55.97 & 21.4 \\
\hline 99 & 50030.4 & 162297.4 & 18.5 & 14337.1 & 20125.3 & 42.74 & 21.2 \\
\hline Qmaulative Average Speed & & & 12.2 & & & 50.25 & 14.9 \\
\hline
\end{tabular}




\begin{tabular}{|c|c|c|c|c|c|c|c|}
\hline \multirow{2}{*}{ Network Description } & \multicolumn{6}{|c|}{ Simulation Set Number } & 9.0 \\
\hline & \multicolumn{3}{|c|}{ Interstate 95 North } & \multicolumn{3}{|c|}{ Highway Route 10} & \\
\hline $\begin{array}{l}\text { Dols AM Volume; } 0 \% \\
\text { Then In }\end{array}$ & $\begin{array}{c}\text { Vehicle } \\
\text { Miles } \\
\text { Traveled } \\
\text { (miles) }\end{array}$ & $\begin{array}{c}\text { Vehicle } \\
\text { Minutes } \\
\text { (min) }\end{array}$ & $\begin{array}{l}\text { Cumulative } \\
\text { Average Speed } \\
\text { I95 and all } \\
\text { Ramps (mph) }\end{array}$ & $\begin{array}{l}\text { Vehicle } \\
\text { Miles } \\
\text { Traveled } \\
\text { (miles) }\end{array}$ & $\begin{array}{l}\text { Vehicle } \\
\text { Minutes } \\
\text { (min) }\end{array}$ & $\begin{array}{l}\text { Cumulative } \\
\text { Average Speed } \\
\text { RT10 and all } \\
\text { Ramps (mph) }\end{array}$ & $\begin{array}{c}\text { Cumulative } \\
\text { Network } \\
\text { Average Speed } \\
\text { (mph) }\end{array}$ \\
\hline Random Seed Number & A & B & $\begin{array}{c}\mathrm{C}=\mathrm{A} /(\mathrm{B} / 60 \\
\mathrm{min} / \mathrm{hr})\end{array}$ & D & $\mathbf{E}$ & $\begin{array}{c}\mathrm{F}=\mathrm{D} /(\mathrm{E} / 60 \\
\mathrm{min} / \mathrm{hr})\end{array}$ & $\begin{array}{c}G=(A+D) / \\
{[(B+E) / 60} \\
\min / h r l\end{array}$ \\
\hline 1 & 43572.6 & 215791.0 & 12.1 & 17031.2 & 19451.4 & 52.53 & 15.5 \\
\hline 33 & 46968.3 & 175084.7 & 16.1 & 15921.6 & 17269.2 & 55.32 & 19.6 \\
\hline 99 & 46968.3 & 175084.7 & 16.1 & 15715.1 & 17112.3 & 55.10 & 19.6 \\
\hline Cumblative Average Speed & & & 14.6 & & & 54.24 & 18.0 \\
\hline \multirow{2}{*}{ Network Description } & \multicolumn{6}{|c|}{ Simulation Set Number } & 10.0 \\
\hline & \multicolumn{3}{|c|}{ Interstate 95 North } & \multicolumn{3}{|c|}{ Highway Route 10} & \\
\hline $\begin{array}{l}\text { AM Volume; } 20 \% \\
\text { In } 1 \text { Lane Block; } 20\end{array}$ & $\begin{array}{l}\text { Vehicle } \\
\text { Miles } \\
\text { Traveled } \\
\text { (miles) }\end{array}$ & $\begin{array}{c}\text { Vehicle } \\
\text { Minutes } \\
\text { (min) }\end{array}$ & $\begin{array}{c}\text { Cumulative } \\
\text { Average Speed } \\
\text { I95 and all } \\
\text { Ramps (mph) }\end{array}$ & $\begin{array}{l}\text { Vehicle } \\
\text { Miles } \\
\text { Traveled } \\
\text { (miles) }\end{array}$ & $\begin{array}{l}\text { Vehicle } \\
\text { Minutes } \\
\text { (min) }\end{array}$ & $\begin{array}{l}\text { Cumulative } \\
\text { Average Speed } \\
\text { RT10 and all } \\
\text { Ramps (mph) }\end{array}$ & $\begin{array}{c}\text { Cumulative } \\
\text { Network } \\
\text { Average Speed } \\
\text { (mph) }\end{array}$ \\
\hline Random Seed Number & A & B & 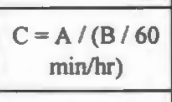 & D & E & $\begin{array}{c}\mathrm{F}=\mathrm{D} /(\mathrm{E} / 60 \\
\mathrm{min} / \mathrm{hr})\end{array}$ & $\begin{array}{c}\mathrm{G}=(\mathrm{A}+\mathrm{D}) / \\
{[(\mathrm{B}+\mathrm{E}) / 60} \\
\mathrm{min} / \mathrm{hr}]\end{array}$ \\
\hline 1 & 56481.8 & 65163.0 & 52.0 & 13393.5 & 87058.4 & 9.23 & 27.5 \\
\hline 33 & 56521.9 & 66575.9 & 50.9 & 15319.9 & 16575.9 & 55.45 & 51.8 \\
\hline 99 & 54390.0 & 74124.5 & 44.0 & 6908.6 & 144300.2 & 2.87 & 16.8 \\
\hline Crmulative Average Speed & & & 48.8 & & & 8.62 & 26.8 \\
\hline \multirow{2}{*}{ Network Description } & \multicolumn{6}{|c|}{ Simulation Set Number } & 11.0 \\
\hline & \multicolumn{3}{|c|}{ Interstate 95 North } & \multicolumn{3}{|c|}{ Highway Route 10} & \\
\hline AM Volume; $20 \%$ & $\begin{array}{l}\text { Vehicle } \\
\text { Miles } \\
\text { Traveled } \\
\text { (miles) }\end{array}$ & $\begin{array}{c}\text { Vehicle } \\
\text { Minutes } \\
\text { (min) }\end{array}$ & $\begin{array}{l}\text { Cumulative } \\
\text { Average Speed } \\
\text { I95 and all } \\
\text { Ramps (mph) }\end{array}$ & $\begin{array}{l}\text { Vehicle } \\
\text { Miles } \\
\text { Traveled } \\
\text { (miles) }\end{array}$ & $\begin{array}{l}\text { Vehicle } \\
\text { Minutes } \\
\text { (min) }\end{array}$ & $\begin{array}{c}\text { Cumulative } \\
\text { Average Speed } \\
\text { RT10 and all } \\
\text { Ramps (mph) }\end{array}$ & $\begin{array}{c}\text { Curnulative } \\
\text { Network } \\
\text { Average Speed } \\
\text { (mph) }\end{array}$ \\
\hline Random Seed Number & A & B & $\begin{array}{c}\mathrm{C}=\mathrm{A} /(\mathrm{B} / 60 \\
\mathrm{min} / \mathrm{hr})\end{array}$ & D & E & $\begin{array}{c}F=\underset{\mathrm{min} / \mathrm{hr})}{\mathrm{D} /(\mathrm{E} / 60} \\
\end{array}$ & $\begin{array}{c}\bar{G}=(A+D) / \\
{[(B+E) / 60} \\
\min / \mathrm{hr}]\end{array}$ \\
\hline 1 & 55554.1 & 63843.7 & 52.2 & 13739.7 & 96082.6 & 8.58 & 26.0 \\
\hline 33 & 55347.5 & 63194.7 & 52.5 & 14894.6 & 28623.4 & 31.22 & 45.9 \\
\hline 99 & 55385.9 & 64120.4 & 51.8 & 6880.3 & 143778.8 & 2.87 & 18.0 \\
\hline Cmmulative Average Speed & & & 52.2 & & & 7.94 & 26.3 \\
\hline \multirow{2}{*}{ Network Description } & \multicolumn{6}{|c|}{ Simulation Set Number } & 12.0 \\
\hline & \multicolumn{3}{|c|}{ Interstate 95 North } & \multicolumn{3}{|c|}{ Highway Route 10} & \\
\hline $\begin{array}{l}\text { AM Volume; } 20 \% \\
\text { ln } 1 \text { Lane Block; } 40\end{array}$ & $\begin{array}{c}\text { Vehicle } \\
\text { Miles } \\
\text { Traveled } \\
\text { (miles) }\end{array}$ & $\begin{array}{c}\text { Vehicle } \\
\text { Minutes } \\
\text { (min) }\end{array}$ & $\begin{array}{c}\text { Cumulative } \\
\text { Average Speed } \\
195 \text { and all } \\
\text { Ramps (mph) }\end{array}$ & $\begin{array}{l}\text { Vehicle } \\
\text { Miles } \\
\text { Traveled } \\
\text { (miles) }\end{array}$ & $\begin{array}{l}\text { Vehicle } \\
\text { Minutes } \\
\text { (min) }\end{array}$ & $\begin{array}{l}\text { Cumulative } \\
\text { Average Speed } \\
\text { RT10 and all } \\
\text { Ramps (mph) }\end{array}$ & $\begin{array}{c}\text { Cumulative } \\
\text { Network } \\
\text { A verage Speed } \\
\text { (mph) }\end{array}$ \\
\hline Rendom Seed Number & A & B & $\begin{array}{c}\mathrm{C}=\mathrm{A} /(\mathrm{B} / 60 \\
\mathrm{min} / \mathrm{hr})\end{array}$ & D & E & $\begin{array}{c}\mathrm{F}=\mathrm{D} /(\mathrm{E} / 60 \\
\mathrm{min} / \mathrm{hr})\end{array}$ & $\begin{array}{c}\mathrm{G}=(A+D) / \\
{[(B+E) / 60} \\
\mathrm{min} / \mathrm{hr}]\end{array}$ \\
\hline 1 & 54670.1 & 62821.1 & 52.2 & 13832.0 & 118958.4 & 6.98 & 22.6 \\
\hline 33 & 54330.3 & 63387.9 & 51.4 & 12916.5 & 98124.8 & 7.90 & 25.0 \\
\hline 99 & 54459.0 & 63784.4 & 51.2 & 6880.3 & 143778.8 & 2.87 & 17.7 \\
\hline Onoulative Average Speed & & & 51.6 & & & 5.59 & 21.5 \\
\hline
\end{tabular}




\begin{tabular}{|c|c|c|c|c|c|c|c|}
\hline \multirow{2}{*}{ Network Description } & \multicolumn{6}{|c|}{ Simulation Set Number } & 13.0 \\
\hline & \multicolumn{3}{|c|}{ Interstate 95 North } & \multicolumn{3}{|c|}{ Highway Route 10} & \multirow[b]{2}{*}{$\begin{array}{c}\text { Cumulative } \\
\text { Network } \\
\text { Average Speed } \\
\text { (mph) }\end{array}$} \\
\hline $\begin{array}{l}\text { AM Volume; } 20 \% \\
2 \text { Lane Block; } 20\end{array}$ & $\begin{array}{c}\text { Vehicle } \\
\text { Miles } \\
\text { Traveled } \\
\text { (miles) }\end{array}$ & $\begin{array}{c}\text { Vehicle } \\
\text { Minutes } \\
\text { (min) }\end{array}$ & $\begin{array}{l}\text { Cumulative } \\
\text { Average Speed } \\
\text { I95 and all } \\
\text { Ramps (mph) }\end{array}$ & $\begin{array}{c}\text { Vehicle } \\
\text { Miles } \\
\text { Traveled } \\
\text { (miles) }\end{array}$ & $\begin{array}{c}\text { Vehicle } \\
\text { Minutes } \\
\text { (min) }\end{array}$ & $\begin{array}{l}\text { Cumulative } \\
\text { Average Speed } \\
\text { RT10 and all } \\
\text { Ramps (mph) }\end{array}$ & \\
\hline Random Seed Number & A & B & $\begin{array}{c}\mathrm{C}=\mathrm{A} /(\mathrm{B} / 60 \\
\mathrm{min} / \mathrm{hr})\end{array}$ & D & E & $\begin{array}{c}\mathrm{F}=\mathrm{D} /(\mathrm{E} / 60 \\
\mathrm{min} / \mathrm{hr})\end{array}$ & $\begin{array}{c}\mathrm{G}=(\mathrm{A}+\mathrm{D}) / \\
{[(\mathrm{B}+\mathrm{E}) / 60} \\
\mathrm{min} / \mathrm{hr}]\end{array}$ \\
\hline 1 & 56549.1 & 98613.8 & 34.4 & 13393.5 & 87058.4 & 9.23 & 22.6 \\
\hline 33 & 56128.8 & 112238.4 & 30.0 & 15319.9 & 16575.9 & 55.45 & 33.3 \\
\hline 99 & 56051.9 & 107450.1 & 31.3 & 6908.6 & 144300.2 & 2.87 & 15.0 \\
\hline Cumulative Average Speed & & & 31.8 & & & 8.62 & 21.7 \\
\hline \multirow{2}{*}{ Network Description } & \multicolumn{6}{|c|}{ Simulation Set Number } & 14.0 \\
\hline & \multicolumn{3}{|c|}{ Interstate 95 North } & \multicolumn{3}{|c|}{ Highway Route 10} & \\
\hline $\begin{array}{l}\text { Phet AM Volume; } 20 \% \\
\text { Dhertions } 2 \text { Lane Block; } 30 \\
\text { Min in }\end{array}$ & $\begin{array}{l}\text { Vehicle } \\
\text { Miles } \\
\text { Traveled } \\
\text { (miles) }\end{array}$ & $\begin{array}{c}\text { Vehicle } \\
\text { Minutes } \\
\text { (min) }\end{array}$ & $\begin{array}{l}\text { Cumulative } \\
\text { Average Speed } \\
\text { I95 and all } \\
\text { Ramps (mph) }\end{array}$ & $\begin{array}{l}\text { Vehicle } \\
\text { Miles } \\
\text { Traveled } \\
\text { (miles) }\end{array}$ & $\begin{array}{l}\text { Vehicle } \\
\text { Minutes } \\
\text { (min) }\end{array}$ & $\begin{array}{l}\text { Cumulative } \\
\text { Average Speed } \\
\text { RT10 and all } \\
\text { Ramps (mph) }\end{array}$ & $\begin{array}{c}\text { Cumulative } \\
\text { Nerwork } \\
\text { Average Speed } \\
\text { (mph) }\end{array}$ \\
\hline Random Seed Number & A & B & $\begin{array}{c}\mathrm{C}=\underset{\mathrm{min} / \mathrm{hr})}{\mathrm{A} /(\mathrm{B} / 60} \\
\text { (1) }\end{array}$ & D & E & $\begin{array}{c}\mathrm{F}=\mathrm{D} /(\mathrm{E} / 60 \\
\mathrm{min} / \mathrm{hr})\end{array}$ & $\begin{array}{c}G=(A+D) / \\
{[(B+E) / 60} \\
\mathrm{min} / \mathrm{hrl}\end{array}$ \\
\hline 1 & 54681.1 & 129266.0 & 25.4 & 13739.7 & 96082.6 & 8.58 & 18.2 \\
\hline 33 & 54136.2 & 134664.1 & 24.1 & 14894.6 & 28623.4 & 31.22 & 25.4 \\
\hline 99 & 56051.9 & 141039.2 & 23.8 & 6880.3 & 143778.8 & 2.87 & 13.3 \\
\hline Cumulative Average Speed & & & 24.4 & & & 7.94 & 17.9 \\
\hline \multirow{2}{*}{ Network Description } & \multicolumn{6}{|c|}{ Simulation Set Number } & 15.0 \\
\hline & \multicolumn{3}{|c|}{ Interstate 95 North } & \multicolumn{3}{|c|}{ Highway Route 10} & \\
\hline $\begin{array}{l}\text { Prals AM Volume; } 20 \% \\
\text { Oineslang } 2 \text { Lane Block; } 40 \\
\text { in }\end{array}$ & $\begin{array}{l}\text { Vehicle } \\
\text { Miles } \\
\text { Traveled } \\
\text { (miles) }\end{array}$ & $\begin{array}{c}\text { Vehicle } \\
\text { Minutes } \\
\text { (min) }\end{array}$ & $\begin{array}{l}\text { Cumulative } \\
\text { Average Speed } \\
195 \text { and all } \\
\text { Ramps (mph) }\end{array}$ & $\begin{array}{l}\text { Vehicle } \\
\text { Miles } \\
\text { Traveled } \\
\text { (miles) }\end{array}$ & $\begin{array}{c}\text { Vehicle } \\
\text { Minutes } \\
\text { (min) }\end{array}$ & $\begin{array}{l}\text { Cumulative } \\
\text { Average Speed } \\
\text { RT10 and all } \\
\text { Ramps (mph) }\end{array}$ & $\begin{array}{c}\text { Cumulative } \\
\text { Network } \\
\text { Average Speed } \\
\text { (mph) }\end{array}$ \\
\hline Random Seed Number & A & B & $\begin{array}{c}\mathrm{C}=\mathrm{A} /(\mathrm{B} / 60 \\
\mathrm{min} / \mathrm{hr})\end{array}$ & D & E & $\begin{array}{c}\mathrm{F}=\mathrm{D} /(\mathrm{E} / 60 \\
\mathrm{min} / \mathrm{hr})\end{array}$ & $\begin{array}{c}\mathrm{G}=(\mathrm{A}+\mathrm{D}) / \\
{[(\mathrm{B}+\mathrm{E}) / 60} \\
\mathrm{min} / \mathrm{hrl}\end{array}$ \\
\hline 1 & 52905.0 & 131516.7 & 24.1 & 13832.0 & 118958.4 & 6.98 & 16.0 \\
\hline 33 & 50232.3 & 128758.3 & 23.4 & 12916.5 & 98124.8 & 7.90 & 16.7 \\
\hline 99 & 51988.2 & 130367.3 & 23.9 & 6880.3 & 143778.8 & 2.87 & 12.9 \\
\hline Crmulative Average Speed & & & 23.8 & & & 5.59 & 15.1 \\
\hline \multirow{2}{*}{ Network Description } & \multicolumn{6}{|c|}{ Simulation Set Number } & 16.0 \\
\hline & \multicolumn{3}{|c|}{ Interstate 95 North } & \multicolumn{3}{|c|}{ Highway Route 10} & \\
\hline $\begin{array}{l}\text { AM Volume; } 20 \% \\
\text { In }\end{array}$ & $\begin{array}{l}\text { Vehicle } \\
\text { Miles } \\
\text { Traveled } \\
\text { (miles) }\end{array}$ & $\begin{array}{c}\text { Vehicle } \\
\text { Minutes } \\
\text { (min) }\end{array}$ & $\begin{array}{l}\text { Cumulative } \\
\text { Average Speed } \\
195 \text { and all } \\
\text { Ramps (mph) }\end{array}$ & $\begin{array}{c}\text { Vehicle } \\
\text { Miles } \\
\text { Traveled } \\
\text { (miles) }\end{array}$ & $\begin{array}{l}\text { Vehicle } \\
\text { Minutes } \\
\text { (min) }\end{array}$ & $\begin{array}{l}\text { Cumulative } \\
\text { Average Speed } \\
\text { RT10 and all } \\
\text { Ramps (mph) }\end{array}$ & $\begin{array}{c}\text { Cumulative } \\
\text { Network } \\
\text { Average Speed } \\
\text { (mph) }\end{array}$ \\
\hline Random Seed Number & A & B & $\begin{array}{c}\mathrm{C}=\mathrm{A} /(\mathrm{B} / 60 \\
\mathrm{min} / \mathrm{hr})\end{array}$ & D & E & $\begin{array}{c}\mathrm{F}=\mathrm{D} /(\mathrm{E} / 60 \\
\mathrm{min} / \mathrm{hr})\end{array}$ & $\begin{array}{c}\mathrm{G}=(\mathrm{A}+\mathrm{D}) / \\
{[(\mathrm{B}+\mathrm{E}) / 60} \\
\mathrm{min} / \mathrm{hr}]\end{array}$ \\
\hline 1 & 54310.2 & 157546.9 & 20.7 & 13393.5 & 87058.4 & 9.23 & 16.6 \\
\hline 33 & 54841.8 & 146243.5 & 22.5 & 15319.9 & 16575.9 & 55.45 & 25.9 \\
\hline $\begin{array}{r}99 \\
\end{array}$ & 54309.7 & 150823.3 & 21.6 & 6908.6 & 144300.2 & 2.87 & 12.4 \\
\hline Curnulative Average Speed & & & 21.6 & & & 8.62 & 17.0 \\
\hline
\end{tabular}




\begin{tabular}{|c|c|c|c|c|c|c|c|}
\hline \multirow{2}{*}{ Network Description } & \multicolumn{6}{|c|}{ Simulation Set Number } & 17.0 \\
\hline & \multicolumn{3}{|c|}{ Interstate 95 North } & \multicolumn{3}{|c|}{ Highway Route 10} & \\
\hline $\begin{array}{l}\text { AM Volume; } 20 \% \\
\text { Monder } 3 \text { Lane Block; } 30\end{array}$ & $\begin{array}{l}\text { Vehicle } \\
\text { Miles } \\
\text { Traveled } \\
\text { (miles) }\end{array}$ & $\begin{array}{c}\text { Vehicle } \\
\text { Minutes } \\
\text { (min) }\end{array}$ & $\begin{array}{c}\text { Cumulative } \\
\text { Average Speed } \\
\text { I95 and all } \\
\text { Ramps (mph) }\end{array}$ & $\begin{array}{l}\text { Vehicle } \\
\text { Miles } \\
\text { Traveled } \\
\text { (miles) }\end{array}$ & $\begin{array}{l}\text { Vehicle } \\
\text { Minutes } \\
\text { (min) }\end{array}$ & $\begin{array}{c}\text { Cumulative } \\
\text { Average Speed } \\
\text { RT10 and all } \\
\text { Ramps (mph) }\end{array}$ & $\begin{array}{c}\text { Cumulative } \\
\text { Network } \\
\text { Average Speed } \\
\text { (mph) }\end{array}$ \\
\hline Random Seed Number & A & B & $\mathrm{C}=\underset{\mathrm{min} / \mathrm{hr})}{\mathrm{A} /(\mathrm{B} / 60}$ & D & E & $\begin{array}{c}\mathrm{F}=\mathrm{D} /(\mathrm{E} / 60 \\
\mathrm{min} / \mathrm{hr})\end{array}$ & $\begin{array}{c}\mathrm{G}=(\mathrm{A}+\mathrm{D}) / \\
{[(\mathrm{B}+\mathrm{E}) / 60} \\
\mathrm{min} / \mathrm{hr}] \\
\end{array}$ \\
\hline 1 & 50435.0 & 161353.4 & 18.8 & 13739.7 & 96082.6 & 8.58 & 15.0 \\
\hline 33 & 51292.6 & 157610.3 & 19.5 & 14894.6 & 28623.4 & 31.22 & 21.3 \\
\hline 99 & 50976.4 & 155352.0 & 19.7 & 6880.3 & 143778.8 & 2.87 & 11.6 \\
\hline Cumulative Average Speed & & & 19.3 & & & 7.94 & 15.2 \\
\hline \multirow{2}{*}{ Network Description } & \multicolumn{6}{|c|}{ Simulation Set Number } & 18.0 \\
\hline & \multicolumn{3}{|c|}{ Interstate 95 North } & \multicolumn{3}{|c|}{ Highway Route 10} & \\
\hline $\begin{array}{l}\text { AM Volume; } 20 \% \\
\text { In }\end{array}$ & $\begin{array}{l}\text { Vehicle } \\
\text { Miles } \\
\text { Traveled } \\
\text { (miles) }\end{array}$ & $\begin{array}{c}\text { Vehicle } \\
\text { Minutes } \\
\text { (min) }\end{array}$ & $\begin{array}{l}\text { Cumulative } \\
\text { Average Speed } \\
\text { I95 and all } \\
\text { Ramps (mph) }\end{array}$ & $\begin{array}{l}\text { Vehicle } \\
\text { Miles } \\
\text { Traveled } \\
\text { (miles) }\end{array}$ & $\begin{array}{c}\text { Vehicle } \\
\text { Minutes } \\
\text { (min) }\end{array}$ & $\begin{array}{c}\text { Cumulative } \\
\text { Average Speed } \\
\text { RT10 and all } \\
\text { Ramps (mph) }\end{array}$ & $\begin{array}{c}\text { Cumulative } \\
\text { Network } \\
\text { Average Speed } \\
\text { (mph) }\end{array}$ \\
\hline Random Seed Number & A & B & $\begin{array}{c}\mathrm{C}=\underset{\min / \mathrm{hr})}{\mathrm{A} /(\mathrm{B} / 60} \\
\text { (1) }\end{array}$ & D & E & $\begin{array}{c}\mathrm{F}=\underset{\mathrm{min} / \mathrm{hr})}{\mathrm{D} /(\mathrm{E} / 60} \\
\text { (1) }\end{array}$ & $\begin{array}{c}G=(A+D) / \\
{[(B+E) / 60} \\
\text { minh } h r]\end{array}$ \\
\hline 1 & 46711.5 & 178909.1 & 15.7 & 16952.1 & 18452.7 & 55.12 & 19.4 \\
\hline 33 & 46028.9 & 179016.2 & 15.4 & 16635.6 & 18058.2 & 55.27 & 19.1 \\
\hline 99 & 46653.4 & 159184.5 & 17.6 & 16739.7 & 17878.1 & 56.18 & 21.5 \\
\hline Cumulative Average Speed & & & 16.2 & & & 55.52 & 19.9 \\
\hline
\end{tabular}




\begin{tabular}{|c|c|c|c|c|c|c|c|}
\hline \multirow{2}{*}{ Network Description } & \multicolumn{6}{|c|}{ Simulation Set Number } & 1 \\
\hline & \multicolumn{3}{|c|}{ Interstate 95 North } & \multicolumn{3}{|c|}{ Highway Route 10} & \\
\hline $\begin{array}{l}\text { AM Volume; } 0 \% \text { Diversion; } 1 \\
\text { |ก Block; } 20 \mathrm{Min} \text { In }\end{array}$ & $\begin{array}{l}\text { Vehicle } \\
\text { Miles } \\
\text { Traveled } \\
\text { (miles) }\end{array}$ & $\begin{array}{l}\text { Vehicle } \\
\text { Minutes } \\
\text { (min) }\end{array}$ & $\begin{array}{c}\text { Cumulative } \\
\text { Average Travel } \\
\text { Time I95 and all } \\
\text { Ramps (min-veh } \\
\text { mile) }\end{array}$ & $\begin{array}{c}\text { Vehicle Miles } \\
\text { Traveled } \\
\text { (miles) }\end{array}$ & $\begin{array}{c}\text { Vehicle } \\
\text { Minutes } \\
\text { (min) }\end{array}$ & $\begin{array}{c}\text { Cumulative } \\
\text { Average Travel } \\
\text { Time RT10 and } \\
\text { all Ramps (mph) }\end{array}$ & $\begin{array}{c}\text { Cumulative } \\
\text { Network } \\
\text { Average Travel } \\
\text { Time (min / veh } \\
\text { mile) }\end{array}$ \\
\hline Random Seed Number & $\mathbf{A}$ & B & $C=B / A$ & $\mathrm{D}$ & $\mathbf{E}$ & $F=E / D$ & $\begin{array}{c}G=(B+E) / \\
(A+D)\end{array}$ \\
\hline 1 & 58683.1 & 86722.3 & 1.48 & 15542.4 & 16832.2 & 1.08 & 1.40 \\
\hline 33 & 58523.4 & 87975.9 & 1.50 & 14248.4 & 15254.3 & 1.07 & 1.42 \\
\hline 99 & 58363.8 & 86059.7 & 1.47 & 14200.7 & 15195.1 & 1.07 & 1.40 \\
\hline Crmulative Average Travel Time & & & 1.49 & & & 1.07 & 1.40 \\
\hline \multirow{2}{*}{ Network Description } & \multicolumn{6}{|c|}{ Simulation Set Number } & 2 \\
\hline & \multicolumn{3}{|c|}{ Interstate 95 North } & \multicolumn{3}{|c|}{ Highway Route 10} & \\
\hline $\begin{array}{l}\text { AM Volume; } 0 \% \text { Diversion; } 1 \\
\text { Block; } 30 \mathrm{Min} \text { In }\end{array}$ & $\begin{array}{l}\text { Vehicle } \\
\text { Miles } \\
\text { Traveled } \\
\text { (miles) }\end{array}$ & $\begin{array}{l}\text { Vehicle } \\
\text { Minutes } \\
\text { (min) }\end{array}$ & $\begin{array}{c}\text { Cumulative } \\
\text { Average Travel } \\
\text { Time } 195 \text { and all } \\
\text { Ramps (min-veh } \\
\text { mile) }\end{array}$ & $\begin{array}{l}\text { Vehicle Miles } \\
\text { Traveled } \\
\text { (miles) }\end{array}$ & $\begin{array}{l}\text { Vehicle } \\
\text { Minutes } \\
\text { (min) }\end{array}$ & $\begin{array}{c}\text { Cumulative } \\
\text { Average Travel } \\
\text { Time RT } 10 \text { and } \\
\text { all Ramps (mph) }\end{array}$ & $\begin{array}{c}\text { Cumulative } \\
\text { Network } \\
\text { Average Travel } \\
\text { Time (min / veh } \\
\text { mile) }\end{array}$ \\
\hline Random Seed Number & A & B & $C=B / A$ & $\mathrm{D}$ & $\mathrm{E}$ & $F=E / D$ & $\begin{array}{c}G=(B+E) / \\
(A+D)\end{array}$ \\
\hline 1 & 58225.7 & 110400.3 & 1.90 & 13621.7 & 15016.0 & 1.10 & 1.75 \\
\hline 33 & 58497.2 & 102618.3 & 1.75 & 14391.6 & 15427.6 & 1.07 & 1.62 \\
\hline 99 & 58497.2 & 102618.3 & 1.75 & 14337.1 & 20125.3 & 1.40 & 1.69 \\
\hline Cumulative Average Travel Time & & & 1.80 & & & 1.19 & 1.68 \\
\hline \multirow{2}{*}{ Network Description } & \multicolumn{6}{|c|}{ Simulation Set Number } & 3 \\
\hline & \multicolumn{3}{|c|}{ Interstate 95 North } & \multicolumn{3}{|c|}{ Highway Route 10} & \\
\hline $\begin{array}{l}\text { Block; } 40 \mathrm{Min} \text { In }\end{array}$ & $\begin{array}{l}\text { Vehicle } \\
\text { Miles } \\
\text { Traveled } \\
\text { (miles) }\end{array}$ & $\begin{array}{c}\text { Vehicle } \\
\text { Minutes } \\
(\min )\end{array}$ & $\begin{array}{c}\text { Cumulative } \\
\text { Average Travel } \\
\text { Time I95 and all } \\
\text { Ramps (min-veh } \\
\text { mile) }\end{array}$ & $\begin{array}{c}\text { Vehicle Miles } \\
\text { Traveled } \\
\text { (miles) }\end{array}$ & $\begin{array}{l}\text { Vehicle } \\
\text { Minutes } \\
\text { (min) }\end{array}$ & $\begin{array}{c}\text { Cumulative } \\
\text { Average Travel } \\
\text { Time RT10 and } \\
\text { all Ramps (mph) }\end{array}$ & $\begin{array}{c}\text { Cumulative } \\
\text { Network } \\
\text { Average Travel } \\
\text { Time (min / veh } \\
\text { mile) }\end{array}$ \\
\hline Random Seed Number & A & B & $C=B / A$ & $\mathrm{D}$ & $\mathrm{E}$ & $F=E / D$ & $\begin{array}{c}G=(B+E) / \\
(A+D)\end{array}$ \\
\hline 1 & 57152.3 & 128820.2 & 2.25 & 17031.2 & 19451.4 & I.14 & 2.00 \\
\hline 33 & 57815.5 & 114224.2 & 1.98 & 15921.6 & 17269.2 & 1.08 & 1.78 \\
\hline 99 & 58197.7 & 110218.9 & 1.89 & 15715.1 & 17112.3 & 1.09 & 1.72 \\
\hline Ounulative Average Travel Time & & & 2.04 & & & 1.11 & 1.84 \\
\hline \multirow{2}{*}{ Network Description } & \multicolumn{6}{|c|}{ Simulation Set Number } & 4 \\
\hline & \multicolumn{3}{|c|}{ Interstate 95 North } & \multicolumn{3}{|c|}{ Highway Route 10} & \\
\hline $\begin{array}{l}\text { AM Volume; } 0 \% \text { Diversion; } 2 \\
\text { Block; } 20 \mathrm{Min} \text { In }\end{array}$ & $\begin{array}{l}\text { Vehicle } \\
\text { Miles } \\
\text { Traveled } \\
\text { (miles) }\end{array}$ & $\begin{array}{c}\text { Vehicle } \\
\text { Minutes } \\
(\min )\end{array}$ & $\begin{array}{c}\text { Cumulative } \\
\text { Average Travel } \\
\text { Time } 195 \text { and all } \\
\text { Ramps (min-veh } \\
\text { mile) }\end{array}$ & $\begin{array}{c}\text { Vehicle Miles } \\
\text { Traveled } \\
\text { (miles) }\end{array}$ & $\begin{array}{l}\text { Vehicle } \\
\text { Minutes } \\
\text { (min) }\end{array}$ & $\begin{array}{c}\text { Cumulative } \\
\text { Average Travel } \\
\text { Time RT } 10 \text { and } \\
\text { all Ramps (mph) }\end{array}$ & $\begin{array}{c}\text { Cumulative } \\
\text { Network } \\
\text { Average Travel } \\
\text { Time (min / veh } \\
\text { mile) }\end{array}$ \\
\hline Random Seed Number & A & B & $C=B / A$ & D & $\mathbf{E}$ & $F=E / D$ & $\begin{array}{c}G=(B+E) / \\
(A+D)\end{array}$ \\
\hline 1 & 57273.2 & 135822.3 & 2.37 & 15542.4 & 16832.2 & 1.08 & 2.10 \\
\hline 33 & 57137.6 & 139388.9 & 2.44 & 14248.4 & 15254.3 & 1.07 & 2.17 \\
\hline 99 & 56936.8 & 139154.4 & 2.44 & 14200.7 & 15195.1 & 1.07 & 2.17 \\
\hline Chmulative Average Travel Time & & & 2.42 & & & 1.07 & 2.14 \\
\hline
\end{tabular}




\begin{tabular}{|c|c|c|c|c|c|c|c|}
\hline \multirow{2}{*}{ Network Description } & \multicolumn{6}{|c|}{ Simulation Set Number } & 5 \\
\hline & \multicolumn{3}{|c|}{ Interstate 95 North } & \multicolumn{3}{|c|}{ Highway Route 10} & \\
\hline $\begin{array}{l}\text { RaM Volume; 0\% Diversion; } 2 \\
\text { Plock; } 30 \mathrm{Min} \text { In }\end{array}$ & $\begin{array}{l}\text { Vehicle } \\
\text { Miles } \\
\text { Traveled } \\
\text { (miles) }\end{array}$ & $\begin{array}{l}\text { Vehicle } \\
\text { Minutes } \\
\text { (min) }\end{array}$ & $\begin{array}{c}\text { Cumulative } \\
\text { Average Travel } \\
\text { Time } 195 \text { and all } \\
\text { Ramps (min-veh } \\
\text { mile) }\end{array}$ & $\begin{array}{c}\text { Vehicle Miles } \\
\text { Traveled } \\
\text { (miles) }\end{array}$ & $\begin{array}{l}\text { Vehicle } \\
\text { Minutes } \\
\text { (min) }\end{array}$ & $\begin{array}{c}\text { Cumulative } \\
\text { Average Travel } \\
\text { Time RT10 and } \\
\text { all Ramps (mph) }\end{array}$ & $\begin{array}{c}\text { Cumulative } \\
\text { Network } \\
\text { Average Travel } \\
\text { Time (min / veh } \\
\text { mile) }\end{array}$ \\
\hline Random Seed Number & $\mathbf{A}$ & B & $C=B / A$ & D & E & $F=E / D$ & $\begin{array}{c}G=(B+E) / \\
(A+D)\end{array}$ \\
\hline 1 & 54399.4 & 147988.0 & 2.72 & 13621.7 & 15016.0 & 1.10 & 2.40 \\
\hline 33 & 54449.0 & 146274.0 & 2.69 & 14391.6 & 15427.6 & 1.07 & 2.35 \\
\hline 99 & 54562.0 & $\lfloor 46057.8$ & 2.68 & 14337.1 & 20125.3 & 1.40 & 2.41 \\
\hline Cumulative Average Travel Time & & & 2.69 & & & 1.19 & 2.39 \\
\hline \multirow{2}{*}{ Network Description } & \multicolumn{6}{|c|}{ Simulation Set Number } & 6 \\
\hline & \multicolumn{3}{|c|}{ Interstate 95 North } & \multicolumn{3}{|c|}{ Highway Route 10} & \\
\hline $\begin{array}{l}\text { RaM Volume; } 0 \% \text { Diversion; } 2 \\
\text { Block; } 40 \mathrm{Min} \text { In }\end{array}$ & $\begin{array}{l}\text { Vehicle } \\
\text { Miles } \\
\text { Traveled } \\
\text { (miles) }\end{array}$ & $\begin{array}{c}\text { Vehicle } \\
\text { Minutes } \\
\text { (min) }\end{array}$ & $\begin{array}{c}\text { Cumulative } \\
\text { Average Travel } \\
\text { Time I95 and all } \\
\text { Ramps (min-veh } \\
\text { mile) }\end{array}$ & $\begin{array}{c}\text { Vehicle Miles } \\
\text { Traveled } \\
\text { (miles) }\end{array}$ & $\begin{array}{c}\text { Vehicle } \\
\text { Minutes } \\
\text { (min) }\end{array}$ & $\begin{array}{c}\text { Cumulative } \\
\text { Average Travel } \\
\text { Time RT } 10 \text { and } \\
\text { all Ramps (mph) }\end{array}$ & $\begin{array}{c}\text { Cumulative } \\
\text { Network } \\
\text { Average Travel } \\
\text { Time (min / veh } \\
\text { mile) }\end{array}$ \\
\hline Random Seed Number & $\mathbf{A}$ & B & $C=B / A$ & $\mathrm{D}$ & E & $F=E / D$ & $\begin{array}{c}G=(B+E) / \\
(A+D)\end{array}$ \\
\hline 1 & 51142.0 & 149656.0 & 2.93 & 17031.2 & 19451.4 & 1.14 & 2.48 \\
\hline 33 & 51858.8 & 145770.9 & 2.81 & 15921.6 & 17269.2 & 1.08 & 2.41 \\
\hline 99 & 51645.1 & 144871.2 & 2.81 & 15715.1 & 17112.3 & 1.09 & 2.40 \\
\hline Cumulative Average Travel Time & & & 2.85 & & & 1.11 & 2.43 \\
\hline \multirow{2}{*}{ Network Description } & \multicolumn{6}{|c|}{ Simulation Set Number } & 7 \\
\hline & \multicolumn{3}{|c|}{ Interstate 95 North } & \multicolumn{3}{|c|}{ Highway Route 10} & \\
\hline $\begin{array}{l}\text { Wh AM Yolume; 0\% Diversion; } 3 \\
\text { Block; } 20 \mathrm{Min} \text { In }\end{array}$ & $\begin{array}{l}\text { Vehicle } \\
\text { Miles } \\
\text { Traveled } \\
\text { (miles) }\end{array}$ & $\begin{array}{c}\text { Vehicle } \\
\text { Minutes } \\
\text { (min) }\end{array}$ & $\begin{array}{c}\text { Cumulative } \\
\text { Average Travel } \\
\text { Time I95 and alI } \\
\text { Ramps (min-veh } \\
\text { mile) }\end{array}$ & $\begin{array}{c}\text { Vehicle Miles } \\
\text { Traveled } \\
\text { (miles) }\end{array}$ & $\begin{array}{l}\text { Vehicle } \\
\text { Minutes } \\
\text { (min) }\end{array}$ & $\begin{array}{c}\text { Cumulative } \\
\text { Average Travel } \\
\text { Time RT10 and } \\
\text { all Ramps (mph) }\end{array}$ & $\begin{array}{c}\text { Cumulative } \\
\text { Network } \\
\text { Average Travel } \\
\text { Time (min / veh } \\
\text { mile) }\end{array}$ \\
\hline Random Seed Number & A & B & $\mathrm{C}=\mathrm{B} / \mathrm{A}$ & $\mathbf{D}$ & E & $\mathbf{F}=\mathbf{E} / \mathrm{D}$ & $\begin{array}{c}G=(B+E) / \\
(A+D)\end{array}$ \\
\hline 1 & 53887.3 & 172143.1 & 3.19 & 15542.4 & 16832.2 & 1.08 & 2.72 \\
\hline 33 & 54510.0 & 153885.4 & 2.82 & 14248.4 & 15254.3 & 1.07 & 2.46 \\
\hline 99 & 54722.5 & 155304.4 & 2.84 & 14200.7 & 15195.1 & 1.07 & 2.47 \\
\hline Cumulative Average Travel Time & & & 2.95 & & & 1.07 & 2.55 \\
\hline \multirow{2}{*}{ Network Description } & \multicolumn{6}{|c|}{ Simulation Set Number } & 8 \\
\hline & \multicolumn{3}{|c|}{ Interstate 95 North } & \multicolumn{3}{|c|}{ Highway Route 10} & \\
\hline \multirow[b]{2}{*}{ Random Seed Number } & $\begin{array}{l}\text { Vehicle } \\
\text { Miles } \\
\text { Traveled } \\
\text { (miles) }\end{array}$ & $\begin{array}{l}\text { Vehicle } \\
\text { Minutes } \\
\text { (min) }\end{array}$ & $\begin{array}{c}\text { Cumulative } \\
\text { Average Travel } \\
\text { Time I95 and all } \\
\text { Ramps (min-veh } \\
\text { mile) }\end{array}$ & $\begin{array}{c}\text { Vehicle Miles } \\
\text { Traveled } \\
\text { (miles) }\end{array}$ & $\begin{array}{l}\text { Vehicle } \\
\text { Minutes } \\
\text { (min) }\end{array}$ & $\begin{array}{c}\text { Cumulative } \\
\text { Average Travel } \\
\text { Time RT } 10 \text { and } \\
\text { all Ramps (mph) }\end{array}$ & $\begin{array}{c}\text { Cumulative } \\
\text { Network } \\
\text { Average Travel } \\
\text { Time (min / veh } \\
\text { mile) }\end{array}$ \\
\hline & $\mathbf{A}$ & B & $\mathrm{C}=\mathrm{B} / \mathrm{A}$ & D & E & $F=E / D$ & $\begin{array}{c}G=(B+E) / \\
(A+D)\end{array}$ \\
\hline 1 & 32628.5 & 326112.3 & 9.99 & 13621.7 & 15016.0 & 1.10 & 7.38 \\
\hline 33 & 50695.4 & 167245.4 & 3.30 & 14391.6 & 15427.6 & 1.07 & 2.81 \\
\hline 99 & 50030.4 & 162297.4 & 3.24 & 14337.1 & 20125.3 & 1.40 & 2.83 \\
\hline Dimulative Average Travel Time & & & 4.92 & & & 1.19 & 4.02 \\
\hline
\end{tabular}




\begin{tabular}{|c|c|c|c|c|c|c|c|}
\hline \multirow{2}{*}{ Network Description } & \multicolumn{6}{|c|}{ Simulation Set Number } & 9 \\
\hline & \multicolumn{3}{|c|}{ Interstate 95 North } & \multicolumn{3}{|c|}{ Highway Route 10} & \\
\hline $\begin{array}{l}\text { AM Volume; 0\% Diversion; } 3 \text {. } \\
\text { Bneck; } 40 \mathrm{Min} \text { In }\end{array}$ & $\begin{array}{l}\text { Vehicle } \\
\text { Miles } \\
\text { Traveled } \\
\text { (miles) }\end{array}$ & $\begin{array}{l}\text { Vehicle } \\
\text { Minutes } \\
\text { (min) }\end{array}$ & $\begin{array}{c}\text { Cumulative } \\
\text { Average Travel } \\
\text { Time I95 and all } \\
\text { Ramps (min-veh } \\
\text { mile) }\end{array}$ & $\begin{array}{c}\text { Vehicle Miles } \\
\text { Traveled } \\
\text { (miles) }\end{array}$ & $\begin{array}{c}\text { Vehicle } \\
\text { Minutes } \\
(\min )\end{array}$ & $\begin{array}{c}\text { Cumulative } \\
\text { Average Travel } \\
\text { Time RTI0 and } \\
\text { all Ramps (mph) }\end{array}$ & $\begin{array}{c}\text { Cumulative } \\
\text { Network } \\
\text { Average Travel } \\
\text { Time (min / veh } \\
\text { mile) }\end{array}$ \\
\hline Random Seed Number & A & B & $\mathbf{C}=\mathbf{B} / \mathbf{A}$ & D & E & $F=E / D$ & $\begin{array}{c}G=(B+E) / \\
(A+D)\end{array}$ \\
\hline 1 & 43572.6 & 215791.0 & 4.95 & 17031.2 & 19451.4 & 1.14 & 3.88 \\
\hline 33 & 46968.3 & 175084.7 & 3.73 & 15921.6 & 17269.2 & 1.08 & 3.06 \\
\hline 99 & 46968.3 & 175084.7 & 3.73 & 15715.1 & 17112.3 & 1.09 & 3.07 \\
\hline Cumulative Average Travel Time & & & 4.12 & & & 1.11 & 3.33 \\
\hline \multirow{2}{*}{ Network Description } & \multicolumn{6}{|c|}{ Simulation Set Number } & 10 \\
\hline & \multicolumn{3}{|c|}{ Interstate 95 North } & \multicolumn{3}{|c|}{ Highway Route 10} & \\
\hline $\begin{array}{l}\text { Dels AM Volume; } 20 \% \text { Diversion; } \\
\text { I Lane Block; } 20 \text { Min in }\end{array}$ & $\begin{array}{l}\text { Vehicle } \\
\text { Miles } \\
\text { Traveled } \\
\text { (miles) }\end{array}$ & $\begin{array}{c}\text { Vehicle } \\
\text { Minutes } \\
\text { (min) }\end{array}$ & $\begin{array}{c}\text { Cumulative } \\
\text { Average Travel } \\
\text { Time I95 and all } \\
\text { Ramps (min-veh } \\
\text { mile) }\end{array}$ & $\begin{array}{c}\text { Vehicle Miles } \\
\text { Traveled } \\
\text { (miles) }\end{array}$ & $\begin{array}{c}\text { Vehicle } \\
\text { Minutes } \\
\text { (min) }\end{array}$ & $\begin{array}{c}\text { Cumulative } \\
\text { Average Travel } \\
\text { Time RT10 and } \\
\text { all Ramps (mph) }\end{array}$ & $\begin{array}{c}\text { Cumulative } \\
\text { Network } \\
\text { Average Travel } \\
\text { Time (min / veh } \\
\text { mile) }\end{array}$ \\
\hline Random Seed Number & A & B & $\mathrm{C}=\mathrm{B} / \mathrm{A}$ & D & $\mathbf{E}$ & $F=E / D$ & $\begin{array}{c}G=(B+E) / \\
(A+D)\end{array}$ \\
\hline 1 & 56481.8 & 65163.0 & 1.15 & 13393.5 & 87058.4 & 6.50 & 2.18 \\
\hline 33 & 56521.9 & 66575.9 & 1.18 & 15319.9 & 16575.9 & 1.08 & 1.16 \\
\hline 99 & 54390.0 & 74124.5 & 1.36 & 6908.6 & 144300.2 & 20.89 & 3.56 \\
\hline Cumulative Average Travel Time & & & 1.23 & & & 6.96 & 2.24 \\
\hline \multirow{2}{*}{ Network Description } & \multicolumn{6}{|c|}{ Simulation Set Number } & 11 \\
\hline & \multicolumn{3}{|c|}{ Interstate 95 North } & \multicolumn{3}{|c|}{ Highway Route 10} & \\
\hline $\begin{array}{l}\text { I Lane Block; } 30 \mathrm{Min} \text { In } \\
\text { AM Volume; } 20 \% \text { Diversion; }\end{array}$ & $\begin{array}{l}\text { Vehicle } \\
\text { Miles } \\
\text { Traveled } \\
\text { (miles) }\end{array}$ & $\begin{array}{c}\text { Vehicle } \\
\text { Minutes } \\
\text { (min) }\end{array}$ & $\begin{array}{c}\text { Cumulative } \\
\text { Average Travel } \\
\text { Time I95 and all } \\
\text { Ramps (min-veh } \\
\text { mile) }\end{array}$ & $\begin{array}{c}\text { Vehicle Miles } \\
\text { Traveled } \\
\text { (miles) }\end{array}$ & $\begin{array}{c}\text { Vehicle } \\
\text { Minutes } \\
(\min )\end{array}$ & $\begin{array}{c}\text { Cumulative } \\
\text { Average Travel } \\
\text { Time RT10 and } \\
\text { all Ramps (mph) }\end{array}$ & \begin{tabular}{|c} 
Cumulative \\
Network \\
Average Travel \\
Time (min / veh \\
mile)
\end{tabular} \\
\hline Random Seed Number & A & B & $C=B / A$ & D & $\mathbf{E}$ & $F=E / D$ & $\begin{array}{c}G=(B+E) / \\
(A+D)\end{array}$ \\
\hline 1 & 55554.1 & 63843.7 & 1.15 & 13739.7 & 96082.6 & 6.99 & 2.31 \\
\hline 33 & 55347.5 & 63194.7 & 1.14 & 14894.6 & 28623.4 & 1.92 & 1.31 \\
\hline 99 & 55385.9 & 64120.4 & 1.16 & 6880.3 & 143778.8 & 20.90 & 3.34 \\
\hline Ommulative Average Travel Time & & & 1.15 & & & 7.56 & 2.28 \\
\hline \multirow{2}{*}{ Network Description } & \multicolumn{6}{|c|}{ Simulation Set Number } & 12 \\
\hline & \multicolumn{3}{|c|}{ Interstate 95 North } & \multicolumn{3}{|c|}{ Highway Route 10} & \\
\hline $\begin{array}{l}1 \text { Lane Block; } 40 \text { Min In } \\
1 \text {. }\end{array}$ & $\begin{array}{c}\text { Vehicle } \\
\text { Miles } \\
\text { Traveled } \\
\text { (miles) }\end{array}$ & $\begin{array}{c}\text { Vehicle } \\
\text { Minutes } \\
\text { (min) }\end{array}$ & $\begin{array}{c}\text { Cumulative } \\
\text { Average Travel } \\
\text { Time } 195 \text { and all } \\
\text { Ramps (min-veh } \\
\text { mile) }\end{array}$ & $\begin{array}{c}\text { Vehicle Miles } \\
\text { Traveled } \\
\text { (miles) }\end{array}$ & $\begin{array}{c}\text { Vehicle } \\
\text { Minutes } \\
(\min )\end{array}$ & $\begin{array}{c}\text { Cumulative } \\
\text { Average Travel } \\
\text { Time RT10 and } \\
\text { all Ramps (mph) }\end{array}$ & $\begin{array}{c}\text { Cumulative } \\
\text { Network } \\
\text { Average Travel } \\
\text { Time (min / veh } \\
\text { mile) }\end{array}$ \\
\hline Random Seed Number & A & B & $\mathrm{C}=\mathrm{B} / \mathrm{A}$ & D & $\mathrm{E}$ & $F=E / D$ & $\begin{array}{c}G=(B+E) / \\
(A+D)\end{array}$ \\
\hline 1 & 54670.1 & 62821.1 & 1.15 & 13832.0 & 118958.4 & 8.60 & 2.65 \\
\hline 33 & 54330.3 & 63387.9 & 1.17 & 12916.5 & 98124.8 & 7.60 & 2.40 \\
\hline 99 & 54459.0 & 63784.4 & 1.17 & 6880.3 & 143778.8 & 20.90 & 3.38 \\
\hline Cumulative Average Travel Time & & & 1.16 & & & 10.73 & 2.79 \\
\hline
\end{tabular}




\begin{tabular}{|c|c|c|c|c|c|c|c|}
\hline \multirow{2}{*}{ Network Description } & \multicolumn{6}{|c|}{ Simulation Set Number } & 13 \\
\hline & \multicolumn{3}{|c|}{ Interstate 95 North } & \multicolumn{3}{|c|}{ Highway Route 10} & \\
\hline $\begin{array}{l}\text { Lane Block; } 20 \text { Min In } \\
\text { Laversion; }\end{array}$ & $\begin{array}{l}\text { Vehicle } \\
\text { Miles } \\
\text { Traveled } \\
\text { (miles) }\end{array}$ & $\begin{array}{c}\text { Vehicle } \\
\text { Minutes } \\
\text { (min) }\end{array}$ & $\begin{array}{c}\text { Cumulative } \\
\text { Average Travel } \\
\text { Time } 195 \text { and all } \\
\text { Ramps (min-veh } \\
\text { mile) }\end{array}$ & $\begin{array}{c}\text { Vehicle Miles } \\
\text { Traveled } \\
\text { (miles) }\end{array}$ & $\begin{array}{c}\text { Vehicle } \\
\text { Minutes } \\
\text { (min) }\end{array}$ & $\begin{array}{c}\text { Cumulative } \\
\text { Average Travel } \\
\text { Time RT } 10 \text { and } \\
\text { all Ramps (mph) }\end{array}$ & $\begin{array}{c}\text { Cumulative } \\
\text { Network } \\
\text { Average Travel } \\
\text { Time (min / veh } \\
\text { mile) }\end{array}$ \\
\hline Random Seed Number & A & B & $\mathrm{C}=\mathrm{B} / \mathrm{A}$ & D & E & $F=E / D$ & $\begin{array}{c}G=(B+E) / \\
(A+D)\end{array}$ \\
\hline 1 & 56549.1 & 98613.8 & 1.74 & 13393.5 & 87058.4 & 6.50 & 2.65 \\
\hline 33 & 56128.8 & 112238.4 & 2.00 & 15319.9 & 16575.9 & 1.08 & 1.80 \\
\hline 99 & 56051.9 & 107450.1 & 1.92 & 6908.6 & 144300.2 & 20.89 & 4.00 \\
\hline Cumulative Average Travel Time & & & 1.89 & & & 6.96 & 2.77 \\
\hline \multirow{2}{*}{ Network Description } & \multicolumn{6}{|c|}{ Simulation Set Number } & 14 \\
\hline & \multicolumn{3}{|c|}{ Interstate 95 North } & \multicolumn{3}{|c|}{ Highway Route 10} & \\
\hline $\begin{array}{l}\text { No AM Volume; } 20 \% \text { Diversion; } \\
\text { Lane Block; } 30 \text { Min In }\end{array}$ & $\begin{array}{l}\text { Vehicle } \\
\text { Miles } \\
\text { Traveled } \\
\text { (miles) }\end{array}$ & $\begin{array}{c}\text { Vehicle } \\
\text { Minutes } \\
\text { (min) }\end{array}$ & $\begin{array}{c}\text { Cumulative } \\
\text { Average Travel } \\
\text { Time I95 and al! } \\
\text { Ramps (min-veh } \\
\text { mile) }\end{array}$ & $\begin{array}{c}\text { Vehicle Miles } \\
\text { Traveled } \\
\text { (miles) }\end{array}$ & $\begin{array}{c}\text { Vehicle } \\
\text { Minutes } \\
\text { (min) }\end{array}$ & $\begin{array}{c}\text { Cumulative } \\
\text { Average Travel } \\
\text { Time RTl0 and } \\
\text { all Ramps (mph) }\end{array}$ & $\begin{array}{c}\text { Cumulative } \\
\text { Network } \\
\text { Average Travel } \\
\text { Time (min / veh } \\
\text { mile) }\end{array}$ \\
\hline Random Seed Number & A & B & $\mathrm{C}=\mathrm{B} / \mathrm{A}$ & D & E & $F=E / D$ & $\begin{array}{c}G=(B+E) / \\
(A+D)\end{array}$ \\
\hline 1 & 54681.1 & 129266.0 & 2.36 & 13739.7 & 96082.6 & 6.99 & 3.29 \\
\hline 33 & 54136.2 & 134664.1 & 2.49 & 14894.6 & 28623.4 & 1.92 & 2.37 \\
\hline 99 & 56051.9 & 141039.2 & 2.52 & 6880.3 & 143778.8 & 20.90 & 4.53 \\
\hline Cumulative Average Travel Time & & & 2.46 & & & 7.56 & 3.36 \\
\hline \multirow{2}{*}{ Network Description } & \multicolumn{6}{|c|}{ Simulation Set Number } & 15 \\
\hline & \multicolumn{3}{|c|}{ Interstate 95 North } & \multicolumn{3}{|c|}{ Highway Route 10} & \\
\hline $\begin{array}{l}\text { Pha AM Volume; } 20 \% \text { Diversion; } \\
\text { 3Lack; } 40 \mathrm{Min} \text { In }\end{array}$ & $\begin{array}{l}\text { Vehicle } \\
\text { Miles } \\
\text { Traveled } \\
\text { (miles) }\end{array}$ & $\begin{array}{c}\text { Vehicle } \\
\text { Minutes } \\
\text { (min) }\end{array}$ & $\begin{array}{c}\text { Cumulative } \\
\text { Average Travel } \\
\text { Time } 195 \text { and all } \\
\text { Ramps (min-veh } \\
\text { mile) }\end{array}$ & $\begin{array}{c}\text { Vehicle Miles } \\
\text { Traveled } \\
\text { (miles) }\end{array}$ & $\begin{array}{c}\text { Vehicle } \\
\text { Minutes } \\
\text { (min) }\end{array}$ & $\begin{array}{c}\text { Cumulative } \\
\text { Average Travel } \\
\text { Time RTI0 and } \\
\text { all Ramps (mph) }\end{array}$ & $\begin{array}{c}\text { Cumulative } \\
\text { Network } \\
\text { Average Travel } \\
\text { Time (min / veh } \\
\text { mile) }\end{array}$ \\
\hline Random Seed Number & A & B & $\mathrm{C}=\mathrm{B} / \mathrm{A}$ & D & E & $F=E / D$ & $\begin{array}{c}G=(B+E) / \\
(A+D)\end{array}$ \\
\hline 1 & 52905.0 & 131516.7 & 2.49 & 13832.0 & 118958.4 & 8.60 & 3.75 \\
\hline 33 & 50232.3 & 128758.3 & 2.56 & 12916.5 & 98124.8 & 7.60 & 3.59 \\
\hline 99 & 51988.2 & 130367.3 & 2.51 & 6880.3 & 143778.8 & 20.90 & 4.66 \\
\hline Cumnlative Average Travel Time & & & 2.52 & & & 10.73 & 3.98 \\
\hline \multirow{2}{*}{ Network Description } & \multicolumn{6}{|c|}{ Simulation Set Number } & 16 \\
\hline & \multicolumn{3}{|c|}{ Interstate 95 North } & \multicolumn{3}{|c|}{ Highway Route 10} & \\
\hline $\begin{array}{l}\text { AM Volume; } 20 \% \text { Diversion; } \\
\text { Lane Block; } 20 \text { Min In }\end{array}$ & $\begin{array}{l}\text { Vehicle } \\
\text { Miles } \\
\text { Traveled } \\
\text { (miles) }\end{array}$ & $\begin{array}{c}\text { Vehicle } \\
\text { Minutes } \\
\text { (min) }\end{array}$ & $\begin{array}{c}\text { Cumulative } \\
\text { Average Travel } \\
\text { Time I95 and all } \\
\text { Ramps (min-veh } \\
\text { mile) }\end{array}$ & $\begin{array}{c}\text { Vehicle Miles } \\
\text { Traveled } \\
\text { (miles) }\end{array}$ & $\begin{array}{c}\text { Vehicle } \\
\text { Minutes } \\
\text { (min) }\end{array}$ & $\begin{array}{c}\text { Cumulative } \\
\text { Average Travel } \\
\text { Time RT10 and } \\
\text { all Ramps (mph) }\end{array}$ & $\begin{array}{c}\text { Cumulative } \\
\text { Network } \\
\text { Average Travel } \\
\text { Time (min / veh } \\
\text { mile) }\end{array}$ \\
\hline Randorm Seed Number & A & B & $\mathrm{C}=\mathrm{B} / \mathrm{A}$ & D & E & $F=E / D$ & $\begin{array}{c}G=(B+E) / \\
(A+D)\end{array}$ \\
\hline 1 & 54310.2 & 157546.9 & 2.90 & 13393.5 & 87058.4 & 6.50 & 3.61 \\
\hline 33 & 54841.8 & 146243.5 & 2.67 & 15319.9 & 16575.9 & 1.08 & 2.32 \\
\hline 99 & 54309.7 & 150823.3 & 2.78 & 6908.6 & 144300.2 & 20.89 & 4.82 \\
\hline Cummulative Average Travel Time & & & 2.78 & & & 6.96 & 3.53 \\
\hline
\end{tabular}




\begin{tabular}{|c|c|c|c|c|c|c|c|}
\hline \multirow{2}{*}{ Network Description } & \multicolumn{6}{|c|}{ Simulation Set Number } & 17 \\
\hline & \multicolumn{3}{|c|}{ Interstate 95 North } & \multicolumn{3}{|c|}{ Highway Route 10} & \\
\hline $\begin{array}{l}\text { S AMe Block; } 30 \text { Min In } \\
\text { S Anersion; }\end{array}$ & $\begin{array}{l}\text { Vehicle } \\
\text { Miles } \\
\text { Traveled } \\
\text { (miles) }\end{array}$ & $\begin{array}{c}\text { Vehicle } \\
\text { Minutes } \\
\text { (min) }\end{array}$ & $\begin{array}{c}\text { Cumulative } \\
\text { Average Travel } \\
\text { Time I95 and all } \\
\text { Ramps (min-veh } \\
\text { mile) }\end{array}$ & $\begin{array}{c}\text { Vehicle Miles } \\
\text { Traveled } \\
\text { (miles) }\end{array}$ & $\begin{array}{l}\text { Vehicle } \\
\text { Minutes } \\
\text { (min) }\end{array}$ & $\begin{array}{c}\text { Cumulative } \\
\text { Average Trave! } \\
\text { Time RTI0 and } \\
\text { all Ramps (mph) }\end{array}$ & $\begin{array}{c}\text { Cumulative } \\
\text { Network } \\
\text { Average Travel } \\
\text { Time (min/veh } \\
\text { mile) }\end{array}$ \\
\hline Random Seed Number & A & B & $\mathrm{C}=\mathrm{B} / \mathrm{A}$ & D & E & $F=E / D$ & $\begin{array}{c}G=(B+E) / \\
(A+D)\end{array}$ \\
\hline 1 & 50435.0 & 161353.4 & 3.20 & 13739.7 & 96082.6 & 6.99 & 4.01 \\
\hline 33 & 51292.6 & 157610.3 & 3.07 & 14894.6 & 28623.4 & 1.92 & 2.81 \\
\hline 99 & 50976.4 & 155352.0 & 3.05 & 6880.3 & 143778.8 & 20.90 & 5.17 \\
\hline Cumulative Average Travel Time & & & 3.11 & & & 7.56 & 3.95 \\
\hline \multirow{2}{*}{ Network Description } & \multicolumn{6}{|c|}{ Simulation Set Number } & 18 \\
\hline & \multicolumn{3}{|c|}{ Interstate 95 North } & \multicolumn{3}{|c|}{ Highway Route 10} & \\
\hline $\begin{array}{l}\text { 7aM Volume; } 20 \% \text { Diversion; } \\
\text { Lane Block; } 40 \text { Min In }\end{array}$ & $\begin{array}{l}\text { Vehicle } \\
\text { Miles } \\
\text { Traveled } \\
\text { (miles) }\end{array}$ & $\begin{array}{l}\text { Vehicle } \\
\text { Minutes } \\
\text { (min) }\end{array}$ & $\begin{array}{c}\text { Cumulative } \\
\text { Average Travel } \\
\text { Time I95 and all } \\
\text { Ramps (min-veh } \\
\text { mile) }\end{array}$ & $\begin{array}{c}\text { Vehicle Miles } \\
\text { Traveled } \\
\text { (miles) }\end{array}$ & $\begin{array}{c}\text { Vehicle } \\
\text { Minutes } \\
\text { (min) }\end{array}$ & $\begin{array}{c}\text { Cumulative } \\
\text { Average Travel } \\
\text { Time RT10 and } \\
\text { all Ramps (mph) }\end{array}$ & $\begin{array}{c}\text { Cumulative } \\
\text { Network } \\
\text { Average Travel } \\
\text { Time (min / veh } \\
\text { mile) }\end{array}$ \\
\hline Random Seed Number & A & B & $C=B / A$ & D & $\mathbf{E}$ & $F=E / D$ & $\begin{array}{c}G=(B+E) / \\
(A+D)\end{array}$ \\
\hline 1 & 46711.5 & 178909.1 & 3.83 & 16952.1 & 18452.7 & 1.09 & 3.10 \\
\hline 33 & 46028.9 & 179016.2 & 3.89 & 16635.6 & 18058.2 & 1.09 & 3.14 \\
\hline 99 & 46653.4 & 159184.5 & 3.41 & 16739.7 & 17878.1 & 1.07 & 2.79 \\
\hline Cumulative Average Travel Time & & & 3.71 & & & 1.08 & 3.01 \\
\hline
\end{tabular}




\begin{tabular}{|c|c|c|c|c|c|c|c|}
\hline \multirow{2}{*}{ Network Description } & \multicolumn{6}{|c|}{ Simulation Set Number } & 1 \\
\hline & \multicolumn{3}{|c|}{ Interstate 95 North } & \multicolumn{3}{|c|}{ Highway Route 10} & \multirow[b]{2}{*}{$\begin{array}{l}\text { Total } \\
\text { Network } \\
\text { Delay } \\
\text { (hours) }\end{array}$} \\
\hline $\begin{array}{l}\text { AM Volume; } 0 \% \text { Diversion; } \\
\text { Lane Block; } 20 \mathrm{Min} \text { In }\end{array}$ & $\begin{array}{l}\text { Vehicle } \\
\text { Miles } \\
\text { Traveled } \\
\text { (miles) }\end{array}$ & $\begin{array}{l}\text { Total } \\
\text { Delay } \\
\text { (min) }\end{array}$ & $\begin{array}{c}\text { Average Delay } \\
\text { Time } 195 \text { and all } \\
\text { Ramps (min-veh } \\
\text { mile) }\end{array}$ & $\begin{array}{l}\text { Vehicle } \\
\text { Miles } \\
\text { Traveled } \\
\text { (miles) }\end{array}$ & $\begin{array}{l}\text { Total } \\
\text { Delay } \\
\text { (min) }\end{array}$ & $\begin{array}{c}\text { Average Delay } \\
\text { Time RT } 10 \text { and } \\
\text { ail Ramps (min } \\
\text { / veh mile) }\end{array}$ & \\
\hline Random Seed Number & A & B & $C=B / A$ & D & $\mathbf{E}$ & $F=E / D$ & $\begin{array}{c}\mathrm{G}=(\mathrm{B}+\mathrm{E}) \\
/[60(\min / \\
\mathrm{hr})]\end{array}$ \\
\hline 1 & 58683.1 & 31534.22 & 0.54 & 15542.4 & 1215.02 & 0.08 & 545.82 \\
\hline 33 & 58523.4 & 33034.02 & 0.56 & 14248.4 & 928.90 & 0.07 & 566.05 \\
\hline 99 & 58363.8 & 31192.47 & 0.53 & 14200.7 & 949.06 & 0.07 & 535.69 \\
\hline Cumulative Average Delay Time & & & 0.55 & & & 0.07 & 549.19 \\
\hline \multirow{2}{*}{ Network Description } & \multicolumn{6}{|c|}{ Simulation Set Number } & 2 \\
\hline & \multicolumn{3}{|c|}{ Interstate 95 North } & \multicolumn{3}{|c|}{ Highway Route 10} & \\
\hline $\begin{array}{l}\text { AM Volume; 0\% Diversion; } \\
1 \text { Lane Block; } 30 \mathrm{Min} \text { In }\end{array}$ & $\begin{array}{l}\text { Vehicle } \\
\text { Miles } \\
\text { Traveled } \\
\text { (miles) }\end{array}$ & $\begin{array}{l}\text { Total } \\
\text { Delay } \\
(\min )\end{array}$ & $\begin{array}{c}\text { Average Delay } \\
\text { Time } 195 \text { and alt } \\
\text { Ramps (min-veh } \\
\text { mile) }\end{array}$ & $\begin{array}{l}\text { Vehicle } \\
\text { Miles } \\
\text { Traveled } \\
\text { (miles) }\end{array}$ & $\begin{array}{l}\text { Total } \\
\text { Delay } \\
\text { (min) }\end{array}$ & $\begin{array}{c}\text { Average Delay } \\
\text { Time RT10 and } \\
\text { all Ramps (min } \\
\text { / veh mile) }\end{array}$ & $\begin{array}{l}\text { Total } \\
\text { Network } \\
\text { Delay } \\
\text { (hours) }\end{array}$ \\
\hline Random Seed Number & A & B & $\mathbf{C}=\mathbf{B} / \mathbf{A}$ & D & E & $F=E / D$ & $\begin{array}{c}\mathrm{G}=(\mathrm{B}+\mathrm{E}) \\
/[60(\mathrm{~min} / \\
\mathrm{hr})]\end{array}$ \\
\hline 1 & 58225.7 & 55579.95 & 0.95 & 13621.7 & 1321.14 & 0.10 & 948.35 \\
\hline 33 & 58497.2 & 47589.29 & 0.81 & 14391.6 & 983.57 & 0.07 & 809.55 \\
\hline 99 & 58497.2 & 47589.29 & 0.81 & 14337.1 & 3448.94 & 0.24 & 850.64 \\
\hline Cumulative Average Delay Time & & & 0.86 & & & 0.14 & 869.51 \\
\hline \multirow{2}{*}{ Network Description } & \multicolumn{6}{|c|}{ Simulation Set Number } & 3 \\
\hline & \multicolumn{3}{|c|}{ Interstate 95 North } & \multicolumn{3}{|c|}{ Highway Route 10} & \\
\hline $\begin{array}{l}\text { AM Volume; } 0 \% \text { Diversion; } \\
\text { Lane Block; } 40 \mathrm{Min} \text { In }\end{array}$ & $\begin{array}{l}\text { Vehicle } \\
\text { Miles } \\
\text { Traveled } \\
\text { (miles) }\end{array}$ & $\begin{array}{l}\text { Total } \\
\text { Delay } \\
\text { (min) }\end{array}$ & $\begin{array}{c}\text { Average Delay } \\
\text { Time I95 and all } \\
\text { Ramps (min-veh } \\
\text { mile) }\end{array}$ & $\begin{array}{c}\text { Vehicle } \\
\text { Miles } \\
\text { Traveled } \\
\text { (miles) }\end{array}$ & $\begin{array}{l}\text { Total } \\
\text { Delay } \\
\text { (min) }\end{array}$ & $\begin{array}{l}\text { Average Delay } \\
\text { Time RT10 and } \\
\text { all Ramps (min } \\
\text { / veh mile) }\end{array}$ & $\begin{array}{l}\text { Total } \\
\text { Network } \\
\text { Delay } \\
\text { (hours) }\end{array}$ \\
\hline Random Seed Number & A & B & $\mathrm{C}=\mathrm{B} / \mathrm{A}$ & D & $\mathbf{E}$ & $F=E / D$ & $\begin{array}{c}\mathrm{G}=(\bar{B}+E) \\
/[60(\min / \\
\mathrm{hr})]\end{array}$ \\
\hline 1 & 57152.3 & 74990.44 & 1.31 & 17031.2 & 1246.57 & 0.07 & 1270.62 \\
\hline 33 & 57815.5 & 59820.70 & 1.03 & 15921.6 & 956.71 & 0.06 & 1012.96 \\
\hline 99 & 58197.7 & 55473.92 & 0.95 & 15715.1 & 1003.01 & 0.06 & 941.28 \\
\hline Curmulative Average Delay Time & & & 1.10 & & & 0.07 & 1074.95 \\
\hline \multirow{2}{*}{ Network Description } & \multicolumn{6}{|c|}{ Simulation Set Number } & 4 \\
\hline & \multicolumn{3}{|c|}{ Interstate 95 North } & \multicolumn{3}{|c|}{ Highway Route 10} & \\
\hline $\begin{array}{l}\text { AM Volume; } 0 \% \text { Diversion; } \\
\text { Lane Block; } 20 \mathrm{Min} \text { In }\end{array}$ & $\begin{array}{l}\text { Vehicle } \\
\text { Miles } \\
\text { Traveled } \\
\text { (miles) }\end{array}$ & $\begin{array}{l}\text { Total } \\
\text { Delay } \\
\text { (min) }\end{array}$ & $\begin{array}{c}\text { Average Delay } \\
\text { Time I95 and all } \\
\text { Ramps (min-veh } \\
\text { mile) }\end{array}$ & $\begin{array}{l}\text { Vehicle } \\
\text { Miles } \\
\text { Traveled } \\
\text { (miles) }\end{array}$ & $\begin{array}{l}\text { Total } \\
\text { Delay } \\
\text { (min) }\end{array}$ & $\begin{array}{c}\text { A verage Delay } \\
\text { Time RT10 and } \\
\text { all Ramps (min } \\
\text { / veh mile) }\end{array}$ & $\begin{array}{l}\text { Total } \\
\text { Network } \\
\text { Delay } \\
\text { (hours) }\end{array}$ \\
\hline Random Seed Number & A & B & $C=B / A$ & D & $\mathrm{E}$ & $F=E / D$ & $\begin{array}{c}\mathrm{G}=(\mathrm{B}+\mathrm{E}) \\
/[60(\mathrm{~min} / \\
\mathrm{hr}) \mathrm{l}\end{array}$ \\
\hline 1 & 57273.2 & 81308.94 & 1.42 & 15542.4 & 1215.02 & 0.08 & 1375.40 \\
\hline 33 & 57137.6 & 85007.60 & 1.49 & 14248.4 & 928.90 & 0.07 & 1432.28 \\
\hline 99 & 56936.8 & 84930.14 & 1.49 & 14200.7 & 949.06 & 0.07 & 1431.32 \\
\hline Crmulative Average Delay Time & & & 1.47 & & & 0.07 & 1413.00 \\
\hline
\end{tabular}




\begin{tabular}{|c|c|c|c|c|c|c|c|}
\hline \multirow{2}{*}{ Network Description } & \multicolumn{6}{|c|}{ Simulation Set Number } & 5 \\
\hline & \multicolumn{3}{|c|}{ Interstate 95 North } & \multicolumn{3}{|c|}{ Highway Route 10} & \multirow[b]{2}{*}{$\begin{array}{l}\text { Total } \\
\text { Network } \\
\text { Delay } \\
\text { (hours) }\end{array}$} \\
\hline $\begin{array}{l}\text { AM Volume; } 0 \% \text { Diversion; } \\
\text { Lane Block; } 30 \mathrm{Min} \text { In }\end{array}$ & $\begin{array}{l}\text { Vehicle } \\
\text { Miles } \\
\text { Traveled } \\
\text { (miles) }\end{array}$ & $\begin{array}{l}\text { Total } \\
\text { Delay } \\
\text { (min) }\end{array}$ & $\begin{array}{c}\text { Average Delay } \\
\text { Time } 195 \text { and ail } \\
\text { Ramps (min-veh } \\
\text { mile) }\end{array}$ & $\begin{array}{l}\text { Vehicle } \\
\text { Miles } \\
\text { Traveled } \\
\text { (miles) }\end{array}$ & $\begin{array}{l}\text { Total } \\
\text { Delay } \\
(\mathrm{min})\end{array}$ & $\begin{array}{c}\text { Average Delay } \\
\text { Time RT10 and } \\
\text { all Ramps (min } \\
\text { / veh mile) }\end{array}$ & \\
\hline Random Seed Number & A & B & $C=B / A$ & $\mathrm{D}$ & $\mathbf{E}$ & $F=E / D$ & $\begin{array}{c}\mathrm{G}=(\mathrm{B}+\mathrm{E}) \\
/[60(\mathrm{~min} / \\
\mathrm{hr} /]\end{array}$ \\
\hline 1 & 54399.4 & 95927.87 & 1.76 & 13621.7 & 1321.14 & 0.10 & 1620.82 \\
\hline 33 & 54449.0 & 94148.17 & 1.73 & 14391.6 & 983.57 & 0.07 & 1585.53 \\
\hline 99 & 54562.0 & 93879.07 & 1.72 & 14337.1 & 3448.94 & 0.24 & 1622.13 \\
\hline Cumulative Average Delay Time & & & 1.74 & & & 0.14 & 1609.49 \\
\hline \multirow{2}{*}{ Network Description } & \multicolumn{6}{|c|}{ Simulation Set Number } & 6 \\
\hline & \multicolumn{3}{|c|}{ Interstate 95 North } & \multicolumn{3}{|c|}{ Highway Route 10} & \\
\hline $\begin{array}{l}\text { LM Volume; } 0 \% \text { Diversion; } \\
\text { Lane Block; } 40 \mathrm{Min} \text { In }\end{array}$ & $\begin{array}{l}\text { Vehicle } \\
\text { Miles } \\
\text { Traveled } \\
\text { (miles) }\end{array}$ & $\begin{array}{l}\text { Total } \\
\text { Delay } \\
\text { (min) }\end{array}$ & $\begin{array}{c}\text { Average Delay } \\
\text { Time } 195 \text { and all } \\
\text { Ramps (min-veh } \\
\text { mile) }\end{array}$ & $\begin{array}{l}\text { Vehicle } \\
\text { Miles } \\
\text { Traveled } \\
\text { (miles) }\end{array}$ & $\begin{array}{l}\text { Total } \\
\text { Delay } \\
\text { (min) }\end{array}$ & $\begin{array}{c}\text { Average Delay } \\
\text { Time RT10 and } \\
\text { all Ramps (min } \\
\text { / veh mile) }\end{array}$ & $\begin{array}{l}\text { Total } \\
\text { Network } \\
\text { Delay } \\
\text { (hours) }\end{array}$ \\
\hline Random Seed Number & A & B & $\mathrm{C}=\mathrm{B} / \mathrm{A}$ & D & E & $F=E / D$ & $\begin{array}{c}\mathrm{G}=(\mathrm{B}+\mathrm{E}) \\
/\left[\begin{array}{c}60(\mathrm{~min} / \\
\mathrm{hr})]\end{array}\right. \\
\end{array}$ \\
\hline 1 & 51142.0 & 100371.50 & 1.96 & 17031.2 & 1246.57 & 0.07 & 1693.63 \\
\hline 33 & 51858.8 & 95838.88 & 1.85 & 15921.6 & 956.71 & 0.06 & 1613.26 \\
\hline 99 & 51645.1 & 95168.14 & 1.84 & 15715.1 & 1003.01 & 0.06 & 1602.85 \\
\hline Cumulative Average Delay Time & & & 1.88 & & & 0.07 & 1636.58 \\
\hline \multirow{2}{*}{ Network Description } & \multicolumn{6}{|c|}{ Simulation Set Number } & 7 \\
\hline & \multicolumn{3}{|c|}{ Interstate 95 North } & \multicolumn{3}{|c|}{ Highway Route 10} & \\
\hline $\begin{array}{l}\text { Lane Block; } 20 \text { Min ln }\end{array}$ & $\begin{array}{l}\text { Vehicle } \\
\text { Miles } \\
\text { Traveled } \\
\text { (miles) }\end{array}$ & $\begin{array}{l}\text { Total } \\
\text { Delay } \\
\text { (min) }\end{array}$ & $\begin{array}{c}\text { Average Delay } \\
\text { Time I95 and all } \\
\text { Ramps (min-veh } \\
\text { mile) }\end{array}$ & $\begin{array}{l}\text { Vehicle } \\
\text { Miles } \\
\text { Traveled } \\
\text { (miles) }\end{array}$ & $\begin{array}{l}\text { Total } \\
\text { Delay } \\
\text { (min) }\end{array}$ & $\begin{array}{c}\text { Average Delay } \\
\text { Time RT10 and } \\
\text { all Ramps (min } \\
\text { / veh mile) }\end{array}$ & $\begin{array}{l}\text { Total } \\
\text { Network } \\
\text { Delay } \\
\text { (hours) }\end{array}$ \\
\hline Random Seed Number & A & B & $C=B / A$ & $\mathrm{D}$ & E & $F=E / D$ & $\begin{array}{c}\mathrm{G}=(\mathrm{B}+\mathrm{E}) \\
/\left[\begin{array}{c}60(\mathrm{~min} / \\
\mathrm{hr})\end{array}\right.\end{array}$ \\
\hline 1 & 53887.3 & 100605.30 & 1.87 & 15542.4 & 1215.02 & 0.08 & 1697.01 \\
\hline 33 & 54510.0 & 91574.73 & 1.68 & 14248.4 & 928.90 & 0.07 & 1541.73 \\
\hline 99 & 54722.5 & 92967.84 & 1.70 & 14200.7 & 949.06 & 0.07 & 1565.28 \\
\hline Cumulative Average Delay Time & & & 1.75 & & & 0.07 & 1601.34 \\
\hline \multirow{2}{*}{ Network Description } & \multicolumn{6}{|c|}{ Simulation Set Number } & 8 \\
\hline & \multicolumn{3}{|c|}{ Interstate 95 North } & \multicolumn{3}{|c|}{ Highway Route 10} & \\
\hline $\begin{array}{l}\text { AM Volume; } 0 \% \text { Diversion; } \\
\text { Lane Block; } 30 \mathrm{Min} \text { In }\end{array}$ & $\begin{array}{l}\text { Vehicle } \\
\text { Miles } \\
\text { Traveled } \\
\text { (miles) }\end{array}$ & $\begin{array}{l}\text { Total } \\
\text { Delay } \\
\text { (min) }\end{array}$ & $\begin{array}{c}\text { Average Delay } \\
\text { Time I95 and alt } \\
\text { Ramps (min-veh } \\
\text { mile) }\end{array}$ & $\begin{array}{l}\text { Vehicle } \\
\text { Miles } \\
\text { Traveled } \\
\text { (miles) }\end{array}$ & $\begin{array}{l}\text { Total } \\
\text { Delay } \\
\text { (min) }\end{array}$ & $\begin{array}{c}\text { Average Delay } \\
\text { Time RT10 and } \\
\text { all Ramps (min } \\
\text { / veh mile) }\end{array}$ & $\begin{array}{l}\text { Total } \\
\text { Network } \\
\text { Delay } \\
\text { (hours) }\end{array}$ \\
\hline Random Seed Number & $A$ & B & $C=B / A$ & D & E & $F=E / D$ & $\begin{array}{c}\mathrm{G}=(\mathrm{B}+\mathrm{E}) \\
/\left[\begin{array}{c}60(\mathrm{~min} / \\
\text { hril }\end{array}\right.\end{array}$ \\
\hline 1 & 32628.5 & 173299.80 & 5.31 & 13621.7 & 1321.14 & 0.10 & 2910.35 \\
\hline 33 & 50695.4 & 102205.10 & 2.02 & 14391.6 & 983.57 & 0.07 & 1719.81 \\
\hline 99 & 50030.4 & 99606.42 & 1.99 & 14337.1 & 3448.94 & 0.24 & 1717.59 \\
\hline Cumulative Average Delay Time & & & 2.81 & & & 0.14 & 2115.92 \\
\hline
\end{tabular}




\begin{tabular}{|c|c|c|c|c|c|c|c|}
\hline \multirow{2}{*}{ Network Description } & \multicolumn{6}{|c|}{ Simulation Set Number } & 9 \\
\hline & \multicolumn{3}{|c|}{ Interstate 95 North } & \multicolumn{3}{|c|}{ Highway Route 10} & \multirow[b]{2}{*}{$\begin{array}{l}\text { Total } \\
\text { Network } \\
\text { Delay } \\
\text { (hours) }\end{array}$} \\
\hline $\begin{array}{l}\text { Wane Block; } 40 \mathrm{Min} \text { In } \\
\text { Lan }\end{array}$ & $\begin{array}{c}\text { Vehicle } \\
\text { Miles } \\
\text { Traveled } \\
\text { (miles) }\end{array}$ & $\begin{array}{l}\text { Total } \\
\text { Delay } \\
\text { (min) }\end{array}$ & $\begin{array}{c}\text { Average Delay } \\
\text { Time } 195 \text { and all } \\
\text { Ramps (min-veh } \\
\text { mile) }\end{array}$ & $\begin{array}{l}\text { Vehicle } \\
\text { Miles } \\
\text { Traveled } \\
\text { (miles) }\end{array}$ & $\begin{array}{l}\text { Total } \\
\text { Delay } \\
\text { (min) }\end{array}$ & $\begin{array}{l}\text { Average Delay } \\
\text { Time RTI0 and } \\
\text { all Ramps (min } \\
\text { / veh mile) }\end{array}$ & \\
\hline Random Seed Number & A & B & $C=B / A$ & D & $\mathbf{E}$ & $F=E / D$ & $\begin{array}{c}G=(B+E) \\
/[60(\mathrm{~min} / \\
\mathrm{hr})]\end{array}$ \\
\hline 1 & 43572.6 & 120522.90 & 2.77 & 17031.2 & 1246.57 & 0.07 & 2029.49 \\
\hline 33 & 46968.3 & 108879.70 & 2.32 & 15921.6 & 956.71 & 0.06 & 1830.61 \\
\hline 99 & 46968.3 & 108879.70 & 2.32 & 15715.1 & 1003.01 & 0.06 & 1831.38 \\
\hline Cumulative Average Delay Time & & & 2.46 & & & 0.07 & 1897.16 \\
\hline \multirow{2}{*}{ Network Description } & \multicolumn{6}{|c|}{ Simulation Set Number } & 10 \\
\hline & \multicolumn{3}{|c|}{ Interstate 95 North } & \multicolumn{3}{|c|}{ Highway Route 10} & \\
\hline $\begin{array}{l}\text { AM Volume; } 20 \% \text { Diversion; } \\
\text { I Lane Block; } 20 \mathrm{Min} \text { In }\end{array}$ & $\begin{array}{l}\text { Vehicle } \\
\text { Miles } \\
\text { Traveled } \\
\text { (miles) }\end{array}$ & $\begin{array}{l}\text { Total } \\
\text { Delay } \\
\text { (min) }\end{array}$ & $\begin{array}{c}\text { Average Delay } \\
\text { Time I95 and all } \\
\text { Ramps (min-veh } \\
\text { mile) }\end{array}$ & $\begin{array}{l}\text { Vehicle } \\
\text { Miles } \\
\text { Traveled } \\
\text { (miles) }\end{array}$ & $\begin{array}{l}\text { Total } \\
\text { Delay } \\
\text { (min) }\end{array}$ & $\begin{array}{l}\text { Average Delay } \\
\text { Time RT10 and } \\
\text { all Ramps (min } \\
\text { / veh mile) }\end{array}$ & $\begin{array}{l}\text { Total } \\
\text { Network } \\
\text { Delay } \\
\text { (hours) }\end{array}$ \\
\hline Random Seed Number & A & B & $C=B / A$ & D & E & $F=E / D$ & $\begin{array}{c}\mathrm{G}=(\mathrm{B}+\mathrm{E}) \\
/\left[\begin{array}{c}60(\mathrm{~min} / \\
\mathrm{hr})]\end{array}\right. \\
\end{array}$ \\
\hline 1 & 56481.8 & 12361.75 & 0.22 & 13393.5 & 66010.95 & 4.93 & 1306.21 \\
\hline 33 & 56521.9 & 13619.35 & 0.24 & 15319.9 & 1177.63 & 0.08 & 246.62 \\
\hline 99 & 54390.0 & 22980.45 & 0.42 & 6908.6 & 69800.70 & 10.10 & 1546.35 \\
\hline Cumulative Average Delay Time & & & 0.29 & & & 3.85 & 1033.06 \\
\hline \multirow{2}{*}{ Network Description } & \multicolumn{6}{|c|}{ Simulation Set Number } & 11 \\
\hline & \multicolumn{3}{|c|}{ Interstate 95 North } & \multicolumn{3}{|c|}{ Highway Route 10} & \\
\hline $\begin{array}{l}\text { Dane Block; } 30 \text { Min In } \\
\text { Lam Volume; } 20 \% \text { Diversion; }\end{array}$ & $\begin{array}{l}\text { Vehicle } \\
\text { Miles } \\
\text { Traveled } \\
\text { (miles) }\end{array}$ & $\begin{array}{l}\text { Total } \\
\text { Delay } \\
\text { (min) }\end{array}$ & $\begin{array}{c}\text { Average Delay } \\
\text { Time } 195 \text { and all } \\
\text { Ramps (min-veh } \\
\text { mile) }\end{array}$ & $\begin{array}{l}\text { Vehicle } \\
\text { Miles } \\
\text { Traveled } \\
\text { (miles) }\end{array}$ & $\begin{array}{l}\text { Total } \\
\text { Delay } \\
\text { (min) }\end{array}$ & $\begin{array}{c}\text { Average Delay } \\
\text { Time RT10 and } \\
\text { all Ramps (min } \\
\text { / veh mile) }\end{array}$ & $\begin{array}{l}\text { Total } \\
\text { Network } \\
\text { Delay } \\
\text { (hours) }\end{array}$ \\
\hline Random Seed Number & A & B & $C=B / A$ & D & E & $F=E / D$ & $\begin{array}{c}\mathrm{G}=(\mathrm{B}+\mathrm{E}) \\
\begin{array}{c}{[60(\mathrm{~min} /} \\
\mathrm{hr})\end{array}\end{array}$ \\
\hline 1 & 55554.1 & 11811.09 & 0.21 & 13739.7 & 74402.27 & 5.42 & 1436.89 \\
\hline 33 & 55347.5 & 11467.40 & 0.21 & 14894.6 & 7564.69 & 0.51 & 317.20 \\
\hline 99 & 55385.9 & 12283.98 & 0.22 & 6880.3 & 69684.73 & 10.13 & 1366.15 \\
\hline Cumulative Average Delay Time & & & 0.21 & & & 4.27 & 1040.08 \\
\hline \multirow{2}{*}{ Network Description } & \multicolumn{6}{|c|}{ Simulation Set Number } & 12 \\
\hline & \multicolumn{3}{|c|}{ Interstate 95 North } & \multicolumn{3}{|c|}{ Highway Route 10} & \\
\hline $\begin{array}{l}\text { I Lane Block; } 40 \text { Min In } \\
\text { In Volume; }\end{array}$ & $\begin{array}{l}\text { Vehicle } \\
\text { Miles } \\
\text { Traveled } \\
\text { (miles) }\end{array}$ & $\begin{array}{l}\text { Total } \\
\text { Delay } \\
\text { (min) }\end{array}$ & $\begin{array}{c}\text { Average Delay } \\
\text { Time } 195 \text { and all } \\
\text { Ramps (min-veh } \\
\text { mile) }\end{array}$ & $\begin{array}{l}\text { Vehicle } \\
\text { Miles } \\
\text { Traveled } \\
\text { (miles) }\end{array}$ & $\begin{array}{l}\text { Total } \\
\text { Delay } \\
\text { (min) }\end{array}$ & $\begin{array}{c}\text { Average Delay } \\
\text { Time RT } 10 \text { and } \\
\text { all Ramps (min } \\
\text { / veh mile) }\end{array}$ & $\begin{array}{l}\text { Total } \\
\text { Network } \\
\text { Delay } \\
\text { (hours) }\end{array}$ \\
\hline Random Seed Number & $\mathbf{A}$ & B & $\mathrm{C}=\mathrm{B} / \mathrm{A}$ & D & $\mathbf{E}$ & $F=E / D$ & $\begin{array}{c}\mathrm{G}=(\mathrm{B}+\mathrm{E}) \\
/\left[\begin{array}{c}60(\mathrm{~min} / \\
\mathrm{hr})]\end{array}\right. \\
\end{array}$ \\
\hline 1 & 54670.1 & 11596.64 & 0.21 & 13832.0 & 94062.26 & 6.80 & 1760.98 \\
\hline 33 & 54330.3 & 11540.39 & 0.21 & 12916.5 & 54578.19 & 4.23 & 1101.98 \\
\hline $\begin{array}{r}99 \\
\end{array}$ & 54459.0 & 12834.74 & 0.24 & 6880.3 & 69684.73 & 10.13 & 1375.32 \\
\hline Comulative Average Delay Time & & & 0.22 & & & 6.49 & 1412.76 \\
\hline
\end{tabular}




\begin{tabular}{|c|c|c|c|c|c|c|c|}
\hline \multirow{2}{*}{ Network Description } & \multicolumn{6}{|c|}{ Simulation Set Number } & 13 \\
\hline & \multicolumn{3}{|c|}{ Interstate 95 North } & \multicolumn{3}{|c|}{ Highway Route 10} & \multirow[b]{2}{*}{$\begin{array}{l}\text { Total } \\
\text { Network } \\
\text { Delay } \\
\text { (hours) }\end{array}$} \\
\hline $\begin{array}{l}\text { 2Lane Block; } 20 \text { Min In }\end{array}$ & $\begin{array}{l}\text { Vehicle } \\
\text { Miles } \\
\text { Traveled } \\
\text { (miles) }\end{array}$ & $\begin{array}{l}\text { Total } \\
\text { Delay } \\
\text { (min) }\end{array}$ & $\begin{array}{c}\text { Average Delay } \\
\text { Time } 195 \text { and all } \\
\text { Ramps (min-veh } \\
\text { mile) }\end{array}$ & $\begin{array}{c}\text { Vehicle } \\
\text { Miles } \\
\text { Traveled } \\
\text { (miles) }\end{array}$ & $\begin{array}{l}\text { Total } \\
\text { Delay } \\
\text { (min) }\end{array}$ & $\begin{array}{c}\text { Average Delay } \\
\text { Time RT10 and } \\
\text { all Ramps (min } \\
\text { / veh mile) }\end{array}$ & \\
\hline Random Seed Number & A & B & $C=B / A$ & $\mathrm{D}$ & $\mathbf{E}$ & $F=E / D$ & $\begin{array}{c}\mathrm{G}=(\mathrm{B}+\mathrm{E}) \\
/[60(\mathrm{~min} / \\
\mathrm{hr})]\end{array}$ \\
\hline 1 & 56549.1 & 45056.55 & 0.80 & 13393.5 & 66010.95 & 4.93 & 1851.13 \\
\hline 33 & 56128.8 & 58994.88 & 1.05 & 15319.9 & 1177.63 & 0.08 & 1002.88 \\
\hline 99 & 56051.9 & 54361.23 & 0.97 & 6908.6 & 69800.70 & 10.10 & 2069.37 \\
\hline Cumulative Average Delay Time & & & 0.94 & & & 3.85 & 1641.12 \\
\hline \multirow{2}{*}{ Network Description } & \multicolumn{6}{|c|}{ Simulation Set Number } & 14 \\
\hline & \multicolumn{3}{|c|}{ Interstate 95 North } & \multicolumn{3}{|c|}{ Highway Route 10} & \\
\hline $\begin{array}{l}\text { Dane Block; } 30 \text { Min In } \\
\text { Lan Volume; } 20 \% \text { Diversion; }\end{array}$ & $\begin{array}{l}\text { Vehicle } \\
\text { Miles } \\
\text { Traveled } \\
\text { (miles) }\end{array}$ & $\begin{array}{l}\text { Total } \\
\text { Delay } \\
(\mathrm{min})\end{array}$ & $\begin{array}{c}\text { Average Delay } \\
\text { Time } 195 \text { and all } \\
\text { Ramps (min-veh } \\
\text { mile) }\end{array}$ & $\begin{array}{l}\text { Vehicle } \\
\text { Miles } \\
\text { Traveled } \\
\text { (miles) }\end{array}$ & $\begin{array}{l}\text { Total } \\
\text { Delay } \\
\text { (min) }\end{array}$ & $\begin{array}{c}\text { Average Delay } \\
\text { Time RT10 and } \\
\text { all Ramps (min } \\
\text { / veh mile) }\end{array}$ & $\begin{array}{l}\text { Total } \\
\text { Network } \\
\text { Delay } \\
\text { (hours) }\end{array}$ \\
\hline Random Seed Number & A & B & $C=B / A$ & D & $\mathbf{E}$ & $F=E / D$ & $\begin{array}{c}\mathrm{G}=(\mathrm{B}+\mathrm{E}) \\
/\left[\begin{array}{c}60(\mathrm{~min} / \\
\mathrm{hr})]\end{array}\right.\end{array}$ \\
\hline 1 & 54681.1 & 77201.34 & 1.41 & 13739.7 & 74402.27 & 5.42 & 2526.73 \\
\hline 33 & 54136.2 & 83043.80 & 1.53 & 14894.6 & 7564.69 & 0.51 & 1510.14 \\
\hline 99 & 56051.9 & 89765.84 & 1.60 & 6880.3 & 69684.73 & 10.13 & 2657.51 \\
\hline Cumulative Average Delay Time & & & 1.52 & & & 4.27 & 2231.46 \\
\hline \multirow{2}{*}{ Network Description } & \multicolumn{6}{|c|}{ Simulation Set Number } & 15 \\
\hline & \multicolumn{3}{|c|}{ Interstate 95 North } & \multicolumn{3}{|c|}{ Highway Route 10} & \\
\hline $\begin{array}{l}\text { Dane Block; } 40 \text { Min In } \\
\text { Lan Volume; }\end{array}$ & $\begin{array}{l}\text { Vehicle } \\
\text { Miles } \\
\text { Traveled } \\
\text { (miles) }\end{array}$ & $\begin{array}{l}\text { Total } \\
\text { Delay } \\
\text { (min) }\end{array}$ & $\begin{array}{c}\text { Average Delay } \\
\text { Time } 195 \text { and all } \\
\text { Ramps (min-veh } \\
\text { mile) }\end{array}$ & $\begin{array}{l}\text { Vehicle } \\
\text { Miles } \\
\text { Traveled } \\
\text { (miles) }\end{array}$ & $\begin{array}{l}\text { Total } \\
\text { Delay } \\
\text { (min) }\end{array}$ & $\begin{array}{c}\text { Average Delay } \\
\text { Time RT10 and } \\
\text { all Ramps (min } \\
\text { / veh mile) }\end{array}$ & $\begin{array}{l}\text { Total } \\
\text { Network } \\
\text { Delay } \\
\text { (hours) }\end{array}$ \\
\hline Random Seed Number & A & B & $C=B / A$ & D & E & $F=E / D$ & $\begin{array}{c}\mathrm{G}=(\mathrm{B}+\mathrm{E}) \\
/[60(\mathrm{~min} / \\
\mathrm{hr})]\end{array}$ \\
\hline 1 & 52905.0 & 80934.82 & 1.53 & 13832.0 & 94062.26 & 6.80 & 2916.62 \\
\hline 33 & 50232.3 & 79961.57 & 1.59 & 12916.5 & 54578.19 & 4.23 & 2242.33 \\
\hline 99 & 51988.2 & 80593.79 & 1.55 & 6880.3 & 69684.73 & 10.13 & 2504.64 \\
\hline Ormulative Average Delay Time & & & 1.56 & & & 6.49 & 2554.53 \\
\hline \multirow{2}{*}{ Network Description } & \multicolumn{6}{|c|}{ Simulation Set Number } & 16 \\
\hline & \multicolumn{3}{|c|}{ Interstate 95 North } & \multicolumn{3}{|c|}{ Highway Route 10} & \\
\hline $\begin{array}{l}\text { Lane Block; } 20 \text { Min In } \\
\text { Lan }\end{array}$ & $\begin{array}{l}\text { Vehicle } \\
\text { Miles } \\
\text { Traveled } \\
\text { (miles) }\end{array}$ & $\begin{array}{l}\text { Total } \\
\text { Delay } \\
\text { (min) }\end{array}$ & $\begin{array}{c}\text { Average Delay } \\
\text { Time I95 and all } \\
\text { Ramps (min-veh } \\
\text { mile) }\end{array}$ & $\begin{array}{l}\text { Vehicle } \\
\text { Miles } \\
\text { Traveled } \\
\text { (miles) }\end{array}$ & $\begin{array}{l}\text { Total } \\
\text { Delay } \\
\text { (min) }\end{array}$ & $\begin{array}{c}\text { Average Delay } \\
\text { Time RT10 and } \\
\text { all Ramps (min } \\
\text { / veh mile) }\end{array}$ & $\begin{array}{l}\text { Total } \\
\text { Network } \\
\text { Delay } \\
\text { (hours) }\end{array}$ \\
\hline Random Seed Number & A & B & $\mathrm{C}=\mathrm{B} / \mathrm{A}$ & D & E & $F=E / D$ & $\begin{array}{c}\mathrm{G}=(\mathrm{B}+\mathrm{E}) \\
/[60(\mathrm{~min} / \\
\mathrm{hr})]\end{array}$ \\
\hline 1 & 54310.2 & 95688.21 & 1.76 & 13393.5 & 66010.95 & 4.93 & 2694.99 \\
\hline 33 & 54841.8 & 84292.55 & 1.54 & 15319.9 & 1177.63 & 0.08 & 1424.50 \\
\hline 99 & 54309.7 & 92545.23 & 1.70 & 6908.6 & 69800.70 & 10.10 & 2705.77 \\
\hline Cumulative Average Delay Time & & & 1.67 & & & 3.85 & 2275.08 \\
\hline
\end{tabular}




\begin{tabular}{|c|c|c|c|c|c|c|c|}
\hline \multirow{2}{*}{ Network Description } & \multicolumn{6}{|c|}{ Simulation Set Number } & 17 \\
\hline & \multicolumn{3}{|c|}{ Interstate 95 North } & \multicolumn{3}{|c|}{ Highway Route 10} & \multirow[b]{2}{*}{$\begin{array}{l}\text { Total } \\
\text { Network } \\
\text { Delay } \\
\text { (hours) }\end{array}$} \\
\hline $\begin{array}{l}\text { AM Volume; } 20 \% \text { Diversion; } \\
\text { Lane Block; } 30 \text { Min In }\end{array}$ & $\begin{array}{l}\text { Vehicle } \\
\text { Miles } \\
\text { Traveled } \\
\text { (miles) }\end{array}$ & $\begin{array}{l}\text { Total } \\
\text { Delay } \\
\text { (min) }\end{array}$ & $\begin{array}{c}\text { Average Delay } \\
\text { Time I95 and all } \\
\text { Ramps (min-veh } \\
\text { mile) }\end{array}$ & $\begin{array}{l}\text { Vehicle } \\
\text { Miles } \\
\text { Traveled } \\
\text { (miles) }\end{array}$ & $\begin{array}{l}\text { Total } \\
\text { Delay } \\
\text { (min) }\end{array}$ & $\begin{array}{l}\text { Average Delay } \\
\text { Time RTI0 and } \\
\text { all Ramps (min } \\
\text { / veh mile) }\end{array}$ & \\
\hline Random Seed Number & $\mathbf{A}$ & B & $\mathrm{C}=\mathrm{B} / \mathrm{A}$ & D & $\mathbf{E}$ & $F=E / D$ & $\begin{array}{c}\mathrm{G}=(\mathrm{B}+\mathrm{E}) \\
/[60(\mathrm{~min} / \\
\mathrm{hr})]\end{array}$ \\
\hline 1 & 50435.0 & 97352.32 & 1.93 & 13739.7 & 74402.27 & 5.42 & 2862.58 \\
\hline 33 & 51292.6 & 94667.09 & 1.85 & I4894.6 & 7564.69 & 0.51 & 1703.86 \\
\hline 99 & 50976.4 & 96641.07 & 1.90 & 6880.3 & 69684.73 & 10.13 & 2772.10 \\
\hline Cumulative Average Delay Time & & & 1.89 & & & 4.27 & 2446.18 \\
\hline \multirow{2}{*}{ Network Description } & \multicolumn{6}{|c|}{ Simulation Set Number } & 18 \\
\hline & \multicolumn{3}{|c|}{ Interstate 95 North } & \multicolumn{3}{|c|}{ Highway Route 10} & \\
\hline $\begin{array}{l}\text { 10ul AM Volume; } 20 \% \text { Diversion; } \\
\text { Lane Block; } 40 \mathrm{Min} \text { In }\end{array}$ & $\begin{array}{l}\text { Vehicle } \\
\text { Miles } \\
\text { Traveled } \\
\text { (miles) }\end{array}$ & $\begin{array}{l}\text { Total } \\
\text { Delay } \\
\text { (min) }\end{array}$ & $\begin{array}{c}\text { Average Delay } \\
\text { Time I95 and all } \\
\text { Ramps (min-veh } \\
\text { mile) }\end{array}$ & $\begin{array}{l}\text { Vehicle } \\
\text { Miles } \\
\text { Traveled } \\
\text { (miles) }\end{array}$ & $\begin{array}{l}\text { Total } \\
\text { Delay } \\
\text { (min) }\end{array}$ & $\begin{array}{l}\text { Average Delay } \\
\text { Time RT10 and } \\
\text { all Ramps (min } \\
\text { / veh mile) }\end{array}$ & $\begin{array}{l}\text { Total } \\
\text { Network } \\
\text { Delay } \\
\text { (hours) }\end{array}$ \\
\hline Random Seed Number & A & B & $C=B / A$ & D & $\mathbf{E}$ & $F=E / D$ & $\begin{array}{c}\mathrm{G}=(\mathrm{B}+\mathrm{E}) \\
/[60(\min / \\
\mathrm{br})] \\
\end{array}$ \\
\hline 1 & 46711.5 & 105717.10 & 2.26 & 16952.1 & 94062.26 & 5.55 & 3329.66 \\
\hline 33 & 46028.9 & 100897.80 & 2.19 & 16635.6 & 54578.19 & 3.28 & 2591.27 \\
\hline 99 & 46653.4 & 101150.90 & 2.17 & 16739.7 & 1315.29 & 0.08 & 1707.77 \\
\hline Cumulative Average Delay Time & & & 2.21 & & & 2.98 & 2542.90 \\
\hline
\end{tabular}




\section{APPENDIX F}

Results for Simulations Modeled with

3/4 AM Peak Traffic Conditions 


\begin{tabular}{|c|c|c|c|c|c|c|c|}
\hline \multirow{2}{*}{ Network Description } & \multicolumn{6}{|c|}{ Simulation Set Number } & 1.0 \\
\hline & \multicolumn{3}{|c|}{ Interstate 95 North } & \multicolumn{3}{|c|}{ Highway Route 10} & \\
\hline 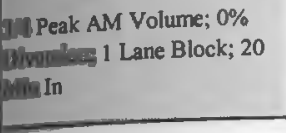 & $\begin{array}{l}\text { Vehicle } \\
\text { Miles } \\
\text { Traveled } \\
\text { (miles) }\end{array}$ & $\begin{array}{c}\text { Vehicle } \\
\text { Minutes } \\
\text { (min) }\end{array}$ & $\begin{array}{c}\text { Cumulative } \\
\text { Average Speed I } \\
95 \text { and all } \\
\text { Ramps (mph) }\end{array}$ & $\begin{array}{c}\text { Vehicle } \\
\text { Miles } \\
\text { Traveled } \\
\text { (miles) }\end{array}$ & $\begin{array}{l}\text { Vehicle } \\
\text { Minutes } \\
\text { (min) }\end{array}$ & $\begin{array}{c}\text { Cwmulative } \\
\text { Average Speed } \\
\text { RI-10 and all } \\
\text { Ramps (mph) }\end{array}$ & $\begin{array}{c}\text { Curmulative } \\
\text { Network } \\
\text { Average Speed } \\
\text { (mph) }\end{array}$ \\
\hline Random Seed Number & A & B & $\begin{array}{c}C=A /(B / 60 \\
\min / h r)\end{array}$ & $\mathrm{D}$ & $\mathbf{E}$ & $\begin{array}{c}\mathrm{F}=\mathrm{D} /(\mathrm{E} / 60 \\
\mathrm{min} / \mathrm{hr})\end{array}$ & $\begin{array}{c}\mathrm{G}=(\mathrm{A}+\mathrm{D}) / \\
{[(\mathrm{B}+\mathrm{E}) / 60} \\
\mathrm{min} / \mathrm{hr}]\end{array}$ \\
\hline 1 & 43923.3 & 45276.5 & 58.2 & 10933.6 & 11554.1 & 56.8 & 57.9 \\
\hline 33 & 43854.0 & 45283.4 & 58.1 & 10858.2 & 11456.9 & 56.9 & 57.9 \\
\hline 99 & 43627.0 & 45129.6 & 58.0 & 10876.7 & 11471.4 & 56.9 & 57.8 \\
\hline Cumulative Average Speed & & & 58.1 & & & 56.8 & 57.8 \\
\hline \multirow{2}{*}{ Network Description } & \multicolumn{6}{|c|}{ Simulation Set Nurnber } & 2.0 \\
\hline & \multicolumn{3}{|c|}{ Interstate 95 North } & \multicolumn{3}{|c|}{ Highway Route 10} & \\
\hline $\begin{array}{l}\text { Peak AM Volume; } 0 \% \\
\text { Wh In }\end{array}$ & $\begin{array}{l}\text { Vehicle } \\
\text { Miles } \\
\text { Traveled } \\
\text { (miles) }\end{array}$ & $\begin{array}{c}\text { Vehicle } \\
\text { Minutes } \\
\text { (min) }\end{array}$ & $\begin{array}{c}\text { Cumulative } \\
\text { Average Speed I } \\
95 \text { and all } \\
\text { Ramps (mph) }\end{array}$ & $\begin{array}{c}\text { Vehicle } \\
\text { Miles } \\
\text { Traveled } \\
\text { (miles) }\end{array}$ & $\begin{array}{l}\text { Vehicle } \\
\text { Minutes } \\
\text { (min) }\end{array}$ & $\begin{array}{c}\text { Cumulative } \\
\text { Average Speed } \\
\text { RI-10 and all } \\
\text { Ramps (mph) }\end{array}$ & $\begin{array}{c}\text { Cumulative } \\
\text { Network } \\
\text { Average Speed } \\
\text { (mph) }\end{array}$ \\
\hline Random Seed Number & A & B & $\begin{array}{c}\mathrm{C}=\mathrm{A} /(\mathrm{B} / 60 \\
\mathrm{min} / \mathrm{hr})\end{array}$ & $\mathrm{D}$ & $\mathbf{E}$ & $\begin{array}{c}\mathrm{F}=\mathrm{D} /(\mathrm{E} / 60 \\
\mathrm{min} / \mathrm{hr})\end{array}$ & $\begin{array}{c}\mathrm{G}=(\mathrm{A}+\mathrm{D}) / \\
{[(\mathrm{B}+\mathrm{E}) / 60} \\
\mathrm{min} / \mathrm{hr}]\end{array}$ \\
\hline 1 & 43542.0 & 45187.3 & 57.8 & 9979.2 & 27395.8 & 21.9 & 44.2 \\
\hline 33 & 44038.0 & 45741.8 & 57.8 & 10965.3 & 11554.9 & 56.9 & 57.6 \\
\hline 99 & 44065.2 & 45701.9 & 57.9 & 10875.2 & 12632.7 & 51.7 & 56.5 \\
\hline Cumulative Average Speed & & & 57.8 & & & 37.0 & 52.1 \\
\hline \multirow{2}{*}{ Network Description } & \multicolumn{6}{|c|}{ Simulation Set Number } & 3.0 \\
\hline & \multicolumn{3}{|c|}{ Interstate 95 North } & \multicolumn{3}{|c|}{ Highway Route 10} & \\
\hline $\begin{array}{l}\text { 1. Peak AM Volume; } 0 \% \\
\text { In } 1 \text { Lane Block; } 40\end{array}$ & $\begin{array}{l}\text { Vehicle } \\
\text { Miles } \\
\text { Traveled } \\
\text { (miles) }\end{array}$ & $\begin{array}{c}\text { Vehicle } \\
\text { Minutes } \\
\text { (min) }\end{array}$ & $\begin{array}{c}\text { Cumulative } \\
\text { Average Speed I } \\
95 \text { and all } \\
\text { Ramps (mph) }\end{array}$ & $\begin{array}{l}\text { Vehicle } \\
\text { Miles } \\
\text { Traveled } \\
\text { (miles) }\end{array}$ & $\begin{array}{l}\text { Vehicle } \\
\text { Minutes } \\
\text { (min) }\end{array}$ & $\begin{array}{c}\text { Cumulative } \\
\text { Average Speed } \\
\text { RI-10 and all } \\
\text { Ramps (mph) }\end{array}$ & $\begin{array}{c}\text { Cumulative } \\
\text { Network } \\
\text { Average Speed } \\
\text { (mph) }\end{array}$ \\
\hline Random Seed Number & A & $\mathbf{B}$ & $\begin{array}{c}\mathrm{C}=\mathrm{A} /(\mathrm{B} / 60 \\
\mathrm{min} / \mathrm{hr})\end{array}$ & $\mathrm{D}$ & E & $\begin{array}{c}\mathrm{F}=\mathrm{D} /(\mathrm{E} / 60 \\
\mathrm{min} / \mathrm{hr})\end{array}$ & $\begin{array}{c}G=(A+D) / \\
{[(B+E) / 60} \\
\text { min } / \mathrm{hr}]\end{array}$ \\
\hline 1 & 43851.9 & 45570.2 & 57.7 & 11112.2 & 11743.2 & 56.8 & 57.5 \\
\hline 33 & 44001.3 & 45751.3 & 57.7 & 10919.2 & 11541.2 & 56.8 & 57.5 \\
\hline 99 & 44134.2 & 45978.2 & 57.6 & 7551.9 & 147457.9 & 3.1 & 16.0 \\
\hline Conmulative Average Speed & & & 57.7 & & & 10.4 & 31.5 \\
\hline Network I & & & & & Simula & ion Set Number & 4.0 \\
\hline & & nterstate 95 & North & & lighway Ro & Ite 10 & \\
\hline $\begin{array}{l}\text { APeak AM Volume; } 0 \% \\
\text { Wirnela } 2 \text { Lane Block; } 20 \\
\text { M/h In }\end{array}$ & $\begin{array}{l}\text { Vehicle } \\
\text { Miles } \\
\text { Traveled } \\
\text { (miles) }\end{array}$ & $\begin{array}{c}\text { Vehicle } \\
\text { Minutes } \\
\text { (min) }\end{array}$ & $\begin{array}{c}\text { Cumulative } \\
\text { Average Speed I } \\
95 \text { and all } \\
\text { Ramps (mph) }\end{array}$ & $\begin{array}{c}\text { Vehicle } \\
\text { Miles } \\
\text { Traveled } \\
\text { (miles) }\end{array}$ & $\begin{array}{l}\text { Vehicle } \\
\text { Minutes } \\
\text { (min) }\end{array}$ & $\begin{array}{c}\text { Cumulative } \\
\text { Average Speed } \\
\text { RI-10 and all } \\
\text { Ramps (mph) }\end{array}$ & $\begin{array}{c}\text { Cumulative } \\
\text { Network } \\
\text { Average Speed } \\
\text { (mph) }\end{array}$ \\
\hline Random Seed Number & A & B & $\begin{array}{c}\mathrm{C}=\mathrm{A} /(\mathrm{B} / 60 \\
\mathrm{min} / \mathrm{hr})\end{array}$ & $\mathrm{D}$ & $\mathrm{E}$ & $\begin{array}{c}\mathrm{F}=\mathrm{D} /(\mathrm{E} / 60 \\
\mathrm{min} / \mathrm{hr})\end{array}$ & $\begin{array}{c}G=(A+D) / \\
{[(B+E) / 60} \\
\text { min/hrl }\end{array}$ \\
\hline 1 & 44053.1 & 55943.9 & 47.2 & 10933.6 & 11554.1 & 56.8 & 48.9 \\
\hline 33 & 43811.6 & 55992.1 & 46.9 & 10858.2 & 11456.9 & 56.9 & 48.6 \\
\hline 99 & 43798.8 & 55348.4 & 47.5 & 10876.7 & 11471.4 & 56.9 & 49.1 \\
\hline Cumulative Average Speed & & & 47.2 & & & 56.8 & 48.9 \\
\hline
\end{tabular}




\begin{tabular}{|c|c|c|c|c|c|c|c|}
\hline \multirow{2}{*}{ Network Description } & \multicolumn{6}{|c|}{ Simulation Set Number } & 5.0 \\
\hline & \multicolumn{3}{|c|}{ Interstate 95 North } & \multicolumn{3}{|c|}{ Highway Route 10} & \\
\hline $\begin{array}{l}\text { Peak AM Volume; } 0 \% \\
2 \text { Lane Block; } 30\end{array}$ & $\begin{array}{c}\text { Vehicle } \\
\text { Miles } \\
\text { Traveled } \\
\text { (miles) }\end{array}$ & $\begin{array}{c}\text { Vehicle } \\
\text { Minutes } \\
\text { (min) }\end{array}$ & $\begin{array}{c}\text { Cumulative } \\
\text { Average Speed I } \\
95 \text { and all } \\
\text { Ramps (mph) }\end{array}$ & $\begin{array}{c}\text { Vehicle } \\
\text { Miles } \\
\text { Traveled } \\
\text { (miles) }\end{array}$ & $\begin{array}{l}\text { Vehicle } \\
\text { Minutes } \\
\text { (min) }\end{array}$ & $\begin{array}{c}\text { Cumulative } \\
\text { Average Speed } \\
\text { RI-10 and all } \\
\text { Rarmps (mph) }\end{array}$ & $\begin{array}{c}\text { Cumulative } \\
\text { Network } \\
\text { Average Speed } \\
\text { (mph) }\end{array}$ \\
\hline Random Seed Number & A & B & $\begin{array}{c}C=A /(B / 60 \\
m i n / h r)\end{array}$ & D & E & $\begin{array}{c}\mathrm{F}=\mathrm{D} /(\mathrm{E} / 60 \\
\mathrm{min} / \mathrm{hr})\end{array}$ & $\begin{array}{c}G=(A+D) / \\
{[(B+E) / 60} \\
\min / h r]\end{array}$ \\
\hline I & 43943.3 & 67862.3 & 38.9 & 9979.2 & 27395.8 & 21.9 & 34.0 \\
\hline 33 & 43775.3 & 68100.5 & 38.6 & 10965.3 & 11554.9 & 56.9 & 41.2 \\
\hline 99 & 43839.0 & 67141.7 & 39.2 & 10875.2 & 12632.7 & 51.7 & 41.2 \\
\hline Cumulative Average Speed & & & 38.9 & & & 37.0 & 38.5 \\
\hline \multirow{2}{*}{ Network Description } & \multicolumn{6}{|c|}{ Simulation Set Number } & 6.0 \\
\hline & \multicolumn{3}{|c|}{ Interstate 95 North } & \multicolumn{3}{|c|}{ Highway Route 10} & \\
\hline 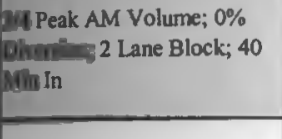 & $\begin{array}{l}\text { Vehicle } \\
\text { Miles } \\
\text { Traveled } \\
\text { (miles) }\end{array}$ & $\begin{array}{c}\text { Vehicle } \\
\text { Minutes } \\
\text { (min) }\end{array}$ & $\begin{array}{c}\text { Cumulative } \\
\text { Average Speed I } \\
95 \text { and all } \\
\text { Ramps (mph) }\end{array}$ & $\begin{array}{l}\text { Vehicle } \\
\text { Miles } \\
\text { Traveled } \\
\text { (miles) }\end{array}$ & $\begin{array}{l}\text { Vehicle } \\
\text { Minutes } \\
\text { (min) }\end{array}$ & $\begin{array}{c}\text { Curmulative } \\
\text { Average Speed } \\
\text { RI-10 and all } \\
\text { Ramps (mph) }\end{array}$ & $\begin{array}{c}\text { Cumulative } \\
\text { Network } \\
\text { Average Speed } \\
\text { (mph) }\end{array}$ \\
\hline Random Seed Number & A & B & $\begin{array}{c}\mathrm{C}=\mathrm{A} /(\mathrm{B} / 60 \\
\mathrm{min} / \mathrm{hr})\end{array}$ & D & E & $\begin{array}{c}\mathrm{F}=\mathrm{D} /(\mathrm{E} / 60 \\
\mathrm{min} / \mathrm{hr})\end{array}$ & $\begin{array}{c}\mathrm{G}=(\mathrm{A}+\mathrm{D}) \\
{[(\mathrm{B}+\mathrm{E}) / 60} \\
\mathrm{min} / \mathrm{hr}]\end{array}$ \\
\hline 1 & 43782.1 & 84979.8 & 30.9 & 11112.2 & 11743.2 & 56.8 & 34.1 \\
\hline 33 & 43813.4 & 86644.6 & 30.3 & 10919.2 & 11541.2 & 56.8 & 33.4 \\
\hline 99 & 43775.0 & 83024.6 & 31.6 & 7551.9 & 147457.9 & 3.1 & 13.4 \\
\hline Cumulative Average Speed & & & 31.0 & & & 10.4 & 22.7 \\
\hline \multirow{2}{*}{ Network Description } & \multicolumn{6}{|c|}{ Simulation Set Number } & 7.0 \\
\hline & \multicolumn{3}{|c|}{ Interstate 95 North } & \multicolumn{3}{|c|}{ Highway Route 10} & \\
\hline $\begin{array}{l}\text { Peak AM Volume; } 0 \% \\
\text { Wh In } 3 \text { Lane Block; } 20\end{array}$ & $\begin{array}{c}\text { Vehicle } \\
\text { Miles } \\
\text { Traveled } \\
\text { (miles) }\end{array}$ & $\begin{array}{c}\text { Vehicle } \\
\text { Minutes } \\
\text { (min) }\end{array}$ & $\begin{array}{c}\text { Cumulative } \\
\text { Average Speed I } \\
95 \text { and all } \\
\text { Ramps (mph) }\end{array}$ & $\begin{array}{l}\text { Vehicle } \\
\text { Miles } \\
\text { Traveled } \\
\text { (miles) }\end{array}$ & $\begin{array}{l}\text { Vehicle } \\
\text { Minutes } \\
\text { (min) }\end{array}$ & $\begin{array}{c}\text { Cumulative } \\
\text { Average Speed } \\
\text { RI-10 and all } \\
\text { Ramps (mph) }\end{array}$ & $\begin{array}{c}\text { Curmulative } \\
\text { Network } \\
\text { Average Speed } \\
\text { (mph) }\end{array}$ \\
\hline Random Seed Number & A & B & $\begin{array}{c}\mathrm{C}=\mathrm{A} /(\mathrm{B} / 60 \\
\mathrm{min} / \mathrm{hr})\end{array}$ & D & $\mathbf{E}$ & $\begin{array}{c}\mathrm{F}=\mathrm{D} /(\mathrm{E} / 60 \\
\min / \mathrm{hr})\end{array}$ & $\begin{array}{c}\mathrm{G}=(\mathrm{A}+\mathrm{D}) / \\
{[(\mathrm{B}+\mathrm{E}) / 60} \\
\text { nin } / \mathrm{hr} \\
\end{array}$ \\
\hline 1 & 43796.7 & 98712.5 & 26.6 & 10933.6 & 11554.1 & 56.8 & 29.8 \\
\hline 33 & 43770.7 & 88247.5 & 29.8 & 10858.2 & 11456.9 & 56.9 & 32.9 \\
\hline 99 & 43813.6 & 89628.5 & 29.3 & 10876.7 & 11471.4 & 56.9 & 32.5 \\
\hline Comulative Average Speed & & & 28.5 & & & 56.8 & 31.6 \\
\hline \multirow{2}{*}{ Network Description } & \multicolumn{6}{|c|}{ Simulation Set Number } & 8.0 \\
\hline & \multicolumn{3}{|c|}{ Interstate 95 North } & \multicolumn{3}{|c|}{ Highway Route 10} & \\
\hline 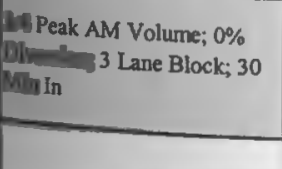 & $\begin{array}{c}\text { Vehicle } \\
\text { Miles } \\
\text { Traveled } \\
\text { (miles) }\end{array}$ & $\begin{array}{c}\text { Vehicle } \\
\text { Minutes } \\
\text { (min) }\end{array}$ & $\begin{array}{c}\text { Cumulative } \\
\text { Average Speed I } \\
95 \text { and all } \\
\text { Ramps (mph) }\end{array}$ & $\begin{array}{l}\text { Vehicle } \\
\text { Miles } \\
\text { Traveled } \\
\text { (miles) }\end{array}$ & $\begin{array}{l}\text { Vehicle } \\
\text { Minutes } \\
\text { (min) }\end{array}$ & $\begin{array}{c}\text { Cumulative } \\
\text { Average Speed } \\
\text { RI-I0 and all } \\
\text { Ramps (mph) }\end{array}$ & $\begin{array}{c}\text { Curmulative } \\
\text { Network } \\
\text { Average Speed } \\
\text { (mph) }\end{array}$ \\
\hline Random Seed Number & A & B & $\begin{array}{c}C=A /(B / 60 \\
\text { min } / \mathrm{hr})\end{array}$ & $\mathrm{D}$ & $\mathrm{E}$ & $\begin{array}{c}F=D /(E / 60 \\
\mathrm{min} / \mathrm{hr})\end{array}$ & $\begin{array}{c}\mathrm{G}=(\mathrm{A}+\mathrm{D})] \\
{[(\mathrm{B}+\mathrm{E}) / 60} \\
\mathrm{min} / \mathrm{hr}]\end{array}$ \\
\hline 1 & 43743.9 & 148656.4 & 17.7 & 9979.2 & 27395.8 & 21.9 & 18.3 \\
\hline 33 & 43745.7 & 121517.8 & 21.6 & 10965.3 & 11554.9 & 56.9 & 24.7 \\
\hline 99 & 43598.2 & 119532.1 & 21.9 & 10875.2 & 12632.7 & 51.7 & 24.7 \\
\hline Cumulative Average Speed & & & 20.2 & & & 37.0 & 22.1 \\
\hline
\end{tabular}




\begin{tabular}{|c|c|c|c|c|c|c|c|}
\hline \multirow{3}{*}{\begin{tabular}{|l} 
Network Description \\
M Peak AM Volume; $0 \%$ \\
The Block; 40
\end{tabular}} & \multicolumn{6}{|c|}{ Simulation Set Number } & 9.0 \\
\hline & \multicolumn{3}{|c|}{ Interstate 95 North } & \multicolumn{3}{|c|}{ Highway Route 10} & \\
\hline & $\begin{array}{l}\text { Vehicle } \\
\text { Miles } \\
\text { Traveled } \\
\text { (miles) }\end{array}$ & $\begin{array}{c}\text { Vehicle } \\
\text { Minutes } \\
\text { (min) }\end{array}$ & $\begin{array}{c}\text { Cumulative } \\
\text { Average Speed I } \\
95 \text { and all } \\
\text { Ramps (mph) }\end{array}$ & $\begin{array}{c}\text { Vehicle } \\
\text { Miles } \\
\text { Traveled } \\
\text { (miles) }\end{array}$ & $\begin{array}{c}\text { Vehicle } \\
\text { Minutes } \\
\text { (min) }\end{array}$ & $\begin{array}{c}\text { Cumulative } \\
\text { Average Speed } \\
\text { RI-10 and all } \\
\text { Ramps (mph) }\end{array}$ & $\begin{array}{c}\text { Cumulative } \\
\text { Network } \\
\text { Average Speed } \\
\text { (mph) }\end{array}$ \\
\hline Random Seed Number & $\mathbf{A}$ & B & $\begin{array}{c}\mathrm{C}=\mathrm{A} /(\mathrm{B} / 60 \\
\mathrm{min} / \mathrm{hr})\end{array}$ & $\mathbf{D}$ & E & $\begin{array}{c}\mathrm{F}=\mathrm{D} /(\mathrm{E} / 60 \\
\mathrm{min} / \mathrm{hr})\end{array}$ & $\begin{array}{c}\mathrm{G}=(\mathrm{A}+\mathrm{D}) / \\
{[(\mathrm{B}+\mathrm{E}) / 60} \\
\mathrm{min} / \mathrm{hr}]\end{array}$ \\
\hline 1 & 43572.6 & 215791.0 & 12.1 & 11112.2 & 11743.2 & 56.8 & 14.4 \\
\hline 33 & 46968.3 & 175084.7 & 16.1 & 10919.2 & 11541.2 & 56.8 & 18.6 \\
\hline 99 & 46968.3 & 175084.7 & 16.1 & 7551.9 & 147457.9 & 3.1 & 10.1 \\
\hline Cumulative Average Speed & & & 14.6 & & & 10.4 & 13.6 \\
\hline \multirow{2}{*}{ Network Description } & \multicolumn{6}{|c|}{ Simulation Set Number } & 10.0 \\
\hline & \multicolumn{3}{|c|}{ Interstate 95 North } & \multicolumn{3}{|c|}{ Highway Route 10} & \\
\hline $\begin{array}{l}\text { Peak AM Volume; } 20 \% \\
\text { In }\end{array}$ & $\begin{array}{l}\text { Vehicle } \\
\text { Miles } \\
\text { Traveled } \\
\text { (miles) }\end{array}$ & $\begin{array}{c}\text { Vehicle } \\
\text { Minutes } \\
\text { (min) }\end{array}$ & $\begin{array}{c}\text { Cumulative } \\
\text { Average Speed I } \\
95 \text { and all } \\
\text { Ramps (mph) }\end{array}$ & $\begin{array}{l}\text { Vehicle } \\
\text { Miles } \\
\text { Traveled } \\
\text { (miles) }\end{array}$ & $\begin{array}{c}\text { Vehicle } \\
\text { Minutes } \\
\text { (min) }\end{array}$ & $\begin{array}{c}\text { Cumulative } \\
\text { Average Speed } \\
\text { RI-10 and all } \\
\text { Ramps (mph) }\end{array}$ & $\begin{array}{c}\text { Cumulative } \\
\text { Network } \\
\text { Average Speed } \\
\text { (mph) }\end{array}$ \\
\hline Random Seed Number & A & B & $\begin{array}{c}\mathrm{C}=\mathrm{A} /(\mathrm{B} / 60 \\
\min / \mathrm{hr})\end{array}$ & D & $\mathbf{E}$ & $\begin{array}{c}\mathrm{F}=\mathrm{D} /(\mathrm{E} / 60 \\
\mathrm{min} / \mathrm{hr})\end{array}$ & $\begin{array}{c}G=(A+D) / \\
{[(B+E) / 60} \\
\text { min/hrl }\end{array}$ \\
\hline 1 & 42494.6 & 43467.1 & 58.7 & 11602.1 & 12314.6 & 56.5 & 58.2 \\
\hline 33 & 42435.9 & 43453.8 & 58.6 & 11724.0 & 12396.1 & 56.7 & 58.2 \\
\hline 99 & 42393.9 & 43402.8 & 58.6 & 11593.9 & 12290.2 & 56.6 & 58.2 \\
\hline Cumulative Average Speed & & & 58.6 & & & 56.6 & 58.2 \\
\hline \multirow{2}{*}{ Network Description } & \multicolumn{6}{|c|}{ Simulation Set Number } & 11.0 \\
\hline & \multicolumn{3}{|c|}{ Interstate 95 North } & \multicolumn{3}{|c|}{ Highway Route 10} & \\
\hline $\begin{array}{l}\text { IS Peak AM Volume; } 20 \% \\
\text { in } 1 \text { Lane Block; } 30\end{array}$ & $\begin{array}{c}\text { Vehicle } \\
\text { Miles } \\
\text { Traveled } \\
\text { (miles) }\end{array}$ & $\begin{array}{c}\text { Vehicle } \\
\text { Minutes } \\
\text { (min) }\end{array}$ & $\begin{array}{c}\text { Cumulative } \\
\text { Average Speed I } \\
95 \text { and all } \\
\text { Ramps (mph) }\end{array}$ & \begin{tabular}{|c} 
Vehicle \\
Miles \\
Traveled \\
(miles)
\end{tabular} & $\begin{array}{l}\text { Vehicle } \\
\text { Minutes } \\
\text { (min) }\end{array}$ & $\begin{array}{c}\text { Cumulative } \\
\text { Average Speed } \\
\text { Rl-10 and all } \\
\text { Ramps (mph) }\end{array}$ & $\begin{array}{c}\text { Cumulative } \\
\text { Network } \\
\text { Average Speed } \\
\text { (mph) }\end{array}$ \\
\hline Random Seed Number & A & B & $\begin{array}{c}\mathrm{C}=\underset{\mathrm{min} / \mathrm{hr})}{\mathrm{A} /(\mathrm{B} / 60} \\
\end{array}$ & D & $\mathbf{E}$ & $\begin{array}{c}\mathrm{F}=\underset{\mathrm{D} /(\mathrm{E} / 60}{\mathrm{min} / \mathrm{hr})}\end{array}$ & $\begin{array}{c}G=(A+D) / \\
{[(B+E) / 60} \\
\min / h r]\end{array}$ \\
\hline 1 & 41476.8 & 42392.8 & 58.7 & 12157.3 & 12871.2 & 56.7 & 58.2 \\
\hline 33 & 41393.8 & 42206.4 & 58.8 & 12162.4 & 12898.8 & 56.6 & 58.3 \\
\hline 99 & 41563.8 & 42526.2 & 58.6 & 12105.0 & 12828.7 & 56.6 & 58.2 \\
\hline Cumulative Average Speed & & & 58.7 & & & 56.6 & 58.2 \\
\hline Network Description & & & & & Simula & on Set Number & 12.0 \\
\hline & & Interstate 95 & 5 North & & Highway Ro & ute 10 & \\
\hline $\begin{array}{l}\text { Peak AM Volume; } 20 \% \\
\text { In }\end{array}$ & $\begin{array}{l}\text { Vehicle } \\
\text { Miles } \\
\text { Traveled } \\
\text { (miles) }\end{array}$ & $\begin{array}{c}\text { Vehicle } \\
\text { Minutes } \\
\text { (min) }\end{array}$ & $\begin{array}{c}\text { Cumulative } \\
\text { Average Speed I } \\
95 \text { and all } \\
\text { Ramps (mph) }\end{array}$ & $\begin{array}{l}\text { Vehicle } \\
\text { Miles } \\
\text { Traveled } \\
\text { (miles) }\end{array}$ & $\begin{array}{c}\text { Vehicle } \\
\text { Minutes } \\
\text { (min) }\end{array}$ & $\begin{array}{c}\text { Cumulative } \\
\text { Average Speed } \\
\text { RI-10 and all } \\
\text { Ramps (mph) }\end{array}$ & $\begin{array}{c}\text { Cumulative } \\
\text { Network } \\
\text { Average Speed } \\
\text { (mph) }\end{array}$ \\
\hline Random Seed Number & A & B & $\begin{array}{c}\mathrm{C}=\mathrm{A} /(\mathrm{B} / 60 \\
\mathrm{min} / \mathrm{hr})\end{array}$ & D & $\mathbf{E}$ & $\begin{array}{c}F=D /(E / 60 \\
\min / \mathrm{hr})\end{array}$ & $\begin{array}{c}\mathrm{G}=(\mathrm{A}+\mathrm{D}) / \\
{[(\mathrm{B}+\mathrm{E}) / 60} \\
\text { min/hr] }\end{array}$ \\
\hline 1 & 40662.6 & 41406.1 & 58.9 & 4881.1 & 213656.0 & 1.4 & 10.7 \\
\hline 33 & 40919.4 & 41829.3 & 58.7 & 12714.5 & 13521.4 & 56.4 & 58.1 \\
\hline $\begin{array}{r}99 \\
\end{array}$ & 40826.5 & 41578.8 & 58.9 & 12564.4 & 13327.7 & 56.6 & 58.3 \\
\hline Crmmulative Average Speed & & & 58.8 & & & 7.5 & 25.1 \\
\hline
\end{tabular}




\begin{tabular}{|c|c|c|c|c|c|c|c|}
\hline \multirow{3}{*}{\begin{tabular}{|c|} 
Network Description \\
C8 Peak AM Volume; $20 \%$ \\
2 Lane Block; 20
\end{tabular}} & \multicolumn{6}{|c|}{ Simulation Set Number } & 13.0 \\
\hline & \multicolumn{3}{|c|}{ Interstate 95 North } & \multicolumn{3}{|c|}{ Highway Route 10} & \\
\hline & $\begin{array}{l}\text { Vehicle } \\
\text { Miles } \\
\text { Traveled } \\
\text { (miles) }\end{array}$ & $\begin{array}{c}\text { Vehicle } \\
\text { Minutes } \\
\text { (min) }\end{array}$ & $\begin{array}{c}\text { Cumulative } \\
\text { Average Speed I } \\
95 \text { and all } \\
\text { Ramps (mph) }\end{array}$ & $\begin{array}{l}\text { Vehicle } \\
\text { Miles } \\
\text { Traveled } \\
\text { (miles) }\end{array}$ & $\begin{array}{l}\text { Vehicle } \\
\text { Minutes } \\
\text { (min) }\end{array}$ & $\begin{array}{c}\text { Cumulative } \\
\text { Average Speed } \\
\text { RI-10 and all } \\
\text { Ramps (mph) }\end{array}$ & $\begin{array}{c}\text { Curmulative } \\
\text { Network } \\
\text { Average Speed } \\
\text { (mph) }\end{array}$ \\
\hline Random Seed Number & A & B & $\begin{array}{c}\mathrm{C}=\mathrm{A} /(\mathrm{B} / 60 \\
\mathrm{min} / \mathrm{hr})\end{array}$ & D & E & $\begin{array}{c}\mathrm{F}=\mathrm{D} /(\mathrm{E} / 60 \\
\mathrm{min} / \mathrm{hr})\end{array}$ & $\begin{array}{c}=(A+D) / \\
{[(B+E) / 60} \\
\text { min } / h r] \\
\end{array}$ \\
\hline 1 & 42338.2 & 47578.6 & 53.4 & 11602.1 & 12314.6 & 56.5 & 54.0 \\
\hline 33 & 42171.2 & 78924.9 & 32.1 & 11724.0 & 12396.1 & 56.7 & 35.4 \\
\hline 99 & 42605.4 & 46819.6 & 54.6 & 11593.9 & 12290.2 & 56.6 & 55.0 \\
\hline Cumulative Average Speed & & & 44.0 & & & 56.6 & 46.2 \\
\hline \multirow{2}{*}{ Network Description } & \multicolumn{6}{|c|}{ Simulation Set Number } & 14.0 \\
\hline & \multicolumn{3}{|c|}{ Interstate 95 North } & \multicolumn{3}{|c|}{ Highway Route 10} & \\
\hline $\begin{array}{l}\text { Peak AM Volume; } 20 \% \\
\text { Milin } 2 \text { Lane Block; } 30\end{array}$ & $\begin{array}{l}\text { Vehicle } \\
\text { Miles } \\
\text { Traveled } \\
\text { (miles) }\end{array}$ & $\begin{array}{c}\text { Vehicle } \\
\text { Minutes } \\
\text { (min) }\end{array}$ & $\begin{array}{c}\text { Cumulative } \\
\text { Average Speed I } \\
95 \text { and all } \\
\text { Ramps (mph) }\end{array}$ & $\begin{array}{c}\text { Vehicle } \\
\text { Miles } \\
\text { Traveled } \\
\text { (miles) }\end{array}$ & $\begin{array}{c}\text { Vehicle } \\
\text { Minutes } \\
\text { (min) }\end{array}$ & $\begin{array}{c}\text { Cumulative } \\
\text { Average Speed } \\
\text { RI-10 and all } \\
\text { Ramps (mph) }\end{array}$ & $\begin{array}{c}\text { Cumulative } \\
\text { Network } \\
\text { Average Speed } \\
\text { (mph) }\end{array}$ \\
\hline Random Seed Number & A & B & $\begin{array}{c}\mathrm{C}=\underset{\min / \mathrm{hr})}{\mathrm{A}} /(\mathrm{B} / 60 \\
\end{array}$ & $\mathrm{D}$ & $\mathbf{E}$ & $\begin{array}{c}\mathrm{F}=\mathrm{D} /(\mathrm{E} / 60 \\
\mathrm{min} / \mathrm{hr})\end{array}$ & $\begin{array}{c}\mathrm{G}=(\mathrm{A}+\mathrm{D})] \\
{[(\mathrm{B}+\mathrm{E}) / 60} \\
\mathrm{min} / \mathrm{hr}]\end{array}$ \\
\hline 1. & 41510.7 & 49937.5 & 49.9 & 12157.3 & 12871.2 & 56.7 & 51.3 \\
\hline 33 & 41462.5 & 128456.1 & 19.4 & 12162.4 & 12898.8 & 56.6 & 22.8 \\
\hline 99 & 41579.6 & 47893.8 & 52.1 & 12105.0 & 12828.7 & 56.6 & 53.0 \\
\hline Cumulative Average Speed & & & 33.0 & & & 56.6 & 36.5 \\
\hline \multirow{2}{*}{ Network Description } & \multicolumn{6}{|c|}{ Simulation Set Number } & 15.0 \\
\hline & \multicolumn{3}{|c|}{ Interstate 95 North } & \multicolumn{3}{|c|}{ Highway Route 10} & \\
\hline $\begin{array}{l}\text { WS Peak AM Volume; } 20 \% \\
\text { Denes } 2 \text { Lane Block; } 40 \\
\text { Minin }\end{array}$ & $\begin{array}{l}\text { Vehicle } \\
\text { Miles } \\
\text { Traveled } \\
\text { (miles) }\end{array}$ & $\begin{array}{c}\text { Vehicle } \\
\text { Minutes } \\
\text { (min) }\end{array}$ & $\begin{array}{c}\text { Cumulative } \\
\text { Average Speed II } \\
95 \text { and all } \\
\text { Ramps (mph) }\end{array}$ & $\begin{array}{l}\text { Vehicle } \\
\text { Miles } \\
\text { Traveled } \\
\text { (miles) }\end{array}$ & $\begin{array}{c}\text { Vehicle } \\
\text { Minutes } \\
\text { (min) }\end{array}$ & $\begin{array}{c}\text { Cumulative } \\
\text { Average Speed } \\
\text { RI-10 and all } \\
\text { Ramps (mph) }\end{array}$ & $\begin{array}{c}\text { Cumulative } \\
\text { Network } \\
\text { Average Speed } \\
\text { (mph) }\end{array}$ \\
\hline Random Seed Number & A & B & $\begin{array}{c}\mathrm{C}=\mathrm{A} /(\mathrm{B} / 60 \\
\mathrm{min} / \mathrm{hr})\end{array}$ & $\mathrm{D}$ & $\mathbf{E}$ & $\begin{array}{c}\mathrm{F}=\mathrm{D} /(\mathrm{E} / 60 \\
\mathrm{min} / \mathrm{hr})\end{array}$ & $\begin{array}{c}G=(A+D)] \\
{[(B+E) / 60} \\
\min / \mathrm{hr}]\end{array}$ \\
\hline 1 & 40731.5 & 52669.5 & 46.4 & 4881.1 & 213656.0 & 1.4 & 10.3 \\
\hline 33 & 40548.4 & 174586.5 & 13.9 & 12714.5 & 13521.4 & 56.4 & 17.0 \\
\hline 99 & 41016.8 & 50242.0 & 49.0 & 12564.4 & 13327.7 & 56.6 & 50.6 \\
\hline Cumulative Average Speed & & & 26.4 & & & 7.5 & 17.7 \\
\hline \multirow{2}{*}{ Network Description } & \multicolumn{6}{|c|}{ Simulation Set Number } & 16.0 \\
\hline & \multicolumn{3}{|c|}{ Interstate 95 North } & \multicolumn{3}{|c|}{ Highway Route 10} & \\
\hline $\begin{array}{l}\text { M6 Peak AM Volume; } 20 \% \\
\text { Mint in } 3 \text { Lane Block; } 20\end{array}$ & $\begin{array}{c}\text { Vehicle } \\
\text { Miles } \\
\text { Traveled } \\
\text { (miles) }\end{array}$ & $\begin{array}{c}\text { Vehicle } \\
\text { Minutes } \\
\text { (min) }\end{array}$ & $\begin{array}{c}\text { Cumulative } \\
\text { Average Speed I } \\
95 \text { and all } \\
\text { Ranps (mph) }\end{array}$ & $\begin{array}{c}\text { Vehicle } \\
\text { Miles } \\
\text { Traveled } \\
\text { (miles) }\end{array}$ & $\begin{array}{c}\text { Vehicle } \\
\text { Minutes } \\
\text { (min) }\end{array}$ & $\begin{array}{c}\text { Cumulative } \\
\text { Average Speed } \\
\text { RI-10 and all } \\
\text { Ramps (mph) }\end{array}$ & $\begin{array}{c}\text { Cumulative } \\
\text { Network } \\
\text { Average Speed } \\
\text { (mph) }\end{array}$ \\
\hline Random Seed Number & A & B & $\begin{array}{c}\mathrm{C}=\mathrm{A} /(\mathrm{B} / 60 \\
\mathrm{min} / \mathrm{hr})\end{array}$ & D & $\mathbf{E}$ & $\begin{array}{c}\mathrm{F}=\mathrm{D} /(\mathrm{E} / 60 \\
\mathrm{min} / \mathrm{hr})\end{array}$ & $\begin{array}{c}G=(A+D) / \\
{[(B+E) / 60} \\
\text { min/hr] }\end{array}$ \\
\hline 1 & 42425.3 & 100926.5 & 25.2 & 11602.1 & 12314.6 & 56.5 & 28.6 \\
\hline 33 & 42173.8 & 74048.9 & 34.2 & 11724.0 & 12396.1 & 56.7 & 37.4 \\
\hline 99 & 42264.6 & 73651.7 & 34.4 & 11593.9 & 12290.2 & 56.6 & 37.6 \\
\hline Cumulative Average Speed & & & 30.6 & & & 56.6 & 34.0 \\
\hline
\end{tabular}




\begin{tabular}{|c|c|c|c|c|c|c|c|}
\hline \multirow{2}{*}{ Network Description } & \multicolumn{6}{|c|}{ Simusation Set Number } & 17.0 \\
\hline & \multicolumn{3}{|c|}{ Interstate 95 North } & \multicolumn{3}{|c|}{ Highway Route 10} & \\
\hline $\begin{array}{l}\text { Peak AM Volume; } 20 \% \\
\text { In }\end{array}$ & $\begin{array}{l}\text { Vehicle } \\
\text { Miles } \\
\text { Traveled } \\
\text { (miles) }\end{array}$ & $\begin{array}{l}\text { Vehicle } \\
\text { Minutes } \\
\text { (min) }\end{array}$ & $\begin{array}{c}\text { Cumulative } \\
\text { Average Speed I } \\
95 \text { and all } \\
\text { Ramps (mph) }\end{array}$ & $\begin{array}{l}\text { Vehicle } \\
\text { Miles } \\
\text { Traveled } \\
\text { (miles) }\end{array}$ & $\begin{array}{l}\text { Vehicle } \\
\text { Minutes } \\
\text { (min) }\end{array}$ & $\begin{array}{l}\text { Cumulative } \\
\text { Average Speed } \\
\text { RI-10 and all } \\
\text { Ramps (mph) }\end{array}$ & $\begin{array}{c}\text { Cumulative } \\
\text { Network } \\
\text { Average Speed } \\
\text { (mph) }\end{array}$ \\
\hline Random Seed Number & A & B & $\begin{array}{c}\mathrm{C}=\mathrm{A} /(\mathrm{B} / 60 \\
\mathrm{min} / \mathrm{hr})\end{array}$ & D & E & $\begin{array}{c}\mathrm{F}=\mathrm{D} /(\mathrm{E} / 60 \\
\mathrm{min} / \mathrm{hr})\end{array}$ & $\begin{array}{c}\mathrm{G}=(\mathrm{A}+\mathrm{D})] \\
{[(\mathrm{B}+\mathrm{E}) / 60} \\
\text { min/hr] }\end{array}$ \\
\hline 1 & 41606.5 & 144752.5 & 17.2 & 12157.3 & 12871.2 & 56.7 & 20.5 \\
\hline 33 & 41290.5 & 118118.9 & 21.0 & 12162.4 & 12898.8 & 56.6 & 24.5 \\
\hline 99 & 41491.6 & 89409.7 & 27.8 & 12105.0 & 12828.7 & 56.6 & 31.5 \\
\hline Cumulative Average Speed & & & 21.2 & & & 56.6 & 24.7 \\
\hline \multirow{2}{*}{ Network Description } & \multicolumn{6}{|c|}{ Simulation Set Number } & 18.0 \\
\hline & \multicolumn{3}{|c|}{ Interstate 95 North } & \multicolumn{3}{|c|}{ Highway Route 10} & \\
\hline $\begin{array}{l}\text { Peak AM Volume; } 20 \% \\
\text { Milves in } 3 \text { Lane Block; } 40\end{array}$ & $\begin{array}{l}\text { Vehicle } \\
\text { Miles } \\
\text { Traveled } \\
\text { (miles) }\end{array}$ & $\begin{array}{c}\text { Vehicle } \\
\text { Minutes } \\
\text { (min) }\end{array}$ & $\begin{array}{c}\text { Cumulative } \\
\text { Average Speed I } \\
95 \text { and all } \\
\text { Ramps (mph) }\end{array}$ & $\begin{array}{l}\text { Vehicle } \\
\text { Miles } \\
\text { Traveled } \\
\text { (miles) }\end{array}$ & $\begin{array}{c}\text { Vehicle } \\
\text { Minutes } \\
(\min )\end{array}$ & $\begin{array}{c}\text { Cumulative } \\
\text { Average Speed } \\
\text { RI-10 and all } \\
\text { Ramps (mph) }\end{array}$ & $\begin{array}{l}\text { Cumulative } \\
\text { Network } \\
\text { Average Speed } \\
\text { (mph) }\end{array}$ \\
\hline Random Seed Number & A & B & $\begin{array}{c}\mathrm{C}=\mathrm{A} /(\mathrm{B} / 60 \\
\mathrm{min} / \mathrm{hr})\end{array}$ & D & E & $\begin{array}{c}F=D /(E / 60 \\
\min / \mathrm{hr})\end{array}$ & $\begin{array}{c}G=(A+D)] \\
{[(B+E) / 60} \\
\text { nin } / \mathrm{hr}] \\
\end{array}$ \\
\hline 1 & 40511.5 & 161909.1 & 15.0 & 16952.1 & 18452.7 & 55.1 & 19.1 \\
\hline 33 & 39828.9 & 159016.2 & 15.0 & 16635.6 & 18058.2 & 55.3 & 19.1 \\
\hline 99 & 40653.4 & 159184.5 & 15.3 & 16739.7 & 17878.1 & 56.2 & 19.4 \\
\hline Cumulative Average Speed & & & 15.1 & & & 55.5 & 19.2 \\
\hline
\end{tabular}




\begin{tabular}{|c|c|c|c|c|c|c|c|}
\hline \multirow{2}{*}{ Network Description } & \multicolumn{6}{|c|}{ Simulation Set Number } & 1 \\
\hline & \multicolumn{3}{|c|}{ Interstate 95 North } & \multicolumn{3}{|c|}{ Highway Route 10} & \\
\hline $\begin{array}{l}\text { 14 Peak AM Volume; } 0 \% \\
1 \text { Lane Block; } 20 \text { Min In }\end{array}$ & $\begin{array}{l}\text { Vehicle } \\
\text { Miles } \\
\text { Traveled } \\
\text { (miles) }\end{array}$ & $\begin{array}{l}\text { Vehicle } \\
\text { Minutes } \\
\text { (min) }\end{array}$ & $\begin{array}{c}\text { Cumulative } \\
\text { Average Travel } \\
\text { Time I-95 and } \\
\text { all Ramps (nin- } \\
\text { veh mile) }\end{array}$ & $\begin{array}{c}\text { Vehicle Miles } \\
\text { Traveled } \\
\text { (miles) }\end{array}$ & $\begin{array}{l}\text { Vehicle } \\
\text { Minutes } \\
\text { (min) }\end{array}$ & $\begin{array}{c}\text { Cumulative } \\
\text { Average Travel } \\
\text { Time RI-I0 and } \\
\text { all Ramps (mph) }\end{array}$ & $\begin{array}{c}\text { Cumulative } \\
\text { Network } \\
\text { Average } \\
\text { Travel Time } \\
\text { (min / veh } \\
\text { mile) }\end{array}$ \\
\hline Rondom Seed Number & A & B & $\mathrm{C}=\mathrm{B} / \mathrm{A}$ & D & $\mathbf{E}$ & $F=E / D$ & $\begin{array}{c}G=(B+E) / \\
(A+D)\end{array}$ \\
\hline 1 & 43923.3 & 45276.5 & 1.03 & 10933.6 & 11554.1 & 1.06 & 1.04 \\
\hline 33 & 43854.0 & 45283.4 & 1.03 & 10858.2 & 11456.9 & 1.06 & 1.04 \\
\hline 99 & 43627.0 & 45129.6 & 1.03 & 10876.7 & 11471.4 & 1.05 & 1.04 \\
\hline Cumlative Average Travel Time & & & 1.03 & & & 1.06 & 1.04 \\
\hline \multirow{2}{*}{ Network Description } & \multicolumn{6}{|c|}{ Simulation Set Number } & 2 \\
\hline & \multicolumn{3}{|c|}{ Interstate 95 North } & \multicolumn{3}{|c|}{ Highway Route 10} & \\
\hline $\begin{array}{l}\text { Peak AM Volune; 0\% } \\
1 \text { Lane Block; } 30 \text { Min In }\end{array}$ & $\begin{array}{l}\text { Vehicle } \\
\text { Miles } \\
\text { Traveled } \\
\text { (miles) }\end{array}$ & $\begin{array}{l}\text { Vehicle } \\
\text { Minutes } \\
\text { (min) }\end{array}$ & $\begin{array}{c}\text { Cumulative } \\
\text { Average Travel } \\
\text { Time I-95 and } \\
\text { all Ramps (min- } \\
\text { veh mile) }\end{array}$ & $\begin{array}{l}\text { Vehicle Miles } \\
\text { Traveled } \\
\text { (miles) }\end{array}$ & $\begin{array}{l}\text { Vehicle } \\
\text { Minutes } \\
\text { (min) }\end{array}$ & $\begin{array}{c}\text { Cumulative } \\
\text { Average Travel } \\
\text { Time RI- } 10 \text { and } \\
\text { all Ramps (mph) }\end{array}$ & $\begin{array}{c}\text { Cumulative } \\
\text { Network } \\
\text { Average } \\
\text { Travel Time } \\
\text { (min / veh } \\
\text { mile) }\end{array}$ \\
\hline Random Seed Number & A & B & $C=B / A$ & D & E & $\mathrm{F}=\mathrm{E} / \mathrm{D}$ & {$\left[\begin{array}{c}G=(B+E) / \\
(A+D)\end{array}\right.$} \\
\hline 1 & 43542.0 & 45187.3 & 1.04 & 9979.2 & 27395.8 & 2.75 & 1.36 \\
\hline 33 & 44038.0 & 45741.8 & 1.04 & 10965.3 & 11554.9 & 1.05 & 1.04 \\
\hline 99 & 44065.2 & 45701.9 & 1.04 & 10875.2 & 12632.7 & 1.16 & 1.06 \\
\hline Cumulative Average Travel Time & & & 1.04 & & & 1.62 & 1.15 \\
\hline \multirow{2}{*}{ Network Description } & \multicolumn{6}{|c|}{ Simulation Set Number } & 3 \\
\hline & \multicolumn{3}{|c|}{ Interstate 95 North } & \multicolumn{3}{|c|}{ Highway Route 10} & \\
\hline $\begin{array}{l}\text { Meak AM Volume; } 0 \% \\
1 \text { Lane Block; } 40 \mathrm{Min} \text { In }\end{array}$ & $\begin{array}{l}\text { Vehicle } \\
\text { Miles } \\
\text { Traveled } \\
\text { (miles) }\end{array}$ & $\begin{array}{l}\text { Vehicle } \\
\text { Minutes } \\
\text { (min) }\end{array}$ & $\begin{array}{c}\text { Curmulative } \\
\text { Average Travel } \\
\text { Time I-95 and } \\
\text { all Ramps (min-- } \\
\text { veh mile) }\end{array}$ & $\begin{array}{c}\text { Vehicle Miles } \\
\text { Traveled } \\
\text { (miles) }\end{array}$ & $\begin{array}{c}\text { Vehicle } \\
\text { Minutes } \\
\text { (min) }\end{array}$ & $\begin{array}{c}\text { Cumulative } \\
\text { Average Travel } \\
\text { Time RI-10 and } \\
\text { all Ramps (nph) }\end{array}$ & \begin{tabular}{|c} 
Cumulative \\
Network \\
Average \\
Travel Time \\
(min/veh \\
mile)
\end{tabular} \\
\hline Random Seed Number & A & B & $C=B / A$ & D & E & $F=E / D$ & $\begin{array}{c}G=(B+E) \\
(A+D)\end{array}$ \\
\hline 1 & 43851.9 & 45570.2 & 1.04 & 11112.2 & 11743.2 & 1.06 & 1.04 \\
\hline 33 & 44001.3 & 45751.3 & 1.04 & 10919.2 & 11541.2 & 1.06 & 1.04 \\
\hline 99 & 44134.2 & 45978.2 & 1.04 & 7551.9 & 147457.9 & 19.53 & 3.74 \\
\hline Cumulative Average Iravel Time & & & 1.04 & & & 5.77 & 1.91 \\
\hline \multirow{2}{*}{ Network Description } & \multicolumn{6}{|c|}{ Simulation Set Number } & 4 \\
\hline & \multicolumn{3}{|c|}{ Interstate 95 North } & \multicolumn{3}{|c|}{ Highway Route 10} & \\
\hline $\begin{array}{l}\text { IJ Peak AM Volume; 0\% } \\
2 \text { Lane Block; } 20 \text { Min In }\end{array}$ & $\begin{array}{l}\text { Vehicle } \\
\text { Miles } \\
\text { Traveled } \\
\text { (miles) }\end{array}$ & $\begin{array}{l}\text { Vehicle } \\
\text { Minutes } \\
\text { (min) }\end{array}$ & $\begin{array}{c}\text { Cumulative } \\
\text { Average Travel } \\
\text { Time I-95 and } \\
\text { all Ramps (nin- } \\
\text { veh mile) }\end{array}$ & $\begin{array}{c}\text { Vehicle Miles } \\
\text { Traveled } \\
\text { (miles) }\end{array}$ & $\begin{array}{c}\text { Vehicle } \\
\text { Minutes } \\
\text { (min) }\end{array}$ & $\begin{array}{c}\text { Cumulative } \\
\text { Average Travel } \\
\text { Time RJ-10 and } \\
\text { all Ramps (nph) }\end{array}$ & $\begin{array}{c}\text { Cumulative } \\
\text { Network } \\
\text { Average } \\
\text { Travel Time } \\
\text { (min / veh } \\
\text { mile) }\end{array}$ \\
\hline Random Seed Number & A & B & $C=B / A$ & D & $\mathbf{E}$ & $F=E / D$ & $\begin{array}{c}G=(B+E) / \\
(A+D)\end{array}$ \\
\hline 1 & 44053.1 & 55943.9 & 1.27 & 10933.6 & 11554.1 & 1.06 & 1.23 \\
\hline 33 & 43811.6 & 55992.1 & 1.28 & 10858.2 & 11456.9 & 1.06 & 1.23 \\
\hline 99 & 43798.8 & 55348.4 & 1.26 & 10876.7 & 11471.4 & 1.05 & 1.22 \\
\hline Cumulative Average Travel Time & & & 1.27 & & & 1.06 & 1.23 \\
\hline
\end{tabular}




\begin{tabular}{|c|c|c|c|c|c|c|c|}
\hline \multirow{2}{*}{ Network Description } & \multicolumn{6}{|c|}{ Simulation Set Number } & 5 \\
\hline & \multicolumn{3}{|c|}{ Interstate 95 North } & \multicolumn{3}{|c|}{ Highway Route 10} & \\
\hline $\begin{array}{l}\text { Deak AM Volume; } 0 \% \\
2 \text { Lane Block; } 30 \text { Min In }\end{array}$ & $\begin{array}{l}\text { Vehicle } \\
\text { Miles } \\
\text { Traveled } \\
\text { (miles) }\end{array}$ & $\begin{array}{c}\text { Vehicle } \\
\text { Minutes } \\
\text { (min) }\end{array}$ & $\begin{array}{c}\text { Cumulative } \\
\text { Average Travel } \\
\text { Time I-95 and } \\
\text { all Ramps (min- } \\
\text { veh mile) }\end{array}$ & $\begin{array}{c}\text { Vehicle Miles } \\
\text { Traveled } \\
\text { (miles) }\end{array}$ & $\begin{array}{c}\text { Vehicle } \\
\text { Minutes } \\
\text { (min) }\end{array}$ & $\begin{array}{c}\text { Cumulative } \\
\text { Average Travel } \\
\text { Time RI-10 and } \\
\text { all Ramps (mph) }\end{array}$ & \begin{tabular}{|c|} 
Cumulative \\
Network \\
Average \\
Travel Time \\
(min/ veh \\
mile)
\end{tabular} \\
\hline Random Seed Number & A & B & $\mathrm{C}=\mathrm{B} / \mathrm{A}$ & D & $\mathbf{E}$ & $F=E / D$ & $\begin{array}{c}G=(B+E) / \\
(A+D)\end{array}$ \\
\hline 1 & 43943.3 & 67862.3 & 1.54 & 9979.2 & 27395.8 & 2.75 & 1.77 \\
\hline 33 & 43775.3 & 68100.5 & 1.56 & 10965.3 & 11554.9 & 1.05 & 1.46 \\
\hline 99 & 43839.0 & 67141.7 & 1.53 & 10875.2 & 12632.7 & 1.16 & 1.46 \\
\hline Cmulative Average Travel Time & & & 1.54 & & & 1.62 & 1.56 \\
\hline \multirow{2}{*}{ Network Description } & \multicolumn{6}{|c|}{ Simulation Set Number } & 6 \\
\hline & \multicolumn{3}{|c|}{ Interstate 95 North } & \multicolumn{3}{|c|}{ Highway Route 10} & \\
\hline $\begin{array}{l}\text { Peak AM Volume; 0\% } \\
2 \text { Lane Block; } 40 \text { Min In }\end{array}$ & $\begin{array}{l}\text { Vehicle } \\
\text { Miles } \\
\text { Traveled } \\
\text { (miles) }\end{array}$ & $\begin{array}{c}\text { Vehicle } \\
\text { Minutes } \\
\text { (min) }\end{array}$ & $\begin{array}{c}\text { Cumulative } \\
\text { Average Travel } \\
\text { Time I-95 and } \\
\text { all Ramps (min- } \\
\text { veh mile) }\end{array}$ & $\begin{array}{c}\text { Vehicle Miles } \\
\text { Traveled } \\
\text { (miles) }\end{array}$ & $\begin{array}{l}\text { Vehicle } \\
\text { Minutes } \\
\text { (min) }\end{array}$ & $\begin{array}{c}\text { Cumulative } \\
\text { A verage Travel } \\
\text { Time RI-10 and } \\
\text { all Ramps (nph) }\end{array}$ & \begin{tabular}{|c|} 
Cumulative \\
Network \\
Average \\
Travel Time \\
(min/ veh \\
mile) \\
\end{tabular} \\
\hline Random Seed Number & $\mathbf{A}$ & B & $\mathrm{C}=\mathrm{B} / \mathrm{A}$ & D & $\mathbf{E}$ & $F=E / D$ & $\begin{array}{c}G=(B+E) / \\
(A+D)\end{array}$ \\
\hline 1 & 43782.1 & 84979.8 & 1.94 & 11112.2 & 11743.2 & 1.06 & 1.76 \\
\hline 33 & 43813.4 & 86644.6 & 1.98 & 10919.2 & 11541.2 & 1.06 & 1.79 \\
\hline 99 & 43775.0 & 83024.6 & 1.90 & 7551.9 & 147457.9 & 19.53 & 4.49 \\
\hline Cumulative Average Travel Time & & & 1.94 & & & 5.77 & 2.64 \\
\hline \multirow{2}{*}{ Network Description } & \multicolumn{6}{|c|}{ Simulation Set Number } & 7 \\
\hline & \multicolumn{3}{|c|}{ Interstate 95 North } & \multicolumn{3}{|c|}{ Highway Route 10} & \\
\hline $\begin{array}{l}\text { Peak AM Volume; } 0 \% \\
3 \text { Lane Block; } 20 \text { Min In }\end{array}$ & $\begin{array}{l}\text { Vehicle } \\
\text { Miles } \\
\text { Traveled } \\
\text { (miles) }\end{array}$ & $\begin{array}{c}\text { Vehicle } \\
\text { Minutes } \\
\text { (min) }\end{array}$ & $\begin{array}{c}\text { Cumulative } \\
\text { Average Travel } \\
\text { Time I-95 and } \\
\text { all Ramps (min- } \\
\text { veh mile) }\end{array}$ & $\begin{array}{c}\text { Vehicle Miles } \\
\text { Traveled } \\
\text { (miles) }\end{array}$ & $\begin{array}{c}\text { Vehicle } \\
\text { Minutes } \\
\text { (min) }\end{array}$ & $\begin{array}{c}\text { Cumulative } \\
\text { Average Travel } \\
\text { Time RI-10 and } \\
\text { all Ramps (mph) }\end{array}$ & \begin{tabular}{|c|} 
Cumulative \\
Network \\
Average \\
Travel Time \\
(min / veh \\
mile) \\
\end{tabular} \\
\hline Random Seed Number & A & B & $C=B / A$ & D & $\mathbf{E}$ & $F=E / D$ & $\begin{array}{c}G=(B+E) / \\
(A+D)\end{array}$ \\
\hline 1 & 43796.7 & 98712.5 & 2.25 & 10933.6 & 11554.1 & 1.06 & 2.01 \\
\hline 33 & 43770.7 & 88247.5 & 2.02 & 10858.2 & 11456.9 & 1.06 & 1.83 \\
\hline 99 & 43813.6 & 89628.5 & 2.05 & 10876.7 & 11471.4 & 1.05 & 1.85 \\
\hline Comulative Average Travel Time & & & 2.11 & & & 1.06 & 1.90 \\
\hline \multirow{2}{*}{ Network Description } & \multicolumn{6}{|c|}{ Simulation Set Number } & 8 \\
\hline & \multicolumn{3}{|c|}{ Interstate 95 North } & \multicolumn{3}{|c|}{ Highway Route 10} & \\
\hline $\begin{array}{l}\text { ak AM Volume; 0\% } \\
3 \text { Lane Block; } 30 \text { Min In }\end{array}$ & $\begin{array}{l}\text { Vehicle } \\
\text { Miles } \\
\text { Traveled } \\
\text { (miles) }\end{array}$ & $\begin{array}{c}\text { Vehicle } \\
\text { Minutes } \\
(\min )\end{array}$ & $\begin{array}{c}\text { Cumulative } \\
\text { Average Travel } \\
\text { Time I-95 and } \\
\text { all Ramps (min- } \\
\text { veh mile) }\end{array}$ & $\begin{array}{c}\text { Vehicle Miles } \\
\text { Traveled } \\
\text { (miles) }\end{array}$ & $\begin{array}{c}\text { Vehicle } \\
\text { Minutes } \\
\text { (min) }\end{array}$ & $\begin{array}{c}\text { Cumulative } \\
\text { Average Travel } \\
\text { Time Rl-10 and } \\
\text { all Ramps (mph) }\end{array}$ & \begin{tabular}{|c|} 
Cumulative \\
Network \\
Average \\
Travel Time \\
(min/ veh \\
mile) \\
\end{tabular} \\
\hline Random Seed Number & A & B & $C=B / A$ & D & $\mathbf{E}$ & $F=E / D$ & $\begin{array}{c}G=(B+E) / \\
(A+D)\end{array}$ \\
\hline 1 & 43743.9 & 148656.4 & 3.40 & 9979.2 & 27395.8 & 2.75 & 3.28 \\
\hline 33 & 43745.7 & 121517.8 & 2.78 & 10965.3 & 11554.9 & 1.05 & 2.43 \\
\hline 99 & 43598.2 & 119532.1 & 2.74 & 10875.2 & 12632.7 & 1.16 & 2.43 \\
\hline Cimmulative Average Travel Time & & & 2.97 & & & 1.62 & 2.71 \\
\hline
\end{tabular}




\begin{tabular}{|c|c|c|c|c|c|c|c|}
\hline \multirow{2}{*}{ Network Description } & \multicolumn{6}{|c|}{ Simulation Set Number } & 9 \\
\hline & \multicolumn{3}{|c|}{ Interstate 95 North } & \multicolumn{3}{|c|}{ Highway Route 10} & \\
\hline $\begin{array}{l}\text { 20 Peak AM Volume; } 0 \% \\
3 \text { Lane Block; } 40 \text { Min in }\end{array}$ & $\begin{array}{l}\text { Vehicle } \\
\text { Miles } \\
\text { Traveled } \\
\text { (miles) }\end{array}$ & $\begin{array}{c}\text { Vehicle } \\
\text { Minutes } \\
\text { (min) }\end{array}$ & $\begin{array}{c}\text { Curmulative } \\
\text { Average Travel } \\
\text { Time I-95 and } \\
\text { all Ranps (min- } \\
\text { veh mile) }\end{array}$ & $\begin{array}{c}\text { Vehicle Miles } \\
\text { Traveled } \\
\text { (miles) }\end{array}$ & $\begin{array}{l}\text { Vehicle } \\
\text { Minutes } \\
\text { (min) }\end{array}$ & $\begin{array}{c}\text { Cumulative } \\
\text { Average Travel } \\
\text { Time RI- } 10 \text { and } \\
\text { all Ramps (mph) }\end{array}$ & \begin{tabular}{|c|} 
Cumulative \\
Network \\
Average \\
Travel Time \\
(min / veh \\
mile)
\end{tabular} \\
\hline Random Seed Number & A & B & $C=B / A$ & D & $\mathrm{E}$ & $F=E / D$ & $\begin{array}{c}G=(B+E) / \\
(A+D)\end{array}$ \\
\hline 1 & 43572.6 & 215791.0 & 4.95 & 11112.2 & 11743.2 & 1.06 & 4.16 \\
\hline 33 & 46968.3 & 175084.7 & 3.73 & 10919.2 & 11541.2 & 1.06 & 3.22 \\
\hline 99 & 46968.3 & 175084.7 & 3.73 & 7551.9 & 147457.9 & 19.53 & 5.92 \\
\hline Curmulative Average Travel Time & & & 4.12 & & & 5.77 & 4.41 \\
\hline \multirow{2}{*}{ Network Description } & \multicolumn{6}{|c|}{ Simulation Set Number } & 10 \\
\hline & \multicolumn{3}{|c|}{ Interstate 95 North } & \multicolumn{3}{|c|}{ Highway Route 10} & \\
\hline $\begin{array}{l}\text { Ty Peak AM Volume; } 20 \% \\
\text { divent I Lane Block; } 20 \text { Min In }\end{array}$ & $\begin{array}{l}\text { Vehicle } \\
\text { Miles } \\
\text { Traveled } \\
\text { (miles) }\end{array}$ & $\begin{array}{c}\text { Vehicle } \\
\text { Minutes } \\
\text { (min) }\end{array}$ & $\begin{array}{c}\text { Cumulative } \\
\text { Average Travel } \\
\text { Time I-95 and } \\
\text { all Ramps (nin- } \\
\text { veb mile) }\end{array}$ & $\begin{array}{c}\text { Vehicle Miles } \\
\text { Traveled } \\
\text { (miles) }\end{array}$ & $\begin{array}{l}\text { Vehicle } \\
\text { Minutes } \\
\text { (min) }\end{array}$ & $\begin{array}{c}\text { Cumulative } \\
\text { Average Travel } \\
\text { Time RI-10 and } \\
\text { all Ranps (mph) }\end{array}$ & \begin{tabular}{|c|} 
Cumulative \\
Network \\
Average \\
Travel Time \\
(min / veh \\
mile) \\
\end{tabular} \\
\hline Random Seed Number & A & B & $C=B / A$ & D & $\mathrm{E}$ & $F=E / D$ & $\begin{array}{c}G=(B+E) / \\
(A+D)\end{array}$ \\
\hline 1 & 42494.6 & 43467.1 & 1.02 & 11602.1 & 12314.6 & 1.06 & 1.03 \\
\hline 33 & 42435.9 & 43453.8 & 1.02 & 11724.0 & 12396.1 & 1.06 & 1.03 \\
\hline 99 & 42393.9 & 43402.8 & 1.02 & 11593.9 & 12290.2 & 1.06 & 1.03 \\
\hline Cumulative Average Travel Time & & & 1.02 & & & 1.06 & 1.03 \\
\hline \multirow{2}{*}{ Network Description } & \multicolumn{6}{|c|}{ Simulation Set Number } & 11 \\
\hline & \multicolumn{3}{|c|}{ Interstate 95 North } & \multicolumn{3}{|c|}{ Highway Route 10} & \\
\hline $\begin{array}{l}\text { Peak AM Volume; } 20 \% \\
1 \text { Lane Block; } 30 \mathrm{Min} \text { In }\end{array}$ & $\begin{array}{l}\text { Vehicle } \\
\text { Miles } \\
\text { Traveled } \\
\text { (miles) }\end{array}$ & $\begin{array}{c}\text { Vehicle } \\
\text { Minutes } \\
\text { (min) }\end{array}$ & $\begin{array}{c}\text { Cumulative } \\
\text { Average Travel } \\
\text { Time I-95 and } \\
\text { all Ramps (mun- } \\
\text { veb mile) }\end{array}$ & $\begin{array}{c}\text { Vehicle Miles } \\
\text { Traveled } \\
\text { (miles) }\end{array}$ & $\begin{array}{l}\text { Vehicle } \\
\text { Minutes } \\
\text { (min) }\end{array}$ & $\begin{array}{c}\text { Cumulative } \\
\text { Average Travel } \\
\text { Time RI-10 and } \\
\text { all Ramps (mph) }\end{array}$ & \begin{tabular}{|c|} 
Cumulative \\
Network \\
Average \\
Travel Time \\
(min / veh \\
mile)
\end{tabular} \\
\hline Random Seed Number & A & B & $\mathrm{C}=\mathrm{B} / \mathrm{A}$ & D & E & $F=E / D$ & $\begin{array}{c}G=(B+E) \\
(A+D)\end{array}$ \\
\hline 1 & 41476.8 & 42392.8 & 1.02 & 12157.3 & 12871.2 & 1.06 & 1.03 \\
\hline 33 & 41393.8 & 42206.4 & 1.02 & 12162.4 & 12898.8 & 1.06 & 1.03 \\
\hline 99 & 41563.8 & 42526.2 & 1.02 & 12105.0 & 12828.7 & 1.06 & 1.03 \\
\hline Cumulative Average Travel Time & & & 1.02 & & & 1.06 & 1.03 \\
\hline \multirow{2}{*}{ Network Description } & \multicolumn{6}{|c|}{ Simulation Set Number } & 12 \\
\hline & \multicolumn{3}{|c|}{ Interstate 95 North } & \multicolumn{3}{|c|}{ Highway Route 10} & \\
\hline $\begin{array}{l}\text { Peak AM Volume; } 20 \% \\
1 \text { Lane Block; } 40 \text { Min In }\end{array}$ & $\begin{array}{l}\text { Vehicle } \\
\text { Miles } \\
\text { Traveled } \\
\text { (miles) }\end{array}$ & $\begin{array}{c}\text { Vehicle } \\
\text { Minutes } \\
\text { (min) }\end{array}$ & $\begin{array}{c}\text { Cumulative } \\
\text { Average Travel } \\
\text { Time } 1-95 \text { and } \\
\text { all Rarnps (min- } \\
\text { veh mile) }\end{array}$ & \begin{tabular}{|c|} 
Velicle Miles \\
Traveled \\
(miles)
\end{tabular} & $\begin{array}{c}\text { Vehicle } \\
\text { Minutes } \\
\text { (min) }\end{array}$ & $\begin{array}{c}\text { Cumulative } \\
\text { Average Travel } \\
\text { Time RI-10 and } \\
\text { all Ranps (nph) }\end{array}$ & \begin{tabular}{|c|}
$\begin{array}{c}\text { Cumulative } \\
\text { Network } \\
\text { Average } \\
\text { Travel Time } \\
\text { (min / veh } \\
\text { nile) }\end{array}$ \\
\end{tabular} \\
\hline Random Seed Number & A & B & $\mathrm{C}=\mathrm{B} / \mathbf{A}$ & D & E & $F=E / D$ & $\begin{array}{c}G=(B+E) / \\
(A+D)\end{array}$ \\
\hline 1 & 40662.6 & 41406.1 & 1.02 & 4881.1 & 213656.0 & 43.77 & 5.60 \\
\hline 33 & 40919.4 & 41829.3 & 1.02 & 12714.5 & 13521.4 & 1.06 & 1.03 \\
\hline 99 & 40826.5 & 41578.8 & 1.02 & 12564.4 & 13327.7 & 1.06 & 1.03 \\
\hline Crmulative Average Travel Time & & & 1.02 & & & 7.97 & 2.39 \\
\hline
\end{tabular}




\begin{tabular}{|c|c|c|c|c|c|c|c|}
\hline \multirow{2}{*}{ Network Description } & \multicolumn{6}{|c|}{ Simulation Set Number } & 13 \\
\hline & \multicolumn{3}{|c|}{ Interstate 95 North } & \multicolumn{3}{|c|}{ Highway Route 10} & \\
\hline $\begin{array}{l}\text { Peak AM Volume; } 20 \% \\
2 \text { Lane Block; } 20 \text { Min In }\end{array}$ & $\begin{array}{l}\text { Vehicle } \\
\text { Miles } \\
\text { Traveled } \\
\text { (miles) }\end{array}$ & $\begin{array}{c}\text { Vehicle } \\
\text { Minutes } \\
\text { (min) }\end{array}$ & $\begin{array}{c}\text { Cumulative } \\
\text { Average Travel } \\
\text { Time I-95 and } \\
\text { all Ramps (min- } \\
\text { veh mile) }\end{array}$ & $\begin{array}{c}\text { Vehicle Miles } \\
\text { Traveled } \\
\text { (miles) }\end{array}$ & $\begin{array}{c}\text { Vehicle } \\
\text { Minutes } \\
\text { (min) }\end{array}$ & $\begin{array}{c}\text { Cumulative } \\
\text { Average Travel } \\
\text { Time RI-10 and } \\
\text { all Ramps (nph) }\end{array}$ & \begin{tabular}{|c|} 
Cumulative \\
Network \\
Average \\
Travel Time \\
(min / veh \\
mile) \\
\end{tabular} \\
\hline Random Seed Number & A & B & $C=B / A$ & $\mathrm{D}$ & $\mathrm{E}$ & $F=E / D$ & $\begin{array}{c}G=(B+E) / \\
(A+D)\end{array}$ \\
\hline 1 & 42338.2 & 47578.6 & 1.12 & 11602.1 & 12314.6 & 1.06 & 1.11 \\
\hline 33 & 42171.2 & 78924.9 & 1.87 & 11724.0 & 12396.1 & 1.06 & 1.69 \\
\hline 99 & 42605.4 & 46819.6 & 1.10 & 11593.9 & 12290.2 & 1.06 & 1.09 \\
\hline Cumulative Average Travel Time & & & 1.36 & & & 1.06 & 1.30 \\
\hline \multirow{2}{*}{ Network Description } & \multicolumn{6}{|c|}{ Simulation Set Number } & 14 \\
\hline & \multicolumn{3}{|c|}{ Interstate 95 North } & \multicolumn{3}{|c|}{ Highway Route 10} & \\
\hline $\begin{array}{l}\text { Peak AM Volume; } 20 \% \\
2 \text { Lane Block; } 30 \text { Min In }\end{array}$ & $\begin{array}{l}\text { Vehicle } \\
\text { Miles } \\
\text { Traveled } \\
\text { (miles) }\end{array}$ & $\begin{array}{c}\text { Vehicle } \\
\text { Minutes } \\
\text { (min) }\end{array}$ & $\begin{array}{c}\text { Cumulative } \\
\text { Average Travel } \\
\text { Time I-95 and } \\
\text { all Ramps (nin- } \\
\text { veh mile) }\end{array}$ & $\begin{array}{c}\text { Vehicle Miles } \\
\text { Traveled } \\
\text { (miles) }\end{array}$ & $\begin{array}{c}\text { Vehicle } \\
\text { Minutes } \\
\text { (min) }\end{array}$ & $\begin{array}{c}\text { Cumulative } \\
\text { Average Travel } \\
\text { Time RI-10 and } \\
\text { all Ramps (nph) }\end{array}$ & $\begin{array}{c}\text { Cumulative } \\
\text { Network } \\
\text { Average } \\
\text { Travel Time } \\
\text { (min/veh } \\
\text { mile) }\end{array}$ \\
\hline Random Seed Number & A & $\mathbf{B}$ & $\mathrm{C}=\mathrm{B} / \mathrm{A}$ & D & $\mathrm{E}$ & $F=E / D$ & $\begin{array}{c}G=(B+E) / \\
(A+D)\end{array}$ \\
\hline 1 & 41510.7 & 49937.5 & 1.20 & 12157.3 & 12871.2 & 1.06 & 1.17 \\
\hline 33 & 41462.5 & 128456.1 & 3.10 & 12162.4 & 12898.8 & 1.06 & 2.64 \\
\hline 99 & 41579.6 & 47893.8 & 1.15 & 12105.0 & 12828.7 & 1.06 & 1.13 \\
\hline Cumulative Average Travel Time & & & 1.82 & & & 1.06 & 1.65 \\
\hline \multirow{2}{*}{ Network Description } & \multicolumn{6}{|c|}{ Simulation Set Number } & 15 \\
\hline & \multicolumn{3}{|c|}{ Interstate 95 North } & \multicolumn{3}{|c|}{ Highway Route 10} & \\
\hline $\begin{array}{l}\text { Peak AM Volume; } 20 \% \\
2 \text { Lane Block; } 40 \text { Min In }\end{array}$ & $\begin{array}{l}\text { Vehicle } \\
\text { Miles } \\
\text { Traveled } \\
\text { (miles) }\end{array}$ & $\begin{array}{c}\text { Vehicle } \\
\text { Minutes } \\
\text { (min) }\end{array}$ & $\begin{array}{c}\text { Cumulative } \\
\text { Average Travel } \\
\text { Time I-95 and } \\
\text { all Ramps (min- } \\
\text { veh mile) }\end{array}$ & $\begin{array}{c}\text { Vehicle Miles } \\
\text { Traveled } \\
\text { (miles) }\end{array}$ & $\begin{array}{c}\text { Vehicle } \\
\text { Minutes } \\
\text { (min) }\end{array}$ & $\begin{array}{c}\text { Cumulative } \\
\text { Average Travel } \\
\text { Time RI-10 and } \\
\text { all Ramps (mph) }\end{array}$ & \begin{tabular}{|c|} 
Cumulative \\
Network \\
Average \\
Travel Time \\
(min/ veh \\
mile) \\
\end{tabular} \\
\hline Random Seed Number & A & B & $C=B / A$ & D & $\mathbf{E}$ & $F=E / D$ & $\begin{array}{c}G=(B+E) / \\
(A+D)\end{array}$ \\
\hline 1 & 40731.5 & 52669.5 & 1.29 & 4881.1 & 213656.0 & 43.77 & 5.84 \\
\hline 33 & 40548.4 & 174586.5 & 4.31 & 12714.5 & 13521.4 & 1.06 & 3.53 \\
\hline 99 & 41016.8 & 50242.0 & 1.22 & 12564.4 & 13327.7 & 1.06 & 1.19 \\
\hline Cumulative Average Travel Time & & & 2.27 & & & 7.97 & 3.40 \\
\hline \multirow{2}{*}{ Network Description } & \multicolumn{6}{|c|}{ Simulation Set Number } & 16 \\
\hline & \multicolumn{3}{|c|}{ Interstate 95 North } & \multicolumn{3}{|c|}{ Highway Route 10} & \\
\hline \multirow{2}{*}{ Random Seed Number } & $\begin{array}{l}\text { Vehicle } \\
\text { Miles } \\
\text { Traveled } \\
\text { (miles) }\end{array}$ & $\begin{array}{c}\text { Vehicle } \\
\text { Minutes } \\
\text { (min) }\end{array}$ & $\begin{array}{c}\text { Cumulative } \\
\text { Average Travel } \\
\text { Time I-95 and } \\
\text { all Ramps (nin- } \\
\text { veh mile) }\end{array}$ & \begin{tabular}{|} 
Vehicle Miles \\
Traveled \\
(miles)
\end{tabular} & $\begin{array}{c}\text { Vehicle } \\
\text { Minutes } \\
\text { (min) }\end{array}$ & $\begin{array}{c}\text { Cumulative } \\
\text { Average Travel } \\
\text { Time RI-10 and } \\
\text { all Ramps (mph) }\end{array}$ & \begin{tabular}{|c|} 
Cumulative \\
Network \\
Average \\
Travel Time \\
(min/veh \\
mile)
\end{tabular} \\
\hline & A & B & $C=B / A$ & $\mathrm{D}$ & E & $F=E / D$ & $\begin{array}{c}G=(B+E) \\
(A+D)\end{array}$ \\
\hline 1 & 42425.3 & 100926.5 & 2.38 & 11602.1 & 12314.6 & 1.06 & 2.10 \\
\hline 33 & 42173.8 & 74048.9 & 1.76 & 11724.0 & 12396.1 & 1.06 & 1.60 \\
\hline 99 & 42264.6 & 73651.7 & 1.74 & 11593.9 & 12290.2 & 1.06 & 1.60 \\
\hline Cumulative Average Travel Time & & & 1.96 & & & 1.06 & 1.77 \\
\hline
\end{tabular}




\begin{tabular}{|c|c|c|c|c|c|c|c|}
\hline \multirow{2}{*}{ Network Description } & \multicolumn{6}{|c|}{ Simulation Set Number } & 17 \\
\hline & \multicolumn{3}{|c|}{ Interstate 95 North } & \multicolumn{3}{|c|}{ Highway Route 10} & \\
\hline $\begin{array}{l}\text { 1Peak AM Volume; } 20 \% \\
3 \text { Lane Block; } 30 \mathrm{Min} \text { In }\end{array}$ & $\begin{array}{l}\text { Vehicle } \\
\text { Miles } \\
\text { Traveled } \\
\text { (miles) }\end{array}$ & $\begin{array}{c}\text { Vehicle } \\
\text { Minutes } \\
\text { (min) }\end{array}$ & $\begin{array}{c}\text { Cumulative } \\
\text { Average Travel } \\
\text { Time 1-95 and } \\
\text { all Ramps (min- } \\
\text { veh mile) }\end{array}$ & $\begin{array}{c}\text { Vehicle Miles } \\
\text { Traveled } \\
\text { (miles) }\end{array}$ & $\begin{array}{l}\text { Vehicle } \\
\text { Minutes } \\
\text { (min) }\end{array}$ & $\begin{array}{c}\text { Cumulative } \\
\text { Average Travel } \\
\text { Time Rl-10 and } \\
\text { all Ramps (nph) }\end{array}$ & \begin{tabular}{|c|} 
Cumulative \\
Network \\
Average \\
Travel Time \\
(min/veh \\
mile)
\end{tabular} \\
\hline Random Seed Number & A & B & $C=B / A$ & D & $\mathrm{E}$ & $F=E / D$ & $\begin{array}{c}G=(B+E) / \\
(A+D)\end{array}$ \\
\hline 1 & 41606.5 & 144752.5 & 3.48 & 12157.3 & 12871.2 & 1.06 & 2.93 \\
\hline 33 & 41290.5 & 118118.9 & 2.86 & 12162.4 & 12898.8 & 1.06 & 2.45 \\
\hline 99 & 41491.6 & 89409.7 & 2.15 & 12105.0 & 12828.7 & 1.06 & 1.91 \\
\hline Cumulative Average Travel Time & & & 2.83 & & & 1.06 & 2.43 \\
\hline \multirow{2}{*}{ Network Description } & \multicolumn{6}{|c|}{ Simulation Set Number } & 18 \\
\hline & \multicolumn{3}{|c|}{ Interstate 95 North } & \multicolumn{3}{|c|}{ Highway Route 10} & \\
\hline $\begin{array}{l}\text { W4 Peak AM Volume; } 20 \% \\
\text { Wuas: } 3 \text { Lane Block; } 40 \text { Min In }\end{array}$ & $\begin{array}{c}\text { Vehicle } \\
\text { Miles } \\
\text { Traveled } \\
\text { (miles) }\end{array}$ & $\begin{array}{c}\text { Vehicle } \\
\text { Minutes } \\
\text { (min) }\end{array}$ & $\begin{array}{c}\text { Cumulative } \\
\text { Average Travel } \\
\text { Time I-95 and } \\
\text { all Ramps (min- } \\
\text { veh mile) }\end{array}$ & $\begin{array}{c}\text { Vehicle Miles } \\
\text { Traveled } \\
\text { (miles) }\end{array}$ & $\begin{array}{l}\text { Vehicle } \\
\text { Minutes } \\
\text { (min) }\end{array}$ & $\begin{array}{c}\text { Cummlative } \\
\text { Average Travel } \\
\text { Time RI-10 and } \\
\text { all Ramps (nupl) }\end{array}$ & $\begin{array}{l}\text { Cumulative } \\
\text { Network } \\
\text { Average } \\
\text { Travel Time } \\
\text { (min/ veh } \\
\text { mile) }\end{array}$ \\
\hline Random Seed Number & A & $\mathbf{B}$ & $\mathbf{C}=\mathbf{B} / \mathbf{A}$ & D & $\mathbf{E}$ & $F=E / D$ & $\begin{array}{c}G=(B+E) / \\
(A+D)\end{array}$ \\
\hline 1 & 40511.5 & 161909.1 & 4.00 & 16952.1 & 18452.7 & 1.09 & 3.14 \\
\hline 33 & 39828.9 & 159016.2 & 3.99 & 16635.6 & 18058.2 & 1.09 & 3.14 \\
\hline 99 & 40653.4 & 159184.5 & 3.92 & 16739.7 & 17878.1 & 1.07 & 3.09 \\
\hline Cumulative Average Travel Time & & & 3.97 & & & 1.08 & 3.12 \\
\hline
\end{tabular}




\begin{tabular}{|c|c|c|c|c|c|c|c|}
\hline \multirow{2}{*}{ Network Description } & \multicolumn{6}{|c|}{ Simulation Set Number } & 1 \\
\hline & \multicolumn{3}{|c|}{ Interstate 95 North } & \multicolumn{3}{|c|}{ Highway Route 10} & \multirow[b]{2}{*}{$\begin{array}{c}\text { Total } \\
\text { Network } \\
\text { Delay } \\
\text { (hours) }\end{array}$} \\
\hline $\begin{array}{l}\text { Peak AM Volume; } 0 \% \\
1 \text { Lane Block; } 20 \text { Min In }\end{array}$ & $\begin{array}{l}\text { Vehicle } \\
\text { Miles } \\
\text { Traveled } \\
\text { (miles) }\end{array}$ & $\begin{array}{l}\text { Total } \\
\text { Delay } \\
\text { (min) }\end{array}$ & $\begin{array}{l}\text { Average Delay } \\
\text { Time } 1-95 \text { and } \\
\text { all Ramps (min- } \\
\text { veh mile) }\end{array}$ & $\begin{array}{l}\text { Vehicle } \\
\text { Miles } \\
\text { Traveled } \\
\text { (miles) }\end{array}$ & $\begin{array}{l}\text { Total } \\
\text { Delay } \\
\text { (min) }\end{array}$ & $\begin{array}{c}\text { Average Delay } \\
\text { Time RI- } 10 \text { and } \\
\text { all Ramps (min } / \\
\text { veh mile) }\end{array}$ & \\
\hline Random Seed Number & $\mathbf{A}$ & B & $C=B / A$ & D & E & $F=E / D$ & $\begin{array}{c}G=(B+E) \\
/[60(\min / 1 \\
(\mathrm{hr})]\end{array}$ \\
\hline 1 & 43923.3 & 4431.25 & 0.10 & 10933.6 & 564.66 & 0.05 & 83.27 \\
\hline 33 & 43854.0 & 4449.67 & 0.10 & 10858.2 & 557.32 & 0.05 & 83.45 \\
\hline 99 & 43627.0 & 4504.10 & 0.10 & 10876.7 & 559.95 & 0.05 & 84.40 \\
\hline Cumulative Average Delay Time & & & 0.10 & & & 0.05 & 83.71 \\
\hline \multirow{2}{*}{ Network Description } & \multicolumn{6}{|c|}{ Simulation Set Nuniber } & 2 \\
\hline & \multicolumn{3}{|c|}{ Interstate 95 North } & \multicolumn{3}{|c|}{ Highway Route 10} & \\
\hline Peak AM Volume; $0 \%$ & $\begin{array}{c}\text { Vehicle } \\
\text { Miles } \\
\text { Traveled } \\
\text { (miles) }\end{array}$ & $\begin{array}{l}\text { Total } \\
\text { Delay } \\
\text { (min) }\end{array}$ & $\begin{array}{c}\text { Average Delay } \\
\text { Time I-95 and } \\
\text { all Ramps (nin- } \\
\text { veh mile) }\end{array}$ & $\begin{array}{l}\text { Vehicle } \\
\text { Miles } \\
\text { Traveled } \\
\text { (miles) }\end{array}$ & $\begin{array}{l}\text { Total } \\
\text { Delay } \\
\text { (min) }\end{array}$ & $\begin{array}{c}\text { Average Delay } \\
\text { Time RI-10 and } \\
\text { all Ramps (min / } \\
\text { veh mile) }\end{array}$ & \begin{tabular}{|} 
Total \\
Network \\
Delay \\
(hours)
\end{tabular} \\
\hline Random Seed Number & $\mathbf{A}$ & B & $C=B / A$ & D & E & $F=E / D$ & $\begin{array}{c}\mathrm{G}=(\mathrm{B}+\mathrm{E}) \\
/[60(\min / \\
\mathrm{hr})]\end{array}$ \\
\hline 1 & 43542.0 & 4638.59 & 0.11 & 9979.2 & 9133.05 & 0.92 & 229.53 \\
\hline 33 & 44038.0 & 4686.42 & 0.11 & 10965.3 & 569.17 & 0.05 & 87.59 \\
\hline 99 & 44065.2 & 4715.10 & 0.11 & 10875.2 & 609.59 & 0.06 & 88.74 \\
\hline Cumulative Average Delay Time & & & 0.11 & & & 0.32 & 135.29 \\
\hline \multirow{2}{*}{ Network Description } & \multicolumn{6}{|c|}{ Simulation Set Number } & 3 \\
\hline & \multicolumn{3}{|c|}{ Interstate 95 North } & \multicolumn{3}{|c|}{ Highway Route 10} & \\
\hline MT AM Volume; $0 \%$ & $\begin{array}{l}\text { Vehicle } \\
\text { Miles } \\
\text { Traveled } \\
\text { (miles) }\end{array}$ & $\begin{array}{l}\text { Total } \\
\text { Delay } \\
\text { (min) }\end{array}$ & $\begin{array}{l}\text { Average Delay } \\
\text { Time I-95 and } \\
\text { all Ramps (nin- } \\
\text { veh mile) }\end{array}$ & $\begin{array}{l}\text { Vehicle } \\
\text { Miles } \\
\text { Traveled } \\
\text { (miles) }\end{array}$ & $\begin{array}{l}\text { Total } \\
\text { Delay } \\
\text { (min) }\end{array}$ & $\begin{array}{c}\text { Average Delay } \\
\text { Time RI-10 and } \\
\text { all Ramps (min } / \\
\text { veh mile) }\end{array}$ & $\begin{array}{c}\text { Total } \\
\text { Network } \\
\text { Delay } \\
\text { (hours) }\end{array}$ \\
\hline Random Seed Number & $\mathbf{A}$ & B & $C=B / A$ & $\mathrm{D}$ & E & $F=E / D$ & $\begin{array}{c}G=(\mathrm{B}+\mathrm{E}) \\
/[60(\mathrm{~min} / \\
\mathrm{hr})]\end{array}$ \\
\hline 1 & 43851.9 & 4726.15 & 0.11 & 11112.2 & 587.20 & 0.05 & 88.56 \\
\hline 33 & 44001.3 & 4731.17 & 0.11 & 10919.2 & 570.08 & 0.05 & 88.35 \\
\hline 99 & 44134.2 & 4874.90 & 0.11 & 7551.9 & 71004.06 & 9.40 & 1264.65 \\
\hline Cumulative Average Delay Time & & & 0.11 & & & 2.44 & 480.52 \\
\hline \multirow{2}{*}{ Network Description } & \multicolumn{6}{|c|}{ Simulation Set Number } & 4 \\
\hline & \multicolumn{3}{|c|}{ Interstate 95 North } & \multicolumn{3}{|c|}{ Highway Route 10} & \\
\hline $\begin{array}{l}\text { Wos Peak AM Volume; } 0 \% \\
\text { hint } 2 \text { Lane Block; } 20 \text { Min In }\end{array}$ & $\begin{array}{l}\text { Vehicle } \\
\text { Miles } \\
\text { Traveled } \\
\text { (miles) }\end{array}$ & $\begin{array}{l}\text { Total } \\
\text { Delay } \\
\text { (min) }\end{array}$ & $\begin{array}{c}\text { Average Delay } \\
\text { Time I-95 and } \\
\text { all Ramps (min- } \\
\text { veh mile) }\end{array}$ & $\begin{array}{l}\text { Vehicle } \\
\text { Miles } \\
\text { Traveled } \\
\text { (miles) }\end{array}$ & $\begin{array}{l}\text { Total } \\
\text { Delay } \\
\text { (min) }\end{array}$ & $\begin{array}{c}\text { Average Delay } \\
\text { Time RI-10 and } \\
\text { all Ramps (min } / \\
\text { veh mile) }\end{array}$ & $\begin{array}{l}\text { Total } \\
\text { Network } \\
\text { Delay } \\
\text { (hours) }\end{array}$ \\
\hline Random Seed Number & A & B & $C=B / A$ & $\mathrm{D}$ & E & $F=E / D$ & $\begin{array}{c}\mathrm{G}=(\mathrm{B}+\mathrm{E}) \\
/[60(\min / \\
(\mathrm{r})]\end{array}$ \\
\hline 1 & 44053.1 & 14403.89 & 0.33 & 10933.6 & $\$ 64.66$ & 0.05 & 249.48 \\
\hline 33 & 43811.6 & 14637.65 & 0.33 & 10858.2 & 557.32 & 0.05 & 253.25 \\
\hline 99 & 43798.8 & 14028.91 & 0.32 & 10876.7 & 559.95 & 0.05 & 243.15 \\
\hline Chumulative Average Delay Time & & & 0.33 & & & 0.05 & 248.62 \\
\hline
\end{tabular}




\begin{tabular}{|c|c|c|c|c|c|c|c|}
\hline \multirow{2}{*}{ Network Description } & \multicolumn{6}{|c|}{ Simulation Set Number } & 5 \\
\hline & \multicolumn{3}{|c|}{ Interstate 95 North } & \multicolumn{3}{|c|}{ Highway Route 10} & \multirow[b]{2}{*}{$\begin{array}{l}\text { Total } \\
\text { Network } \\
\text { Delay } \\
\text { (hours) }\end{array}$} \\
\hline $\begin{array}{l}\text { 78 Peak AM Volume; } 0 \% \\
2 \text { Lane Block; } 30 \text { Min In }\end{array}$ & $\begin{array}{l}\text { Vehicle } \\
\text { Miles } \\
\text { Traveled } \\
\text { (miles) }\end{array}$ & $\begin{array}{l}\text { Total } \\
\text { Delay } \\
\text { (min) }\end{array}$ & $\begin{array}{c}\text { Average Delay } \\
\text { Time I-95 and } \\
\text { all Ramps (min- } \\
\text { veh mile) }\end{array}$ & $\begin{array}{l}\text { Vehicle } \\
\text { Miles } \\
\text { Traveled } \\
\text { (miles) }\end{array}$ & $\begin{array}{l}\text { Total } \\
\text { Delay } \\
\text { (min) }\end{array}$ & $\begin{array}{c}\text { Average Delay } \\
\text { Time RI-10 and } \\
\text { all Ramps (min / } \\
\text { veh mile) }\end{array}$ & \\
\hline Random Seed Number & A & B & $\mathrm{C}=\mathrm{B} / \mathrm{A}$ & D & $\mathbf{E}$ & $\mathbf{F}=\mathbf{E} / \mathbf{D}$ & $\begin{array}{c}\mathrm{G}=(\mathrm{B}+\mathrm{E}) \\
/\left[\begin{array}{c}600(\mathrm{~min} / \\
\mathrm{hr})]\end{array}\right.\end{array}$ \\
\hline 1 & 43943.3 & 26101.50 & 0.59 & 9979.2 & 9133.05 & 0.92 & 587.24 \\
\hline 33 & 43775.3 & 26415.28 & 0.60 & 10965.3 & 569.17 & 0.05 & 449.74 \\
\hline 99 & 43839.0 & 25483.88 & 0.58 & 10875.2 & 609.59 & 0.06 & 434.89 \\
\hline Cumulative Average Delay Time & & & 0.59 & & & 0.32 & 490.62 \\
\hline \multirow{2}{*}{ Network Description } & \multicolumn{6}{|c|}{ Simulation Set Number } & 6 \\
\hline & \multicolumn{3}{|c|}{ Interstate 95 North } & \multicolumn{3}{|c|}{ Highway Route 10} & \\
\hline $\begin{array}{l}\text { 19. Peak AM Volume; } 0 \% \\
2 \text { Lane Block; } 40 \mathrm{Min} \text { In }\end{array}$ & $\begin{array}{l}\text { Vehicle } \\
\text { Miles } \\
\text { Traveled } \\
\text { (miles) }\end{array}$ & $\begin{array}{l}\text { Total } \\
\text { Delay } \\
\text { (min) }\end{array}$ & $\begin{array}{l}\text { Average Delay } \\
\text { Time I-95 and } \\
\text { all Ramps (nin- } \\
\text { veh mile) }\end{array}$ & $\begin{array}{l}\text { Vehicle } \\
\text { Miles } \\
\text { Traveled } \\
\text { (miles) }\end{array}$ & $\begin{array}{l}\text { Total } \\
\text { Delay } \\
\text { (min) }\end{array}$ & $\begin{array}{c}\text { Average Delay } \\
\text { Time RI-10 and } \\
\text { all Ramps (min / } \\
\text { veh mile) }\end{array}$ & $\begin{array}{l}\text { Total } \\
\text { Network } \\
\text { Delay } \\
\text { (hours) }\end{array}$ \\
\hline Random Seed Number & A & B & $C=B / A$ & D & $\mathbf{E}$ & $F=E / D$ & $\begin{array}{c}\mathrm{G}=(\mathrm{B}+\mathrm{E}) \\
/[60(\mathrm{~min} / \\
\mathrm{hr})]\end{array}$ \\
\hline 1 & 43782.1 & 42651.51 & 0.97 & 11112.2 & 587.20 & 0.05 & 720.65 \\
\hline 33 & 43813.4 & 44627.92 & 1.02 & 10919.2 & 570.08 & 0.05 & 753.30 \\
\hline 99 & 43775.0 & 41118.84 & 0.94 & 7551.9 & 71004.06 & 9.40 & 1868.72 \\
\hline Cumulative Average Delay Time & & & 0.98 & & & 2.44 & 1114.22 \\
\hline \multirow{2}{*}{ Network Description } & \multicolumn{6}{|c|}{ Simulation Set Number } & 7 \\
\hline & \multicolumn{3}{|c|}{ Interstate 95 North } & \multicolumn{3}{|c|}{ Highway Route 10} & \\
\hline $\begin{array}{l}\text { Peak AM Volume; } 0 \% \\
3 \text { Lane Block; } 20 \text { Min In }\end{array}$ & $\begin{array}{c}\text { Vehicle } \\
\text { Miles } \\
\text { Traveled } \\
\text { (miles) }\end{array}$ & $\begin{array}{l}\text { Total } \\
\text { Delay } \\
\text { (min) }\end{array}$ & $\begin{array}{l}\text { Average Delay } \\
\text { Time I-95 and } \\
\text { all Ramps (min- } \\
\text { veh mile) }\end{array}$ & $\begin{array}{l}\text { Vehicle } \\
\text { Miles } \\
\text { Traveled } \\
\text { (miles) }\end{array}$ & $\begin{array}{l}\text { Total } \\
\text { Delay } \\
\text { (min) }\end{array}$ & $\begin{array}{l}\text { Average Delay } \\
\text { Time RI- } 10 \text { and } \\
\text { all Ramps (min / } \\
\text { veh mile) }\end{array}$ & $\begin{array}{l}\text { Total } \\
\text { Network } \\
\text { Delay } \\
\text { (hours) }\end{array}$ \\
\hline Random Seed Number & A & $\mathbf{B}$ & $\mathrm{C}=\mathrm{B} / \mathrm{A}$ & D & E & $F=E / D$ & $\begin{array}{c}\mathrm{G}=(\mathrm{B}+\mathrm{E}) \\
/[60(\mathrm{~min} / \\
\mathrm{hr})] \\
\end{array}$ \\
\hline 1 & 43796.7 & 44833.90 & 1.02 & 10933.6 & 564.66 & 0.05 & 756.64 \\
\hline 33 & 43770.7 & 38587.56 & 0.88 & 10858.2 & 557.32 & 0.05 & 652.41 \\
\hline 99 & 43813.6 & 38942.69 & 0.89 & 10876.7 & 559.95 & 0.05 & 658.38 \\
\hline Cumulative Average Delay Time & & & 0.93 & & & 0.05 & 689.14 \\
\hline \multirow{2}{*}{ Network Description } & \multicolumn{6}{|c|}{ Simulation Set Number } & 8 \\
\hline & \multicolumn{3}{|c|}{ Interstate 95 North } & \multicolumn{3}{|c|}{ Highway Route 10} & \\
\hline $\begin{array}{l}1 \text { Peak AM Volume; } 0 \% \\
3 \text { Lane Block; } 30 \mathrm{Min} \text { In }\end{array}$ & $\begin{array}{l}\text { Vehicle } \\
\text { Miles } \\
\text { Traveled } \\
\text { (miles) }\end{array}$ & $\begin{array}{l}\text { Total } \\
\text { Delay } \\
\text { (min) }\end{array}$ & $\begin{array}{l}\text { Average Delay } \\
\text { Time I-95 and } \\
\text { all Ramps (min- } \\
\text { veh mile) }\end{array}$ & $\begin{array}{l}\text { Vehicle } \\
\text { Miles } \\
\text { Traveled } \\
\text { (miles) }\end{array}$ & $\begin{array}{l}\text { Total } \\
\text { Delay } \\
\text { (min) }\end{array}$ & $\begin{array}{c}\text { Average Delay } \\
\text { Time RI-10 and } \\
\text { all Ramps (min } / \\
\text { veh mile) }\end{array}$ & $\begin{array}{l}\text { Total } \\
\text { Network } \\
\text { Delay } \\
\text { (bours) }\end{array}$ \\
\hline Random Seed Number & A & B & $C=B / A$ & D & $\mathbf{E}$ & $F=E / D$ & $\begin{array}{c}\mathrm{G}=(\mathrm{B}+\mathrm{E}) \\
/[60(\min / \\
\mathrm{hr})]\end{array}$ \\
\hline 1 & 43743.9 & 77664.63 & 1.78 & 9979.2 & 9133.05 & 0.92 & 1446.63 \\
\hline 33 & 43745.7 & 65983.14 & 1.51 & 10965.3 & 569.17 & 0.05 & 1109.21 \\
\hline 99 & 43598.2 & 63086.88 & 1.45 & 10875.2 & 609.59 & 0.06 & 1061.61 \\
\hline Gmulative Average Delay Time & & & 1.58 & & & 0.32 & 1205.81 \\
\hline
\end{tabular}




\begin{tabular}{|c|c|c|c|c|c|c|c|}
\hline \multirow{2}{*}{ Network Description } & \multicolumn{6}{|c|}{ Simulation Set Number } & 9 \\
\hline & \multicolumn{3}{|c|}{ Interstate 95 North } & \multicolumn{3}{|c|}{ Highway Route 10} & \multirow[b]{2}{*}{$\begin{array}{l}\text { Total } \\
\text { Network } \\
\text { Delay } \\
\text { (hours) }\end{array}$} \\
\hline $\begin{array}{l}\text { Pak AM Volume; } 0 \% \\
3 \text { Lane Block; } 40 \text { Min In }\end{array}$ & $\begin{array}{l}\text { Vehicle } \\
\text { Miles } \\
\text { Traveled } \\
\text { (miles) }\end{array}$ & $\begin{array}{l}\text { Total } \\
\text { Delay } \\
\text { (min) }\end{array}$ & $\begin{array}{l}\text { Average Delay } \\
\text { Time I-95 and } \\
\text { all Ramps (min- } \\
\text { veh mile) }\end{array}$ & $\begin{array}{l}\text { Vehicle } \\
\text { Miles } \\
\text { Traveled } \\
\text { (miles) }\end{array}$ & $\begin{array}{l}\text { Total } \\
\text { Delay } \\
\text { (min) }\end{array}$ & $\begin{array}{c}\text { Average Delay } \\
\text { Time } \mathrm{RI}-10 \text { and } \\
\text { all Ramps ( } \mathrm{min} \\
\text { veh mile) }\end{array}$ & \\
\hline Random Seed Number & A & B & $C=B / A$ & D & $\mathrm{E}$ & $F=E / D$ & $\begin{array}{c}\mathrm{G}=(\mathrm{B}+\mathrm{E}) \\
/\left[\begin{array}{c}60(\mathrm{~min} / \\
\mathrm{hr})]\end{array}\right. \\
\end{array}$ \\
\hline 1 & 43572.6 & 120522.90 & 2.77 & 11112.2 & 587.20 & 0.05 & 2018.50 \\
\hline 33 & 46968.3 & 108879.70 & 2.32 & 10919.2 & 570.08 & 0.05 & 1824.16 \\
\hline 99 & 46968.3 & 108879.70 & 2.32 & 7551.9 & 71004.06 & 9.40 & 2998.06 \\
\hline Cumulative Average Delay Time & & & 2.46 & & & 2.44 & 2280.24 \\
\hline \multirow{2}{*}{ Network Description } & \multicolumn{6}{|c|}{ Simulation Set Number } & 10 \\
\hline & \multicolumn{3}{|c|}{ Interstate 95 North } & \multicolumn{3}{|c|}{ Highway Route 10} & \\
\hline $\begin{array}{l}\text { 1) Peak AM Volume; } 20 \% \\
\text { Dive-5n; } 1 \text { Lane Block; } 20 \text { Min In }\end{array}$ & $\begin{array}{l}\text { Vehicle } \\
\text { Miles } \\
\text { Traveled } \\
\text { (miles) }\end{array}$ & $\begin{array}{l}\text { Total } \\
\text { Delay } \\
\text { (min) }\end{array}$ & $\begin{array}{c}\text { Average Delay } \\
\text { Time I-95 and } \\
\text { all Ramps (nin- } \\
\text { veh mile) }\end{array}$ & $\begin{array}{l}\text { Vehicle } \\
\text { Miles } \\
\text { Traveled } \\
\text { (miles) }\end{array}$ & $\begin{array}{l}\text { Total } \\
\text { Delay } \\
\text { (min) }\end{array}$ & $\begin{array}{c}\text { Average Delay } \\
\text { Time RI- } 10 \text { and } \\
\text { all Ramps ( } \mathrm{min} / \\
\text { veh mile) }\end{array}$ & $\begin{array}{l}\text { Total } \\
\text { Network } \\
\text { Delay } \\
\text { (hours) }\end{array}$ \\
\hline Random Seed Number & A & B & $C=B / A$ & D & $\mathbf{E}$ & $F=E / D$ & $\begin{array}{c}\mathrm{G}=(\mathrm{B}+\mathrm{E}) \\
/\left[\begin{array}{c}60(\min / \\
\mathrm{hr})]\end{array}\right.\end{array}$ \\
\hline 1 & 42494.6 & 3983.29 & 0.09 & 11602.1 & 641.12 & 0.06 & 77.07 \\
\hline 33 & 42435.9 & 3943.44 & 0.09 & 11724.0 & 642.86 & 0.05 & 76.44 \\
\hline 99 & 42393.9 & 3977.34 & 0.09 & 11593.9 & 649.13 & 0.06 & 77.11 \\
\hline Cumulative Average Delay Time & & & 0.09 & & & 0.06 & 76.87 \\
\hline \multirow{2}{*}{ Network Description } & \multicolumn{6}{|c|}{ Simulation Set Number } & 11 \\
\hline & \multicolumn{3}{|c|}{ Interstate 95 North } & \multicolumn{3}{|c|}{ Highway Route 10} & \\
\hline $\begin{array}{l}\text { APeak AM Volume; } 20 \% \\
\text { Wherin } 1 \text { Lane Block; } 30 \text { Min In }\end{array}$ & $\begin{array}{l}\text { Vehicle } \\
\text { Miles } \\
\text { Traveled } \\
\text { (miles) }\end{array}$ & $\begin{array}{l}\text { Total } \\
\text { Delay } \\
\text { (min) }\end{array}$ & $\begin{array}{l}\text { Average Delay } \\
\text { Time I-95 and } \\
\text { all Ramps (min- } \\
\text { veh mile) }\end{array}$ & $\begin{array}{l}\text { Vehicle } \\
\text { Miles } \\
\text { Traveled } \\
\text { (miles) }\end{array}$ & $\begin{array}{l}\text { Total } \\
\text { Delay } \\
\text { (min) }\end{array}$ & $\begin{array}{l}\text { Average Delay } \\
\text { Time RI- } 10 \text { and } \\
\text { all Ramps (min } / \\
\text { veh mile) }\end{array}$ & $\begin{array}{l}\text { Total } \\
\text { Network } \\
\text { Delay } \\
\text { (hours) }\end{array}$ \\
\hline Random Seed Number & $\mathbf{A}$ & B & $C=B / A$ & D & E & $F=E / D$ & $\begin{array}{c}\mathrm{G}=(\mathrm{B}+\mathrm{E}) \\
/[60(\mathrm{~min} / \\
\mathrm{br})]\end{array}$ \\
\hline 1 & 41476.8 & 3762.68 & 0.09 & 12157.3 & 680.62 & 0.06 & 74.06 \\
\hline 33 & 41393.8 & 3682.65 & 0.09 & 12162.4 & 694.01 & 0.06 & 72.94 \\
\hline 99 & 41563.8 & 3851.54 & 0.09 & 12105.0 & 678.75 & 0.06 & 75.50 \\
\hline Cumulative Average Delay Time & & & 0.09 & & & 0.06 & 74.17 \\
\hline \multirow{2}{*}{ Network Description } & \multicolumn{6}{|c|}{ Simulation Set Number } & 12 \\
\hline & \multicolumn{3}{|c|}{ Interstate 95 North } & \multicolumn{3}{|c|}{ Highway Route 10} & \\
\hline $\begin{array}{l}\text { Nof Peak AM Volume; } 20 \% \\
\text { Diner:An; I Lane Block; } 40 \text { Min In }\end{array}$ & $\begin{array}{l}\text { Vehicle } \\
\text { Miles } \\
\text { Traveled } \\
\text { (miles) }\end{array}$ & $\begin{array}{l}\text { Total } \\
\text { Delay } \\
\text { (min) }\end{array}$ & $\begin{array}{l}\text { Average Delay } \\
\text { Time } 1-95 \text { and } \\
\text { all Ramps (min- } \\
\text { veh mile) }\end{array}$ & $\begin{array}{l}\text { Vehicle } \\
\text { Miles } \\
\text { Traveled } \\
\text { (miles) }\end{array}$ & $\begin{array}{l}\text { Total } \\
\text { Delay } \\
\text { (min) }\end{array}$ & $\begin{array}{c}\text { Average Delay } \\
\text { Time RI-10 and } \\
\text { all Ramps (nin } / \\
\text { veh mile) }\end{array}$ & $\begin{array}{l}\text { Total } \\
\text { Network } \\
\text { Delay } \\
\text { (hours) }\end{array}$ \\
\hline Random Seed Number & A & B & $C=B / A$ & D & E & $F=E / D$ & $\begin{array}{c}\mathrm{G}=(\mathrm{B}+\mathrm{E}) \\
/[60(\mathrm{~min} / \\
\mathrm{hr})]\end{array}$ \\
\hline 1 & 40662.6 & 3581.56 & 0.09 & 4881.1 & 106397.00 & 21.80 & 1832.98 \\
\hline 33 & 40919.4 & 3725.70 & 0.09 & 12714.5 & 755.63 & 0.06 & 74.69 \\
\hline 99 & 40826.5 & 3605.33 & 0.09 & 12564.4 & 728.52 & 0.06 & 72.23 \\
\hline Cumulative Average Delay Time & & & 0.09 & & & 3.58 & 659.97 \\
\hline
\end{tabular}




\begin{tabular}{|c|c|c|c|c|c|c|c|}
\hline \multirow{2}{*}{ Network Description } & \multicolumn{6}{|c|}{ Simulation Set Number } & 13 \\
\hline & \multicolumn{3}{|c|}{ Interstate 95 North } & \multicolumn{3}{|c|}{ Highway Route 10} & \\
\hline $\begin{array}{l}\text { 19t Peak AM Volume; } 20 \% \\
\text { Tix } 2 \text { Lane Block; } 20 \text { Min In }\end{array}$ & $\begin{array}{l}\text { Vehicle } \\
\text { Miles } \\
\text { Traveled } \\
\text { (miles) }\end{array}$ & $\begin{array}{l}\text { Total } \\
\text { Delay } \\
\text { (min) }\end{array}$ & $\begin{array}{l}\text { Average Delay } \\
\text { Time I-95 and } \\
\text { all Ramps (min- } \\
\text { veh mile) }\end{array}$ & $\begin{array}{l}\text { Vehicle } \\
\text { Miles } \\
\text { Traveled } \\
\text { (miles) }\end{array}$ & $\begin{array}{l}\text { Total } \\
\text { Delay } \\
\text { (min) }\end{array}$ & $\begin{array}{c}\text { Average Delay } \\
\text { Time RI-10 and } \\
\text { all Ramps (min } / \\
\text { veh mile) }\end{array}$ & $\begin{array}{l}\text { Total } \\
\text { Network } \\
\text { Delay } \\
\text { (hours) }\end{array}$ \\
\hline Random Seed Number & A & B & $C=B / A$ & D & $\mathrm{E}$ & $F=E / D$ & $\begin{array}{c}G=(B+E) \\
/[60(\mathrm{~min} / \\
\mathrm{hr})]\end{array}$ \\
\hline 1 & 42338.2 & 7884.88 & 0.19 & 11602.1 & 641.12 & 0.06 & 142.10 \\
\hline 33 & 42171.2 & 27334.25 & 0.65 & 11724.0 & 642.86 & 0.05 & 466.29 \\
\hline 99 & 42605.4 & 6830.03 & 0.16 & 11593.9 & 649.13 & 0.06 & 124.65 \\
\hline Cumulative Average Delay Time & & & 0.33 & & & 0.06 & 244.35 \\
\hline \multirow{2}{*}{ Network Description } & \multicolumn{6}{|c|}{ Simulation Set Number } & 14 \\
\hline & \multicolumn{3}{|c|}{ Interstate 95 North } & \multicolumn{3}{|c|}{ Highway Route 10} & \\
\hline $\begin{array}{l}\text { Meak AM Volume; } 20 \% \\
\text { Whes } 2 \text { Lane Block; } 30 \text { Min In }\end{array}$ & $\begin{array}{l}\text { Vehicle } \\
\text { Miles } \\
\text { Traveled } \\
\text { (miles) }\end{array}$ & $\begin{array}{l}\text { Total } \\
\text { Delay } \\
\text { (min) }\end{array}$ & $\begin{array}{l}\text { Average Delay } \\
\text { Time I-95 and } \\
\text { all Ramps (min- } \\
\text { veh mile) }\end{array}$ & $\begin{array}{l}\text { Vehicle } \\
\text { Miles } \\
\text { Traveled } \\
\text { (miles) }\end{array}$ & $\begin{array}{l}\text { Total } \\
\text { Delay } \\
\text { (min) }\end{array}$ & $\begin{array}{c}\text { Average Delay } \\
\text { Time RI-10 and } \\
\text { all Ramps (min } \\
\text { veh mile) }\end{array}$ & $\begin{array}{l}\text { Total } \\
\text { Network } \\
\text { Delay } \\
\text { (hours) }\end{array}$ \\
\hline Random Seed Number & A & B & $C=B / A$ & D & $\mathbf{E}$ & $F=E / D$ & $\begin{array}{c}G=(B+E) \\
/[60(\mathrm{~min} / \\
\mathrm{hr})]\end{array}$ \\
\hline 1 & 41510.7 & 10817.04 & 0.26 & 12157.3 & 680.62 & 0.06 & 191.63 \\
\hline 33 & 41462.5 & 59784.57 & 1.44 & 12162.4 & 694.01 & 0.06 & 1007.98 \\
\hline 99 & 41579.6 & 8603.75 & 0.21 & 12105.0 & 678.75 & 0.06 & 154.71 \\
\hline Cumulative Average Delay Time & & & 0.64 & & & 0.06 & 451.44 \\
\hline \multirow{2}{*}{ Network Description } & \multicolumn{6}{|c|}{ Simulation Set Number } & 15 \\
\hline & \multicolumn{3}{|c|}{ Interstate 95 North } & \multicolumn{3}{|c|}{ Highway Route 10} & \\
\hline $\begin{array}{l}\text { MS Peak AM Volume; } 20 \% \\
2 \text { Lane Block; } 40 \text { Min In }\end{array}$ & $\begin{array}{l}\text { Vehicle } \\
\text { Miles } \\
\text { Traveled } \\
\text { (miles) }\end{array}$ & $\begin{array}{l}\text { Total } \\
\text { Delay } \\
\text { (min) }\end{array}$ & $\begin{array}{l}\text { Average Delay } \\
\text { Time I-95 and } \\
\text { all Ramps (min- } \\
\text { veh mile) }\end{array}$ & $\begin{array}{l}\text { Vehicle } \\
\text { Miles } \\
\text { Traveled } \\
\text { (niles) }\end{array}$ & $\begin{array}{l}\text { Total } \\
\text { Delay } \\
\text { (min) }\end{array}$ & $\begin{array}{l}\text { Average Delay } \\
\text { Time RI-10 and } \\
\text { all Ramps ( } \mathrm{min} / \\
\text { veh mile) }\end{array}$ & $\begin{array}{l}\text { Total } \\
\text { Network } \\
\text { Delay } \\
\text { (hours) }\end{array}$ \\
\hline Random Seed Number & A & B & $C=B / A$ & $\mathrm{D}$ & E & $F=E / D$ & $\begin{array}{c}\mathrm{G}=(\mathrm{B}+\mathrm{E}) \\
/[60(\min / \\
\mathrm{hr})]\end{array}$ \\
\hline 1 & 40731.5 & 14075.86 & 0.35 & 4881.1 & 106397.00 & 21.80 & 2007.88 \\
\hline 33 & 40548.4 & 88430.17 & 2.18 & 12714.5 & 755.63 & 0.06 & 1486.43 \\
\hline 99 & 41016.8 & 11270.47 & 0.27 & 12564.4 & 728.52 & 0.06 & 199.98 \\
\hline Cumulative Average Delay Tíme & & & 0.93 & & & 3.58 & 1231.43 \\
\hline \multirow{2}{*}{ Network Description } & \multicolumn{6}{|c|}{ Simulation Set Number } & 16 \\
\hline & \multicolumn{3}{|c|}{ Interstate 95 North } & \multicolumn{3}{|c|}{ Highway Route 10} & \\
\hline $\begin{array}{l}\text { Peak AM Volume; } 20 \% \\
3 \text { Lane Block; } 20 \text { Min In }\end{array}$ & $\begin{array}{l}\text { Vehicle } \\
\text { Miles } \\
\text { Traveled } \\
\text { (miles) }\end{array}$ & $\begin{array}{l}\text { Total } \\
\text { Delay } \\
\text { (min) }\end{array}$ & $\begin{array}{l}\text { Average Delay } \\
\text { Time I-95 and } \\
\text { all Ramps (min- } \\
\text { veh mile) }\end{array}$ & $\begin{array}{l}\text { Vehicle } \\
\text { Miles } \\
\text { Traveled } \\
\text { (miles) }\end{array}$ & $\begin{array}{l}\text { Total } \\
\text { Delay } \\
\text { (min) }\end{array}$ & $\begin{array}{c}\text { Average Delay } \\
\text { Time RI-10 and } \\
\text { all Ramps (min / } \\
\text { veh mile) }\end{array}$ & $\begin{array}{l}\text { Total } \\
\text { Network } \\
\text { Delay } \\
\text { (hours) }\end{array}$ \\
\hline Random Seed Number & A & B & $C=B / A$ & D & $\mathbf{E}$ & $\mathbf{F}=\mathbf{E} / \mathbf{D}$ & $\begin{array}{c}\mathrm{G}=(\mathrm{B}+\mathrm{E}) \\
/\left[\begin{array}{c}60(\mathrm{~min} / \\
\mathrm{hr})]\end{array}\right.\end{array}$ \\
\hline 1 & 42425.3 & 42226.49 & 1.00 & 11602.1 & 641.12 & 0.06 & 714.46 \\
\hline 33 & 42173.8 & 28365.75 & 0.67 & 11724.0 & 642.86 & 0.05 & 483.48 \\
\hline 99 & 42264.6 & 28021.13 & 0.66 & 11593.9 & 649.13 & 0.06 & 477.84 \\
\hline Dumulative Average Delay Time & & & 0.78 & & & 0.06 & 558.59 \\
\hline
\end{tabular}




\begin{tabular}{|c|c|c|c|c|c|c|c|}
\hline \multirow{2}{*}{ Network Description } & \multicolumn{6}{|c|}{ Simulation Set Number } & 17 \\
\hline & \multicolumn{3}{|c|}{ Interstate 95 North } & \multicolumn{3}{|c|}{ Highway Route 10} & \multirow[b]{2}{*}{$\begin{array}{l}\text { Total } \\
\text { Network } \\
\text { Delay } \\
\text { (hours) }\end{array}$} \\
\hline $\begin{array}{l}\text { Peak AM Volume; } 20 \% \\
\text { Dler } 3 \text { Lane Block; } 30 \mathrm{Min} \text { In }\end{array}$ & $\begin{array}{l}\text { Vehicle } \\
\text { Miles } \\
\text { Traveled } \\
\text { (miles) }\end{array}$ & $\begin{array}{l}\text { Total } \\
\text { Delay } \\
\text { (min) }\end{array}$ & $\begin{array}{l}\text { Average Delay } \\
\text { Time I-95 and } \\
\text { all Ramps (min- } \\
\text { veh mile) }\end{array}$ & $\begin{array}{l}\text { Vehicle } \\
\text { Miles } \\
\text { Traveled } \\
\text { (miles) }\end{array}$ & $\begin{array}{l}\text { Total } \\
\text { Delay } \\
\text { (min) }\end{array}$ & $\begin{array}{c}\text { Average Delay } \\
\text { Time RI- } 10 \text { and } \\
\text { all Ramps (min } / \\
\text { veh mile) }\end{array}$ & \\
\hline Random Seed Number & ${ }^{A}$ & B & $C=B / A$ & D & E & $F=E / D$ & $\begin{array}{c}=(B+E) \\
/[60(\min / \\
\text { hri) } / \\
\end{array}$ \\
\hline 1 & 41606.5 & 68758.37 & 1.65 & 12157.3 & 680.62 & 0.06 & 1157.32 \\
\hline 33 & 41290.5 & 57661.52 & 1.40 & 12162.4 & 694.01 & 0.06 & 972.59 \\
\hline 99 & 41491.6 & 42226.66 & 1.02 & 12105.0 & 678.75 & 0.06 & 715.09 \\
\hline Cumulative Average Delay Time & & & 1.36 & & & 0.06 & 948.33 \\
\hline \multirow{2}{*}{ Network Description } & \multicolumn{6}{|c|}{ Simulation Set Number } & 18 \\
\hline & \multicolumn{3}{|c|}{ Interstate 95 North } & \multicolumn{3}{|c|}{ Highway Route 10} & \\
\hline 19eak AM Volume; $20 \%$ & $\begin{array}{l}\text { Vehicle } \\
\text { Miles } \\
\text { Traveled } \\
\text { (miles) }\end{array}$ & $\begin{array}{l}\text { Total } \\
\text { Delay } \\
\text { (min) }\end{array}$ & $\begin{array}{l}\text { Average Delay } \\
\text { Tirme I-95 and } \\
\text { all Ramps (min- } \\
\text { veh mile) }\end{array}$ & $\begin{array}{l}\text { Vehicle } \\
\text { Miles } \\
\text { Traveled } \\
\text { (miles) }\end{array}$ & $\begin{array}{l}\text { Total } \\
\text { Delay } \\
\text { (min) }\end{array}$ & $\begin{array}{c}\text { Average Delay } \\
\text { Time } \mathrm{R}-10 \text { and } \\
\text { all Ramps (min / } \\
\text { veh mile) }\end{array}$ & $\begin{array}{l}\text { Total } \\
\text { Network } \\
\text { Delay } \\
\text { (hours) }\end{array}$ \\
\hline Random Seed Number & A & B & $C=B / A$ & D & E & $F=E / D$ & $\begin{array}{c}\mathrm{G}=(\mathrm{B}+\mathrm{E}) \\
/[60(\mathrm{~min} / \\
\mathrm{hrd}]\end{array}$ \\
\hline 1 & 40511.5 & 95717.10 & 2.36 & 16952.1 & 106397.00 & 6.28 & 3368.57 \\
\hline 33 & 39828.9 & 90897.80 & 2.28 & 16635.6 & 755.63 & 0.05 & 1527.56 \\
\hline 99 & 40653.4 & 91150.90 & 2.24 & 16739.7 & 728.52 & 0.04 & 1531.32 \\
\hline Cumulative Average Delay Time & & & 2.30 & & & 2.14 & 2142.48 \\
\hline
\end{tabular}




\section{APPENDIX G}

Results for Simulations Modeled with

2/3 AM Peak Traffic Conditions 


\begin{tabular}{|c|c|c|c|c|c|c|c|}
\hline \multirow{2}{*}{ Network Description } & \multicolumn{6}{|c|}{ Simulation Set Number } & 1.0 \\
\hline & \multicolumn{3}{|c|}{ Interstate 95 North } & \multicolumn{3}{|c|}{ Highway Route 10} & \\
\hline $\begin{array}{l}\text { Peak AM Volume; } 0 \% \\
\text { In }\end{array}$ & $\begin{array}{l}\text { Vehicle } \\
\text { Miles } \\
\text { Traveled } \\
\text { (miles) }\end{array}$ & $\begin{array}{c}\text { Vehicle } \\
\text { Minutes } \\
\text { (min) }\end{array}$ & $\begin{array}{c}\text { Cumulative } \\
\text { Average Speed } \\
195 \text { and all } \\
\text { Ramps (mph) }\end{array}$ & $\begin{array}{l}\text { Vehicle } \\
\text { Miles } \\
\text { Traveled } \\
\text { (miles) }\end{array}$ & $\begin{array}{l}\text { Vehicle } \\
\text { Minutes } \\
\text { (min) }\end{array}$ & $\begin{array}{l}\text { Cumulative } \\
\text { Average Speed } \\
\text { RT10 and all } \\
\text { Ramps (mph) }\end{array}$ & $\begin{array}{l}\text { Cumulative } \\
\text { Network } \\
\text { Average } \\
\text { Speed (mph) }\end{array}$ \\
\hline Random Seed Number & A & B & $\begin{array}{c}\mathrm{C}=\mathrm{A} /(\mathrm{B} / 60 \\
\mathrm{min} / \mathrm{hr})\end{array}$ & D & $\mathbf{E}$ & $\begin{array}{c}\mathrm{F}=\mathrm{D} /(\mathrm{E} / 60 \\
\mathrm{min} / \mathrm{hr})\end{array}$ & $\begin{array}{c}\mathrm{G}=(\mathrm{A}+\mathrm{D}) / \\
{[(\mathrm{B}+\mathrm{E}) / 60} \\
\mathrm{min} / \mathrm{hr}] \\
\end{array}$ \\
\hline 1 & 38925.4 & 39244.4 & 59.5 & 9496.6 & 9983.2 & 57.1 & 59.0 \\
\hline 33 & 38952.8 & 39317.3 & 59.4 & 9627.6 & 10096.5 & 57.2 & 59.0 \\
\hline 99 & 39120.8 & 39475.9 & 59.5 & 9625.7 & 9891.3 & 58.4 & 59.2 \\
\hline Cumulative Average Speed & & & 59.5 & & & 57.6 & 59.1 \\
\hline \multirow{2}{*}{ Network Description } & \multicolumn{6}{|c|}{ Simulation Set Number } & 2.0 \\
\hline & \multicolumn{3}{|c|}{ Interstate 95 North } & \multicolumn{3}{|c|}{ Highway Route 10} & \\
\hline $\begin{array}{l}\text { 2.0 Peak AM Volume; } 0 \% \\
\text { Mine in }\end{array}$ & $\begin{array}{l}\text { Vehicle } \\
\text { Miles } \\
\text { Traveled } \\
\text { (miles) }\end{array}$ & $\begin{array}{c}\text { Vehicle } \\
\text { Minutes } \\
(\min )\end{array}$ & $\begin{array}{c}\text { Cumulative } \\
\text { Average Speed } \\
\text { I95 and all } \\
\text { Ramps (mph) }\end{array}$ & $\begin{array}{l}\text { Vehicle } \\
\text { Miles } \\
\text { Traveled } \\
\text { (miles) }\end{array}$ & $\begin{array}{l}\text { Vehicle } \\
\text { Minutes } \\
\text { (min) }\end{array}$ & $\begin{array}{c}\text { Cumulative } \\
\text { Average Speed } \\
\text { RT10 and all } \\
\text { Ramps (mph) }\end{array}$ & $\begin{array}{l}\text { Cumulative } \\
\text { Network } \\
\text { Average } \\
\text { Speed (mph) }\end{array}$ \\
\hline Random Seed Number & A & B & $\begin{array}{c}\mathrm{C}=\mathrm{A} /(\mathrm{B} / 60 \\
\mathrm{min} / \mathrm{hr})\end{array}$ & D & $\mathrm{E}$ & $\begin{array}{c}F=D /(E / 60 \\
\text { min/hr })\end{array}$ & $\begin{array}{c}\mathrm{G}=(\mathrm{A}+\mathrm{D}) / \\
{[(\mathrm{B}+\mathrm{E}) / 60} \\
\mathrm{min} / \mathrm{hr}]\end{array}$ \\
\hline 1 & 38964.7 & 39346.5 & 59.4 & 9778.1 & 10284.3 & 57.0 & 58.9 \\
\hline 33 & 39002.4 & 39372.0 & 59.4 & 9764.2 & 10269.0 & 57.1 & 58.9 \\
\hline 99 & 38989.9 & 39554.8 & 59.1 & 6251.7 & 87516.1 & 4.3 & 21.4 \\
\hline Cumulative Average Speed & & & 59.3 & & & 14.3 & 37.8 \\
\hline \multirow{2}{*}{ Nerwork Description } & \multicolumn{6}{|c|}{ Simulation Set Number } & 3.0 \\
\hline & \multicolumn{3}{|c|}{ Interstate 95 North } & \multicolumn{3}{|c|}{ Highway Route 10} & \\
\hline $\begin{array}{l}3 \text { Peak AM Volume; } 0 \% \\
\text { Dive } 1 \text { Lane Block; } 40\end{array}$ & $\begin{array}{l}\text { Vehicle } \\
\text { Miles } \\
\text { Traveled } \\
\text { (miles) }\end{array}$ & $\begin{array}{c}\text { Vehicle } \\
\text { Minutes } \\
\text { (min) }\end{array}$ & $\begin{array}{c}\text { Cumulative } \\
\text { Average Speed } \\
195 \text { and all } \\
\text { Ramps (mph) }\end{array}$ & $\begin{array}{l}\text { Vehicle } \\
\text { Miles } \\
\text { Traveled } \\
\text { (miles) }\end{array}$ & $\begin{array}{l}\text { Vehicle } \\
\text { Minutes } \\
\text { (min) }\end{array}$ & $\begin{array}{c}\text { Cumulative } \\
\text { Average Speed } \\
\text { RT10 and all } \\
\text { Ramps (mph) }\end{array}$ & $\begin{array}{c}\text { Cumulative } \\
\text { Network } \\
\text { Average } \\
\text { Speed (mph) }\end{array}$ \\
\hline Random Seed Number & A & B & $\begin{array}{c}C=A /(B / 60 \\
\min / h r)\end{array}$ & D & E & $\begin{array}{c}F=D /(E / 60 \\
\mathrm{min} / \mathrm{hr})\end{array}$ & $\begin{array}{c}\mathrm{G}=(\mathrm{A}+\mathrm{D}) / \\
{[(\mathrm{B}+\mathrm{E}) / 60} \\
\mathrm{min} / \mathrm{hr}]\end{array}$ \\
\hline 1 & 38932.0 & 39426.3 & 59.2 & 6212.3 & 90762.1 & 4.1 & 20.8 \\
\hline 33 & 39056.6 & 39403.6 & 59.5 & 9741.1 & 17269.2 & 33.8 & 51.7 \\
\hline 99 & 38915.0 & 39376.9 & 59.3 & 9753.6 & 17112.3 & 34.2 & 51.7 \\
\hline Cumulative Average Speed & & & 59.3 & & & 12.3 & 35.2 \\
\hline \multirow{2}{*}{ Network Description } & \multicolumn{6}{|c|}{ Simulation Set Number } & 4.0 \\
\hline & \multicolumn{3}{|c|}{ Interstate 95 North } & \multicolumn{3}{|c|}{ Highway Route 10} & \\
\hline $\begin{array}{l}\text { Peak AM Volume; } 0 \% \\
\text { 2hos } 2 \text { Lane Block; } 20\end{array}$ & $\begin{array}{l}\text { Vehicle } \\
\text { Miles } \\
\text { Traveled } \\
\text { (miles) }\end{array}$ & $\begin{array}{c}\text { Vehicle } \\
\text { Minutes } \\
\text { (min) }\end{array}$ & $\begin{array}{c}\text { Cumulative } \\
\text { Average Speed } \\
195 \text { and al] } \\
\text { Ramps (mph) }\end{array}$ & $\begin{array}{l}\text { Vehicle } \\
\text { Miles } \\
\text { Traveled } \\
\text { (miles) }\end{array}$ & $\begin{array}{l}\text { Vehicle } \\
\text { Minutes } \\
\text { (min) }\end{array}$ & $\begin{array}{c}\text { Cumulative } \\
\text { Average Speed } \\
\text { RT10 and all } \\
\text { Ramps (mph) }\end{array}$ & $\begin{array}{c}\text { Cumulative } \\
\text { Network } \\
\text { Average } \\
\text { Speed (mph) }\end{array}$ \\
\hline Random Seed Number & $\mathbf{A}$ & B & $\begin{array}{c}\mathrm{C}=\mathrm{A} /(\mathrm{B} / 60 \\
\mathrm{min} / \mathrm{hr})\end{array}$ & D & $\mathrm{E}$ & $\begin{array}{c}F=D /(E / 60 \\
\mathrm{min} / \mathrm{hr})\end{array}$ & $\begin{array}{c}G=(A+D)] \\
{[(B+E) / 60} \\
\min / \mathrm{hr}]\end{array}$ \\
\hline 1 & 39060.3 & 45826.2 & 51.1 & 9496.6 & 9983.2 & 57.1 & 52.2 \\
\hline 33 & 39001.1 & 45627.6 & 51.3 & 9627.6 & 10096.5 & 57.2 & 52.4 \\
\hline 99 & 38808.3 & 45231.6 & 51.5 & 9625.7 & 9891.3 & 58.4 & 52.7 \\
\hline Oumulative Average Speed & & & 51.3 & & & 57.6 & 52.4 \\
\hline
\end{tabular}




\begin{tabular}{|c|c|c|c|c|c|c|c|}
\hline \multirow{3}{*}{$\begin{array}{l}\text { Network Description } \\
\text { Peak AM Volume; } 0 \% \\
\text { in Lane Block; } 30\end{array}$} & \multicolumn{6}{|c|}{ Simulation Set Number } & 5.0 \\
\hline & \multicolumn{3}{|c|}{ Interstate 95 North } & \multicolumn{3}{|c|}{ Highway Route 10} & \multirow[b]{2}{*}{$\begin{array}{l}\text { Cumulative } \\
\text { Network } \\
\text { Average } \\
\text { Speed (mph) }\end{array}$} \\
\hline & $\begin{array}{l}\text { Vehicle } \\
\text { Miles } \\
\text { Traveled } \\
\text { (miles) }\end{array}$ & $\begin{array}{c}\text { Vehicle } \\
\text { Minutes } \\
\text { (min) }\end{array}$ & $\begin{array}{l}\text { Cumulative } \\
\text { Average Speed } \\
\text { I95 and all } \\
\text { Ramps (mph) }\end{array}$ & $\begin{array}{l}\text { Vehicle } \\
\text { Miles } \\
\text { Traveled } \\
\text { (miles) }\end{array}$ & $\begin{array}{l}\text { Vehicle } \\
\text { Minutes } \\
\text { (min) }\end{array}$ & $\begin{array}{l}\text { Cumulative } \\
\text { Average Speed } \\
\text { RT10 and all } \\
\text { Ramps (mph) }\end{array}$ & \\
\hline Random Seed Number & A & B & $\begin{array}{c}\mathrm{C}=\mathrm{A} /(\mathrm{B} / 60 \\
\mathrm{min} / \mathrm{hr})\end{array}$ & D & $\mathbf{E}$ & $\begin{array}{c}F=D /(E / 60 \\
\mathrm{min} / \mathrm{hr})\end{array}$ & $\begin{array}{c}\mathrm{G}=(\mathrm{A}+\mathrm{D}) / \\
{[(\mathrm{B}+\mathrm{E}) / 60} \\
\mathrm{min} / \mathrm{hrl}\end{array}$ \\
\hline 1 & 39060.1 & 53689.8 & 43.7 & 9778.1 & 10284.3 & 57.0 & 45.8 \\
\hline 33 & 38894.7 & 52874.1 & 44.1 & 9764.2 & 10269.0 & 57.1 & 46.2 \\
\hline 99 & 39010.1 & 52596.1 & 44.5 & 6251.7 & 87516.1 & 4.3 & 19.4 \\
\hline Cumulative Average Speed & & & 44.1 & & & 14.3 & 32.1 \\
\hline \multirow{2}{*}{ Network Description } & \multicolumn{6}{|c|}{ Simulation Set Number } & 6.0 \\
\hline & \multicolumn{3}{|c|}{ Interstate 95 North } & \multicolumn{3}{|c|}{ Highway Route 10} & \\
\hline 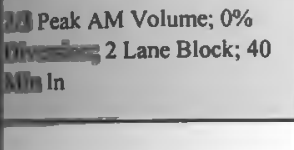 & $\begin{array}{l}\text { Vehicle } \\
\text { Miles } \\
\text { Traveled } \\
\text { (miles) }\end{array}$ & $\begin{array}{c}\text { Vehicle } \\
\text { Minutes } \\
(\min )\end{array}$ & $\begin{array}{c}\text { Cumulative } \\
\text { Average Speed } \\
195 \text { and all } \\
\text { Ramps (mph) }\end{array}$ & $\begin{array}{l}\text { Vehicle } \\
\text { Miles } \\
\text { Traveled } \\
\text { (miles) }\end{array}$ & $\begin{array}{l}\text { Vehicle } \\
\text { Minutes } \\
\text { (min) }\end{array}$ & $\begin{array}{l}\text { Cumulative } \\
\text { Average Speed } \\
\text { RT10 and all } \\
\text { Ramps (mph) }\end{array}$ & $\begin{array}{l}\text { Cumulative } \\
\text { Network } \\
\text { Average } \\
\text { Speed (mph) }\end{array}$ \\
\hline Random Seed Number & A & B & $\begin{array}{c}\mathrm{C}=\mathrm{A} /(\mathrm{B} / 60 \\
\mathrm{min} / \mathrm{hr})\end{array}$ & $\mathrm{D}$ & $\mathbf{E}$ & $\begin{array}{c}\mathrm{F}=\mathrm{D} /(\mathrm{E} / 60 \\
\mathrm{min} / \mathrm{hr})\end{array}$ & $\begin{array}{c}\mathrm{G}=(\mathrm{A}+\mathrm{D}) / \\
{[(\mathrm{B}+\mathrm{E}) / 60} \\
\mathrm{min} / \mathrm{hr}]\end{array}$ \\
\hline 1 & 38808.1 & 61677.7 & 37.8 & 6212.3 & 90762.1 & 4.1 & 17.7 \\
\hline 33 & 39133.1 & 62452.1 & 37.6 & 9741.1 & 17269.2 & 33.8 & 36.8 \\
\hline 99 & 38840.5 & 60412.2 & 38.6 & 9753.6 & 17112.3 & 34.2 & 37.6 \\
\hline Cumulative Average Speed & & & 38.0 & & & 12.3 & 27.6 \\
\hline \multirow{2}{*}{ Network Description } & \multicolumn{6}{|c|}{ Simulation Set Number } & 7.0 \\
\hline & \multicolumn{3}{|c|}{ Interstate 95 North } & \multicolumn{3}{|c|}{ Highway Route 10} & \\
\hline $\begin{array}{l}37 \text { Peak AM Volume; } 0 \% \\
\text { Whas } 3 \text { Lane Block; } 20\end{array}$ & $\begin{array}{l}\text { Vehicle } \\
\text { Miles } \\
\text { Traveled } \\
\text { (miles) }\end{array}$ & $\begin{array}{c}\text { Vehicle } \\
\text { Minutes } \\
\text { (min) }\end{array}$ & $\begin{array}{c}\text { Cumulative } \\
\text { Average Speed } \\
195 \text { and all } \\
\text { Ramps (mph) }\end{array}$ & $\begin{array}{l}\text { Vehicle } \\
\text { Miles } \\
\text { Traveled } \\
\text { (miles) }\end{array}$ & $\begin{array}{l}\text { Vehicle } \\
\text { Minutes } \\
\text { (min) }\end{array}$ & $\begin{array}{c}\text { Cumulative } \\
\text { Average Speed } \\
\text { RT10 and all } \\
\text { Ramps (mph) }\end{array}$ & $\begin{array}{l}\text { Cumulative } \\
\text { Network } \\
\text { Average } \\
\text { Speed (mph) }\end{array}$ \\
\hline Random Seed Number & A & B & $\begin{array}{c}\mathrm{C}=\mathrm{A} /(\mathrm{B} / 60 \\
\mathrm{min} / \mathrm{hr})\end{array}$ & $\mathrm{D}$ & E & $\begin{array}{c}\mathrm{F}=\mathrm{D} /(\mathrm{E} / 60 \\
\mathrm{min} / \mathrm{hr})\end{array}$ & $\begin{array}{c}G=(A+D) / \\
{[(B+E) / 60} \\
\mathrm{min} / \mathrm{hr}]\end{array}$ \\
\hline 1 & 38838.0 & 78764.4 & 29.6 & 9496.6 & 9983.2 & 57.1 & 32.7 \\
\hline 33 & 38842.2 & 68449.3 & 34.0 & 9627.6 & 10096.5 & 57.2 & 37.0 \\
\hline 99 & 38834.5 & 66716.8 & 34.9 & 9625.7 & 9891.3 & 58.4 & 38.0 \\
\hline Cumulative Average Speed & & & 32.7 & & & 57.6 & 35.7 \\
\hline \multirow{2}{*}{ Network Description } & \multicolumn{6}{|c|}{ Simulation Set Number } & 8.0 \\
\hline & \multicolumn{3}{|c|}{ Interstate 95 North } & \multicolumn{3}{|c|}{ Highway Route 10} & \\
\hline $\begin{array}{l}\text { Peak AM Volume; } 0 \% \\
3 \text { Lane Block; } 30\end{array}$ & $\begin{array}{l}\text { Vehicle } \\
\text { Miles } \\
\text { Traveled } \\
\text { (miles) }\end{array}$ & $\begin{array}{c}\text { Vehicle } \\
\text { Minutes } \\
(\min )\end{array}$ & $\begin{array}{c}\text { Cumulative } \\
\text { Average Speed } \\
195 \text { and all } \\
\text { Ramps (mph) }\end{array}$ & $\begin{array}{l}\text { Vehicle } \\
\text { Miles } \\
\text { Traveled } \\
\text { (miles) }\end{array}$ & $\begin{array}{l}\text { Vehicle } \\
\text { Minutes } \\
\text { (min) }\end{array}$ & $\begin{array}{l}\text { Cumulative } \\
\text { Average Speed } \\
\text { RT10 and all } \\
\text { Ramps (mph) }\end{array}$ & $\begin{array}{l}\text { Cumulative } \\
\text { Network } \\
\text { Average } \\
\text { Speed (mph) }\end{array}$ \\
\hline Random Seed Number & A & B & $\begin{array}{c}\mathrm{C}=\mathrm{A} /(\mathrm{B} / 60 \\
\min / \mathrm{hr})\end{array}$ & $\mathrm{D}$ & E & $\mathrm{F}=\underset{\mathrm{m} /(\mathrm{E} / 60}{\mathrm{min} / \mathrm{hr})}$ & $\begin{array}{c}\mathrm{G}=(\mathrm{A}+\mathrm{D}) / \\
{[(\mathrm{B}+\mathrm{E}) / 60} \\
\mathrm{min} / \mathrm{hr}]\end{array}$ \\
\hline 1 & 38958.2 & 126844.5 & 18.4 & 9778.1 & 10284.3 & 57.0 & 21.3 \\
\hline 33 & 39111.9 & 97495.6 & 24.1 & 9764.2 & 10269.0 & 57.1 & 27.2 \\
\hline 99 & 38861.0 & 92274.2 & 25.3 & 6251.7 & 87516.1 & 4.3 & 15.1 \\
\hline Cumulative Average Speed & & & 22.2 & & & 14.3 & 20.2 \\
\hline
\end{tabular}




\begin{tabular}{|c|c|c|c|c|c|c|c|}
\hline \multirow{3}{*}{$\begin{array}{l}\text { Network Description } \\
\text { Peak AM Volume; } 0 \% \\
\text { In } 3 \text { Lane Block; } 40\end{array}$} & \multicolumn{6}{|c|}{ Simulation Set Number } & 9.0 \\
\hline & \multicolumn{3}{|c|}{ Interstate 95 North } & \multicolumn{3}{|c|}{ Highway Route 10} & \multirow[b]{2}{*}{$\begin{array}{l}\text { Cumulative } \\
\text { Network } \\
\text { Average } \\
\text { Speed (mph) }\end{array}$} \\
\hline & $\begin{array}{l}\text { Vehicle } \\
\text { Miles } \\
\text { Traveled } \\
\text { (miles) }\end{array}$ & $\begin{array}{c}\text { Vehicle } \\
\text { Minutes } \\
\text { (min) }\end{array}$ & $\begin{array}{c}\text { Cumulative } \\
\text { Average Speed } \\
\text { I95 and all } \\
\text { Ramps (mph) }\end{array}$ & $\begin{array}{l}\text { Vehicle } \\
\text { Miles } \\
\text { Traveled } \\
\text { (miles) }\end{array}$ & $\begin{array}{l}\text { Vehicle } \\
\text { Minutes } \\
\text { (min) }\end{array}$ & $\begin{array}{c}\text { Cumulative } \\
\text { Average Speed } \\
\text { RT10 and all } \\
\text { Ramps (mph) }\end{array}$ & \\
\hline Random Seed Number & $\mathbf{A}$ & B & 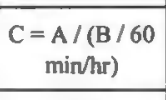 & D & E & $\begin{array}{c}\mathrm{F}=\mathrm{D} /(\mathrm{E} / 60 \\
\mathrm{min} / \mathrm{hr})\end{array}$ & $\begin{array}{c}G=(A+D) / \\
{[(B+E) / 60} \\
\mathrm{min} / \mathrm{hr}]\end{array}$ \\
\hline 1 & 39049.6 & 174983.4 & 13.4 & 6212.3 & 90762.1 & 4.1 & 10.2 \\
\hline 33 & 39001.5 & 145872.6 & 16.0 & 9741.1 & 17269.2 & 33.8 & 17.9 \\
\hline 99 & 38929.8 & 130574.4 & 17.9 & 9753.6 & 17112.3 & 34.2 & 19.8 \\
\hline Cumulative Average Speed & & & 15.5 & & & 12.3 & 14.8 \\
\hline \multirow{2}{*}{ Network Description } & \multicolumn{6}{|c|}{ Simulation Set Number } & 10.0 \\
\hline & \multicolumn{3}{|c|}{ Interstate 95 North } & \multicolumn{3}{|c|}{ Highway Route 10} & \\
\hline $\begin{array}{l}\text { Deak AM Volume; } 20 \% \\
\text { Dluartor; } 1 \text { Lane Block; } 20 \\
\text { Min In }\end{array}$ & $\begin{array}{l}\text { Vehicle } \\
\text { Miles } \\
\text { Traveled } \\
\text { (miles) }\end{array}$ & $\begin{array}{c}\text { Vehicle } \\
\text { Minutes } \\
\text { (min) }\end{array}$ & $\begin{array}{c}\text { Cumulative } \\
\text { Average Speed } \\
195 \text { and all } \\
\text { Ramps (mph) }\end{array}$ & $\begin{array}{l}\text { Vehicle } \\
\text { Miles } \\
\text { Traveled } \\
\text { (miles) }\end{array}$ & $\begin{array}{c}\text { Vehicle } \\
\text { Minutes } \\
\text { (min) }\end{array}$ & $\begin{array}{l}\text { Cumulative } \\
\text { Average Speed } \\
\text { RT10 and all } \\
\text { Ramps (mph) }\end{array}$ & $\begin{array}{l}\text { Cumulative } \\
\text { Network } \\
\text { Average } \\
\text { Speed (mph) }\end{array}$ \\
\hline Random Seed Number & A & B & $\begin{array}{c}\mathrm{C}=\mathrm{A} /(\mathrm{B} / 60 \\
\mathrm{min} / \mathrm{hr})\end{array}$ & $\mathrm{D}$ & E & $\begin{array}{c}\mathrm{F}=\mathrm{D} /(\mathrm{E} / 60 \\
\mathrm{min} / \mathrm{hr})\end{array}$ & $\begin{array}{c}\mathrm{G}=(\mathrm{A}+\mathrm{D}) / \\
{[(\mathrm{B}+\mathrm{E}) / 60} \\
\mathrm{min} / \mathrm{hr}]\end{array}$ \\
\hline 1 & 37672.9 & 37709.0 & 59.9 & 10343.7 & 10901.3 & 56.9 & 59.3 \\
\hline 33 & 37698.1 & 37836.2 & 59.8 & 10273.2 & 10818.6 & 57.0 & 59.2 \\
\hline 99 & 37308.3 & 37389.9 & 59.9 & 10227.7 & 10763.2 & 57.0 & 59.2 \\
\hline Cumulative Average Speed & & & 59.9 & & & 57.0 & 59.2 \\
\hline \multirow{2}{*}{ Network Description } & \multicolumn{6}{|c|}{ Simulation Set Number } & 11.0 \\
\hline & \multicolumn{3}{|c|}{ Interstate 95 North } & \multicolumn{3}{|c|}{ Highway Route 10} & \\
\hline $\begin{array}{l}\text { Peak AM Volume; } 20 \% \\
\text { Wherlon; } 1 \text { Lane Block; } 30 \\
\text { Mlh In }\end{array}$ & $\begin{array}{l}\text { Vehicle } \\
\text { Miles } \\
\text { Traveled } \\
\text { (miles) }\end{array}$ & $\begin{array}{c}\text { Vehicle } \\
\text { Minutes } \\
\text { (min) }\end{array}$ & $\begin{array}{l}\text { Cumulative } \\
\text { Average Speed } \\
\text { [95 and all } \\
\text { Ramps (mph) }\end{array}$ & $\begin{array}{l}\text { Vehicle } \\
\text { Miles } \\
\text { Traveled } \\
\text { (miles) }\end{array}$ & $\begin{array}{l}\text { Vehicle } \\
\text { Minutes } \\
\text { (min) }\end{array}$ & $\begin{array}{l}\text { Cumulative } \\
\text { Average Speed } \\
\text { RT10 and all } \\
\text { Ramps (mph) }\end{array}$ & $\begin{array}{l}\text { Cumulative } \\
\text { Network } \\
\text { Average } \\
\text { Speed (mph) }\end{array}$ \\
\hline Random Seed Number & A & B & $\begin{array}{c}\mathrm{C}=\mathrm{A} /(\mathrm{B} / 60 \\
\mathrm{min} / \mathrm{hr})\end{array}$ & D & E & $\begin{array}{c}\mathrm{F}=\mathrm{D} /(\mathrm{E} / 60 \\
\min / \mathrm{hr})\end{array}$ & $\begin{array}{c}\mathrm{G}=(\mathrm{A}+\mathrm{D}) / \\
{[(\mathrm{B}+\mathrm{E}) / 60} \\
\mathrm{min} / \mathrm{hr}]\end{array}$ \\
\hline 1 & 37089.0 & 37143.5 & 59.9 & 10889.0 & 11476.8 & 56.9 & 59.2 \\
\hline 33 & 37080.8 & 37235.6 & 59.8 & 10730.8 & 11307.3 & 56.9 & 59.1 \\
\hline 99 & 36691.4 & 36741.5 & 59.9 & 10830.3 & 11424.6 & 56.9 & 59.2 \\
\hline Cumulative Average Speed & & & 59.9 & & & 56.9 & 59.2 \\
\hline \multirow{2}{*}{ Network Description } & \multicolumn{6}{|c|}{ Simulation Set Number } & 12.0 \\
\hline & \multicolumn{3}{|c|}{ Interstate 95 North } & \multicolumn{3}{|c|}{ Highway Route 10} & \\
\hline 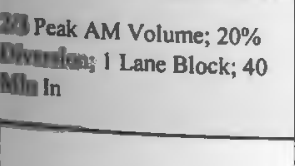 & $\begin{array}{l}\text { Vehicle } \\
\text { Miles } \\
\text { Traveled } \\
\text { (miles) }\end{array}$ & $\begin{array}{c}\text { Vehicle } \\
\text { Minutes } \\
\text { (min) }\end{array}$ & $\begin{array}{c}\text { Cumulative } \\
\text { Average Speed } \\
195 \text { and all } \\
\text { Ramps (mph) }\end{array}$ & $\begin{array}{l}\text { Vehicle } \\
\text { Miles } \\
\text { Traveled } \\
\text { (miles) }\end{array}$ & $\begin{array}{c}\text { Vehicle } \\
\text { Minutes } \\
\text { (min) }\end{array}$ & $\begin{array}{l}\text { Cumulative } \\
\text { Average Speed } \\
\text { RT10 and all } \\
\text { Ramps (mph) }\end{array}$ & $\begin{array}{l}\text { Cumulative } \\
\text { Network } \\
\text { Average } \\
\text { Speed (mph) }\end{array}$ \\
\hline Random Seed Number & A & B & $\begin{array}{c}\mathrm{C}=\mathrm{A} /(\mathrm{B} / 60 \\
\mathrm{min} / \mathrm{hr})\end{array}$ & D & E & $\begin{array}{c}F=D /(E / 60 \\
\min / \mathrm{hr})\end{array}$ & $\begin{array}{c}\mathrm{G}=(\mathrm{A}+\mathrm{D}) / \\
{[(\mathrm{B}+\mathrm{E}) / 60} \\
\mathrm{min} / \mathrm{hr}] \\
\end{array}$ \\
\hline 1 & 36242.3 & 36168.6 & 60.1 & 11211.0 & 11816.9 & 56.9 & 59.3 \\
\hline 33 & 36584.5 & 36822.9 & 59.6 & 11262.6 & 11897.6 & 56.8 & 58.9 \\
\hline 99 & 36080.6 & 36094.3 & 60.0 & 11310.3 & 11931.3 & 56.9 & 59.2 \\
\hline Cumbulative Average Speed & & & 59.9 & & & 56.9 & 59.2 \\
\hline
\end{tabular}




\begin{tabular}{|c|c|c|c|c|c|c|c|}
\hline \multirow{3}{*}{ 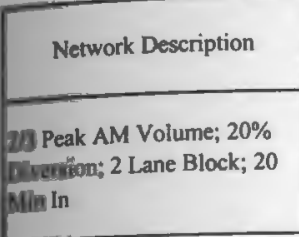 } & \multicolumn{6}{|c|}{ Simulation Set Number } & 13.0 \\
\hline & \multicolumn{3}{|c|}{ Interstate 95 North } & \multicolumn{3}{|c|}{ Highway Route 10} & \multirow[b]{2}{*}{$\begin{array}{l}\text { Cumulative } \\
\text { Network } \\
\text { Average } \\
\text { Speed (mph) }\end{array}$} \\
\hline & $\begin{array}{l}\text { Vehicle } \\
\text { Miles } \\
\text { Traveled } \\
\text { (miles) }\end{array}$ & $\begin{array}{c}\text { Vehicle } \\
\text { Minutes } \\
\text { (min) }\end{array}$ & $\begin{array}{c}\text { Cumulative } \\
\text { Average Speed } \\
\text { I95 and all } \\
\text { Ramps (mph) }\end{array}$ & $\begin{array}{l}\text { Vehicle } \\
\text { Miles } \\
\text { Traveled } \\
\text { (miles) }\end{array}$ & $\begin{array}{l}\text { Vehicie } \\
\text { Minutes } \\
\text { (min) }\end{array}$ & $\begin{array}{l}\text { Cumulative } \\
\text { Average Speed } \\
\text { RT10 and all } \\
\text { Ramps (mph) }\end{array}$ & \\
\hline Random Seed Number & A & B & $\begin{array}{c}\mathrm{C}=\mathrm{A} /(\mathrm{B} / 60 \\
\mathrm{min} / \mathrm{hr})\end{array}$ & D & E & $\begin{array}{c}\mathrm{F}=\mathrm{D} /(\mathrm{E} / 60 \\
\mathrm{min} / \mathrm{hr})\end{array}$ & $\begin{array}{c}\mathrm{G}=(\mathrm{A}+\mathrm{D}) / \\
{[(\mathrm{B}+\mathrm{E}) / 60} \\
\mathrm{min} / \mathrm{hr}]\end{array}$ \\
\hline 1 & 37458.1 & 37883.7 & 59.3 & 10343.7 & 10901.3 & 56.9 & 58.8 \\
\hline 33 & 37562.0 & 38442.4 & 58.6 & 10273.2 & 10818.6 & 57.0 & 58.3 \\
\hline 99 & 37552.9 & 38152.1 & 59.1 & 10227.7 & 10763.2 & 57.0 & 58.6 \\
\hline Curmulative Average Speed & & & 59.0 & & & 57.0 & 58.6 \\
\hline \multirow{2}{*}{ Network Description } & \multicolumn{6}{|c|}{ Simulation Set Number } & 14.0 \\
\hline & \multicolumn{3}{|c|}{ Interstate 95 North } & \multicolumn{3}{|c|}{ Highway Route 10} & \\
\hline $\begin{array}{l}23 \text { Peak AM Volume; } 20 \% \\
\text { Dluerstona; } 2 \text { Lane Block; } 30 \\
\text { Mln In }\end{array}$ & $\begin{array}{l}\text { Vehicle } \\
\text { Miles } \\
\text { Traveled } \\
\text { (miles) }\end{array}$ & $\begin{array}{l}\text { Vehicle } \\
\text { Minutes } \\
\text { (min) }\end{array}$ & $\begin{array}{c}\text { Cumulative } \\
\text { Average Speed } \\
195 \text { and all } \\
\text { Ramps (mph) }\end{array}$ & $\begin{array}{l}\text { Vehicle } \\
\text { Miles } \\
\text { Traveled } \\
\text { (miles) }\end{array}$ & $\begin{array}{l}\text { Vehicle } \\
\text { Minutes } \\
\text { (min) }\end{array}$ & $\begin{array}{l}\text { Cumulative } \\
\text { Average Speed } \\
\text { RT10 and all } \\
\text { Ramps (mph) }\end{array}$ & $\begin{array}{l}\text { Cumulative } \\
\text { Network } \\
\text { Average } \\
\text { Speed (mph) }\end{array}$ \\
\hline Random Seed Number & A & B & $\begin{array}{c}\mathrm{C}=\mathrm{A} /(\mathrm{B} / 60 \\
\mathrm{min} / \mathrm{hr})\end{array}$ & D & E & $\begin{array}{c}\mathrm{F}=\mathrm{D} /(\mathrm{E} / 60 \\
\mathrm{min} / \mathrm{hr})\end{array}$ & $\begin{array}{c}\mathrm{G}=(\mathrm{A}+\mathrm{D}) / \\
{[(\mathrm{B}+\mathrm{E}) / 60} \\
\mathrm{min} / \mathrm{hr}]\end{array}$ \\
\hline I & 36727.7 & 37166.9 & 59.3 & 10889.0 & 11476,8 & 56.9 & 58.7 \\
\hline 33 & 36816.7 & 37700.5 & 58.6 & 10730.8 & 11307.3 & 56.9 & 58.2 \\
\hline 99 & 36960.9 & 37658.4 & 58.9 & 10830.3 & 11424.6 & 56.9 & 58.4 \\
\hline Cumulative Average Speed & & & 58.9 & & & 56.9 & 58.5 \\
\hline \multirow{2}{*}{ Network Description } & \multicolumn{6}{|c|}{ Simulation Set Number } & 15.0 \\
\hline & \multicolumn{3}{|c|}{ Interstate 95 North } & \multicolumn{3}{|c|}{ Highway Route 10} & \\
\hline $\begin{array}{l}\text { Peak AM Volume; } 20 \% \\
\text { Biventan; } 2 \text { Lane Block; } 40\end{array}$ & $\begin{array}{l}\text { Vehicle } \\
\text { Miles } \\
\text { Traveled } \\
\text { (miles) }\end{array}$ & $\begin{array}{c}\text { Vehicle } \\
\text { Minutes } \\
\text { (min) }\end{array}$ & $\begin{array}{c}\text { Cumulative } \\
\text { Average Speed } \\
195 \text { and all } \\
\text { Ramps (mph) }\end{array}$ & $\begin{array}{l}\text { Vehicle } \\
\text { Miles } \\
\text { Traveled } \\
\text { (miles) }\end{array}$ & $\begin{array}{l}\text { Vehicle } \\
\text { Minutes } \\
\text { (min) }\end{array}$ & $\begin{array}{l}\text { Cumulative } \\
\text { Average Speed } \\
\text { RT10 and all } \\
\text { Ramps (mph) }\end{array}$ & $\begin{array}{c}\text { Cumulative } \\
\text { Network } \\
\text { Average } \\
\text { Speed (mph) }\end{array}$ \\
\hline Random Seed Number & A & B & $\begin{array}{c}\mathrm{C}=\underset{\mathrm{A}}{\mathrm{A} /(\mathrm{B} / 60} \\
\mathrm{min} / \mathrm{hr})\end{array}$ & D & $\mathbf{E}$ & $\begin{array}{c}\mathrm{F}=\mathrm{D} /(\mathrm{E} / 60 \\
\mathrm{min} / \mathrm{hr})\end{array}$ & $\begin{array}{c}\mathrm{G}=(\mathrm{A}+\mathrm{D}) / \\
{[(\mathrm{B}+\mathrm{E}) / 60} \\
\text { minthr }] \\
\end{array}$ \\
\hline 1 & 36318.7 & 36870.1 & 59.1 & 11211.0 & 11816.9 & 56.9 & 58.6 \\
\hline 33 & 36191.2 & 37199.1 & 58.4 & 11262.6 & 11897.6 & 56.8 & 58.0 \\
\hline 99 & 36148.0 & 37038.5 & 58.6 & 11310.3 & 11931.3 & 56.9 & 58.1 \\
\hline Cumulative Average Speed & & & 58.7 & & & 56.9 & 58.2 \\
\hline \multirow{2}{*}{ Network Description } & \multicolumn{6}{|c|}{ Simulation Set Number } & 16.0 \\
\hline & \multicolumn{3}{|c|}{ Interstate 95 North } & \multicolumn{3}{|c|}{ Highway Route 10} & \\
\hline $\begin{array}{l}\text { Peak AM Volume; } 20 \% \\
\text { Therlin; } 3 \text { Lane Block; } 20\end{array}$ & $\begin{array}{l}\text { Vehicle } \\
\text { Miles } \\
\text { Traveled } \\
\text { (miles) }\end{array}$ & $\begin{array}{c}\text { Vehicle } \\
\text { Minutes } \\
\text { (min) }\end{array}$ & $\begin{array}{c}\text { Cumulative } \\
\text { Average Speed } \\
195 \text { and all } \\
\text { Ramps (mph) }\end{array}$ & $\begin{array}{l}\text { Vehicle } \\
\text { Miles } \\
\text { Traveled } \\
\text { (miles) }\end{array}$ & $\begin{array}{c}\text { Vehicle } \\
\text { Minutes } \\
\text { (min) }\end{array}$ & $\begin{array}{c}\text { Cumulative } \\
\text { Average Speed } \\
\text { RT10 and all } \\
\text { Ramps (mph) }\end{array}$ & $\begin{array}{l}\text { Cumulative } \\
\text { Network } \\
\text { Average } \\
\text { Speed (mph) }\end{array}$ \\
\hline Random Seed Number & A & B & $\begin{array}{c}\mathrm{C}=\mathrm{A} /(\mathrm{B} / 60 \\
\mathrm{min} / \mathrm{hr})\end{array}$ & D & E & $\begin{array}{c}\mathrm{F}=\mathrm{D} /(\mathrm{E} / 60 \\
\mathrm{min} / \mathrm{hr})\end{array}$ & $\begin{array}{c}\mathrm{G}=(\mathrm{A}+\mathrm{D}) / \\
{[(\mathrm{B}+\mathrm{E}) / 60} \\
\min / \mathrm{hr}]\end{array}$ \\
\hline 1 & 37590.2 & 79511.2 & 28.4 & 10343.7 & 10901.3 & 56.9 & 31.8 \\
\hline 33 & 37541.9 & 53922.3 & 41.8 & 10273.2 & 10818.6 & 57.0 & 44.3 \\
\hline 99 & 37516.5 & 77950.7 & 28.9 & 10227.7 & 10763.2 & 57.0 & 32.3 \\
\hline Cumulative Average Speed & & & 32.0 & & & 57.0 & 35.3 \\
\hline
\end{tabular}




\begin{tabular}{|c|c|c|c|c|c|c|c|}
\hline \multirow{3}{*}{$\begin{array}{l}\text { Network Description } \\
\text { Peak AM Volume; } 20 \% \\
\text { Mine In }\end{array}$} & \multicolumn{6}{|c|}{ Simulation Set Number } & 17.0 \\
\hline & \multicolumn{3}{|c|}{ Interstate 95 North } & \multicolumn{3}{|c|}{ Highway Route 10} & \multirow[b]{2}{*}{$\begin{array}{l}\text { Cumulative } \\
\text { Network } \\
\text { Average } \\
\text { Speed (mph) }\end{array}$} \\
\hline & $\begin{array}{l}\text { Vehicle } \\
\text { Miles } \\
\text { Traveled } \\
\text { (miles) }\end{array}$ & $\begin{array}{c}\text { Vehicle } \\
\text { Minutes } \\
\text { (min) }\end{array}$ & $\begin{array}{l}\text { Cumulative } \\
\text { Average Speed } \\
\text { I95 and all } \\
\text { Ramps (mph) }\end{array}$ & $\begin{array}{l}\text { Vehicle } \\
\text { Miles } \\
\text { Traveled } \\
\text { (miles) }\end{array}$ & $\begin{array}{c}\text { Vehicle } \\
\text { Minutes } \\
\text { (min) }\end{array}$ & $\begin{array}{l}\text { Cumulative } \\
\text { Average Speed } \\
\text { RT10 and all } \\
\text { Ramps (mph) }\end{array}$ & \\
\hline Random Seed Number & $\mathbf{A}$ & B & $\begin{array}{c}\mathrm{C}=\mathrm{A} /(\mathrm{B} / 60 \\
\mathrm{min} / \mathrm{hr})\end{array}$ & D & E & $\begin{array}{c}\mathrm{F}=\mathrm{D} /(\mathrm{E} / 60 \\
\min / \mathrm{kr})\end{array}$ & $\begin{array}{c}\mathrm{G}=(\mathrm{A}+\mathrm{D}) / \\
{[(\mathrm{B}+\mathrm{E}) / 60} \\
\mathrm{min} / \mathrm{hr}]\end{array}$ \\
\hline 1 & 36719.8 & 121751.9 & 18.1 & 10889.0 & 11476.8 & 56.9 & 21.4 \\
\hline 33 & 37064.0 & 68895.5 & 32.3 & 10730.8 & 11307.3 & 56.9 & 35.8 \\
\hline 99 & 36789.0 & 121027.0 & 18.2 & 10830.3 & 11424.6 & 56.9 & 21.6 \\
\hline Cumulative Average Speed & & & 21.3 & & & 56.9 & 24.8 \\
\hline \multirow{2}{*}{ Network Description } & \multicolumn{6}{|c|}{ Simulation Set Number } & 18.0 \\
\hline & \multicolumn{3}{|c|}{ Interstate 95 North } & \multicolumn{3}{|c|}{ Highway Route 10} & \\
\hline $\begin{array}{l}17 \text { Peak AM Volume; } 20 \% \\
\text { Mhation In } 3 \text { Lane Block; } 40\end{array}$ & $\begin{array}{l}\text { Vehicle } \\
\text { Miles } \\
\text { Traveled } \\
\text { (miles) }\end{array}$ & $\begin{array}{c}\text { Vehicle } \\
\text { Minutes } \\
\text { (min) }\end{array}$ & $\begin{array}{l}\text { Cumulative } \\
\text { Average Speed } \\
\text { I95 and all } \\
\text { Ramps (mph) }\end{array}$ & $\begin{array}{l}\text { Vehicle } \\
\text { Miles } \\
\text { Traveled } \\
\text { (miles) }\end{array}$ & $\begin{array}{c}\text { Vehicle } \\
\text { Minutes } \\
\text { (min) }\end{array}$ & $\begin{array}{l}\text { Cumulative } \\
\text { Average Speed } \\
\text { RT10 and all } \\
\text { Ramps (mph) }\end{array}$ & $\begin{array}{l}\text { Cumulative } \\
\text { Network } \\
\text { Average } \\
\text { Speed (mph) }\end{array}$ \\
\hline Random Seed Number & A & B & $\begin{array}{c}\mathrm{C}=\mathrm{A} /(\mathrm{B} / 60 \\
\mathrm{min} / \mathrm{hr})\end{array}$ & D & E & $\begin{array}{c}F=D /(E / 60 \\
\min / 2 r)\end{array}$ & $\begin{array}{c}G=(A+D) / \\
{[(B+E) / 60} \\
\min / \mathrm{hrl}]\end{array}$ \\
\hline 1 & 36137.4 & 164387.2 & 13.2 & 11211.0 & 11816.9 & 56.9 & 16.1 \\
\hline 33 & 36475.5 & 91368.3 & 24.0 & 11262.6 & 11897.6 & 56.8 & 27.7 \\
\hline 99 & 35996.1 & 166021.3 & 13.0 & 11310.3 & 11931.3 & 56.9 & 16.0 \\
\hline Cumulative Average Speed & & & 15.5 & & & 56.9 & 18.7 \\
\hline
\end{tabular}




\begin{tabular}{|c|c|c|c|c|c|c|c|}
\hline \multirow{2}{*}{ Network Description } & \multicolumn{6}{|c|}{ Simulation Set Number } & 1 \\
\hline & \multicolumn{3}{|c|}{ Interstate 95 North } & \multicolumn{3}{|c|}{ Highway Route 10} & \\
\hline $\begin{array}{l}\text { Peak AM Volume; } 0 \% \\
\text { Dhos }\end{array}$ & $\begin{array}{l}\text { Vehicie Miles } \\
\text { Traveled } \\
\text { (miles) }\end{array}$ & $\begin{array}{l}\text { Vehicle } \\
\text { Minutes } \\
\text { (min) }\end{array}$ & $\begin{array}{c}\text { Cumulative } \\
\text { Average Travel } \\
\text { Time I95 and ali } \\
\text { Ramps (min-veh } \\
\text { mile) }\end{array}$ & $\begin{array}{l}\text { Vehicle Miles } \\
\text { Traveled } \\
\text { (miles) }\end{array}$ & $\begin{array}{l}\text { Vehicle } \\
\text { Minutes } \\
\text { (min) }\end{array}$ & $\begin{array}{c}\text { Cumulative } \\
\text { Average Travel } \\
\text { Time RT10 and } \\
\text { all Ramps (mph) }\end{array}$ & \begin{tabular}{|c|} 
Cumulative \\
Network \\
Average \\
Travel Time \\
(min / veh \\
mile) \\
\end{tabular} \\
\hline Random Seed Number & A & B & $\mathrm{C}=\mathrm{B} / \mathrm{A}$ & D & E & $F=E / D$ & $\begin{array}{c}G=(B+E) / \\
(A+D)\end{array}$ \\
\hline 1 & 38925.4 & 39244.4 & 1.01 & 9496.6 & 9983.2 & 1.05 & $\mathrm{I} .02$ \\
\hline 33 & 38952.8 & 39317.3 & 1.01 & 9627.6 & 10096.5 & 1.05 & 1.02 \\
\hline 99 & 39120.8 & 39475.9 & 1.01 & 9625.7 & 9891.3 & 1.03 & 1.01 \\
\hline Curmulative Average Travel Time & & & 1.01 & & & 1.04 & 1.02 \\
\hline \multirow{2}{*}{ Network Description } & \multicolumn{6}{|c|}{ Simulation Set Number } & 2 \\
\hline & \multicolumn{3}{|c|}{ Interstate 95 North } & \multicolumn{3}{|c|}{ Highway Route 10} & \\
\hline $\begin{array}{l}\text { Peak AM Volume; } 0 \% \\
2\end{array}$ & $\begin{array}{c}\text { Vehicle Miles } \\
\text { Traveled } \\
\text { (miles) }\end{array}$ & $\begin{array}{l}\text { Vehicle } \\
\text { Minutes } \\
\text { (min) }\end{array}$ & $\begin{array}{c}\text { Cumulative } \\
\text { Average Travel } \\
\text { Time I95 and all } \\
\text { Ramps (min-veh } \\
\text { mile) }\end{array}$ & $\begin{array}{c}\text { Vehicle Miles } \\
\text { Traveled } \\
\text { (miles) }\end{array}$ & $\begin{array}{l}\text { Vehicle } \\
\text { Minutes } \\
\text { (min) }\end{array}$ & $\begin{array}{c}\text { Cumulative } \\
\text { Average Travel } \\
\text { Time RT10 and } \\
\text { all Ramps (mph) }\end{array}$ & $\begin{array}{c}\text { Cumulative } \\
\text { Network } \\
\text { Average } \\
\text { Travel Time } \\
\text { (min / veh } \\
\text { mile) } \\
\end{array}$ \\
\hline Random Seed Number & A & B & $\mathrm{C}=\mathrm{B} / \mathrm{A}$ & D & E & $F=E / D$ & $\begin{array}{c}G=(B+E) \prime \\
(A+D)\end{array}$ \\
\hline 1 & 38964.7 & 39346.5 & 1.01 & 9778.1 & 10284.3 & 1.05 & 1.02 \\
\hline 33 & 39002.4 & 39372.0 & 1.01 & 9764.2 & 10269.0 & 1.05 & 1.02 \\
\hline 99 & 38989.9 & 39554.8 & 1.01 & 6251.7 & 87516.1 & 14.00 & 2.81 \\
\hline Cumulative Average Travel Time & & & 1.01 & & & 4.19 & 1.59 \\
\hline \multirow{2}{*}{ Network Description } & \multicolumn{6}{|c|}{ Simulation Set Number } & 3 \\
\hline & \multicolumn{3}{|c|}{ Interstate 95 North } & \multicolumn{3}{|c|}{ Highway Route 10} & \\
\hline $\begin{array}{l}\text { Peak AM Volume; } 0 \% \\
\text { IT } 1 \text { Lane Block; } 40 \text { Min }\end{array}$ & $\begin{array}{c}\text { Vehicle Miles } \\
\text { Traveled } \\
\text { (miles) }\end{array}$ & $\begin{array}{l}\text { Vehicle } \\
\text { Minutes } \\
\text { (min) }\end{array}$ & $\begin{array}{c}\text { Cumulative } \\
\text { Average Travel } \\
\text { Time } 195 \text { and all } \\
\text { Ramps (min-veh } \\
\text { mile) }\end{array}$ & $\begin{array}{l}\text { Vehicle Miles } \\
\text { Traveled } \\
\text { (miles) }\end{array}$ & $\begin{array}{l}\text { Vehicle } \\
\text { Minutes } \\
\text { (min) }\end{array}$ & $\begin{array}{c}\text { Cumulative } \\
\text { Average Travel } \\
\text { Time RT10 and } \\
\text { all Ramps (mph) }\end{array}$ & $\begin{array}{c}\text { Cumulative } \\
\text { Network } \\
\text { Average } \\
\text { Travel Time } \\
\text { (min / veh } \\
\text { mile) } \\
\end{array}$ \\
\hline Random Seed Number & A & B & $\mathrm{C}=\mathrm{B} / \mathrm{A}$ & D & $\mathbf{E}$ & $F=E / D$ & $\begin{array}{c}G=(B+E) / \\
(A+D)\end{array}$ \\
\hline 1 & 38932.0 & 39426.3 & 1.01 & 6212.3 & 90762.1 & 14.61 & 2.88 \\
\hline 33 & 39056.6 & 39403.6 & 1.01 & 9741.1 & 17269.2 & 1.77 & 1.16 \\
\hline 99 & 38915.0 & 39376.9 & 1.01 & 9753.6 & 17112.3 & 1.75 & 1.16 \\
\hline Cumulative Average Travel Time & & & 1.01 & & & 4.87 & 1.71 \\
\hline \multirow{2}{*}{ Network Description } & \multicolumn{6}{|c|}{ Simulation Set Number } & 4 \\
\hline & \multicolumn{3}{|c|}{ Interstate 95 North } & \multicolumn{3}{|c|}{ Highway Route 10} & \\
\hline $\begin{array}{l}\text { Peak AM Volume; } 0 \% \\
\text { in } 2 \text { Lane Block; } 20 \text { Min }\end{array}$ & $\begin{array}{c}\text { Vehicle Miles } \\
\text { Traveled } \\
\text { (miles) }\end{array}$ & $\begin{array}{l}\text { Vehicle } \\
\text { Minutes } \\
\text { (min) }\end{array}$ & $\begin{array}{c}\text { Cumulative } \\
\text { Average Travel } \\
\text { Time I95 and all } \\
\text { Ramps (min-veh } \\
\text { mile) }\end{array}$ & $\begin{array}{c}\text { Vehicle Miles } \\
\text { Traveled } \\
\text { (miles) }\end{array}$ & $\begin{array}{l}\text { Vehicle } \\
\text { Minutes } \\
\text { (min) }\end{array}$ & $\begin{array}{c}\text { Cumulative } \\
\text { Average Travel } \\
\text { Time RT } 10 \text { and } \\
\text { all Ramps (mph) }\end{array}$ & $\begin{array}{l}\text { Cumulative } \\
\text { Network } \\
\text { Average } \\
\text { Travel Time } \\
\text { (min / veh } \\
\text { mile) } \\
\end{array}$ \\
\hline Random Seed Number & $\mathbf{A}$ & $\mathbf{B}$ & $\mathbf{C}=\mathbf{B} / \mathbf{A}$ & D & $\mathrm{E}$ & $F=E / D$ & $\begin{array}{c}G=(B+E) / \\
(A+D)\end{array}$ \\
\hline 1 & 39060.3 & 45826.2 & 1.17 & 9496.6 & 9983.2 & 1.05 & 1.15 \\
\hline 33 & 39001.1 & 45627.6 & 1.17 & 9627.6 & 10096.5 & 1.05 & 1.15 \\
\hline 99 & 38808.3 & 45231.6 & 1.17 & 9625.7 & 9891.3 & 1.03 & 1.14 \\
\hline Curmulative Average Travel Time & & & 1.17 & & & 1.04 & 1.14 \\
\hline
\end{tabular}




\begin{tabular}{|c|c|c|c|c|c|c|c|}
\hline \multirow{2}{*}{ Network Description } & \multicolumn{6}{|c|}{ Simulation Set Number } & 5 \\
\hline & \multicolumn{3}{|c|}{ Interstate 95 North } & \multicolumn{3}{|c|}{ Highway Route 10} & \\
\hline $\begin{array}{l}23 \text { Peak AM Volume; } 0 \% \\
\text { Doxe } 10 \text { Lane Block; } 30 \text { Min }\end{array}$ & $\begin{array}{c}\text { Vehicle Miles } \\
\text { Traveled } \\
\text { (miles) }\end{array}$ & $\begin{array}{l}\text { Vehicle } \\
\text { Minutes } \\
\text { (min) }\end{array}$ & $\begin{array}{c}\text { Cumulative } \\
\text { Average Trave! } \\
\text { Time } 195 \text { and all } \\
\text { Ramps (min-veh } \\
\text { mile) }\end{array}$ & $\begin{array}{c}\text { Vehicle Miles } \\
\text { Traveled } \\
\text { (miles) }\end{array}$ & $\begin{array}{l}\text { Vehicle } \\
\text { Minutes } \\
\text { (min) }\end{array}$ & $\begin{array}{c}\text { Cumulative } \\
\text { Average Travel } \\
\text { Time RT10 and } \\
\text { all Ramps (mph) }\end{array}$ & \begin{tabular}{|c|} 
Cumulative \\
Network \\
Average \\
Travel Time \\
(min/veh \\
mile) \\
\end{tabular} \\
\hline Random Seed Number & A & B & $\mathrm{C}=\mathrm{B} / \mathrm{A}$ & D & E & $F=E / D$ & $\begin{array}{c}G=(B+E) / \\
(A+D)\end{array}$ \\
\hline 1 & 39060.1 & 53689.8 & 1.37 & 9778.1 & 10284.3 & 1.05 & 1.31 \\
\hline 33 & 38894.7 & 52874.1 & 1.36 & 9764.2 & 10269.0 & 1.05 & 1.30 \\
\hline 99 & 39010.1 & 52596.1 & 1.35 & 6251.7 & 87516.1 & 14.00 & 3.10 \\
\hline Cumulative Average Travel Time & & & 1.36 & & & 4.19 & 1.87 \\
\hline \multirow{2}{*}{ Network Description } & \multicolumn{6}{|c|}{ Simulation Set Number } & 6 \\
\hline & \multicolumn{3}{|c|}{ Interstate 95 North } & \multicolumn{3}{|c|}{ Highway Route 10} & \\
\hline $\begin{array}{l}\text { Peak AM Volume; } 0 \% \\
\text { Dhecriti: } 2 \text { Lane Block; } 40 \mathrm{Min} \\
\text { th }\end{array}$ & $\begin{array}{c}\text { Vehicle Miles } \\
\text { Traveled } \\
\text { (miles) }\end{array}$ & $\begin{array}{c}\text { Vehicle } \\
\text { Minutes } \\
\text { (min) }\end{array}$ & $\begin{array}{c}\text { Cumulative } \\
\text { Average Travel } \\
\text { Time } 195 \text { and all } \\
\text { Rarnps (min-veh } \\
\text { mile) }\end{array}$ & $\begin{array}{l}\text { Vehicle Miles } \\
\text { Traveled } \\
\text { (miles) }\end{array}$ & $\begin{array}{c}\text { Vehicle } \\
\text { Minutes } \\
\text { (min) }\end{array}$ & $\begin{array}{c}\text { Cumulative } \\
\text { Average Travel } \\
\text { Time RT10 and } \\
\text { all Ramps (mph) }\end{array}$ & \begin{tabular}{|c|}
$\begin{array}{c}\text { Cumulative } \\
\text { Network } \\
\text { Average } \\
\text { Travel Time } \\
\text { (min / veh } \\
\text { mile) }\end{array}$ \\
\end{tabular} \\
\hline Random Seed Number & A & B & $C=B / A$ & D & E & $F=E / D$ & $\begin{array}{c}G=(B+E) / \\
(A+D)\end{array}$ \\
\hline 1 & 38808.1 & 61677.7 & 1.59 & 6212.3 & 90762.1 & 14.61 & 3.39 \\
\hline 33 & 39133.1 & 62452.1 & 1.60 & 9741.1 & 17269.2 & 1.77 & 1.63 \\
\hline 99 & 38840.5 & 60412.2 & 1.56 & 9753.6 & 17112.3 & 1.75 & 1.60 \\
\hline Cumulative Average Travel Time & & & 1.58 & & & 4.87 & 2.17 \\
\hline \multirow{2}{*}{ Network Description } & \multicolumn{6}{|c|}{ Simulation Set Number } & 7 \\
\hline & \multicolumn{3}{|c|}{ Interstate 95 North } & \multicolumn{3}{|c|}{ Highway Route 10} & \\
\hline $\begin{array}{l}\text { Peak AM Volume; } 0 \% \\
\text { Dherforg } 3 \text { Lane Block; } 20 \text { Min }\end{array}$ & $\begin{array}{c}\text { Vehicle Miles } \\
\text { Traveled } \\
\text { (miles) }\end{array}$ & $\begin{array}{l}\text { Vehicle } \\
\text { Minutes } \\
\text { (min) }\end{array}$ & $\begin{array}{c}\text { Cumulative } \\
\text { Average Travel } \\
\text { Time } 195 \text { and all } \\
\text { Ramps (min-veh } \\
\text { mile) }\end{array}$ & $\begin{array}{c}\text { Vehicle Miles } \\
\text { Traveled } \\
\text { (miles) }\end{array}$ & $\begin{array}{c}\text { Vehicle } \\
\text { Minutes } \\
(\min )\end{array}$ & $\begin{array}{c}\text { Cumulative } \\
\text { Average Travel } \\
\text { Time RT10 and } \\
\text { all Ramps (mph) }\end{array}$ & \begin{tabular}{|c|} 
Cumulative \\
Network \\
Average \\
Travel Time \\
(min / veh \\
mile) \\
\end{tabular} \\
\hline Random Seed Number & A & B & $\mathrm{C}=\mathrm{B} / \mathrm{A}$ & D & E & $F=E / D$ & $\begin{array}{c}G=(B+E) / \\
(A+D)\end{array}$ \\
\hline 1 & 38838.0 & 78764.4 & 2.03 & 9496.6 & 9983.2 & 1.05 & 1.84 \\
\hline 33 & 38842.2 & 68449.3 & 1.76 & 9627.6 & 10096.5 & 1.05 & 1.62 \\
\hline 99 & 38834.5 & 66716.8 & 1.72 & 9625.7 & 9891.3 & 1.03 & 1.58 \\
\hline Cumulative Average Travel Time & & & 1.84 & & & 1.04 & 1.68 \\
\hline \multirow{2}{*}{ Network Description } & \multicolumn{6}{|c|}{ Simulation Set Number } & 8 \\
\hline & \multicolumn{3}{|c|}{ Interstate 95 North } & \multicolumn{3}{|c|}{ Highway Route 10} & \\
\hline $\begin{array}{l}\text { Peak AM Volume; } 0 \% \\
\text { The }\end{array}$ & $\begin{array}{c}\text { Vehicle Miles } \\
\text { Traveled } \\
\text { (miles) }\end{array}$ & $\begin{array}{l}\text { Vehicle } \\
\text { Minutes } \\
\text { (min) }\end{array}$ & $\begin{array}{c}\text { Cumulative } \\
\text { Average Travel } \\
\text { Time } 195 \text { and all } \\
\text { Ramps (min-veh } \\
\text { mile) }\end{array}$ & $\begin{array}{c}\text { Vehicle Miles } \\
\text { Traveled } \\
\text { (miles) }\end{array}$ & $\begin{array}{c}\text { Vehicle } \\
\text { Minutes } \\
\text { (min) }\end{array}$ & $\begin{array}{c}\text { Cumulative } \\
\text { Average Travel } \\
\text { Time RT10 and } \\
\text { all Ramps (mph) }\end{array}$ & 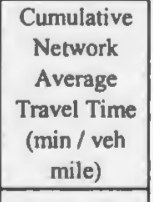 \\
\hline Random Seed Number & A & B & $\mathrm{C}=\mathrm{B} / \mathrm{A}$ & D & E & $F=E / D$ & $\begin{array}{c}G=(B+E) / \\
(A+D)\end{array}$ \\
\hline 1 & 38958.2 & 126844.5 & 3.26 & 9778.1 & 10284.3 & 1.05 & 2.81 \\
\hline 33 & 39111.9 & 97495.6 & 2.49 & 9764.2 & 10269.0 & 1.05 & 2.20 \\
\hline 99 & 38861.0 & 92274.2 & 2.37 & 6251.7 & 87516.1 & 14.00 & 3.99 \\
\hline Cumulative Average Travel Time & & & 2.71 & & & 4.19 & 2.98 \\
\hline
\end{tabular}




\begin{tabular}{|c|c|c|c|c|c|c|c|}
\hline \multirow{2}{*}{ Network Description } & \multicolumn{6}{|c|}{ Simulation Set Number } & 9 \\
\hline & \multicolumn{3}{|c|}{ Interstate 95 North } & \multicolumn{3}{|c|}{ Highway Route 10} & \\
\hline 23. Peak AM Volume; $0 \%$ & $\begin{array}{l}\text { Vehicle Miles } \\
\text { Traveled } \\
\text { (miles) }\end{array}$ & $\begin{array}{c}\text { Vehicle } \\
\text { Minutes } \\
\text { (min) }\end{array}$ & $\begin{array}{c}\text { Cumulative } \\
\text { Average Travel } \\
\text { Time I95 and all } \\
\text { Ramps (min-veh } \\
\text { mile) }\end{array}$ & $\begin{array}{c}\text { Vehicle Miles } \\
\text { Traveled } \\
\text { (miles) }\end{array}$ & $\begin{array}{l}\text { Vehicle } \\
\text { Minutes } \\
\text { (min) }\end{array}$ & $\begin{array}{c}\text { Cumulative } \\
\text { Average Travel } \\
\text { Time RT10 and } \\
\text { all Ramps (mph) }\end{array}$ & \begin{tabular}{|c|} 
Cumulative \\
Network \\
Average \\
Travel Time \\
(min / veh \\
mile) \\
\end{tabular} \\
\hline Random Seed Number & A & $\mathbf{B}$ & $C=B / A$ & D & 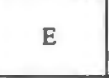 & $F=E / D$ & $\begin{array}{c}G=(B+E) / \\
(A+D)\end{array}$ \\
\hline 1 & 39049.6 & 174983.4 & 4.48 & 6212.3 & 90762.1 & 14.61 & 5.87 \\
\hline 33 & 39001.5 & 145872.6 & 3.74 & 9741.1 & 17269.2 & 1.77 & 3.35 \\
\hline 99 & 38929.8 & 130574.4 & 3.35 & 9753.6 & 17112.3 & 1.75 & 3.03 \\
\hline Cumulative Average Travel Time & & & 3.86 & & & 4.87 & 4.04 \\
\hline \multirow{2}{*}{ Network Description } & \multicolumn{6}{|c|}{ Simulation Set Number } & 10 \\
\hline & \multicolumn{3}{|c|}{ Interstate 95 North } & \multicolumn{3}{|c|}{ Highway Route 10} & \\
\hline $\begin{array}{l}20 \text { Peak AM Volume; } 20 \% \\
\text { Dhestion; } 1 \text { Lane Block; } 20 \text { Min } \\
\text { In }\end{array}$ & $\begin{array}{c}\text { Vehicle Miles } \\
\text { Traveled } \\
\text { (miles) }\end{array}$ & $\begin{array}{l}\text { Vehicle } \\
\text { Minutes } \\
\text { (min) }\end{array}$ & $\begin{array}{c}\text { Cumulative } \\
\text { Average Travel } \\
\text { Time I95 and ali } \\
\text { Ramps (min-veh } \\
\text { mile) }\end{array}$ & $\begin{array}{c}\text { Vehicle Miles } \\
\text { Traveled } \\
\text { (miles) }\end{array}$ & $\begin{array}{l}\text { Vehicle } \\
\text { Minutes } \\
\text { (min) }\end{array}$ & $\begin{array}{c}\text { Cumulative } \\
\text { Average Travel } \\
\text { Time RT10 and } \\
\text { all Ramps (mph) }\end{array}$ & \begin{tabular}{|c|} 
Cumulative \\
Network \\
Average \\
Travel Time \\
(min/ veh \\
mile) \\
\end{tabular} \\
\hline Randorn Seed Number & A & B & $\mathrm{C}=\mathrm{B} / \mathrm{A}$ & D & $E$ & $F=E / D$ & $\begin{array}{c}G=(B+E) / \\
(A+D)\end{array}$ \\
\hline 1 & 37672.9 & 37709.0 & 1.00 & 10343.7 & 10901.3 & 1.05 & 1.01 \\
\hline 33 & 37698.1 & 37836.2 & 1.00 & 10273.2 & 10818.6 & 1.05 & 1.01 \\
\hline 99 & 37308.3 & 37389.9 & 1.00 & 10227.7 & 10763.2 & 1.05 & 1.01 \\
\hline Cumulative Average Travel Time & & & 1.00 & & & 1.05 & 1.01 \\
\hline \multirow{2}{*}{ Network Description } & \multicolumn{6}{|c|}{ Simulation Set Number } & 11 \\
\hline & \multicolumn{3}{|c|}{ Interstate 95 North } & \multicolumn{3}{|c|}{ Highway Route 10} & \\
\hline $\begin{array}{l}29 \text { Peak AM Volume; } 20 \% \\
\text { Divesion; } 1 \text { Lane Block; } 30 \text { Min } \\
\text { In }\end{array}$ & $\begin{array}{c}\text { Vehicle Miles } \\
\text { Traveled } \\
\text { (miles) }\end{array}$ & $\begin{array}{l}\text { Vehicle } \\
\text { Minutes } \\
\text { (min) }\end{array}$ & $\begin{array}{c}\text { Cumulative } \\
\text { Average Travel } \\
\text { Time } 195 \text { and all } \\
\text { Ramps (min-veh } \\
\text { mile) }\end{array}$ & $\begin{array}{c}\text { Vehicle Miles } \\
\text { Traveled } \\
\text { (miles) }\end{array}$ & $\begin{array}{c}\text { Vehicle } \\
\text { Minutes } \\
\text { (min) }\end{array}$ & $\begin{array}{c}\text { Cumulative } \\
\text { Average Travel } \\
\text { Time RT10 and } \\
\text { all Ramps (mph) }\end{array}$ & \begin{tabular}{|c|} 
Cumulative \\
Network \\
Average \\
Travel Time \\
(min/ veh \\
mile) \\
\end{tabular} \\
\hline Randorn Seed Number & A & B & $C=B / A$ & D & $E$ & $F=E / D$ & $\begin{array}{c}G=(B+E) / \\
(A+D)\end{array}$ \\
\hline 1 & 37089.0 & 37143.5 & 1.00 & 10889.0 & 11476.8 & 1.05 & 1.01 \\
\hline 33 & 37080.8 & 37235.6 & 1.00 & 10730.8 & 11307.3 & 1.05 & 1.02 \\
\hline 99 & 36691.4 & 36741.5 & 1.00 & 10830.3 & 11424.6 & 1.05 & 1.01 \\
\hline Cumulative Average Travel Time & & & 1.00 & & & 1.05 & 1.01 \\
\hline \multirow{2}{*}{ Network Description } & \multicolumn{6}{|c|}{ Simulation Set Number } & 12 \\
\hline & \multicolumn{3}{|c|}{ Interstate 95 North } & \multicolumn{3}{|c|}{ Highway Route 10} & \\
\hline \multirow[b]{2}{*}{ Random Seed Number } & $\begin{array}{l}\text { Vehicle Miles } \\
\text { Traveled } \\
\text { (miles) }\end{array}$ & $\begin{array}{l}\text { Vehicle } \\
\text { Minutes } \\
\text { (min) }\end{array}$ & $\begin{array}{c}\text { Cumulative } \\
\text { Average Travel } \\
\text { Time I95 and all } \\
\text { Ramps (min-veh } \\
\text { mile) }\end{array}$ & $\begin{array}{l}\text { Vehicle Miles } \\
\text { Traveled } \\
\text { (miles) }\end{array}$ & $\begin{array}{l}\text { Vehicle } \\
\text { Minutes } \\
\text { (min) }\end{array}$ & $\begin{array}{c}\text { Cumulative } \\
\text { A verage Travel } \\
\text { Time RT10 and } \\
\text { all Ramps (mph) }\end{array}$ & $\begin{array}{c}\text { Cumulative } \\
\text { Network } \\
\text { Average } \\
\text { Travel Time } \\
\text { (min/veh } \\
\text { mile) } \\
\end{array}$ \\
\hline & A & B & $\mathrm{C}=\mathrm{B} / \mathrm{A}$ & D & $E$ & $F=E / D$ & $\begin{array}{c}G=(B+E) / \\
(A+D)\end{array}$ \\
\hline 1 & 36242.3 & 36168.6 & 1.00 & 11211.0 & 11816.9 & 1.05 & 1.01 \\
\hline 33 & 36584.5 & 36822.9 & 1.01 & 11262.6 & 11897.6 & 1.06 & 1.02 \\
\hline 99 & 36080.6 & 36094.3 & 1.00 & 11310.3 & 11931.3 & 1.05 & 1.01 \\
\hline Cumulative Average Travel Time & & & 1.00 & & & 1.06 & 1.01 \\
\hline
\end{tabular}




\begin{tabular}{|c|c|c|c|c|c|c|c|}
\hline \multirow{2}{*}{ Network Description } & \multicolumn{6}{|c|}{ Simulation Set Number } & 13 \\
\hline & \multicolumn{3}{|c|}{ Interstate 95 North } & \multicolumn{3}{|c|}{ Highway Route 10} & \\
\hline $\begin{array}{l}\text { 23) Peak AM Volume; } 20 \% \\
\text { Diversien; } 2 \text { Lane Block; } 20 \text { Min }\end{array}$ & $\begin{array}{l}\text { Vehicle Miles } \\
\text { Traveled } \\
\text { (miles) }\end{array}$ & $\begin{array}{l}\text { Vehicle } \\
\text { Minutes } \\
\text { (min) }\end{array}$ & $\begin{array}{c}\text { Cumulative } \\
\text { Average Travel } \\
\text { Time I95 and all } \\
\text { Ramps (min-veh } \\
\text { mile) }\end{array}$ & $\begin{array}{c}\text { Vehicle Miles } \\
\text { Traveled } \\
\text { (miles) }\end{array}$ & $\begin{array}{c}\text { Vehicle } \\
\text { Minutes } \\
\text { (min) }\end{array}$ & $\begin{array}{c}\text { Cumulative } \\
\text { Average Travel } \\
\text { Time RT } 10 \text { and } \\
\text { all Ramps (mph) }\end{array}$ & $\begin{array}{c}\text { Cumulative } \\
\text { Network } \\
\text { Average } \\
\text { Travel Time } \\
\text { (min/veh } \\
\text { mile) } \\
\end{array}$ \\
\hline Random Seed Number & A & B & $C=B / A$ & D & E & $F=E / D$ & $\begin{array}{c}G=(B+E) / \\
(A+D)\end{array}$ \\
\hline 1 & 37458.1 & 37883.7 & 1.01 & 10343.7 & 10901.3 & 1.05 & 1.02 \\
\hline 33 & 37562.0 & 38442.4 & 1.02 & 10273.2 & 10818.6 & 1.05 & 1.03 \\
\hline 99 & 37552.9 & 38152.1 & 1.02 & 10227.7 & 10763.2 & 1.05 & 1.02 \\
\hline Cumulative Average Travel Time & & & 1.02 & & & 1.05 & 1.02 \\
\hline \multirow{2}{*}{ Network Description } & \multicolumn{6}{|c|}{ Simulation Set Number } & 14 \\
\hline & \multicolumn{3}{|c|}{ Interstate 95 North } & \multicolumn{3}{|c|}{ Highway Route 10} & \\
\hline $\begin{array}{l}\text { 2. Peak AM Volume; } 20 \% \\
\text { Plowion; } 2 \text { Lane Block; } 30 \text { Min }\end{array}$ & $\begin{array}{c}\text { Vehicle Miles } \\
\text { Traveled } \\
\text { (miles) }\end{array}$ & $\begin{array}{l}\text { Vehicle } \\
\text { Minutes } \\
\text { (min) }\end{array}$ & $\begin{array}{c}\text { Cumulative } \\
\text { Average Travel } \\
\text { Time } 195 \text { and all } \\
\text { Ramps (min-veh } \\
\text { mile) }\end{array}$ & \begin{tabular}{|} 
Vehicle Miles \\
Traveled \\
(miles)
\end{tabular} & $\begin{array}{c}\text { Vehicle } \\
\text { Minutes } \\
\text { (min) }\end{array}$ & $\begin{array}{c}\text { Cumulative } \\
\text { Average Travel } \\
\text { Time RTI0 and } \\
\text { all Ramps (mph) }\end{array}$ & $\begin{array}{c}\text { Cumulative } \\
\text { Network } \\
\text { Average } \\
\text { Travel Time } \\
\text { (min / veh } \\
\text { mile) } \\
\end{array}$ \\
\hline Random Seed Number & A & B & $C=B / A$ & D & $\mathrm{E}$ & $F=E / D$ & $\begin{array}{c}G=(B+E) / \\
(A+D)\end{array}$ \\
\hline 1 & 36727.7 & 37166.9 & 1.01 & 10889.0 & 11476.8 & 1.05 & 1.02 \\
\hline 33 & 36816.7 & 37700.5 & 1.02 & 10730.8 & 11307.3 & 1.05 & 1.03 \\
\hline 99 & 36960.9 & 37658.4 & 1.02 & 10830.3 & 11424.6 & 1.05 & 1.03 \\
\hline Cumulative Average Travel Time & & & 1.02 & & & 1.05 & 1.03 \\
\hline \multirow{2}{*}{ Network Description } & \multicolumn{6}{|c|}{ Simulation Set Number } & 15 \\
\hline & \multicolumn{3}{|c|}{ Interstate 95 North } & \multicolumn{3}{|c|}{ Highway Route 10} & \\
\hline 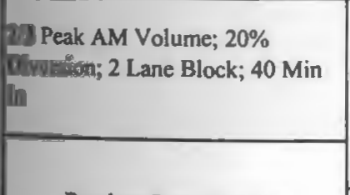 & $\begin{array}{c}\text { Vehicle Miles } \\
\text { Traveled } \\
\text { (miles) }\end{array}$ & $\begin{array}{l}\text { Vehicle } \\
\text { Minutes } \\
\text { (min) }\end{array}$ & $\begin{array}{c}\text { Cumulative } \\
\text { Average Travel } \\
\text { Time } 195 \text { and all } \\
\text { Ramps (min-veh } \\
\text { mile) }\end{array}$ & $\begin{array}{c}\text { Vehicle Miles } \\
\text { Traveled } \\
\text { (miles) }\end{array}$ & $\begin{array}{l}\text { Vehicle } \\
\text { Minutes } \\
\text { (min) }\end{array}$ & $\begin{array}{c}\text { Cumulative } \\
\text { Average Travel } \\
\text { Time RT10 and } \\
\text { all Ramps (mph) }\end{array}$ & $\begin{array}{c}\text { Cumulative } \\
\text { Network } \\
\text { Average } \\
\text { Travel Time } \\
\text { (min/ veh } \\
\text { mile) } \\
\end{array}$ \\
\hline Random Seed Number & $\mathbf{A}$ & B & $C=B / A$ & D & $\mathbf{E}$ & $F=E / D$ & $\begin{array}{c}G=(B+E) / \\
(A+D)\end{array}$ \\
\hline 1 & 36318.7 & 36870.1 & 1.02 & 11211.0 & 11816.9 & 1.05 & 1.02 \\
\hline 33 & 36191.2 & 37199.1 & 1.03 & 11262.6 & 11897.6 & 1.06 & 1.03 \\
\hline 99 & 36148.0 & 37038.5 & 1.02 & 11310.3 & 11931.3 & 1.05 & 1.03 \\
\hline Cumulative Average Travel Time & & & 1.02 & & & 1.06 & 1.03 \\
\hline \multirow{2}{*}{ Network Description } & \multicolumn{6}{|c|}{ Simulation Set Number } & 16 \\
\hline & \multicolumn{3}{|c|}{ Interstate 95 North } & \multicolumn{3}{|c|}{ Highway Route 10} & \\
\hline $\begin{array}{l}2 \text { Peak AM Volume; } 20 \% \\
\text { Olyour } 3 \text { Lane Block; } 20 \text { Min } \\
\text { the }\end{array}$ & $\begin{array}{c}\text { Vehicle Miles } \\
\text { Traveled } \\
\text { (miles) }\end{array}$ & $\begin{array}{l}\text { Vehicle } \\
\text { Minutes } \\
\text { (min) }\end{array}$ & $\begin{array}{c}\text { Cumulative } \\
\text { Average Travel } \\
\text { Time } 195 \text { and all } \\
\text { Ramps (min-veh } \\
\text { mile) }\end{array}$ & $\begin{array}{c}\text { Vehicle Miles } \\
\text { Traveled } \\
\text { (miles) }\end{array}$ & $\begin{array}{l}\text { Vehicle } \\
\text { Minutes } \\
\text { (min) }\end{array}$ & $\begin{array}{c}\text { Cumulative } \\
\text { Average Travel } \\
\text { Time RT10 and } \\
\text { all Ramps (mph) }\end{array}$ & $\begin{array}{c}\text { Cumulative } \\
\text { Network } \\
\text { Average } \\
\text { Travel Time } \\
\text { (min/ veh } \\
\text { mile) } \\
\end{array}$ \\
\hline Random Seed Number & A & B & $C=B / A$ & D & $\mathbf{E}$ & $F=E / D$ & $\begin{array}{c}G=(B+E) / \\
(A+D)\end{array}$ \\
\hline 1 & 37590.2 & 79511.2 & 2.12 & 10343.7 & 10901.3 & 1.05 & 1.89 \\
\hline 33 & 37541.9 & 53922.3 & 1.44 & 10273.2 & 10818.6 & 1.05 & 1.35 \\
\hline 99 & 37516.5 & 77950.7 & 2.08 & 10227.7 & 10763.2 & 1.05 & 1.86 \\
\hline Cumulative Average Travel Time & & & 1.88 & & & 1.05 & 1.70 \\
\hline
\end{tabular}




\begin{tabular}{|c|c|c|c|c|c|c|c|}
\hline \multirow{2}{*}{ Network Description } & \multicolumn{6}{|c|}{ Simulation Set Number } & 17 \\
\hline & \multicolumn{3}{|c|}{ Interstate 95 North } & \multicolumn{3}{|c|}{ Highway Route 10} & \\
\hline $\begin{array}{l}\text { Peak AM Volume; } 20 \% \\
3 \text { Lane Block; } 30 \text { Min }\end{array}$ & $\begin{array}{c}\text { Vehicle Miles } \\
\text { Traveled } \\
\text { (miles) }\end{array}$ & $\begin{array}{l}\text { Vehicle } \\
\text { Minutes } \\
\text { (min) }\end{array}$ & $\begin{array}{c}\text { Cumulative } \\
\text { Average Travel } \\
\text { Time } 195 \text { and all } \\
\text { Ramps (min-veh } \\
\text { mile) }\end{array}$ & $\begin{array}{c}\text { Vehicle Miles } \\
\text { Traveled } \\
\text { (miles) }\end{array}$ & $\begin{array}{l}\text { Vehicle } \\
\text { Minutes } \\
\text { (min) }\end{array}$ & $\begin{array}{c}\text { Cumulative } \\
\text { Average Travel } \\
\text { Time RT } 10 \text { and } \\
\text { all Ramps (mph) }\end{array}$ & $\begin{array}{c}\text { Cumulative } \\
\text { Network } \\
\text { Average } \\
\text { Travel Time } \\
\text { (min / veh } \\
\text { mile) }\end{array}$ \\
\hline Random Seed Number & A & B & $\mathrm{C}=\mathrm{B} / \mathrm{A}$ & $\mathrm{D}$ & E & $F=E / D$ & $\begin{array}{c}G=(B+E) / \\
(A+D)\end{array}$ \\
\hline 1 & 36719.8 & 121751.9 & 3.32 & 10889.0 & 11476.8 & 1.05 & 2.80 \\
\hline 33 & 37064.0 & 68895.5 & 1.86 & 10730.8 & 11307.3 & 1.05 & 1.68 \\
\hline 99 & 36789.0 & 121027.0 & 3.29 & 10830.3 & 11424.6 & 1.05 & 2.78 \\
\hline Cumulative Average Travel Time & & & 2.82 & & & 1.05 & 2.42 \\
\hline \multirow{2}{*}{ Network Description } & \multicolumn{6}{|c|}{ Simulation Set Number } & 18 \\
\hline & \multicolumn{3}{|c|}{ Interstate 95 North } & \multicolumn{3}{|c|}{ Highway Route 10} & \\
\hline $\begin{array}{l}\text { 1. Peak AM Volume; } 20 \% \\
3 \text { Lane Block; } 40 \text { Min }\end{array}$ & $\begin{array}{c}\text { Vehicle Miles } \\
\text { Traveled } \\
\text { (miles) }\end{array}$ & $\begin{array}{l}\text { Vehicle } \\
\text { Minutes } \\
\text { (min) }\end{array}$ & $\begin{array}{c}\text { Cumulative } \\
\text { Average Travel } \\
\text { Time } 195 \text { and all } \\
\text { Ramps (min-veh } \\
\text { mile) }\end{array}$ & $\begin{array}{c}\text { Vehicle Miles } \\
\text { Traveled } \\
\text { (miles) }\end{array}$ & $\begin{array}{l}\text { Vehicle } \\
\text { Minutes } \\
\text { (min) }\end{array}$ & $\begin{array}{c}\text { Cumulative } \\
\text { Average Travel } \\
\text { Time RT } 10 \text { and } \\
\text { all Ramps (mph) }\end{array}$ & $\begin{array}{c}\text { Cumulative } \\
\text { Network } \\
\text { Average } \\
\text { Travel Time } \\
\text { (min / veh } \\
\text { mile) }\end{array}$ \\
\hline Random Seed Number & A & $\mathbf{B}$ & $\mathrm{C}=\mathrm{B} / \mathrm{A}$ & D & $\mathbf{E}$ & $F=E / D$ & $\begin{array}{c}G=(B+E) / \\
(A+D)\end{array}$ \\
\hline 1 & 36137.4 & 164387.2 & 4.55 & 11211.0 & 11816.9 & 1.05 & 3.72 \\
\hline 33 & 36475.5 & 91368.3 & 2.50 & 11262.6 & 11897.6 & 1.06 & 2.16 \\
\hline 99 & 35996.1 & 166021.3 & 4.61 & 11310.3 & 11931.3 & 1.05 & 3.76 \\
\hline Cumulative Average Travel Time & & & 3.88 & & & 1.06 & 3.21 \\
\hline
\end{tabular}




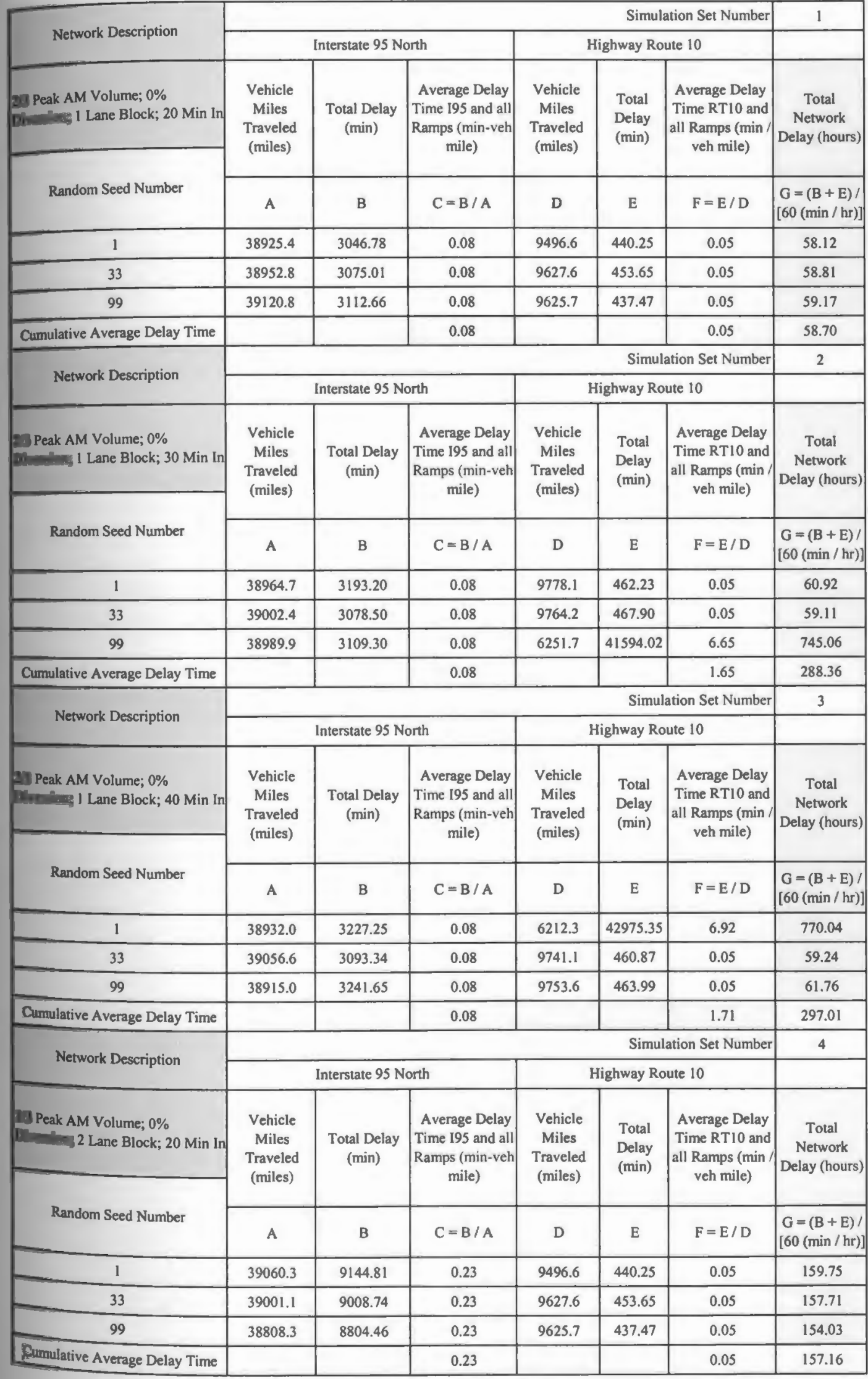




\begin{tabular}{|c|c|c|c|c|c|c|c|}
\hline \multirow{2}{*}{ Network Description } & \multicolumn{6}{|c|}{ Simulation Set Number } & 5 \\
\hline & \multicolumn{3}{|c|}{ Interstate 95 North } & \multicolumn{3}{|c|}{ Highway Route 10} & \\
\hline Peak AM Volume; $0 \%$ & $\begin{array}{l}\text { Vehicle } \\
\text { Miles } \\
\text { Traveled } \\
\text { (miles) }\end{array}$ & $\begin{array}{c}\text { Total Delay } \\
\text { (min) }\end{array}$ & $\begin{array}{c}\text { Average Delay } \\
\text { Time } 195 \text { and all } \\
\text { Ramps (min-veh } \\
\text { mile) }\end{array}$ & $\begin{array}{l}\text { Vehicle } \\
\text { Miles } \\
\text { Traveled } \\
\text { (miles) }\end{array}$ & $\begin{array}{l}\text { Total } \\
\text { Delay } \\
\text { (min) }\end{array}$ & $\begin{array}{c}\text { Average Delay } \\
\text { Time RT10 and } \\
\text { all Ramps (min } \\
\text { veh mile) }\end{array}$ & $\begin{array}{c}\text { Total } \\
\text { Network } \\
\text { Delay (hours) }\end{array}$ \\
\hline Random Seed Number & A & B & $C=B / A$ & D & $\mathbf{E}$ & $F=E / D$ & $\begin{array}{c}G=(B+E) / \\
{[60(\min / \mathrm{hr})]}\end{array}$ \\
\hline 1 & 39060.1 & 16776.43 & 0.43 & 9778.1 & 462.23 & 0.05 & 287.31 \\
\hline 33 & 38894.7 & 16101.71 & 0.41 & 9764.2 & 467.90 & 0.05 & 276.16 \\
\hline 99 & 39010.1 & 15758.73 & 0.40 & 6251.7 & 459.45 & 0.07 & 270.30 \\
\hline Cumulative Average Delay Time & & & 0.42 & & & 0.05 & 277.92 \\
\hline \multirow{2}{*}{ Network Description } & \multicolumn{6}{|c|}{ Simulation Set Number } & 6 \\
\hline & \multicolumn{3}{|c|}{ Interstate 95 North } & \multicolumn{3}{|c|}{ Highway Route 10} & \\
\hline $\begin{array}{l}23 \text { Peak AM Volume; } 0 \% \\
2 \text { Lane Block; } 40 \mathrm{Min} \text { In }\end{array}$ & $\begin{array}{l}\text { Vehicle } \\
\text { Miles } \\
\text { Traveled } \\
\text { (miles) }\end{array}$ & $\begin{array}{l}\text { Total Delay } \\
\text { (min) }\end{array}$ & $\begin{array}{c}\text { Average Delay } \\
\text { Time } 195 \text { and all } \\
\text { Ramps (min-veh } \\
\text { mile) }\end{array}$ & $\begin{array}{l}\text { Vehicle } \\
\text { Miles } \\
\text { Traveled } \\
\text { (miles) }\end{array}$ & $\begin{array}{l}\text { Total } \\
\text { Delay } \\
\text { (min) }\end{array}$ & $\begin{array}{c}\text { Average Delay } \\
\text { Time RT10 and } \\
\text { all Ramps (min } \\
\text { veh mile) }\end{array}$ & $\begin{array}{c}\text { Total } \\
\text { Network } \\
\text { Delay (hours) }\end{array}$ \\
\hline Random Seed Number & A & B & $C=B / A$ & D & E & $F=E / D$ & $\begin{array}{c}G=(B+E) / \\
{[60(\min / h r)]}\end{array}$ \\
\hline . 1 & 38808.1 & 24859.54 & 0.64 & 6212.3 & 462.51 & 0.07 & 422.03 \\
\hline 33 & 39133.1 & 25257.13 & 0.65 & 9741.1 & 460.87 & 0.05 & 428.63 \\
\hline 99 & 38840.5 & 23557.80 & 0.61 & 9753.6 & 463.99 & 0.05 & 400.36 \\
\hline Cumulative Average Delay Time & & & 0.63 & & & 0.05 & 417.01 \\
\hline \multirow{2}{*}{ Network Description } & \multicolumn{6}{|c|}{ Simulation Set Number } & 7 \\
\hline & \multicolumn{3}{|c|}{ Interstate 95 North } & \multicolumn{3}{|c|}{ Highway Route 10} & \\
\hline Peak AM Volume; $0 \%$ & $\begin{array}{l}\text { Vehicle } \\
\text { Miles } \\
\text { Traveled } \\
\text { (miles) }\end{array}$ & $\begin{array}{l}\text { Total Delay } \\
\text { (min) }\end{array}$ & $\begin{array}{c}\text { Average Delay } \\
\text { Time } 195 \text { and all } \\
\text { Ramps (min-veh } \\
\text { mile) }\end{array}$ & $\begin{array}{l}\text { Vehicle } \\
\text { Miles } \\
\text { Traveled } \\
\text { (miles) }\end{array}$ & $\begin{array}{l}\text { Total } \\
\text { Delay } \\
\text { (min) }\end{array}$ & $\begin{array}{c}\text { Average Delay } \\
\text { Time RT10 and } \\
\text { all Ramps (min } \\
\text { veh mile) }\end{array}$ & $\begin{array}{c}\text { Total } \\
\text { Network } \\
\text { Delay (hours) }\end{array}$ \\
\hline Random Seed Number & A & B & $\mathbf{C}=\mathrm{B} / \mathbf{A}$ & D & E & $F=E / D$ & $\begin{array}{r}G=(B+E) / \\
{[60(\min / \mathrm{hr})]} \\
\end{array}$ \\
\hline 1 & 38838.0 & 31749.11 & 0.82 & 9496.6 & 440.25 & 0.05 & 536.49 \\
\hline 33 & 38842.2 & 26815.47 & 0.69 & 9627.6 & 453.65 & 0.05 & 454.49 \\
\hline 99 & 38834.5 & 24544.27 & 0.63 & 9625.7 & 437.47 & 0.05 & 416.36 \\
\hline Cumulative Average Delay Time & & & 0.71 & & & 0.05 & 469.11 \\
\hline \multirow{2}{*}{ Network Description } & \multicolumn{6}{|c|}{ Simulation Set Number } & 8 \\
\hline & \multicolumn{3}{|c|}{ Interstate 95 North } & \multicolumn{3}{|c|}{ Highway Route 10} & \\
\hline $\begin{array}{l}\text { Peak AM Volume; } 0 \% \\
3 \text { Lane Block; } 30 \text { Min In }\end{array}$ & $\begin{array}{l}\text { Vehicle } \\
\text { Miles } \\
\text { Traveled } \\
\text { (miles) }\end{array}$ & $\begin{array}{l}\text { Total Delay } \\
\text { (min) }\end{array}$ & \begin{tabular}{|c|} 
\\
Average Delay \\
Time 195 and all \\
Ramps (min-veh \\
mile)
\end{tabular} & $\begin{array}{l}\text { Vehicle } \\
\text { Miles } \\
\text { Traveled } \\
\text { (miles) }\end{array}$ & $\begin{array}{l}\text { Total } \\
\text { Delay } \\
\text { (min) }\end{array}$ & $\begin{array}{c}\text { Average Delay } \\
\text { Time RTIO and } \\
\text { all Ramps (min } / \\
\text { veh mile) }\end{array}$ & $\begin{array}{c}\text { Total } \\
\text { Network } \\
\text { Delay (hours) }\end{array}$ \\
\hline Random Seed Number & A & B & $\mathrm{C}=\mathrm{B} / \mathrm{A}$ & D & $\mathrm{E}$ & $F=E / D$ & $\left.\begin{array}{l}\mathrm{G}=(\mathrm{B}+\mathrm{E}) / \\
{[60(\mathrm{~min} / \mathrm{hr})]}\end{array}\right]$ \\
\hline 1 & 38958.2 & 61870.80 & 1.59 & 9778.1 & 462.23 & 0.05 & 1038.88 \\
\hline 33 & 39111.9 & 49115.24 & 1.26 & 9764.2 & 467.90 & 0.05 & 826.39 \\
\hline 99 & 38861.0 & 44265.97 & 1.14 & 6251.7 & 459.45 & 0.07 & 745.42 \\
\hline Ormulative Average Delay Time & & & 1.33 & & & 0.05 & 870.23 \\
\hline
\end{tabular}




\begin{tabular}{|c|c|c|c|c|c|c|c|}
\hline \multirow{2}{*}{ Network Description } & \multicolumn{6}{|c|}{ Simulation Set Number } & 9 \\
\hline & \multicolumn{3}{|c|}{ Interstate 95 North } & \multicolumn{3}{|c|}{ Highway Route 10} & \multirow[b]{2}{*}{$\begin{array}{c}\text { Total } \\
\text { Network } \\
\text { Delay (hours) }\end{array}$} \\
\hline $\begin{array}{l}\text { 293 Peak AM Volume; } 0 \% \\
\text { Divensima } 3 \text { Lane Block; } 40 \text { Min In }\end{array}$ & $\begin{array}{l}\text { Vehicle } \\
\text { Miles } \\
\text { Traveled } \\
\text { (miles) }\end{array}$ & $\begin{array}{c}\text { Total Delay } \\
\text { (min) }\end{array}$ & $\begin{array}{c}\text { Average Delay } \\
\text { Time I95 and all } \\
\text { Ramps (min-veh } \\
\text { mile) }\end{array}$ & $\begin{array}{l}\text { Vehicle } \\
\text { Miles } \\
\text { Traveled } \\
\text { (miles) }\end{array}$ & $\begin{array}{l}\text { Total } \\
\text { Delay } \\
\text { (min) }\end{array}$ & $\begin{array}{c}\text { Average Delay } \\
\text { Time RT10 and } \\
\text { all Ramps (min } / \\
\text { veh mile) }\end{array}$ & \\
\hline Random Seed Number & A & B & $C=B / A$ & $\mathrm{D}$ & E & $F=E / D$ & $\begin{array}{c}G=(B+E) / \\
{[60(\min / \mathrm{hr})]}\end{array}$ \\
\hline 1 & 39049.6 & 91998.49 & 2.36 & 6212.3 & 462.51 & 0.07 & 1541.02 \\
\hline 33 & 39001.5 & 85356.90 & 2.19 & 9741.1 & 460.87 & 0.05 & 1430.30 \\
\hline 99 & 38929.8 & 73211.11 & 1.88 & 9753.6 & 463.99 & 0.05 & 1227.92 \\
\hline Cumulative Average Delay Time & & & 2.14 & & & 0.05 & 1399.74 \\
\hline \multirow{2}{*}{ Network Description } & \multicolumn{6}{|c|}{ Simulation Set Number } & 10 \\
\hline & \multicolumn{3}{|c|}{ Interstate 95 North } & \multicolumn{3}{|c|}{ Highway Route 10} & \\
\hline $\begin{array}{l}\text { 2. Peak AM Volume; } 20 \% \\
\text { Diwnition; } 1 \text { Lane Block; } 20 \text { Min In }\end{array}$ & $\begin{array}{l}\text { Vehicle } \\
\text { Miles } \\
\text { Traveled } \\
\text { (miles) }\end{array}$ & $\begin{array}{l}\text { Total Delay } \\
\text { (min) }\end{array}$ & $\begin{array}{c}\text { Average Delay } \\
\text { Time I95 and all } \\
\text { Ramps (min-veh } \\
\text { mile) }\end{array}$ & $\begin{array}{l}\text { Vehicle } \\
\text { Miles } \\
\text { Traveled } \\
\text { (miles) }\end{array}$ & $\begin{array}{l}\text { Total } \\
\text { Delay } \\
(\mathrm{min})\end{array}$ & $\begin{array}{c}\text { Average Delay } \\
\text { Time RTI0 and } \\
\text { all Ramps (min } / \\
\text { veh mile) }\end{array}$ & \begin{tabular}{|c|} 
Total \\
Network \\
Delay (hours)
\end{tabular} \\
\hline Random Seed Number & A & B & $C=B / A$ & D & $\mathbf{E}$ & $F=E / D$ & $\begin{array}{c}G=(B+E) / \\
{[60(\min / \mathrm{hr})]}\end{array}$ \\
\hline 1 & 37672.9 & 2746.83 & 0.07 & 10343.7 & 524.20 & 0.05 & 54.52 \\
\hline 33 & 37698.1 & 2766.38 & 0.07 & 10273.2 & 521.39 & 0.05 & 54.80 \\
\hline 99 & 37308.3 & 2709.41 & 0.07 & 10227.7 & 505.45 & 0.05 & 53.58 \\
\hline Cumulative Average Delay Time & & & 0.07 & & & 0.05 & 54.30 \\
\hline \multirow{2}{*}{ Network Description } & \multicolumn{6}{|c|}{ Simulation Set Number } & 11 \\
\hline & \multicolumn{3}{|c|}{ Interstate 95 North } & \multicolumn{3}{|c|}{ Highway Route 10} & \\
\hline $\begin{array}{l}\text { Peak AM Volume; } 20 \% \\
\text { Whin; I Lane Block; } 30 \text { Min In }\end{array}$ & $\begin{array}{l}\text { Vehicle } \\
\text { Miles } \\
\text { Traveled } \\
\text { (miles) }\end{array}$ & $\begin{array}{l}\text { Total Delay } \\
\text { (min) }\end{array}$ & $\begin{array}{c}\text { Average Delay } \\
\text { Time I95 and all } \\
\text { Ramps (min-veh } \\
\text { mile) }\end{array}$ & $\begin{array}{l}\text { Vehicle } \\
\text { Miles } \\
\text { Traveled } \\
\text { (miles) }\end{array}$ & $\begin{array}{l}\text { Total } \\
\text { Delay } \\
\text { (min) }\end{array}$ & $\begin{array}{c}\text { Average Delay } \\
\text { Time RT } 10 \text { and } \\
\text { all Ramps (min } / \\
\text { veh mile) }\end{array}$ & \begin{tabular}{|c|} 
Total \\
Network \\
Delay (hours)
\end{tabular} \\
\hline Random Seed Number & A & B & $\mathrm{C}=\mathrm{B} / \mathrm{A}$ & D & $\mathbf{E}$ & $F=E / D$ & $\begin{array}{c}G=(B+E) / \\
{[60(\min / \mathrm{hr})]}\end{array}$ \\
\hline 1 & 37089.0 & 2679.92 & 0.07 & 10889.0 & 565.13 & 0.05 & 54.08 \\
\hline 33 & 37080.8 & 2701.30 & 0.07 & 10730.8 & 544.97 & 0.05 & 54.10 \\
\hline 99 & 36691.4 & 2600.84 & 0.07 & 10830.3 & 566.06 & 0.05 & 52.78 \\
\hline Cumulative Average Delay Time & & & 0.07 & & & 0.05 & 53.66 \\
\hline \multirow{2}{*}{ Network Description } & \multicolumn{6}{|c|}{ Simulation Set Number } & 12 \\
\hline & \multicolumn{3}{|c|}{ Interstate 95 North } & \multicolumn{3}{|c|}{ Highway Route 10} & \\
\hline $\begin{array}{l}23 \text { Peak AM Volume; } 20 \% \\
\text { Wherion; } 1 \text { Lane Block; } 40 \text { Min In }\end{array}$ & $\begin{array}{l}\text { Vehicie } \\
\text { Miles } \\
\text { Traveled } \\
\text { (miles) }\end{array}$ & $\begin{array}{l}\text { Total Delay } \\
\text { (min) }\end{array}$ & $\begin{array}{c}\text { Average Delay } \\
\text { Time } 195 \text { and all } \\
\text { Ramps (min-veh } \\
\text { mile) }\end{array}$ & $\begin{array}{l}\text { Vehicle } \\
\text { Miles } \\
\text { Traveled } \\
\text { (miles) }\end{array}$ & $\begin{array}{l}\text { Total } \\
\text { Delay } \\
\text { (min) }\end{array}$ & $\begin{array}{c}\text { Average Delay } \\
\text { Time RT10 and } \\
\text { all Ramps (min } \\
\text { veh mile) }\end{array}$ & \begin{tabular}{|c|} 
Total \\
Network \\
Delay (hours)
\end{tabular} \\
\hline Random Seed Number & A & B & $C=B / A$ & D & E & $F=E / D$ & $\begin{array}{r}G=(B+E) / \\
{[60(\min / \mathrm{hr})]} \\
\end{array}$ \\
\hline 1 & 36242.3 & 2513.11 & 0.07 & 11211.0 & 579.44 & 0.05 & 51.54 \\
\hline 33 & 36584.5 & 2754.97 & 0.08 & 11262.6 & 580.55 & 0.05 & 55.59 \\
\hline 99 & 36080.6 & 2544.44 & 0.07 & 11310.3 & 603.51 & 0.05 & 52.47 \\
\hline Cumulative Average Delay Time & & & 0.07 & & & 0.05 & 53.20 \\
\hline
\end{tabular}




\begin{tabular}{|c|c|c|c|c|c|c|c|}
\hline \multirow{2}{*}{ Network Description } & \multicolumn{6}{|c|}{ Simulation Set Number } & 13 \\
\hline & \multicolumn{3}{|c|}{ Interstate 95 North } & \multicolumn{3}{|c|}{ Highway Route 10} & \multirow[b]{2}{*}{$\begin{array}{c}\text { Total } \\
\text { Network } \\
\text { Delay (hours) }\end{array}$} \\
\hline $\begin{array}{l}\text { Peak AM Volume; } 20 \% \\
\text { Crotion; } 2 \text { Lane Block; } 20 \text { Min In }\end{array}$ & $\begin{array}{l}\text { Vehicle } \\
\text { Miles } \\
\text { Traveled } \\
\text { (miles) }\end{array}$ & $\begin{array}{l}\text { Total Delay } \\
\text { (min) }\end{array}$ & $\begin{array}{c}\text { Average Delay } \\
\text { Time } 195 \text { and all } \\
\text { Ramps (min-veh } \\
\text { mile) }\end{array}$ & $\begin{array}{l}\text { Vehicle } \\
\text { Miles } \\
\text { Traveled } \\
\text { (miles) }\end{array}$ & $\begin{array}{l}\text { Total } \\
\text { Delay } \\
(\mathrm{min})\end{array}$ & $\begin{array}{c}\text { Average Delay } \\
\text { Time RT10 and } \\
\text { all Ramps (min } / \\
\text { veh mile) }\end{array}$ & \\
\hline Random Seed Number & A & B & $\mathrm{C}=\mathrm{B} / \mathrm{A}$ & $\mathrm{D}$ & $\mathbf{E}$ & $F=E / D$ & $\begin{array}{l}\mathrm{G}=(\mathrm{B}+\mathrm{E}) / \\
{[60(\mathrm{~min} / \mathrm{hr})]}\end{array}$ \\
\hline 1 & 37458.1 & 3025.48 & 0.08 & 10343.7 & 524.20 & 0.05 & 59.16 \\
\hline 33 & 37562.0 & 3348.19 & 0.09 & 10273.2 & 521.39 & 0.05 & 64.49 \\
\hline 99 & 37552.9 & 3173.14 & 0.08 & 10227.7 & 505.45 & 0.05 & 61.31 \\
\hline Curmulative Average Delay Time & & & 0.08 & & & 0.05 & 61.65 \\
\hline \multirow{2}{*}{ Network Description } & \multicolumn{6}{|c|}{ Simulation Set Number } & 14 \\
\hline & \multicolumn{3}{|c|}{ Interstate 95 North } & \multicolumn{3}{|c|}{ Highway Route 10} & \\
\hline $\begin{array}{l}23 \text { Peak AM Volume; } 20 \% \\
\text { Detassion; } 2 \text { Lane Block; } 30 \text { Min In }\end{array}$ & $\begin{array}{l}\text { Vehicle } \\
\text { Miles } \\
\text { Traveled } \\
\text { (miles) }\end{array}$ & $\begin{array}{l}\text { Total Delay } \\
\text { (min) }\end{array}$ & $\begin{array}{c}\text { Average Delay } \\
\text { Time } 195 \text { and all } \\
\text { Ramps (min-veh } \\
\text { mile) }\end{array}$ & $\begin{array}{l}\text { Vehicle } \\
\text { Miles } \\
\text { Traveled } \\
\text { (miles) }\end{array}$ & $\begin{array}{l}\text { Total } \\
\text { Delay } \\
\text { (min) }\end{array}$ & $\begin{array}{c}\text { Average Delay } \\
\text { Time RTI } 0 \text { and } \\
\text { all Ramps (min/ } \\
\text { veh mile) }\end{array}$ & $\begin{array}{c}\text { Total } \\
\text { Network } \\
\text { Delay (hours) }\end{array}$ \\
\hline Random Seed Number & A & B & $\mathrm{C}=\mathrm{B} / \mathrm{A}$ & D & $\mathbf{E}$ & $F=E / D$ & $\begin{array}{c}G=(B+E) / \\
{[60(\min / \mathrm{hr})]}\end{array}$ \\
\hline 1 & 36727.7 & 2826.57 & 0.08 & 10889.0 & 565.13 & 0.05 & 56.53 \\
\hline 33 & 36816.7 & 3285.08 & 0.09 & 10730.8 & 544.97 & 0.05 & 63.83 \\
\hline 99 & 36960.9 & 3228.12 & 0.09 & 10830.3 & 566.06 & 0.05 & 63.24 \\
\hline Cumulative Average Delay Time & & & 0.08 & & & 0.05 & 61.20 \\
\hline \multirow{2}{*}{ Network Description } & \multicolumn{6}{|c|}{ Simulation Set Number } & 15 \\
\hline & \multicolumn{3}{|c|}{ Interstate 95 North } & \multicolumn{3}{|c|}{ Highway Route 10} & \\
\hline $\begin{array}{l}\text { 2. Peak AM Volume; } 20 \% \\
\text { Ditursion; } 2 \text { Lane Block; } 40 \text { Min In }\end{array}$ & $\begin{array}{l}\text { Vehicle } \\
\text { Miles } \\
\text { Traveled } \\
\text { (miles) }\end{array}$ & $\begin{array}{l}\text { Total Delay } \\
\text { (min) }\end{array}$ & $\begin{array}{c}\text { Average Delay } \\
\text { Time } 195 \text { and all } \\
\text { Ramps (min-veh } \\
\text { mile) }\end{array}$ & $\begin{array}{l}\text { Vehicle } \\
\text { Miles } \\
\text { Traveled } \\
\text { (miles) }\end{array}$ & $\begin{array}{l}\text { Total } \\
\text { Delay } \\
(\mathrm{min})\end{array}$ & $\begin{array}{c}\text { Average Delay } \\
\text { Time RT10 and } \\
\text { all Ramps (min } / \\
\text { veh mile) }\end{array}$ & $\begin{array}{c}\text { Total } \\
\text { Network } \\
\text { Delay (hours) }\end{array}$ \\
\hline Random Seed Number & A & B & $\mathrm{C}=\mathrm{B} / \mathrm{A}$ & $\mathrm{D}$ & E & $F=E / D$ & $\begin{array}{l}G=(B+E) / \\
{[60(\min / \mathrm{hr})]}\end{array}$ \\
\hline 1 & 36318.7 & 3020.44 & 0.08 & 11211.0 & 579.44 & 0.05 & 60.00 \\
\hline 33 & 36191.2 & 3306.70 & 0.09 & 11262.6 & 580.55 & 0.05 & 64.79 \\
\hline 99 & 36148.0 & 3298.72 & 0.09 & 11310.3 & 603.51 & 0.05 & 65.04 \\
\hline Cumulative Average Delay Time & & & 0.09 & & & 0.05 & 63.27 \\
\hline \multirow{2}{*}{ Network Description } & \multicolumn{6}{|c|}{ Simulation Set Number } & 16 \\
\hline & \multicolumn{3}{|c|}{ Interstate 95 North } & \multicolumn{3}{|c|}{ Highway Route 10} & \\
\hline $\begin{array}{l}27 \text { Peak AM Volume; } 20 \% \\
\text { Timmasion; } 3 \text { Lane Block; } 20 \text { Min In }\end{array}$ & $\begin{array}{l}\text { Vehicle } \\
\text { Miles } \\
\text { Traveled } \\
\text { (miles) }\end{array}$ & $\begin{array}{l}\text { Total Delay } \\
\text { (min) }\end{array}$ & $\begin{array}{c}\text { Average Delay } \\
\text { Time I95 and all } \\
\text { Ramps (min-veh } \\
\text { mile) }\end{array}$ & $\begin{array}{l}\text { Vehicle } \\
\text { Miles } \\
\text { Traveled } \\
\text { (miles) }\end{array}$ & $\begin{array}{l}\text { Total } \\
\text { Delay } \\
\text { (min) }\end{array}$ & $\begin{array}{c}\text { Average Delay } \\
\text { Time RT10 and } \\
\text { all Ramps (min } / \\
\text { veh mile) }\end{array}$ & $\begin{array}{c}\text { Total } \\
\text { Network } \\
\text { Delay (hours) }\end{array}$ \\
\hline Random Seed Number & A & B & $\mathrm{C}=\mathrm{B} / \mathrm{A}$ & D & $\mathbf{E}$ & $F=E / D$ & $\begin{array}{c}G=(B+E) l \\
{[60(\min / \mathrm{hr})]}\end{array}$ \\
\hline 1 & 37590.2 & 29396.52 & 0.78 & 10343.7 & 524.20 & 0.05 & 498.68 \\
\hline 33 & 37541.9 & 16063.37 & 0.43 & 10273.2 & 521.39 & 0.05 & 276.41 \\
\hline 99 & 37516.5 & 28126.70 & 0.75 & 10227.7 & 505.45 & 0.05 & 477.20 \\
\hline Cumulative Average Delay Time & & & 0.65 & & & 0.05 & 417.43 \\
\hline
\end{tabular}




\begin{tabular}{|c|c|c|c|c|c|c|c|}
\hline \multirow{2}{*}{ Network Description } & \multicolumn{6}{|c|}{ Simulation Set Number } & 17 \\
\hline & \multicolumn{3}{|c|}{ Interstate 95 North } & \multicolumn{3}{|c|}{ Highway Route 10} & \multirow[b]{2}{*}{$\begin{array}{c}\text { Total } \\
\text { Network } \\
\text { Delay (hours) }\end{array}$} \\
\hline $\begin{array}{l}\text { Peak AM Volume; } 20 \% \\
\text { Whatulion; } 3 \text { Lane Block; } 30 \text { Min In }\end{array}$ & $\begin{array}{l}\text { Vehicle } \\
\text { Miles } \\
\text { Traveled } \\
\text { (miles) }\end{array}$ & $\begin{array}{l}\text { Total Delay } \\
\text { (min) }\end{array}$ & $\begin{array}{c}\text { Average Delay } \\
\text { Time } 195 \text { and all } \\
\text { Ramps (min-veh } \\
\text { mile) }\end{array}$ & $\begin{array}{l}\text { Vehicle } \\
\text { Miles } \\
\text { Traveled } \\
\text { (miles) }\end{array}$ & $\begin{array}{l}\text { Total } \\
\text { Delay } \\
\text { (min) }\end{array}$ & $\begin{array}{c}\text { Average Delay } \\
\text { Time RTI0 and } \\
\text { all Ramps (min } \\
\text { veh mile) }\end{array}$ & \\
\hline Random Seed Number & A & B & $\mathrm{C}=\mathrm{B} / \mathrm{A}$ & D & E & $F=E / D$ & $\begin{array}{c}\mathrm{G}=(\mathrm{B}+\mathrm{E}) \\
{[60(\mathrm{~min} / \mathrm{hr})}\end{array}$ \\
\hline 1 & 36719.8 & 55516.43 & 1.51 & 10889.0 & 565.13 & 0.05 & 934.69 \\
\hline 33 & 37064.0 & 28770.97 & 0.78 & 10730.8 & 544.97 & 0.05 & 488.60 \\
\hline 99 & 36789.0 & 53891.87 & 1.46 & 10830.3 & 566.06 & 0.05 & 907.63 \\
\hline Cumulative Average Delay Time & & & 1.25 & & & 0.05 & 776.97 \\
\hline \multirow{2}{*}{ Network Description } & \multicolumn{6}{|c|}{ Simulation Set Number } & 18 \\
\hline & \multicolumn{3}{|c|}{ Interstate 95 North } & \multicolumn{3}{|c|}{ Highway Route 10} & \\
\hline 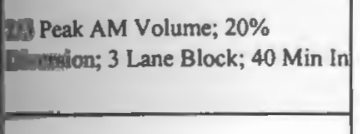 & $\begin{array}{l}\text { Vehicle } \\
\text { Miles } \\
\text { Traveled } \\
\text { (miles) }\end{array}$ & $\begin{array}{l}\text { Total Delay } \\
\text { (min) }\end{array}$ & $\begin{array}{c}\text { Average Delay } \\
\text { Time } 195 \text { and all } \\
\text { Ramps (min-veh } \\
\text { mile) }\end{array}$ & $\begin{array}{l}\text { Vehicle } \\
\text { Miles } \\
\text { Traveled } \\
\text { (miles) }\end{array}$ & $\begin{array}{l}\text { Total } \\
\text { Delay } \\
\text { (min) }\end{array}$ & $\begin{array}{c}\text { Average Delay } \\
\text { Time RT10 and } \\
\text { all Ramps (min } \\
\text { veh mile) }\end{array}$ & $\begin{array}{c}\text { Total } \\
\text { Network } \\
\text { Delay (hours) }\end{array}$ \\
\hline Random Seed Number & A & B & $C=B / A$ & $\mathrm{D}$ & $\mathbf{E}$ & $F=E / D$ & $\begin{array}{c}G=(B+E) / \\
{[60(\mathrm{~min} / \mathrm{hr})]}\end{array}$ \\
\hline 1 & 36137.4 & 80760.30 & 2.23 & 11211.0 & 579.44 & 0.05 & 1355.66 \\
\hline 33 & 36475.5 & 46773.50 & 1.28 & 11262.6 & 580.55 & 0.05 & 789.23 \\
\hline 99 & 35996.1 & 80351.36 & 2.23 & 11310.3 & 603.51 & 0.05 & 1349.25 \\
\hline Cumulative Average Delay Time & & & 1.91 & & & 0.05 & 1164.71 \\
\hline
\end{tabular}




\section{APPENDIX H}

Results for Simulations Modeled with

$1 / 2$ AM Peak Traffic Conditions 


\begin{tabular}{|c|c|c|c|c|c|c|c|}
\hline \multirow{2}{*}{ Network Description } & \multicolumn{6}{|c|}{ Simulation Set Number } & 1.0 \\
\hline & \multicolumn{3}{|c|}{ Interstate 95 North } & \multicolumn{3}{|c|}{ Highway Route 10} & \multirow[b]{2}{*}{$\begin{array}{c}\text { Cumulative } \\
\text { Network } \\
\text { Average Speed } \\
\text { (niph) }\end{array}$} \\
\hline $\begin{array}{l}\text { I/2 Peak AM Volume; 0\% } \\
\text { MT In }\end{array}$ & $\begin{array}{l}\text { Vehicle } \\
\text { Miles } \\
\text { Traveled } \\
\text { (miles) }\end{array}$ & $\begin{array}{l}\text { Vehicle } \\
\text { Minutes } \\
\text { (min) }\end{array}$ & $\begin{array}{c}\text { Cumulative } \\
\text { Average Speed } \\
\text { I95 and all } \\
\text { Ranps (n甲) }\end{array}$ & $\begin{array}{l}\text { Vehicle } \\
\text { Miles } \\
\text { Traveled } \\
\text { (miles) }\end{array}$ & $\begin{array}{l}\text { Vehicle } \\
\text { Minutes } \\
\text { (min) }\end{array}$ & $\begin{array}{c}\text { Cumulative } \\
\text { Average Speed } \\
\text { RT10 and all } \\
\text { Ramps (nph) }\end{array}$ & \\
\hline Random Seed Number & A & B & $\begin{array}{c}\mathrm{C}=\mathrm{A} /(\mathrm{B} / 60 \\
\mathrm{min} / \mathrm{hr})\end{array}$ & D & E & $\begin{array}{c}\mathrm{F}=\mathrm{D} /(\mathrm{E} / 60 \\
\mathrm{min} / \mathrm{hr})\end{array}$ & $\begin{array}{c}G=(A+D)] \\
{[(B+E) / 60} \\
\text { min/hr] } \\
\end{array}$ \\
\hline 1 & 29084.2 & 28455.8 & 61.3 & 7256.8 & 7586.6 & 57.4 & 60.5 \\
\hline 33 & 28816.9 & 28180.0 & 61.4 & 7028.8 & 7343.5 & 57.4 & 60.5 \\
\hline 99 & 28978.8 & 28331.2 & 61.4 & 7243.5 & 7547.6 & 57.6 & 60.6 \\
\hline Cumpulative Average Speed & & & 61.4 & & & 57.5 & 60.5 \\
\hline \multirow{2}{*}{ Network Description } & \multicolumn{6}{|c|}{ Simulation Set Number } & 2.0 \\
\hline & \multicolumn{3}{|c|}{ Interstate 95 North } & \multicolumn{3}{|c|}{ Highway Route 10} & \\
\hline $\begin{array}{l}\text { I/2 Peak AM Volume; } 0 \% \\
\text { Wh In }\end{array}$ & $\begin{array}{l}\text { Vehicle } \\
\text { Miles } \\
\text { Traveled } \\
\text { (miles) }\end{array}$ & $\begin{array}{l}\text { Vehicle } \\
\text { Minutes } \\
\text { (min) }\end{array}$ & $\begin{array}{l}\text { Cumulative } \\
\text { Average Speed } \\
\text { I95 and all } \\
\text { Ranps (n甲h) }\end{array}$ & $\begin{array}{l}\text { Vehicle } \\
\text { Miles } \\
\text { Traveled } \\
\text { (miles) }\end{array}$ & $\begin{array}{l}\text { Vehicle } \\
\text { Minutes } \\
\text { (min) }\end{array}$ & $\begin{array}{c}\text { Curmulative } \\
\text { Average Speed } \\
\text { RT10 and all } \\
\text { Ramps (mph) }\end{array}$ & $\begin{array}{c}\text { Cumulative } \\
\text { Network } \\
\text { Average Speed } \\
\text { (mph) }\end{array}$ \\
\hline Random Seed Number & A & B & $\begin{array}{c}\mathrm{C}=\mathrm{A} /(\mathrm{B} / 60 \\
\mathrm{min} / \mathrm{hr})\end{array}$ & D & $\mathbf{E}$ & $\begin{array}{c}\mathrm{F}=\mathrm{D} /(\mathrm{E} / 60 \\
\mathrm{min} / \mathrm{hr})\end{array}$ & $\begin{array}{c}G=(A+D) / \\
{[(B+E) / 60} \\
\text { min/hr] }\end{array}$ \\
\hline 1 & 28780.2 & 28152.6 & 61.3 & 7374.6 & 7706.9 & 57.4 & 60.5 \\
\hline 33 & 29160.8 & 28522.9 & 61.3 & 7222.3 & 7547.1 & 57.4 & 60.5 \\
\hline 99 & 29132.2 & 28434.5 & 61.5 & 7215.2 & 7434.2 & 58.2 & 60.8 \\
\hline Cummlative Average Speed & & & 61.4 & & & 57.7 & 60.6 \\
\hline \multirow{2}{*}{ Network Description } & \multicolumn{6}{|c|}{ Simulation Set Number } & 3.0 \\
\hline & \multicolumn{3}{|c|}{ Interstate 95 North } & \multicolumn{3}{|c|}{ Highway Route 10} & \\
\hline $\begin{array}{l}\text { 1/2 Peak AM Volume; } 0 \% \\
\text { In }\end{array}$ & $\begin{array}{l}\text { Vehicle } \\
\text { Miles } \\
\text { Traveled } \\
\text { (miles) }\end{array}$ & $\begin{array}{c}\text { Vehicle } \\
\text { Minutes } \\
\text { (min) }\end{array}$ & $\begin{array}{c}\text { Cumulative } \\
\text { Average Speed } \\
\text { I95 and all } \\
\text { Ramps (mph) }\end{array}$ & $\begin{array}{l}\text { Vehicle } \\
\text { Miles } \\
\text { Traveled } \\
\text { (miles) }\end{array}$ & $\begin{array}{c}\text { Vehicle } \\
\text { Minutes } \\
\text { (min) }\end{array}$ & $\begin{array}{c}\text { Cumulative } \\
\text { Average Speed } \\
\text { RT10 and all } \\
\text { Ramps (mph) }\end{array}$ & $\begin{array}{c}\text { Cumulative } \\
\text { Network } \\
\text { Average Speed } \\
\text { (mph) }\end{array}$ \\
\hline Random Seed Number & A & B & $\begin{array}{c}\mathrm{C}=\mathrm{A} /(\mathrm{B} / 60 \\
\mathrm{min} / \mathrm{hr})\end{array}$ & D & E & $\begin{array}{c}\mathrm{F}=\mathrm{D} /(\mathrm{E} / 60 \\
\mathrm{min} / \mathrm{hr})\end{array}$ & $\begin{array}{c}G=(A+D) / \\
{[B+E) / 60} \\
\text { min/hrl }\end{array}$ \\
\hline 1 & 28906.8 & 28270.0 & 61.4 & 7310.7 & 7621.6 & 57.6 & 60.5 \\
\hline 33 & 28872.6 & 28237.5 & 61.3 & 7305.2 & 7627.7 & 57.5 & 60.5 \\
\hline 99 & 28838.9 & 28160.8 & 61.4 & 7191.6 & 7488.7 & 57.6 & 60.6 \\
\hline Cumulative Average Speed & & & 61.4 & & & 57.5 & 60.6 \\
\hline \multirow{2}{*}{ Wetwork Description } & \multicolumn{6}{|c|}{ Simulation Set Number } & 4.0 \\
\hline & \multicolumn{3}{|c|}{ Interstate 95 North } & \multicolumn{3}{|c|}{ Highway Route 10} & \\
\hline $\begin{array}{l}\text { 1/2 Peak AM Volume; } 0 \% \\
\text { M.tary } 2 \text { Lane Block; } 20 \\
\text { MhIn }\end{array}$ & $\begin{array}{l}\text { Vehicle } \\
\text { Miles } \\
\text { Traveled } \\
\text { (miles) }\end{array}$ & $\begin{array}{l}\text { Vehicle } \\
\text { Minutes } \\
\text { (min) }\end{array}$ & $\begin{array}{c}\text { Cumulative } \\
\text { Average Speed } \\
195 \text { and all } \\
\text { Ranps (mph) }\end{array}$ & $\begin{array}{l}\text { Vehicle } \\
\text { Miles } \\
\text { Traveled } \\
\text { (miles) }\end{array}$ & $\begin{array}{l}\text { Vehicle } \\
\text { Minutes } \\
\text { (min) }\end{array}$ & $\begin{array}{c}\text { Curmulative } \\
\text { Average Speed } \\
\text { RT10 and all } \\
\text { Ramps (nqh) }\end{array}$ & $\begin{array}{c}\text { Cumulative } \\
\text { Network } \\
\text { Average Speed } \\
\text { (nゅh) }\end{array}$ \\
\hline Random Seed Number & A & B & $\begin{array}{c}\mathrm{C}=\mathrm{A} /(\mathrm{B} / 60 \\
\mathrm{min} / \mathrm{hr})\end{array}$ & D & E & $\begin{array}{c}\mathrm{F}=\mathrm{D} /(\mathrm{E} / 60 \\
\mathrm{min} / \mathrm{hr})\end{array}$ & $\begin{array}{c}G=(A+D) / \\
{[(B+E) / 60} \\
m i n / h r]\end{array}$ \\
\hline 1 & 29084.2 & 28455.8 & 61.3 & 7256.8 & 7586.6 & 57.4 & 60.5 \\
\hline 33 & 28122.4 & 28105.4 & 60.0 & 7028.8 & 7343.5 & 57.4 & 59.5 \\
\hline 99 & 28978.8 & 28331.2 & 61.4 & 7243.5 & 7547.6 & 57.6 & 60.6 \\
\hline Cumulative Average Speed & & & 60.9 & & & 57.5 & 60.2 \\
\hline
\end{tabular}




\begin{tabular}{|c|c|c|c|c|c|c|c|}
\hline \multirow{2}{*}{ Network Description } & \multicolumn{6}{|c|}{ Simulation Set Number } & 5.0 \\
\hline & \multicolumn{3}{|c|}{ Interstate 95 North } & \multicolumn{3}{|c|}{ Highway Route 10} & \\
\hline $\begin{array}{l}\text { 1/2 Peak AM Volume; } 0 \% \\
\text { Dluswion; } 2 \text { Lane Block; } 30 \\
\text { Whiti }\end{array}$ & $\begin{array}{l}\text { Vehicle } \\
\text { Miles } \\
\text { Traveled } \\
\text { (miles) }\end{array}$ & $\begin{array}{c}\text { Vehicle } \\
\text { Minutes } \\
\text { (min) }\end{array}$ & $\begin{array}{c}\text { Cumulative } \\
\text { Average Speed } \\
195 \text { and all } \\
\text { Ramps (mph) }\end{array}$ & $\begin{array}{l}\text { Vehicle } \\
\text { Miles } \\
\text { Traveled } \\
\text { (miles) }\end{array}$ & $\begin{array}{c}\text { Vehicle } \\
\text { Minutes } \\
\text { (min) }\end{array}$ & $\begin{array}{l}\text { Cumulative } \\
\text { A verage Speed } \\
\text { RT10 and all } \\
\text { Ramps (mph) }\end{array}$ & $\begin{array}{c}\text { Cumulative } \\
\text { Network } \\
\text { Average Speed } \\
\text { (mph) }\end{array}$ \\
\hline Random Seed Number & A & B & $\begin{array}{c}\mathrm{C}=\mathrm{A} /(\mathrm{B} / 60 \\
\mathrm{min} / \mathrm{hr})\end{array}$ & D & E & $\begin{array}{c}\mathrm{F}=\mathrm{D} /(\mathrm{E} / 60 \\
\mathrm{min} / \mathrm{hr})\end{array}$ & $\begin{array}{c}\mathrm{G}=(\mathrm{A}+\mathrm{D})] \\
{[(\mathrm{B}+\mathrm{E}) / 60} \\
\text { min } / \mathrm{hrl}\end{array}$ \\
\hline 1 & 28869.9 & 28607.7 & 60.5 & 7374.6 & 7706.9 & 57.4 & 59.9 \\
\hline 33 & 29046.0 & 28760.8 & 60.6 & 7222.3 & 7547.1 & 57.4 & 59.9 \\
\hline 99 & 29034.5 & 28745.7 & 60.6 & 7215.2 & 7434.2 & 58.2 & 60.1 \\
\hline Cumulative Average Speed & & & 60.6 & & & 57.7 & 60.0 \\
\hline \multirow{2}{*}{ Network Description } & \multicolumn{6}{|c|}{ Simulation Set Number } & 6.0 \\
\hline & \multicolumn{3}{|c|}{ Interstate 95 North } & \multicolumn{3}{|c|}{ Highway Route 10} & \\
\hline $\begin{array}{l}\text { 1/2 Peak AM Volume; } 0 \% \\
\text { Dongrilow; } 2 \text { Lane Block; } 40 \\
\text { Thy In }\end{array}$ & $\begin{array}{l}\text { Vehicle } \\
\text { Miles } \\
\text { Traveled } \\
\text { (miles) }\end{array}$ & $\begin{array}{l}\text { Vehicle } \\
\text { Minutes } \\
\text { (min) }\end{array}$ & $\begin{array}{c}\text { Cumulative } \\
\text { Average Speed } \\
\text { } 95 \text { and all } \\
\text { Ramps (mph) }\end{array}$ & $\begin{array}{l}\text { Vehicle } \\
\text { Miles } \\
\text { Traveled } \\
\text { (miles) }\end{array}$ & $\begin{array}{l}\text { Vehicle } \\
\text { Minutes } \\
\text { (min) }\end{array}$ & $\begin{array}{c}\text { Cumulative } \\
\text { Average Speed } \\
\text { RT10 and all } \\
\text { Ramps (mph) }\end{array}$ & $\begin{array}{c}\text { Curmulative } \\
\text { Network } \\
\text { Average Speed } \\
\text { (mph) }\end{array}$ \\
\hline Random Seed Number & $\mathbf{A}$ & B & $\begin{array}{c}\mathrm{C}=\mathrm{A} /(\mathrm{B} / 60 \\
\min / \mathrm{hr})\end{array}$ & D & E & $\begin{array}{c}\mathrm{F}=\mathrm{D} /(\mathrm{E} / 60 \\
\min / \mathrm{hr})\end{array}$ & $\begin{array}{c}G=(A+D) / \\
{[(B+E) / 60} \\
\text { min } / h r]\end{array}$ \\
\hline 1 & 28655.0 & 28893.2 & 59.5 & 7310.7 & 7621.6 & 57.6 & 59.1 \\
\hline 33 & 28695.2 & 28434.1 & 60.6 & 7305.2 & 7627.7 & 57.5 & 59.9 \\
\hline 99 & 28859.2 & 28742.6 & 60.2 & 7191.6 & 7488.7 & 57.6 & 59.7 \\
\hline Cumulative Average Speed & & & 60.1 & & & 57.5 & 59.6 \\
\hline \multirow{2}{*}{ Network Description } & \multicolumn{6}{|c|}{ Simulation Set Number } & 7.0 \\
\hline & \multicolumn{3}{|c|}{ Interstate 95 North } & \multicolumn{3}{|c|}{ Highway Route 10} & \\
\hline $\begin{array}{l}\text { 1/2 Peak AM Volume; } 0 \% \\
\text { Diverom; } 3 \text { Lane Block; } 20 \\
\text { Min In }\end{array}$ & $\begin{array}{l}\text { Vehicle } \\
\text { Miles } \\
\text { Traveled } \\
\text { (miles) }\end{array}$ & $\begin{array}{c}\text { Vehicle } \\
\text { Minutes } \\
\text { (min) }\end{array}$ & $\begin{array}{c}\text { Cumulative } \\
\text { Average Speed } \\
\text { I95 and all } \\
\text { Ramps (mph) }\end{array}$ & $\begin{array}{l}\text { Vehicle } \\
\text { Miles } \\
\text { Traveled } \\
\text { (miles) }\end{array}$ & $\begin{array}{l}\text { Vehicle } \\
\text { Minutes } \\
\text { (min) }\end{array}$ & $\begin{array}{c}\text { Cumulative } \\
\text { Average Speed } \\
\text { RT10 and all } \\
\text { Ramps (mph) }\end{array}$ & $\begin{array}{c}\text { Curmulative } \\
\text { Network } \\
\text { Average Speed } \\
\text { (mph) }\end{array}$ \\
\hline Random Seed Number & $\mathbf{A}$ & B & $\begin{array}{c}\mathrm{C}=\mathrm{A} /(\mathrm{B} / 60 \\
\mathrm{min} / \mathrm{hr})\end{array}$ & D & E & $\begin{array}{c}\mathrm{F}=\mathrm{D} /(\mathrm{E} / 60 \\
\mathrm{min} / \mathrm{hr})\end{array}$ & $\begin{array}{c}G=(A+D)] \\
{[(B+E) / 60} \\
\min / h r]\end{array}$ \\
\hline 1 & 28869.2 & 53011.3 & 32.7 & 7256.8 & 7586.6 & 57.4 & 35.8 \\
\hline 33 & 28854.8 & 39071.7 & 44.3 & 7028.8 & 7343.5 & 57.4 & 46.4 \\
\hline 99 & 28854.8 & 39071.7 & 44.3 & 7243.5 & 7547.6 & 57.6 & 46.5 \\
\hline Cumulative Average Speed & & & 39.6 & & & 57.5 & 42.2 \\
\hline \multirow{2}{*}{ Network Description } & \multicolumn{6}{|c|}{ Simulation Set Number } & 8.0 \\
\hline & \multicolumn{3}{|c|}{ Interstate 95 North } & \multicolumn{3}{|c|}{ Highway Route 10} & \\
\hline $\begin{array}{l}\text { 1/2 Peak AM Volume; } 0 \% \\
\text { Drwas bn; } 3 \text { Lane Block; } 30 \\
\text { Min In }\end{array}$ & $\begin{array}{l}\text { Vehicle } \\
\text { Miles } \\
\text { Traveled } \\
\text { (miles) }\end{array}$ & $\begin{array}{l}\text { Vehicle } \\
\text { Minutes } \\
\text { (min) }\end{array}$ & $\begin{array}{c}\text { Cumulative } \\
\text { Average Speed } \\
\text { I95 and all } \\
\text { Ramps (mph) }\end{array}$ & $\begin{array}{l}\text { Vehicle } \\
\text { Miles } \\
\text { Traveled } \\
\text { (miles) }\end{array}$ & $\begin{array}{c}\text { Vehicle } \\
\text { Minutes } \\
\text { (min) }\end{array}$ & \begin{tabular}{|} 
Cumulative \\
Average Speed \\
RT10 and all \\
Ranps (mph)
\end{tabular} & $\begin{array}{c}\text { Cumulative } \\
\text { Network } \\
\text { Average Speed } \\
\text { (mph) }\end{array}$ \\
\hline Random Seed Number & A & B & $\begin{array}{c}\mathrm{C}=\mathrm{A} /(\mathrm{B} / 60 \\
\mathrm{min} / \mathrm{hr})\end{array}$ & D & $\mathrm{E}$ & $\begin{array}{c}\mathrm{F}=\mathrm{D} /(\mathrm{E} / 60 \\
\mathrm{min} / \mathrm{hr})\end{array}$ & $\begin{array}{c}G=(A+D)] \\
{[(B+E) / 60} \\
\min / h r]\end{array}$ \\
\hline 1 & 26330.8 & 85066.5 & 18.6 & 7374.6 & 7706.9 & 57.4 & 21.8 \\
\hline 33 & 28783.6 & 49829.7 & 34.7 & 7222.3 & 7547.1 & 57.4 & 37.7 \\
\hline 99 & 28587.1 & 51391.3 & 33.4 & 7215.2 & 7434.2 & 58.2 & 36.5 \\
\hline Cumulative Average Speed & & & 27.0 & & & 57.7 & 30.3 \\
\hline
\end{tabular}




\begin{tabular}{|c|c|c|c|c|c|c|c|}
\hline \multirow{2}{*}{ Network Description } & \multicolumn{6}{|c|}{ Simulation Set Number } & 9.0 \\
\hline & \multicolumn{3}{|c|}{ Interstate 95 North } & \multicolumn{3}{|c|}{ Highway Route 10} & \\
\hline $\begin{array}{l}\text { 1/2 Peak AM Volume; 0\% } \\
\text { Min In }\end{array}$ & $\begin{array}{l}\text { Vehicle } \\
\text { Miles } \\
\text { Traveled } \\
\text { (miles) }\end{array}$ & $\begin{array}{l}\text { Vehicle } \\
\text { Minutes } \\
\text { (min) }\end{array}$ & $\begin{array}{c}\text { Cumulative } \\
\text { Average Speed } \\
\text { I95 and all } \\
\text { Ramps (mph) }\end{array}$ & $\begin{array}{l}\text { Vehicle } \\
\text { Miles } \\
\text { Traveled } \\
\text { (miles) }\end{array}$ & $\begin{array}{l}\text { Vehicle } \\
\text { Minutes } \\
\text { (min) }\end{array}$ & $\begin{array}{c}\text { Cumulative } \\
\text { Average Speed } \\
\text { RT10 and all } \\
\text { Ramps (mph) }\end{array}$ & $\begin{array}{c}\text { Cumulative } \\
\text { Network } \\
\text { Average Speed } \\
\text { (mph) }\end{array}$ \\
\hline Random Seed Number & A & B & $\begin{array}{c}\mathrm{C}=\mathrm{A} /(\mathrm{B} / 60 \\
\mathrm{min} / \mathrm{hr})\end{array}$ & D & $\mathbf{E}$ & $\begin{array}{c}\mathrm{F}=\mathrm{D} /(\mathrm{E} / 60 \\
\mathrm{min} / \mathrm{hr})\end{array}$ & $\begin{array}{c}\mathrm{G}=(\mathrm{A}+\mathrm{D}) / \\
{[(\mathrm{B}+\mathrm{E}) / 60} \\
\min \mathrm{hr}]\end{array}$ \\
\hline 1 & 28688.4 & 132992.5 & 12.9 & 7310.7 & 7621.6 & 57.6 & 15.4 \\
\hline 33 & 28825.0 & 68640.4 & 25.2 & 7305.2 & 7627.7 & 57.5 & 28.4 \\
\hline 99 & 28684.7 & 75715.1 & 22.7 & 7191.6 & 7488.7 & 57.6 & 25.9 \\
\hline Cumulative Average Speed & & & 18.6 & & & 57.5 & 21.6 \\
\hline \multirow{2}{*}{ Network Description } & \multicolumn{6}{|c|}{ Simulation Set Number } & 10.0 \\
\hline & \multicolumn{3}{|c|}{ Interstate 95 North } & \multicolumn{3}{|c|}{ Highway Route 10} & \\
\hline $\begin{array}{l}\text { 1/2 Peak AM Volume; } 20 \% \\
\text { 9herton; } 1 \text { Lane Block; } 20 \\
\text { Mhin In }\end{array}$ & $\begin{array}{l}\text { Vehicle } \\
\text { Miles } \\
\text { Traveled } \\
\text { (miles) }\end{array}$ & $\begin{array}{l}\text { Vehicle } \\
\text { Minutes } \\
\text { (min) }\end{array}$ & $\begin{array}{c}\text { Cumulative } \\
\text { Average Speed } \\
\text { I95 and all } \\
\text { Ramps (mph) }\end{array}$ & $\begin{array}{l}\text { Vehicle } \\
\text { Miles } \\
\text { Traveled } \\
\text { (miles) }\end{array}$ & $\begin{array}{l}\text { Vehicle } \\
\text { Minutes } \\
\text { (min) }\end{array}$ & $\begin{array}{c}\text { Cumulative } \\
\text { Average Speed } \\
\text { RT10 and all } \\
\text { Ramps (mph) }\end{array}$ & $\begin{array}{l}\text { Cumulative } \\
\text { Network } \\
\text { Average Speed } \\
\text { (mph) }\end{array}$ \\
\hline Random Seed Number & A & B & $\begin{array}{c}\mathrm{C}=\mathrm{A} /(\mathrm{B} / 60 \\
\mathrm{min} / \mathrm{hr})\end{array}$ & D & $\mathrm{E}$ & $\begin{array}{c}\mathrm{F}=\mathrm{D} /(\mathrm{E} / 60 \\
\mathrm{min} / \mathrm{hr})\end{array}$ & $\begin{array}{c}G=(A+D) / \\
{[(B+E) / 60} \\
\text { minchr }\end{array}$ \\
\hline 1 & 28378.1 & 27628.3 & 61.6 & 7756.4 & 8120.0 & 57.3 & 60.6 \\
\hline 33 & 28288.0 & 27468.5 & 61.8 & 7655.0 & 8010.0 & 57.3 & 60.8 \\
\hline 99 & 28116.6 & 28002.3 & 60.2 & 7717.4 & 8074.8 & 57.3 & 59.6 \\
\hline Cumulative Average Speed & & & 61.2 & & & 57.3 & 60.3 \\
\hline \multirow{2}{*}{ Network Description } & \multicolumn{6}{|c|}{ Simulation Set Number } & 11.0 \\
\hline & \multicolumn{3}{|c|}{ Interstate 95 North } & \multicolumn{3}{|c|}{ Highway Route 10} & \\
\hline $\begin{array}{l}\text { 1/2 Peak AM Volume; } 20 \% \\
\text { Powatpa; } 1 \text { Lane Block; } 30 \\
\text { MInIn }\end{array}$ & $\begin{array}{l}\text { Vehicle } \\
\text { Miles } \\
\text { Traveled } \\
\text { (miles) }\end{array}$ & $\begin{array}{l}\text { Vehicle } \\
\text { Minutes } \\
\text { (min) }\end{array}$ & $\begin{array}{c}\text { Cumulative } \\
\text { Average Speed } \\
\text { I95 and all } \\
\text { Ramps (mph) }\end{array}$ & $\begin{array}{l}\text { Vehicle } \\
\text { Miles } \\
\text { Traveled } \\
\text { (miles) }\end{array}$ & $\begin{array}{l}\text { Vehicle } \\
\text { Minutes } \\
\text { (min) }\end{array}$ & $\begin{array}{c}\text { Cumulative } \\
\text { Average Speed } \\
\text { RT10 and all } \\
\text { Ramps (mph) }\end{array}$ & $\begin{array}{l}\text { Cumulative } \\
\text { Network } \\
\text { Average Speed } \\
\text { (mph) }\end{array}$ \\
\hline Random Seed Number & A & B & $\begin{array}{c}C=A /(B / 60 \\
\min / h r)\end{array}$ & $\mathrm{D}$ & $\mathrm{E}$ & $\begin{array}{c}F=D /(E / 60 \\
\min / \mathrm{hr})\end{array}$ & $\begin{array}{c}G=(A+D)] \\
{[(B+E) / 60} \\
\text { min/hrl }\end{array}$ \\
\hline 1 & 27746.5 & 27030.4 & 61.6 & 8069.5 & 8440.2 & 57.4 & 60.6 \\
\hline 33 & 27982.1 & 27271.5 & 61.6 & 7913.9 & 8638.4 & 55.0 & 60.0 \\
\hline 99 & 27577.6 & 26859.0 & 61.6 & 8161.9 & 8542.3 & 57.3 & 60.6 \\
\hline Cumulative Average Speed & & & 61.6 & & & 56.5 & 60.4 \\
\hline \multirow{2}{*}{ Network Description } & \multicolumn{6}{|c|}{ Simulation Set Number } & 12.0 \\
\hline & \multicolumn{3}{|c|}{ Interstate 95 North } & \multicolumn{3}{|c|}{ Highway Route 10} & \\
\hline $\begin{array}{l}\text { 19 Peak AM Volume; } 20 \% \\
\text { Whetha; } 1 \text { Lane Block; } 40 \\
\text { MonIn }\end{array}$ & $\begin{array}{l}\text { Vehicle } \\
\text { Miles } \\
\text { Traveled } \\
\text { (miles) }\end{array}$ & $\begin{array}{l}\text { Vehicle } \\
\text { Minutes } \\
\text { (min) }\end{array}$ & $\begin{array}{c}\text { Cumulative } \\
\text { Average Speed } \\
195 \text { and all } \\
\text { Ramps (mph) }\end{array}$ & $\begin{array}{l}\text { Vehicle } \\
\text { Miles } \\
\text { Traveled } \\
\text { (miles) }\end{array}$ & $\begin{array}{l}\text { Vehicle } \\
\text { Minutes } \\
\text { (min) }\end{array}$ & $\begin{array}{c}\text { Cumulative } \\
\text { Average Speed } \\
\text { RT10 and all } \\
\text { Ramps (mph) }\end{array}$ & $\begin{array}{c}\text { Cumulative } \\
\text { Network } \\
\text { Average Speed } \\
\text { (mph) }\end{array}$ \\
\hline Random Seed Number & A & B & $\begin{array}{c}\mathrm{C}=\mathrm{A} /(\mathrm{B} / 60 \\
\mathrm{min} / \mathrm{hr})\end{array}$ & D & E & $\begin{array}{c}\mathrm{F}=\mathrm{D} /(\mathrm{E} / 60 \\
\mathrm{min} / \mathrm{hr})\end{array}$ & $\begin{array}{c}G=(A+D) / \\
{[(B+E) / 60} \\
\min / h r]\end{array}$ \\
\hline 1 & 27415.1 & 26737.1 & 61.5 & 8337.6 & 8701.2 & 57.5 & 60.5 \\
\hline 33 & 27154.4 & 26516.8 & 61.4 & 8308.5 & 8695.2 & 57.3 & 60.4 \\
\hline 99 & 27241.7 & 26578.1 & 61.5 & 8419.4 & 8814.6 & 57.3 & 60.5 \\
\hline Cumulative Average Speed & & & 61.5 & & & 57.4 & 60.5 \\
\hline
\end{tabular}




\begin{tabular}{|c|c|c|c|c|c|c|c|}
\hline \multirow{3}{*}{\begin{tabular}{l}
\multicolumn{1}{|c|}{ Network Description } \\
$\begin{array}{l}\text { 1M Peak AM Volume; } 20 \% \\
\text { Diversion; } 2 \text { Lane Block; } 20 \\
\text { Min In }\end{array}$
\end{tabular}} & \multicolumn{4}{|c|}{ - } & \multicolumn{2}{|c|}{ Simulation Set Nunber } & 13.0 \\
\hline & \multicolumn{3}{|c|}{ Interstate 95 North } & \multicolumn{3}{|c|}{ Highway Route 10} & \multirow[b]{2}{*}{$\begin{array}{c}\text { Cumulative } \\
\text { Network } \\
\text { Average Speed } \\
\text { (mph) }\end{array}$} \\
\hline & $\begin{array}{l}\text { Vehicle } \\
\text { Miles } \\
\text { Traveled } \\
\text { (miles) }\end{array}$ & $\begin{array}{l}\text { Vehicle } \\
\text { Minutes } \\
\text { (min) }\end{array}$ & $\begin{array}{c}\text { Cumulative } \\
\text { Average Speed } \\
\text { I95 and all } \\
\text { Ramps (mph) }\end{array}$ & $\begin{array}{l}\text { Vehicle } \\
\text { Miles } \\
\text { Traveled } \\
\text { (miles) }\end{array}$ & $\begin{array}{l}\text { Vehicle } \\
\text { Minutes } \\
\text { (min) }\end{array}$ & $\begin{array}{l}\text { Cumulative } \\
\text { Average Speed } \\
\text { RT10 and all } \\
\text { Ramps (mph) }\end{array}$ & \\
\hline Random Seed Number & $\mathbf{A}$ & B & $\begin{array}{c}\mathrm{C}=\mathrm{A} /(\mathrm{B} / 60 \\
\mathrm{min} / \mathrm{hr})\end{array}$ & $\mathrm{D}$ & E & $\begin{array}{c}\mathrm{F}=\mathrm{D} /(\mathrm{E} / 60 \\
\mathrm{min} / \mathrm{hr})\end{array}$ & $\begin{array}{c}G=(A+D)] \\
{[(B+E) / 60} \\
\text { min/hr] }\end{array}$ \\
\hline 1 & 28114.3 & 27673.7 & 61.0 & 7756.4 & 8120.0 & 57.3 & 60.1 \\
\hline 33 & 28128.9 & 27520.7 & 61.3 & 7655.0 & 8010.0 & 57.3 & 60.4 \\
\hline 99 & 27950.3 & 27360.3 & 61.3 & 7717.4 & 8074.8 & 57.3 & 60.4 \\
\hline Cumulative Average Speed & & & 61.2 & & & 57.3 & 60.3 \\
\hline \multirow{2}{*}{ Network Description } & \multicolumn{6}{|c|}{ Simulation Set Number } & 14.0 \\
\hline & \multicolumn{3}{|c|}{ Interstate 95 North } & \multicolumn{3}{|c|}{ Highway Route 10} & \\
\hline $\begin{array}{l}12 \text { Peak AM Volume; } 20 \% \\
\text { Dikersion; } 2 \text { Lane Block; } 30 \\
\text { Min In }\end{array}$ & $\begin{array}{l}\text { Vehicle } \\
\text { Miles } \\
\text { Traveled } \\
\text { (miles) }\end{array}$ & $\begin{array}{c}\text { Vehicle } \\
\text { Minutes } \\
\text { (min) }\end{array}$ & $\begin{array}{c}\text { Cumulative } \\
\text { Average Speed } \\
195 \text { and all } \\
\text { Ramps (mph) }\end{array}$ & $\begin{array}{l}\text { Vehicle } \\
\text { Miles } \\
\text { Traveled } \\
\text { (miles) }\end{array}$ & $\begin{array}{c}\text { Vehicle } \\
\text { Minutes } \\
\text { (min) }\end{array}$ & $\begin{array}{c}\text { Cumulative } \\
\text { Average Speed } \\
\text { RT } 10 \text { and all } \\
\text { Ramps (mph) }\end{array}$ & $\begin{array}{c}\text { Cumulative } \\
\text { Network } \\
\text { Average Speed } \\
\text { (mph) }\end{array}$ \\
\hline Random Seed Number & A & B & $\begin{array}{c}\mathrm{C}=\mathrm{A} /(\mathrm{B} / 60 \\
\min / \mathrm{hr})\end{array}$ & D & E & $\begin{array}{c}\mathrm{F}=\mathrm{D} /(\mathrm{E} / 60 \\
\mathrm{min} / \mathrm{hr})\end{array}$ & $\begin{array}{c}G=(A+D)] \\
{[(B+E) / 60} \\
\text { min } / h r]\end{array}$ \\
\hline 1 & 27846.4 & 27452.0 & 60.9 & 8069.5 & 8440.2 & 57.4 & 60.0 \\
\hline 33 & 27799.1 & 27312.8 & 61.1 & 7913.9 & 8638.4 & 55.0 & 59.6 \\
\hline 99 & 27765.3 & 27270.0 & 61.1 & 8161.9 & 8542.3 & 57.3 & 60.2 \\
\hline Cumulative Average Speed & & & 61.0 & & & 56.5 & 59.9 \\
\hline \multirow{2}{*}{ Network Description } & \multicolumn{6}{|c|}{ Simulation Set Number } & 15.0 \\
\hline & \multicolumn{3}{|c|}{ Interstate 95 North } & \multicolumn{3}{|c|}{ Highway Route 10} & \\
\hline $\begin{array}{l}1 / 2 \text { Peak AM Volume; } 20 \% \\
\text { Difursion; } 2 \text { Lane Block; } 40 \\
\text { Mina In }\end{array}$ & $\begin{array}{l}\text { Vehicle } \\
\text { Miles } \\
\text { Traveled } \\
\text { (miles) }\end{array}$ & $\begin{array}{c}\text { Vehicle } \\
\text { Minutes } \\
\text { (min) }\end{array}$ & $\begin{array}{c}\text { Cumulative } \\
\text { Average Speed } \\
\text { I95 and all } \\
\text { Ramps (mph) }\end{array}$ & $\begin{array}{l}\text { Vehicle } \\
\text { Miles } \\
\text { Traveled } \\
\text { (miles) }\end{array}$ & $\begin{array}{l}\text { Vehicle } \\
\text { Minutes } \\
\text { (min) }\end{array}$ & $\begin{array}{c}\text { Cumulative } \\
\text { Average Speed } \\
\text { RT10 and all } \\
\text { Ramps (mph) }\end{array}$ & $\begin{array}{c}\text { Cumulative } \\
\text { Network } \\
\text { Average Speed } \\
\text { (mph) }\end{array}$ \\
\hline Random Seed Number & A & B & $\begin{array}{c}\mathrm{C}=\mathrm{A} /(\mathrm{B} / 60 \\
\mathrm{min} / \mathrm{hr})\end{array}$ & D & E & $\begin{array}{c}\mathrm{F}=\mathrm{D} /(\mathrm{E} / 60 \\
\mathrm{min} / \mathrm{hr})\end{array}$ & $\begin{array}{c}\mathrm{G}=(\mathrm{A}+\mathrm{D}) / \\
{[(\mathrm{B}+\mathrm{E}) / 60} \\
\mathrm{min} / \mathrm{hr}]\end{array}$ \\
\hline 1 & 27329.7 & 26925.7 & 60.9 & 8337.6 & 8701.2 & 57.5 & 60.1 \\
\hline 33 & 27169.7 & 26714.3 & 61.0 & 8308.5 & 8695.2 & 57.3 & 60.1 \\
\hline 99 & 27103.1 & 26674.2 & 61.0 & 8419.4 & 8814.6 & 57.3 & 60.1 \\
\hline Cumulative Average Speed & & & 61.0 & & & 57.4 & 60.1 \\
\hline \multirow{2}{*}{ Network Description } & \multicolumn{6}{|c|}{ Simulation Set Number } & 16.0 \\
\hline & \multicolumn{3}{|c|}{ Interstate 95 North } & \multicolumn{3}{|c|}{ Highway Route 10} & \\
\hline $\begin{array}{l}\text { 14: Peak AM Volume; } 20 \% \\
\text { Whersion; } 3 \text { Lane Block; } 20 \\
\text { Wh In }\end{array}$ & $\begin{array}{l}\text { Vehicle } \\
\text { Miles } \\
\text { Traveled } \\
\text { (miles) }\end{array}$ & $\begin{array}{l}\text { Vehicle } \\
\text { Minutes } \\
\text { (min) }\end{array}$ & $\begin{array}{c}\text { Cumulative } \\
\text { Average Speed } \\
\text { [95 and all } \\
\text { Ramps (mph) }\end{array}$ & $\begin{array}{l}\text { Vehicle } \\
\text { Miles } \\
\text { Traveled } \\
\text { (miles) }\end{array}$ & $\begin{array}{l}\text { Vehicle } \\
\text { Minutes } \\
\text { (min) }\end{array}$ & \begin{tabular}{|c|} 
Cumulative \\
Average Speed \\
RT10 and all \\
Ramps (mph)
\end{tabular} & $\begin{array}{c}\text { Cumulative } \\
\text { Network } \\
\text { Average Speed } \\
\text { (mph) }\end{array}$ \\
\hline Random Seed Number & $A$ & B & $\begin{array}{c}\mathrm{C}=\mathrm{A} /(\mathrm{B} / 60 \\
\mathrm{min} / \mathrm{hr})\end{array}$ & D & E & $\begin{array}{c}\mathrm{F}=\mathrm{D} /(\mathrm{E} / 60 \\
\mathrm{min} / \mathrm{hr})\end{array}$ & $\begin{array}{c}G=(A+D)] \\
{[(B+E) / 60} \\
\text { min } / \mathrm{hr}]\end{array}$ \\
\hline 1 & 28050.9 & 34400.4 & 48.9 & 7756.4 & 8120.0 & 57.3 & 50.5 \\
\hline 33 & 28086.3 & 46748.2 & 36.0 & 7655.0 & 8010.0 & 57.3 & 39.2 \\
\hline 99 & 28017.1 & 35132.9 & 47.8 & 7717.4 & 8074.8 & 57.3 & 49.6 \\
\hline Curnulative Average Speed & & & 43.4 & & & 57.3 & 45.8 \\
\hline
\end{tabular}




\begin{tabular}{|c|c|c|c|c|c|c|c|}
\hline \multirow{2}{*}{ Network Description } & \multicolumn{6}{|c|}{ Simulation Set Number } & 17.0 \\
\hline & \multicolumn{3}{|c|}{ Interstate 95 North } & \multicolumn{3}{|c|}{ Highway Route 10} & \\
\hline $\begin{array}{l}\text { Deak AM Volume; } 20 \% \\
\text { Dharaion; } 3 \text { Lane Block; } 30 \\
\text { Xlin In }\end{array}$ & $\begin{array}{l}\text { Vehicle } \\
\text { Miles } \\
\text { Traveled } \\
\text { (miles) }\end{array}$ & $\begin{array}{l}\text { Vehicle } \\
\text { Minutes } \\
\text { (min) }\end{array}$ & $\begin{array}{c}\text { Cumulative } \\
\text { Average Speed } \\
195 \text { and all } \\
\text { Ramps (mph) }\end{array}$ & $\begin{array}{l}\text { Vehicle } \\
\text { Miles } \\
\text { Traveled } \\
\text { (miles) }\end{array}$ & $\begin{array}{l}\text { Vehicle } \\
\text { Minutes } \\
\text { (min) }\end{array}$ & $\begin{array}{l}\text { Cumulative } \\
\text { Average Speed } \\
\text { RT10 and all } \\
\text { Ramps (mph) }\end{array}$ & $\begin{array}{c}\text { Cumulative } \\
\text { Network } \\
\text { Average Speed } \\
\text { (mph) }\end{array}$ \\
\hline Random Seed Number & A & B & $\begin{array}{c}\mathrm{C}=\mathrm{A} /(\mathrm{B} / 60 \\
\mathrm{min} / \mathrm{hr})\end{array}$ & $\mathrm{D}$ & $\mathbf{E}$ & $\begin{array}{c}\mathrm{F}=\mathrm{D} /(\mathrm{E} / 60 \\
\mathrm{min} / \mathrm{hr})\end{array}$ & $\begin{array}{c}G=(A+D) / \\
{[B+E) / 60} \\
\text { min } / \mathrm{hr}]\end{array}$ \\
\hline 1 & 27676.1 & 41944.4 & 39.6 & 8069.5 & 8440.2 & 57.4 & 42.6 \\
\hline 33 & 27785.7 & 74346.5 & 22.4 & 7913.9 & 8638.4 & 55.0 & 25.8 \\
\hline 99 & 27785.7 & 74346.5 & 22.4 & 8161.9 & 8542.3 & 57.3 & 26.0 \\
\hline Cumulative Average Speed & & & 26.2 & & & 56.5 & 29.8 \\
\hline \multirow{2}{*}{ Network Description } & \multicolumn{6}{|c|}{ Simulation Set Number } & 18.0 \\
\hline & \multicolumn{3}{|c|}{ Interstate 95 North } & \multicolumn{3}{|c|}{ Highway Route 10} & \\
\hline $\begin{array}{l}\text { 1/2 Peak AM Volume; } 20 \% \\
\text { Dixwrion; } 3 \text { Lane Block; } 40 \\
\text { Mili In }\end{array}$ & $\begin{array}{l}\text { Vehicle } \\
\text { Miles } \\
\text { Traveled } \\
\text { (miles) }\end{array}$ & $\begin{array}{l}\text { Vehicle } \\
\text { Minutes } \\
\text { (min) }\end{array}$ & $\begin{array}{c}\text { Cumulative } \\
\text { Average Speed } \\
\text { I95 and all } \\
\text { Ramps (mph) }\end{array}$ & $\begin{array}{l}\text { Vehicle } \\
\text { Miles } \\
\text { Traveled } \\
\text { (miles) }\end{array}$ & $\begin{array}{c}\text { Vehicle } \\
\text { Minutes } \\
\text { (min) }\end{array}$ & $\begin{array}{c}\text { Cumulative } \\
\text { Average Speed } \\
\text { RT10 and all } \\
\text { Ramps (nph) }\end{array}$ & $\begin{array}{c}\text { Curmulative } \\
\text { Network } \\
\text { Average Speed } \\
\text { (nाph) }\end{array}$ \\
\hline Random Seed Number & A & B & $\begin{array}{c}\mathrm{C}=\mathrm{A} /(\mathrm{B} / 60 \\
\mathrm{min} / \mathrm{hr})\end{array}$ & $\mathrm{D}$ & E & $\begin{array}{c}\mathrm{F}=\mathrm{D} /(\mathrm{E} / 60 \\
\mathrm{min} / \mathrm{hr})\end{array}$ & $\begin{array}{c}\mathrm{G}=(\mathrm{A}+\mathrm{D}) / \\
{[(\mathrm{B}+\mathrm{E}) / 60} \\
\text { min/hr] }\end{array}$ \\
\hline 1 & 46711.5 & 178909.1 & 15.7 & 8337.6 & 8701.2 & 57.5 & 17.6 \\
\hline 33 & 46028.9 & 179016.2 & 15.4 & 8308.5 & 8695.2 & 57.3 & 17.4 \\
\hline 99 & 46653.4 & 159184.5 & 17.6 & 8419.4 & 8814.6 & 57.3 & 19.7 \\
\hline Cumulative Average Speed & & & 16.2 & & & 57.4 & 18.2 \\
\hline
\end{tabular}




\begin{tabular}{|c|c|c|c|c|c|c|c|}
\hline \multirow{2}{*}{ Nelwork Description } & \multicolumn{6}{|c|}{ Simulation Set Number } & 1 \\
\hline & \multicolumn{3}{|c|}{ Interstate 95 North } & \multicolumn{3}{|c|}{ Highway Route 10} & \\
\hline $\begin{array}{l}\text { 1/2 Peak AM Volume; 0\% Diversion; } \\
\text { I Lane Block; } 20 \mathrm{Min} \text { In }\end{array}$ & $\begin{array}{l}\text { Vehicle } \\
\text { Miles } \\
\text { Traveled } \\
\text { (miles) }\end{array}$ & $\begin{array}{l}\text { Vehicle } \\
\text { Minutes } \\
\text { (min) }\end{array}$ & $\begin{array}{c}\text { Cumulative } \\
\text { Average Travel } \\
\text { Time } 195 \text { and all } \\
\text { Ramps (min-veh } \\
\text { mile) }\end{array}$ & $\begin{array}{l}\text { Vehicle } \\
\text { Miles } \\
\text { Traveled } \\
\text { (miles) }\end{array}$ & $\begin{array}{l}\text { Vehicle } \\
\text { Minutes } \\
\text { (min) }\end{array}$ & $\begin{array}{c}\text { Cumulative } \\
\text { Average Travel } \\
\text { Time RT10 } \\
\text { and all Ramps } \\
\text { (mph) }\end{array}$ & $\begin{array}{c}\text { Curmulative } \\
\text { Network } \\
\text { Average Travel } \\
\text { Time (min / veh } \\
\text { mile) }\end{array}$ \\
\hline Random Seed Number & A & $\mathbf{B}$ & $C=B / A$ & D & $\mathrm{E}$ & $F=E / D$ & $\begin{array}{c}G=(B+E) /(A \\
+D)\end{array}$ \\
\hline 1 & 29084.2 & 28455.8 & 0.98 & 7256.8 & 7586.6 & 1.05 & 0.99 \\
\hline 33 & 28816.9 & 28180.0 & 0.98 & 7028.8 & 7343.5 & 1.04 & 0.99 \\
\hline 99 & 28978.8 & 28331.2 & 0.98 & 7243.5 & 7547.6 & 1.04 & 0.99 \\
\hline Cumulative Average Travel Speed & & & 0.98 & & & 1.04 & 0.99 \\
\hline \multirow{2}{*}{ Network Description } & \multicolumn{6}{|c|}{ Simulation Set Number } & 2 \\
\hline & \multicolumn{3}{|c|}{ Interstate 95 North } & \multicolumn{3}{|c|}{ Highway Route 10} & \\
\hline $\begin{array}{l}19 \text { Peak AM Volune; 0\% Diversion; } \\
1 \text { Lane Block; } 30 \text { Min In }\end{array}$ & $\begin{array}{l}\text { Vehicle } \\
\text { Miles } \\
\text { Traveled } \\
\text { (miles) }\end{array}$ & $\begin{array}{l}\text { Vehicle } \\
\text { Minutes } \\
\text { (min) }\end{array}$ & $\begin{array}{c}\text { Cumulative } \\
\text { Average Travel } \\
\text { Time I95 and al! } \\
\text { Ramps (min-veh } \\
\text { mile) }\end{array}$ & $\begin{array}{c}\text { Vehicle } \\
\text { Miles } \\
\text { Traveled } \\
\text { (miles) }\end{array}$ & $\begin{array}{l}\text { Vehicle } \\
\text { Minutes } \\
\text { (min) }\end{array}$ & $\begin{array}{c}\text { Cumulative } \\
\text { Average Trave] } \\
\text { Time RT10 } \\
\text { and all Ramps } \\
\text { (mph) }\end{array}$ & $\begin{array}{c}\text { Cumulative } \\
\text { Network } \\
\text { Average Travel } \\
\text { Time (min / veh } \\
\text { mile) }\end{array}$ \\
\hline Random Seed Number & A & B & $C=B / A$ & D & E & $\mathrm{F}=\mathrm{E} / \mathrm{D}$ & $\begin{array}{c}\mathrm{G}=(\mathrm{B}+\mathrm{E}) /(\mathrm{A} \\
+\mathrm{D})\end{array}$ \\
\hline 1 & 28780.2 & 28152.6 & 0.98 & 7374.6 & 7706.9 & 1.05 & 0.99 \\
\hline 33 & 29160.8 & 28522.9 & 0.98 & 7222.3 & 7547.1 & 1.04 & 0.99 \\
\hline 99 & 29132.2 & 28434.5 & 0.98 & 7215.2 & 7434.2 & 1.03 & 0.99 \\
\hline Cumulative Average Travel Speed & & & 0.98 & & & 1.04 & 0.99 \\
\hline \multirow{2}{*}{ Network Description } & \multicolumn{6}{|c|}{ Simulation Set Nunber } & 3 \\
\hline & \multicolumn{3}{|c|}{ Interstate 95 North } & \multicolumn{3}{|c|}{ Highway Route 10} & \\
\hline $\begin{array}{l}\text { 18 Peak AM Volume; 0\% Diversion; } \\
1 \text { Lane Block; } 40 \mathrm{Min} \text { In }\end{array}$ & $\begin{array}{l}\text { Vehicle } \\
\text { Miles } \\
\text { Traveled } \\
\text { (miles) }\end{array}$ & $\begin{array}{l}\text { Vehicle } \\
\text { Minutes } \\
\text { (min) }\end{array}$ & $\begin{array}{c}\text { Cumulative } \\
\text { Average Travel } \\
\text { Time } 195 \text { and all } \\
\text { Ranms (min-veh } \\
\text { mile) }\end{array}$ & $\begin{array}{l}\text { Vehicle } \\
\text { Miles } \\
\text { Traveled } \\
\text { (miles) }\end{array}$ & $\begin{array}{l}\text { Vehicle } \\
\text { Minutes } \\
\text { (min) }\end{array}$ & $\begin{array}{c}\text { Curmulative } \\
\text { Average Travel } \\
\text { Time RT10 } \\
\text { and all Ramps } \\
\text { (mph) }\end{array}$ & $\begin{array}{c}\text { Cumulative } \\
\text { Network } \\
\text { Average Travel } \\
\text { Time (min / veh } \\
\text { mile) }\end{array}$ \\
\hline Random Seed Number & A & B & $\mathrm{C}=\mathrm{B} / \mathrm{A}$ & D & $\mathbf{E}$ & $F=E / D$ & $\begin{array}{c}\mathrm{G}=(\mathrm{B}+\mathrm{E}) /(\mathrm{A} \\
+\mathrm{D})\end{array}$ \\
\hline 1 & 28906.8 & 28270.0 & 0.98 & 7310.7 & 7621.6 & 1.04 & 0.99 \\
\hline 33 & 28872.6 & 28237.5 & 0.98 & 7305.2 & 7627.7 & 1.04 & 0.99 \\
\hline 99 & 28838.9 & 28160.8 & 0.98 & 7191.6 & 7488.7 & 1.04 & 0.99 \\
\hline Cumulative Average Travel Speed & & & 0.98 & & & 1.04 & 0.99 \\
\hline \multirow{2}{*}{ Network Description } & \multicolumn{6}{|c|}{ Simulation Set Nunber } & 4 \\
\hline & \multicolumn{3}{|c|}{ Interstate 95 North } & \multicolumn{3}{|c|}{ Highway Route 10} & \\
\hline $\begin{array}{l}\text { 19 Peak AM Volume; 0\% Diversion; } \\
\text { SLane Block; } 20 \text { Min In }\end{array}$ & $\begin{array}{l}\text { Vehicle } \\
\text { Miles } \\
\text { Traveled } \\
\text { (miles) }\end{array}$ & $\begin{array}{c}\text { Vehicle } \\
\text { Minutes } \\
\text { (min) }\end{array}$ & $\begin{array}{c}\text { Cumulative } \\
\text { Average Travel } \\
\text { Tine } 195 \text { and all } \\
\text { Ramps (nin-veh } \\
\text { mile) }\end{array}$ & $\begin{array}{c}\text { Vehicle } \\
\text { Miles } \\
\text { Traveled } \\
\text { (miles) }\end{array}$ & $\begin{array}{l}\text { Vehicle } \\
\text { Minutes } \\
\text { (min) }\end{array}$ & $\begin{array}{c}\text { Cumulative } \\
\text { Average Travel } \\
\text { Time RT10 } \\
\text { and all Ramps } \\
\text { (mph) }\end{array}$ & $\begin{array}{c}\text { Cumulative } \\
\text { Network } \\
\text { Average Travel } \\
\text { Time (min / veh } \\
\text { mile) }\end{array}$ \\
\hline Random Seed Number & A & B & $\mathrm{C}=\mathrm{B} / \mathrm{A}$ & D & $\mathbf{E}$ & $\mathbf{F}=\mathrm{E} / \mathrm{D}$ & $\begin{array}{c}G=(B+E) /(A \\
+D)\end{array}$ \\
\hline 1 & 29084.2 & 28455.8 & 0.98 & 7256.8 & 7586.6 & 1.05 & 0.99 \\
\hline 33 & 28122.4 & 28105.4 & 1.00 & 7028.8 & 7343.5 & 1.04 & 1.01 \\
\hline 99 & 28978.8 & 28331.2 & 0.98 & 7243.5 & 7547.6 & 1.04 & 0.99 \\
\hline Cumulative Average Travel Speed & & & 0.98 & & & 1.04 & 1.00 \\
\hline
\end{tabular}




\begin{tabular}{|c|c|c|c|c|c|c|c|}
\hline \multirow{2}{*}{ Network Description } & \multicolumn{6}{|c|}{ Simulation Set Number } & 5 \\
\hline & \multicolumn{3}{|c|}{ Interstate 95 North } & \multicolumn{3}{|c|}{ Highway Route 10} & \\
\hline $\begin{array}{l}\text { 19. Peak AM Volume; 0\% Diversion; } \\
\text { Lane Block; } 30 \text { Min In }\end{array}$ & $\begin{array}{l}\text { Vehicle } \\
\text { Miles } \\
\text { Traveled } \\
\text { (miles) }\end{array}$ & $\begin{array}{c}\text { Vehicle } \\
\text { Minutes } \\
\text { (min) }\end{array}$ & $\begin{array}{c}\text { Cumulative } \\
\text { Average Travel } \\
\text { Time I95 and all } \\
\text { Ramps (min-veh } \\
\text { mile) }\end{array}$ & $\begin{array}{c}\text { Vehicle } \\
\text { Miles } \\
\text { Traveled } \\
\text { (miles) }\end{array}$ & $\begin{array}{l}\text { Vehicle } \\
\text { Minutes } \\
\text { (min) }\end{array}$ & $\begin{array}{c}\text { Cumulative } \\
\text { Average Travel } \\
\text { Time RT10 } \\
\text { and all Ramps } \\
\text { (mph) }\end{array}$ & $\begin{array}{c}\text { Cumulative } \\
\text { Network } \\
\text { Average Travel } \\
\text { Time (min / veh } \\
\text { mile) }\end{array}$ \\
\hline Random Seed Number & A & B & $C=B / A$ & D & $\mathrm{E}$ & $F=E / D$ & $\begin{array}{c}\mathrm{G}=(\mathrm{B}+\mathrm{E}) /(\mathrm{A} \\
+\mathrm{D})\end{array}$ \\
\hline 1 & 28869.9 & 28607.7 & 0.99 & 7374.6 & 7706.9 & 1.05 & 1.00 \\
\hline 33 & 29046.0 & 28760.8 & 0.99 & 7222.3 & 7547.1 & 1.04 & 1.00 \\
\hline 99 & 29034.5 & 28745.7 & 0.99 & 7215.2 & 7434.2 & 1.03 & 1.00 \\
\hline Cumulative Average Travel Speed & & & 0.99 & & & 1.04 & 1.00 \\
\hline \multirow{2}{*}{ Network Description } & \multicolumn{6}{|c|}{ Simulation Set Number } & 6 \\
\hline & \multicolumn{3}{|c|}{ Interstate 95 North } & \multicolumn{3}{|c|}{ Highway Route 10} & \\
\hline $\begin{array}{l}\text { 18 Peak AM Volume; 0\% Diversion; } \\
\text { 3. Lane Block; } 40 \mathrm{Min} \text { In }\end{array}$ & $\begin{array}{l}\text { Vehicle } \\
\text { Miles } \\
\text { Traveled } \\
\text { (miles) }\end{array}$ & $\begin{array}{c}\text { Vehicle } \\
\text { Minutes } \\
\text { (min) }\end{array}$ & $\begin{array}{c}\text { Cumulative } \\
\text { Average Travel } \\
\text { Time I95 and all } \\
\text { Rants (min-veh } \\
\text { mile) }\end{array}$ & $\begin{array}{c}\text { Vehicle } \\
\text { Miles } \\
\text { Traveled } \\
\text { (miles) }\end{array}$ & $\begin{array}{l}\text { Vehicle } \\
\text { Minutes } \\
\text { (min) }\end{array}$ & $\begin{array}{c}\text { Cumulative } \\
\text { Average Travel } \\
\text { Time RT10 } \\
\text { and all Ramps } \\
\text { (mph) }\end{array}$ & $\begin{array}{c}\text { Cumulative } \\
\text { Network } \\
\text { Average Travel } \\
\text { Time (min/veh } \\
\text { mile) }\end{array}$ \\
\hline Random Seed Number & A & B & $C=B / A$ & D & E & $F=E / D$ & $\begin{array}{c}G=(B+E) /(A \\
+D)\end{array}$ \\
\hline 1 & 28655.0 & 28893.2 & 1.01 & 7310.7 & 7621.6 & 1.04 & 1.02 \\
\hline 33 & 28695.2 & 28434.1 & 0.99 & 7305.2 & 7627.7 & 1.04 & 1.00 \\
\hline 99 & 28859.2 & 28742.6 & 1.00 & 7191.6 & 7488.7 & 1.04 & 1.01 \\
\hline Cumulative Average Travel Speed & & & 1.00 & & & 1.04 & 1.01 \\
\hline \multirow{2}{*}{ Network Description } & \multicolumn{6}{|c|}{ Simulation Set Number } & 7 \\
\hline & \multicolumn{3}{|c|}{ Interstate 95 North } & \multicolumn{3}{|c|}{ Highway Route 10} & \\
\hline $\begin{array}{l}\text { 19. Peak AM Volume; 0\% Diversion; } \\
3 \text { Lane Block; } 20 \mathrm{Min} \text { In }\end{array}$ & $\begin{array}{l}\text { Vehicle } \\
\text { Miles } \\
\text { Traveled } \\
\text { (miles) }\end{array}$ & $\begin{array}{c}\text { Vehicle } \\
\text { Minutes } \\
\text { (min) }\end{array}$ & $\begin{array}{c}\text { Cumulative } \\
\text { Average Travel } \\
\text { Time I95 and all } \\
\text { Ranips (min-veh } \\
\text { mile) }\end{array}$ & $\begin{array}{c}\text { Vehicle } \\
\text { Miles } \\
\text { Traveled } \\
\text { (miles) }\end{array}$ & $\begin{array}{l}\text { Vehicle } \\
\text { Minutes } \\
\text { (min) }\end{array}$ & $\begin{array}{c}\text { Cumulative } \\
\text { Average Travel } \\
\text { Time RT10 } \\
\text { and all Ramps } \\
\text { (mph) }\end{array}$ & $\begin{array}{c}\text { Cumulative } \\
\text { Network } \\
\text { Average Travel } \\
\text { Time (min / veh } \\
\text { mile) }\end{array}$ \\
\hline Random Seed Number & A & B & $C=B / A$ & D & E & $F=E / D$ & $\begin{array}{c}G=(B+E) /(A \\
+D)\end{array}$ \\
\hline 1 & 28869.2 & 53011.3 & 1.84 & 7256.8 & 7586.6 & 1.05 & 1.68 \\
\hline 33 & 28854.8 & 39071.7 & 1.35 & 7028.8 & 7343.5 & 1.04 & 1.29 \\
\hline 99 & 28854.8 & 39071.7 & 1.35 & 7243.5 & 7547.6 & 1.04 & 1.29 \\
\hline Curnulative Average Travel Speed & & & 1.51 & & & 1.04 & 1.42 \\
\hline \multirow{2}{*}{ Network Description } & \multicolumn{6}{|c|}{ Simulation Set Nunber } & 8 \\
\hline & \multicolumn{3}{|c|}{ Interstate 95 North } & \multicolumn{3}{|c|}{ Highway Route 10} & \\
\hline $\begin{array}{l}18 \text { Peak AM Volume; 0\% Diversion; } \\
\text { Lane Block; } 30 \mathrm{Min} \text { In }\end{array}$ & $\begin{array}{l}\text { Vehicle } \\
\text { Miles } \\
\text { Traveled } \\
\text { (miles) }\end{array}$ & $\begin{array}{l}\text { Vehicle } \\
\text { Minutes } \\
\text { (min) }\end{array}$ & $\begin{array}{c}\text { Cumulative } \\
\text { Average Travel } \\
\text { Tinue I95 and all } \\
\text { Ramps (min-veh } \\
\text { mile) }\end{array}$ & $\begin{array}{c}\text { Vehicle } \\
\text { Miles } \\
\text { Traveled } \\
\text { (miles) }\end{array}$ & $\begin{array}{c}\text { Vehicle } \\
\text { Minutes } \\
\text { (min) }\end{array}$ & $\begin{array}{c}\text { Cumulative } \\
\text { Average Travel } \\
\text { Time RT10 } \\
\text { and all Ramps } \\
\text { (mph) }\end{array}$ & $\begin{array}{c}\text { Cumulative } \\
\text { Network } \\
\text { Average Travel } \\
\text { Time (min / veh } \\
\text { mile) }\end{array}$ \\
\hline Random Seed Number & A & B & $C=B / A$ & D & $\mathrm{E}$ & $F=E / D$ & $\begin{array}{c}G=(B+E) /(A \\
+D)\end{array}$ \\
\hline 1 & 26330.8 & 85066.5 & 3.23 & 7374.6 & 7706.9 & 1.05 & 2.75 \\
\hline 33 & 28783.6 & 49829.7 & 1.73 & 7222.3 & 7547.1 & 1.04 & 1.59 \\
\hline 99 & 28587.1 & 51391.3 & 1.80 & 7215.2 & 7434.2 & 1.03 & 1.64 \\
\hline Curmulative Average Travel Speed & & & 2.23 & & & 1.04 & 1.98 \\
\hline
\end{tabular}




\begin{tabular}{|c|c|c|c|c|c|c|c|}
\hline \multirow{2}{*}{ Network Description } & \multicolumn{6}{|c|}{ Simulation Set Number } & 9 \\
\hline & \multicolumn{3}{|c|}{ Interstate 95 North } & \multicolumn{3}{|c|}{ Highway Route 10} & \\
\hline $\begin{array}{l}\text { 1/2 Peak AM Volume; 0\% Diversion; } \\
\text { L Lane Block; } 40 \mathrm{Min} \text { In }\end{array}$ & $\begin{array}{l}\text { Vehicle } \\
\text { Miles } \\
\text { Traveled } \\
\text { (miles) }\end{array}$ & $\begin{array}{l}\text { Vehicle } \\
\text { Minutes } \\
\text { (min) }\end{array}$ & $\begin{array}{c}\text { Cumulative } \\
\text { Average Travel } \\
\text { Time I95 and all } \\
\text { Ramps (min-veh } \\
\text { mile) }\end{array}$ & $\begin{array}{l}\text { Vehicle } \\
\text { Miles } \\
\text { Traveled } \\
\text { (miles) }\end{array}$ & $\begin{array}{l}\text { Vehicle } \\
\text { Minutes } \\
\text { (min) }\end{array}$ & $\begin{array}{c}\text { Cumulative } \\
\text { Average Travel } \\
\text { Time RT10 } \\
\text { and all Ramps } \\
\text { (mph) }\end{array}$ & $\begin{array}{c}\text { Cumulative } \\
\text { Network } \\
\text { Average Travel } \\
\text { Time (min / veh } \\
\text { mile) }\end{array}$ \\
\hline Random Seed Number & A & B & $C=B / A$ & $\mathrm{D}$ & $\mathbf{E}$ & $F=E / D$ & $\begin{array}{c}\mathrm{G}=(\mathrm{B}+\mathrm{E}) /(\mathrm{A} \\
+\mathrm{D})\end{array}$ \\
\hline 1 & 28688.4 & 132992.5 & 4.64 & 7310.7 & 7621.6 & 1.04 & 3.91 \\
\hline 33 & 28825.0 & 68640.4 & 2.38 & 7305.2 & 7627.7 & 1.04 & 2.11 \\
\hline 99 & 28684.7 & 75715.1 & 2.64 & 7191.6 & 7488.7 & 1.04 & 2.32 \\
\hline Cumulative Average Travel Speed & & & 3.22 & & & 1.04 & 2.78 \\
\hline \multirow{2}{*}{ Network Description } & \multicolumn{6}{|c|}{ Simulation Set Number } & 10 \\
\hline & \multicolumn{3}{|c|}{ Interstate 95 North } & \multicolumn{3}{|c|}{ Highway Route 10} & \\
\hline $\begin{array}{l}\text { 12) Peak AM Volume; } 20 \% \\
\text { plitwasion; } 1 \text { Lane Block; } 20 \text { Min In }\end{array}$ & $\begin{array}{l}\text { Vehicle } \\
\text { Miles } \\
\text { Traveled } \\
\text { (miles) }\end{array}$ & $\begin{array}{l}\text { Vehicle } \\
\text { Minutes } \\
\text { (min) }\end{array}$ & $\begin{array}{c}\text { Cumulative } \\
\text { Average Travel } \\
\text { Time } 195 \text { and all } \\
\text { Ranps (min-veh } \\
\text { mile) }\end{array}$ & $\begin{array}{l}\text { Vehicle } \\
\text { Miles } \\
\text { Traveled } \\
\text { (miles) }\end{array}$ & $\begin{array}{c}\text { Vehicle } \\
\text { Minutes } \\
\text { (min) }\end{array}$ & $\begin{array}{c}\text { Cumulative } \\
\text { Average Travel } \\
\text { Time RT10 } \\
\text { and all Ramps } \\
\text { (mph) }\end{array}$ & $\begin{array}{c}\text { Cumulative } \\
\text { Network } \\
\text { Average Travel } \\
\text { Time (min / vel } \\
\text { mile) }\end{array}$ \\
\hline Random Seed Number & A & B & $C=B / A$ & D & E & $F=E / D$ & $\begin{array}{c}G=(B+E) /(A \\
+D)\end{array}$ \\
\hline 1 & 28378.1 & 27628.3 & 0.97 & 7756.4 & 8120.0 & 1.05 & 0.99 \\
\hline 33 & 28288.0 & 27468.5 & 0.97 & 7655.0 & 8010.0 & 1.05 & 0.99 \\
\hline 99 & 28116.6 & 28002.3 & 1.00 & 7717.4 & 8074.8 & 1.05 & 1.01 \\
\hline Cumulative Average Travel Speed & & & 0.98 & & & 1.05 & 0.99 \\
\hline \multirow{2}{*}{ Network Description } & \multicolumn{6}{|c|}{ Simulation Set Nunber } & 11 \\
\hline & \multicolumn{3}{|c|}{ Interstate 95 North } & \multicolumn{3}{|c|}{ Highway Route 10} & \\
\hline $\begin{array}{l}1 / 2 \text { Peak AM Volume; } 20 \% \\
\text { Dibression; } 1 \text { Lane Block; } 30 \text { Min In }\end{array}$ & $\begin{array}{l}\text { Vehicle } \\
\text { Miles } \\
\text { Traveled } \\
\text { (miles) }\end{array}$ & $\begin{array}{l}\text { Vehicle } \\
\text { Minutes } \\
\text { (min) }\end{array}$ & $\begin{array}{c}\text { Cumulative } \\
\text { Average Travel } \\
\text { Tine } 195 \text { and all } \\
\text { Ramps (min-veh } \\
\text { mile) }\end{array}$ & $\begin{array}{c}\text { Vehicle } \\
\text { Miles } \\
\text { Traveled } \\
\text { (miles) }\end{array}$ & $\begin{array}{l}\text { Vehicle } \\
\text { Minutes } \\
\text { (min) }\end{array}$ & $\begin{array}{c}\text { Cumulative } \\
\text { Average Travel } \\
\text { Time RT10 } \\
\text { and all Ramps } \\
\text { (mph) }\end{array}$ & $\begin{array}{c}\text { Cumulative } \\
\text { Network } \\
\text { Average Travel } \\
\text { Time (min / veh } \\
\text { mile) }\end{array}$ \\
\hline Random Seed Number & A & B & $C=B / A$ & $\mathrm{D}$ & $\mathrm{E}$ & $F=E / D$ & $\begin{array}{c}G=(B+E) /(A \\
+D)\end{array}$ \\
\hline 1 & 27746.5 & 27030.4 & 0.97 & 8069.5 & 8440.2 & 1.05 & 0.99 \\
\hline 33 & 27982.1 & 27271.5 & 0.97 & 7913.9 & 8638.4 & 1.09 & 1.00 \\
\hline 99 & 27577.6 & 26859.0 & 0.97 & 8161.9 & 8542.3 & 1.05 & 0.99 \\
\hline Curmulative Average Travel Speed & & & 0.97 & & & 1.06 & 0.99 \\
\hline \multirow{2}{*}{ Network Description } & & & & & Simulat & tion Set Nunber & 12 \\
\hline & & terstate 95 & North & & ighway Ro & ute 10 & \\
\hline $\begin{array}{l}\text { 1/2 Peak AM Volume; } 20 \% \\
\text { 9Miession; } 1 \text { Lane Block; } 40 \text { Min In }\end{array}$ & $\begin{array}{l}\text { Vehicle } \\
\text { Miles } \\
\text { Traveled } \\
\text { (miles) }\end{array}$ & $\begin{array}{c}\text { Vehicle } \\
\text { Minutes } \\
\text { (min) }\end{array}$ & $\begin{array}{c}\text { Cumulative } \\
\text { Average Travel } \\
\text { Time } 195 \text { and all } \\
\text { Ranps (min-veh } \\
\text { mile) }\end{array}$ & $\begin{array}{l}\text { Vehicle } \\
\text { Miles } \\
\text { Traveled } \\
\text { (miles) }\end{array}$ & $\begin{array}{c}\text { Vehicle } \\
\text { Minutes } \\
\text { (min) }\end{array}$ & $\begin{array}{c}\text { Cumulative } \\
\text { Average Travel } \\
\text { Time RT10 } \\
\text { and all Ramps } \\
\text { (mph) }\end{array}$ & $\begin{array}{c}\text { Cumulative } \\
\text { Network } \\
\text { Average Travel } \\
\text { Time (min / veh } \\
\text { mile) }\end{array}$ \\
\hline Random Seed Number & A & B & $C=B / A$ & $\mathrm{D}$ & $\mathbf{E}$ & $F=E / D$ & $\begin{array}{c}\mathrm{G}=(\mathrm{B}+\mathrm{E}) /(\mathrm{A} \\
+\mathrm{D})\end{array}$ \\
\hline 1 & 27415.1 & 26737.1 & 0.98 & 8337.6 & 8701.2 & 1.04 & 0.99 \\
\hline 33 & 27154.4 & 26516.8 & 0.98 & 8308.5 & 8695.2 & 1.05 & 0.99 \\
\hline 99 & 27241.7 & 26578.1 & 0.98 & 8419.4 & 8814.6 & 1.05 & 0.99 \\
\hline Cumulative Average Travel Speed & & & 0.98 & & & 1.05 & 0.99 \\
\hline
\end{tabular}




\begin{tabular}{|c|c|c|c|c|c|c|c|}
\hline \multirow{2}{*}{ Network Description } & \multicolumn{6}{|c|}{ Simulation Set Number } & 13 \\
\hline & \multicolumn{3}{|c|}{ Interstate 95 North } & \multicolumn{3}{|c|}{ Highway Route 10} & \\
\hline $\begin{array}{l}\text { If. Peak AM Volume; } 20 \% \\
\text { Thinersion; } 2 \text { Lane Block; } 20 \text { Min In }\end{array}$ & $\begin{array}{l}\text { Vehicle } \\
\text { Miles } \\
\text { Traveled } \\
\text { (miles) }\end{array}$ & $\begin{array}{l}\text { Vehicle } \\
\text { Minules } \\
\text { (min) }\end{array}$ & $\begin{array}{c}\text { Cumulative } \\
\text { Average Travel } \\
\text { Time } 195 \text { and all } \\
\text { Ramps (min-veh } \\
\text { mile) }\end{array}$ & $\begin{array}{l}\text { Vehicle } \\
\text { Miles } \\
\text { Traveled } \\
\text { (miles) }\end{array}$ & $\begin{array}{l}\text { Vehicle } \\
\text { Minutes } \\
\text { (min) }\end{array}$ & $\begin{array}{c}\text { Cumulative } \\
\text { Average Travel } \\
\text { Time RT10 } \\
\text { and all Ramps } \\
\text { (mph) }\end{array}$ & $\begin{array}{c}\text { Cumulative } \\
\text { Network } \\
\text { Average Travel } \\
\text { Time (min / veh } \\
\text { mile) }\end{array}$ \\
\hline Random Seed Number & A & B & $\mathrm{C}=\mathrm{B} / \mathrm{A}$ & D & E & $F=E / D$ & $\begin{array}{c}G=(B+E) /(A \\
+D)\end{array}$ \\
\hline 1 & 28114.3 & 27673.7 & 0.98 & 7756.4 & 8120.0 & 1.05 & 1.00 \\
\hline 33 & 28128.9 & 27520.7 & 0.98 & 7655.0 & 8010.0 & 1.05 & 0.99 \\
\hline 99 & 27950.3 & 27360.3 & 0.98 & 7717.4 & 8074.8 & 1.05 & 0.99 \\
\hline Cumulative Average Travel Speed & & & 0.98 & & & 1.05 & 0.99 \\
\hline \multirow{2}{*}{ Network Description } & \multicolumn{6}{|c|}{ Simulation Set Number } & 14 \\
\hline & \multicolumn{3}{|c|}{ Interstate 95 North } & \multicolumn{3}{|c|}{ Highway Roure 10} & \\
\hline $\begin{array}{l}1 / 2 \text { Peak AM Volume; } 20 \% \\
\text { Bikersion; } 2 \text { Lane Block; } 30 \text { Min In }\end{array}$ & $\begin{array}{l}\text { Vehicle } \\
\text { Miles } \\
\text { Traveled } \\
\text { (miles) }\end{array}$ & $\begin{array}{c}\text { Vehicle } \\
\text { Minutes } \\
\text { (min) }\end{array}$ & $\begin{array}{c}\text { Cumulative } \\
\text { Average Travel } \\
\text { Time } 195 \text { and all } \\
\text { Ranps (nin-veh } \\
\text { mile) }\end{array}$ & $\begin{array}{l}\text { Vehicle } \\
\text { Miles } \\
\text { Traveled } \\
\text { (miles) }\end{array}$ & $\begin{array}{c}\text { Vehicle } \\
\text { Minutes } \\
\text { (min) }\end{array}$ & $\begin{array}{c}\text { Cumulative } \\
\text { Average Travel } \\
\text { Time RT10 } \\
\text { and all Ramps } \\
\text { (mph) }\end{array}$ & $\begin{array}{c}\text { Cumulative } \\
\text { Network } \\
\text { Average Travel } \\
\text { Time (min / veh } \\
\text { mile) }\end{array}$ \\
\hline Random Seed Number & A & B & $\mathrm{C}=\mathrm{B} / \mathrm{A}$ & D & E & $F=E / D$ & $\begin{array}{c}G=(B+E) /(A \\
+D)\end{array}$ \\
\hline 1 & 27846.4 & 27452.0 & 0.99 & 8069.5 & 8440.2 & 1.05 & 1.00 \\
\hline 33 & 27799.1 & 27312.8 & 0.98 & 7913.9 & 8638.4 & 1.09 & 1.01 \\
\hline 99 & 27765.3 & 27270.0 & 0.98 & 8161.9 & 8542.3 & 1.05 & 1.00 \\
\hline Curnulative Average Travel Speed & & & 0.98 & & & 1.06 & 1.00 \\
\hline \multirow{2}{*}{ Network Description } & \multicolumn{6}{|c|}{ Simulation Set Number } & 15 \\
\hline & \multicolumn{3}{|c|}{ Interstate 95 North } & \multicolumn{3}{|c|}{ Highway Route 10} & \\
\hline $\begin{array}{l}\text { 12. Peak AM Volume; } 20 \% \\
\text { Diversion; } 2 \text { Lane Block; } 40 \text { Min In }\end{array}$ & $\begin{array}{l}\text { Vehicle } \\
\text { Miles } \\
\text { Traveled } \\
\text { (miles) }\end{array}$ & $\begin{array}{c}\text { Vehicle } \\
\text { Minutes } \\
\text { (min) }\end{array}$ & $\begin{array}{c}\text { Cumulative } \\
\text { Average Travel } \\
\text { Time I95 and all } \\
\text { Ramps (nin-veh } \\
\text { mile) }\end{array}$ & $\begin{array}{c}\text { Vehicle } \\
\text { Miles } \\
\text { Traveled } \\
\text { (miles) }\end{array}$ & $\begin{array}{l}\text { Vehicle } \\
\text { Minutes } \\
\text { (min) }\end{array}$ & $\begin{array}{c}\text { Cumulative } \\
\text { Average Travel } \\
\text { Time RT10 } \\
\text { and all Ramps } \\
\text { (mph) }\end{array}$ & $\begin{array}{c}\text { Cumulative } \\
\text { Network } \\
\text { Average Travel } \\
\text { Time (min / veh } \\
\text { mile) }\end{array}$ \\
\hline Random Seed Number & A & B & $\mathrm{C}=\mathrm{B} / \mathrm{A}$ & D & E & $F=E / D$ & $\begin{array}{c}G=(B+E) /(A \\
+D)\end{array}$ \\
\hline 1 & 27329.7 & 26925.7 & 0.99 & 8337.6 & 8701.2 & 1.04 & 1.00 \\
\hline 33 & 27169.7 & 26714.3 & 0.98 & 8308.5 & 8695.2 & 1.05 & 1.00 \\
\hline 99 & 27103.1 & 26674.2 & 0.98 & 8419.4 & $88 I 4.6$ & 1.05 & 1.00 \\
\hline Cumulative Average Travel Speed & & & 0.98 & & & 1.05 & 1.00 \\
\hline \multirow{2}{*}{ Network Description } & \multicolumn{6}{|c|}{ Simulation Set Number } & 16 \\
\hline & \multicolumn{3}{|c|}{ Interstate 95 North } & \multicolumn{3}{|c|}{ Highway Route 10} & \\
\hline $\begin{array}{l}\text { 1/2 Peak AM Volume; } 20 \% \\
\text { Ditursion; } 3 \text { Lane Block; } 20 \text { Min In }\end{array}$ & $\begin{array}{l}\text { Vehicle } \\
\text { Miles } \\
\text { Traveled } \\
\text { (miles) }\end{array}$ & $\begin{array}{c}\text { Vehicle } \\
\text { Minutes } \\
\text { (min) }\end{array}$ & $\begin{array}{c}\text { Cumulative } \\
\text { Average Travel } \\
\text { Time I95 and all } \\
\text { Ramps (min-veh } \\
\text { mile) }\end{array}$ & $\begin{array}{l}\text { Vehicle } \\
\text { Miles } \\
\text { Traveled } \\
\text { (miles) }\end{array}$ & $\begin{array}{c}\text { Vehicle } \\
\text { Minutes } \\
\text { (min) }\end{array}$ & $\begin{array}{c}\text { Cumulative } \\
\text { Average Travel } \\
\text { Time RTI0 } \\
\text { and all Ramps } \\
\text { (mph) }\end{array}$ & $\begin{array}{c}\text { Cumulative } \\
\text { Network } \\
\text { Average Travel } \\
\text { Time (min / veh } \\
\text { mile) }\end{array}$ \\
\hline Random Seed Number & A & B & $C=B / A$ & D & E & $F=E / D$ & $\begin{array}{c}G=(B+E) /(A \\
+D)\end{array}$ \\
\hline 1 & 28050.9 & 34400.4 & 1.23 & 7756.4 & 8120.0 & 1.05 & 1.19 \\
\hline 33 & 28086.3 & 46748.2 & 1.66 & 7655.0 & 8010.0 & 1.05 & 1.53 \\
\hline 99 & 28017.1 & 35132.9 & 1.25 & 7717.4 & 8074.8 & 1.05 & 1.21 \\
\hline Cumulative Average Travel Speed & & & 1.38 & & & 1.05 & 1.31 \\
\hline
\end{tabular}




\begin{tabular}{|c|c|c|c|c|c|c|c|}
\hline \multirow{2}{*}{ Network Description } & \multicolumn{6}{|c|}{ Simulation Set Number } & 17 \\
\hline & \multicolumn{3}{|c|}{ Interstate 95 North } & \multicolumn{3}{|c|}{ Highway Route 10} & \\
\hline $\begin{array}{l}\text { 1/2 Peak AM Volume; } 20 \% \\
\text { Diversion; } 3 \text { Lane Block; } 30 \text { Min In }\end{array}$ & $\begin{array}{l}\text { Vehicle } \\
\text { Miles } \\
\text { Traveled } \\
\text { (miles) }\end{array}$ & $\begin{array}{c}\text { Vehicle } \\
\text { Minutes } \\
\text { (min) }\end{array}$ & $\begin{array}{c}\text { Cumulative } \\
\text { Average Travel } \\
\text { Tine } 195 \text { and all } \\
\text { Ramps (min-veh } \\
\text { mile) }\end{array}$ & $\begin{array}{l}\text { Vehicle } \\
\text { Miles } \\
\text { Traveled } \\
\text { (miles) }\end{array}$ & $\begin{array}{l}\text { Vehicle } \\
\text { Minutes } \\
\text { (min) }\end{array}$ & $\begin{array}{c}\text { Cumulative } \\
\text { Average Travel } \\
\text { Time RT10 } \\
\text { and all Ramps } \\
\text { (mph) }\end{array}$ & $\begin{array}{c}\text { Cumulative } \\
\text { Network } \\
\text { Average Travel } \\
\text { Time (min / veh } \\
\text { mile) }\end{array}$ \\
\hline Random Seed Number & A & B & $\mathrm{C}=\mathrm{B} / \mathrm{A}$ & D & E & $F=E / D$ & $\begin{array}{c}G=(B+E) /(A \\
+D)\end{array}$ \\
\hline 1 & 27676.1 & 41944.4 & 1.52 & 8069.5 & 8440.2 & 1.05 & 1.41 \\
\hline 33 & 27785.7 & 74346.5 & 2.68 & 7913.9 & 8638.4 & 1.09 & 2.32 \\
\hline 99 & 27785.7 & 74346.5 & 2.68 & 8161.9 & 8542.3 & 1.05 & $2.3 \mathrm{I}$ \\
\hline Cumulative Average Travel Speed & & & 2.29 & & & 1.06 & 2.01 \\
\hline \multirow{2}{*}{ Network Description } & \multicolumn{6}{|c|}{ Simulation Set Number } & 18 \\
\hline & \multicolumn{3}{|c|}{ Interstate 95 North } & \multicolumn{3}{|c|}{ Highway Route 10} & \\
\hline $\begin{array}{l}1 / 2 \text { Peak AM Volume; } 20 \% \\
\text { Tiversion; } 3 \text { Lane Block; } 40 \text { Min In }\end{array}$ & $\begin{array}{l}\text { Vehicle } \\
\text { Miles } \\
\text { Traveled } \\
\text { (miles) }\end{array}$ & $\begin{array}{c}\text { Vehicle } \\
\text { Minutes } \\
\text { (min) }\end{array}$ & $\begin{array}{c}\text { Cumulative } \\
\text { Average Travel } \\
\text { Time I95 and all } \\
\text { Ramps (min-veh } \\
\text { mile) }\end{array}$ & $\begin{array}{l}\text { Vehicle } \\
\text { Miles } \\
\text { Traveled } \\
\text { (miles) }\end{array}$ & $\begin{array}{c}\text { Vehicle } \\
\text { Minutes } \\
\text { (min) }\end{array}$ & $\begin{array}{c}\text { Cumulative } \\
\text { Average Travel } \\
\text { Time RT10 } \\
\text { and all Ramps } \\
\text { (mph) }\end{array}$ & $\begin{array}{c}\text { Cumulative } \\
\text { Network } \\
\text { Average Travel } \\
\text { Time (min / veh } \\
\text { mile) }\end{array}$ \\
\hline Random Seed Number & A & B & $C=B / A$ & D & E & $F=E / D$ & $\begin{array}{c}G=(B+E) /(A \\
+D)\end{array}$ \\
\hline 1 & 46711.5 & 178909.1 & 3.83 & 8337.6 & 8701.2 & 1.04 & 3.41 \\
\hline 33 & 46028.9 & 179016.2 & 3.89 & 8308.5 & 8695.2 & 1.05 & 3.45 \\
\hline 99 & 46653.4 & 159184.5 & 3.41 & 8419.4 & 8814.6 & 1.05 & 3.05 \\
\hline Cumulative Average Travel Speed & & & 3.71 & & & 1.05 & 3.30 \\
\hline
\end{tabular}




\begin{tabular}{|c|c|c|c|c|c|c|c|}
\hline \multirow{2}{*}{ Network Description } & \multicolumn{6}{|c|}{ Simulation Set Number } & 1 \\
\hline & \multicolumn{3}{|c|}{ Interstate 95 North } & \multicolumn{3}{|c|}{ Highway Route 10} & \\
\hline $\begin{array}{l}\text { 1/2 Peak AM Volume; } 0 \% \\
\text { Diversion; } 1 \text { Lane Block; } 20 \text { Min } \\
\text { to }\end{array}$ & $\begin{array}{l}\text { Vehicle } \\
\text { Miles } \\
\text { Traveled } \\
\text { (miles) }\end{array}$ & $\begin{array}{l}\text { Total } \\
\text { Delay } \\
\text { (min) }\end{array}$ & $\begin{array}{c}\text { Average } \\
\text { Delay Time } \\
195 \text { and all } \\
\text { Ramps (mir- } \\
\text { veh mile) }\end{array}$ & $\begin{array}{l}\text { Vehicle } \\
\text { Miles } \\
\text { Traveled } \\
\text { (miles) }\end{array}$ & $\begin{array}{l}\text { Total } \\
\text { Delay } \\
\text { (min) }\end{array}$ & $\begin{array}{c}\text { Average } \\
\text { Delay Time } \\
\text { RT10 and all } \\
\text { Ramps (min } \\
\text { / veh mile) }\end{array}$ & $\begin{array}{l}\text { Total Network } \\
\text { Delay (hours) }\end{array}$ \\
\hline Random Seed Number & A & B & $C=B / A$ & $\mathrm{D}$ & E & $F=E / D$ & $\begin{array}{l}G=(B+E) / \\
{[60(\min / h r)]}\end{array}$ \\
\hline 1 & 29084.2 & 1468.70 & 0.05 & 7256.8 & 300.42 & 0.04 & 29.49 \\
\hline 33 & 28816.9 & 1413.41 & 0.05 & 7028.8 & 294.70 & 0.04 & 28.47 \\
\hline 99 & 28978.8 & 1405.92 & 0.05 & 7243.5 & 297.48 & 0.04 & 28.39 \\
\hline Curnulative Average Delay Time & & & 0.05 & & & 0.04 & 28.78 \\
\hline \multirow{2}{*}{ Network Description } & \multicolumn{6}{|c|}{ Simulation Set Number } & 2 \\
\hline & \multicolumn{3}{|c|}{ Interstate 95 North } & \multicolumn{3}{|c|}{ Highway Route 10} & \\
\hline $\begin{array}{l}\text { 12 Peak AM Volume; } 0 \% \\
\text { Divetsion; } 1 \text { Lane Block; } 30 \text { Min } \\
\text { In }\end{array}$ & $\begin{array}{l}\text { Vehicle } \\
\text { Miles } \\
\text { Traveled } \\
\text { (miles) }\end{array}$ & $\begin{array}{l}\text { Total } \\
\text { Delay } \\
\text { (min) }\end{array}$ & $\begin{array}{c}\text { Average } \\
\text { Delay Time } \\
\text { I95 and all } \\
\text { Ramps (min- } \\
\text { veh mile) }\end{array}$ & $\begin{array}{l}\text { Vehicle } \\
\text { Miles } \\
\text { Traveled } \\
\text { (miles) }\end{array}$ & $\begin{array}{l}\text { Total } \\
\text { Delay } \\
(\mathrm{min})\end{array}$ & \begin{tabular}{|c|} 
Average \\
Delay Time \\
RT10 and all \\
Ramps (min \\
/ veh mile)
\end{tabular} & $\begin{array}{l}\text { Total Network } \\
\text { Delay (hours) }\end{array}$ \\
\hline Random Seed Number & A & B & $C=B / A$ & D & E & $F=E / D$ & $\begin{array}{c}\mathrm{G}=(\mathrm{B}+\mathrm{E}) / \\
{[60(\min / \mathrm{hr})]}\end{array}$ \\
\hline 1 & 28780.2 & 1437.44 & 0.05 & 7374.6 & 308.20 & 0.04 & 29.09 \\
\hline 33 & 29160.8 & 1451.98 & 0.05 & 7222.3 & 297.68 & 0.04 & 29.16 \\
\hline 99 & 29132.2 & 1415.53 & 0.05 & 7215.2 & 290.18 & 0.04 & 28.43 \\
\hline Cumulative Average Delay Time & & & 0.05 & & & 0.04 & 28.89 \\
\hline \multirow{2}{*}{ Network Description } & \multicolumn{6}{|c|}{ Símulation Set Number } & 3 \\
\hline & \multicolumn{3}{|c|}{ Interstate 95 North } & \multicolumn{3}{|c|}{ Highway Route 10} & \\
\hline $\begin{array}{l}\text { 1/2 Peak AM Volume; } 0 \% \\
\text { Dinession; } 1 \text { Lane Block; } 40 \text { Min } \\
\text { in }\end{array}$ & $\begin{array}{l}\text { Vehicle } \\
\text { Miles } \\
\text { Traveled } \\
\text { (miles) }\end{array}$ & $\begin{array}{l}\text { Total } \\
\text { Delay } \\
\text { (min) }\end{array}$ & $\begin{array}{c}\text { Average } \\
\text { Delay Time } \\
195 \text { and all } \\
\text { Ramps (min- } \\
\text { veh mile) }\end{array}$ & $\begin{array}{l}\text { Vehicle } \\
\text { Miles } \\
\text { Traveled } \\
\text { (miles) }\end{array}$ & $\begin{array}{l}\text { Total } \\
\text { Delay } \\
\text { (min) }\end{array}$ & $\begin{array}{c}\text { Average } \\
\text { Delay Time } \\
\text { RT10 and all } \\
\text { Ramps (min } \\
\text { / veh mile) }\end{array}$ & $\begin{array}{l}\text { Total Network } \\
\text { Delay (hours) }\end{array}$ \\
\hline Random Seed Number & A & B & $C=B / A$ & D & E & $F=E / D$ & $\begin{array}{l}G=(B+E) / \\
{[60(\min / \mathrm{hr})]}\end{array}$ \\
\hline 1 & 28906.8 & 1462.93 & 0.05 & 7310.7 & 302.76 & 0.04 & 29.43 \\
\hline 33 & 28872.6 & 1450.24 & 0.05 & 7305.2 & 299.06 & 0.04 & 29.16 \\
\hline 99 & 28838.9 & 1411.81 & 0.05 & 7191.6 & 287.72 & 0.04 & 28.33 \\
\hline Cumulative Average Delay Time & & & 0.05 & & & 0.04 & 28.97 \\
\hline \multirow{2}{*}{ Network Description } & \multicolumn{6}{|c|}{ Simulation Set Number } & 4 \\
\hline & \multicolumn{3}{|c|}{ Interstate 95 North } & \multicolumn{3}{|c|}{ Highway Route 10} & \\
\hline $\begin{array}{l}\text { Pas Peak AM Volume; } 0 \% \\
\text { Dinasion; } 2 \text { Lane Block; } 20 \text { Min } \\
\text { In }\end{array}$ & $\begin{array}{l}\text { Vehicle } \\
\text { Miles } \\
\text { Traveled } \\
\text { (miles) }\end{array}$ & $\begin{array}{l}\text { Total } \\
\text { Delay } \\
\text { (min) }\end{array}$ & $\begin{array}{c}\text { Average } \\
\text { Delay Time } \\
195 \text { and all } \\
\text { Ramps (min- } \\
\text { veh mile) }\end{array}$ & $\begin{array}{l}\text { Vehicle } \\
\text { Miles } \\
\text { Traveled } \\
\text { (miles) }\end{array}$ & $\begin{array}{l}\text { Total } \\
\text { Delay } \\
\text { (min) }\end{array}$ & $\begin{array}{c}\text { Average } \\
\text { Delay Time } \\
\text { RT10 and all } \\
\text { Ramps (min } \\
\text { / veh mile) }\end{array}$ & $\begin{array}{l}\text { Total Network } \\
\text { Delay (hours) }\end{array}$ \\
\hline Random Seed Number & A & B & $C=B / A$ & D & $\mathbf{E}$ & $F=E / D$ & $\begin{array}{c}\mathrm{G}=(\mathrm{B}+\mathrm{E}) / \\
{[60(\min / \mathrm{hr})]}\end{array}$ \\
\hline 1 & 29084.2 & 1468.70 & 0.05 & 7256.8 & 300.4 & 0.04 & 29.49 \\
\hline 33 & 28122.4 & 1456.21 & 0.05 & 7028.8 & 294.7 & 0.04 & 29.18 \\
\hline 99 & 28978.8 & 1405.92 & 0.05 & 7243.5 & 297.5 & 0.04 & 28.39 \\
\hline Cumulative Average Delay Tìne & & & 0.05 & & & 0.04 & 29.02 \\
\hline
\end{tabular}




\begin{tabular}{|c|c|c|c|c|c|c|c|}
\hline \multirow{2}{*}{ Network Description } & \multicolumn{6}{|c|}{ Simulation Set Number } & 5 \\
\hline & \multicolumn{3}{|c|}{ Interstate 95 North } & \multicolumn{3}{|c|}{ Highway Route 10} & \\
\hline $\begin{array}{l}\text { 1/2 Peak AM Volume; } 0 \% \\
\text { lus }\end{array}$ & $\begin{array}{l}\text { Vehicle } \\
\text { Miles } \\
\text { Traveled } \\
\text { (miles) }\end{array}$ & $\begin{array}{l}\text { Total } \\
\text { Delay } \\
\text { (min) }\end{array}$ & $\begin{array}{c}\text { Average } \\
\text { Delay Time } \\
195 \text { and all } \\
\text { Ramps (min- } \\
\text { veh mile) }\end{array}$ & $\begin{array}{l}\text { Vehicle } \\
\text { Miles } \\
\text { Traveled } \\
\text { (miles) }\end{array}$ & $\begin{array}{l}\text { Total } \\
\text { Delay } \\
\text { (min) }\end{array}$ & \begin{tabular}{|c|} 
Average \\
Delay Time \\
RT10 and all \\
Ramps (min \\
/ veh mile)
\end{tabular} & $\begin{array}{l}\text { Total Network } \\
\text { Delay (hours) }\end{array}$ \\
\hline Random Seed Number & A & B & $C=B / A$ & $\mathrm{D}$ & $\mathbf{E}$ & $F=E / D$ & $\begin{array}{l}G=(B+E) / \\
{[60(\min / h r)]}\end{array}$ \\
\hline 1 & 28869.9 & 1706.23 & 0.06 & 7374.6 & 308.20 & 0.04 & 33.57 \\
\hline 33 & 29046.0 & 1757.61 & 0.06 & 7222.3 & 297.68 & 0.04 & 34.25 \\
\hline 99 & 29034.5 & 1731.46 & 0.06 & 7215.2 & 290.18 & 0.04 & 33.69 \\
\hline Cumulative Average Delay Time & & & 0.06 & & & 0.04 & 33.84 \\
\hline \multirow{2}{*}{ Network Description } & \multicolumn{6}{|c|}{ Simulation Set Number } & 6 \\
\hline & \multicolumn{3}{|c|}{ Interstate 95 North } & \multicolumn{3}{|c|}{ Highway Route 10} & \\
\hline $\begin{array}{l}\text { 1/2 Peak AM Volume; } 0 \% \\
\text { Diversion; } 2 \text { Lane Block; } 40 \text { Min } \\
\text { hit }\end{array}$ & $\begin{array}{l}\text { Vehicle } \\
\text { Miles } \\
\text { Traveled } \\
\text { (miles) }\end{array}$ & $\begin{array}{l}\text { Total } \\
\text { Delay } \\
\text { (min) }\end{array}$ & $\begin{array}{l}\text { Average } \\
\text { Delay Time } \\
\text { I95 and all } \\
\text { Ramps (min- } \\
\text { veh mile) }\end{array}$ & $\begin{array}{l}\text { Vehicle } \\
\text { Miles } \\
\text { Traveled } \\
\text { (miles) }\end{array}$ & $\begin{array}{l}\text { Total } \\
\text { Delay } \\
\text { (min) }\end{array}$ & \begin{tabular}{|c|} 
Average \\
Delay Time \\
RT10 and all \\
Ramps (min \\
/ veh mile)
\end{tabular} & $\begin{array}{l}\text { Total Network } \\
\text { Delay (hours) }\end{array}$ \\
\hline Random Seed Number & A & B & $C=B / A$ & D & $\mathbf{E}$ & $F=E / D$ & {$\left[\begin{array}{c}G=(B+E) / \\
{[60(\min / \mathrm{hr})]}\end{array}\right]$} \\
\hline 1 & 28655.0 & 2095.91 & 0.07 & 7310.7 & 302.76 & 0.04 & 39.98 \\
\hline 33 & 28695.2 & 1740.06 & 0.06 & 7305.2 & 299.06 & 0.04 & 33.99 \\
\hline 99 & 28859.2 & 1860.87 & 0.06 & 7191.6 & 287.72 & 0.04 & 35.81 \\
\hline Cumulative Average Delay Time & & & 0.07 & & & 0.04 & 36.59 \\
\hline \multirow{2}{*}{ Network Description } & \multicolumn{6}{|c|}{ Simulation Set Number } & 7 \\
\hline & \multicolumn{3}{|c|}{ Interstate 95 North } & \multicolumn{3}{|c|}{ Highway Route 10} & \\
\hline $\begin{array}{l}\text { Peak AM Volume; } 0 \% \\
\text { Divarsion; } 3 \text { Lane Block; } 20 \text { Min } \\
\text { In }\end{array}$ & $\begin{array}{l}\text { Vehicle } \\
\text { Miles } \\
\text { Traveled } \\
\text { (miles) }\end{array}$ & $\begin{array}{l}\text { Total } \\
\text { Delay } \\
\text { (min) }\end{array}$ & $\begin{array}{l}\text { Average } \\
\text { Delay Time } \\
\text { 195 and all } \\
\text { Ramps (rnin- } \\
\text { veh mile) }\end{array}$ & $\begin{array}{l}\text { Vehicle } \\
\text { Miles } \\
\text { Traveled } \\
\text { (miles) }\end{array}$ & $\begin{array}{l}\text { Total } \\
\text { Delay } \\
\text { (min) }\end{array}$ & $\begin{array}{c}\text { Average } \\
\text { Delay Time } \\
\text { RT10 and all } \\
\text { Ramps (min } \\
\text { / veh mile) }\end{array}$ & $\begin{array}{l}\text { Total Network } \\
\text { Delay (hours) }\end{array}$ \\
\hline Random Seed Number & A & B & $\mathrm{C}=\mathrm{B} / \mathrm{A}$ & D & E & $F=E / D$ & $\begin{array}{c}\mathrm{G}=(\mathrm{B}+\mathrm{E}) / \\
{[60(\mathrm{~min} / \mathrm{hr})]}\end{array}$ \\
\hline 1 & 28869.2 & 16305.34 & 0.56 & 7256.8 & 300.42 & 0.04 & 276.76 \\
\hline 33 & 28854.8 & 10186.02 & 0.35 & 7028.8 & 294.70 & 0.04 & 174.68 \\
\hline 99 & 28854.8 & 10186.02 & 0.35 & 7243.5 & 297.48 & 0.04 & 174.73 \\
\hline Cumulative Average Delay Time & & & 0.42 & & & 0.04 & 208.72 \\
\hline \multirow{2}{*}{ Network Description } & \multicolumn{6}{|c|}{ Simulation Set Number } & 8 \\
\hline & \multicolumn{3}{|c|}{ Interstate 95 North } & \multicolumn{3}{|c|}{ Highway Route 10} & \\
\hline $\begin{array}{l}\text { 12. Peak AM Volume; } 0 \% \\
\text { Dhikrsion; } 3 \text { Lane Block; } 30 \mathrm{Min} \\
\text { th }\end{array}$ & $\begin{array}{l}\text { Vehicle } \\
\text { Miles } \\
\text { Traveled } \\
\text { (miles) }\end{array}$ & $\begin{array}{l}\text { Total } \\
\text { Delay } \\
\text { (min) }\end{array}$ & $\begin{array}{l}\text { Average } \\
\text { Delay Time } \\
\text { I95 and all } \\
\text { Ramps (min- } \\
\text { veh mile) }\end{array}$ & $\begin{array}{l}\text { Vehicle } \\
\text { Miles } \\
\text { Traveled } \\
\text { (miles) }\end{array}$ & $\begin{array}{l}\text { Total } \\
\text { Delay } \\
\text { (min) }\end{array}$ & $\begin{array}{c}\text { Average } \\
\text { Delay Time } \\
\text { RT10 and all } \\
\text { Ramps (min } \\
\text { / veh mile) }\end{array}$ & $\begin{array}{l}\text { Total Network } \\
\text { Delay (hours) }\end{array}$ \\
\hline Random Seed Number & A & B & $\mathrm{C}=\mathrm{B} / \mathrm{A}$ & D & E & $F=E / D$ & $\begin{array}{c}G=(B+E) / \\
{[60(\min / \mathrm{hr})]}\end{array}$ \\
\hline 1 & 26330.8 & 35662.42 & 1.35 & 7374.6 & 308.20 & 0.04 & 599.51 \\
\hline 33 & 28783.6 & 18898.18 & 0.66 & 7222.3 & 297.68 & 0.04 & 319.93 \\
\hline 99 & 28587.1 & 20269.58 & 0.71 & 7215.2 & 290.18 & 0.04 & 342.66 \\
\hline Cumulative Average Delay Time & & & 0.89 & & & 0.04 & 420.70 \\
\hline
\end{tabular}




\begin{tabular}{|c|c|c|c|c|c|c|c|}
\hline \multirow{2}{*}{ Network Description } & \multicolumn{6}{|c|}{ Simulation Set Number } & 9 \\
\hline & \multicolumn{3}{|c|}{ Interstate 95 North } & \multicolumn{3}{|c|}{ Highway Route 10} & \\
\hline $\begin{array}{l}\text { 1/2 Peak AM Volume; } 0 \% \\
\text { Damesion; } 3 \text { Lane Block; } 40 \text { Min } \\
\text { Dii }\end{array}$ & $\begin{array}{l}\text { Vehicle } \\
\text { Miles } \\
\text { Traveled } \\
\text { (miles) }\end{array}$ & $\begin{array}{l}\text { Total } \\
\text { Delay } \\
\text { (min) }\end{array}$ & $\begin{array}{c}\text { Average } \\
\text { Delay Time } \\
\text { I95 and all } \\
\text { Ramps (min- } \\
\text { veh mile) }\end{array}$ & $\begin{array}{l}\text { Vehicle } \\
\text { Miles } \\
\text { Traveled } \\
\text { (miles) }\end{array}$ & $\begin{array}{l}\text { Total } \\
\text { Delay } \\
\text { (min) }\end{array}$ & $\begin{array}{c}\text { Average } \\
\text { Delay Time } \\
\text { RT10 and all } \\
\text { Ramps (min } \\
\text { / veh mile) }\end{array}$ & $\begin{array}{l}\text { Total Network } \\
\text { Delay (hours) }\end{array}$ \\
\hline Random Seed Number & A & B & $C=B / A$ & $\mathrm{D}$ & $\mathbf{E}$ & $F=E / D$ & $\begin{array}{l}\mathrm{G}=(\mathrm{B}+\mathrm{E}) / \\
{[60(\mathrm{~min} / \mathrm{hr})]}\end{array}$ \\
\hline 1 & 28688.4 & 61496.04 & 2.14 & 7310.7 & 302.76 & 0.04 & 1029.98 \\
\hline 33 & 28825.0 & 33212.79 & 1.15 & 7305.2 & 299.06 & 0.04 & 558.53 \\
\hline 99 & 28684.7 & 37881.26 & 1.32 & 7191.6 & 287.72 & 0.04 & 636.15 \\
\hline Cumulative Average Delay Time & & & 1.54 & & & 0.04 & 741.55 \\
\hline \multirow{2}{*}{ Network Description } & \multicolumn{6}{|c|}{ Simulation Set Number } & 10 \\
\hline & \multicolumn{3}{|c|}{ Interstate 95 North } & \multicolumn{3}{|c|}{ Highway Route 10} & \\
\hline $\begin{array}{l}\text { 1/2 Peak AM Volume; } 20 \% \\
\text { Wiversion; } 1 \text { Lane Block; } 20 \text { Min } \\
\text { lin }\end{array}$ & $\begin{array}{l}\text { Vehicle } \\
\text { Miles } \\
\text { Traveled } \\
\text { (miles) }\end{array}$ & $\begin{array}{l}\text { Total } \\
\text { Delay } \\
\text { (min) }\end{array}$ & $\begin{array}{c}\text { Average } \\
\text { Delay Time } \\
195 \text { and all } \\
\text { Ramps (min- } \\
\text { veb mile) }\end{array}$ & $\begin{array}{l}\text { Vehicle } \\
\text { Miles } \\
\text { Traveled } \\
\text { (miles) }\end{array}$ & $\begin{array}{l}\text { Total } \\
\text { Delay } \\
\text { (min) }\end{array}$ & $\begin{array}{c}\text { Average } \\
\text { Delay Time } \\
\text { RT10 and all } \\
\text { Ramps (min } \\
\text { / veh mile) }\end{array}$ & $\begin{array}{c}\text { Total Network } \\
\text { Delay (hours) }\end{array}$ \\
\hline Random Seed Number & A & B & $\mathrm{C}=\mathrm{B} / \mathrm{A}$ & D & $\mathbf{E}$ & $F=E / D$ & $\begin{array}{c}G=(B+E) / \\
{[60(\min / \mathrm{hr})]}\end{array}$ \\
\hline 1 & 28378.1 & 1426.17 & 0.05 & 7756.4 & 331.42 & 0.04 & 29.29 \\
\hline 33 & 28288.0 & 1314.90 & 0.05 & 7655.0 & 325.06 & 0.04 & 27.33 \\
\hline 99 & 28116.6 & 1357.60 & 0.05 & 7717.4 & 326.29 & 0.04 & 28.06 \\
\hline Cumulative Average Delay Time & & & 0.05 & & & 0.04 & 28.23 \\
\hline \multirow{2}{*}{ Network Description } & \multicolumn{6}{|c|}{ Simulation Set Number } & 11 \\
\hline & \multicolumn{3}{|c|}{ Interstate 95 North } & \multicolumn{3}{|c|}{ Highway Route 10} & \\
\hline $\begin{array}{l}1 / 2 \text { Peak AM Volume; } 20 \% \\
\text { in } \\
\text { in }\end{array}$ & $\begin{array}{l}\text { Vehicle } \\
\text { Miles } \\
\text { Traveled } \\
\text { (miles) }\end{array}$ & $\begin{array}{l}\text { Total } \\
\text { Delay } \\
\text { (min) }\end{array}$ & $\begin{array}{c}\text { Average } \\
\text { Delay Time } \\
195 \text { and all } \\
\text { Ramps (min- } \\
\text { veh mile) }\end{array}$ & $\begin{array}{l}\text { Vehicle } \\
\text { Miles } \\
\text { Traveled } \\
\text { (miles) }\end{array}$ & $\begin{array}{l}\text { Total } \\
\text { Delay } \\
\text { (min) }\end{array}$ & $\begin{array}{c}\text { Average } \\
\text { Delay Time } \\
\text { RT10 and all } \\
\text { Ranps (min } \\
\text { / veb mile) }\end{array}$ & $\begin{array}{l}\text { Total Network } \\
\text { Delay (hours) }\end{array}$ \\
\hline Random Seed Number & A & B & $C=B / A$ & D & E & $F=E / D$ & $\begin{array}{c}\mathrm{G}=(\mathrm{B}+\mathrm{E}) / \\
{[60(\mathrm{~min} / \mathrm{hr})]}\end{array}$ \\
\hline 1 & 27746.5 & 1290.72 & 0.05 & 8069.5 & 346.89 & 0.04 & 27.29 \\
\hline 33 & 27982.1 & 1304.93 & 0.05 & 7913.9 & 530.74 & 0.07 & 30.59 \\
\hline 99 & 27577.6 & 1273.16 & 0.05 & 8161.9 & 360.51 & 0.04 & 27.23 \\
\hline Cumulative Average Delay Time & & & 0.05 & & & 0.05 & 28.37 \\
\hline \multirow{2}{*}{ Network Description } & \multicolumn{6}{|c|}{ Simulation Set Number } & 12 \\
\hline & \multicolumn{3}{|c|}{ Interstate 95 North } & \multicolumn{3}{|c|}{ Highway Route 10} & \\
\hline $\begin{array}{l}\text { 1/2 Peak AM Volume; } 20 \% \\
\text { Dituersion; } 1 \text { Lane Block; } 40 \text { Min } \\
\text { fn }\end{array}$ & $\begin{array}{l}\text { Vehicle } \\
\text { Miles } \\
\text { Traveled } \\
\text { (miles) }\end{array}$ & $\begin{array}{l}\text { Total } \\
\text { Delay } \\
\text { (min) }\end{array}$ & $\begin{array}{l}\text { Average } \\
\text { Delay Time } \\
\text { I95 and all } \\
\text { Ramps (min- } \\
\text { veb mile) }\end{array}$ & $\begin{array}{l}\text { Vehicle } \\
\text { Miles } \\
\text { Traveled } \\
\text { (miles) }\end{array}$ & $\begin{array}{l}\text { Total } \\
\text { Delay } \\
\text { (min) }\end{array}$ & $\begin{array}{c}\text { Average } \\
\text { Delay Time } \\
\text { RT10 and all } \\
\text { Ramps (min } \\
\text { / veh mile) }\end{array}$ & $\begin{array}{l}\text { Total Network } \\
\text { Delay (hours) }\end{array}$ \\
\hline Random Seed Number & A & B & $C=B / A$ & D & $E$ & $F=E / D$ & $\begin{array}{c}G=(B+E) / \\
{[60(\min / h r)]}\end{array}$ \\
\hline 1 & 27415.1 & 1275.34 & 0.05 & 8337.6 & 359.80 & 0.04 & 27.25 \\
\hline 33 & 27154.4 & 1310.45 & 0.05 & 8308.5 & 360.58 & 0.04 & 27.85 \\
\hline 99 & 27241.7 & 1266.32 & 0.05 & 8419.4 & 370.33 & 0.04 & 27.28 \\
\hline Cumulative Average Delay Time & & & 0.05 & & & 0.04 & 27.46 \\
\hline
\end{tabular}




\begin{tabular}{|c|c|c|c|c|c|c|c|}
\hline \multirow{3}{*}{\begin{tabular}{|l}
\multicolumn{1}{|c}{ Network Description } \\
1/2 Peak AM Volume; $20 \%$ \\
Diversion; 2 Lane Block; $20 \mathrm{Min}$
\end{tabular}} & \multicolumn{6}{|c|}{ Simulation Set Number } & 13 \\
\hline & \multicolumn{3}{|c|}{ Interstate 95 North } & \multicolumn{3}{|c|}{ Highway Route 10} & \\
\hline & $\begin{array}{l}\text { Vehicle } \\
\text { Miles } \\
\text { Traveled } \\
\text { (miles) }\end{array}$ & $\begin{array}{l}\text { Total } \\
\text { Delay } \\
\text { (min) }\end{array}$ & $\begin{array}{l}\text { Average } \\
\text { Delay Time } \\
\text { I95 and all } \\
\text { Ramps (min- } \\
\text { veh mile) }\end{array}$ & $\begin{array}{l}\text { Vehicle } \\
\text { Miles } \\
\text { Traveled } \\
\text { (miles) }\end{array}$ & $\begin{array}{l}\text { Total } \\
\text { Delay } \\
\text { (min) }\end{array}$ & $\begin{array}{l}\text { Average } \\
\text { Delay Time } \\
\text { RT10 and all } \\
\text { Ramps (min } \\
\text { / veh mile) }\end{array}$ & $\begin{array}{l}\text { Total Network } \\
\text { Delay (hours) }\end{array}$ \\
\hline Random Seed Number & A & B & $C=B / A$ & D & E & $F=E / D$ & $\begin{array}{c}\mathrm{G}=(\mathrm{B}+\mathrm{E}) / \\
{[60(\mathrm{~min} / \mathrm{hr})]}\end{array}$ \\
\hline 1 & 28114.3 & 1523.81 & 0.05 & 7756.4 & 331.42 & 0.04 & 30.92 \\
\hline 33 & 28128.9 & 1414.99 & 0.05 & 7655.0 & 325.06 & 0.04 & 29.00 \\
\hline 99 & 27950.3 & 1416.37 & 0.05 & 7717.4 & 326.29 & 0.04 & 29.04 \\
\hline Cumulative Average Delay Time & & & 0.05 & & & 0.04 & 29.66 \\
\hline \multirow{2}{*}{ Network Description } & \multicolumn{6}{|c|}{ Simulation Set Number } & 14 \\
\hline & \multicolumn{3}{|c|}{ Interstate 95 North } & \multicolumn{3}{|c|}{ Highway Route 10} & \\
\hline $\begin{array}{l}\text { 1/2 Peak AM Volume; } 20 \% \\
\text { Oiversion; } 2 \text { Lane Block; } 30 \text { Min } \\
\text { Tin }\end{array}$ & $\begin{array}{l}\text { Vehicle } \\
\text { Miles } \\
\text { Traveled } \\
\text { (miles) }\end{array}$ & $\begin{array}{l}\text { Total } \\
\text { Delay } \\
\text { (min) }\end{array}$ & $\begin{array}{c}\text { Average } \\
\text { Delay Time } \\
\text { [95 and all } \\
\text { Ramps (min- } \\
\text { veh mile) }\end{array}$ & $\begin{array}{l}\text { Vehicle } \\
\text { Miles } \\
\text { Traveled } \\
\text { (miles) }\end{array}$ & $\begin{array}{l}\text { Total } \\
\text { Delay } \\
\text { (min) }\end{array}$ & $\begin{array}{c}\text { Average } \\
\text { Delay Time } \\
\text { RT10 and all } \\
\text { Ramps (min } \\
\text { / veh mile) }\end{array}$ & $\begin{array}{l}\text { Total Network } \\
\text { Delay (hours) }\end{array}$ \\
\hline Random Seed Number & A & B & $C=B / A$ & D & E & $F=E / D$ & $\begin{array}{c}G=(B+E) / \\
{[60(\min / \mathrm{hr})]}\end{array}$ \\
\hline 1 & 27846.4 & 1507.72 & 0.05 & 8069.5 & 346.89 & 0.04 & 30.91 \\
\hline 33 & 27799.1 & 1462.69 & 0.05 & 7913.9 & 530.74 & 0.07 & 33.22 \\
\hline 99 & 27765.3 & 1435.52 & 0.05 & 8161.9 & 360.51 & 0.04 & 29.93 \\
\hline Cumulative Average Delay Time & & & 0.05 & & & 0.05 & 31.36 \\
\hline \multirow{2}{*}{ Network Description } & \multicolumn{6}{|c|}{ Simulation Set Number } & 15 \\
\hline & \multicolumn{3}{|c|}{ Interstate 95 North } & \multicolumn{3}{|c|}{ Highway Route 10} & \\
\hline $\begin{array}{l}1 / 2 \text { Peak AM Volume; } 20 \% \\
\text { Diversion; } 2 \text { Lane Block; } 40 \text { Min } \\
\text { Pin }\end{array}$ & $\begin{array}{l}\text { Vehicle } \\
\text { Miles } \\
\text { Traveled } \\
\text { (miles) }\end{array}$ & $\begin{array}{l}\text { Total } \\
\text { Delay } \\
\text { (min) }\end{array}$ & $\begin{array}{l}\text { Average } \\
\text { Delay Time } \\
\text { I95 and all } \\
\text { Ramps (min- } \\
\text { veh mile) }\end{array}$ & $\begin{array}{l}\text { Vehicle } \\
\text { Miles } \\
\text { Traveled } \\
\text { (miles) }\end{array}$ & $\begin{array}{l}\text { Total } \\
\text { Delay } \\
\text { (min) }\end{array}$ & $\begin{array}{c}\text { Average } \\
\text { Delay Time } \\
\text { RT10 and all } \\
\text { Ramps (min } \\
\text { / veh mile) }\end{array}$ & \begin{tabular}{|c|} 
Total Network \\
Delay (hours)
\end{tabular} \\
\hline Random Seed Number & A & B & $C=B / A$ & $\mathrm{D}$ & $\mathbf{E}$ & $F=E / D$ & $\begin{array}{c}G=(B+E) / \\
{[60(\min / \mathrm{hr})]}\end{array}$ \\
\hline 1 & 27329.7 & 1516.26 & 0.06 & 8337.6 & 359.80 & 0.04 & 31.27 \\
\hline 33 & 27169.7 & 1437.28 & 0.05 & 8308.5 & 360.58 & 0.04 & 29.96 \\
\hline 99 & 27103.1 & 1460.43 & 0.05 & 8419.4 & 370.33 & 0.04 & 30.51 \\
\hline Cumulative Average Delay Time & & & 0.05 & & & 0.04 & 30.58 \\
\hline Netwark Descrintion & & & & & Simulati & on Set Nunber & 16 \\
\hline & & terstate 95 ) & North & & hway Rou & te 10 & \\
\hline $\begin{array}{l}1 / 2 \text { Peak AM Volume; } 20 \% \\
\text { Diversion; } 3 \text { Lane Block; } 20 \text { Min } \\
\text { If }\end{array}$ & $\begin{array}{l}\text { Vehicle } \\
\text { Miles } \\
\text { Traveled } \\
\text { (miles) }\end{array}$ & $\begin{array}{l}\text { Total } \\
\text { Delay } \\
\text { (min) }\end{array}$ & $\begin{array}{c}\text { Average } \\
\text { Delay Time } \\
195 \text { and all } \\
\text { Ramps (min- } \\
\text { veh mile) }\end{array}$ & $\begin{array}{l}\text { Vehicle } \\
\text { Miles } \\
\text { Traveled } \\
\text { (miles) }\end{array}$ & $\begin{array}{l}\text { Total } \\
\text { Delay } \\
\text { (min) }\end{array}$ & \begin{tabular}{|c|} 
Average \\
Delay Time \\
RT10 and all \\
Ramps (min \\
/ veh mile)
\end{tabular} & $\begin{array}{l}\text { Total Network } \\
\text { Delay (hours) }\end{array}$ \\
\hline Random Seed Number & A & B & $\mathrm{C}=\mathrm{B} / \mathrm{A}$ & D & E & $F=E / D$ & $\begin{array}{c}\mathrm{G}=(\mathrm{B}+\mathrm{E}) / \\
{[60(\min / \mathrm{hr})]}\end{array}$ \\
\hline 1 & 28050.9 & 7269.98 & 0.26 & 7756.4 & 331.42 & 0.04 & 126.69 \\
\hline 33 & 28086.3 & 12899.67 & 0.46 & 7655.0 & 325.06 & 0.04 & 220.41 \\
\hline 99 & 28017.1 & 7522.84 & 0.27 & 7717.4 & 326.29 & 0.04 & 130.82 \\
\hline Cumulative Average Delay Time & & & 0.33 & & & 0.04 & 159.31 \\
\hline
\end{tabular}




\begin{tabular}{|c|c|c|c|c|c|c|c|}
\hline \multirow{2}{*}{ Network Description } & \multicolumn{6}{|c|}{ Simulation Set Number } & 17 \\
\hline & \multicolumn{3}{|c|}{ Interstate 95 North } & \multicolumn{3}{|c|}{ Highway Route 10} & \\
\hline $\begin{array}{l}\text { 112 Peak AM Volume; } 20 \% \\
\text { Diversion; } 3 \text { Lane Block; } 30 \text { Min } \\
\text { In }\end{array}$ & $\begin{array}{l}\text { Vehicle } \\
\text { Miles } \\
\text { Traveled } \\
\text { (miles) }\end{array}$ & $\begin{array}{l}\text { Total } \\
\text { Delay } \\
\text { (min) }\end{array}$ & $\begin{array}{l}\text { Average } \\
\text { Delay Time } \\
\text { I95 and all } \\
\text { Ramps (min- } \\
\text { veh mile) }\end{array}$ & $\begin{array}{l}\text { Vehicle } \\
\text { Miles } \\
\text { Traveled } \\
\text { (miles) }\end{array}$ & $\begin{array}{l}\text { Total } \\
\text { Delay } \\
\text { (min) }\end{array}$ & $\begin{array}{c}\text { Average } \\
\text { Delay Time } \\
\text { RT10 and all } \\
\text { Ramps (min } \\
\text { / veh mile) }\end{array}$ & $\begin{array}{l}\text { Total Network } \\
\text { Delay (hours) }\end{array}$ \\
\hline Random Seed Number & $\mathbf{A}$ & B & $\mathrm{C}=\mathrm{B} / \mathrm{A}$ & D & $\mathbf{E}$ & $F=E / D$ & $\begin{array}{c}G=(B+E) / \\
{[60(\min / h r)]}\end{array}$ \\
\hline 1 & 27676.1 & 13529.56 & 0.49 & 8069.5 & 346.89 & 0.04 & 231.27 \\
\hline 33 & 27785.7 & 28961.64 & 1.04 & 7913.9 & 530.74 & 0.07 & 491.54 \\
\hline 99 & 27785.7 & 28961.64 & 1.04 & 8161.9 & 360.51 & 0.04 & 488.70 \\
\hline Cumulative Average Delay Time & & & 0.86 & & & 0.05 & 403.84 \\
\hline \multirow{2}{*}{ Network Description } & \multicolumn{6}{|c|}{ Simulation Set Number } & 18 \\
\hline & \multicolumn{3}{|c|}{ Interstate 95 North } & \multicolumn{3}{|c|}{ Highway Route 10} & \\
\hline $\begin{array}{l}1 / 2 \text { Peak AM Volume; } 20 \% \\
\text { Diversion; } 3 \text { Lane Block; } 40 \text { Min } \\
\text { in }\end{array}$ & $\begin{array}{l}\text { Vehicle } \\
\text { Miles } \\
\text { Traveled } \\
\text { (miles) }\end{array}$ & $\begin{array}{l}\text { Total } \\
\text { Delay } \\
\text { (min) }\end{array}$ & $\begin{array}{c}\text { Average } \\
\text { Delay Time } \\
\text { I95 and all } \\
\text { Ramps (min- } \\
\text { veh mile) }\end{array}$ & $\begin{array}{l}\text { Vehicle } \\
\text { Miles } \\
\text { Traveled } \\
\text { (miles) }\end{array}$ & $\begin{array}{l}\text { Total } \\
\text { Delay } \\
\text { (min) }\end{array}$ & \begin{tabular}{|c|} 
Average \\
Delay Time \\
RT10 and all \\
Ramps (min \\
/ veh mile)
\end{tabular} & $\begin{array}{l}\text { Total Network } \\
\text { Delay (hours) }\end{array}$ \\
\hline Random Seed Number & A & B & $\mathrm{C}=\mathrm{B} / \mathrm{A}$ & D & E & $F=E / D$ & $\begin{array}{l}G=(B+E) / \\
{[60(\min / h r)]}\end{array}$ \\
\hline 1 & 46711.5 & 20932.75 & 0.45 & 8337.6 & 359.80 & 0.04 & 354.88 \\
\hline 33 & 46028.9 & 50657.02 & 1.10 & 8308.5 & 360.58 & 0.04 & 850.29 \\
\hline 99 & 46653.4 & 22864.65 & 0.49 & 8419.4 & 1315.29 & 0.16 & 403.00 \\
\hline Curnulative Average Delay Time & & & 0.68 & & & 0.08 & 536.06 \\
\hline
\end{tabular}


APPENDIX I

Summary of Modeling Procedure 


\section{Summary of the Research Methodology}

This appendix presents a concise summary of the research methodology in accordance with one of the four primary objectives of the research. Although the summarized methodology presented is minimal in procedural explanation, its substance should not be underestimated. This summary methodology is a framework outline that is intended to ensure that others performing similar modeling studies do not neglect any phases of model development or analysis.

The summary methodology was produced directly from the complete research methodology described in Chapter 3. It is presented as a set of six stages each containing a series of open-ended tasks. The tasks are presented as general actions, as opposed to set procedures, because each could be completed utilizing various modeling and analysis techniques. For more information on any stage or task presented, Chapter 3 of this document could be used as a reference.

\section{STAGE-I DEVELOPING MODEL FOUNDATION}

Task I-1: Define the Study Area

Task I-2: Define the Necessary Modeling Assumptions

Task I-3: Define the Measures of Effectiveness (MOE)

STAGE-II OBTAINING THE DATA REQUIRED TO MODEL THE

\section{TRANSPORTATION NETWORK}

Task II-1: $\quad$ Obtain the Necessary Network Coordinates for the Defined Study Area Task II-2: $\quad$ Obtain the Network Traffic Volume Data for All Entry Points 
Task II-3: Determine the Total Simulation Time and Any Intermediate Time Intervals

Task II-4: Determine the Number of Samples Necessary (and Specify the Random Seed Numbers that will be used to Represent Each Sample)

\section{STAGE-III MODELING THE TRANSPORTATION NETWORK IN ITRAF}

Task III-1: $\quad$ Model the Roadway and Ramp Geometry

Task III-2: $\quad$ Input All Roadway and Ramp Traffic Volumes for All Time Periods

Task III-3: $\quad$ Run Simulations at Normal Traffic Conditions

\section{STAGE-IV VALIDATING THE SIMULATION MODEL DEVELOPED}

Task IV-1: Visually Observe the Network Closely for Any Problems using TRAFVU

Task IV-2: $\quad$ Refine Model Based on the Problems found in Task IV-1

Task IV-3: Re-Run Simulations with the Network at Normal Conditions

Task IV-3a: Repeat Tasks IV-1, IV-2, and IV-3 Until the Model Visually

Resembles the Actual Conditions Sought through Simulation

Task IV-4: Obtain Speed and Travel Time for a Typical Segment of Simulated Roadway for Comparison to Actual Segment of Roadway

Task IV-5: Establish Statistical Test and Level of Significance for the Comparison of Field Data to Simulation Data

Task IV-6: Perform Field (Floating-Car) Analysis on the Real-World Segment that Corresponds to the Simulated Segment Chosen in Task IV-5 
Task IV-7: Statistically Compare the Data from the Actual Segment with the Data Obtained from Simulation

Task IV-8: Refine the Model Where Necessary and Repeat the Comparison with the New Simulation Data Obtained

Task IV-8a: Repeat Tasks IV-7 and IV-8 Until the Model meets the Criteria of Acceptance Established

\section{STAGE-V PERFORMING THE ANALYSIS}

Task V-1: Define the Factors Involved in Situation to be Evaluated (Example: Situation could be Traffic Incidents and Diversion)

Task V-2: $\quad$ State the "High" and "Low" Limits of Levels for the Factors Stated

Task V-3: Determine the $2^{\mathrm{k}}$ Factorial Experimental Design with the Stated Factors and One of the Established MOE's

Task V-4: Simulate and Obtain the Necessary MOE for all the Experiments defined by the $2^{\mathrm{k}}$ Factorial Experimental Design

Task V-5: Determine the General Linear Model ANOVA Table for the $2^{\mathrm{k}}$ Factorial Experimental Design (Use Statistical Software)

Task V-6: Based on the Significance of Each Factor and the Combinations of the Factors, as Given in the ANOVA Table, Establish an Expanded Experimental Design by Varying the Significant Factors as Necessary and Fixing the Insignificant Factors at the Levels Set in the $2^{\mathrm{k}}$ Factorial Experiment

Task V-7: Model, Simulate and Determine the MOE's for All Situations Defined by the Expanded Experimental Design 


\section{STAGE-IV EVALUATING THE RESULTS}

Task IV-1: State the Decision Criteria that will be Used in the Evaluation of the Results

Task IV-2: Evaluate Results Based on Established Decision Criteria

Task IV-3 State Conclusions 


\section{APPENDIX J}

Deployment Plan Developed Using the National ITS Architecture 
The recommended deployment plan focuses on the ITS components required to deploy a route diversion strategy. By focusing on one diversion route strategy an ATMC could establish its role as an accurate information provider to the travelers using I-95 through the Providence Metropolitan Area (PMA). Once the people of RI and frequent travelers through the PMA realize the benefits of the information supplied through the visual ITS components, they will apply the actions recommended by the ATMC with greater confidence. Also, by concentrating on one area at the onset of the program, the incident management and response team can fine tune procedures before approaching other areas on the state's freeways and arterials. It is most important that the ITS infrastructure put in place for incident management be compatible with all regional equipment and any future ITS equipment RI utilizes.

The National ITS Logical Architecture (NITSA) was developed using structured analysis techniques and consists of data flow diagrams, process specifications, and data dictionary entries. NITSA is designed to ensure that ITS projects are planned as flexible systems that will be compatable with regional and future ITS developments. In order to determine exactly which components and functions of ITS, the project should incorporate; the user benefits, or user services, must be defined onset of the system design. The user services represent the functions that the deployment is envisioned to provide to the travelers.

\section{User Services}

The following user services were identified using the NITSA:

* Pre-Trip Travel Information

$>$ Traffic Management Web-Site 
$>$ En-route Driver Information

$>$ Permanent Dynamic Message Signs (DMS)

$>$ Highway Advisory Radio (HAR)

$>$ Alternate Route Trailblazers

* Traveler Services Information

$>$ Traffic Management Web-Site

$>$ Permanent Dynamic Message Signs (DMS)

$>$ Highway Advisory Radio (HAR)

$>$ Roadside Call Boxes

* Traffic Control

$>$ Permanent Dynamic Message Signs (DMS)

$>$ Highway Advisory Radio (HAR)

$>$ (Future: Possible Ramp Metering and Dynamic Traffic Assignment)

* Incident Management

$>$ Inductive Loop Detectors

$>$ Closed Circuit Television (CCTV) Surveillance

- Travel Demand Management

$>$ Advanced Traffic Management Center (ATMC)

$>$ Permanent Dynamic Message Signs (DMS)

$>$ Highway Advisory Radio

$>$ (Future: Possible Ramp Metering)

The logical architecture and physical architecture described in the following sections are developed based on the user services described above. 


\section{Logical Architecture}

One approach to developing a deployment package using NITSA is to begin with the Logical Architecture. The logical architecture defines what has to be done to support the ITS user services described in the previous section. It defines the processes that perform ITS functions and the information or data flows that are shared between these processes. The Logical Architecture is also referred to as an "Essential Model" because it is not technology specific, nor does it dictate a particular implementation. This technology independence makes the logical architecture accommodating to innovation, scaleable from small-scale implementations to large regional systems, and supportive of widely varied system designs. Figure J-1 essentially provides a basic understanding of what the system must do and exposes the major data flows between the functions. Figure $\mathrm{J}-1$ is a diagram of the logical architecture for the system to be deployed. 


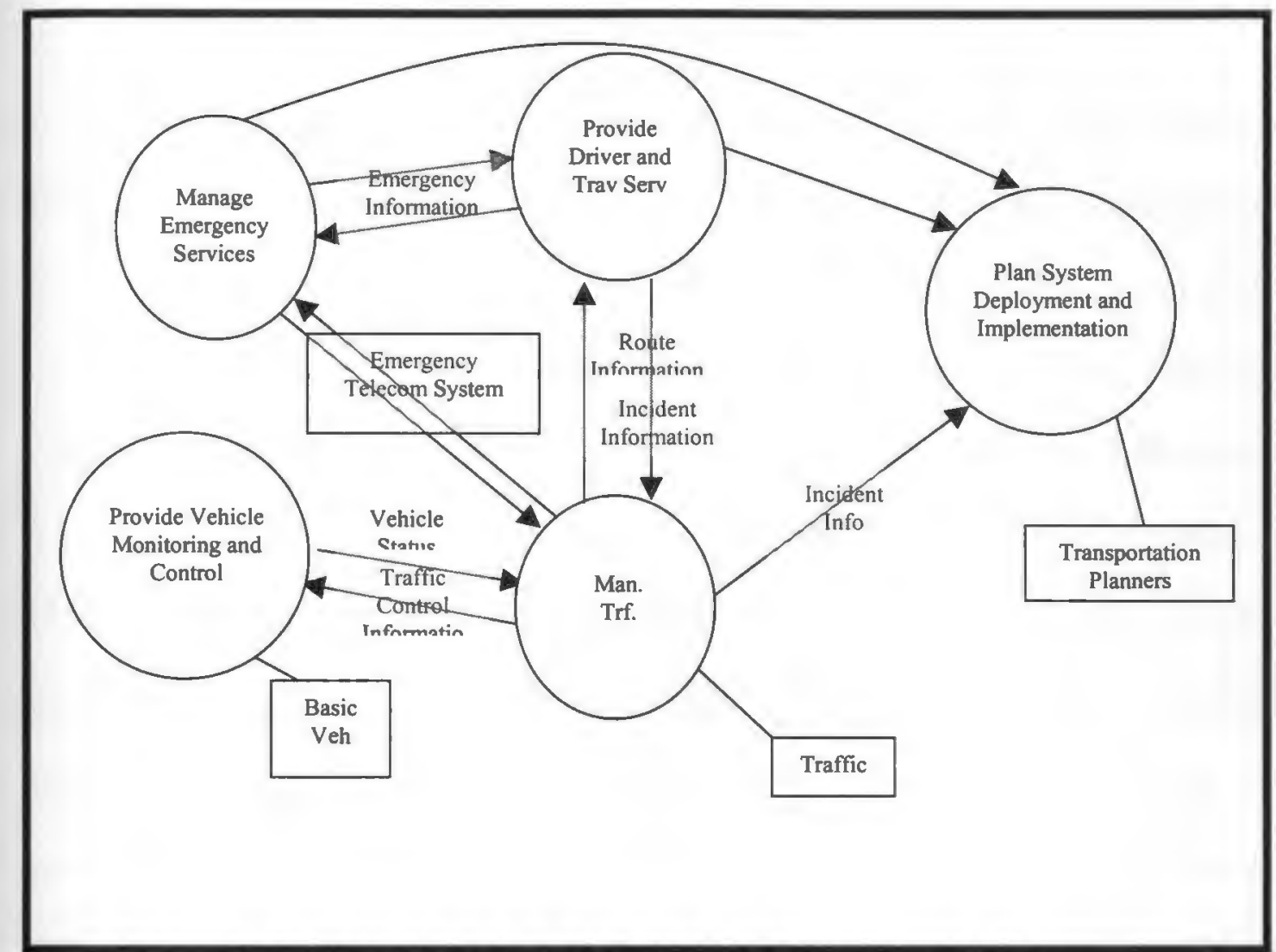

Figure J-1 Depicts the Logical Architecture for this project. Circles represent the processes or functions that do the work; Rectangles represent terminators; Arrows represent data flows. 


\section{Physical Architecture}

The Physical Architecture provides agencies with a physical representation (though not a detailed design) of the important ITS interfaces and major system components. It provides a high-level structure around the processes and data flows defined in the Logical Architecture. The principal elements in the Physical Architecture are the subsystems and architecture flows that connect these subsystems and terminators into an overall structure. A physical architecture takes the processes identified in the logical architecture and assigns them to subsystems. In addition, the data flows (also from the logical architecture) are grouped together into architecture flows. These architecture flows and their communication requirements define the interfaces required between subsystems, which form the basis for much of the ongoing standards work in the ITS program. A representative diagram of the physical architecture can be found in Figure J-2. 


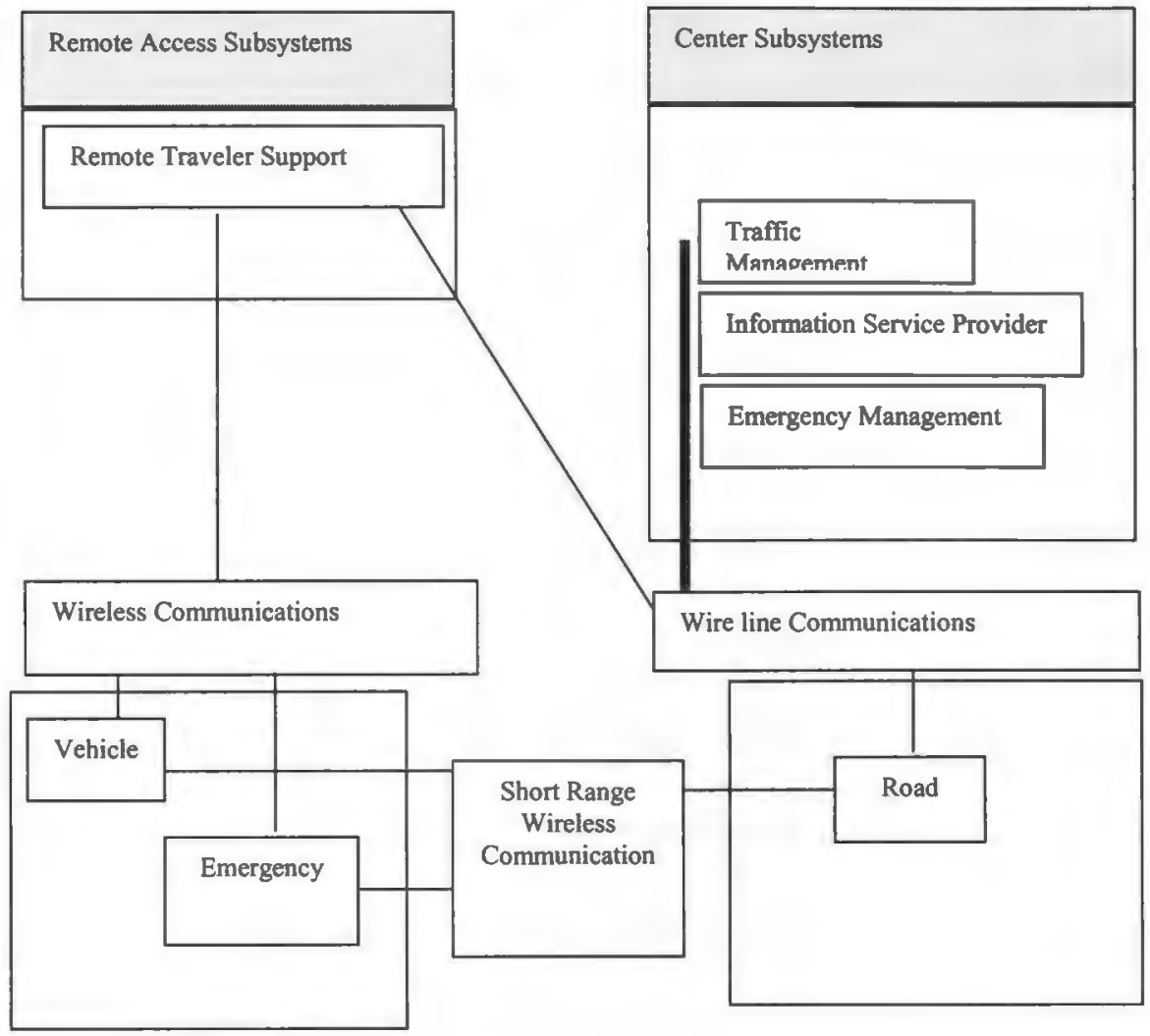

\section{Figure J-2 Depicts the Physical Architecture for this project.}


Figure J-2 is most important from a communications point of view. The figure shows the physical components of the system that must be connected in some way by either wire line or wireless communications.

\section{System Inventory}

With the logical and physical architectures in place the actual system components can be specified. The system inventory will be presented in five subsections that represent the most important systems of the project deployment. The sub-sections have been divided as follows: (1) analysis system, (2) communication system, (3) detection, verification, and monitoring system, (4) advanced transportation information system (ATIS), and (5) advanced transportation management system. Following the sub-sections is Table J-1. Table J-1 is a summary table listing the ITS components and estimates of quantities needed for complete project deployment. This section is designed to aid in the development of the detailed scope of work document necessary for successful procurement of consultants, operators, and contractors.

\section{(1) Analysis System:}

Essentially: CORSIM, ITRAF, TSIS, and a Windows based computer. However, as the detection, verification, and monitoring systems begin compiling data, the analysis system will expand to include these tools as model validation and calibration tools. The combination of the new data and the existing analysis system will make for more accurate traffic analysis in the future.

(2) Communication System: 
The communication system is the backbone of any ITS deployment. Special consideration must be given to exactly what is installed and where because future ITS deployments will realize much greater benefits if they can utilize an adequate and established communication system. With future ITS projects in mind, it was decided that $\mathrm{T} 1$ fiber optic cable will be installed along approximately five miles of Rt. 10 and along six miles of I-95. This $\mathrm{T} 1$ line will be used to transmit large amounts of information to and from the ATMC in Providence. The CCTV cameras and loop detectors will be connected by coaxial cable and copper wire, respectively, to 6 multiplexers located roadside. The multiplexers will digitize and structure the information according to existing data-communication standards before transmitting it to the ATMC. Once at the ATMC the information will be decoded using another multiplexer and monitored. All cameras will constantly relay video images to the ATMC, however only images that the operator requests will be viewed on the display monitors. Four multiplexers will be located along I-95 and two will be located along Rt. 10. The multiplexers along I-95 will be stored at the base of the permanent DMS. The T1 line will also transmit the data from the ATMC to be displayed on the DMS signs through the multiplexer at their respective bases and a short line of co-axial cable. Video switching equipment has not been specified at this point because all but two cameras will constantly be displayed at the ATMC on one of the 15 small screen displays. Also connected to the multiplexers will be three HAR AM radio emitting beacons. These will also be connected using copper wire lines.

It will be very important to establish excellent emergency communications links as well. The emergency communications will begin with the eight roadside call 
boxes. The roadside call boxes will be connected by copper wire line to multiplexers then onto the incident management center at the ATMC. In addition to the roadside call boxes an emergency cell phone number will be established and posted on signage as well as on the traffic management web site. Finally, three HAR broadcast beacons will be placed in a configuration so that their combined broadcast range will cover the entire PMA and approximately five miles to the south and for two miles north of the metropolitan line.

(3) Detection, Verification, and Monitoring System:

The detection and monitoring systems allow the operators to constantly assess exactly how the system is functioning. The monitoring system consists of 17 surveillance CCTV video cameras, with pan, tilt and zoom capabilities, located along the mainline and alternate route. The detection and verification system will consist of 10 sets of loop detectors. CCTV and loop detection was chosen for this system because it is a proven technique that lends itself to the level of funding that was allotted for this project.

\section{(4) Advanced Transportation Information System (ATIS):}

From a roadway system user standpoint, the advanced transportation information systems (ATIS) will present the most identifiable aspects of this project. The ATIS must be strategically located and rigorously maintained. The appearance and locale of the equipment is directly related to the user's perspective of the value of the information provided. Any aspect of the ATIS that detracts from the information will encourage a learned disregard for the system and information. For these reasons 
location, number, and connection to the ATMC have been given thorough consideration.

The ATIS consists of four permanent DMS, 8 flashing HAR signs; an HAR broadcast frequency, automated HAR message updates, 3 alternate route trailblazer signs, and a continuously updated traffic management web site.

\section{(5) Advanced Transportation Central System:}

The central system is the ATMC. The ATMC is located in the heart of the PMA and takes in and disseminates all the information from and to the previously described systems.

Besides computing and display equipment, the ATMC is the place where human operators constantly monitor the network. The equipment that must be incorporated in the ATMC for this project includes: fax machines, Windows NT based computers, large screen and a matrix of 15 smaller screen video displays, a multiplexer, CODECS, telephones, internet, HAR message center and agency hot lines.

The most important feature of the central system is the responsive database software. This software will be developed using the results of the CORSIM analysis and the real-time information that is attained from the ITS. The database will consist of the range of messages to be played over HAR, the messages to be displayed on the DMS, and the links to posted on the web site. All this information will be determined based on manual input from the operator, based on the conditions they are witnessing, and the downstream and upstream occupancy determined by the inductive loop detectors. 
Table J-1 Displays the Systems, Components, and Estimated Quantities for

the

project

\begin{tabular}{|c|c|c|}
\hline System & Components & Estimated Quantities \\
\hline \multirow{4}{*}{ 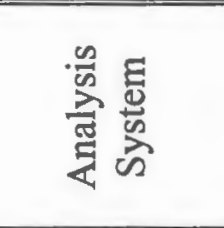 } & CORSIM Software & 1 Unit \\
\hline & ITRAF Software & 1 Unit \\
\hline & TSIS Software & 1 Unit \\
\hline & IBM Computer & 1 Unit \\
\hline \multirow{8}{*}{ 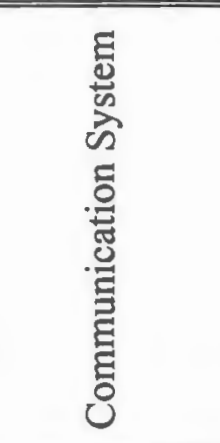 } & T1 Fiber Optic Cable & 10-11 Miles \\
\hline & Coaxial Cable & $15-20$ Miles \\
\hline & Copper Wire & $20-30$ Miles \\
\hline & Multiplexers & 7 units \\
\hline & CODEC & 1 Unit \\
\hline & Wireless Phones & 4 Units \\
\hline & Roadside Call Boxes & 8 Units \\
\hline & HAR Radio Beacons & 3 Units \\
\hline \multirow{2}{*}{ 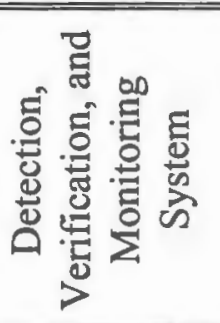 } & CCTV Surveillance Video & 17 Units \\
\hline & $\begin{array}{l}10 \text { Loop Detection } \\
\text { Installations }\end{array}$ & 10 Sets \\
\hline \multirow{5}{*}{ 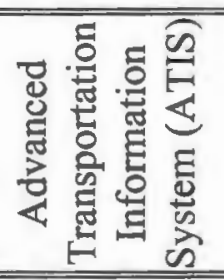 } & Permanent DMS & 4 Units \\
\hline & HAR & 1 Frequency \\
\hline & Flashing HAR Signage & 8 Units \\
\hline & Trailblazer Signage & 3 Units \\
\hline & Web Site & 1 \\
\hline \multirow{6}{*}{ 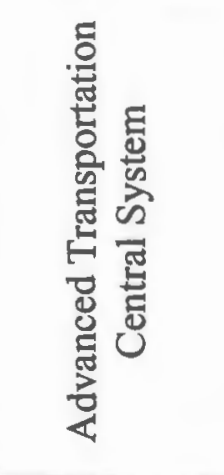 } & Wall Video Display & 2 Units \\
\hline & Fax Machine & 1 Unit \\
\hline & Emergency Agency Line & 1 \\
\hline & $\begin{array}{l}\text { Windows NT Based } \\
\text { Computer }\end{array}$ & 3 Units \\
\hline & Small Screen Video Display & 15 Units \\
\hline & $\begin{array}{l}\text { HAR Automatic Message } \\
\text { Equipment }\end{array}$ & 1 Unit \\
\hline
\end{tabular}




\section{Public Outreach}

ITS technology and route diversion are not new applications in transportation planning and engineering. However, the deployment of a project like this one must be accompanied by public outreach. The outreach is designed to inform the public about the systems that will be in place, how they can use them, and, most importantly how they can benefit from them.

The outreach for this project will begin one month before implementation and will continue though deployment. The following techniques will be used:

$>$ Advertisements during local news programs.

$>$ Advertisements in local papers

$>$ Public Workshops

$>$ Distributed Flyers

Possible articles and news reports by local news media

\section{System Example}

The following general example describes a hypothetical incident situation that could occur after this project is deployed. The example is provided to give a general sense of how the system will perform during an actual un-planned incident. The incident will occur at some given time of day on I-95 north. Motorists, either involved or uninvolved in the incident, will use cell phone hot line number to alert incident response team of the incident. If no motorist calls, an operator at the ATMC will detect the abnormal flow conditions over displays and through inductive loop detection. Based on general location given by callers the ATMC operator pan-tilts- 
and-zooms the appropriate CCTV cameras to pin point the freeway location. Once the image of the incident is clear, the operator determines the level of incident and then, based on training and the Incident Management Handbook developed using the results of the CORSIM analysis, enters into system the correct number. Based on this number, the proper incident response agencies are notified and the incident response team is en-route to the location. Also, based on the number the correct set of inductive loop detectors upstream from the incident are closely monitored by the system to determine if congestion is developing.

As this information is being monitored, the operator of the ATMC displays the images from the CCTV cameras on the alternate route to check if normal flow conditions exist in case traffic diversion is warranted. The operator enters the number 1 or 2 for normal or abnormal flow conditions on the alternate route. With the occupancy of I-95 determined by the loop detectors and the state of the alternate route entered, the central computer determines whether or not diversion is recommended.

With this information in place, the operator has one more choice: whether to accept the computer's recommended decision for diversion or no diversion; or, based on their experience enter some other course of action. If the computer's recommendations are accepted, the system automatically begins flashing the HAR roadside signs for travelers to tune in to the AM frequency and playing the predetermined and pre-recorded HAR message. At the same time the correct message is posted on all the DMS in the system and the appropriate internet message or link is posted on the DOT's traffic management web site. At this time the operator should have been joined by at least one other ATMC operator. This group of ATMC 
operators monitor I95 upstream of the incident for secondary incidents and Rt. 10 to insure that the diversion, if warranted, is not causing congestion at any of the on or off ramps. In addition to these duties, the operators must monitor the incident response and determine any needed equipment or personal at the scene. As the incident is cleared, the operators switch off the messages, but continue to monitor the flow as it returns to normal. 


\section{BIBLIOGRAPHY}

Aycin, M.F. and Benekohal, R.F. (1999) "Comparison of Car-Following Models for Simulation", Transportation Research Board Paper No. 99-1200, in Transportation Research Record 1678, National Research Council, Washington, D.C., pp. 116-127.

Banks, J.H. (1999) "Investigation of Some Characteristics of Congested Flow", Transportation Research Board Paper No. 99-0125, in Transportation Research Record 1678, National Research Council, Washington, D.C., pp 128 -134.

Benekohal, R.F. (1991) "Procedure for Validation of Microscopic Traffic Flow Simulation Models" in Transportation Research Record 1320, Transportation Research Board, National Research Council, Washington, D.C., pp. 190-202.

Brock, et al. (1996) "A Compendium of Traffic Model Validation Documentation and Recommendations - Phase 1 - Tasks A-H", Federal Highway Administration, Washington, D.C.

Dunn, W.M. and Reiss, R.A. (1991) Freeway Incident Management Handbook, Report No. Federal Highway Administration-SA-91-056, Federal Highway Administration, Washington, D.C.

Dunn, W.M., Latoski, S., and Reiss, R. (1999) Roadway Incident Diversion Practices, National Cooperative Highway Research Program (NCHRP) Synthesis of Highway Practice 279, Transportation Research Board (Transportation Research Board), National Research Council, Washington, D.C.

Dutta, U., Tadi, R., Devadoss, D., and Poola, M. (1997) "Freeway Courtesy Patrol as a Roadside Assistance Program: Experience of Two Large Metropolitan Areas" paper presented at the $76^{\text {th }}$ Annual Meeting of Transportation Research Board, Washington, D.C.

Elefteriadou, L et al. (1999) "Beyond the Highway Capacity Manual Framework for Selecting Simulation Models in Traffic Operational Analyses", in Transportation Research Record 1678, National Research Council, Washington, D.C., pp 96-106.

Fazio, J. and Rouphail, N.M. (1990) "Conflict in INTRAS: Application to Weaving Area Capacity Analysis", in Transportation Research Record 1287, National Research Council, Washington, D.C., pp 96-107.

Federal Highway Administration (1998) CORSIM User's Manual: Version 1.04, U.S. Department of Transportation, Washington, D.C. 
Federal Highway Administration (1998) ITRAF User Guide: Version 2.0, U.S. Department of Transportation, Washington, D.C.

Federal Highway Administration (1998) TRAFVU User's Manual: Version 1.01, U.S. Department of Transportation, Washington, D.C.

Federal Highway Administration (1998) TSIS User Guide: Version 4.2, U.S. Department of Transportation, Washington, D.C.

Gragg, C.A. and Demetsky, M. J. (1995) Final Report: Simulation of Route Diversion Strategies for Freeway Incident Management, Federal Highway Administration, Charlottesville, VA

Garrison, D. and Mannering, F. (1990) "Assessing the Traffic Impacts of Freeway Incidents and Driver Information", in ITE Journal 60(8), Institute of Tranportation Engineers, Washington, D.C., pp. 19-23.

Guiliano, G. (1988) Incident Characteristics, Frequency, and Duration of a High Volume Urban Freeway, Report No. Federal Highway Administration UCI-ITSWP-022, Federal Highway Administration, Washington, D.C.

Hall, F.L. and Zhou, M. (1999) "Investigation of Speed-Flow Relationship Under Congested Conditions on a Freeway", Transportation Research Board Paper No. 99-0402, Transportation Research Record 1678, National Research Board, Washington, D.C., pp. 64-72.

Institute of Transportation Engineers (1992) "Mobility Facts", Washington, D.C.

Levin, M. (1977) "Evaluating Location Effectiveness of Freeway Directional and Diversion Signs", Transportation Research Record (TRR) 644, Transportation Research Board, National Research Council, Washington, D.C., pp. 122-129.

Mass, Jr., C. (1998) "Estimating the Benefits of ITS technology in Incident Management: The Case of Northern Virginia" paper presented at the $77^{\text {th }}$ Annual Meeting of Transportation Research Board, Washington, D.C.

May, A.D. (1990) Traffic Flow Fundamentals, Prentice Hall Inc., Englewood Cliffs, NJ

McShane, W.R., Prassas, E.S., Roess, R.P. (1998) Traffic Engineering, PrenticeHall, Inc., Upper Saddle River, NJ

Myers, R.H., Myers, S.L., and Walpole, R.E. (1998) Probability and Statistics for Engineers and Scientists, Prentice Hall Inc., Upper Saddle River, NJ 
Roess, R.P. and Ulerio, J.M. (1997) Comparison of the 1994 Highway Capacity Manual's Ramp Analysis Procedures and the FRESIM Model, NCHRP Synthesis of Highway Practice 345, Transportation Research Board, National Research Council, Washington, D.C.

Roper, D.H. (1990) Freeway Incident Management, NCHRP Synthesis of Highway Practice 156, Transportation Research Board, National Research Council, Washington, D.C.

Transportation Research Board (1997) Highway Capacity Manuel, Special Report 209, Transportation Research Board, Washington, D.C., 